CONOCIMIENTO PROFESIONAL DEL PROFESOR DE CIENCIAS AL ABORDAR CUESTIONES SOCIOCIENTÍFICAS: UN ESTUDIO DE CASO DE UN GRUPO DE INVESTIGACIÓN EN LA INTERACCIÓN UNIVERSIDAD-ESCUELA

BLANCA RODRÍGUEZ HERNÁNDEZ

UNIVERSIDAD PEDAGÓGICA NACIONAL

ÉNFASIS EDUCACIÓN EN CIENCIAS

DOCTORADO INTERINSTITUCIONAL EN EDUCACIÓN

Bogotá, Colombia, 2017 
CONOCIMIENTO PROFESIONAL DEL PROFESOR DE CIENCIAS AL ABORDAR CUESTIONES SOCIOCIENTÍFICAS: UN ESTUDIO DE CASO DE UN GRUPO DE INVESTIGACIÓN EN LA INTERACCIÓN UNIVERSIDAD-ESCUELA

Blanca Rodríguez Hernández

Tesis presentada para optar el título de Doctor en Educación

DIRECTOR:

Dr. LEONARDO FABIO MARTÍNEZ PEREZ

Jurados:

Dra. CARMEN ALICIA MARTINEZ

Dra. DAISI TERESINHA CHAPANI

Dr. PEDRO GUILHERME ROCHA DOS REIS

UNIVERSIDAD PEDAGÓGICA NACIONAL

ÉNFASIS EDUCACIÓN EN CIENCIAS

DOCTORADO INTERINSTITUCIONAL EN EDUCACIÓN

Bogotá, Colombia, 2017 


\section{AGRADECIMIENTOS}

Esta tesis representa el pensamiento colectivo en donde la interacción, el diálogo y el trabajo colaborativo con los profesores participantes permitió asumirme como investigadora, así como también reconocer el deber ser, sentir y actuar de todos los profesores como profesionales. Fue el camino además para transitar con ellos por una serie de escalas de progresión/regresión, entre un "ver confuso inicial" caótico, y fragmentario a un "ver formativo" estilizado y configurado (Fleck, 1986).

Tendría que nombrar a muchas personas, compañeros de trabajo del colegio, de la universidad, compañeros de clase, del grupo Alternaciencias, estudiantes en formación inicial, tesistas, etc.; a quienes agradezco de corazón. Sin embargo, quiero nombrar a algunas de ellas, esas personas especiales que siempre confiaron en mí y de las cuales seguiré aprendiendo y creciendo como persona y profesional:

Mi director de tesis, El profesor Leonardo Fabio Martínez $\mathrm{P}$, gracias a quien pude desarrollar la investigación e interactuar con diversos colectivos de pensamiento, producto de su voto de confianza y orientación.

A la profesora Diana Lineth Parga $L$ por sus recomendaciones, siempre tan pertinentes, oportunas y llenas de valor agregado, en beneficio profesional y personal.

A la Profesora Isabel Garzón, por su disposición y ayuda, por ser tan humana, bondadosa y pertinente en sus recomendaciones en el momento adecuado.

Al profesor Luis Carlos Trujillo de la Universidad Nacional, por su sencillez, generosidad y calidad humana; por todo el tiempo que destinó para enseñarme a manejar Nvivo, además del soporte tecnológico suministrado.

A la profesora Carmen Alicia Martínez, quien a través del seminario me ofreció las herramientas de análisis pertinentes para la elaboración de la presente investigación, por sus enseñanzas, las orientaciones dadas y la calidez que siempre me manifestó.

A la profesora Daisi Chapani, quien además de su calidez, hospedaje y seminario aportó en la consolidación del soporte político e ideológico a la presente investigación.

Finalmente, a la profesora Ximena Ibáñez C, por su amistad, por permitirme reintegrarme a la Universidad en el momento oportuno y por su disposición sincera y el reconocimiento que siempre ha hecho a mi trabajo. 
Mil y mil gracias a la profesora Diana Moreno, Nidia Tuay, Libia Stella Niño Z y el profesor Alfonso Cárdenas de la UPN; a la profesora Llzete, Ana Flavia, los profesores Paulo Gabriel Thiago Mendonça, Michel Carnio, Washington (Unesp), la profesora Alicia Gutiérrez (Argentina) y William Mora (U. Distrital) por sus comentarios, observaciones, solidaridad, compañía y por la acogida que me brindaron; a todos mil y mil gracias por siempre, por estar ahí, por permitirme interactuar con ustedes y sus colectivos. 


\section{DEDICATORIA}

Ämi famifia, por vaforar mis aciertos y desaciertos, por sus reconocimientos independientemente de fa dureza y exigencia que siempre he manifestado; pero especialmente a mis padres, por enseñarme a trafajar con honestidad, responsafifidad y ser fumidde y feaf con todas aqueJfas personas que permitieron construir mi camino y, desarroffar fa sensibifidad for fos animales, quienes además de ser seres sintientes, son maraviffosos, fieles y con una gran capacidad de amar. 


\section{LISTA DE TABLAS}

Tabla 1. Revistas consultadas del campo de la Enseñanza de las Ciencias ................................ 49

Tabla 2. Identificación de número de artículos por temáticas de interés. .......................................50

Tabla 3. Modelos de enseñanza para abordar CSC ..................................................................... 95

Tabla 4. Perspectivas de enseñanza CTSA ........................................................................ 118

Tabla 5. Comparación entre entrevista individual y focal ......................................................... 159

Tabla 6. Instrumentos utilizados durante el proceso de formación de profesores en la IUE al

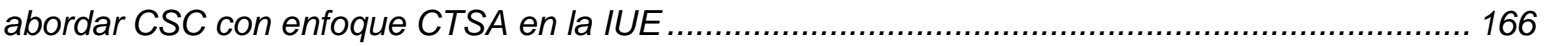

Tabla 7. Funcionalidad del software NVivo11 en investigación cualitativa................................... 187

Tabla 8. Analogía entre ATD y las funciones del software NVivo11 .......................................... 192

Tabla 9. Libro de códigos (Nodos/Categorías Creadas y emergentes a partir del ATD) .............. 199

Tabla 10. Intervenciones vivencias de los profesores en las aulas ...........................................217

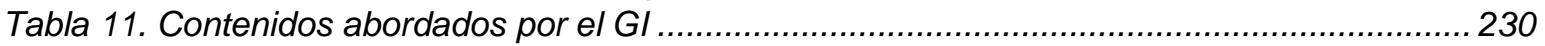

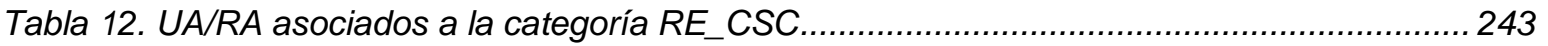

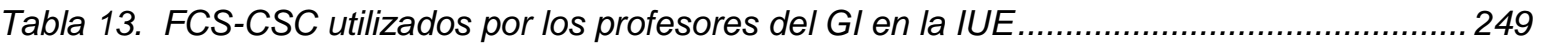

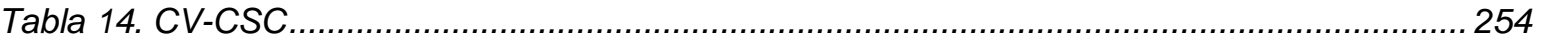

Tabla 15. CV utilizados por los profesores del Gl.............................................................. 260

Tabla 16. Intervenciones de los profesores del Gl en las que se identifican las características de las

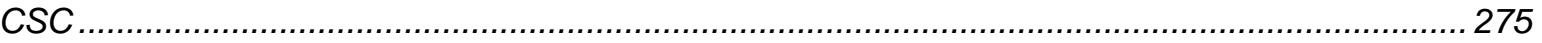

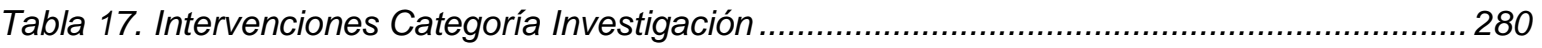

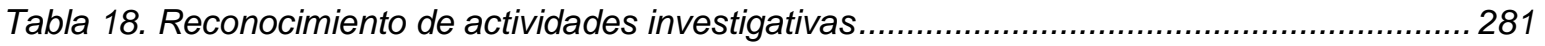

Tabla 19. Intervenciones concepción de investigación ................................................................283

Tabla 20. Intervenciones de los profesores de Gl al hablar de las dificultades de abordar CSC .. 293

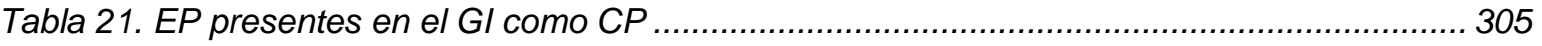

Tabla 22. Circulación inter e intracolectiva de ideas ................................................................ 306 


\section{INDICE DE FIGURAS}

Figura 1. Modelo de relación entre los dominios del conocimiento del profesor (Grossman 1990) y modelos básicos para implementar aspectos relacionados con el desarrollo sostenible en la

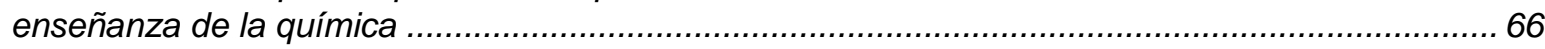

Figura 2. Tendencia de la formación permanente de profesores. ..............................................68 68

Figura 3. Reducido número de referencias del CPP en comparación con el CDC .........................69 69

Figura 4. Tendencia de abordaje del CPP en artículos como CDC........................................... 70

Figura 5. Tendencia de las CSC en procesos de formación y forma de abordaje ......................... 71

Figura 6. Abordaje de las CSC en la formación de profesores.................................................. 72

Figura 7. CSC abordadas en contextos locales y en países Latinoamericanos............................. 72 Figura 8. Fuentes y componentes del conocimiento (Ballenilla, 2003; Rafael Porlán \& Rivero, 1998)

Figura 9. Conocimiento Profesional del Profesor según IRES (Ballenilla, 2003; Solís \& Rivero,

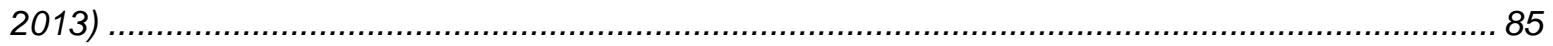

Figura 10. Componentes del conocimiento profesional según distintas orientaciones. ................. 86

Figura 11. Categorías y niveles de formulación en el análisis del CPP. ..................................... 88

Figura 12. Algunas características del conocimiento profesional del docente de ciencias y el

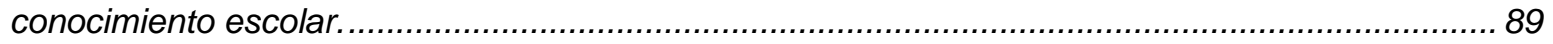

Figura 13. Conexiones interinstitucionales entre la Universidad y la Escuela............................. 100

Figura 14. Teoría de la Acción comunicativa de Habermas (TAC) ............................................. 102

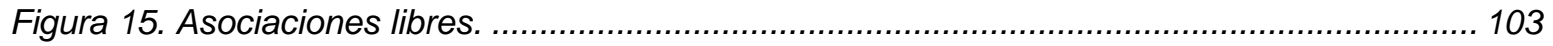

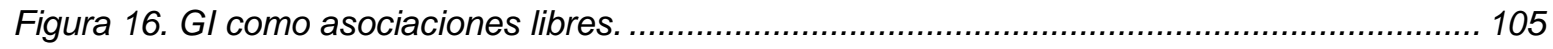

Figura 17. Hibrido de propuestas Huberman \& Levinson, (1988) / Martínez \& Salazar (2014) .... 106

Figura 18. Circulación intercolectiva e intracolectiva de ideas entre los círculos esotéricos y

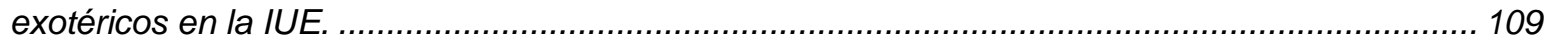

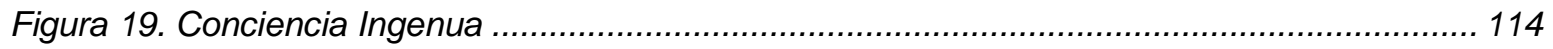

Figura 20. No neutralidad de la Ciencia y la Tecnología ........................................................ 114

Figura 21. Articulación entre parámetros CTS y propósitos educacionales ................................. 117

Figura 22. Matriz de relación entre parámetros CTSA y educacionales por niveles de complejidad

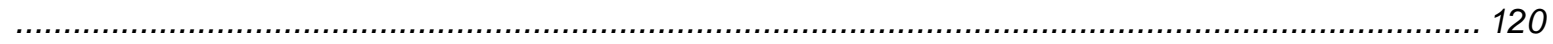

Figura 23. Referentes CTSA, principios educativos de enseñanza de las ciencias y CSC .......... 124

Figura 24. Relación entre CTSA, CSC y CPP .................................................................... 129

Figura 25. Investigaciones en torno a la formación de profesores en el contexto epistemológico de

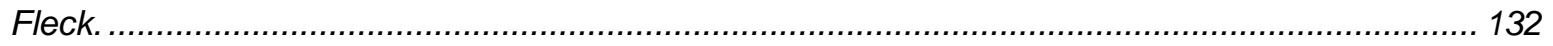

Figura 26. Relación sujeto y objeto en el estado del conocimiento: "Fenomenología Fleckiana".. 134

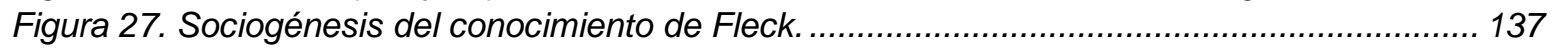

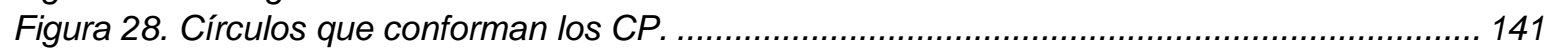

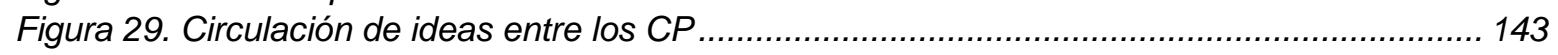

Figura 30. Ciencia Especializada Vs Ciencia Popular ......................................................... 147

Figura 31. AC y $A D$ en un continuo de características polarizadas ............................................ 161

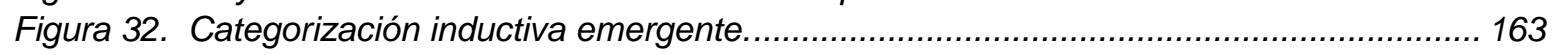

Figura 33. Fases metodológicas de la investigación ............................................................ 164

Figura 34. Frecuencia de palabras en el corpus de análisis textual del CPP al abordas CSC/CTSA

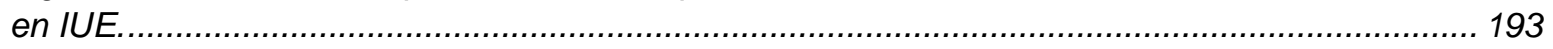

Figura 35. Mapa ramificado de frecuencia de palabras del proyecto: CCP al abordar CSC/CTSA en

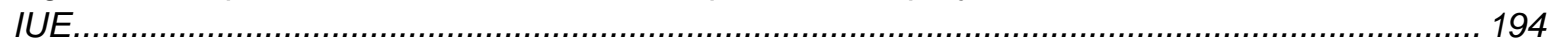

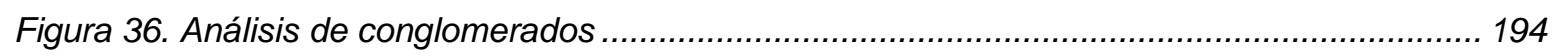




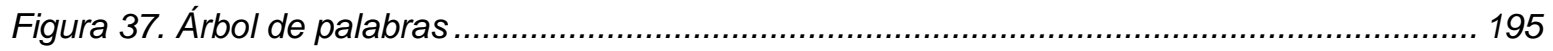

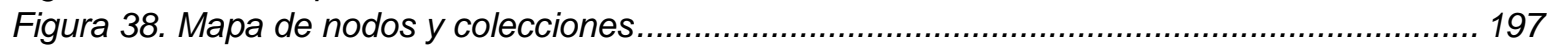

Figura 39. GI GCl (G1 profesores horas extras/G2 profesores de planta) ............................................ 209

Figura 40. HdRP referente de CPP al abordar CSC/CTSA en Ia IUE ................................................... 214

Figura 41. Otras actividades independientes de la jornada escolar en espacios no formales ...... 220

Figura 42. Número de estudiantes a cargo en la jornada laboral. ............................................... 221

Figura 43. Nodos/categorías y subcategorías iniciales ......................................................... 224

Figura 44. Categorías y subcategorías/Nodos asociados a las CSC ...................................... 225

Figura 45.Categorías emergentes: Aportes/Dificultades CP_EP/Formación IUE ........................ 226

Figura 46. Categorías iniciales y emergentes/AC-AD/ATD analogía figura 30 (Moraes \& Galiazzi,

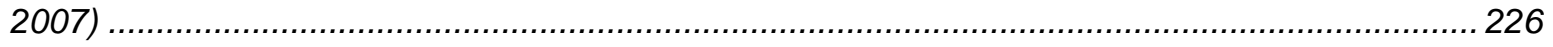

Figura 47. Contenidos utilizados por los profesores GI .................................................. 230

Figura 48 Contenidos abordados por los profesores del PGI2 ............................................. 237

Figura 49. Contenidos que abordan en talleres, $S D$, debates, como fuente del currículo. ............ 238

Figura 50. Árbol de palabras, alrededor de SPA como CSC ...................................................2. 240

Figura 51. Formación de texto -intencionalidad del participante del GI..................................... 241

Figura 52. valores como aspecto a considerar al abordar CSC_CTSA como contenido ............... 241

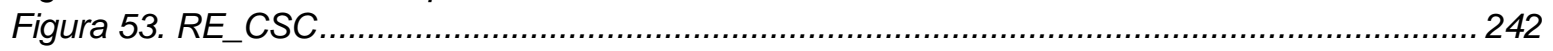

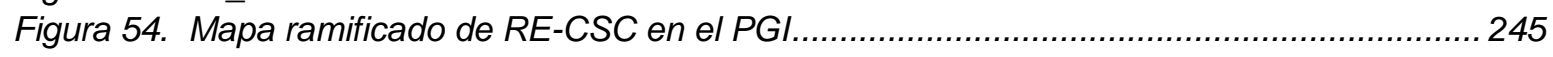

Figura 55. Análisis de conglomerados de los RE-CSC ................................................................... 246

Figura 56. Estrategia metodológica como referente del conocimiento IT de los profesores del PGI

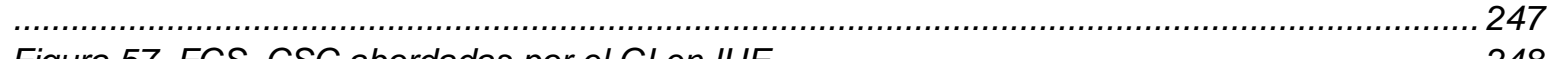

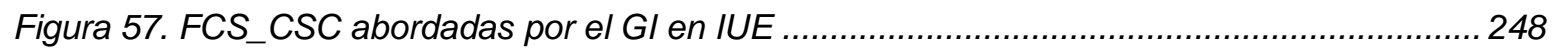

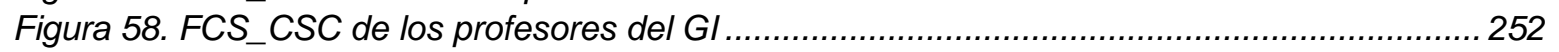

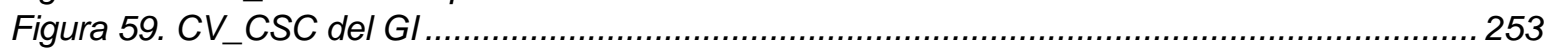

Figura 60. CV utilizados por los profesores al abordar CSC ............................................... 258

Figura 61. Debate como CV utilizado por los profesores del GI ............................................ 258

Figura 62. Árbol de palabras, indica el contexto de la participación como CV asumido por el

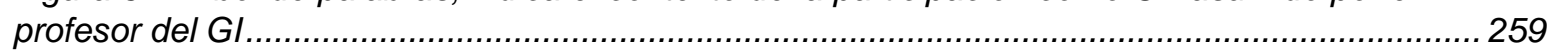

Figura 63. Categorías (nodos) asociados al CPP como ejes DOC ........................................ 263

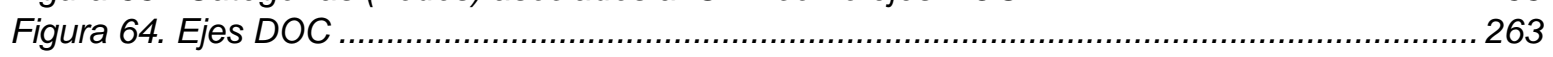

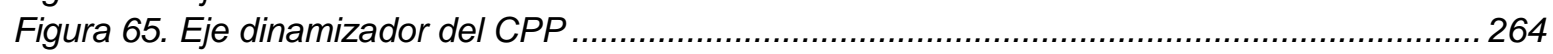

Figura 66. Eje Obstáculo en el CPP al abordar CSC/CTSA en IUE............................................ 265

Figura 67. Eje cuestionamiento del CPP al abordar CSC ..................................................... 266

Figura 68. Frecuencia de palabras codificadas como ejes dinamizadores del CPP .................... 268

Figura 69. Eje Obstáculo del CPP al asumir CSC ................................................................ 269

Figura 70. Eje Cuestionamiento del CPP al abordar CSC .................................................... 270

Figura 71. Ejes DOC complejidad del CPP al asumir CSC .................................................2.272

Figura 72. Características de las CSC que contribuyen al CPP ........................................................2. 273

Figura 73. Características usadas con mayor frecuencia por los profesores del Gl .................... 274

Figura 74. Conglomerados por similitud de codificación de las características de las CSC ......... 277

Figura 75. Razonamientos éticos y morales al abordar CSC ................................................. 278

Figura 76. Visión que tiene los docentes del PGI de la investigación ........................................... 279

Figura 77. Aportes y dificultades del abordaje de CSC_CTSA en la formación de profesores en

ejercicio en IUE ........................................................................................................... 285

Figura 78. Aportes mencionados por los profesores al participar del programa de formación en IUE

Figura 79. Dificultades en el abordaje de CSC

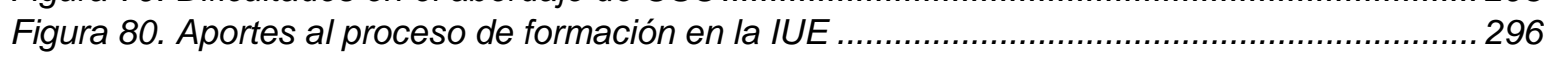

Figura 81. Dificultades de los profesores del GI al asumir las CSC .......................................... 297 
Figura 82. EP relacionado con la CSC en torno a la drogadicción

Figura 83. Aspectos abordados por el CP alrededor de la legalización como CSC....................... 301

Figura 84. EP en el que se movilizaron los profesores del Gl ................................................ 308

Figura 85. EP de tres profesores en particular ................................................................. 308

Figura 86. Aportes del proceso de IUE al proceso de formación y al CPP .................................. 309

Figura 87. EP a la luz de la HdPR de los profesores del Gl ................................................... 310

\section{LISTA DE ABREVIATURAS Y SIGLAS}

\begin{tabular}{c|l} 
CPP & Conocimiento Profesional del Profesor \\
\hline IUE & Interacción Universidad Escuela \\
\hline CTSA & Ciencia Tecnología Sociedad Ambiente \\
\hline CSV & Cuestión Socialmente Viva \\
\hline CSA & Cuestión Socio Ambiental \\
\hline CSC & Cuestión Sociocientífica \\
\hline CP & Colectivo de Pensamiento \\
\hline AT & Estilo de Pensamiento \\
\hline ATD & Análisis Textual \\
\hline AC & Análisis Textual Discursivo \\
\hline AD & Análisis de Contenido \\
\hline HdPR & Hipálisis de Discurso \\
\hline CPD & Conocisieniento Profesión Regresión \\
\hline CPd & Conocimiento Profesional deseable \\
\hline GI & Grupo de Investigación \\
\hline GI1 & Grupo de Investigación Profesores de planta \\
\hline GI2 & Grupo de Investigación de Profesores de horas extras \\
\hline SPA & Sustancias Psicoactivas \\
\hline PEI & Proyecto Educativo Escolar \\
\hline TAC & Teoría de Acción Comunicativa \\
\hline SD & Secuencia Didáctica \\
\hline IED_GCI & Institución Educativa Distrital Guillermo Cano Isaza \\
\hline UPN & Universidad Pedagógica Nacional \\
\hline UNESP & Universidad Estadual Paulista \\
\hline DOC & Dinamizadores Obstáculo Cuestionamiento \\
\hline CEA_CSC & Contenido Escolar Asociado a la Cuestión Sociocientífica \\
\hline CEDID & Centro de Enseñanza Diversificada Distrital \\
\hline INEM & Instituto Nacional de enseñanza Media \\
\hline
\end{tabular}




\begin{tabular}{c|l} 
SENA & Servicio nacional de Aprendizaje Sena \\
\hline PLACTS & $\begin{array}{l}\text { Pensamiento Latino Americano de Ciencia Tecnología y } \\
\text { Sociedad }\end{array}$ \\
\hline CTS & Ciencia Tecnología y Sociedad \\
\hline GDHC & Génesis y Desarrollo de un Hecho Científico \\
\hline SED & Secretaria de Educación \\
\hline MEN & Ministerio de Educación Nacional \\
\hline EJA & Educación de Jóvenes y Adultos
\end{tabular}




\begin{tabular}{|c|c|}
\hline (R) & FORMATO \\
\hline 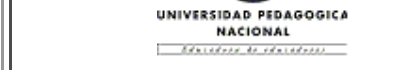 & RESUMEN ANALÍTICO EN EDUCACIÓN - RAE \\
\hline \multicolumn{2}{|c|}{ Código: FOR020GIB } \\
\hline \multicolumn{2}{|c|}{ Fecha de Aprobación: 10-10-2012 } \\
\hline \multicolumn{2}{|r|}{ 1. Información General } \\
\hline Tipo de documento & Tesis de grado \\
\hline Acceso al documento & Universidad Pedagógica Nacional. Biblioteca Central \\
\hline Titulo del documento & $\begin{array}{l}\text { Conocimiento profesional del profesor de ciencias al abordar } \\
\text { cuestiones sociocientíficas: un estudio de caso de un grupo } \\
\text { de investigación en la interacción universidad-escuela }\end{array}$ \\
\hline Autor(es) & Rodríguez Hernández, Blanca Florinda. \\
\hline Director & Martínez Pérez, Leonardo Fabio \\
\hline Publicación & Bogotá, Universidad Pedagógica Nacional, 2018. 322 p. \\
\hline Unidad Patrocinante & Universidad Pedagógica Nacional \\
\hline Palabras Claves & 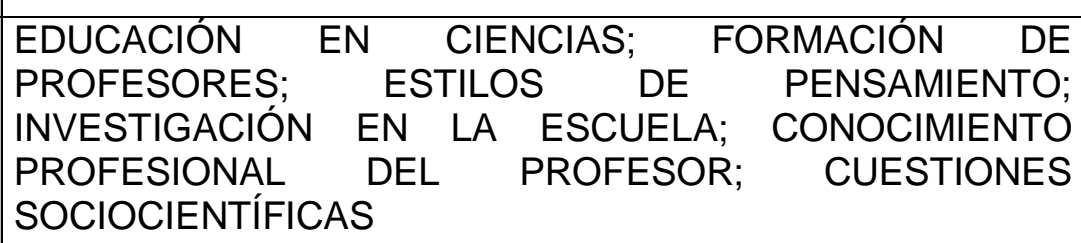 \\
\hline \multicolumn{2}{|r|}{ 2. Descripción } \\
\hline \multicolumn{2}{|c|}{$\begin{array}{l}\text { La presente investigación se construyó en el marco del programa colombo-brasileño de } \\
\text { formación de profesores de ciencias en la interfaz universidad escuela (IUE) establecido } \\
\text { entre la Universidad Pedagógica Nacional, la Universidade Estadual Paulista y } \\
\text { COLCIENCIAS; cuyo objetivo consistió en constituir y analizar el desarrollo de un } \\
\text { programa de formación de profesores enfocado en las discusiones de Cuestiones } \\
\text { Sociocientíficas (CSC) que permitiera establecer recomendaciones curriculares para la } \\
\text { construcción de políticas educativas que articularan las prácticas de los profesores de las } \\
\text { escuelas y la investigación académica desarrollada en los cursos de maestría y doctorado } \\
\text { en la Enseñanza de las Ciencias. }\end{array}$} \\
\hline \multicolumn{2}{|c|}{$\begin{array}{l}\text { En este contexto, se propuso como objetivo general de la investigación describir e } \\
\text { interpretar las características del Conocimiento Profesional del Profesor de Ciencias (CPP) } \\
\text { como eje central para la construcción de conocimientos alrededor de las CSC. Así mismo, } \\
\text { se propuso caracterizar el proceso formativo de la constitución y consolidación de un } \\
\text { Grupo de Investigación (GI) interesado en el abordaje de CSC, identificando la incidencia }\end{array}$} \\
\hline
\end{tabular}


de las características de las mismas en la construcción del CPP de los profesores del GI y la evaluación del aporte del abordaje de las CSC en la construcción del Conocimiento Profesional deseable (CPd) de los profesores en ejercicio a la luz de una hipótesis de progresión-regresión (HdPR).

En términos de metodología, la investigación adoptó una perspectiva cualitativa con método de estudio de caso y técnicas de observación participante; al asumir, el Gl como un estudio de caso único, la preocupación central de la investigación fue la comprensión del CPP como algo singular, único que presenta unas características particulares de cada docente, pero que al estudiar y caracterizarlos de forma individual no es suficiente, ya que la intervención y proceso de formación se realizó en forma colectiva, y a título de hipótesis de trabajo se interpreta cómo el discurso abordado por cada docente, permeó en los de los otros, haciendo que se movilizaran nuevas ideas, se elaboraran constructos conceptuales y epistemológicos, que incidieron en el CPP de cada uno de los profesores participantes del GI, así como también posiblemente hizo que algunos se movilizaran a un estilo de pensamiento en transición.

Se realizó una descripción comprensiva y contextualizada del discurso del grupo usando como dispositivo analítico, el Análisis Textual Discursivo (ATD) y como herramienta de análisis el software Nvivo11 a la luz de la Epistemología Fleckiana; que permitió comprender la construcción del conocimiento en términos de colectivo de pensamiento $(\mathrm{CP})$, estilos de pensamiento (EP), círculos esotéricos y exotéricos, circulación intra e intercolectiva de ideas y hecho científico; así como, entender la IUE en términos de los actores constituyentes, tales como los profesores de la Universidad y los profesores de las Escuelas, que a su vez fundamentaron los referentes de las hipótesis emergentes para analizar las contribuciones de las discusiones epistemológicas del abordaje de CSC en la construcción del CPP en el contexto del proyecto de formación permanente de profesores.

Finalmente, las conclusiones de la investigación, hacen énfasis en las bondades y dificultades que ofrece el abordaje de CSC en la Enseñanza de las Ciencias, en especial a través de proceso de formación permanente de docentes en IUE, en la que se beneficia la escuela como constructora de conocimientos escolares, el profesor como investigador crítico-reflexivo que posee un CPP epistemológicamente diferenciado y la universidad como innovadora/creadora de conocimiento que lidera procesos de investigación y de formación.

\section{Fuentes}

Álvarez, C., \& Osoro, J. M. (2011). Colaboración Universidad-Escuela para el desarrollo profesional docente. In Actas del III Congreso Internacional "Nuevas tendencias en la formación permanente del profesorado.

Anagün, Ş. S., \& Özden, M. (2010). Teacher candidates' perceptions regarding socio-scientific issues and their competencies in using socio-scientific issues in science and technology instruction. Procedia - Social and Behavioral Sciences, 9, 981-985. https://doi.org/10.1016/j.sbspro.2010.12.271

Apple, M. (1993). El libro de texto y la política cultural. Revista de Educación, 301, 109-126. 
Apple, M., \& García, F. P. (2003). Argumentando contra el neoliberalismo y el neoconservadurismo. Luchas por una democracia crítica en educación. Conferencia y coloquio. Con-Ciencia Social: Anuario de Didáctica de La Geografía, La Historia y Las Ciencias Sociales, 7, 83-127.

Arruda, Sergio, Lima, J. P. C., \& Passos, M. M. (2012). Um novo instrumento para a análise da ação do professor em sala de aula. Revista Brasileira de Pesquisa Em Educação Em Ciências, 11(2), 139-160.

Auler, D. (2007). Enfoque Ciência-Tecnologia-Sociedade: pressupostos para o contexto brasileiro. Ciência \& Ensino (ISSN 1980-8631), 1.

Auler, D. (2011). Novos caminhos para a educação CTS: ampliando a participação. CTS e Educação Científica: Desafios, Tendências e Resultados de Pesquisas. Brasília: Editora Universidade de Brasília, 73-97.

Auler, D., \& Bazzo, W. A. (2001). Reflexões para a implementação do movimento cts no contexto educacional brasileiro. Ciência \& Educação (Bauru), 7(1), 1-13. https://doi.org/10.1590/S151673132001000100001

Auler, D., \& Delizoicov, D. (2001). Alfabetização científico-tecnológica para quê? Ensaio Pesquisa Em Educação Em Ciências (Belo Horizonte), 3(2), 122-134.

Auler, D., \& Delizoicov, D. (2015). Investigação de temas CTS no contexto do pensamento latinoamericano. Linhas Críticas, 21(45), 275-296.

Azevedo, M., Ghedin, E., Clara, M., Forsberg, S., Gonzaga, A., \& Oliveira. (2013). O enfoque CTS na formação de professores de ciências e a abordagem de questões sóciocientíficas. Atas Do IX Encontro Nacional de Pesquisa Em Educação Em Ciências, 1-8.

Azevedo, M. N., \& Abib, M. L. V. S. (2013). PESQUISA-AÇÃO E A ELABORAÇÃO DE SABERES DOCENTES EM CIÊNCIAS (Action-research and the elaboration of teaching knowledge in sciences). Investigações Em Ensino de Ciências, 18(1), 55.

Baca, L., Onofre, M., \& Paixão, F. (2014). O CONHECIMENTO DIDÁTICO DO CONTEÚDO DO PROFESSOR E SUA RELAÇÃO COM A UTILIZAÇÃO DE ATIVIDADES PRÁTICAS NAS AULAS DE QUÍMICA: UM ESTUDO COM PROFESSORES PERITOS DO SISTEMA EDUCATIVO ANGOLANO (Teacher Didactic Content Knowledge and its relation with the util. Investigações Em Ensino de Ciências, 19(1), 29.

Ballenilla, F. (2003). El practicum en la formación inicial del profesorado deficiencias de secundaria. Estudio de caso. Tesis Doctoral I: Planteamiento teórico, diseño y conclusiones de la investigación. Universidad de Sevilla.

Ballenilla, F. de G., \& Porlán, R. A. (2003). El" practicum" en la formación inicial del profesorado de ciencias de enseñanza secundaria: estudio de caso. Liberlibro.

Bañas, C., Pavón, R., Ruiz, C., \& Mellado, V. (2011). An action-research program with secondary education teachers' on teaching-learning energy: a case study. Revista Brasileira de Ensino de Física, 33(3), 1-9.

Bardin, L. (1991). Análisis de contenido (Vol. 89). Ediciones Akal.

Batista, G., El-Hani, C., \& Carvalho, G. S. de. (2012). Condições de trabalho escolar, sua influência na saúde e no desenvolvimento profissional de professores de ciências: um estudo de caso com professores da Bahia. In VIII Encontro Nacional de Pesquisa em Educação em Ciências (ENPEC); Congresso Iberoamericano de Investigación en Enseñanza de las Ciéncias (CIEC) (pp. 1-12). ABRAPEC.

Bazzo, J. L. S., \& Bazzo, W. A. (2011). INTERSEÇÕES CTS, DO DIREITO À ENGENHARIA: O HUMANO COMO FUNDAMENTO BÁSICO.

Beane, J., \& Apple, M. (2000). Escuelas democráticas. Madrid: Morata.

Behrsin, M. C. D. (2011). TEACHING VOICES: ANALYSIS OF THE REFLECTIONS OF SCIENCE 
TEACHERS ABOUT THEIR PROFESSIONAL EXPERIENCE. Ensaio Pesquisa Em Educação Em Ciências (Belo Horizonte), 13(1), 73-86.

Beltrán, M. J. C., \& Martínez, L. F. P. (2014). ANÁLISIS DE LAS ESTRUCTURAS ARGUMENTATIVAS, CONSTRUIDAS POR ESTUDIANTES DE EDUCACIÓN MEDIA, SOBRE LA CUESTIÓN LOCAL DEL USO DEL AGUA DE LOS VALLADOS DE CAJICÁ. Gondola: Ensenanza Aprendizaje de Las Ciencias, 9(1), 103.

Bencze, J. L., Carter, L., \& Krstovic, M. (2014). Science \& Technology Education for personal, social \& environmental wellbeing: challenging capitalists' consumerist strategies. Revista Brasileira de Pesquisa Em Educação Em Ciências, 14(2), 39-56.

Beraza, M. A. Z. (2011). El practicum en la formación universitaria: Estado de la cuestiónn. Revista de Educacion, 354, 21-43. https://doi.org/issn: 0034-8082

Bernardino, A. J. (2008). Exigências na formação dos professores de EJA. VII Seminário de Pesquisa Em Educação Da Região Sul.

Bertram, A. (2014). CoRes y PaP-eRs como una estrategia para ayudar a los maestros de primaria principiantes a desarrollar su conocimiento didáctico del contenido. Educación Química, 25(3), 292-303.

Binatto, P. F., Chapani, D. T., \& Duarte, A. C. S. (2015). Formação reflexiva de professores de ciências e enfoque ciência, tecnologia e sociedade: possíveis aproximações. Alexandria: Revista de Educação Em Ciência e Tecnologia, 8(1), 131-152.

Bisquerra, R. A. (2005). DE LA INVESTIGACIÓN EDUCATIVA. Revista Mexicana de Investigación Educativa, 10(25), 593-596.

Bortoletto, A., Freitas, Z. L., Oliveira, E. R. de, \& Carvalho, L. M. O. de. (2016). Sobre a constituição de um programa de formação de professores: a história de um grupo de pesquisa. In Formação de professores, questões sociocientíficas y avalição em larga escala Aproximando a pós-graduação da escola (p. 334). Bauru.

Bourdieu, P. (1974). O mercado de bens simbólicos. A Economia Das Trocas Simbólicas, 2.

Bourdieu, P. (1990). Una ciencia que incomoda. Sociología y Cultura, 79-94.

Bourdieu, P. (1996). Razões práticas: sobre a teoria da ação. Papirus Editora.

Bourdieu, P. (2008). El campo científico. Revista Redes, 24(7), 130-160. https://doi.org/10.1017/UPO9781844654031

Bourdieu, P., \& Passeron, J.-C. (2001a). Fundamentos de una teoría de la violencia simbólica. La Reproducción. Elementos Para Una Teoría Del Sistema de Enseñanza, 15-85.

Bromme, R. (1988). Conocimientos profesionales de los profesores. Enseñanza de Las Ciencias: Revista de Investigación y Experiencias Didácticas, 6(1), 19-29.

Budel, G. J. (2016). Ensino de química para a educação de jovens e adultos buscando uma abordagem ciência, tecnologia e sociedade. Universidade Tecnológica Federal do Paraná.

Burmeister, M., Rauch, F., \& Eilks, I. (2012). Education for Sustainable Development (ESD) and chemistry education. Chemistry Education Research and Practice, 13(2), 59-68. https://doi.org/10.1039/C1RP90060A

Cachapuz, A. F. (2000). A procura da excelência na aprendizagem. Série-Estudos-Periódico Do Programa de Pós-Graduação Em Educação Da UCDB, (10).

Cachapuz, A., Paixão, F., Lopes, B., \& Guerra, C. (2008). Do estado da arte da pesquisa em educação em ciências: linhas de pesquisa e o caso "Ciência-Tecnologia-Sociedade." ALEXANDRIA Revista de Educação Em Ciência e Tecnologia, 27-49.

Caetano, A., Costa, A. R., \& Domingues, S. C. (2009). A produção do conhecimento das Universidades e a realidade escolar: uma análise crítica sobre o modelo atual de sociedade. 

Motrivivência, (30), 185-196.
Camarotti, A. C., Kornblit, A. L., \& Leo, P. F. Di. (2013). Prevención del consumo problemático de drogas en la escuela: estrategia de formación docente en Argentina utilizando TIC. Interface- Comunicação, Saúde, Educação, 17(46).
Carnio, M. P. (2011). TRATAMIENTO DE PROBLEMAS SOCIO-CIENTíFICOS EN LA FORMACIÓN DE PROFESORES DE BIOLOGÍA: ALGUNOS ASPECTOS. Gondola: Ensenanza Aprendizaje de Las Ciencias, 6(1), 21.

Carr \& Kemmis. (1988). Teoría Crítica De La Enseñanza .Pdf.

Carta de Belem. (2009). SOCIAL, DPDELIII DE SALUD, MUNDIAL.

Carvajal, I. X., \& Martínez, L. F. (2014). ENCULTURACIÓN CIENTÍFICA A PARTIR DE LA ARGUMENTACIÓN: UNA CUESTIÓN SOCIOCIENTÍFICA (CSC) SOBRE IMPLANTES ESTÉTICOS. Góndola, Enseñanza y Aprendizaje de Las Ciencias.(Bogotá, Colombia), 9(1), 96-102.

Carvalho, L. M. O. de. (2015). Interação entre a escola básica e a pós-graduação: uma rede de Pequenos Grupos de Pesquisa (PGP). Eventos Pedagógicos, 78-97.

Carvalho, L. M. O. de, \& Chapani, D. T. (2012). A formação docente no âmbito das esferas $p$ úblicas democráticas. In W. L. ORQUIZA-DE CARVALHO, L. M.; CARVALHO (Ed.), Formação de Professores e Questões Sociocientíficas no Ensino de Ciências. (pp. 21-42). São Paulo: Educação para a Ciência.

Carvalho, P. W. De, Carvalho, L. M. O. de, \& Junior, J. (2016). Formação de professores, questões sociocientíficas e avaliação em larga escala.

Carvalho, L. (2015). Formação de professores e questões sociocientíficas no ensino de ciências. Escrituras Editora e Distribuirdora de Livros Ltda.

Castro, G. J., \& Hernández, U. (2013). El saber del maestro en contextos de diversidad sociocultural: recuperación de las experiencias pedagógicas desde la interacción en red. Nodos y Nudos, 4(32).

Chapani, D. T. (2010). Políticas públicas e história de formação de professores de Ciências: uma análise a partir da teoria social de Habermas. Universidade Estadual Paulista (UNESP).

Chinn, P. W. U. (2012). Developing teachers' place-based and culture-based pedagogical content knowledge and agency. In Second international handbook of science education (pp. 323-334). Springer.

Cohen, J. (2004). Lograr una reduccion de los daños asociados a las drogas mediante la educación. (N. Heather, A. Wodak, E. Nadelmann, \& P. O'Hare, Eds.). La cultura de las drogas en la sociedad del riesgo.

Connelly, F. M., \& Clandinin, D. J. (1982). Personal Practical Knowledge at Bay Street School.

Conrado, D. M., \& El-Hani, C. N. (2010). Formação de cidadãos na perspectiva CTS: reflexões para o ensino de ciências. II Simpósio Nacional de Ensino de Ciência e Tecnologia (II SINECT), Ponta Grossa, UTFPR.

Contreras, J. D. (1997). La autonomía del profesorado. Ediciones Morata.

Correa, L. F., \& Bazzo, W. A. (2017). Contribuições da Abordagem Ciência, Tecnologia e Sociedade para a Humanização do Trabalho Docente. Revista Contexto \& Educação, 32(102), 57-80.

Cruz, E. P., \& Barzano, M. A. L. (2016). SABERES DOCENTES: UM OLHAR PARA UMA DIMENSÃO NÃO EXIGIDA NAS TRAJETÓRIAS DE PROFESSORES-PESQUISADORES DO CURSO DE LICENCIATURA EM CIÊNCIAS BIOLÓGICAS. Investigações Em Ensino de Ciências, 19(1), 117-139.

Cruz, L. (2011). El conocimiento práctico docente del profesor universitario en su interrelación con el marco epistemológico personal Departamento de Didáctica y Organización Educativa 

Universidad de Barcelona. Universidad de Barcelona.
Cutcliffe, S. H. (2004). Ideas, máquinas y valores: Los estudios de Ciencia, Tecnología y Sociedad (Vol. 15). Anthropos Editorial.
Delizoicov, D., \& Auler, D. (2011). Ciência, Tecnologia e Formação Social do Espaço: questões sobre a não-neutralidade. Alexandria: Revista de Educação Em Ciência e Tecnologia, 4(2), 247-273.
Delizoicov, D., Castilho, N., Cutolo, L. R. A., Ros, M. A. Da, \& Lima, A. M. C. (2002). Sociogênese do conhecimento e pesquisa em ensino: contribuições a partir do referencial fleckiano. Caderno Brasileiro de Ensino de Física, 19, 52-69.
Delizoicov, N. C., Carneiro, M. H. S., \& Delizoicov, D. (2004). O MOVIMENTO DO SANGUE NO CORPO HUMANO: DO CONTEXTO DA PRODUÇÃO DO CONHECIMENTO PARA O DO SEU ENSINO The motion of blood in human body: from the knowledge production context to its teaching. Ciência \& Educação, 10(3), 443-460.
Denzin, N. K., \& Lincoln, Y. S. (1994). Ingresando al campo de la investigación cialitativa. Research in Education: A Conceptual Introduction. Glenview: Scott, Foresman and Company, 15.
Denzin, N. K., \& Lincoln, Y. S. (1994). Manual de investigación cualitativa (Vol. 1). Gedisa.
Denzin, N. K., \& Lincoln, Y. S. (2011). The Sage handbook of qualitative research. Sage.
Denzin, N. K., \& Lincon, Y. S. (2006). Introdução da Pesquisa Qualitativa. O Planejamento Da Pesquisa Qualitativa.

Díaz, M. N., \& Jiménez, L. M. R. (2012). Las controversias sociocientíficas: temáticas e importancia para la educación científica. Revista Eureka Sobre Enseñanza y Divulgación de Las Ciencias, $9(1)$.

Duarte, R. (2004). Entrevistas em pesquisas qualitativas. Educar Em Revista, (24).

Elliot, J. (1990). La investigación-acción en la escuela. Madrid: Morata.

Farré, A. S., \& Lorenzo, M. G. (2014). Para no seguir reinventando la rueda: El conocimiento didáctico en uso sobre los compuestos aromáticos. Educación Química, 25(3), 304-311.

Fleck, L. (1929). Zur Krise der „Wirklichkeit “. Naturwissenschaften, 17(23), 425-430.

Fleck, L. (1971). La Génesis y El Desarrollo De Un Hecho Científico, 7(1), 45-98. Retrieved from http://www.tec-

digital.itcr.ac.cr/file/2785165/Fleck,_La_génesis_y_el_desarrollo_de_un_hecho_científico.pdf

Fleck, L. (1979). Genesis and development of a scientific fact. Genesis and development of a scientific fact. University of Chicago Press Chicago.

Fleck, L. (1986). La génesis y el desarrollo de un hecho científico.

Flick, U. (2004). Introducción a la investigación cualitativa. Ediciones Morata SL Madrid.

Freire, P. (1994). Cartas a quien pretende enseñar. Siglo XXI.

Freire, P. (2005). Pedagogía del oprimido. Siglo xxi.

Freire, P. (2006). Pedagogía de la autonomía: saberes necesarios para la práctica educativa. Siglo $\mathrm{XXI}$.

Freitas, Z. L., Carvalho, L. M. O. de, \& Oliveira, E. R. de. (2012). Educação de professores da universidade no contexto de interação universidade-escola. Ciência \& Educação (Bauru), 18(2), 323-334. https://doi.org/10.1590/S1516-73132012000200006

Fürkotter, M., Garboggini, D. G. A., Miotto, M. M., Mendonça, L. N., Moreira, M. L. V., \& Ferrari, L. Y. (2014). O que a Formação Contínua deve Contemplar?: o que dizem os professores. Educação \& Realidade, 39(3).

Galvão, C., \& Reis, P. (2008). A promoção do interesse e da relevância do ensino da ciência através da discussão de controvérsias sociocientíficas La promoción del interés y de la relevancia de la enseñanza de la ciencia a traves de la discusión de controversias sociocientíficas, 131-135. 
García, C. (2007). La formación docente en la sociedad del conocimiento y la información: avances y temas pendientes. Olhar de Professor, 10(1).

Garritz. (1994). Ciencia-Tecnología-Sociedad a diez años de iniciada la corriente. Educación Química, 5(4), 217-223.

Garritz, A. (2012). Conocimiento didáctico del contenido. Mis últimas investigaciones: CDC en lo afectivo, sobre la estequiometría y la indagación. TED: Tecné, Episteme y Didaxis, 0(30)., 6881.

Garritz, A. (2014). Celebración del vigésimo quinto aniversario de Educación Química. Elsevier.

Garritz, A., \& Ortega, N. (2013). El aspecto afectivo en la enseñanza universitaria. Cómo cinco profesores enseñan el enlace químico en la materia condensada. Las Emociones En La Enseñanza y El Aprendizaje de Las Ciencias y Las Matemáticas, 279.

Gaviria, M. B., \& Ospina, H. F. (2009). ¿ Es la institución educativa productora y reproductora de exclusión social? Infancias Imágenes, 8(1), 12.

Gentil, V. K. (2005). EJA: contexto histórico e desafios da formação docente. Centro de Referência Em Educação de Jovens e Adultos-CEREJA.

Gentile, N., Bosch, B., Mañas, F., Gorla, N., \& Aiassa, D. (2013). LA SITUACION AMBIENTAL DE UNA ZONA DE CULTIVO AFECTADA POR PLAGUICIDAS Y LAS REPERCUSIONES EN LA SALUD HUMANA.

Gianina, D., Leal, F., Comelin, A., Parra, M., \& Varelas, P. (2013). Conocimiento práctico de los profesores: sus características y contradicciones en el contexto universitario actual. Revista de La Educación Superior, 42(166), 35-53.

Giroux, H. (1990). Los profesores como intelectuales. Barcelona: Paidós.

Girox, H. (1990). Los profesores como intelectuales. Hacia Una Pedagogía Crítica.

Goes, L. F. De, Leal, S. H., Corio, P., \& Fernandez, C. (2013). Aspectos do conhecimento pedagógico do conteúdo de química verde em professores universitários de química. Educacion Quimica, 24(SPL.ISSUE1), 113-123. https://doi.org/10.1016/S0187893X(13)72504-7

Gómez, V. M. (2005). Modalidades de educación secundaria y formación de actitudes y disposiciones frente al conocimiento en Colombia. Revista Colombiana de Sociología, (25), 25.

Grossman, P. L., Wilson, S. M., \& Shulman, L. S. (1989). Teachers of substance: Subject matter knowledge for teaching. Profesorado, Revista de Currículum y Formación Del Profesorado, 9(2), 1-25.

Gutiérrez, A. B. (2004). Poder, hábitus y representaciones: recorrido por el concepto de violencia simbólica en Pierre Bourdieu. Revista Complutense de Educación, 15, 289-300.

Habermas, J. (1987). Teoría de la acción comunicativa, I. Racionalidad de la acción y racionalidad social. Versión Castellana de Manuel Jiménez Rendón. Editorial Taurus. Madrid España.

Hodson, D. (2009). Teaching and Learning about Science: Language, Theories, Methods, History, Traditions and Values. Sense Publishers.

Holbrook, J., \& Rannikmae, M. (2009). The meaning of scientific literacy. International Journal of Environmental and Science Education, 4(3), 275-288.

Hopenhayn, M. (2002). Vida insular en la aldea global: paradojas en curso. Polis. Revista Latinoamericana, (2).

Huberman, M., \& Levinson, N. (1988). "Un modelo para el intercambio de conocimientos docentes entre universidad y escuelas." Revista de Educación, 286, 61-78.

Huberman, M., \& Middlebrooks, S. (2000). The dilution of inquiry: A qualitative study. International Journal of Qualitative Studies in Education, 13(3), 281-304.

Hygino, C. B., Janeiro, R. De, \& Janeiro, R. De. (2013). Modelos didáticos presentes na formação de 
futuros professores de química e física da região norte do estado do Rio de Janeiro , Brasil : encontros e desencontros entre concepções e formação, 49-58.

Imbernón, F. (1994). La formación del profesorado.

Imbernón, F. (2009). Formação permanente do professorado: novas tendências. São Paulo: Cortez.

Imbernón, F. (2011). Un nuevo desarrollo professional de professorado pada una nueva educación.

Revista de Ciências Humanas, 12(19), 75-86.

Imbernón, F. (2012). Un nuevo desarrollo profesional del profesorado para una nueva educación. Revista de Ciencias Humanas, 12(19), 75-86.

Imbernon, F., \& Canto, P. J. (2013). La formación y el desarrollo profesional del profesorado en España y Latinoamérica. Sinéctica. scielomx.

Ireland, T. D. (2013). Revisitando a CONFINTEA: sessenta anos de defesa e promoção da educação de adultos. Revista Brasileira de Educação de Jovens e Adultos, 1(1), 14-28.

Jarauta, B.-B., \& Medina, J. L.-M. (2012). Saberes docentes y enseñanza universitaria.

Johnston, L. (2006). Software and method: Reflections on teaching and using QSR NVivo in doctoral research. International Journal of Social Research Methodology, 9(5), 379-391.

Kemmis, S., \& McTaggart, R. (2005). Communicative action and the public sphere. The Sage Handbook of Qualitative Research, 3, 559-603.

Kolsto, S. D. (2001). "To trust or not to trust,...'-pupils" ways of judging information encountered in a socio-scientific issue. International Journal of Science Education, 23(9), 877-901.

Lage, M. C. (2011). Utilização do software NVivo em pesquisa qualitativa: uma experiência em EaD Using NVivo software in qualitative research: a distance learning experience. ETD - Educação Temática Digital, 12(mar.), 198-226.

Lederman, N. G., \& Abell, S. K. (2014). Handbook of research on science education (Vol. 2). Routledge.

Leonard, A. (2010). La historia de las COSAS, De cómo nuestra obsesión por las cosas está destruyendo el planeta, nuestra comunidades y nuestra salud. Y Una Visión Del Cambio.

Levin, L. (2011). La construcción de la adicción como problema de conocimiento neurobiológico y las perspectivas de tratamientos. Una crítica al modelo médico hegemónico. Redes, 17(32).

Levinson, J. D. (2007). Forgotten racial equality: Implicit bias, decisionmaking, and misremembering. Duke Law Journal, 345-424.

Levinson, R. (2006a). SOCIO-SCIENTIFIC ISSUES : A STUDY OF TEACHERS ' REFLECTIONS, 41(4), 24-41.

Levinson, R. (2006b). Teachers' perceptions of the role of evidence in teaching controversial socioscientific issues. The Curriculum Journal, 17(3), 247-262.

Levinson, R. (2006c). Towards a Theoretical Framework for Teaching Controversial Socio-scientific Issues, 28(10), 1201-1224. https://doi.org/10.1080/09500690600560753

Levinson, R. (2007). Teaching controversial socio-scientific issues to gifted and talented students.

Levinson, R. (2008). Promoting the role of the personal narrative in teaching controversial socioscientific issues. Science \& Education, 17(8-9), 855-871.

Levinson, R. (2010). Science education and democratic participation: An uneasy congruence? Studies in Science Education, 46(1), 69-119.

Lima, A. A., \& Nuñez, I. B. (2013). A análise do conhecimento pedagógico do conteúdo no planejamento de atividades com a utilização de modelos no ensino de química. Química Nova Na Escola, 36, 123-131.

Lima, V. A., \& Marcondes, M. E. R. (2011). Saindo Também se Aprende-O Protagonismo como um Processo de Ensino-Aprendizagem de Química.

Linn, M. C., Shear, L., Bell, P., \& Slotta, J. D. (1999). Organizing principles for science education 
\begin{tabular}{|ll}
\hline \hline partnerships: Case studies of students' learning about 'rats in space' and 'deformed frogs.' \\
Educational Technology Research and Development, 47(2), 61-84.
\end{tabular} https://doi.org/10.1007/BF02299466

Linsingen, I. Von. (2007). Perspectiva educacional CTS: aspectos de um campo em consolidação na América Latina. Ciência \& Ensino (ISSN 1980-8631), 1.

Lipovetsky, G. (2016). De la ligereza (Vol. 501). Anagrama.

Lombana, C., Delgado, F., \& Rickenmann, R. (2011). Un programa de formación continua con profesores de ciencias en el contexto de la relación museo-escuela.

Lopes, A. C. (2005a). Por que somos tão disciplinares? Educação Temática Digital, 9, 201.econtextualização e Hibridismo. Currículo Sem Fronteiras, 5(2), 50-64.

Lopes, A. C. (2005b). Recontextualização e Hibridismo. Currículo Sem Fronteiras, 5(2), 50-64.

Lopes, A. C. (2008). Por que somos tão disciplinares? Educação Temática Digital, 9, 201.

Lopes, N. C. (2013). A constituição de associações livres e o trabalho com as questões sociocientíficas na formação de professores. Universidade Estadual Paulista (UNESP).

Lopes, N. C., \& Carvalho, W. L. P. de. (2013). Possibilidades e limitações da prática do professor na experiência com a temática energia e desenvolvimento humano no ensino de ciências. Revista Brasileira de Pesquisa Em Educação Em Ciências, 207-226.

Lopes, N. C., \& Carvalho, W. L. P. de. (2017). Initial and continued teacher training: from licensees to the constitution of small research groups as free associations. Educação Em Revista, 33.

Ludke, M., \& André, M. (1986). Pesquisa em Educação: Abordagens Qualitativas. (Editora Pedagógica e Universitária - EPU, Ed.). São Paulo.

Lüdke, M., \& André, M. E. D. A. (1986). Metodologia científica para o professor pesquisador. Rio de janeiro: Lamparina.quisa em educação: abordagens qualitativas. Editora Pedagógica e Universitária.

Machado, M. A., \& Queiróz, G. R. P. (2012). A cultura de projetos, construída via parceria escolauniversidade, contribuindo para a qualidade da formação inicial e continuada de professores.

Revista Brasileira de Pesquisa Em Educação Em Ciências, 12(1), 93-116.

Maldaner, O. A. (2014). Formação de professores para um contexto de referência conhecido. Formação de Professores: Compreensões Em Novos Programas e Ações. Ijuí, RS: Ed. UNIJUI, 15-41.

Manzini, E. J. (2004). Entrevista semi-estruturada: análise de objetivos e de roteirosSeminário internacional sobre pesquisa e estudos qualitativos. Anais... Bauru: Universidade de São Carlos, 2004Disponível Em:<Http://Scholar. Google. Com/Scholar.

Marbà, A., Gairín, J., \& Talavera, M. (2013). Evaluación del conocimiento didáctico y científico del profesorado: el caso del sistema educativo de Panamá. Enseñanza de Las Ciencias: Revista de Investigación y Experiencias Didácticas, 31(3), 229-247.

Martínez, C. (2000). Las propuestas curriculares sobre el conocimiento escolar en el área de conocimiento del medio: dos estudios de caso en profesores de primaria. Tesis Doctoral. Programa Didáctica de las Ciencias Experimentales y Sociales, un enfoque interdisciplinar. Universidad de Sevilla, 648 p., Sevilla, España.

Martínez, C. (2005). De los contenidos al conocimiento escolar en las clases deficiencias. Revista Educación y Pedagogía, 17(43), 149-162.

Martínez, C. (2016). mor.

Martínez, C. A. (2016). El conocimiento profesional de los profesores de ciencias sobre el conocimiento escolar: dos estudios de caso, en aulas vivas y aulas hospitalarias del Distrito Capital de BogotáMartínez,. Universidad Distrital Francisco José de Caldas.

Martínez, C. A. (2017). Ser maestro de ciencias: productor de conocimiento profesional y de 
conocimiento escolar. Universidad Distrital Francisco José de Caldas.

Martínez, C. A. R., \& Martínez, V. (2012). El conocimiento escolar y las Hipótesis de Progresión: algunos fundamentos y desarrollos. Nodos y Nudos, 4(32), 50-64.

Martínez, C. A. R., \& Valbuena, E. U. (2013). El conocimiento profesional de los profesores deficiencias sobre el conocimiento escolar: resultados de investigación. Libros de los énfasis del Doctorado Interinstitucional en Educación. Bogotá, Colombia. Universidad Distrital Francisco José de Caldas.

Martínez, C. A. R., \& Valvuena, E. O. (2013). El conocimiento profesional de los profesores de ciencias de primaria sobre el conocimiento escolar: Un caso sobre los tipos de contenidos y referentes epistemológicos.

Martínez, C. A., \& Valbuena, E. O. (2013). El conocimiento profesional de los profesores de ciencias sobre el conocimiento escolar: resultados de investigación. Universidad Distrital Francisco José de Caldas.

Martínez, L. (2014). Cuestiones sociocientíficas en la formación de profesores de ciencias: aportes y desafíos. TED: Tecné, Episteme y Didaxis, (36).

Martínez, L. F. (2010). A abordagem de questões sociocientíficas na formação continuada de professores de ciências: contribuições e dificuldades. Universidade Estadual Paulista (UNESP).

Martínez, L. F. (2010). A abordagem de questões sociocientíficas na formação continuada de professores de ciências: contribuições e dificuldades.

Martínez, L. F. P. (2012). Questões sociocientíficas na prática docente: ideologia, autonomia e formação de professores. SciELO-Editora UNESP.

Martínez, L. F. P. (2014). Cuestiones sociocientíficas en la formación de profesores de ciencias: aportes y desafíos. Tecné, Episteme y Didacxis, (36), 77-94. Retrieved from http://revistas.pedagogica.edu.co/index.php/TED/article/viewFile/2913/2634

Martínez, L. F., Parga, D., Zapata, P. N., Rodríguez, B., \& Garzón, I. (2015). Formación de profesores y cuestiones sociocientíficas. Experinecias yb desafios en la interfaz universidad escuela. (L. F. Martínez, D. Parga, \& I. Garzón, Eds.). Bogotá.

Martínez, L., \& Parga, D. (2013). Discurso ético y ambiental sobre cuestiones sociocientíficas: aportes para la formación del profesorado. Bogotá, DC: Universidad Pedagógica Nacional.

Martínez, L., \& Parga, D. (2014). Formación permanente de profesores en la interfaz universidadescuela: currículo, fundamentos y roles. Una experiencia en construcción. Bogotá: Fondo Editorial, Universidad Pedagógica Nacional.[Links].

Martínez Pérez, L. F., \& Carvalho, W. L. P. de. (2012). Contribuições e dificuldades da abordagem de questões sociocientíficas na prática de professores de ciências. Educação e Pesquisa, 38(3), 727-741. https://doi.org/10.1590/S1517-97022012005000014

Massoni, N. T., \& Moreira, M. A. (2015). A Epistemologia de Fleck: Uma Contribuição ao Debate sobre a Natureza da Ciência. Alexandria, 8(1), 237-264.

Matos, S. A. de. (2014). Abordagem Ciência, Tecnologia e Sociedade em uma disciplina do curso de especialização em ensino de ciências por investigação.

Medina, N. A., Ferriani, M. das G., \& Carvalho. (2010). Factores protectores de las familias para prevenir el consumo de drogas en un municipio de Colombia. Revista Latino-Americana de Enfermagem, 18.

Mellado, V. (2014). A formação eo desenvolvimento profissional de professores de ciências experimentais. Tecné, Episteme y Didaxis: TED, (35), 7-10.

Mellado, V., Borrachero, A. B., Brígido, M., Melo, L. V, Dávila, M. A., Conde, M. C., ... Guadalupe, M. (2014). Las emociones en la enseñanza de las ciencias. Enseñanza de Las Ciencias, 32(3), 


\section{1-36.}

Melo, M. R., \& Villani, A. (2011). A evolução de uma professora na formação de licenciandos de Química numa perspectiva sócio-ambiental. Investigações Em Ensino de Ciências, 16(2), 291315.

Miranda, C. T., Santos, J., Pinheiros, N., \& Silveira, R. (2011). Matemática e CTS: o ensino de medidas de áreas sob o enfoque da ciência tecnologia e sociedade em umPedretti, E. (2003). Teaching science, technology, society and environment (STSE) education. The role of moral reasoning on socioscientific issues and disc. Atas Do VIIIEncontro Nacional de Pesquisa Em Educação Em Ciências (ENPEC). Campinas (SP).

Moraes, R., \& Galiazz, do C. (2007). Análise textual: discursiva. (Editora Unijuí., Ed.).

Moraes, R., \& Galiazzi, M. (2007). Análise textual: discursiva. Editora Unijuí.

Moreira, H., \& Caleffe, L. G. (2008). Metodologia científica para o professor pesquisador. Rio de Janeiro: Lamparina.

Moreira, M. A. (2002). Pesquisa em educação em ciências: métodos qualitativos. Programa Internacional de Doctorado En Enseñanza de Las Ciencias. Universidad de Burgos, Espanha, $25-55$.

Moreira, M. A. (2002). Pesquisa em Educação em Ciências: Métodos Qualitativos. Actas Del PIDEC, 4, 25-55.

Moreno, D. F. S. (2015). Compreensões sobre a natureza da ciência de licenciandos a partir da experiência com questões sociocientíficas: possibilidades para a formação inicial. Universidade Estadual Paulista (UNESP).

Mundim, J. V., \& Santos, W. L. dos. (2012). Ensino de ciências no ensino fundamental por meio de temas sociocientíficos: análise de uma prática pedagógica com vista à superação do ensino disciplinar. Ciência \& Educação (Bauru), 18(4).

Muñoz, T. G. (2003). El cuestionario como instrumento de investigación/evaluación. Centro Universitario Santa Ana. Recuperado de Http://Cvonline. Uaeh. Edu. Mx/Cursos/Maestria/MTE/Gen02/Seminario_de_tesis/Unidad_4_anterior/Lect_El_Cuestionario. Pdf.

Naiff, L. A. M., Naiff, D. G. M., Pereira, J. M. M., \& Ávila, R. F. de. (2015). O que pensam os professores sobre seus alunos: aspectos psicossociais da Educação de Jovens e Adultos. Gerais: Revista Interinstitucional de Psicologia, 8(1), 19-32.

Nelkin, D. (2001). Molecular metaphors: the gene in popular discourse. Nature Reviews Genetics, 2, 555. Retrieved from http://dx.doi.org/10.1038/35080583

Niño, L. S. Z. (2005). Conceptos y prácticas del currículo y la evaluación:¿ Predominio de un enfoque? De La Perspectiva Instrumental a La Perspectiva Crítica., 119.

Niño, L. S. Z. (2013). Currículo y evaluación críticos: pedagogía para la autonomía y la democracia. Universidad Pedagógica Nacional, CIUP.

Nóvoa, A. (2009). Para una formación de profesores construida dentro de la profesión Towards a teacher training developed inside the profession. Revista de Educación, 350, 203-221.

Nussbaum, M. C. (2010). Sin fines de lucro. Por qué la democracia necesita de las huLipovetsky, G. (2016). De la ligereza (Vol. 501). Anagrama.manidades. Katz Editores.

Oliveira, B. E. T., \& Pino, J. C. (2013). Currículo escolar en el contexto de la situación de estudio: drogas - efectos y consecuencias en el ser humano. Educación Química, 24(3), 351-357. https://doi.org/10.1016/S0187-893X(13)72486-8

Oliveira, C. L., \& Santos, R. S. (2011). Impacts on the Emissions Monitoring System (OBD) Due to the Use of Biodiesel and Higher NOx Emissions. SAE Technical Paper.

Oliveira, E. (2012). " Reflexões sobre o ensino de inglês com língua estrangeira"-professores de 

inglês em curso. Trabalhos Em Linguística Aplicada, 39(1).
Ormart, E., \& Brunetti, J. (2013). La formación de los docentes en competencias éticas. Nodos y Nudos, 4(35), 10-21.
Palacios, E. M. G., Galbarte, J. C. G., Cerezo, J. A. L., Luján, J. L., Gordillo, M. M., Osorio, C., \& Valdés, C. (2005). Ciencia, tecnología y sociedad: una aproximación conceptual. Organización de Estados Iberoamericanos (OEI).
Parga, D., Mora, W., \& Cárdenas, Y. (2014). Dimensión ambiental: una inclusión necesaria para la formación de profesores de química. Gondola: Ensenanza Aprendizaje de Las Ciencias, 9(1), 38.

Parga, D., \& Mora, W. M. (2014). El PCK, un espacio de diversidad teórica: Conceptos y experiencias unificadoras en relación con la didáctica de los contenidos en química. Educación Química, 25(3), 332-342. https://doi.org/https://doi.org/10.1016/S0187-893X(14)70549-X

Parga, D., \& Pinzón, Y. (2014). El currículo del programa de formación de profesores en la interfaz universidad escuela. Martínez, D. et Al., Formación Permanente de Profesores En La Interfaz Universidad-Escuela: Currículo, Fundamentos y Roles. Una Experiencia En Construcción. Universidad Pedagógica Nacional. Bogotá.

Park, S., \& Oliver, J. S. (2008). Revisiting the conceptualisation of pedagogical content knowledge (PCK): PCK as a conceptual tool to understand teachers as professionals. Research in Science Education, 38(3), 261-284.

Pedretti, E. (2003). Teaching science, technology, society and environment (STSE) education. The Role of Moral Reasoning on Socioscientific Issues and Discourse in Science Education, 219239.

Pedretti, E., \& Nazir, J. (2011). Currents in STSE education: Mapping a complex field, 40 years on. Science Education, 95(4), 601-626.

Perafán, A. (2015). El conocimiento profesional específico del profesor de ciencias asociado a una categoría, 10, 34-48.

Perafán, G. A. E. (2013). La transposición didáctica como estatuto epistemológico fundante de los saberes académicos del profesor. Revista Folios, (37).

Pinheiro, N. M. A., Silveira, R. C. F., \& Bazzo, W. A. (2007). Ciência, tecnologia e sociedade: a relevância do enfoque CTS para o contexto do ensino médio. Ciência \& Educação (Bauru), 13(1).

Pinheiro, N. M., Silveira, R. M., \& Bazzo, W. A. (2007). Ciência, tecnologia e sociedade: a relevância do enfoque CTS para o contexto do ensino médio. Ciência \& Educação (Bauru), 13(1).

Porlán, R. A., Rivero, A. G., \& Pozo, M. del. (1997). Conocimiento profesional y epistemología de los profesores I: Teoría, métodos e instrumentos. Enseñanza de Las Ciencias, 15(2), 155-171. Retrieved from http://ddd.uab.cat/pub/edlc/02124521v15n2p155.pdf

Porlán, R. A., Rivero, A. G., \& Pozo, R. M. del. (1998). Conocimiento Profesional y Epistemología de los Profesores, II: Estudios Empíricos y Conclusiones. Enseñanza de Las Ciencias. Revista de Investigación y Experiencias Didácticas. 16 (2), 271-288.

Porlán, R., Pozo, R. M. del, Rivero, A. G., Harres, J., Azcárate, P., \& Pizzato, M. (2010). El cambio del profesorado de ciencias I: marco teórico y formativo. Enseñanza de Las Ciencias, 28(1), $31-46$.

Porlán, R., \& Rivero, A. (1998). El conocimiento de los profesores: una propuesta formativa en el área de ciencias.

Porlán, R., Rivero, A., \& Pozo, M. del. (1998). Conocimiento profesional y epistemología de los profesores, II: Estudios empíricos y conclusiones. Enseñanza de Las Ciencias, 16(2), 271-288. https://doi.org/10.1016/j.sbspro.2015.11.222 
Puello, J. F. S. (2013). “¿Quién sabe qué, cuándo, cómo?...jPara qué? Política, Políticas y Ciencia (nexos Criticos y critica de sus inconexiones)." In El Análisis y la Evaluación de las Políticas Públicas en la era de la Participación. Refleciones teóricas y estudios de casos. (pp. 141-171).

Ramírez, E. S. (2005). Concepciones Curriculares del Profesorado de Física y Química en Formación Inicial. Universidad de Sevilla.

Ratcliffe, M., \& Grace, M. (2003a). Science education for citizenship: Teaching socio-scientific issues. McGraw-Hill Education (UK).

Ratcliffe, M., \& Grace, M. (2003b). The nature of socio-scientific issues. Science Education for Citizenship, 178.

Recine, E., Gomes, Romeiro, R. C. F., Pinheiro, A. A. F., Oliveira, A. R. de, Teixeira, B. de A., Sousa, J. S. de, ... Monteiro, R. A. (2012). A formação em saúde pública nos cursos de graduação de nutrição no Brasil.

Reis, Pedro \& Galvão, C. (2008). Os professores de Ciências Naturais e a discussão de controvérsias sociocientíficas : dois casos distintos. Revista Electrónica de Enseñanza de Las Ciencias, 7, 746-772.

Reis. (2004). Controvérsias sócio-científicas: discutir ou não discutir?:Percursos de aprendizagem na disciplina de ciências da terra e da vida. Retrieved from http://hdl.handle.net/10400.15/89

Reis, P. G. R. dos. (2004). Controvérsias sócio-científicas: discutir ou não discutir: percursos de aprendizagem na disciplina de ciências da terra e da vida. Universidade de Lisboa.

Reis, P. (2014a). Acción Socio-Política sobre Cuestiones Socio-Científicas: Reconstruyendo la Formación Docente y el Currículo1. Uni-Pluri/Versidad, 14(2), 16.

Reis, P. (2014b). Activist Science and Technology Education, 9. https://doi.org/10.1007/978-94-0074360-1

Reis, P. (2016a). A Educação em Direitos Humanos através da discussão e ação sociopolítica sobre controvérsias sociocientíficas e socioambientais. Tecendo Diálogos Sobre Direitos Humanos Na Educação Em Ciências, 305-318.

Reis, P. (2016b). Formación de profesores: perspectivas de Brasil, Colombia, España y Portugal. Revista Electrónica Interuniversitaria de Formación Del Profesorado, 19(2).

Reis, P., \& Climent, N. (2012). Narrativas de profesores : refl exiones en torno al desarrollo personal y $p$ rofesional.

Rios, P. P. S., Vieira, A. R. L., \& Silva, T. O. (2017). EDUCAÇÃO DE JOVENS E ADULTOS NO CONTEXTO SEMIÁRIDO: SUJEITOS, CONTEXTOS E FORMAÇÃO DOCENTE. Encontro Internacional de Formação de Professores e Fórum Permanente de Inovação Educacional, 10(1).

Rivero, A., Pozo, R. M., Solís, E., Azcárate, P., \& Porlán, R. (2017). Cambio del conocimiento sobre la enseñanza de las ciencias de futuros maestros. Enseñanza de Las Ciencias: Revista de Investigación y Experiencias Didácticas, 35(1), 29-52.

Rodriguez, B., \& Martinez, L. (2014). Análisis del discurso didáctico crítico de profesores de ciencias al abordar cuestiones sociocientíficas. In Análisis del discurso didáctico crítico de profesores de ciencias al abordar cuestiones sociocientíficas (pp. 80-86).

Rodriguez, B., \& Martinez, L. (2015). ¿Las sustancias psicoactivas se debaten o combaten en la escuela? "Controversia por la legalidad/ilegalidad": una experiencia de formacion de docentes en la interfaz Universidad - escuela. In formación de profesores y Cuestiones Sociocientíficas experiencias y desafios en la interfaz universidad - escuela.

Rodríguez, B., \& Martínez, L. (2016). Reflexiones teóricas sobre el conocimiento didáctico del contenido y sus aportes a la formación del profesorado de ciencias. In D. L. Parga (Ed.), El Conocimiento Didáctico del Contenido en Quimica (pp. 177-200). Bogotá. 
Rodríguez, G., Gil, J., \& García, E. (1996). Tradición y enfoques en la investigación cualitativa. Barcelona, Ediciones Aljibe.

Rodríguez, P. G. Z. (2013). ¿ PRÓTESIS PARA LA INMORTALIDAD? REFLEXIONES EN TORNO AL CÓDIGO TÉCNICO DE LA BIOMEDICALIZACIÓN DEL ENVEJECIMIENTO. Redes, 19(37).

Romao, J. E., \& Gadotti, M. (2011). Educação de adultos: cenários, perspectivas e formação de educadores. Educação de Adultos: Cenários, Perspectivas e Formação de Educadores.

Ruse, M. S. (2005). Technology and the evolution of the human: From Bergson to the philosophy of technology. Essays in Philosophy, 6(1), 27.

Sá, L. P., Kasseboehmer, A. C., \& Queiroz, S. L. (2013). Casos investigativos de caráter sociocientífico: aplicação no ensino superior de Química. Educación Química, 24, 522-528.

Sadler, T. D. (2004). Moral and ethical dimensions of socioscientific decision-making as integral components of scientific literacy. Science Educator, 13(1), 39.

Sadler, T. D., \& Murakami, C. D. (2014). Socio - scientific Issues based Teaching and Learning: Hydrofracturing as an Illustrative context of a Framework for Implementation and Research, 14, 331-342.

Sadler, T. D., \& Zeidler, D. L. (2004a). The morality of socioscientific issues: Construal and resolution of genetic engineering dilemmas. Science Education, 88(1), 4-27.

Sadler, T. D., \& Zeidler, D. L. (2004b). The Morality of Socioscientific Issues: Construal and Resolution of Genetic Engineering Dilemmas. Science Education, 88(1), 4-27. https://doi.org/10.1002/sce.10101

Santos, M. dos, Amaral, C. L., \& Maciel, M. D. (2010). TEMAS SOCIOCIENTÍFICOS (CERVEJA) EM AULAS PRÁTICAS DE QUÍMICA NA EDUCAÇÃO PROFISSIONAL: UMA ABORDAGEM CTS. HOLOS, 4.

Santos, W. L. D. P. (2008). Educação científica humanística em uma perspectiva freireana: resgatando a função do ensino de CTS. Alexandria: Revista de Educação Em Ciência e Tecnologia, 1(1), 109-131.

Santos, W. L. P., \& Mortimer, E. F. (2016). Abordagem de aspectos sociocientíficos em aulas de ciências: possibilidades e limitações. Investigações Em Ensino de Ciências, 14(2), 191-218.

Schön, D. A. (1995). Knowing-in-action: The new scholarship requires a new epistemology. Change: The Magazine of Higher Learning, 27(6), 27-34.

Shulman, L. S. (2005). Conocimiento y enseñanza: fundamentos de la nueva reforma. Profesorado: Revista de Curriculum y Formación Del Profesorado, 9(2), 1-30.

Silva, P. F. da, \& Krasilchik, M. (2013). Bioética e ensino de ciências: o tratamento de temas controversos-dificuldades apresentadas por futuros professores de ciências e de biologia. Ciência \& Educação (Bauru), 19(2).

Silva, P. da, \& Krasilchik, M. (2013). Bioética e ensino de ciências: o tratamento de temas controversos-dificuldades apresentadas por futuros professores de ciências e de biologia. Ciência \& Educação (Bauru), 19(2).

Silva, J. (2016). Dialogos Formativos com os/as Professores/as da EJA e os pressupostos teóricos metodológicos Freirianos. Universidades do Estado de Bahia.

Silva, O. B., Oliveira, J. R. S. da, \& Queiroz, S. L. (2011). SOS Mogi-Guaçu: contribuições de um Estudo de Caso para a educação química no nível médio.

Silva, R. C. S., Costa, A. T., \& Jesus, M. P. de. (2016). O GRUPO FOCAL COMO TÉCNICA DE COLETA DE DADOS NA PESQUISA EM EDUCAÇÃO: ASPECTOS ÉTICOS E EPISTEMOLÓGICOS. Encontro Internacional de Formação de Professores e Fórum Permanente de Inovação Educacional, 9(1). 
Simonneaux, J., \& Legardez, A. (2010). The epistemological and didactical challenges involved in teaching socially acute questions. The example of globalization. JSSE-Journal of Social Science Education, 9(4).

Siqueira, J. B., Pinto, P., \& Cattani, G. C. (2013). UM ESTUDO EXPLORATÓRIO INTERNACIONAL SOBRE O DISTANCIAMENTO ENTRE A ESCOLA E A UNIVERSIDADE NO ENSINO DE CIÊNCIAS/(An international exploratory study about the gap between school and university on science education). Investigações Em Ensino de Ciências, 18(2), 365.

Solbes, J. (2013a). Contribución de las cuestiones sociocientíficas al desarrollo del pensamiento crítico (I): Introducción. Revista Eureka Sobre Enseñanza y Divulgación de Las Ciencias, 10(1).

Solbes, J. (2013b). Contribución de las cuestiones sociocientíficas al desarrollo del pensamiento crítico (II): Ejemplos. Revista Eureka Sobre Enseñanza y Divulgación de Las Ciencias, 10(2).

Solís, E. (2005a). Concepciones Curriculares del Profesorado de Física y Química en Formación Inicial. Universidad de Sevilla.

Solís, E. (2005b). Concepciones Curriculares del Profesorado de Física y Química en Formación Inicial. Universidad de Sevilla.

Solís, E., Porlán, R., \& Rivero, A. (2008). ¿ Qué Concepciones Curriculares del Profesorado de Ciencias en Formación Inicial pueden suponer un obstáculo. XXIII Encuentros de Didáctica de Las Ciencias Experimentales, Almería.

Solís, E. R., Porlán, R. A., \& Rivero, A. G. (2012). ¿ Cómo representar el conocimiento curricular de los profesores de ciencias y su evolución? Enseñanza de Las Ciencias. Revista de Investigación y Experiencias Didácticas, 30 (3) 9-30.

Solís, E. R., \& Rivero, A. G. (2012). La investigación en la formación inicial del profesorado: una aproximación a las concepciones curriculares del profesorado de Ciencias de Educación Secundaria., 1-35.

Solís, E. R., \& Rivero, A. G. (2013). La investigación en la formación inicial del profesorado: una aproximación a las concepciones curriculares del profesorado de Ciencias de Educación Secundaria. Conocimiento Profesional Del Profesor de Primaria y Conocimiento Escolar (Pp. 143-178).

Sousa, B. S. (2016). Para uma revolução democrática da justiça. Leya.

Sousa, B. S. (2017). Democracia y transformación social (Vol. 1). Siglo del Hombre Editores.

Sousa, R. S. de, Rocha, P. D. P., \& Garcia, I. T. S. (2012). Estudo de Caso em Aulas de Química: Percepção dos Estudantes de Nível Médio sobre o Desenvolvimento de suas Habilidades. Química Nova Na Escola, 34(4), 220-228.

Souza, R. D. de. (2015). Circulações de conhecimentos e práticas na formação inicial de professores de ciências: complicações, subsídios e possibilidades. Universidade Tecnológica Federal do Paraná.

Stake, R. E. (2007). Investigación con estudio de casos. Ediciones Morata.

Strieder, R. B. (2012). Abordagens CTS na educação científica no Brasil: sentidos e perspectivas. Universidade de São Paulo.

Strieder, R. B., \& Kawamura, R. D. (2014). Perspectivas de participação social no âmbito da educação CTS1. Uni-Pluri/Versidad, 14(2), 101.

Talanquer, V. (2014a). Razonamiento Pedagógico Específico sobre el Contenido (RPEC). Educación Química, 25(3), 391-397. https://doi.org/https://doi.org/10.1016/S0187893X(14)70554-3

Talanquer, V. (2014b). Razonamiento Pedagógico Específico sobre el Contenido (RPEC). Educacion Quimica, 25(3), 391-397. https://doi.org/10.1016/S0187-893X(14)70554-3

Tardif, M. (2000). Saberes profissionais dos professores e conhecimentos universitários. Revista 
Brasileira de Educação, 13(5), 5-24.

Taylor, S. J., \& Bogdan, R. (1986). Introducción a los métodos cualitativos de inveRodríguez, G., Gil, J., \& García, E. (1996). Tradición y enfoques en la investigación cualitativa. Barcelona, ediciones Aljibe.stigación. La búsqueda de significado. Buenos Aires: Paidós.

Teixeira, S. M., Souza, B. de F. E., Raposo, R. E., \& Silva, M. da F. N. (2014). CENAS E CENÁRIOS DAS QUESTÕES SOCIOAMBIENTAIS: MEDIAÇÕES PELA FOTOGRAFIA. Ensaio Pesquisa Em Educação Em Ciências, 16(1).

Teles, F. P., \& Ibiapina, I. M. L. de M. (2009). A pesquisa colaborativa como proposta inovadora de investigação educacional. Diversa. Ano, 2.

Topcu, M. S., Sadler, T. D., \& Yilmaz-Tuzun, O. (2010). Preservice science teachers' informal reasoning about socioscientific issues: The influence of issue context. International Journal of Science Education, 32(18), 2475-2495.

Torres, N. Y., \& Martínez, L. F. (2011). Desarrollo de pensamiento crítico en estudiantes de Fisioterapia, a partir del estudio de las implicaciones sociocientíficas de los xenobióticos. TED: Tecné, Episteme y Didaxis, (29).

Torres, Y. M. N., \& Solbes, J. M. (2014). Aspectos convergentes del pensamiento crítico y las cuestiones sociocientíficas. Góndola, Enseñanza y Aprendizaje de Las Ciencias, 2014, Vol. 9 , Num. 1, p. 1-13.

Valvuena, E. (2007). El conocimiento didáctico del contenido biológico: estudio de las concepciones disciplinares y didácticas de futuros docentes de la universidad pedagógica nacional (Colombia). Universidad Complutense de Madrid. https://doi.org/ISBN: 978-84-693-1123-3

Vázquez, Á. A., Aponte, A., Manassero, M.-A.-M., \& Montesano, M. (2014). Una secuencia de enseñanza-aprendizaje sobre un tema socio-científico: análisis y evaluación de su aplicación en el aula. Educación Química, 25, 190-202.

Vázquez, Á., \& Cruz, A. M. (2014). Formación del profesorado en naturaleza de la ciencia mediante investigación-acción. Praxis \& Saber, 5(9).

Vilches, A., Gil, D. P., Toscano, J. C., \& Macías, Ó. (2008). Obstáculos que pueden estar impidiendo la implicación de la ciudadanía y, en particular, de los educadores, en la construcción de un futuro sostenible: Formas de superarlos. Revista Iberoamericana de Ciencia Tecnología y Sociedad, 4(11), 139-162.

Walters, J. M., \& Gardner, H. (1984). The Development and Education of Intelligences.

Wendel, F. M., \& Silva, C. A. da T. e. (2011). As fotonovelas no ensino de química. Química Nova Na Escola, 33(1), 25-31.

Wu, Y., \& Tsai, C. (2007). High School Students' Informal Reasoning on a Socio-scientific Issue: Qualitative and quantitative analyses. International Journal of Science Education, 29(9), 11631187. https://doi.org/10.1080/09500690601083375

Yin, R. (1994). Investigación sobre estudio de casos. Diseño y métodos. Applied Social Research Methods Series, 5(2).

Zeidler, D. L., Sadler, T. D., Simmons, M. L., \& Howes, E. V. (2005). Beyond STS: A research-based framework for socioscientific issues education. Science Education, 89(3), 357-377. https://doi.org/10.1002/sce.20048

Zeidler, D. L., Walker, K. A., Ackett, W. A., \& Simmons, M. L. (2002). Tangled up in views: Beliefs in the nature of science and responses to socioscientific dilemmas. Science Education, 86(3), 343-367. https://doi.org/10.1002/sce.10025

\section{Contenidos}


En el capítulo 1, se hace un recuento de los antecedentes de la investigación de los últimos cuatro años encontrados en revistas indexadas, teniendo como eje de búsqueda las palabras claves de la investigación, como son el CPP, las CSC en el contexto CTSA, la formación de profesores en IUE.

El capítulo dos, titulado Conocimiento Profesional del Profesor de Ciencias en Ejercicio y abordaje de CSC, presenta una caracterización de la naturaleza y de los componentes del CPP, desde los contenidos disciplinares, pedagógicos, didácticos, contextuales, experienciales, y hasta emocionales, finalizando con las características de las CSC como posible eje interdisciplinar e integrador de cada uno de los componentes del CPP.

En el capítulo 3, titulado Epistemología Fleckiana, se hace una bosquejo general de la fundamentación epistemológica que enriqueció la investigación y que basada en categorías propuestas por Fleck (1986), permitió comprender la construcción del conocimiento en términos de colectivo de pensamiento (CP), estilos de pensamiento (EP), círculos esotéricos y exotéricos, circulación intra e intercolectiva de ideas y hecho científico; posibilitan entender la IUE en términos de los actores constituyentes, como los profesores de la Universidad y los profesores de las Escuelas, que a su vez constituyeron los referentes de las hipótesis emergentes para analizar las contribuciones de las discusiones epistemológicas del abordaje de CSC en la construcción del CPP en el contexto del proyecto de formación permanente de profesores. Además, este capítulo permite comprender que la construcción del CPP es análoga a la construcción de conocimientos científicos y, por tanto, para ser comprendido, debe recurrirse al desarrollo social, histórico, cultural y contextual de dichos saberes transformados a lo largo del tiempo.

Fleck recurre a la sociología del conocimiento para la elaboración teórica de conceptos que muestra como una construcción social del conocimiento; determina el EP de un grupo de individuos que al apropiarse del mismo y compartirlo (consumirlo) forman un CP, estos EP son los que direccionan el pensar y el actuar en un campo de conocimiento determinado, en este caso el científico y el popular. Por tanto este capítulo se constituye como un referente teórico que permite explicar a partir de las categorías emergentes, la consolidación del Gl como $\mathrm{CP}$, así como la relación entre las categorías fleckianas y las estrategias realizadas en el proceso de formación en IUE como el medio que favorece la construcción del CPP.

En el capítulo 4, se realiza el abordaje metodológico, en el que se muestra cada una de las etapas de la investigación, justificando la constitución del $\mathrm{Gl}$ del $\mathrm{GCl}$ como un estudio de caso único, el uso del ATD como dispositivo de análisis que al articularse con el software NVivo11, permite categorizar cada uno de los componentes del CPP, establecer nuevas categorías emergentes que se constituyen en un modelo explicativo para comprender el CPP como un constructo social, histórico y cultural.

En el capítulo 5, se aborda el análisis de los resultados a la luz de la HdPR, en la que se articulan los componentes del CPP planteados por Martínez (2000, 2016, 2017), las características de las CSC (Martínez, 2014; Ratcliffe \& Grace, 2003a), el enfoque formativo (Levinson, 2006c, 2008, 2010; Pedretti \& Nazir, 2011; Strieder, 2012), así como la conformación del Gl a la luz de las teorías de Habermas (1987) y las relaciones de poder de Bourdieu (1990;2008); Bourdieu \& Passeron (2001a); Gutiérrez (2004), las cuales han sido consideradas propuestas contrahegemónicas a los procesos tradicionales de formación de profesores en la IUE. 
En el capítulo 6, se retoman los planteamientos de la formación de profesores al abordar las CSC y después de establecer los aportes y las dificultades de dicha intervención, se presenta un modelo explicativo que responde a la manera como se construye y reconstruye el CPP al abordar estas CSC en el proceso de formación de profesores en IUE a la luz de la teoría epistemológica de Fleck (1986).

Finalmente, se presentan las conclusiones de la investigación, haciendo énfasis en las bondades y dificultades que ofrece el abordaje de CSC en la Enseñanza de las Ciencias, en especial a través de proceso de formación permanente de docentes en IUE, que beneficia y concibe a la escuela como constructora de conocimientos escolares, al profesor como investigador crítico, reflexivo que posee un CPP epistemológicamente diferenciado y a la universidad como innovadora/creadora de conocimiento que lidera procesos de investigación y de formación.

\section{Metodología}

En términos metodológicos, para el desarrollo de la investigación se optó por una perspectiva cualitativa centrada en el estudio de caso, con la ayuda de técnicas de observación participante. Según Denzin \& Lincoln $(1994,2011)$ la investigación cualitativa es un proceso interpretativo, multimetódico y naturalista; situado en los espacios sociales en los que ocurren las acciones, experiencias o interacciones humanas, donde los detalles descriptivos de las personas, los lugares y las conversaciones entre los miembros del grupo investigado son una fuente directa de los datos obtenidos, donde el investigador es el instrumento principal para capturar la información y dar sentido al proceso de construcción y reconfiguración de saberes.

En esta investigación se considera que las personas comprenden e interpretan el mundo de forma diferente, lo que implicó estudiar y conocer las experiencias de los docentes en el contexto en que se lleva a cabo su práctica, para lo cual el investigador utilizando diversos instrumentos de recolección de datos, tales como la entrevista, la observación, las historias de vida, las grabaciones, los diálogos informales, las producciones textuales, entre otras, busca permitir una mejor comprensión del CPP y sus implicaciones al asumir CSC.

Respecto a la investigación cualitativa, Denzin \& Lincon (2006) reconocen que tiene un foco multiparadigmático, que permite que visiones emergentes se constituyan por la búsqueda de los significados presentes en la complejidad de las relaciones humanas a partir de las relaciones causa-efecto. Para estos autores un paradigma corresponde a un conjunto básico de creencias que orientan a la acción, basados en conceptos éticos, epistemológicos, ontológicos y metodológicos. En este sentido, se pueden distinguir en la investigación cualitativa diferentes diseños y tradiciones que se agrupan en enfoques biográficos, fenomenológicos, etnográficos y estudio de caso; este último base de esta investigación.

El estudio de caso no es producto solamente de la elección de un método, sino más bien de la elección de un objeto a ser estudiado. Se elige estudiar un caso, que puede ser un hecho, un grupo, una relación, una institución, una organización, un proceso social, una situación o escenario específico escogido a partir de un determinado recorte empírico y 
conceptual de la realidad social, que conforma un tema /o problemática de investigación.

Según Moreira (2002), se parte del supuesto holístico de la investigación cualitativa que no sólo limita su atención en un objeto o parte de un problema, sino que implica la comprensión de las partes y de sus interrelaciones con el todo. Hacer este tipo de investigación requiere que el investigador comprenda y describa cómo ocurren las cosas y por qué ocurren. Por tanto, fue necesario asumir el Gl como caso, analizando las interdependencias de las partes y de los patrones que emergían, es decir, se conoció y caracterizó el CPP al asumir CSC de los docentes del Gl y no el CPP de cada uno de los docentes.

La metodología de estudio de caso entonces, se focalizó sólo en el grupo de docentes del Gl analizando detallada y repetidas veces las interacciones humanas (escenas, situaciones claves) con la ayuda de los registros audiovisuales, entrevistas semiestructuradas, estructuradas, narraciones, transcripciones de audio, registros escritos (talleres y secuencias didácticas presentadas en forma individual y grupal) fotografías, etc.; de tal manera que se pudiera caracterizar el CPP de los participantes en el escenario del GI.

Al asumir el Gl como un estudio de caso único, la preocupación central de la investigación era que el CPP se concibiera como algo singular, único que presenta unas características particulares de cada docente, cuando en realidad significa todo lo contario, ya que la intervención y proceso de formación se realizó en forma colectiva. Con base en lo anterior, a título de hipótesis de trabajo se deduce que el discurso abordado por cada docente, atravesó el de los otros, haciendo que se movilizaran nuevas ideas, se elaboraran constructos conceptuales y epistemológicos que incidieron en el CPP de cada uno de los profesores participantes del Gl, así como también posiblemente hizo que algunos se movilizaran a un estilo de pensamiento en transición.

La investigadora entonces, gracias a la intuición, empatía y otras habilidades, sumadas al uso de instrumentos, estrategias y con el referente teórico consolidado, interpretó y describió las ideas, creencias, valores, supuestos, comportamientos y en general todo lo que sucede en el interior del GI cuando abordó algunas CSC del interés de sus integrantes; es decir, realizó una descripción comprensiva y contextualizada del discurso del grupo usando como dispositivo analítico, el Análisis Textual Discursivo (ATD), acorde a las categorías referenciadas por (Martínez, C., 2000; Martínez, C., 2016; Martínez,L., 2010) y las elaboradas en el transcurso de la investigación, así como las emergentes producto de su consolidación.

EI ATD concebido como una modalidad de investigación con algunas cercanías del análisis del contenido (AC) propuesto por Bardin (1991) y de las modalidades del análisis del discurso(AD), se aproxima al AC por su naturaleza interpretativa para la comprensión del fenómeno investigado, por su carácter hermenéutico, de construcción y reconstrucción de comprensiones sociales y culturales; también es próximo al AD de naturaleza crítica lo que le permite examinar los fenómenos a partir de una mirada teórica externa, donde emerja lo 
no dicho, lo implícito, lo latente, lo dialéctico (Moraes \& Galiazzi, 2007).

En la presenta investigación, también se usó como herramienta de análisis el software Nvivo11 que se articula con la metodología de análisis e interpretación de textos (ATD), posibilitando la fusión de la información (recursos/elementos internos), la organización y el procesamiento de la misma (unidades de significado (codificación), la aparición de las primeras categorías de análisis (nodos libres o las establecidas previamente), de las intermedias (ramificación de los nodos, categorías emergentes) y finales (nodos); adicionalmente el software permite establecer relaciones entre nodos, atributos, documentos, casos, etc., favoreciendo la construcción de nuevas categorías, la interpretación y comprensión de las mismas, así como el planteamiento de metatextos (matrices), de nuevos constructos y/o explicaciones teóricas.

Para el desarrollo metodológico de la investigación se llevaron a cabo las siguientes fases:

1. Caracterización de la conformación del caso (Gl) y selección de la temática a abordar como CSC.

2. Desarrollo de actividades pedagógicas, didácticas e investigativas a partir de la CSC al interior del grupo, que permitieran desarrollar el proceso de comprensión de la incidencia de la CSC elegida al ser abordada de forma interdisciplinar y desde un razonamiento sociopolítico, ético-moral, sociocultural, de riesgo (ambiente y salud) y científico-tecnológico en la construcción del CPP; para lo cual se realizaron debates, puestas en común, confrontación con especialistas y talleres (de sensibilización, de autoformación sobre el tema, elaboración de material didáctico y planteamiento de un taller una vez finalizado el acompañamiento de IUE).

3. Organización de la información en el software Nvivo11 bajo la metodología de ATD teniendo como categorías iniciales las propuestas en la hipótesis de progresión/regresión del CPP por Martínez (2016;2017), evidenciadas en la figura 5, de las que emergen nuevas categorías que son explicadas a la luz de la teoría epistemológica de Fleck (1986) sobre estilos y colectivos de pensamiento, comunicación intra e intercolectiva de pensamientos; permitiendo al investigador comprender la dificultad de la movilidad de los EP de los profesores del Gl cuando aparecen hechos nuevos, como es el caso de las CSC.

\section{Conclusiones}

A partir del análisis realizado en los dos capítulos anteriores, se puede comprender que el abordaje de CSC favorece el CPP en un contexto de formación de profesores en la IUE, en la que los profesores constituyen un $\mathrm{Gl}$, que al configurarse como $\mathrm{CP}$, direcciona y perfila su EP. Para lo anterior se requirió:

1. conformar un Gl a la luz de la teoría de la acción comunicativa de Habermas (1987), en el que todos los profesores del grupo podían actuar libremente, sin coerción, pero que conscientes que ninguna investigación es neutra, la autora de la tesis como observadora participante, tuvo que alejar sus preconcepciones y acompañar el trabajo de formación estableciendo relaciones horizontales, que favorecieran un clima de trabajo al interior del Gl.

2. El EP estructurado por el CP tiende a ser transformador, especialmente porque 
aborda las CSC como ejes transversales y articuladores del currículo, pero las fuentes y criterios de selección, al igual que los referentes epistemológicos se configuran en estilos de pensamiento de transición, posiblemente porque al ser conocimientos de frontera, cuyos referentes están más en direccionamiento de los medios de comunicación que hacen parte en mayor proporción de la racionalidad instrumental, y no del mundo de la vida, los profesores por los procesos de formación en los que han sido formados, posiblemente ausentes del establecimiento de relaciones CTSA y de una formación crítica, asumen como una debilidad el abordaje de dichas cuestiones.

3. Los aportes al CPP se pudieron caracterizar a la luz de una HdPR en la que el ATD y el software NVivo11 facilitaron encontrar las unidades de análisis que permitieran comprender los contenidos, criterios de validez, referentes epistemológicos, fuentes y criterios de selección que utilizan los profesores al abordar las CSC, así como los ejes DOC, que finalmente evidencian la complejidad del CPP. En este sentido los contenidos escolares asociados a la CSC permiten comprender al profesor la naturaleza de la ciencia, posibilitan que tenga la opción de opinar a título de hipótesis y respaldarla teniendo en cuenta fuentes y criterios de selección que a su vez sean controversiales, simultáneamente posibilita al profesor evaluar de una forma crítica dichos medios y seleccionar acorde a los propósitos de enseñanza de la ciencia en el contexto de la racionalidad científica, de desarrollo tecnológico y de compromiso social, movilizando su pensamiento por diferentes estilos de pensamiento; las CSC por su carácter controversial se constituyen en ejes dinamizadores que acorde a la complejidad del conocimiento del profesor lo llevan a estados de transición, es en estos estados que la IUE es fundamental para acompañar al profesor a movilizar su Ep a estados que le permitan un desarrollo profesional y un CPd.

4. Los ejes DOC evidenciaron que las CSC son realmente dinamizadores del CPP, posiblemente por sus características como menciona Martínez (2014) y Ratcliffe \& Grace (2003a); pero también pueden ser obstáculo, cuando priman los saberes dominantes o CPD, constituyéndose en obstáculo de contenido, que acorde a las intervenciones realizadas por los profesores, abordar CSC les exige mayor tiempo de preparación de las clases, le exige la interacción interdisciplinar y transdiciplinar que no forma parte de la cultura del profesor, y los ejes cuestionamiento, que al indicar las fisuras del CPP se presentan en los referentes epistemológicos de las CSC asumidas como contenidos.

5. Del ATD surge la categoría emergente CP y EP que son equivalentes con GI y CPP a la luz de la teoría epistemológica de Fleck; en este contexto el CP se identifica por tener un EP que direcciona a dicho colectivo, pero para estilizar este pensamiento se asume una suave inmersión didáctica, en la que el profesor cuyo pensamiento está en la armonía de las ilusiones empieza a luchar internamente para comprender y asumir la inestabilidad que generan las CSC, es cuando a partir del par académico como colectivo de otro EP, empiezan a constituir uno nuevo, un 


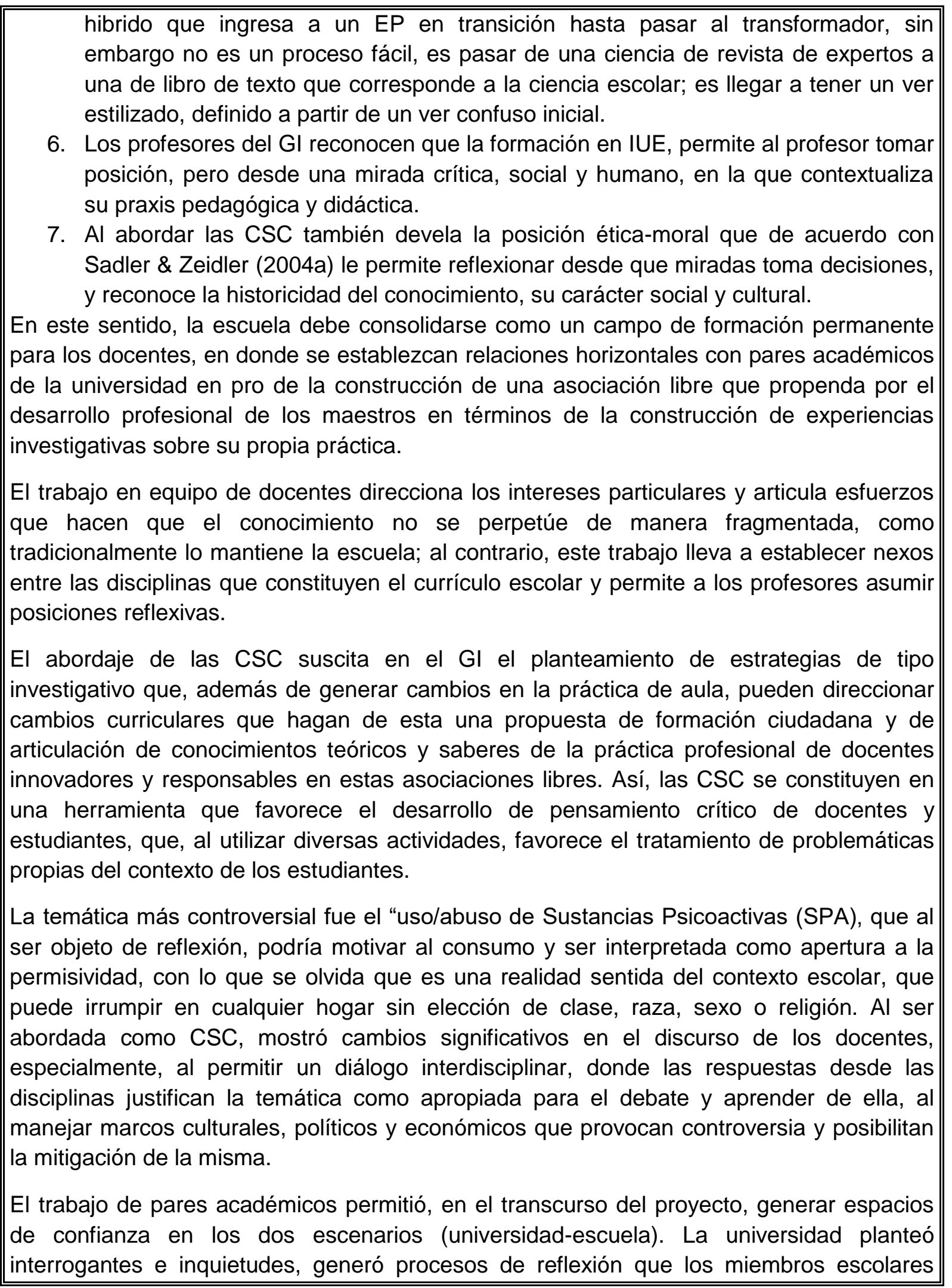


asumieron con respeto, gusto y con liderazgo, punto que toman los representantes universitarios para invitar a plantear nuevos proyectos sobre temas controversiales de tipo local que involucren a los estudiantes, de tal manera que la escuela tome un papel dinamizador en la posible solución de problemas que afectan a la comunidad en general.

El diseño de unidades didácticas para ser abordadas por docentes permite caracterizar la práctica de aula de cada uno de los docentes, caracterizar sus pensamientos y gestar investigaciones de tipo universitario sobre el conocimiento profesional del profesor.

El abordaje de CSC como herramienta que posibilita la puesta en escena de un diálogo reflexivo entre la universidad y la escuela hace que el maestro pueda poner en escena las capacidades ciudadanas que debe fomentar en sus estudiantes y establece entre los maestros un ambiente reflexivo que les permite escucharse, aprender del discurso del otro y asumir posiciones críticas como formadores de cultura.

El planteamiento de actividades para los estudiantes semejantes a las desarrolladas por los docentes muestra la intencionalidad de escuchar a estos últimos, de conocer su posición y, acorde al nombre de la institución (Guillermo Cano) y en calidad de estudiantes de EJA, fomentar la actividad crítica como estrategia metodológica que posibilita un aprendizaje individual y colectivo.

Al plantear actividades a los estudiantes como cursos de fotografía, visitas a museos y charlas con expertos, se posibilitó en ellos el desarrollo de habilidades prácticas y argumentativas que posiblemente los convocan a reflexionar sobre el uso de las SPA en su vida y la forma como han transformado e involucrado a sus familiares y amigos, aspectos que, al ser socializados en la última etapa, se convirtieron en temas de reflexión y de diseño de nuevas secuencias para los maestros, nuevos retos de investigación para los docentes universitarios y un acercamiento a profesionales interesados en la investigación social en el campo de la drogadicción.

En este contexto, y de acuerdo con los planteamientos de Maldaner (2014), la universidad a través de los programas de formación posgradual o de formación continua de profesores, debe gestar espacios colectivos de investigación entre los docentes en ejercicio y los universitarios, de tal manera que la formación se asuma en el contexto escolar que a su vez determina el tipo de experiencia que necesita desarrollar según las condiciones y pautas de trabajo con las que atiende a los estudiantes. Así, se establece un modelo de formación donde confluyen los intereses, conocimientos y situaciones universitarias con las necesidades escolares, de tal manera que escuela y universidad aprenden, investigan y trabajan como pares académicos.

\begin{tabular}{|l|l||}
\hline Elaborado por: & Rodríguez Hernández, Blanca Florinda \\
\hline Revisado por: & Martínez Pérez, Leonardo Fabio \\
\hline
\end{tabular}

Fecha de elaboración del

Resumen:

2018 


\section{CONTENIDO}

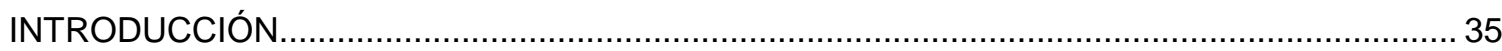

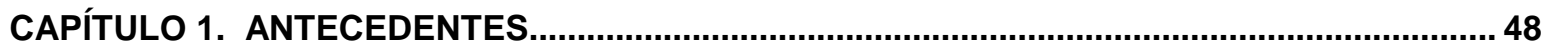

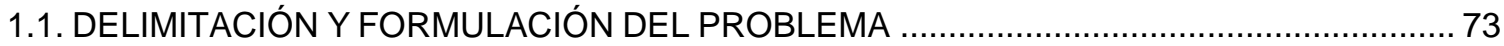

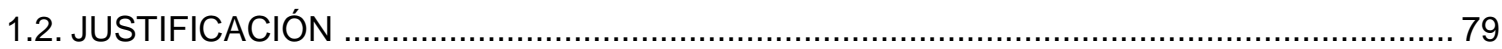

1.3. OBJETIVOS

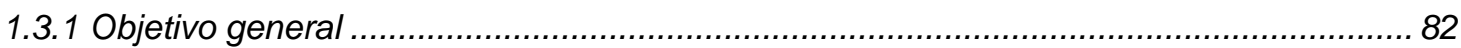

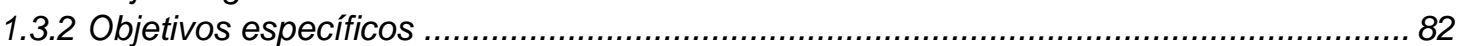

CAPÍTULO 2. CONOCIMIENTO PROFESIONAL DEL PROFESOR DE CIENCIAS EN EJERCICIO Y EL ABORDAJE CUESTIONES SOCIOCIENTÍFICAS .......................................................... 83

2.1. EL CONOCIMIENTO PRÁCTICO PROFESIONAL DEL PROFESOR .................................. 83

2.2. CONOCIMIENTO PROFESIONAL DEL PROFESOR (CPP) Y CUESTIONES

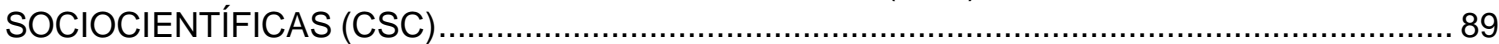

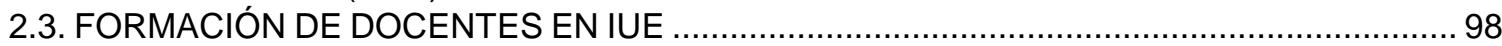

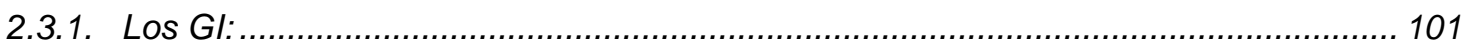

2.4. ENFOQUE CTSA Y CSC EN LA FORMACIÓN DE PROFESORES .................................... 110

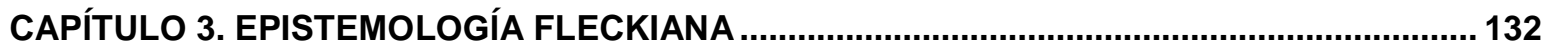

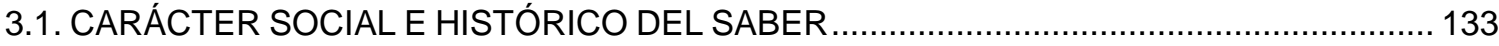

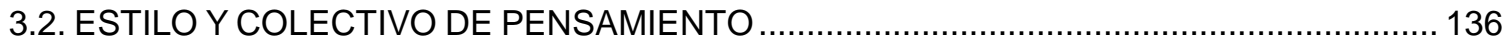

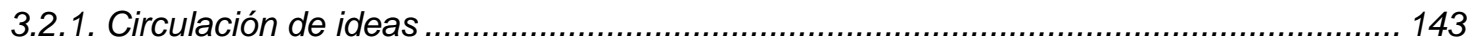

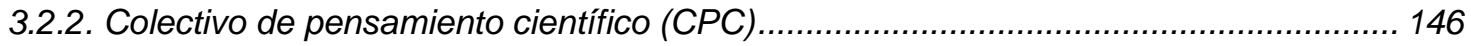

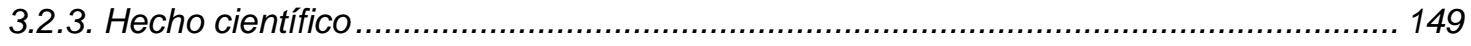

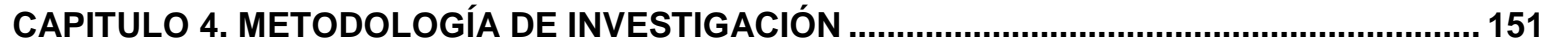

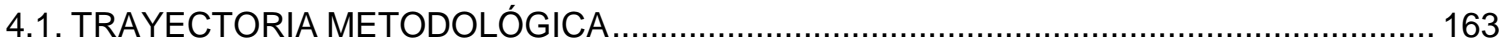

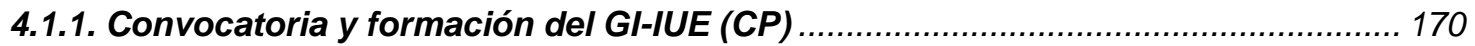

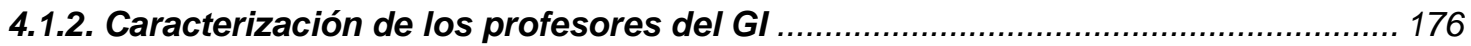

4.2. SEGUNDA FASE O INTERVENCIÓN: FORMACIÓN DE PROFESORES EN IUE .............178

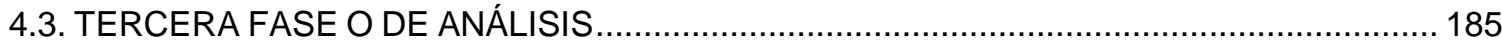

CAPITULO 5. CONOCIMIENTO PROFESIONAL DEL PROFESOR DE CIENCIAS SOBRE

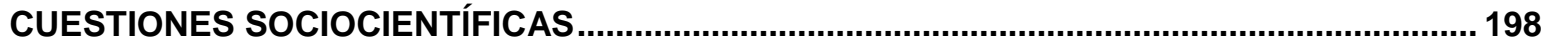

CAPITULO 6. COMPRENSIÓN DE CONSTRUCCIÓN DEL CPP A LA LUZ DE LA TEORIA EPISTEMOLOGICA DE FLECK

CONCLUSIONES

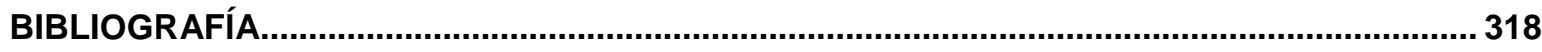

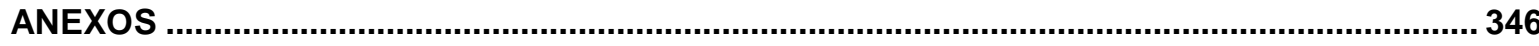




\section{INTRODUCCIÓN}

El enfoque de Enseñanza Ciencia Tecnología Sociedad y Ambiente (CTSA) tiene unos presupuestos teóricos, que no logran articularse a las prácticas de los profesores en ejercicio, permaneciendo en muchos casos al margen de las mismas (Martínez, 2010a). Sin embargo, hay ejemplos en los que se evidencia la presencia del enfoque CTSA, como Ciencia en Contexto Social (SISCON) en Inglaterra, inicialmente para la educación superior y posteriormente llevado a las escuelas (SISCON - in Schools) con el objetivo de preparar ciudadanos capaces de elegir y participar de las discusiones públicas relacionadas con la Ciencia y la Tecnología.

Según Garritz (1994), inicialmente surge el enfoque CTS(A) como una reforma educativa y no simplemente como una forma especial de educación, cuyo objetivo esencial se basa en el desarrollo de actividades enfocadas a la promoción de habilidades en los estudiantes para tomar decisiones sobre aspectos sociales del mundo real; bajo este supuesto también se fomentó el uso de materiales escritos por miembros del proyecto Science e Technology in Society (SATIS), propuesto por profesionales de ciencias que no contaban con formación en educación y terminaron instrumentalizando la visión de la misma, centrándola en aplicaciones materiales que ni siquiera eran elaborados por los propios docentes (Martínez, 2010a).

Debido a su pertinencia en la década de 1990, especialmente en el contexto latinoamericano, se retomó el enfoque CTS como una línea de investigación en la Enseñanza de las Ciencias experimentales y se hizo énfasis en la dimensión ambiental (CTSA), debido a la importancia que tiene para abordar la crisis, obedeciendo a una ruptura epistemológica entre la sociedad humana y la naturaleza. Así pues, se hace necesaria una reflexión educativa en la Enseñanza de las Ciencias, además surge el abordaje de cuestiones sociocientíficas (CSC) 
como una manera de concretar CTSA en la práctica docente (Martínez, 2010; Torres \& Martínez, 2011).

En este orden de ideas, esta investigación surge como parte de un proyecto mancomunado de carácter internacional entre la Universidad Pedagógica Nacional de Colombia (UPN) y la Universidade Estadual Paulista (UNESP) de Brasil, en donde se indagaron los elementos que caracterizan un programa de formación de profesores en la interacción universidad-escuela (IUE), a través de la discusión de CSC; así, se origina un grupo de investigación (GI) de docentes en ejercicio de todas las áreas del conocimiento.

La investigación está caracterizada por el trabajo conjunto entre profesores de la universidad y profesores de la escuela, en este caso, del colegio Guillermo Cano Isaza jornada nocturna; la IUE se realiza gracias a la tarea de la investigadora, teniendo en cuenta que la formación permanente y continuada de profesores debe realizarse desde las necesidades de la escuela, del contexto escolar e in situ (Imbernón, 1994, 2012; Imbernon \& Canto, 2013). Cuando los docentes universitarios interactúan en el campo escolar producen conocimiento relacionado con la docencia, la didáctica específica de sus disciplinas y la función misma de los docentes de la escuela; se reivindican como profesores investigadoresreflexivos de su práctica de aula, trabajando en red y fundamentando su propio Conocimiento Profesional del Profesor (CPP), lo que favorece su desarrollo profesional y la mejora de la escuela.

El CPP es un elemento fundante que permite la promoción de políticas de formación y desarrollo profesional de los profesores, especialmente cuando se desea con su participación reivindicar el trabajo docente, fomentar el trabajo en equipo, propiciar la interacción universidad - escuela, incentivar el rol del docente como investigador e intelectual reflexivo, favorecer la formación ciudadana y el pensamiento crítico.

Lo anterior coincide con las investigaciones de Solís (2005b) quien afirma que los modelos que han permitido un desarrollo profesional a los profesores, son los que 
están basados en una perspectiva crítica e integradora, que favorecen el desarrollo del Conocimiento Profesional del Profesorado bajo una perspectiva epistemológica que constituye un conocimiento Práctico Profesional: el Conocimiento Profesional Deseable (CPD).

EI CPP planteado desde el proyecto IRES, retomado de Rivero (2003) (Citada por Solís (2005b) es:

Un conocimiento práctico, dirigido a la intervención en el ámbito educativo; es complejo e integrador, pues no es un conjunto de técnicas didácticas estandarizadas ni un conjunto de rutinas y principios elaborados a partir de la experiencia, sino que requiere de la interacción e integración rigurosa de saberes de distinto tipo; es crítico, porque orienta la actuación de los profesores en una determinada dirección y eso implica también una opción ideológica; y es profesionalizado, ya que debe abordar específicamente los problemas relacionados con la práctica de la enseñanza.

El desarrollo de este conocimiento no puede realizarse mediante la apropiación formal de sus significados - no se puede estudiar-, ni se puede "descubrir" -no "esta" en la práctica-, sino que debe ser construido de manera progresiva, desde las concepciones de partida que toda persona tiene y en un constante ir y venir a la teoría y a la práctica mediante procesos de investigación. (p. 47)

Por tanto, el CPP no es sinónimo de dominio de contenidos determinados, ni de didácticas específicas, no se trata tampoco de tener un baúl de trucos de donde se saquen soluciones cuando el docente esté en la práctica de aula (Cruz, 2011), es un constructo complejo de construcción permanente, que requiere procesos de regresión; sin embargo, las investigaciones en torno al CPP se han referido a los contenidos convencionales de ciencias especialmente (Física, Química, Biología y matemáticas) en el conocimiento escolar, siendo muy pocos los que buscan comprender y favorecer el desarrollo del CPP referido a CSC.

Por otro lado, uno de los resultados de la consolidación de la IUE, es el reconocimiento de este espacio, como un lugar de formación permanente de 
docentes que posibilita la ruptura de fronteras que han separado a los actores del campo educativo, promoviendo un diálogo en el contexto de investigación escolar, que privilegia los saberes de los profesores de la escuela a través del estudio y abordaje de las CSC, cuyas temáticas no curricularizadas, les permiten reflexionar, indagar, modelar, contextualizar y argumentar en torno a las mismas, de tal manera que al abordarlas se favorece el proceso de caracterización del CPP (Carvalho, 2015; Freitas, Carvalho, \& Oliveira, 2012; Lopes, 2013).

La realización de puestas en común que promueven el debate, la toma de posturas como ciudadanos críticos y reflexivos, el establecimiento de las relaciones CTSA, así como la realización de material didáctico (secuencias didácticas (SD)). El dialogo permanente y reflexivo en torno a las CSC, permite a la vez promover una alfabetización científica y tecnológica (Aikenhead \& Ogawa, 2007).

Al comprender y sustentar la formación de profesores en el ámbito de las asociaciones libres, consideradas como espacios potenciales de formación y comunicación (Habermas, 1987), conocidas en el contexto de la investigación como Gl, se promueve el trabajo interdisciplinar, la gestión de procesos de comprensión del contexto escolar, especialmente al asumir CSC que surgen de las mismas problemáticas escolares como es el caso de la drogadicción ${ }^{1}$ (en el contexto de la Institución Educativa Guillermo Cano en la Educación de Jóvenes y Adultos (EJA). A partir de dicha problemática, se aborda el uso/abuso de sustancias psicoactivas (SPA), adicionalmente, al ser este un problema global, se aborda desde lo local ya que se evidencia en el contexto de los estudiantes de la jornada noche de la institución en mención.

\footnotetext{
${ }^{1}$ http://editoramelhoramentos.com.br/v2/wp-content/uploads/2015/12/DOCES-VENENOS.pdf http://bibliotecadigital.ilce.edu.mx/sites/ciencia/volumen3/ciencia3/130/html/lassusta.html
} 
Abordar CSC en las clases, desestabiliza la organización tradicional de la escuela promoviendo el trabajo interdisciplinar y en equipo de docentes, concibiendo el tiempo escolar en virtud del trabajo colectivo, invitando a los docentes a mediar en dilemas éticos complejos que sólo se asumían en algunas áreas específicas y que ahora exigen un análisis complejo, una postura crítica y reflexiva que invita al establecimiento de metas comunes en pro de mejorar las relaciones de horizontalidad entre los miembros de la escuela y de la transformación de las prácticas de aula que favorezcan las relaciones entre profesores y alumnos.

Las CSC de acuerdo con Martínez (2010), al ser abordadas por los docentes en sus clases favorecen la construcción de autonomía profesional y cuestionan la ideología tecnicista del currículo tradicional. Además, les permite investigar sobre su propia práctica profesional fortaleciendo la toma de decisiones, el nivel argumentativo y el desarrollo de pensamiento crítico importante para la formación ciudadana.

Concebir la escuela como un escenario para la construcción de saberes, por medio de la consolidación de grupos de investigación (Gl), de docentes interesados en el abordaje de CSC, puede favorecer el desarrollo profesional desde el trabajo colaborativo entre la universidad y la escuela.

La presente investigación, a partir de la evidenciación de las necesidades anteriormente mencionadas, se construyó en el marco del programa colombobrasileño de formación de profesores de ciencias en la interfaz universidad escuela (IUE), consolidado en el contrato 531 del 2012 establecido entre la Universidad Pedagógica Nacional y COLCIENCIAS; cuyo objetivo fue constituir y analizar el desarrollo de un programa de formación de profesores enfocado en las discusiones de CSC, que permitiera establecer recomendaciones curriculares para la construcción de políticas educativas que articularan las prácticas de los profesores de las escuelas y la investigación académica desarrollada en los cursos de maestría y doctorado en la Enseñanza de las Ciencias. 
Así mismo, se consideró como antecedente central otro proyecto de investigación financiado por la sub-dirección de investigaciones CIUP de la UPN, en el que se caracterizaron los discursos movilizados por los profesores de ciencias en ejercicio y en formación inicial, enfocados en el diseño de unidades didácticas centradas en CSC surgidas desde los intereses de los propios profesores. Con lo anterior se logró evidenciar el surgimiento de discurso ético utilitarista, deontológico y relativista, así como discurso ético de lo ambiental, político y económico; dichos discursos inciden en el diseño de las unidades didácticas propuestas por profesores en ejercicio y en formación inicial (Martínez \& Parga, 2013).

A partir de lo anterior se constató, después de haber realizado una revisión bibliográfica en revistas y tesis de doctorado sobre aspectos propios de la formación de profesores, el CPP y el abordaje de CSC basado en el enfoque CTSA, la ausencia de estudios en los que se analice el CPP a partir del abordaje de CSC en el aula. Así pues, se evidenció la necesidad de invertir mayores esfuerzos para explorar las posibilidades de espacios de formación permanente de docentes, que permitieran la interacción universidad-escuela, concibiéndolos como aquellos lugares de formación interdisciplinar, que posibilitan la innovación en la Enseñanza de las Ciencias y permitan transformar las prácticas de los docentes cuando se enfrentan con situaciones didácticas en diversos contextos (Talanquer, 2014a).

En ese mismo sentido, Reis (2014) plantea la necesidad de generar espacios de formación de docentes que propendan por un desarrollo profesional que garantice confianza, motivación y posibilidades de asumir nuevos conocimientos para la realización de acciones informadas y negociadas sobre problemáticas sociales y ambientales asociadas a la Ciencia y la Tecnología.

La formación de profesores es un eje central en los estudios y debates del campo educativo, especialmente cuando hay una intención de imponer reformas educacionales propuestas por las políticas y políticos de turno a través de los planes decenales de educación, más aún cuando se afirma que la calidad de la 
educación depende de la calidad de los profesores. En este sentido, es necesario realizar una lectura profunda de las trasformaciones que afectan la sociedad y que provocan cambios desafiantes para la escuela y para todos los que conviven en su cotidianidad.

En correspondencia con lo anteriormente mencionado, se han propuesto diferentes modelos de formación de profesores que favorezcan el desarrollo profesional y la transformación de la escuela; estos modelos tienden a reivindicar el trabajo del profesor reconociéndolo como un intelectual crítico - reflexivo, investigador y constructor de saberes con capacidad de autogestión, innovación y autonomía. (Huberman \& Levinson, 1988; Imbernón, 2011; Imbernon \& Canto, 2013; Martínez, Parga, Zapata, Rodríguez, \& Garzón, 2015; Reis, 2014, 2016; Reis, 2004; Solís, 2005). Lo mencionado, implica una interacción continua y colaborativa entre investigadores universitarios e investigadores de la escuela, que permita establecer diálogos horizontales, reflexiones continuas, interactivas y contextualizadas de las prácticas docentes.

En correspondencia con dicho contexto, se propuso como objetivo general de la investigación caracterizar el Conocimiento Profesional (CPP) de los profesores del Gl, para la construcción de conocimientos alrededor de las CSC en el marco de un programa de formación de profesores en la interfaz universidad-escuela. Así mismo, se propuso caracterizar el proceso formativo evidenciado en la constitución y consolidación de un GI interesado en el abordaje de CSC; asimismo, identificar los posibles aportes del abordaje de las CSC a la dinámica del aula de los profesores del Gl a la luz de una hipótesis de progresión-regresión (HdPR).

En términos metodológicos, para el desarrollo de la investigación se optó por una perspectiva cualitativa centrada en el estudio de caso, con la ayuda de técnicas de observación participante. Según Denzin \& Lincoln $(1994,2011)$ la investigación cualitativa es un proceso interpretativo, multimetódico y naturalista; situado en los espacios sociales en los que ocurren las acciones, experiencias o interacciones 
humanas, donde los detalles descriptivos de las personas, los lugares y las conversaciones entre los miembros del grupo investigado son una fuente directa de los datos obtenidos, donde el investigador es el instrumento principal para capturar la información y dar sentido al proceso de construcción y reconfiguración de saberes.

En esta investigación se considera que las personas comprenden e interpretan el mundo de forma diferente, lo que implicó estudiar y conocer las experiencias de los docentes en el contexto en que se lleva a cabo su práctica, para lo cual el investigador utilizando diversos instrumentos de recolección de datos, tales como la entrevista, la observación, las historias de vida, las grabaciones, los diálogos informales, las producciones textuales, entre otras, busca permitir una mejor comprensión del CPP y sus implicaciones al asumir CSC.

Respecto a la investigación cualitativa, Denzin \& Lincon (2006) reconocen que tiene un foco multiparadigmático, que permite que visiones emergentes se constituyan por la búsqueda de los significados presentes en la complejidad de las relaciones humanas a partir de las relaciones causa-efecto. Para estos autores un paradigma corresponde a un conjunto básico de creencias que orientan a la acción, basados en conceptos éticos, epistemológicos, ontológicos y metodológicos. En este sentido, se pueden distinguir en la investigación cualitativa diferentes diseños y tradiciones que se agrupan en enfoques biográficos, fenomenológicos, etnográficos y estudio de caso; este último base de esta investigación.

El estudio de caso no es producto solamente de la elección de un método, sino más bien de la elección de un objeto a ser estudiado. Se elige estudiar un caso, que puede ser un hecho, un grupo, una relación, una institución, una organización, un proceso social, una situación o escenario específico escogido a partir de un determinado recorte empírico y conceptual de la realidad social, que conforma un tema /o problemática de investigación. 
Según Moreira (2002), se parte del supuesto holístico de la investigación cualitativa que no sólo limita su atención en un objeto o parte de un problema, sino que implica la comprensión de las partes y de sus interrelaciones con el todo. Hacer este tipo de investigación requiere que el investigador comprenda y describa cómo ocurren las cosas y por qué ocurren. Por tanto, fue necesario asumir el Gl como caso, analizando las interdependencias de las partes y de los patrones que emergían, es decir, se conoció y caracterizó el CPP al asumir CSC de los docentes del Gl y no el CPP de cada uno de los docentes.

La metodología de estudio de caso entonces, se focalizó sólo en el grupo de docentes del Gl analizando detallada y repetidas veces las interacciones humanas (escenas, situaciones claves) con la ayuda de los registros audiovisuales, entrevistas semiestructuradas, estructuradas, narraciones, transcripciones de audio, registros escritos (talleres y secuencias didácticas presentadas en forma individual y grupal) fotografías, etc.; de tal manera que se pudiera caracterizar el CPP de los participantes en el escenario del GI.

Al asumir el Gl como un estudio de caso único, la preocupación central de la investigación era que el CPP se concibiera como algo singular, único que presenta unas características particulares de cada docente, cuando en realidad significa todo lo contario, ya que la intervención y proceso de formación se realizó en forma colectiva. Con base en lo anterior, a título de hipótesis de trabajo se deduce que el discurso abordado por cada docente, atravesó el de los otros, haciendo que se movilizaran nuevas ideas, se elaboraran constructos conceptuales y epistemológicos que incidieron en el CPP de cada uno de los profesores participantes del GI, así como también posiblemente hizo que algunos se movilizaran a un estilo de pensamiento en transición.

La investigadora entonces, gracias a la intuición, empatía y otras habilidades, sumadas al uso de instrumentos, estrategias y con el referente teórico consolidado, interpretó y describió las ideas, creencias, valores, supuestos, comportamientos y en general todo lo que sucede en el interior del Gl cuando 
abordó algunas CSC del interés de sus integrantes; es decir, realizó una descripción comprensiva y contextualizada del discurso del grupo usando como dispositivo analítico, el Análisis Textual Discursivo (ATD), acorde a las categorías referenciadas por (Martínez, C., 2000; Martínez, C., 2016; Martínez,L., 2010) y las elaboradas en el transcurso de la investigación, así como las emergentes producto de su consolidación.

El ATD concebido como una modalidad de investigación sustancialmente distante del análisis del contenido (AC) propuesto por Bardin (1991) y de las modalidades del análisis del discurso(AD), se aproxima al AC por su naturaleza interpretativa para la comprensión del fenómeno investigado, por su carácter hermenéutico, de construcción y reconstrucción de comprensiones sociales y culturales; también es próximo al $A D$ de naturaleza crítica lo que le permite examinar los fenómenos a partir de una mirada teórica externa, donde emerja lo no dicho, lo implícito, lo latente, lo dialéctico (Moraes \& Galiazzi, 2007).

En la presenta investigación, también se usó como herramienta de análisis el software Nvivo11 que se articula con la metodología de análisis e interpretación de textos (ATD), posibilitando la fusión de la información (recursos/elementos internos), la organización y el procesamiento de la misma (unidades de significado (codificación), la aparición de las primeras categorías de análisis (nodos libres o las establecidas previamente), de las intermedias (ramificación de los nodos, categorías emergentes) y finales (nodos)); adicionalmente el software permite establecer relaciones entre nodos, atributos, documentos, casos, etc., favoreciendo la construcción de nuevas categorías, la interpretación y comprensión de las mismas, así como el planteamiento de metatextos (matrices), de nuevos constructos y/o explicaciones teóricas.

Para el desarrollo metodológico de la investigación se llevaron a cabo las siguientes fases:

4. Caracterización de la conformación del caso (GI) y selección de la temática a abordar como CSC. 
5. Desarrollo de actividades pedagógicas, didácticas e investigativas a partir de la CSC al interior del grupo, que permitieran desarrollar el proceso de comprensión de la incidencia de la CSC elegida al ser abordada de forma interdisciplinar y desde un razonamiento sociopolítico, ético-moral, sociocultural, de riesgo (ambiente y salud) y científico-tecnológico en la construcción del CPP; para lo cual se realizaron debates, puestas en común, confrontación con especialistas y talleres (de sensibilización, de autoformación sobre el tema, elaboración de material didáctico y planteamiento de un taller una vez finalizado el acompañamiento de IUE).

6. Organización de la información en el software Nvivo11 bajo la metodología de ATD teniendo como categorías iniciales las propuestas en la hipótesis de progresión/regresión del CPP por Martínez (2016;2017), evidenciadas en la figura 5 , de las que emergen nuevas categorías que son explicadas a la luz de la teoría epistemológica de Fleck (1986) sobre estilos y colectivos de pensamiento, comunicación intra e intercolectiva de pensamientos; permitiendo al investigador comprender la dificultad de la movilidad de los EP de los profesores del Gl cuando aparecen hechos nuevos, como es el caso de las CSC.

Los referentes teóricos mencionados, el procedimiento metodológico y el análisis realizado serán profundizados en el cuerpo del documento así:

En el capítulo 1, se hace un recuento de los antecedentes de la investigación de los últimos cuatro años encontrados en revistas indexadas, teniendo como eje de búsqueda las palabras claves de la investigación, como son el CPP, las CSC en el contexto CTSA, la formación de profesores en IUE; lo anterior se presenta en una tabla que resume la búsqueda en términos de revisados y seleccionados.

El capítulo dos, titulado Conocimiento Profesional del Profesor de Ciencias en Ejercicio y abordaje de CSC, presenta una caracterización de la naturaleza y de los componentes del CPP, desde los contenidos disciplinares, pedagógicos, didácticos, contextuales, experienciales, y hasta emocionales, finalizando con las 
características de las CSC como posible eje interdisciplinar e integrador de cada uno de los componentes del CPP.

En el capítulo 3, titulado Epistemología Fleckiana, se hace una bosquejo general de la fundamentación epistemológica que enriqueció la investigación y que basada en categorías propuestas por Fleck (1986), permitió comprender la construcción del conocimiento en términos de colectivo de pensamiento (CP), estilos de pensamiento (EP), círculos esotéricos y exotéricos, circulación intra e intercolectiva de ideas y hecho científico; posibilitan entender la IUE en términos de los actores constituyentes, como los profesores de la Universidad y los profesores de las Escuelas, que a su vez constituyeron los referentes de las hipótesis emergentes para analizar las contribuciones de las discusiones epistemológicas del abordaje de CSC en la construcción del CPP en el contexto del proyecto de formación permanente de profesores. Además, este capítulo permite comprender que la construcción del CPP es análoga a la construcción de conocimientos científicos y, por tanto, para ser comprendido, debe recurrirse al desarrollo social, histórico, cultural y contextual de dichos saberes transformados a lo largo del tiempo.

Fleck recurre a la sociología del conocimiento para la elaboración teórica de conceptos que muestra como una construcción social del conocimiento; determina el EP de un grupo de individuos que al apropiarse del mismo y compartirlo (consumirlo) forman un CP, estos EP son los que direccionan el pensar y el actuar en un campo de conocimiento determinado, en este caso el científico y el popular. Por tanto este capítulo se constituye como un referente teórico que permite explicar a partir de las categorías emergentes, la consolidación del Gl como CP, así como la relación entre las categorías fleckianas y las estrategias realizadas en el proceso de formación en IUE como el medio que favorece la construcción del CPP.

En el capítulo 4, se realiza el abordaje metodológico, en el que se muestra cada una de las etapas de la investigación, justificando la constitución del GI del GCl 
como un estudio de caso único, el uso del ATD como dispositivo de análisis que al articularse con el software NVivo11, permite categorizar cada uno de los componentes del CPP, establecer nuevas categorías emergentes que se constituyen en un modelo explicativo para comprender el CPP como un constructo social, histórico y cultural.

En el capítulo 5, se aborda el análisis de los resultados a la luz de la HdPR, en la que se articulan los componentes del CPP planteados por Martínez (2000, 2016, 2017), las características de las CSC (Martínez, 2014; Ratcliffe \& Grace, 2003a), el enfoque formativo (Levinson, 2006c, 2008, 2010; Pedretti \& Nazir, 2011; Strieder, 2012), así como la conformación del Gl a la luz de las teorías de Habermas (1987) y las relaciones de poder de Bourdieu (1990;2008); Bourdieu \& Passeron (2001a); Gutiérrez (2004), las cuales han sido consideradas propuestas contrahegemónicas a los procesos tradicionales de formación de profesores en la IUE.

En el capítulo 6, se retoman los planteamientos de la formación de profesores al abordar las CSC y después de establecer los aportes y las dificultades de dicha intervención, se presenta un modelo explicativo que responde a la manera como se construye y reconstruye el CPP al abordar estas CSC en el proceso de formación de profesores en IUE a la luz de la teoría epistemológica de Fleck (1986).

Finalmente, se presentan las conclusiones de la investigación, haciendo énfasis en las bondades y dificultades que ofrece el abordaje de CSC en la Enseñanza de las Ciencias, en especial a través de proceso de formación permanente de docentes en IUE, que beneficia y concibe a la escuela como constructora de conocimientos escolares, al profesor como investigador crítico, reflexivo que posee un CPP epistemológicamente diferenciado y a la universidad como innovadora/creadora de conocimiento que lidera procesos de investigación y de formación. 


\section{CAPÍTULO 1. ANTECEDENTES}

Para efectos de la construcción de los antecedentes de esta investigación se realizó una revisión de los artículos publicados en los últimos cuatro años sobre aspectos propios de la formación de profesores, el CPP y el abordaje de CSC con enfoque CTSA, todos estos temas tratados en estudios elaborados con profesores en ejercicio. La selección de los artículos se realizó a partir de la revisión de las revistas especializadas en Enseñanza de las Ciencias o Didáctica de las Ciencias publicadas en el contexto iberoamericano. De forma complementaria se acudió a otros artículos publicados en años anteriores debido a la falta de información en el periodo más reciente.

La selección de dichas revistas estuvo limitada a aquellas que están indexadas en el Sistema regional de información en línea para revistas científicas de América Latina, el Caribe, España y Portugal (Latindex), Sistema de Indexación y Homologación de Revistas Especializadas de Ciencia, Tecnología e Innovación (Publindex-Colombia), (Redalyc), (IRESIE) y Scientific Electronic Library Online (SciELO), por considerarse publicaciones importantes en el contexto iberoamericano. Además, dichos sistemas de indexación visibilizan publicaciones de alta calidad y son de libre acceso bajo el sistema Open Journal System (OPJ), lo que facilita el acceso a profesores de distintos niveles educativos interesados en los temas tratados en esta tesis. Fueron revisados algunos números de revistas especializadas en Educación que tenían artículos relacionados con el tema, estas también cumplen los criterios de calidad expuestos anteriormente.

En la tabla 1, se presenta el número de artículos revisados en las revistas de Enseñanza de las Ciencias presentes en los distintos sistemas bibliográficos y los artículos seleccionados por estar directamente relacionados con el tema de esta investigación. Para la selección de los artículos se tuvo en cuenta el título del artículo, el resumen y las palabras claves. 
Tabla 1. Revistas consultadas del campo de la Enseñanza de las Ciencias

\begin{tabular}{|c|c|c|c|c|c|c|c|c|c|c|c|}
\hline \multirow{2}{*}{ 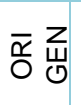 } & \multirow[b]{2}{*}{ REVISTAS } & \multicolumn{2}{|c|}{2011} & \multicolumn{2}{|c|}{2012} & \multicolumn{2}{|c|}{2013} & \multicolumn{2}{|c|}{2014} & \multicolumn{2}{|c|}{ TOTAL } \\
\hline & & AR & AS & AR & AS & AR & AS & AR & AS & $\mathbf{R}$ & $\mathbf{S}$ \\
\hline \multirow{7}{*}{$\begin{array}{l}\frac{\pi}{0} \\
\text { 음 } \\
\frac{0}{0} \\
0\end{array}$} & $\begin{array}{l}\text { Revista de la Facultad de Ciencia y } \\
\text { Tecnología TED }\end{array}$ & 2 & 2 & & & & & 4 & 4 & 6 & 6 \\
\hline & Revista Nodos y Nudos & 1 & 1 & 1 & 1 & 1 & 1 & & & 3 & 3 \\
\hline & $\begin{array}{l}\text { Revista Góndola Universidad } \\
\text { Distrital. }\end{array}$ & 1 & 1 & & & 1 & 1 & 7 & 7 & 9 & 9 \\
\hline & Luna Azul & 2 & 2 & 1 & 1 & 2 & 1 & 1 & 1 & 6 & 5 \\
\hline & Pluriuni-diversidad & & & & & 1 & 1 & 5 & 3 & 6 & 4 \\
\hline & Revista Colombiana de Educación & 1 & 1 & 1 & 1 & 6 & 3 & 4 & 2 & 12 & 7 \\
\hline & $\begin{array}{l}\text { Revista Latino Americana de } \\
\text { estudios educativos }\end{array}$ & 1 & 1 & 3 & 1 & 5 & 4 & & & 9 & 6 \\
\hline \multirow{8}{*}{ 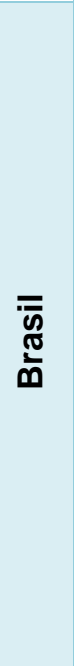 } & $\begin{array}{l}\text { Caderno Brasileiro de Ensino de } \\
\text { Física }\end{array}$ & 1 & 1 & & & 1 & 1 & & & 2 & 2 \\
\hline & Ciência \& Educação & 1 & 1 & 2 & 1 & 3 & 2 & 5 & 3 & 11 & 7 \\
\hline & $\begin{array}{l}\text { Consciência. Revista Eletrônica de } \\
\text { Jornalismo Científico }\end{array}$ & & & & & & & 1 & & 1 & 0 \\
\hline & $\begin{array}{l}\text { Ensaio. Pesquisa em educação em } \\
\text { ciências }\end{array}$ & 4 & 2 & 4 & 2 & & & 7 & 3 & 15 & 7 \\
\hline & $\begin{array}{l}\text { Investigações em Ensino de } \\
\text { Ciências }\end{array}$ & 2 & 1 & 4 & 2 & 5 & 3 & 3 & & 14 & 6 \\
\hline & $\begin{array}{l}\text { Revista Brasileira de Ensino de } \\
\text { Física }\end{array}$ & 1 & 1 & 1 & 1 & & & & & 2 & 2 \\
\hline & $\begin{array}{l}\text { Revista Brasileira de Pesquisa em } \\
\text { Educação em Ciências }\end{array}$ & 2 & 1 & 4 & 2 & 2 & 1 & 7 & 4 & 15 & 8 \\
\hline & Revista Química Nova na Escola & 5 & 3 & 6 & 4 & 2 & 1 & 5 & 3 & 18 & 11 \\
\hline \multirow{7}{*}{ 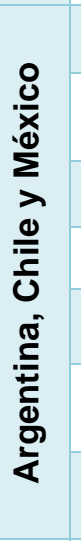 } & Revista de Educación en Biología & 1 & 1 & 2 & 1 & 2 & 1 & & & 5 & 3 \\
\hline & $\begin{array}{l}\text { Revista de estudios sociales de la } \\
\text { ciencia REDES }\end{array}$ & 1 & 1 & 1 & 1 & 1 & 1 & & & 3 & 3 \\
\hline & Ciencia, docencia y tecnología & 4 & 2 & 1 & 1 & & & 1 & 1 & 6 & 4 \\
\hline & Aleph Zero & 1 & 1 & & & & & & & 1 & 1 \\
\hline & Educación en Química & 1 & 1 & 3 & 2 & 5 & 2 & 12 & 12 & 21 & 17 \\
\hline & $\begin{array}{ll}\text { Revista } & \text { Investigaciones en } \\
\text { Educación } & \end{array}$ & & & & & 1 & 1 & & & 1 & 1 \\
\hline & $\begin{array}{l}\text { Revista Electrónica de la Red de } \\
\text { Investigación Educativa }\end{array}$ & 2 & 1 & 3 & 2 & 2 & 1 & 1 & 1 & 8 & 5 \\
\hline \multicolumn{2}{|c|}{$\underset{\mathbf{x}}{\mathscr{\prime}}$} & 5 & 3 & 2 & 1 & 5 & 4 & 16 & 10 & 28 & 18 \\
\hline
\end{tabular}




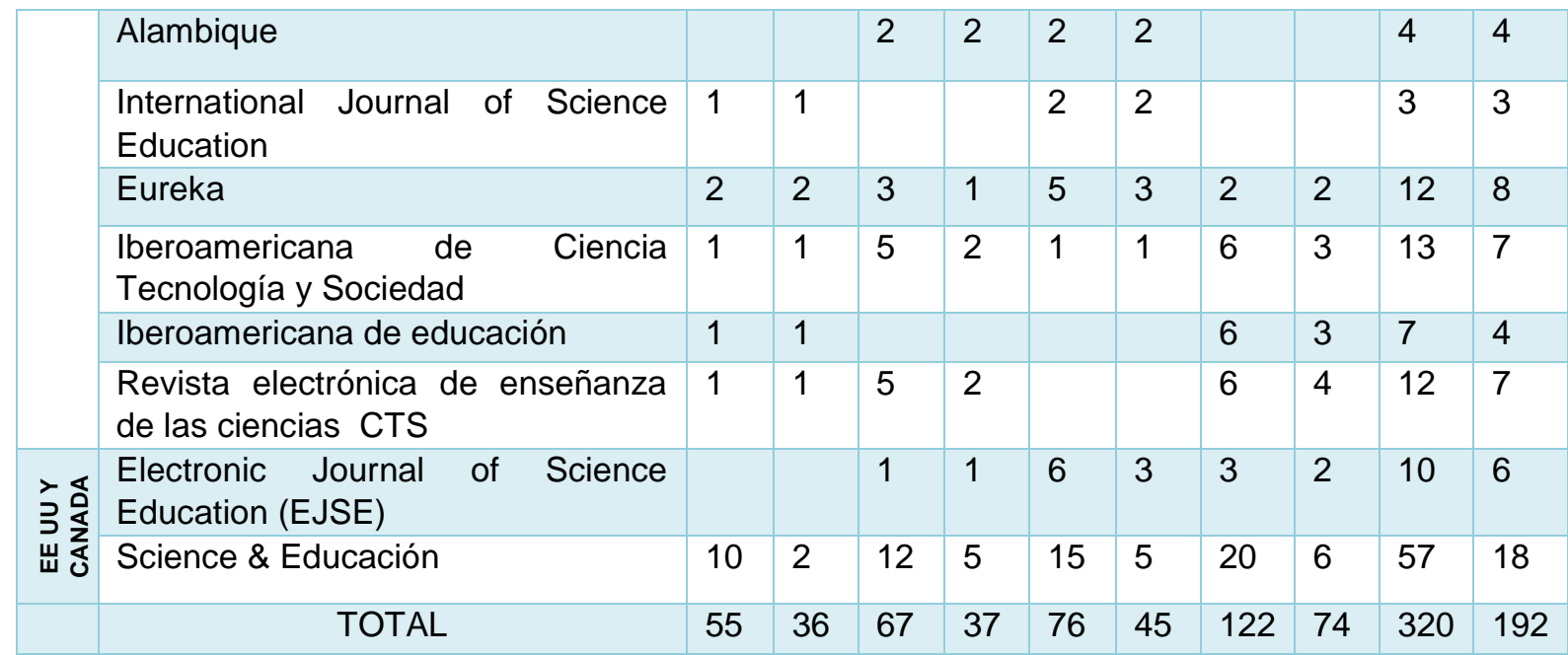

R: revisada S: seleccionada Fuente: autora

De la revisión hecha se identificaron y seleccionaron el número de artículos asociados a CSC, CPP y Formación de Docentes en ejercicio, que se relacionan en la Tabla 2.

Tabla 2. Identificación de número de artículos por temáticas de interés.

\begin{tabular}{|l|c|c|c|c|}
\hline PAISES/REVISTAS & $\begin{array}{c}\text { CUESTIONES } \\
\text { SOCIOCIENTIFCAS(CSC Y } \\
\text { CSA) }\end{array}$ & $\begin{array}{c}\text { CONOCIMIENTO } \\
\text { PROFESIONAL DEL } \\
\text { PROFESOR (CPP) }\end{array}$ & $\begin{array}{c}\text { FORMACION DE } \\
\text { DOCENTES EN } \\
\text { EJERCICIO }\end{array}$ & TOTAL \\
\hline COLOMBIA & 15 & 11 & 25 & 51 \\
\hline BRASIL & 21 & 8 & 49 & 78 \\
\hline ARG,CH Y MEX & 6 & 19 & 20 & 45 \\
\hline EUROPA & 24 & 24 & 31 & 79 \\
\hline EEUU-CANADA & 23 & 19 & 25 & 67 \\
\hline TOTAL & 89 & 81 & 150 & 320 \\
\hline Seleccionadas & 44 & 58 & 90 & 192 \\
\hline
\end{tabular}

Fuente: autora

Los 192 artículos seleccionados, aunque con mayor número los correspondientes a la formación de docentes, están centrados en experiencias de Enseñanza de las Ciencias desde una concepción disciplinar y metodológica, sin hacer alusión centrada en los procesos formativos realizados en la IUE y al abordaje de CSC. Lo que evidencia la importancia de esta temática desarrollada en la presente 
investigación, en términos de la construcción de conocimiento que posibilite articular la investigación académica con las experiencias e investigaciones llevadas a cabo en las escuelas.

Vale la pena mencionar que la clasificación por palabras claves y resúmenes, se realizó de tal forma que, aunque muchos artículos revisados encajaban en todas las temáticas de interés, se integraran a aquella que fuera central.

También es importante comentar que el mayor número de artículos que muestran experiencias de formación de docentes en ejercicio en un proceso de IUE son de Brasil.

A continuación, se realiza una síntesis de los aspectos o investigaciones llevadas a cabo en torno a los tres aspectos referenciados en la tabla 2.

Los artículos organizados bajo la categoría de formación de profesores parten de la reflexión del rol del docente como ejemplo de calidad y excelencia educativa en una época de profundos cambios, en la que la escuela es cada vez más compleja, heterogénea y sobre todo instrumentalizada por presiones gubernamentales, económicas de corte capitalista centradas en pruebas estandarizadas que la escuela debe cumplir; de la misma manera, se crean políticas locales que tienden a satisfacer visiones nacionales y globales que haciendo que los gobernantes diseñen leyes que obligan a la escuela a adaptarse a estos cambios por medio del planteamiento de reformas curriculares, pero manteniendo viejas estructuras en su organización (Acosta, 2011; Mellado, 2014; Ormart \& Brunetti, 2013).

Nuestros gobiernos de orden Latinoamericano han adoptado acríticamente propuestas educativas de otros países, especialmente de aquellos que le brindan posibilidades de financiación, asesorías, o cuyos intereses están centrados en lo deseable para el estado, el mercado o la misma política de turno; olvidando que son los maestros quienes desde el aula construyen conocimientos prácticos que ponen en juego saberes disciplinares, didácticos, culturales, contextuales en pro 
del desarrollo de un conocimiento escolar y de un conocimiento profesional construido sobre su práctica, a partir de lo cual de manera más favorable, es posible plantear políticas educativas y fortalecer conocimientos escolares que posibiliten mejorar la educación.

En relación con lo anterior, Imbernón (2011, 2009) e Imbernon \& Canto (2013) plantean que las propuestas orientadas hacia la formación del profesor no se hacen pensando en el contexto escolar, en las relaciones laborales del docente y/o la administración; menos aún, se tienen en cuenta las condiciones emocionales, de edad, de expectativas del docente y de la escuela, evidenciando así que la oferta de formación permanente de docentes es en su mayoría descontextualizada, aislada de las necesidades reales de la escuela, del docente y que por lo tanto no conlleva a una cultura de investigación escolar que promueva el desarrollo profesional y la transformación de la escuela.

Algunos modelos de formación de docentes han orientado sus acciones al ofrecimiento de cursos de extensión como semilleros de Astronomía, Interacción Museos - Escuela, utilización de software específico para enseñanza de las ciencias (Física, Química, Biología, Matemáticas), trabajos cooperativos con docentes de artes, uso de TIC, uso de prácticas de laboratorio y motivación por la enseñanza de las ciencias y el aprendizaje de conceptos propios de cada disciplina científica; aunque gracias a dichas orientaciones se obtiene resultados novedosos, no han trascendido como parte de la cultura escolar y han quedado en el ámbito de experiencias exitosas puntuales (Fürkotter et al., 2014; Lombana, Delgado, \& Rickenmann, 2011).

En un estudio realizado sobre las creencias del aprendizaje por investigación de profesores en ejercicio y en formación inicial se aborda un instrumento tipo Likert, que permite visualizar la importancia que dan los maestros, a la formación permanente y al aprendizaje por investigación guiada, encontrando que los profesores en ejercicio dudan de la eficiencia de la formación continuada y dan a conocer los obstáculos que generaría llevarla a cabo por la falta de recursos y de 
tiempo, lo que impediría llevar a buen término el plan de estudios; los profesores en formación inicial, por el contrario consideran que tanto los contenidos, como las metodologías compartidas en dichos procesos de formación van a incidir en su futura práctica profesional (Gallego, Ariza, Armenteros, \& García, 2014)

Investigaciones como la anterior, permiten develar la manera como los profesores en ejercicio posiblemente se han dejado alienar profesionalmente, quizás a espera de soluciones de expertos, de "cursos de formación" que continúen perpetuando el trabajo individual, descontextualizado que limita el desarrollo autónomo y profesional, imposibilitando el reconocimiento de los profesores como agentes sociales, planificadores y gestores del conocimiento, que están en toda la capacidad de intervenir en las complejas decisiones que surgen en sus prácticas profesionales (Imbernón, 2011).

Al respecto, Beraza (2011) plantea una serie de reflexiones sobre la formación inicial y permanente del profesorado alrededor de tres ejes:

- La importancia del profesorado: propone que la figura docente debe ser considerada desde la dimensión personal, profesional y laboral.

- La evolución de la figura del profesor: implica dejar de lado una visión excesiva y errónea de la profesionalidad, para contemplar una perspectiva de profesionalidad doble (científica y docente) abierta a la dinámica cultural del propio entorno; pasar de ser experto en los contenidos disciplinares a ser experto en la didáctica para el abordaje de los mismos; pasar de ser un profesor de una clase (aula) determinada a ser el profesor del centro educativo; permitir la apertura a la globalidad y al trabajo en red.

- La estructura de la formación y su evolución: a través de la movilización (asistencia a congresos no solo como sujeto de escucha sino como participante activa de cursos, congresos y grupos de trabajo), pasar de la formación por asimilación a la formación por acomodación; ser consciente de los nuevos modelos de formación, en especial el cultural y considerar la 
existencia de nuevas líneas de desarrollo de la formación del profesorado, que es el aprendizaje a lo largo de la vida.

Se han realizado propuestas de formación de docentes en el marco de encuentros académicos entre la Universidad y la Escuela, con el fin de innovar en contextos diversos socioculturalmente a través de metodologías de investigación-acción o estudio de caso, allí interactúan profesores en formación inicial, profesores en ejercicio y formadores de profesores, quienes han presentado dificultades debido a las concepciones antagónicas de los docentes de la escuela y los docentes universitarios (Castro \& Hernández, 2013; Siqueira, Pinto, \& Cattani, 2013).

Otras experiencias de articulación Universidad-Escuela se han desarrollado a través de las prácticas pedagógicas de los maestros en formación inicial o de los docentes universitarios con interés de realizar investigaciones de tipo formativo en el campo disciplinar y/o pedagógico en contexto escolar, en menor cantidad se identifican experiencias de IUE en torno al uso de CSC como estrategia para promover las relaciones CTSA y favorecer procesos argumentativos en los estudiantes; es decir, se ha dado más énfasis a las experiencias de aula orientadas desde la universidad y desarrolladas por los docentes de la escuela, sin trascender a otros espacios o hacerla más extensiva a otros docentes como una de las dinámicas del trabajo escolar (Lima \& Marcondes, 2011; Sousa, Rocha, \& Garcia, 2012).

En el mismo contexto de IUE, Machado \& Queiróz (2012) a través de un estudio de caso diseñaron un trabajo de investigación continuada de docentes asumiendo una postura crítica-reflexiva que promoviera la emancipación de profesores y se posicionara como parte de la cultura escolar, de cuya continuidad surgió una estrategia de acompañamiento, de planteamiento de iniciativas de aula y se reconoció como uno de los aspectos positivos que se generan en estos espacios de formación e IUE.

Oliveira (2012) menciona las reflexiones que realizan los docentes universitarios al asumir la docencia en la escuela, quienes la identifican como un espacio que 
genera conocimiento, sin embargo, al no constituirse como espacios en los que generalmente ejercen su profesión, no tienen las herramientas de actuación.

Estudios exploratorios de tipo internacional sobre el distanciamiento entre la universidad y la escuela en la Enseñanza de las Ciencias, puso en evidencia la necesidad de fomentar un diálogo más fructífero entre investigadores y educadores. Se hace evidente la insatisfacción de carácter social que hay en los docentes de la escuela al no tener un salario acorde al trabajo que realizan; sin embargo, se encuentra que hay docentes investigadores que buscan mejorar sus didácticas particulares a partir de la práctica cotidiana; los docentes universitarios mencionan adicionalmente, que la escuela presenta barreras burocráticas en la infraestructura y excesiva carga horaria de los docentes, lo que dificulta procesos de participación que hacen que el docente emplee tiempos adicionales para esta interacción (Siqueira et al., 2013).

En el contexto colombiano se realizó el programa de formación de profesores en la Interfaz Universidad-Escuela desarrollada por dos universidades públicas, una colombiana (UPN) y otra brasileña (Unesp), cuyo objetivo era analizar el desarrollo de un programa de formación de profesores en torno a la discusión de CSC y ambientales, con la pretensión de establecer recomendaciones curriculares para la construcción de políticas orientadas a la articulación entre las prácticas de los profesores de ciencias de las escuelas y la investigación académica desarrollada en la universidad. Esta investigación fue de corte cualitativa, participaron 31 profesores de cinco instituciones educativas de Bogotá, quedando organizados cinco Gl consolidados como espacios de formación continua de profesores, evidenciando que la articulación entre la investigación académica universitaria y las experiencias investigativas de la escuela favorecen el desarrollo profesional en términos de mejoramiento de los procesos de enseñanza aprendizaje y los procesos de innovación que se generan dentro de la escuela, en un contexto local particular (Martínez et al., 2015). 
Adicionalmente Martínez (2014), Martínez \& Parga (2014) comentan que estos Gl mencionados anteriormente, son espacios donde pueden participar docentes en ejercicio (docentes de escuela, estudiantes de maestría, doctorado, docentes de intercambio, grupos de investigación interinstitucional), docentes en formación inicial, docentes universitarios y otros estamentos de tipo escolar que deseen fortalecer el liderazgo de la escuela y la mejora de la práctica educativa de sus maestros, así como el fortalecimiento de los conocimientos escolares.

La revisión de artículos en torno al $\boldsymbol{C P P}$ de autores como Lederman \& Abell (2014); Martínez (2000); Porlán, Rivero, \& Pozo (1998); Valvuena (2007); entre otros, consideran a este tipo de conocimiento como propio, diverso, complejo, con estatus epistemológico propio, proveniente de la integración de saberes basados de la experiencia de la práctica de aula, de las teorías implícitas, de las rutinas y de sus guiones de acción; además muestran como a partir de los trabajos de Shulman (2005) se empiezan a proliferar investigaciones en este tema, así como las realizadas por los grupos de investigación de las Universidades Pedagógica, Distrital y de Antioquia en torno al Conocimiento Profesional del Profesor de ciencias de primaria y al conocimiento escolar (Martínez, 2016; Martínez \& Valbuena, 2013).

El CPP ha sido abordado en algunas investigaciones de orden latinoamericano desde la perspectiva del Conocimiento Didáctico del Contenido (CDC) y en otros casos como Conocimiento Pedagógico del Contenido (CPC), el primero se ha centrado en la disciplina o a la enseñanza de conceptos específicos como el de estequiometria, enlace químico, reacción química, ácido-base, energía, célula, etc.; también en estrategias de enseñanza al usar como eje de aprendizaje las prácticas de laboratorio y/o Modelos de enseñanza de la química (Baca, Onofre, \& Paixão, 2014; Bañas, Pavón, Ruiz, \& Mellado, 2011; Connelly \& Clandinin, 1982; Garritz, 2012; Lima \& Nuñez, 2013; Recine et al., 2012; Reis \& Climent, 2012).

En esa misma perspectiva, Garritz (2012) plantea la necesidad de incorporar una nueva dimensión al CDC: la afectividad, dada la complejidad de abordar el 
conocimiento de los profesores; sin embargo, lo propone como tema de discusión. Otras investigaciones aluden al uso de las narrativas (Reis \& Climent, 2012), CoRe (Representación de Contenido) y PaPeR (Repertorios de Experiencia Pedagógica y Profesional) como materiales curriculares que se pueden utilizar en el proceso de formación inicial de maestros (Boris, Rodríguez, Fernando \& Viafara, 2014) y apuestas otras de naturaleza curricular plantean la necesidad de integrar la educación ambiental al currículo, gestando nuevas posibilidades de investigación en torno a la incidencia en el CDC de los docentes (Parga, Mora, \& Cárdenas, 2014).

Por otro lado, Marbà, Gairín, \& Talavera (2013) presentan los resultados de una investigación realizada a profesores de ciencias en el contexto de un plan de evaluación de los aprendizajes de las ciencias y las matemáticas por parte de la Secretaria Nacional de Ciencia y Tecnología e Innovación (SENACYT) de Panamá. El CPP (considerado como el conocimiento del contenido, el didáctico del contenido y el pedagógico general) fue evaluado a través de un instrumento que daba prioridad a los conocimientos didácticos y científicos, con la pretensión de identificar las debilidades en los saberes de los docentes que justificaran la creación de políticas de formación y desarrollo profesional que generaran cambios en la práctica escolar y empezaran a consolidar una cultura científica-tecnológica en sus estudiantes.

Vázquez \& Cruz (2014) socializan los resultados de un proyecto de investigación realizado por un docente, quien haciendo uso de la metodología de Investigaciónacción, caracteriza su propia práctica, mostrando el desarrollo de su CDC como resultado de un proceso de autoformación sobre temas de la Naturaleza de la Ciencia y la Tecnología (NdCyT) y la forma como el modelo integrador CDCNdCyT en el contexto del aula permiten a los estudiantes reflexionar sobre aspectos teóricos basados en observaciones, argumentación, aprendizaje autónomo, trabajo en equipo, y apertura de un diálogos permanentes entre sus 
pares; así, se evidencia que es menester favorecer cambios didácticos que le permitan plantear nuevos significados a la profesión docente.

Mellado et al. (2014) presentan los resultados de un programa de investigación de la universidad de Extremadura, donde explican la importancia del estudio de las emociones desde la didáctica de las ciencias, su vulnerabilidad y la necesidad de establecer programas de intervención meta cognitivos y meta emocionales en el aprendizaje y en la formación de profesores, quienes al ser conscientes de sus emociones podrán controlarlas y autorregularlas; menciona además, que es debatible considerar que las emociones tienen el mismo status que los propósitos y que actúan como una lente a través de la que el profesor percibe los otros componentes del CDC así como su desarrollo; postura defendida también por Garritz \& Ortega (2013) cuando afirma que las emociones son el sexto componente del CDC.

Otras investigaciones en torno del CPP se han desarrollado bajo los términos de saberes docentes y/o vida profesional, en el marco de la formación permanente de docentes o realización de Maestrías; tomando como punto de partida las historias de vida profesional o de biografías de algunos profesores de ciencias se ha buscado identificar las percepciones que tienen en torno a la escuela, la educación o el trabajo docente, y se ha dado a conocer su formación pedagógica y trayectoria. En otras casos, las historias permiten crear situaciones de aprendizaje que se pueden desarrollar en el escenario de la Enseñanza de las Ciencias en un contexto sociocultural caracterizado por las reflexiones y debates en torno a los saberes de dichos docentes, las preocupaciones relacionadas con la enseñanzaaprendizaje de sus alumnos, con el contenido y los saberes de la formación profesional, disciplinar, curricular y experiencial de los mismos. (Aires \& Tobaldino, 2013; Arruda, Lima \& Passos, 2012; Azevedo \& Abib, 2013; Behrsin, 2011; Cassiano \& Ribeiro, 2013; Cruz \& Barzano, 2016).

La Revista Educación Química de México dedicó el 2014 al CDC, se propuso publicar 14 capítulos que dieran como resultado un texto de carácter 
iberoamericano sobre el CDC, con la participación de autores de Brasil, Colombia, Estados Unidos y México. En algunos capítulos se enfatizó en el uso de CoRe y de los PaPeRs como instrumentos que permiten articular y representar el CDC; otros mostraron como el análisis del discurso favorece el estudio del CDC en el contexto disciplinar; adicionalmente, se planteó el PCK para Dummies y se resaltó la importancia de caracterizar el razonamiento pedagógico específico sobre un contenido (RPEC) cuando hay que enfrentarse a situaciones didácticas en contextos variados (Bertram, 2014; Farré \& Lorenzo, 2014; Garritz, 2014; Parga \& Mora, 2014; Talanquer, 2014).

A pesar del amplio rango de investigaciones en torno al CDC como uno de los aspectos del CPP, se puede afirmar que aún es incipiente el desarrollo de trabajos que establezcan relaciones de dicho conocimiento con la formación permanente de docentes y en menor número cuando a la vez se abordan temas polémicos o controversiales como son las CSC. Así pues, se inicia un acercamiento a través del relato de una experiencia que buscaba documentar el CDC desde la Química Verde $(\mathrm{QV})$ con profesores de un Instituto de Química de la Universidad de Sao Paulo (Brasil), quienes toman como referente el modelo de Grossman y encuentran que hay una dependencia significativa entre el conocimiento específico de los profesores de química orgánica, con las estrategias de enseñanza de la QV cuando la abordan desde un enfoque sociocientífico (Gianina, Leal, Comelin, Parra, \& Varelas, 2013).

El uso de CSC o ambientales en la formación de docentes en ejercicio se ha convertido en la última década en un tema importante en la Enseñanza de las Ciencias, dando respuesta a los estudios que han evidenciado que la formación docente es insuficiente, especialmente cuando tratan cuestiones relacionadas con la ciencia, la tecnología y la sociedad (CTS); posiblemente, por la fragilidad epistemológica, la carencia de posturas investigativas y prácticas en el proceso formativo, que han llevado a tener una visión de mundo fragmentado, sin 
posibilidad de tomar posiciones éticas y asumir un compromiso con la formación ciudadana (Azevedo et al., 2013).

Son considerados CSC aquellos problemas sociales, manifestados en preguntas abiertas, complejas, dialécticas y controvertidas, teniendo en cuenta que su causa, y su posible vía de solución, o ambas, deben basarse en la ciencia y/o tecnología de frontera; las problemáticas generalmente se transmiten por medios masivos (televisión, prensa, internet, etc.), muchas sin respuesta definitiva, sujetas a debate, donde cualquiera que sea la postura que el individuo o la sociedad tenga de ellas no va a ser ajena, ya que su importancia será progresiva en la medida que prosigan los avances científicos y tecnológicos y más aún si tienen efectos ambientales.

Las CSC son temáticas que tienen base científica, están en la frontera del conocimiento, involucran toma de decisiones de índole personal y social, se divulgan en los medios masivos de comunicación, tratan problemas locales, nacionales y globales, involucran análisis costo-beneficio en donde se asumen valores con raciocinio ético, pueden involucrar actividades sustentables que al ser orientadas en procesos de formación docente, pueden tomar dos direcciones, en primera medida como temas controversiales y/o como contenidos problematizados culturalmente; pero independiente de la dirección que tomen, pueden contribuir en la formación de profesores con capacidad crítica, constructores de saberes con significado científico, social y cultural (Martínez, 2012, 2014; Ratcliffe \& Grace, 2003a).

Aquellas CSC se ubican en la frontera del conocimiento constituyen buenos contextos para ilustrar el razonamiento informal, para Zeidler, Walker, Ackett, \& Simmons (2002) este razonamiento incluye la intuición y la incorporación de información continua y cambiante, con pros y contras para su posible solución, favoreciendo que tanto estudiantes como docentes construyan argumentos que develan sus preconcepciones sobre la naturaleza de la ciencia y la tecnología, así como su posición ética-moral, cultural, socio-política cuando asume papeles de la 
comunidad científica o roles de la sociedad en general; lo anterior posibilita la construcción de posturas críticas de docentes y estudiantes.

Según Solbes (2013a, 2013b) las CSC permiten tomar asuntos de actualidad para evidenciar aspectos específicos que involucren competencias propias del futuro profesional, donde las emociones juegan un papel central en su configuración, como resultado del trabajo con estudiantes de secundaria, de universidad y con profesores en formación. Concluye que las CSC han tenido acogida, favoreciendo la argumentación, el debate y el desarrollo de competencias críticas, entre las que cita:

1. Comprender la ciencia como actividad humana y las múltiples relaciones CTSA.

2. Estar informado sobre el tema, sin limitarse al discurso dominante, cuestionando la validez de los argumentos, rechazando conclusiones no basadas en pruebas y evaluando la credibilidad de las fuentes teniendo en cuenta los intereses subyacentes.

3. Estudiar las CSC de manera integral, en su complejidad, de manera que se involucren dimensiones científicas, técnicas, éticas, culturales, sociales, económicas, ambientales, etc.

4. Realizar juicios éticos en torno a la CSC atendiendo a la contribución de la misma a la satisfacción de necesidades humanas.

5. Propiciar conclusiones que lleven a tomar decisiones fundamentadas y a promover acciones para el mejoramiento de la calidad de vida (p.181).

Desde esta perspectiva las CSC constituyen una estrategia que favorece el desarrollo del CPP, ya que al abordarlas se combinan estrategias de enseñanza basadas en modelos alternativos, contextualizados, investigativos, así como grupos de discusión interdisciplinar sobre aspectos ético-morales, implicaciones socio-políticas, culturales, científicas y tecnológicas, de riesgo ambiental y de salud ; así, al abordar estas cuestiones en los GI, se trabaja en equipo, se construye un diálogo de saberes que permite analizar, develar y caracterizar lo que Talanquer (2014) define como Razonamiento Pedagógico Especifico del Contenido (RPED). 
EI RPED facilita la comprensión de las bases cognitivas y afectivas que utiliza un docente al enfrentarse a situaciones didácticas en diversos contextos y en especial el de las CSC, que a título de hipótesis pondrán en evidencia sus fortalezas y debilidades disciplinares y didácticas, posibilitando la búsqueda de alternativas que justifican sus acciones y decisiones, donde sus propias creencias se pueden transformar al tener que escuchar otros saberes, recurrir a otras áreas para argumentar y construir modelos explicativos ante esas nuevas situaciones.

A partir del análisis de este conocimiento se puede establecer un proceso de autoafirmación que propenda por una enseñanza de las ciencias dialógica, que potencie la participación de los estudiantes y favorezca una educación crítica, contribuyendo con la formación de ciudadanos informados; de tal manera que el futuro del conocimiento científico no sea solamente responsabilidad de científicos o gobiernos, sino de ciudadanos que participan en las discusiones que afectan a la aldea global, especialmente las que abordan implicaciones socio ambiéntales. (Díaz \& Jiménez, 2012).

Por su parte, Reis (2004) evidencia como las CSC estimulan la reflexión en la acción y sobre la acción de profesores de escuela, favoreciendo el desarrollo personal y profesional de los mismos, así como la reconstrucción del currículo y de sus prácticas de aula.

En esa misma vía, Levinson $(2006,2007)$ plantea un referente teórico para el uso de CSC en la enseñanza secundaria en el contexto sociopolítico contemporáneo de los países industrializados, que permitan implementar un plan de estudios basado en la formación ciudadana y el desarrollo de la ciencia del siglo XXI, a la luz de tres líneas epistemológicas: las categorías de desacuerdo razonable, las disposiciones comunicativas para entablar un desacuerdo razonable y los modos de pensamiento y de experiencia que permiten iluminar dichos desacuerdos.

En el contexto escolar se han reportado un número significativo de experiencias de aula, donde los docentes utilizan como estrategias de Enseñanza de las 
Ciencias el diseño de secuencias y unidades didácticas en torno a CSC, algunas de ellas son:

- El uso doméstico de plaguicidas en ambientes rurales y urbanos, con la que se pretendió prevenir enfermedades, mejorar la salud de la población, favorecer la imagen empobrecida de la ciencia y formar ciudadanía, acorde a las exigencias del mundo actual (Gentile, Bosch, Mañas, Gorla, \& Aiassa, 2013).

- Organismos Genéticamente Modificados (OGM) Dourado \& Matos, (2014a, 2014b) mencionan que las CSC articulan las relaciones CTSA, promueven la formación de ciudadanos informados, responsables y activos.

- Producción/acceso a la energía eléctrica y desarrollo humano; Consumo/uso y abuso de aditivos alimentarios como estrategia de cambio de hábitos alimentarios agrotóxicos como forma de articular las temáticas en la enseñanza de la química y mitigar la contaminación ambiental.

- La drogadicción, la adicción y el tabaquismo, abordadas en forma independiente y usando estrategias como fotonovelas, juego de roles, lectura de imágenes fotográficas, narrativa, uso de prácticas de laboratorio y secuencias en el contexto CTSA, permitió a los estudiantes asumir posición frente estas problemáticas sociales en un contexto de salud y enfermedad.

Estas CSC, fueron abordadas como estrategia para la enseñanza de la Química para un futuro sostenible (QV) (Albuquerque, Santos, Cerqueira, \& Silva, 2012; Barbosa, Caixeta, \& Machado, 2012; Braibante \& Zappe, 2012; Goes, Leal, Corio, \& Fernandez, 2013; Levin, 2011; Lopes, 2013; Mundim \& Santos, 2012; Santos, Amaral, \& Maciel, 2010; Wendel \& Silva, 2011).

Otras investigaciones en el campo de la formación de docentes en torno al uso de CSC, han permitido a través del análisis de discurso conocer la potencialidad de estas actividades como posibilitadoras de actitudes favorables para el estudio de 
la ciencia, así como también para el fortalecimiento del pensamiento crítico, generación de opiniones, abordaje de contenidos manejados en los medios masivos de comunicación, identificación de problemáticas locales, nacionales y globales, reconocimiento de escenarios políticos, sociales, económicos y culturales en los que están inmersa dichas controversias, así como fuente de razonamientos éticos-Morales (Carnio, 2011; Melo \& Villani, 2011; Sá, Kasseboehmer, \& Queiroz, 2013; Teixeira, Souza, Raposo, \& Silva, 2014).

También, se han abordado controversias en la historia y desarrollo de la ciencia, los desastres de Chernobyl y de Bhopal; la crisis de las vacas locas; el uso, producción y consumo de transgénicos; uso de algunos colorantes y medicamentos; el mercadeo del carbono; la experimentación animal; la energía; la polución de ambientes acuáticos; el desarrollo humano; terapia genética; clonación; aborto; uso de pesticidas; la explotación minera; la articulación entre la educación ambiental y educación científica a través de las hidroeléctricas, entre otras. (Brum \& Schuhmacher, 2014; Levinson, 2006b; Lopes \& Carvalho, 2013; Martínez \& Parga, 2013; Oliveira \& Pino, 2013; Oliveira \& Santos, 2011; Sadler \& Murakami, 2014; Silva, Oliveira, \& Queiroz, 2011; Silva \& Krasilchik, 2013; Torres \& Solbes, 2014; Vázquez, Aponte, Manassero, \& Montesano, 2014)

También Bencze, Carter \& Krstovic (2014), muestran cómo a través de la Enseñanza de las Ciencias se puede promover la formación de personas con perspectiva política-crítica, frente al sistema económico global que compromete el bienestar de muchos individuos, sociedades y ambientes, propiciando el enriquecimiento de unos pocos a través de disposiciones de gobiernos neoliberales y de organizaciones extra nacionales (Organización Mundial del Comercio), que diseñan estrategias mercantiles para promover el consumo excesivo por parte de personas con menor poder adquisitivo. Un ejemplo que evidencia lo anteriormente mencionado, es la promoción y mercadeo de smartphones provocando que los consumidores cambien constantemente de modelo, bajo el desconocimiento de los riesgos ambientales y sociales presentes 
en todo el proceso de producción (uso de Plomo, Bromo, Cloro, Mercurio y Cadmio) como la injusticia social (esclavitud actual) que sufren los trabajadores producto de la explotación minera que subyace a estos adelantos tecnológicos, que tal parece son el resultado de la aceptación de ciclos producción/consumo y obsolescencia programada que se pueden mitigar desde su abordaje en los escenarios de científicos escolares (Leonard, 2010).

Britton, Tippins, \& Freeman (2014) abordan el tema de la filosofía de la ecojusticia ${ }^{2}$ en un curso de formación de profesores de ciencias, con el propósito de promover el liderazgo escolar por parte de docentes inconformes por la linealidad con la que se enseña la ciencia, administradores de aulas versátiles, desafiantes de la estructura rígida de la escuela, y promotores de cambios de tipo local, que permitan la comprensión-mitigación de situaciones de orden nacional y global.

Rodríguez (2013) analiza críticamente la dimensión tecnológica de la medicalización del envejecimiento en el contexto de la biopolítica contemporánea, promoviendo la argumentación; reflexionando el diseño de tecnologías antiage y proage; evaluando el concepto de la cultura tecnológica por la biomedicalización y la construcción de conocimiento científico-biomédico sobre el proceso de envejecimiento con el fin de regularlo y postergarlo.

Goes et al. (2013) utiliza el modelo de Grossman para develar el CDC de un grupo de profesores universitarios expertos en los campos tradicionales de la enseñanza de la química (Química pura, Química Ambiental, Educación de Profesores de Química e Industria Química), al abordar la química verde (QV) bajo la orientación de tres modelos didácticos: tradicional, contextualizado y sociocientífico (figura 1) se evidenció la dependencia entre el conocimiento que tienen los docentes de la materia y su CDC, en términos de consistencia entre los propósitos y las

\footnotetext{
2 entendida como aquella que enfatiza en el beneficio de las hipótesis desafiadoras que promocionan el empoderamiento de profesores con capacidad de considerar perspectivas diferentes a la alienación y, la diversidad de pensamiento y la acción
} 
estrategias que orientan la enseñanza de la QV, la comprensión de las dificultades estudiantiles y el conocimiento del currículo; así como la estrecha relación entre la QV y el CDC de los docentes de Química Orgánica al preferir como enfoque de enseñanza el sociocientífico.

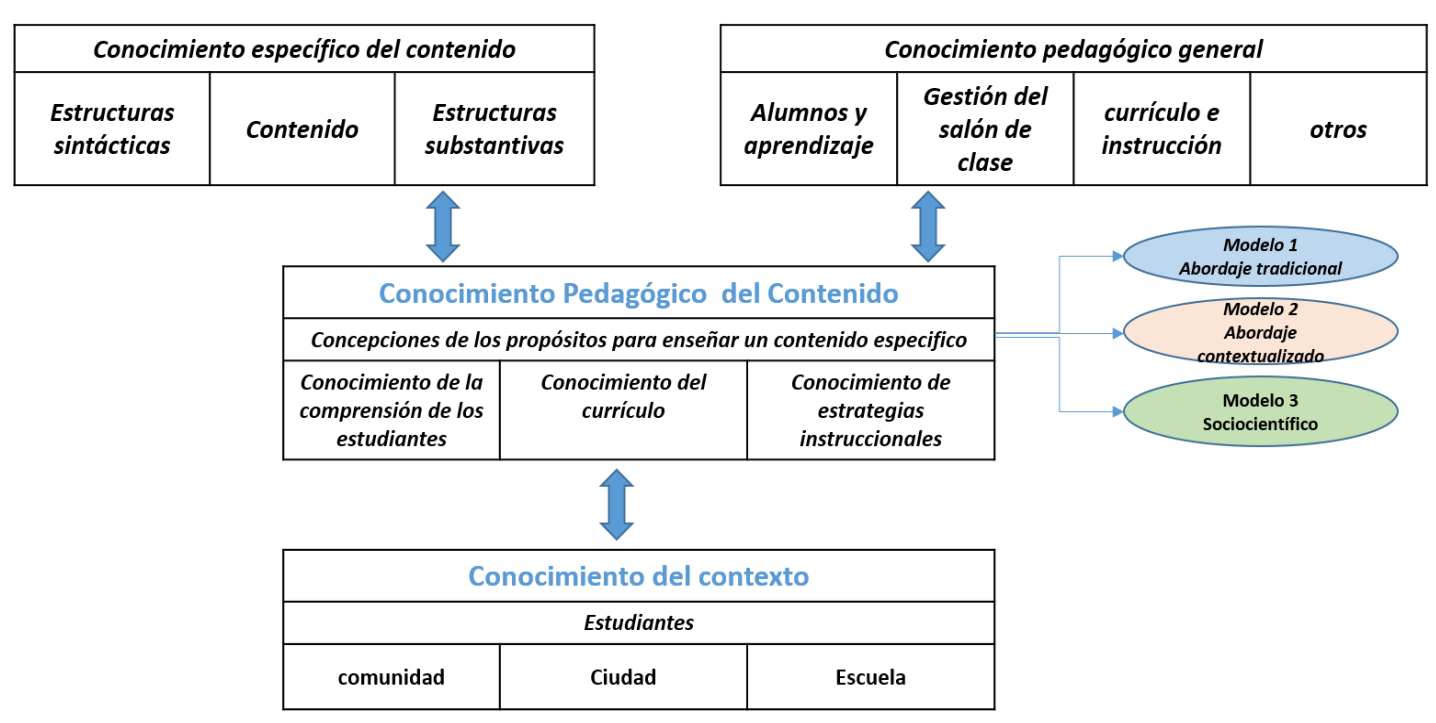

Figura 1. Modelo de relación entre los dominios del conocimiento del profesor (Grossman 1990) y modelos básicos para implementar aspectos relacionados con el desarrollo sostenible en la enseñanza de la química Fuente. Burmeister, Rauch, \& Eilks (2012)

En el contexto Colombiano se han desarrollado propuestas de investigación centradas en la formación de docentes, estas han permitido analizar los aportes y desafíos de los CSC en la formación de profesores de ciencias en el campo CTSA y se han establecido propuestas curriculares a partir de su abordaje. Las temáticas han sido el uso de implantes estéticos, uso de agro tóxicos, el agua de riego, aditivos alimentarios, seguridad alimentaria, Coltan, Organismos genéticamente modificados, entre otros; en algunas oportunidades, los docentes mencionan la dificultad de asumir la dimensión ética en sus propuestas (Beltrán \& Martínez, 2014; Carvajal \& Martínez, 2014; Martínez, 2010b; Martínez, 2014; Martínez \& Parga, 2013)

Teniendo en cuenta que esta investigación es de corte cualitativo, además de la revisión bibliográfica que exige un trabajo académico de esta naturaleza, para 
efectos de la delimitación del problema se tuvieron en cuenta las experiencias de la investigadora en el proceso de conformación de un Gl en la Institución Educativa Distrital Guillermo Cano Isaza (IED GCI).

El GI del IED GCl, como se mencionó, se consolidó en el marco del Programa colombo-brasileño de formación de profesores en la interfaz Universidad-Escuela y está constituido por docentes en ejercicio de la jornada nocturna, quienes preocupados por el alto consumo de sustancias psicoactivas (SPA) por parte de los estudiantes, se interesaron en participar del programa propuesto por la Universidad Pedagógica Nacional (UPN), a través de la autora de esta tesis que hace parte de las dos instituciones educativas. La importancia del tema se respalda en una encuesta realizada por la Orientadora de la institución escolar (anexo 22 y 23), que devela que un $70 \%$ de los estudiantes son consumidores de SPA en diferentes niveles: abusivo, experimental, social e inicial, siendo el primero el de mayor proporción. Acorde con el lema institucional: “o a la droga!, ¡Sí la vida!"; aquí trabajamos por el conocimiento, la dignidad, la paz y la democracia con justicia social, los docentes abordan la controversia denominada "Legalización de la droga (producción/consumo) en Colombia: un mal o una solución" (Rodriguez \& Martinez, 2014, 2015).

Como parte de la organización del $\mathrm{Gl}$, los docentes realizan encuentros semanales, quincenales $\mathrm{y} / \mathrm{o}$ mensuales realizando una secuencia didáctica diseñada por la autora de esta tesis, con el fin de conocer la postura de cada uno de los docentes e interpretar cómo se movilizaba el discurso como producto del mismo debate, de las actividades realizadas, de las charlas con un psicólogo especialista en el tema, las charlas con invitados internacionales (Unesp) y los argumentos que utilizaban ellos mismos a la luz de su formación disciplinar, sus rutinas y guiones de acción, creencias e identidad como profesionales y seres humanos que de una u otra manera se ven afectados por el fenómeno de la drogadicción. 
Finalmente, se puede establecer un balance de las tendencias identificadas en cada una de las categorías de búsqueda realizada, así, países como Brasil, seguidos de Países Europeos y Norte Americanos han dado mayor énfasis en la formación permanente de profesores (figura 2), caracterizada por el uso de modelos de corte capitalista y de rendición de cuentas, a los que la escuela se adapta acríticamente desconociendo su contexto y los saberes que allí circulan. Generalmente, estas propuestas son consideradas de innovación, de formación de semilleros, que solo se reconocen localmente y luego son recordadas como experiencias exitosas de momento, sin trascender ni formar parte de la cultura escolar, en las que la investigación solo se reconoce para los actores universitarios.

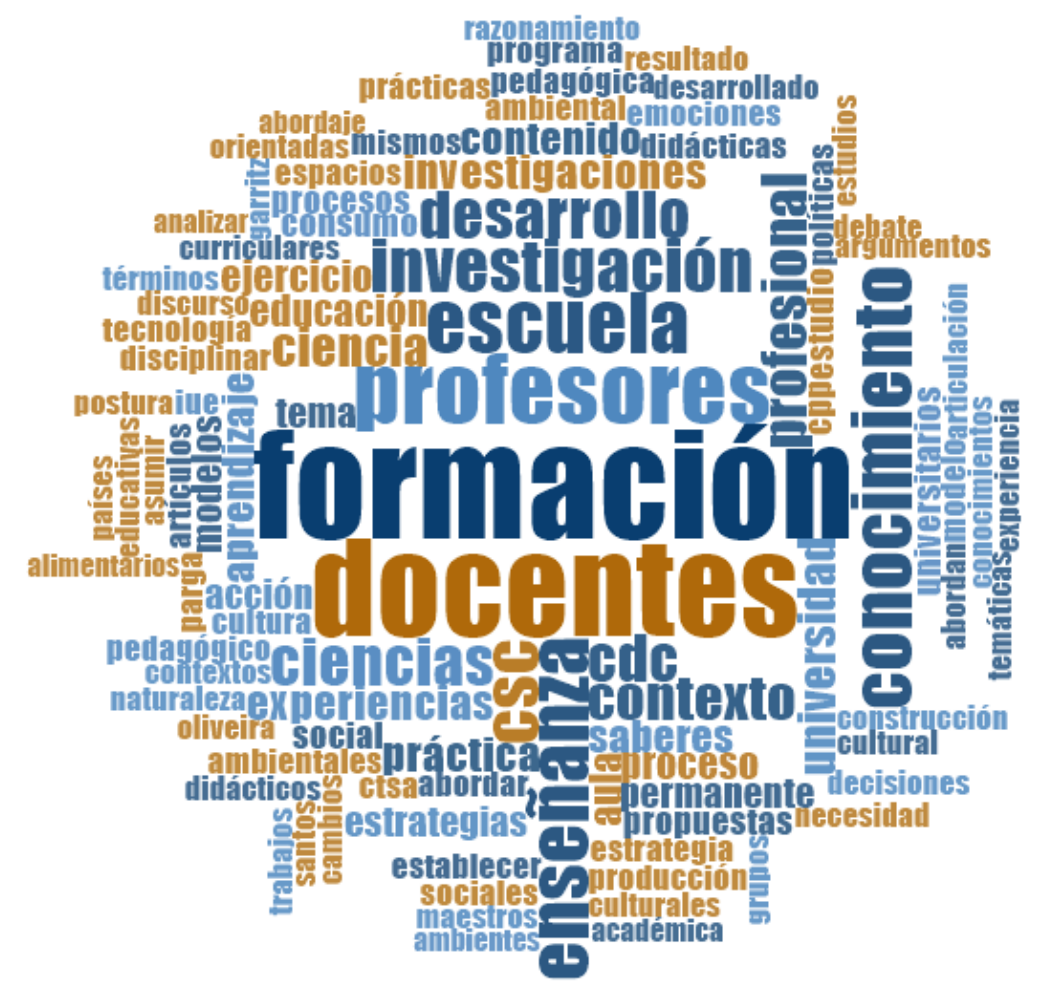

Figura 2. Tendencia de la formación permanente de profesores. Fuente. Artículos seleccionados de la tabla 1.

Se encuentra un menor número de experiencias de formación de profesores en la IUE, a excepción de Brasil, que además cuenta con el mayor número de experiencias y artículos de investigación en formación docente en CSC. En 
Colombia, dicha interacción se da a través de la Práctica Pedagógica y Didáctica de los estudiantes en formación inicial y a través de propuestas de investigación, como la realizada entre la Unesp y la Universidad Pedagógica, en la que se consolidaron cinco $\mathrm{Gl}$; sin embargo, dichas experiencias no han trascendido en la formulación de políticas de formación, ni se han consolidado como parte de la cultura escolar, pero han sido el semillero de nuevas propuestas de investigación o de continuidad de las iniciadas como sucedió con la presente investigación.

En cuanto a la categoría CPP, acorde al periodo revisado, han aumentado las investigaciones publicadas en las revistas Europeas, seguidas de las norteamericanas y en menor frecuencia las realizadas en Colombia y Brasil. En Latinoamérica el CPP se ha abordado como CDC, CPC, CDC y Afectividad, CDCNdCyT, CDC-emociones, perspectiva Iberoamericana CDC (PCK/RPEC) y un número reducido de investigaciones en torno al CDC asociado a CSC o a la QV, como se evidencia en las figuras 3 y 4 , indicando que aún es un campo emergente, en el que las posibilidades de investigación en la formación de profesores en IUE con el abordaje de CSC posibilita la investigación y la emergencia de futuras líneas de investigación.

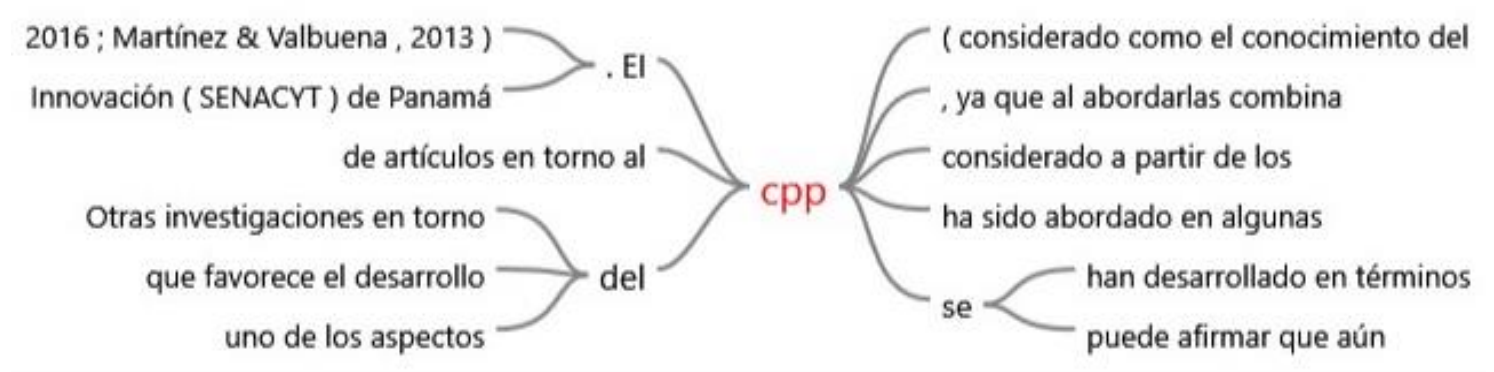

Figura 3. Reducido número de referencias del CPP en comparación con el CDC Fuente. Revistas seleccionadas según categoría CPP 


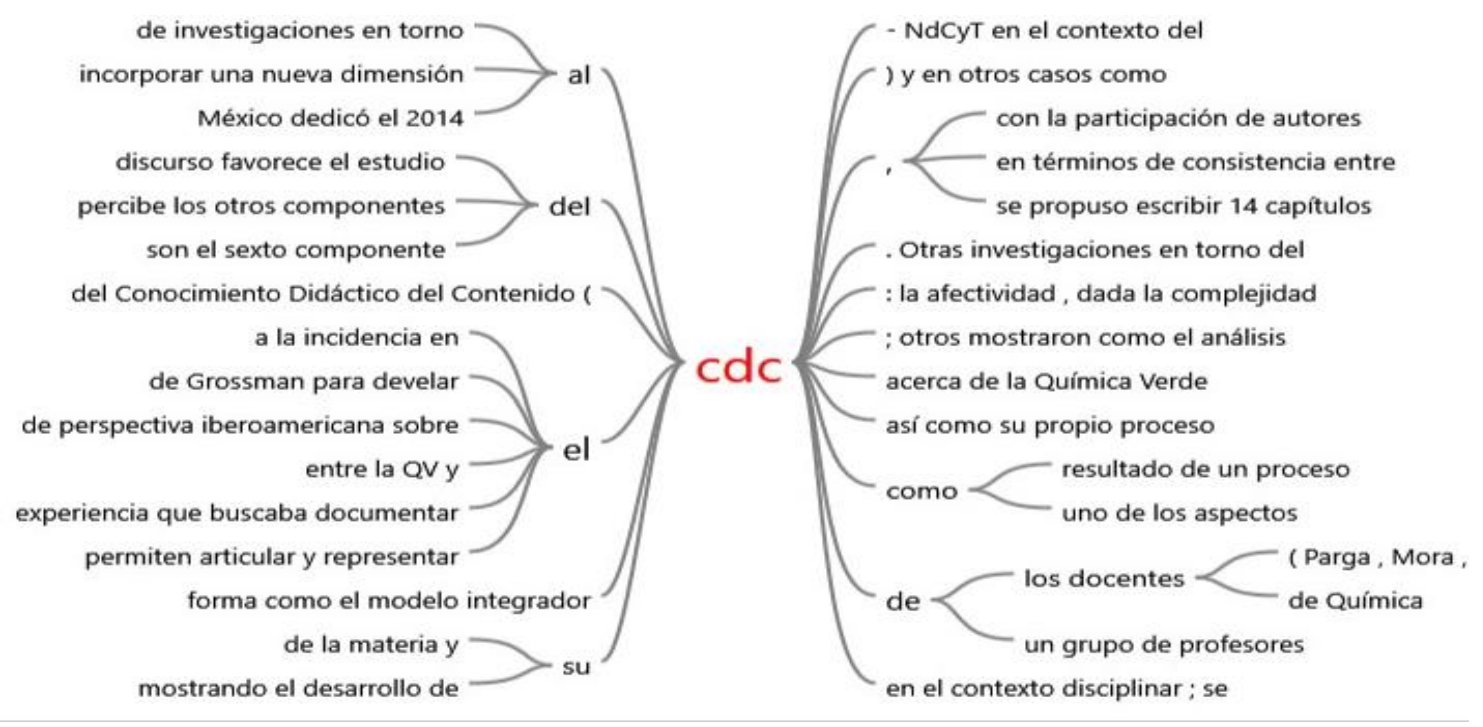

Figura 4. Tendencia de abordaje del CPP en artículos como CDC

Fuente. Artículos seleccionados tabla 19 
Finalmente, la categoría CSC ha sido abordada en procesos de formación de profesores, especialmente en el campo investigativo como se observa en la figura 5.

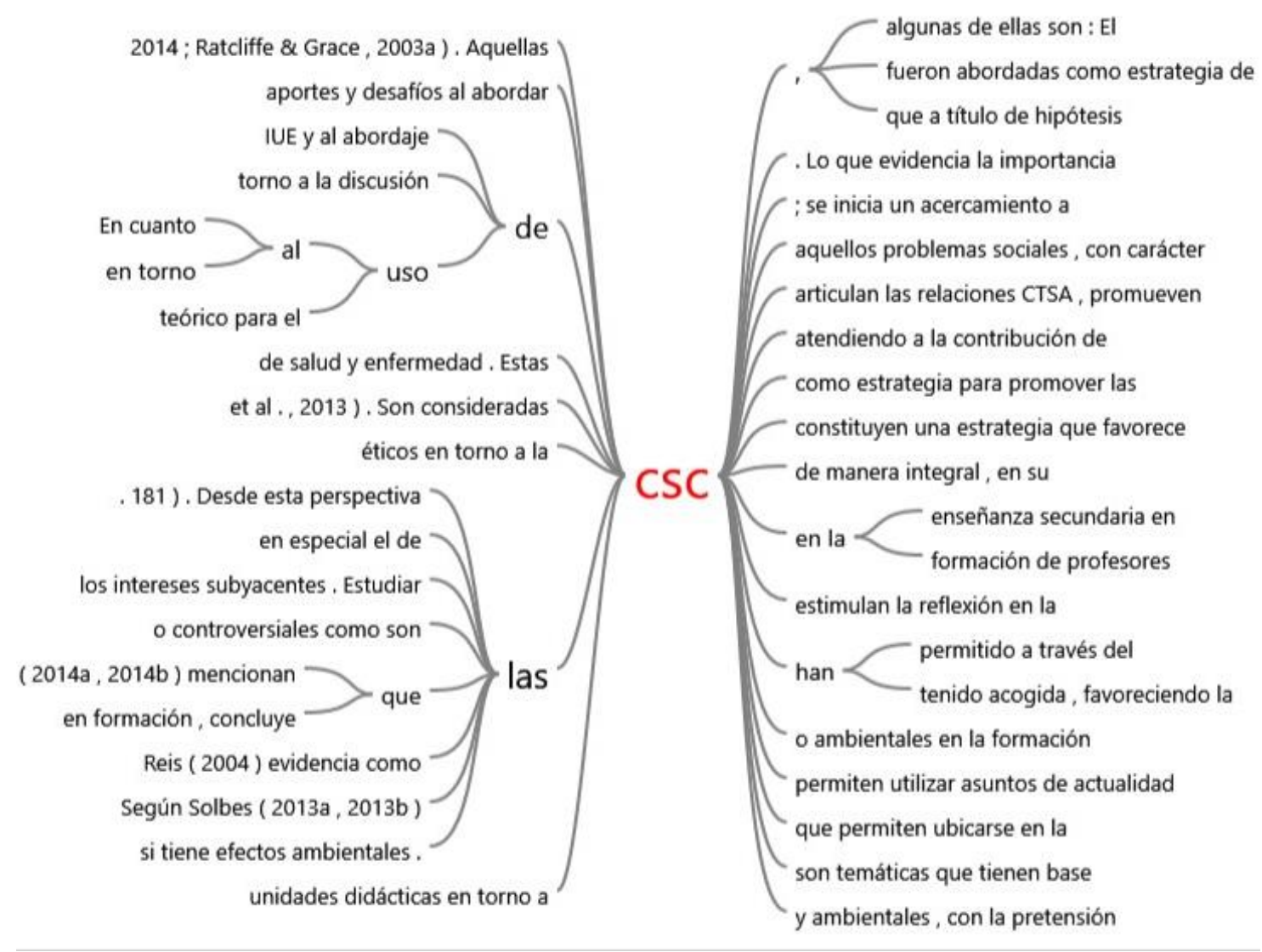

Figura 5. Tendencia de las CSC en procesos de formación y forma de abordaje Fuente: artículos seleccionados tabla 1

El abordaje de las CSC asociadas a la formación de profesores en las revistas seleccionadas evidencia sus las características, sus aportes a la formación de profesores y al conocimiento de los mismos. En la figura 6 se observa la frecuencia con la que se mencionan las CSC asociadas a la formación de profesores, indicando que han sido el eje de actividades centradas en la discusión o controversia, así como las fuentes de selección y contenidos asociados a las mismas (cuyo autor es Pedro Reis, profesor investigador con mayor producción académica en torno al abordaje de CSC en la formación de profesores, en este periodo seleccionado); la figura 7 muestra la presencia de las CSC en artículos 
seleccionados, cuyo contexto han sido las aulas de países latinos, es decir, se abordan CSC como la drogadicción y/o el consumo en el contexto del aula como manera de generar prevención y dar información a los estudiantes, pero sin ser asociada a procesos de formación de profesores.

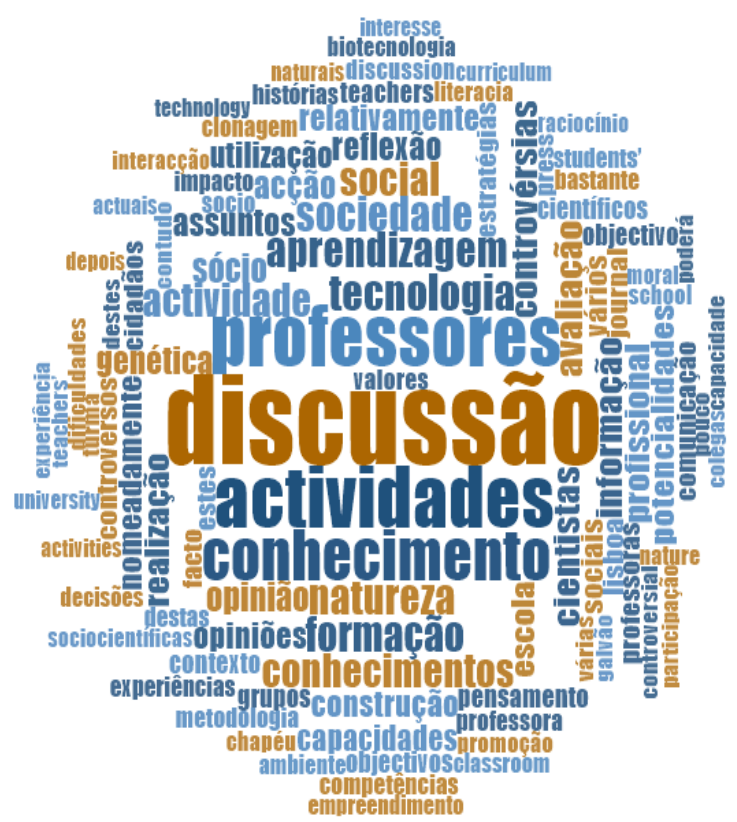

Figura 6. Abordaje de las CSC en la formación de profesores

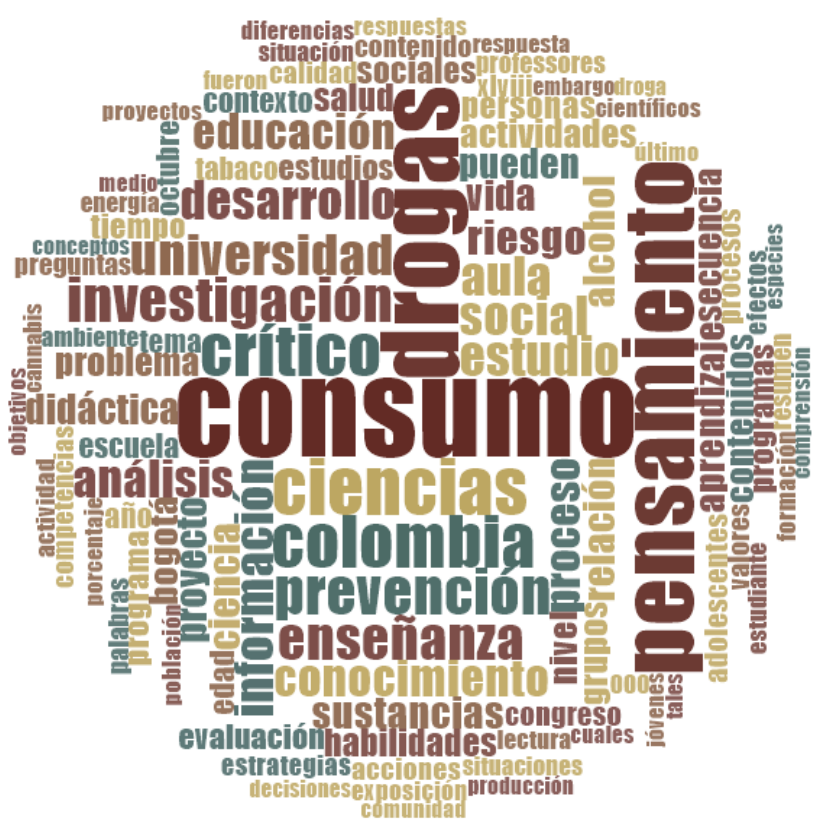

Figura 7. CSC abordadas en contextos locales y en países Latinoamericanos

En este sentido, se hace evidente la necesidad de generar investigaciones en procesos de formación de profesores que integren las bondades del abordaje de CSC asociadas al CPP en la IUE. 


\subsection{DELIMITACIÓN Y FORMULACIÓN DEL PROBLEMA}

Como se caracterizó en la revisión de antecedentes, desde un punto de vista crítico es necesario cuestionar la idea de que el profesor como trabajador debe ejecutar tareas sin propósitos, este planteamiento aniquila los espacios de reflexión que le permiten desempeñarse profesionalmente, es decir, devela la pérdida de autonomía profesional. En palabras de Contreras (1997):

[...] los docentes, como colectivo, han sufrido o están sufriendo una transformación tanto en las características de sus condiciones de trabajo, como en las de las tareas que realizan, que los acercan cada vez más a las condiciones y a los intereses de la clase obrera. [...]. (p.19).

Sumado a la proletarización del trabajo del profesor, las propuestas de formación no se contextualizan a las necesidades de la escuela, al ejercicio de unas relaciones laborales de tipo horizontal, se desconocen factores personales como la emocionalidad, la edad, expectativas del profesor y de las escuelas; se mantienen procesos de formación que acentúan la individualidad, limitan la autonomía y el desarrollo profesional del profesor, así como desconocen la construcción del conocimiento escolar y del mismo CPP (Imbernón, 2011; Imbernon \& Canto, 2013).

La literatura muestra que la formación de profesores basada en un modelo de racionalidad técnica, responde al mercado que pretende suministrar cursos en los que el profesor aprenda técnicas y procedimientos que le permitan formar sujetos técnicos, a la vez que sepan aplicar conocimientos que conduzcan al cumplimiento de los objetivos curriculares que garanticen la formación de mano de obra barata (Apple \& García, 2003). Mientras una formación basada en un modelo prácticoreflexivo, permite al profesor reflexionar sobre la acción, de tal manera que pueda mejorar su práctica de aula (-conocimiento en la acción-reflexión en y durante la acción - reflexión sobre la acción y sobre la reflexión en la acción) (Schön, 1995); sin embargo, no es suficiente, ya que es un modelo que muestra la mirada 
individualista del oficio del profesor, diferente a la construcción de conocimiento en colectivo.

Opuesto a los modelos anteriores, el modelo crítico fundamentado en los presupuestos de la teoría crítica de la Escuela de Frankfurt, exige una reflexión permanente del profesor sobre sus propios conocimientos teóricos y prácticos, para que la enseñanza se convierta en una práctica profesional comprometida con la investigación de las problemáticas pedagógicas que enfrentan las instituciones educativas, en donde se cuestionen las normas que se establecen, critiquen sus límites en lo referente a la función política, cultural y económica; sin embargo, la investigación educativa no se puede reducir a producir teorías o desarrollar prácticas más eficaces, lo que se busca realmente es hacer de la práctica un proceso crítico que le permita comprenderla y transformarla (Contreras, 1997; Martínez, 2010b).

Así, la formación de profesores en un contexto crítico y humanístico que incluya lo afectivo, lo ético, estético, físico y político, debe configurarse como un escenario vivencial de respeto por el otro, caracterizado por la comprensión, la escucha y el deseo de crecer juntos como seres humanos, en el que se lucha por superar las tensiones de las políticas externas y se consolidan como espacios de dialogo, de reflexión conjunta de profesores que luchan por su autonomía, construyendo políticas de formación pertinentes al contexto de sus escuelas, planeando y diseñando propuestas curriculares que permitan a los niños, jóvenes, adultos y a los ciudadanos en general ser interpretes críticos de la sociedad en la que están inmersos, a despejarse del rol de consumidores pasivos de conocimientos y asumir el papel activo de fabricantes de significado (Beane \& Apple, 2000; Carr \& Kemmis, 1988; Chapani, 2010; Contreras, 1997; Niño, 2005, 2013; Santos, 2008).

Una de las líneas de investigación de Enseñanza de las Ciencias que ha permitido la formación de docentes bajo las dimensiones mencionadas, es la perspectiva CTSA, en la que la Ciencia y la tecnología (CT) son cuestionables (ruptura de mitos del proceso educacional, no neutralidad, ni universalidad de la CT), se 
discuten problemas, transformaciones e impactos sociales de la CT; se identifican contradicciones y establecimiento de mecanismos de presión y, comprensión de las políticas públicas, así como la participación en el ámbito de las esferas políticas (Auler \& Delizoicov, 2001; Pinheiro, Silveira, \& Bazzo, 2007; Strieder \& Kawamura, 2014).

Sin embargo, la enseñanza de las ciencias con enfoque CTSA presenta dificultades cuando el profesor en la práctica de aula, decide abordar cuestiones 0 temáticas con respecto a la compresión de amenazas ambientales que afectan la calidad de vida, aspectos económicos e industriales de la tecnología o la naturaleza de la ciencia con la pretensión de generar discusiones en términos argumentativos pobres y valores personales descontextualizados de la realidad sentida por medio de estrategias de enseñanza que reflejan una visión simplista y estéril de la ciencia y en las que prima la memorización, el dominio y ejemplificación del corpus de la Ciencia, desconociéndola como una actividad humana, con valores, creencias y convenciones, como un constructo social, cultural e histórico.

Lo anterior es consecuencia de los procesos de formación de profesores de ciencias especialistas en una disciplina específica, en la que existen limitaciones para el desarrollo de habilidades y conocimientos acerca de los aspectos sociales, políticos, éticos que fundamentan el desarrollo del enfoque CTSA en la práctica del profesor; posiblemente no fueron formados críticamente en relación a los procesos civilizatorios de la sociedad moderna que fortalecen los modelos hegemónicos, priorizando la competición y la alienación del trabajo docente (Batista, El-Hani, \& Carvalho, 2012; Contreras, 1997; Correa \& Bazzo, 2017; Vilches, Gil, Toscano, \& Macías, 2008).

Al asumir la enseñanza con enfoque CTSA de forma tradicional, se sigue fortaleciendo la lógica positivista que fundamenta las acciones de la ciencia como actividades individuales, donde los métodos mecanicistas la hacen neutra y legitima ante la sociedad (Miranda, Santos, Pinheiros, \& Silveira, 2011); por el 
contrario, al asumir una Enseñanza de la Ciencia desde una perspectiva crítica y humanística con enfoque CTSA que favorezca la formación de ciudadanos autónomos, sujetos políticos que luchan por la igualdad y la justicia social, así como Strieder (2012) lo plantea, permite explicitar la racionalidad científica, el desarrollo tecnológico y la participación social.

Vale la pena mencionar, que una de las formas de lograr el abordaje crítico del enfoque CTSA es a través de las CSC, ya que permitiría que los ciudadanos participen en las discusiones, debates o procesos decisorios al abordar controversias en un contexto multidisciplinar, en medio de una cultura de colaboración que en el caso de la formación de profesores valorice la autonomía del profesor independiente del área de su formación (Galvão \& Reis, 2008; Levinson, 2006c, 2008, 2010; Pedretti, 2003; Pedretti \& Nazir, 2011).

Propuestas de formación de profesores de ciencias con enfoque CTSA, abordando CSC, permite la problematización de la visión cientificista e instrumental que fue adquiriendo históricamente la ciencia y la tecnología; además de permitir el análisis y discusión de los procesos que influyen en la construcción del conocimiento científico, las relaciones (ético morales, políticas, socioculturales, económicas, los intereses, las relaciones de poder, entre otros) que permean la toma de decisiones acerca de las mismas CSC o el desarrollo y/o aplicaciones controversiales de los conocimientos Científicos y tecnológicos (Binatto, Chapani, \& Duarte, 2015; Lopes, 2013; Martínez, 2010, 2014; Moreno, 2015; Ratcliffe \& Grace, 2003a; Reis, 2004, 2014a, 2016a, 2016b; Topcu, Sadler, \& Yilmaz- Tuzun, 2010).

Al igual como se mencionó en la revisión bibliográfica, existen propuestas de formación de profesores en la IUE con enfoque CTSA que han utilizado CSC como estrategia que permite articular dichas relaciones, entre las cuales están los programas de formación de profesores en IUE basados en la teoría critica, en la teoría de la acción comunicativa de Habermas (1987), en el referente sociológico de Bourdieu que permite comprender las relaciones de poder, en la educación 
libertadora de Freire, entre otros, que sirven como base para la conformación de Gl concebidos como esferas públicas, a través de las cuales se favorece la autonomía y emancipación de los profesores como profesionales, se promueva una formación cultural, una evaluación formativa y se consolidan como espacios de formación e investigación (Álvarez \& Osoro, 2011; Carvalho, 2015; Carvalho, Carvalho, \& Junior, 2016; Chapani, 2010; Lopes, 2013; Lopes \& Carvalho, 2017; Martínez et al., 2015)

El CPP es otra de las líneas de investigación en la formación de profesores, igualmente se constituye en otro de los pilares referenciales de la presente investigación, ya que de la misma manera que el trabajo docente y el conocimiento profesional del profesor, es el resultado de una construcción de saberes teóricos y prácticos, dominantes y deseables; es un conocimiento epistemológicamente diferenciado e interesado, propio de cada docente, posiblemente marcado por el proyecto educativo en el que ejerce su práctica pedagógica y didáctica, que a su vez contempla un proyecto de sociedad o de sujeto social bajo las orientaciones disciplinares y el modelo de formación que le han permitido configurar su CPP, sin desconocer los saberes propios, ligados a su cosmovisión evolucionada cada vez más compleja, cuya trayectoria y especificidad se ha construido en contextos sociales, culturales e históricos (Martínez, 2016, 2017; Porlán, Rivero, \& Pozo, 1997, 1998; Rivero, Pozo, Solís, Azcárate, \& Porlán, 2017).

En la revisión bibliográfica sobre la formación de profesores, el CPP y el abordaje de CSC basado en el enfoque CTSA en la IUE, se encontraron pocos estudios en los que se reflexionara el resultado de prácticas docentes al tratar dichas CSC en el aula, su contribución al CPP y a la formación ciudadana. En este contexto, se evidenció la necesidad de explorar las posibilidades de espacios de formación permanente de docentes que permitan la IUE, que posibiliten la innovación en la Enseñanza de las Ciencias y permitan transformar las prácticas de los docentes 
cuando se enfrentan con situaciones didácticas en diversos contextos (Reis, 2014a; Talanquer, 2014).

En este orden de ideas, se propusieron las siguientes preguntas que orientaron la investigación:

Pregunta principal:

¿Qué caracteriza el Conocimiento Profesional de los Profesores (CPP) del Grupo de Investigación (Gl) cuyo eje central es la construcción de conocimientos alrededor de las Cuestiones Sociocientíficas (CSC)?

Subpreguntas:

1. ¿Cómo se estructura y se consolida un GI enfocado en el abordaje de CSC locales?

2. ¿Qué aportes y dificultades aparecen en la construcción del Conocimiento Profesional del Profesor (CPP) en ejercicio a partir del abordaje de cuestiones sociocientíficas (CSC) en el marco de un programa de formación del profesorado en la interfaz universidad - escuela?

3. ¿Qué aportes a la dinámica del aula de los profesores del Gl se consolidan como resultado del abordaje de CSC a la luz de una HdPR? 


\subsection{JUSTIFICACIÓN}

La formación de profesores es un eje central en los estudios y debates en el campo educativo, especialmente cuando se pretende plantear reformas educacionales generadas por las políticas de turno a través de los planes decenales de educación y más aún cuando se afirma que la calidad de la educación depende de la calidad de los profesores. En ese sentido, es necesario percibir las trasformaciones que afectan la sociedad y que provocan cambios desafiantes para la escuela, por tal razón se han propuesto diferentes modelos de formación de profesores que favorezcan el desarrollo profesional (Huberman \& Levinson, 1988; Imbernón, 2011; Martínez et al., 2015; Solís, 2005b)

Dichos enfoques, tienden a reivindicar el trabajo del profesor, reconociéndolo como un intelectual, profesional crítico-reflexivo, investigador y constructor de saberes, quien tiene un conocimiento particular, un CPP con una epistemología propia que lo hace ser un líder, activista y empoderado por la formación de ciudadanos, con capacidad de autogestión, innovación y autonomía.

Un proceso de formación permanente de docentes, implica una interacción continua entre investigadores de la academia e investigadores de la escuela, en la que se se establezcan diálogos horizontales que permitan una reflexión continua, interactiva y contextualizada de las prácticas docentes, estableciendo relaciones teórico - prácticas, es decir, donde los docentes de la escuela puedan desarrollar su CPP fundamentado.

Las características de las CSC y las implicaciones científicas, éticas, sociopolíticas, culturales, de riesgo que yacen de su abordaje, se constituyen en una categoría de análisis a tener en cuenta en el proceso de construcción del CPP y los posibles cambios que se generen en la práctica de aula; así, estas CSC tienen exigencias particulares en relación a la formación de profesores, siendo necesario un posicionamiento teórico para la orientación en los procesos de 
formación de docentes.

Las experiencias del abordaje de CSC en procesos de formación de docentes, evidencian la movilidad de sus discursos cuando asumen posiciones sociales de naturaleza ética y política, lo que les permite analizar críticamente su práctica de aula y comprometerse con una enseñanza que propenda por el conocimiento de la naturaleza humana, de la Ciencia, de la Tecnología y su incidencia en la formación de ciudadanos críticos e informados (Martínez et al., 2015; Martínez \& Parga, 2014; Martínez \& Carvalho, 2012; Reis \& Galvão, 2008).

Estas investigaciones permiten comprender la importancia de la formación de docentes con base en un modelo de formación con didácticas críticas, donde los postulados de Freire (1994, 2005), Girox (1990) y Apple (1993) sean referentes de análisis para que los profesores cuestionen su racionalidad técnica dominante y reviertan sus prácticas hacia una racionalidad ética-existencialista, que contribuya con la formación de ciudadanía y permita el desarrollo de la autonomía docente.

Martínez (2012) muestra una síntesis de las contribuciones de Adorno sobre la formación cultural y las ideas de Giroux sobre la formación del profesor intelectual-trasformador: la teoría de Adorno ayuda a pensar y a asumir una apropiación subjetiva de la cultura humana, intentado develar los mitos creados por la industria cultural contribuyendo con una comprensión compleja de la realidad, en la que se favorezcan experiencias humanas que construyan conocimientos y permitan la comprensión de un mundo donde el respeto por el otro y la solidaridad sean los ejes que articulan el actuar humano.

La formación de profesores como intelectuales, debe romper con la naturaleza individualista que ha caracterizado históricamente su trabajo, posiblemente por la fragmentación curricular tradicional, que organiza la enseñanza en actividades que deben ser desarrolladas por el mismo profesor acorde a su especialidad y que no generan oportunidad de discusión entre las diferentes áreas, negando así, la posibilidad de trabajar colectivamente. Así, el abordaje de temas 
descontextualizados de la realidad de los estudiantes no posibilita que los profesores estructuren la enseñanza en torno a problemas comunes, de tipo local, nacional o global, y menos aún permiten a los estudiantes construir el conocimiento escolar, participar de la solución de problemáticas reales y actuales, en términos de Walters \& Gardner (1984), apasionarse posiblemente por las temáticas más controvertidas de la ciencia.

La falta de una discusión crítica del currículo escolar, favorece las orientaciones de la política de turno que privilegian habilidades y conocimientos que hacen que el estudiante sea un buen ciudadano y se prepare para participar de la lógica del mundo del trabajo. En este sentido, la propuesta de investigación es una apuesta a la formación permanente y continua de los profesores, en la medida que asumir CSC en la IUE, hace que los maestros reflexionen, evalúen y propongan nuevas estructuras curriculares, en donde además de permitir la construcción de conocimientos, sea posible la mitigación de los problemas del contexto escolar, favoreciendo el CPP, cuestionando la ideología del currículo tradicional, favoreciendo el trabajo en equipo e interdisciplinar y estimulando procesos de innovación y autonomía profesional.

Teniendo en cuenta los planteamientos mencionados se considera importante realizar este trabajo, por el aporte que puede ofrecer en el contexto investigativo en la línea en la cual se inscribe y a los aportes a la construcción del conocimiento profesional de los profesores, en especial a los del GI en la IUE.

En el contexto investigativo es pertinente, porque es una línea emergente de un proyecto de investigación internacional que pretende mitigar las falencias de la formación de docentes en formación y en ejercicio en la IUE; el cual ha sido poco explorado y menos aun cuando se abordan CSC en el mismo proceso (Martínez et al., 2015; Martínez \& Parga, 2014). 


\subsection{OBJETIVOS}

\subsubsection{Objetivo general}

Describir e interpretar las características del CPP de los profesores del Gl como eje central para la construcción de conocimientos alrededor de las CSC.

\subsubsection{Objetivos específicos}

- Caracterizar la conformación y consolidación de un pequeño grupo de investigación interesado en el abordaje de CSC.

- Analizar los aportes y las dificultades del abordaje de las CSC en la construcción del CPP del profesor en ejercicio en el marco de un programa de formación de profesores en la IUE

- Evaluar el aporte del abordaje de las CSC en la dinámica del aula de los profesores en ejercicio a través de las actividades diseñadas para ser realizadas con sus estudiantes a la luz de una HdPR. 


\section{CAPÍTULO 2. CONOCIMIENTO PROFESIONAL DEL PROFESOR DE CIENCIAS EN EJERCICIO Y EL ABORDAJE CUESTIONES SOCIOCIENTÍFICAS}

EI CPP es un conocimiento personal, particular y específico construido a partir de la interacción entre los conocimientos teóricos y los conocimientos prácticos durante el proceso de formación, el ejercicio de la práctica pedagógica y didáctica $y$ el ejercicio laboral en espacios formales y no formales, que le permiten al maestro tener una epistemología particular, diferenciada de otros y de otras profesiones afines a su formación, en este sentido en el presente capítulo se abordarán esos conocimientos desde las concepciones del grupo IRES de España y los trabajos de Martínez (2016, 2017); Martínez \& Valvuena (2013); Perafán (2013, 2015) y Rodríguez \& Martínez (2016), los aspectos centrales del CPP.

\subsection{EL CONOCIMIENTO PRÁCTICO PROFESIONAL DEL PROFESOR}

Desde la perspectiva del grupo de Investigación y Renovación Escolar (IRES) el CPP se aborda desde una perspectiva epistemológica constituida por dos componentes: el conocimiento profesional dominante (CPD) y el Conocimiento profesional deseable (CPd) (Figura 8). 


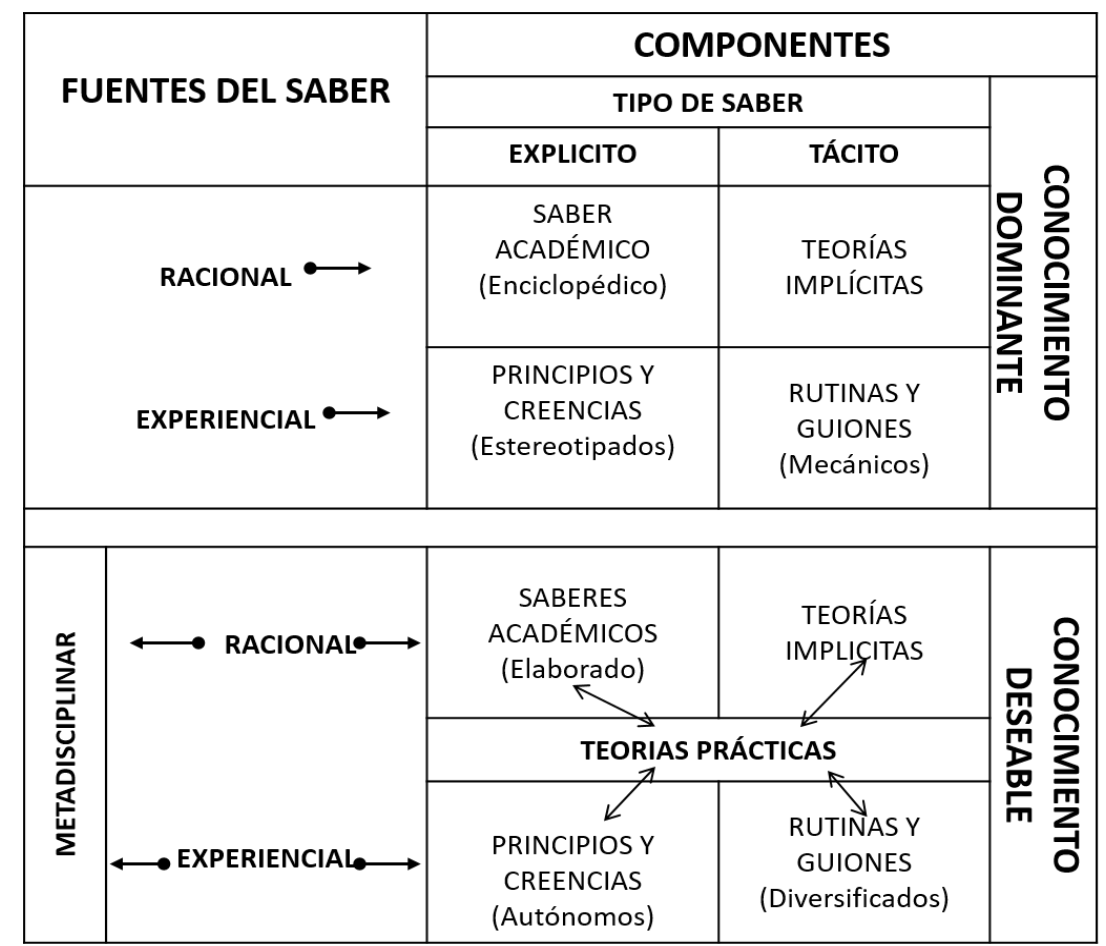

Figura 8. Fuentes y componentes del conocimiento (Ballenilla, 2003; Rafael Porlán \& Rivero, 1998)

Fuente. Elaboración de la autora con base en Ballenilla, 2003 y Rafael Porlán \& Rivero, 1998).

EI CPD está constituido por cuatro tipos de saberes (académicos, fundamentados en la experiencia, rutinas y guiones de acción y teorías implícitas), generados en distintas circunstancias y espacios temporales; sin embargo, estos permanecen aislados en la mente de los profesores, aunque se pueden manifestar en distintas situaciones de la vida profesional del profesor sin que se tenga conciencia de lo implícito o tácito y sin reflexión entre lo racional y experiencial (Ballenilla \& Porlán, 2003; Porlán, Rivero, \& Pozo, 1998).

EI CPD tiene como fuente los saberes metadisciplinares, los disciplinares básicos y los experienciales; considerando los primeros como el entendimiento de la naturaleza del conocimiento propio de la escuela, de la asignatura, de los fines y objetivos a conseguir (Bromme, 1988); en este caso, las ideologías del profesor se constituyen en una fuente esencial del conocimiento profesional y el saber curricular emerge como eje orientador del saber práctico, como se ilustra en la figura 9 (Solís, Porlán, \& Rivero, 2012). 


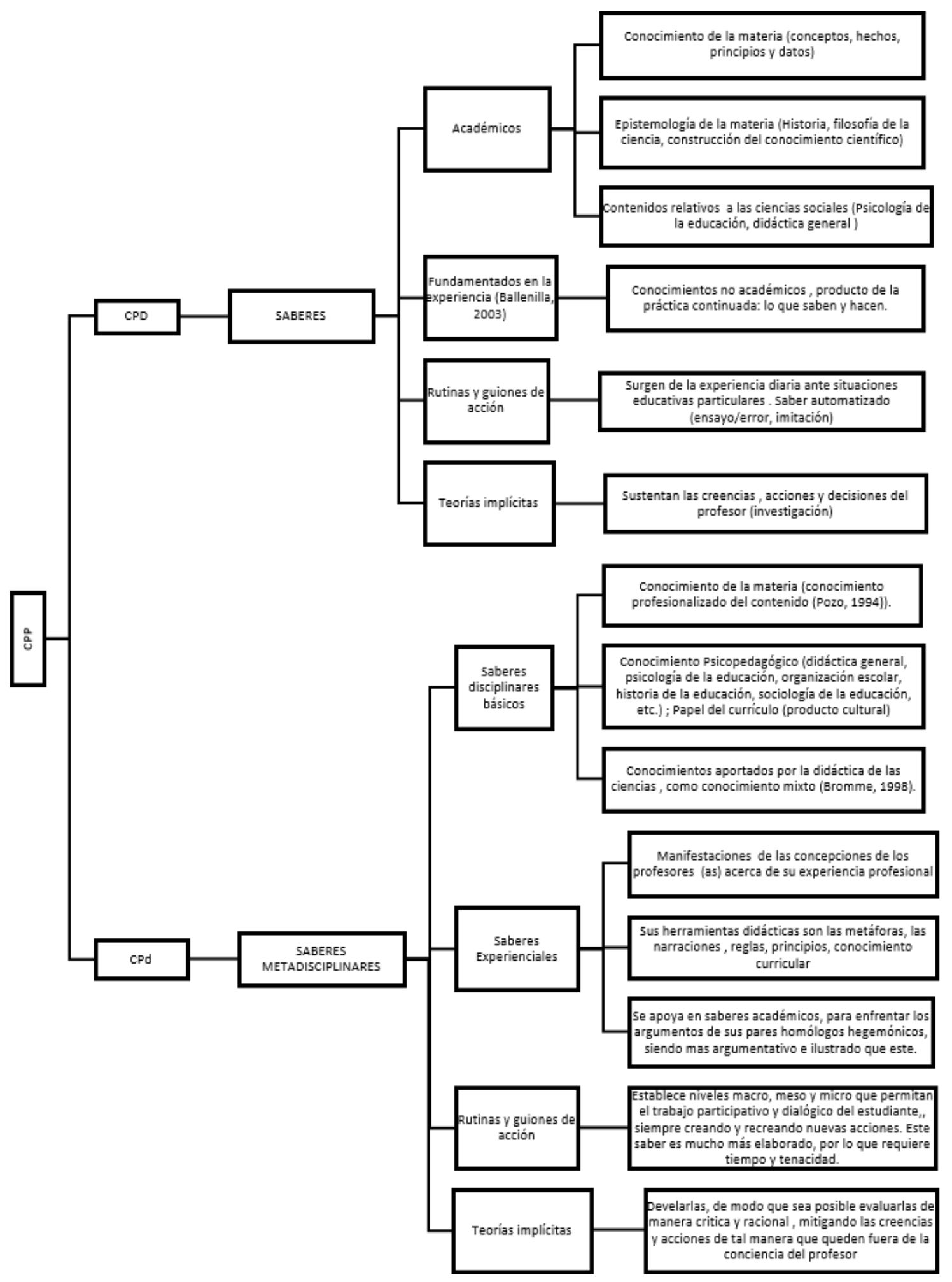

Figura 9. Conocimiento Profesional del Profesor según IRES (Ballenilla, 2003; Solís \& Rivero, 2013)

Fuente. Elaboración de la autora con base en Solís y Rivero (2013) 
Por lo anterior, el CPD no sólo se constituye como un estadio ideal, sino en un itinerario de progresión, que implica la superación de obstáculos que se presentan en el sistema teórico/práctico de sus conocimientos (Porlán et al., 2010).

Rivero, Pozo, Solís, Azcárate, \& Porlán (2017) resaltan la importancia de diseñar progresiones de aprendizaje que permitan describir y analizar el cambio del conocimiento de los profesores, teniendo en cuenta los componentes del CPP y la orientación sobre la enseñanza de las ciencias que se adopte, bien sea transmisiva o basada en la investigación como se ve en la figura 10.

\begin{tabular}{|c|c|c|c|c|}
\hline \multirow{2}{*}{ 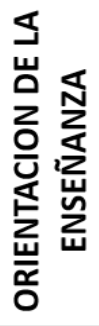 } & & \multicolumn{2}{|c|}{ COMPONENTES } & \\
\hline & $\begin{array}{l}\text { Presentación de } \\
\text { los contenidos a } \\
\text { los alumnos }\end{array}$ & $\begin{array}{l}\text { Utilización } \\
\text { didáctica de las } \\
\text { ideas de los } \\
\text { alumnos }\end{array}$ & $\begin{array}{c}\text { Secuencias } \\
\text { metodológicas }\end{array}$ & $\begin{array}{l}\text { Sentido de la } \\
\text { evaluación }\end{array}$ \\
\hline 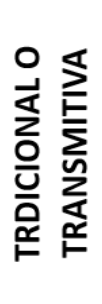 & $\begin{array}{l}\text { Los contenidos } \\
\text { se presentan a } \\
\text { los alumnos con } \\
\text { la lógica } \\
\text { disciplinar, como } \\
\text { un listado } \\
\text { similar de los } \\
\text { libros de texto }\end{array}$ & $\begin{array}{l}\text { Las ideas de los } \\
\text { alumnos no e } \\
\text { utilizan por el } \\
\text { profesor }\end{array}$ & $\begin{array}{l}\text { La secuencia } \\
\text { metodológica es } \\
\text { transmisiva y viene } \\
\text { determinada por la } \\
\text { lógica de los } \\
\text { contenidos }\end{array}$ & $\begin{array}{l}\text { Evaluar para } \\
\text { comprender si se } \\
\text { ha alcanzado el } \\
\text { nivel de contenidos } \\
\text { según los objetivos } \\
\text { previstos. }\end{array}$ \\
\hline 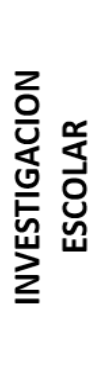 & $\begin{array}{l}\text { los contenidos } \\
\text { se presentan } \\
\text { en forma de } \\
\text { problemas } \\
\text { escolares a } \\
\text { investigar con } \\
\text { los alumnos }\end{array}$ & $\begin{array}{l}\text { Las ideas de los } \\
\text { alumnos se } \\
\text { utilizan por el } \\
\text { profesor y los } \\
\text { alumnos durante } \\
\text { todo el proceso de } \\
\text { enseñanza- } \\
\text { aprendizaje para } \\
\text { conseguir su } \\
\text { evolución gradual }\end{array}$ & $\begin{array}{l}\text { Los contenidos se } \\
\text { presentan en } \\
\text { forma de } \\
\text { problemas } \\
\text { escolares a } \\
\text { investigar con los } \\
\text { alumnos }\end{array}$ & $\begin{array}{l}\text { Evaluar para la } \\
\text { regulación del } \\
\text { proceso de } \\
\text { enseñanza y } \\
\text { aprendizaje }\end{array}$ \\
\hline
\end{tabular}

Figura 10. Componentes del conocimiento profesional según distintas orientaciones. Fuente. Rivero et al.(2017)

Investigaciones recientes enmarcadas en esta línea de investigación (CPP) realizadas por Martínez \& Valbuena (2013) y Martínez (2016) destacan las 
preguntas que de manera explícita o implícita los profesores abordan en los procesos de enseñanza (¿Qué enseñar?, ¿Para qué enseñar?, ¿Por qué enseñar?, ¿Cómo enseñar?, ¿Cómo evaluar?, ¿Qué actividades y propuestas metodológicas desarrollar?) y desde las cuales construyen su CPP, además de presentar las diversas posibilidades de este conocimiento a la luz de una hipótesis de progresión/regresión (HdPR), organizando el conocimiento en tendencias o niveles que van desde el tradicional hasta el integrador transformador, cada uno acompañado de cuatro categorías que permiten la comprensión del CPP, resaltando que esta progresión no es lineal, es un proceso de subidas y bajadas, avances laterales, diagonales, etc., con sus respectivos retrocesos; adicionalmente plantea ejes DOC (Dinamizadores, Obstáculos y Cuestionamientos) que contribuyen a la comprensión de la complejidad del CPP como se evidencia en la figura 11. 


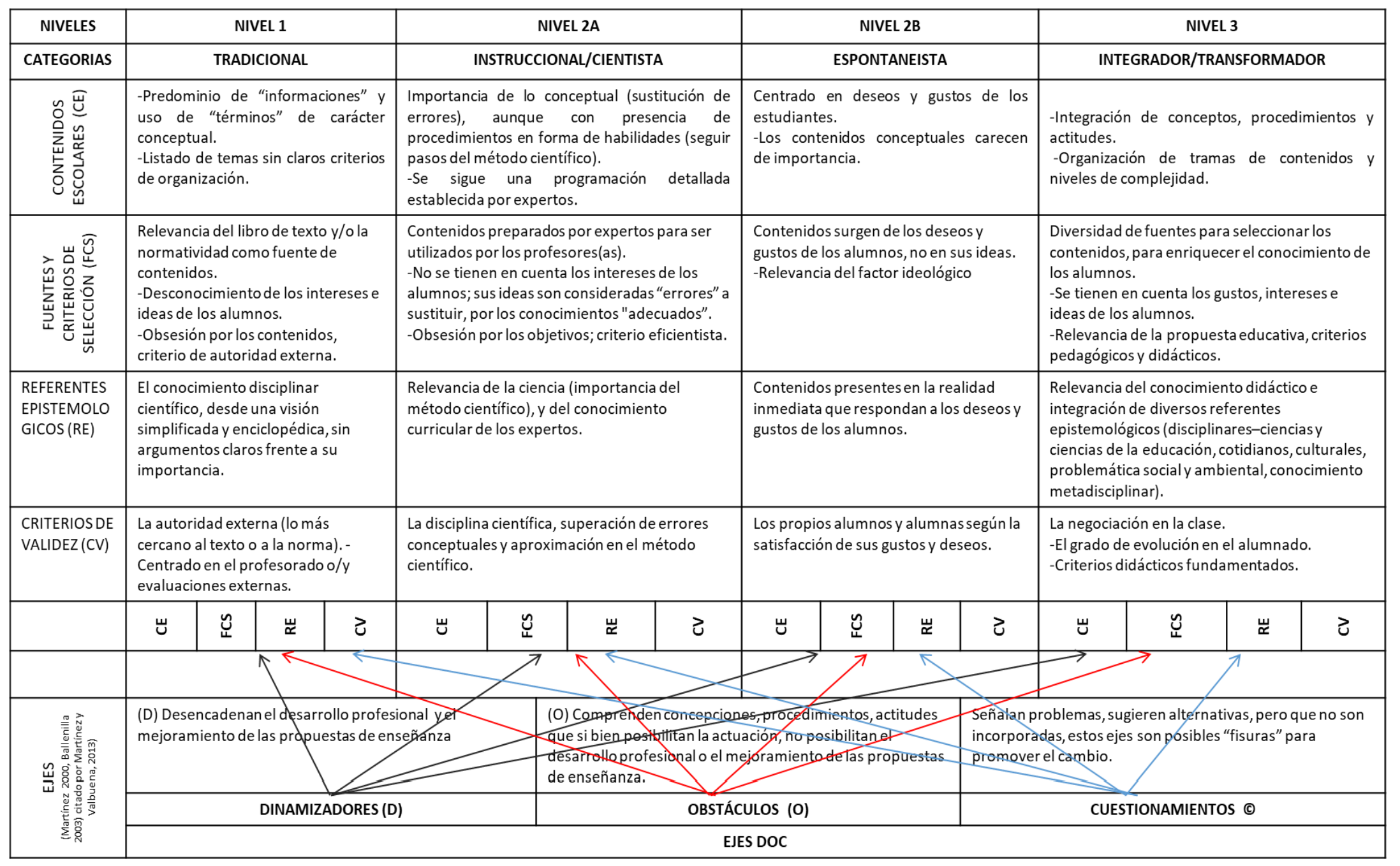

Figura 11. Categorías y niveles de formulación en el análisis del CPP.

Fuente. Autora con base en Martínez, C. (2000), Martínez \& Valbuena (2013) y Martínez (2016, 2017) 
Martínez (2017) en su libro: Ser maestro de ciencias: productor de conocimiento profesional y conocimiento escolar, hace un recuento de los resultados de las investigaciones que buscan relacionar conclusiones de diversos autores que conciben al maestro como depositario de saberes en nombre de una profesionalización crítica, centrada en la posibilidad de producir conocimiento; además de ofrecer una amplia bibliografía sobre el tema, enfatizando en la aproximación entre conocimiento profesional del profesor y el conocimiento escolar (figura 12).

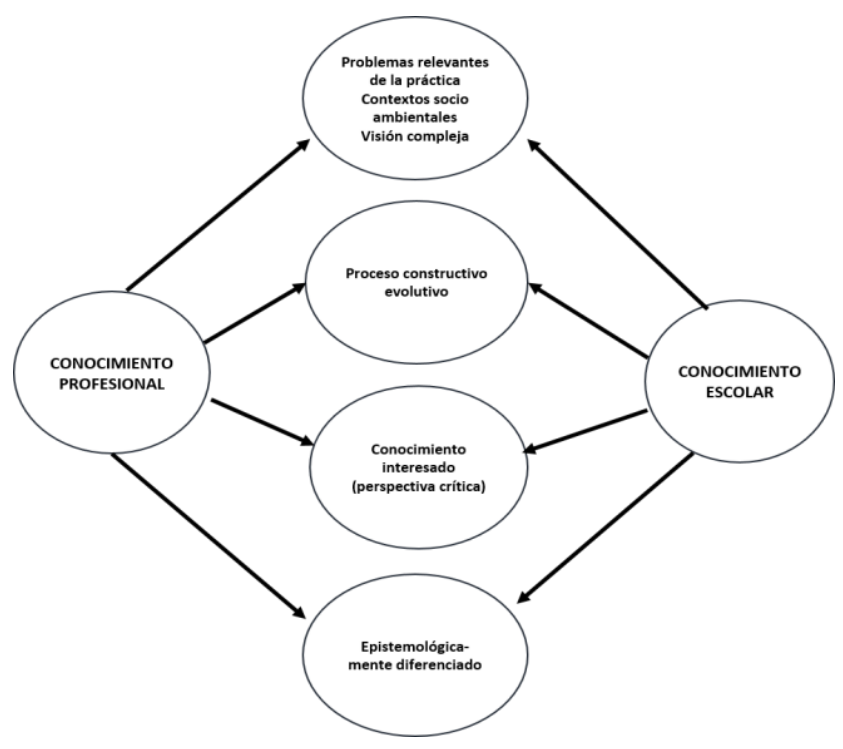

Figura 12. Algunas características del conocimiento profesional del docente de ciencias y el conocimiento escolar.

Fuente. Martínez (2017, p.117)

\subsection{CONOCIMIENTO PROFESIONAL DEL PROFESOR (CPP) Y CUESTIONES SOCIOCIENTÍFICAS (CSC)}

Para lograr un desarrollo profesional, de acuerdo con los planteamientos de Imbernon \& Canto (2013) se debe garantizar un proceso de formación de docentes que se ajuste a las necesidades y exigencias del siglo XXI, en el que los formadores de docentes realicen propuestas y programas que permitan la construcción y reconstrucción permanente de sus conocimientos, donde se desarrollen alternativas de aprendizaje como pares académicos, en los que la 
universidad garantice a la escuela la formación de profesionales capaces de superar las brechas existentes entre los docentes que investigan y los que realizan la práctica escolar, donde se generen nuevas conocimientos didácticos y formas alternativas de resolver problemas contextualizados. Es decir, se deben plantear espacios de formación permanente de docentes libres de intereses particulares 0 de direccionamiento externo, para que el maestro en el contexto de su práctica profesional y laboral desarrolle nuevas estrategias y planteamientos curriculares que le permitan mantener un diálogo horizontal con sus pares académicos, con los estudiantes y con las problemáticas propias del mundo globalizado, dando como resultado, que el profesor sea un investigador y constructor crítico de su propio conocimiento.

Abell (2008), afirma que el conocimiento del profesor, no sólo es importante para la realización de una investigación educativa, sino que es un insumo útil para los formadores de formadores, quienes al conocer el tipo de conocimiento que ponen en juego los buenos maestros cuando planean y desarrollan el trabajo en el aula, suministran información valiosa para definir las metas de los programas y cursos, para preparar nuevos profesores o para favorecer el desarrollo profesional de profesores en servicio.

Lo anterior, permite afirmar que la formación de profesores es uno de los pilares del desarrollo de la sociedad, ya que, al formar docentes creativos e innovadores, con capacidad de decisión, reflexivos, críticos, humanos, investigadores y soñadores, éstos pueden proponer y generar nuevas estrategias de aprendizaje, nuevas formas de organización social con capacidad transformadora y propositiva frente a los problemas que afronta la sociedad actual. Para ello es necesario que los formadores de formadores también planteen nuevas alternativas, nuevas investigaciones encaminadas a articular los resultados de investigaciones del conocimiento de los profesores con los de formación de docentes, para promover así su desarrollo profesional y resignificar la labor docente. 
Sin embargo, no basta con conocer o develar el CPP de los docentes cuando realizan el trabajo práctico del aula. No se debe olvidar la trayectoria a través de la cual el profesorado ha construido sus conocimientos ni el contexto en que desarrollaron sus prácticas de enseñanza, ya que al ser prácticas sociales se inscriben en una institución que las condiciona y al mismo tiempo las determina, bien sea por las políticas externas a las que debe acogerse o por las que ha creado localmente. Además, los docentes como sujetos tienen sus propios intereses, ocupan una determinada posición en el área de trabajo, en la escuela y se relacionan con otros docentes que también tienen intereses particulares; es decir, que están configurados por las condiciones institucionales y sociales en las que se han consolidado sus trayectorias de vida y de trabajo:

Se trata de revisar, junto al profesorado, las razones y motivos que orientan sus actuaciones en el aula, ayudándoles a hacer explícito aquello que saben, intuyen o anhelan para buscarlo, transformarlo o intensificarlo. En definitiva, prácticas de formación que potencien el desarrollo de la dimensión intelectual de la docencia y la adquisición de capacidades de reflexión y análisis, que conduzcan a una mayor comprensión de la propia práctica docente y del contexto científico, social y cultural en el que se desarrolla (Jarauta \& Medina, 2012, p.196).

Investigaciones sobre el conocimiento de los profesores en el campo tecnológico mencionan la importancia de utilizar la tecnología como medio para la especialización, también de manejo de contenidos que favorecen la dimensión disciplinar y la investigación. Desde el planteamiento del Conocimiento Pedagógico y Tecnológico del Contenido (TPACK), se ha encontrado que los docentes al participar en propuestas de formación en torno a contenidos, métodos y herramientas del campo disciplinar, reflexionan sobre el contenido mismo, conocen nuevos materiales, equipos y formas de abordar temáticas tradicionales que posibilitan el abordaje de cuestiones de frontera como las CSC; permiten al docente cuestionarse sobre sus propios conocimientos y asumir una postura crítica frente a la información dada por los medios masivos de comunicación, lo 
que se devela al seleccionar el material que utilizan en el diseño de los recursos tecnológicos.

Así, investigar sobre CPP permite conocer las manifestaciones de actuación en las prácticas de enseñanza, analizar cómo a partir de la reflexión se logra el desarrollo profesional del profesor, caracterizar los conocimientos que tienen los profesores cuando secuencian y presentan los diversos temas a enseñar, cuáles estrategias dinamizan sus clases, además de reconocer que trabajar en pares académicos o a través de la observación de los expertos, desde la formación inicial hasta la continuada, es un proceso de investigación y retroalimentación en los diferentes escenarios en que se efectúe (García, 1999, 2007).

Atendiendo las sugerencias de Grossman, Wilson, \& Shulman (1989), Park \& Oliver (2008), Goes et al. (2013) y Talanquer (2014b) entre otros, es necesario que el docente investigue sobre su propia práctica, conozca experiencias de aula desde su posición como estudiante y como docente en formación.

La propuesta de un modelo de formación de profesores que promueva el desarrollo profesional a través de la consolidación de grupos interdisciplinares de docentes enfocado en las discusiones de CSC, podría favorecer el desarrollo del CPP y posiblemente se constituirá como un eje disciplinar o conocimiento específico del modelo, es decir, será una apuesta a la interacción de la teoría con la práctica, que permita a los docentes o lideres universitarios el relacionamiento de los saberes académicos con los saberes prácticos como investigadores de su propio trabajo escolar; las CSC asumidas como estrategias de enseñanza o categorías específicas serán el eje central de este modelo de formación y configuración del CPP.

Levinson (2006b) menciona que enseñar CSC en la escuela no es nuevo, ya existen proyectos curriculares basados en la controversia, como el de humanidades desde 1970; sin embargo, estudios posteriores evidenciaron una disminución en la presencia de estas temáticas y currículos, debido a la desconfianza que presentan los profesores de ciencias, adicionalmente por las 
dificultades pedagógicas para abordar estos temas, ya que al ser muy polémicos podrían tocar aspectos éticos, económicos, políticos, científicos, antropológicos y normativos, frente a los cuales los profesores no están bien informados, contando además con que su especialidad disciplinar no es suficiente para abordarlos a pesar de las emociones que podían generarse en la discusión.

Adicionalmente, se caracteriza el abordaje de las CSC en el contexto de cinco modelos de enseñanza cuyo propósito es el logro de la alfabetización científica (Tabla 3), asociando cada uno de ellos con una jerarquía que relaciona al científico, al profesor y al alumno, a las fuentes epistemológicas del conocimiento, a la visión que se tiene de la ciencia, a la forma como los participantes del proceso de enseñanza/aprendizaje se posicionan en relación con la controversia, la orientación pedagógica para la enseñanza y la concepción de evaluación; el modelo deficitario corresponde a un abordaje centrado en el conocimiento sustantivo, asociado a una visión de ciencia absoluta que produce un conocimiento verdadero, sin espacio para la duda; por lo tanto, el aprendizaje de la CSC se presenta de la misma forma en que se aprenden los contenidos científicos y el profesor es quien determina cuáles conocimientos de la problemática se abordan (Levinson, 2008, 2010).

En el modelo de cuestiones escolares y sociales hay un espacio para discutir y debatir las CSC, sin embargo, se espera que se demuestren las evidencias científicas de la controversia; en el sociopragmático los alumnos pueden profundizar en la discusión, participar de los cambios y este conocimiento no tiene que estar curricularizado; a propósito Levinson afirma que los docentes se encuentran en el mismo nivel de desconocimiento que los estudiantes, lo que genera en los profesores angustia o limitación en el abordaje de ciertas temáticas (Levinson, 2006b). 
Tabla 3. Modelos de enseñanza para abordar CSC.

\begin{tabular}{|c|c|c|c|c|c|c|}
\hline 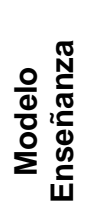 & $\frac{\frac{\pi}{2}}{\frac{\pi}{\frac{\pi}{\pi}}}$ & $\begin{array}{c}\text { Fuente de } \\
\text { conocimiento }\end{array}$ & $\begin{array}{c}\text { Visión del conocimiento } \\
\text { (referentes } \\
\text { epistemológicos) }\end{array}$ & Controversia & $\begin{array}{l}\text { Referentes } \\
\text { Pedagógicos de } \\
\text { la Enseñanza }\end{array}$ & Evaluación \\
\hline $\begin{array}{l}\frac{0}{\frac{\pi}{2}} \\
\frac{10}{0} \\
\frac{0}{0} \\
0 \\
0\end{array}$ & 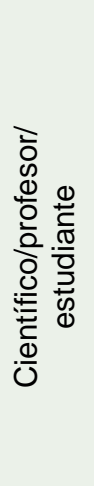 & $\begin{array}{l}\text { Corpus de la } \\
\text { ciencia. }\end{array}$ & $\begin{array}{l}\text { La ciencia para ser conocida } \\
\text { es correcta y cierta. La } \\
\text { naturaleza es cognoscible. } \\
\text { La incertidumbre y } \\
\text { conocimiento provisional son } \\
\text { de dominio de los } \\
\text { especialistas, la ciencia dura } \\
\text { se difunde en las } \\
\text { aplicaciones científicas. }\end{array}$ & $\begin{array}{l}\text { Es improbable que los } \\
\text { estudiantes y ciudadanos } \\
\text { comunes tengan el } \\
\text { conocimiento y la } \\
\text { comprensión necesaria } \\
\text { para participar en } \\
\text { cuestiones controvertidas. } \\
\text { Sin embargo, además del } \\
\text { contenido científico, se les } \\
\text { puede enseñar CSC a } \\
\text { través de los métodos de } \\
\text { la ciencia y las } \\
\text { controversias. }\end{array}$ & $\begin{array}{l}\text { La autoridad del } \\
\text { conocimiento } \\
\text { reside en la } \\
\text { ciencia y el } \\
\text { docente como } \\
\text { representante de } \\
\text { la ciencia. El } \\
\text { conocimiento } \\
\text { necesario para } \\
\text { una controversia } \\
\text { puede llamar la } \\
\text { atención de los } \\
\text { estudiantes. }\end{array}$ & $\begin{array}{l}\text { Prueba } \\
\text { conocimiento / } \\
\text { hechos de la } \\
\text { ciencia relevantes a } \\
\text { una controversia. }\end{array}$ \\
\hline 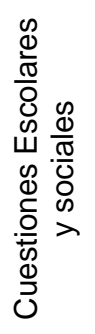 & 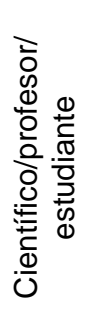 & $\begin{array}{l}\text { Corpus de la } \\
\text { ciencia y otras } \\
\text { disciplinas. }\end{array}$ & $\begin{array}{l}\text { La ciencia para ser conocida } \\
\text { es verdadera, pero el énfasis } \\
\text { está en los métodos y } \\
\text { procedimientos de la ciencia } \\
\text { en lugar de los hechos. La } \\
\text { ciencia se difunde en las } \\
\text { aplicaciones sociales, pero } \\
\text { hay cierta transparencia } \\
\text { sobre el proceso científico. }\end{array}$ & $\begin{array}{l}\text { Se lleva a cabo dentro del } \\
\text { aula, pero puede implicar } \\
\text { el análisis de la ciencia en } \\
\text { los periódicos que } \\
\text { distinguen la retórica de la } \\
\text { evidencia. }\end{array}$ & $\begin{array}{l}\text { El docente } \\
\text { controla r el } \\
\text { contenido, pero } \\
\text { puede ser un } \\
\text { facilitador en la } \\
\text { discusión. }\end{array}$ & $\begin{array}{l}\text { Prueba habilidades } \\
\text { de argumentación, } \\
\text { uso de } \\
\text { justificaciones para } \\
\text { respaldar reclamos. }\end{array}$ \\
\hline
\end{tabular}




\begin{tabular}{|c|c|c|c|c|c|c|}
\hline 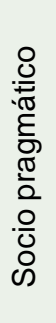 & 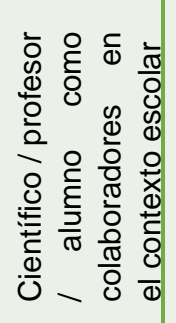 & $\begin{array}{l}\text { Ciencia } \\
\text { necesidad. }\end{array}$ & $\begin{array}{l}\text { Los profesores / expertos } \\
\text { delinean áreas de } \\
\text { controversia, pero la ciencia } \\
\text { se ve como contestable y } \\
\text { receptiva a las necesidades } \\
\text { sociales. }\end{array}$ & Participativa & $\begin{array}{l}\text { Maestro como } \\
\text { facilitador. } \\
\text { Conocimiento } \\
\text { compartido entre } \\
\text { docentes r y } \\
\text { estudiantes. }\end{array}$ & $\begin{array}{lr}\text { Podrían ser } \\
\text { conocimientos y } \\
\text { habilidades que los } \\
\text { participantes traen } \\
\text { para resolver un } \\
\text { problema pero son } \\
\text { difíciles de } \\
\text { determinar. }\end{array}$ \\
\hline 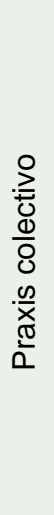 & 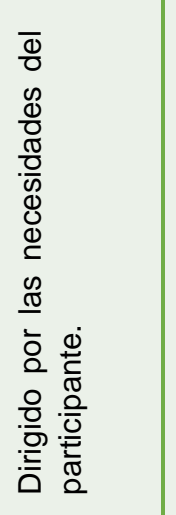 & $\begin{array}{l}\text { Emerge de las } \\
\text { necesidades de los } \\
\text { participantes y, por } \\
\text { lo general, de los } \\
\text { "conocimientos" } \\
\text { locales. } \\
\text { conocimiento } \\
\text { científico está } \\
\text { subordinado a las } \\
\text { necesidades de los } \\
\text { colectivos y } \\
\text { frecuentemente } \\
\text { desafiado. }\end{array}$ & $\begin{array}{l}\text { Compartido y distribuido. } \\
\text { Los hechos y las teorías de } \\
\text { la ciencia "académica" se } \\
\text { consideran irrelevantes para } \\
\text { las necesidades de la } \\
\text { comunidad. La ciencia se } \\
\text { distribuye } \\
\text { heterogéneamente entre } \\
\text { grupos y comunidades. }\end{array}$ & $\begin{array}{l}\text { Podría tratarse de un tema } \\
\text { en particular, pero la } \\
\text { opinión de la ciencia es } \\
\text { polémica. } \\
\text { Se aborda una injusticia } \\
\text { social. 'Alfabetización } \\
\text { científica es el resultado } \\
\text { recibido de manera } \\
\text { contingente'. } \\
\text { orientada. Acción }\end{array}$ & $\begin{array}{l}\text { Conocimiento } \\
\text { compartido y } \\
\text { distribuido entre } \\
\text { los participantes. } \\
\text { Autoridad } \\
\text { formada por la } \\
\text { praxis. }\end{array}$ & Problémico. \\
\hline
\end{tabular}

Fuente. Autora con base en Levinson (2008) 
En el modelo dialógico se toman decisiones en un ambiente de confianza, ya que el conocimiento se desplaza del saber de los especialistas a un abordaje más amplio lo que permite que se develen las incertidumbres de la ciencia; por lo tanto, los ciudadanos "estudiantes" buscan dar posibles soluciones a las CSC con ayuda de diferentes fuentes del conocimiento, a la vez que se negocia; en el modelo colectivo, tanto profesores como estudiantes son agentes de cambio y la ciencia se torna asequible para ellos, permitiendo comprender y plantear posibles soluciones, es decir, "producir conocimiento escolar".

Como Levinson (2006b) afirma, "no hay modelos únicos", generalmente se combinan o se crean nuevos, lo importante es la idoneidad de los mismos, acorde a los principios que orienten las prácticas pedagógicas; para el autor los que más se ajustan a las CSC son los métodos pragmáticos y dialógicos, acordes al enfoque epistemológico de la propuesta de formación de profesores en esta investigación; en el contexto de la formación de docentes en IUE se realizan procesos de praxis colectiva, dialógicos/negociados, donde se abordan CSC en el contexto de las problemáticas de la institución y las necesidades de los profesores participantes.

En este sentido, es coherente el uso de CSC en el proceso de formación inicial y permanente de profesores, al ser estas abordadas favorecen el desarrollo de procesos de pensamiento científico, la toma de decisiones, asumir posturas desde una perspectiva ética/moral, el fortalecimiento del ser político y participar en las posibles soluciones de las diversas problematicas o temáticas controversiales en las que como ciudadanos del mundo contemporáneo tienen parte. Abordar dichas problemáticas de forma crítica, además de favorecer el desarrollo profesional, contribuyen al CPP, permitiendo la interdisciplinariedad como integradora metodológica en la enculturación científica, asumiéndola como uno de los fundamentos que constituye la construcción del saber analítico y reflexivo de las ciencias naturales. 
Finalmente, se puede afirmar que el CPP sobre CSC es un tema de investigación poco trabajado, que en la presente investigación se pretende caracterizar al ser asumido como un proceso de formación de docentes en la IUE en el que el interés de los participantes además de cumplir con su jornada laboral es el de aprender; en ese mismo sentido, el propósito del investigador que tiene vínculo con la universidad y la escuela es conformar un $\mathrm{Gl}$, donde se aborden CSC con enfoque CTSA, planteados por los mismos docentes en concordancia con las necesidades del contexto escolar. El CPP es individual, es decir cada docente tendrá este tipo de conocimiento de acuerdo con los saberes base para la enseñanza, los conocimientos específicos de la disciplina y su epistemología personal, sin embargo, todo lo anterior es producto de un contexto cultural y social, es decir producto de una praxis colectiva.

En este contexto, las CSC vienen a formar parte del conocimiento disciplinar especifico, pero en una dimensión interdisciplinar, donde el maestro evidencia los significados que ha construido de su disciplina según las características socioculturales y la epistemología propia del conocimiento. Chinn (2012), a través de un programa de formación de docentes inmersos en un contexto indígena, evidencia como el CPP adquiere nuevas dimensiones al entender la cultura como parte fundamental del proceso de contextualización de la enseñanza de las ciencias enfocadas a la sostenibilidad y al entendimiento de las relaciones CTSA.

\subsection{FORMACIÓN DE DOCENTES EN IUE}

En las últimas décadas se han visto favorecidas las relaciones de colaboración entre la universidad y la escuela que buscan fortalecer el CPP y mitigar el distanciamiento de las dos instituciones, en las que se ha mitificado que el ejercicio investigativo de desarrolla en la universidad, en cambio la escuela se dedica a enseñar, promoviendo la fractura entre la teoría y la práctica y 
visibilizando una relación instrumental, en la que se establecen intercambios cuando una necesita de la otra.

Huberman \& Levinson (1988) comentan la preocupación existente por la falta de conexiones sólidas entre universidad-escuela y muestran cómo se pueden establecer algunos acuerdos de cooperación entre ambas instituciones que posiblemente garanticen la investigación, la enseñanza y el acercamiento entre la teoría y práctica, que el maestro configura como resultado de la formación inicial y continuada desvinculada del contexto escolar. Los autores mencionan dos enfoques conceptuales dominantes que se pueden tener en cuenta en los procesos de interacción universidad-escuela: la teoría de la transferencia de conocimientos y la teoría interinstitucional.

La teoría de la transferencia es una rama de la comunicación, donde diferentes tipos de conocimiento interactúan en redes, bien sea entre personas o entre instituciones. Estas relaciones de transferencia se pueden descomponer en cuatro elementos: generación del conocimiento en el sistema fuente, transferencia, utilización de los conocimientos transferidos dentro del sistema usuario y la comunicación de necesidades, preocupaciones y reacciones desde el sistema usuario al sistema fuente. Este conocimiento puede fluir en ambas direcciones, las escuelas no sólo lo consumen, lo pueden reorientar y cualificar y la universidad lo retoma para cualificar la enseñanza e investigar en otros ámbitos que le permitan conocer la naturaleza de las interacciones que se dan o que interfieren en el proceso de transferencia, sin embargo, si no son direccionadas desde los actores escolares tiende a convertirse una visión de tipo tradicional, direccionada, con tendencia a la homogenización y a la consolidación de relaciones de poder.

La teoría interinstitucional, está basada en un proceso de interacción, en el que las conexiones se ven como un conjunto de acuerdos de intercambio entre partes interesadas, donde los mecanismos de transacción son usados por personas interesadas de manera informal a través de unidades estacionales y sociales diferentes, lo que permite inferir que esta segunda teoría está más exenta de 
conflictos y menos direccionada verticalmente, por iniciativa propia de cualquiera de las instituciones se negocia el tipo de interacción y se establecen acuerdos que permitan dar continuidad o terminar dichas relaciones.

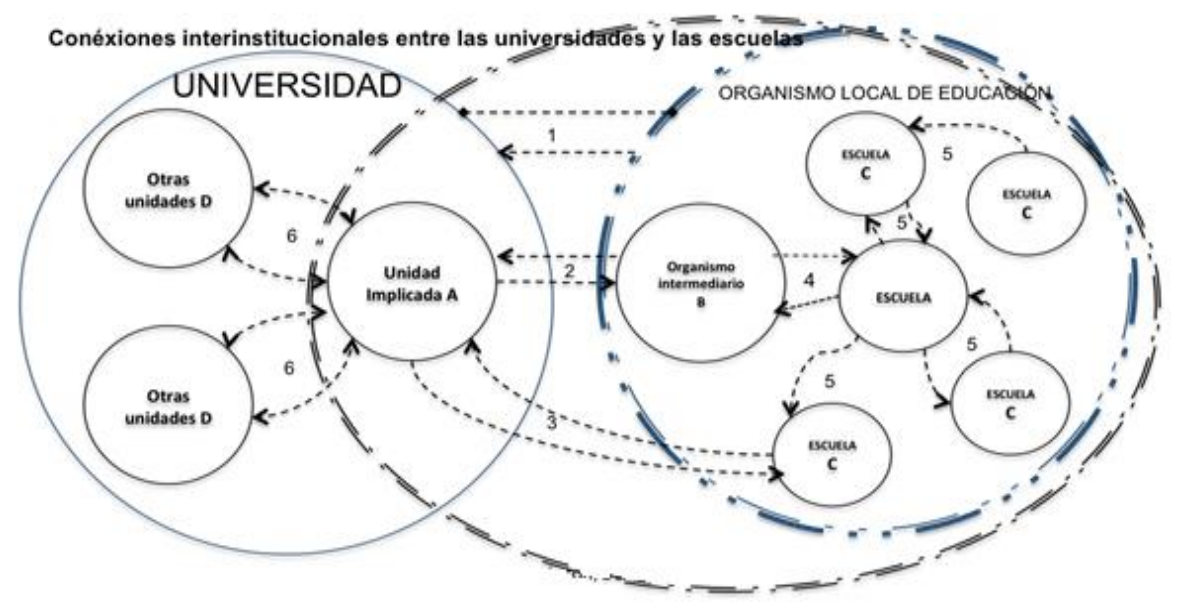

Figura 13. Conexiones interinstitucionales entre la Universidad y la Escuela. Fuente. Huberman \& Levinson (1988)

La figura 13 evidencia las conexiones interinstitucionales que implica esta teoría, evidencia seis tipos de transferencia: entre la universidad y las demás partes del acuerdo (organismos locales de educación (indicadas por la líneas dobles discontinuas), entre la unidad universitaria (A) y cualquier organismo que actúe como coordinador o intermediario de los participantes escolares (A-B), entre la universidad y las escuela $(A-C)$, entre la unidad intermedia $(B)$ y las escuelas $(C)$, entre las diferentes escuelas directamente; y entre la universidad y otras instancias de la misma (A-D).

Nóvoa (2009) propone una nueva interacción entre los profesores en formación inicial (novatos/noveles) y profesores en formación permanente (expertos), en la que los docentes noveles participan del contexto escolar, establecen vínculos emocionales, comunicacionales y de experiencias prácticas con los docentes en ejercicio, los estudiantes y la comunidad escolar en general. 
Teniendo en cuenta las dos últimas experiencias en formación de profesores, el grupo Alternaciencias de la Universidad Pedagógica Nacional, diseña una experiencia a través de la conformación de los Gl entre docentes de algunas escuelas públicas y privadas, docentes en ejercicio y en formación inicial de la UPN y de la Unesp de Brasil; esta experiencia además de promover la formación de profesores, se constituyó en un escenario de construcción de saberes escolares, de dialogo horizontal y de promoción de capacidades investigativas por todos los docentes participantes del proceso, aunque en algunos colegios se quiso institucionalizar, no se consolidó la propuesta, ya que por ser experiencias piloto existe la posibilidad que actores externos lo asimilen como una manera de comunicar y socializar políticas direccionadas al mercantilismo o al control. Al constituirse estos escenarios de formación para docentes (en formación inicial y ejercicio) se posibilita el planteamiento de políticas de formación lideradas desde la escuela y que permiten el desarrollo profesional del profesor. (Martínez \& Parga, 2014; Rodriguez \& Martinez, 2014).

\subsubsection{Los Gl:}

La concepción de la TAC de Jürgen Habermas busca devolver a la razón su capacidad emancipadora, superando las limitaciones impuestas por la visión reduccionista de la racionalidad instrumental a través de un nuevo paradigma: la racionalidad comunicativa. Este pensador (1987) concibe la sociedad moderna de forma bidimensional desde el mundo de la vida y el sistema, el sistema regido por la razón instrumental que comprende dos subsistemas: el estado y el mercado.

El mundo de la vida comprende las intersubjetividades de los actores inmersos en situaciones concretas de la experiencia, contemporáneamente el modo de vida de las personas ha adquirido un nuevo perfil ético, cultural, social y económico; los sujetos en esta realidad, crean, recrean, inventan y establecen nuevas formas de 
relacionarse entre sí y cuando aumenta la complejidad del sistema social, se da una sobrecarga en los procesos de entendimiento lo que posibilita la existencia y la mantenimiento de medios de control independientes del lenguaje (el dinero que es un instrumento del mercado y el poder el instrumento del estado). Por dicho aumento en la complejidad sistémica, los procesos mediados por el diálogo pasan a un segundo plano y van siendo colonizados por el sistema. (Figura 14).

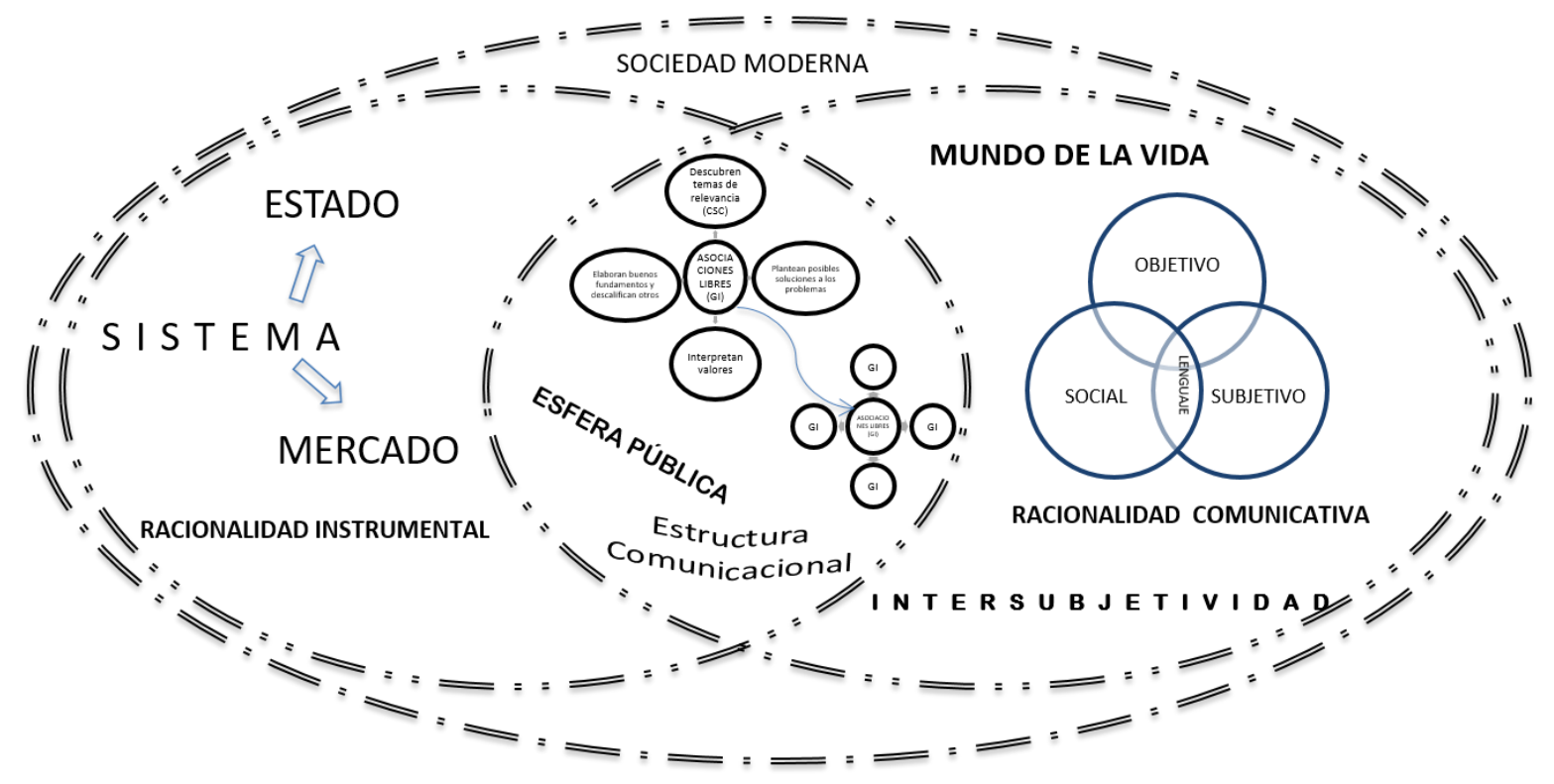

Figura 14. Teoría de la Acción comunicativa de Habermas (TAC) Fuente. Autora con base en Habermas (1987)

En razón de lo anterior, la esfera pública va tomando un lugar intermediario entre el sistema y el mundo de la vida, caracterizada por la universalidad e igualdad en la participación y en la racionalidad en la búsqueda de entendimiento y la publicidad crítica (Carvalho, 2015; Carvalho \& Chapani, 2012).

Relacionado con el concepto de esfera pública, está el de asociaciones libres, caracterizadas por ser organizaciones no institucionalizadas (o poco), en las que personas privadas haciendo uso de la razón, debaten libre e igualitariamente sobre temas de interés común, produciendo una opinión pública capaz de orientar sus acciones, más no de tomar decisiones; forman conceptos, debaten en torno a problemáticas de la sociedad, plantean posibles soluciones, interpretan valores, 
hacen política, constituyéndose en nuevas redes que apoyan las esferas públicas como se ve en la figura 15 (Carvalho \& Chapani, 2012; Carvalho, 2015).

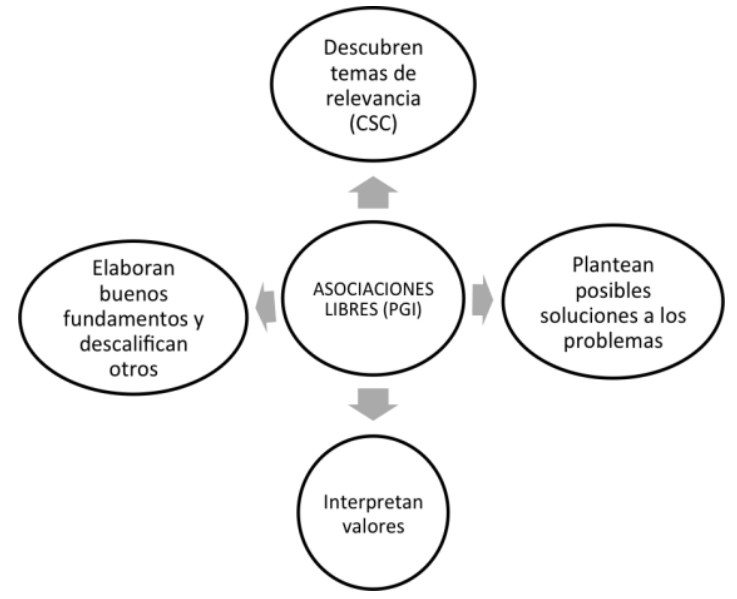

Figura 15. Asociaciones libres.

Fuente. Autora con base en Carvalho \& Chapani (2012)

En el marco de la TAC de Habermas, los programas de formación de profesores en la IUE y la elaboración de políticas públicas como foros públicos integrados (FPI) de Puello (2013), se plantea una nueva propuesta híbrida de formación de profesores, que permita estructurar un programa contra-hegemónico a través de los GI.

Los Gl formados por profesores de las escuelas, profesores en formación inicial, profesores universitarios, y posiblemente otros actores que se involucren en el proceso asumiendo el rol de sujetos políticos, establecen un dialogo horizontal, que les permite organizarse en dos direcciones:

- La primera, para asumir una formación política de sus miembros, liderar, proponer y formar parte de la organización institucional, que les garantice tiempos y espacios para el desarrollo de la propuesta, así como establecer redes entre otras escuelas de la localidad, participar en las mesas sectoriales de educación o de las organizaciones locales, en los foros existentes o convocando la realización de FPI locales, que posteriormente, unidos a sindicatos o con el apoyo de movimientos pedagógicos puedan 
participar en la elaboración de las políticas educativas, en síntesis: consolidarse como gremio docente (Bauman, 2016; Sousa, 2017).

- La segunda, para asumir el rol de profesor intelectual/transformador/crítico/reflexivo tejedor de sociedad, que forma ciudadanos del mundo, como lo plantea Nussbaum (2010) sujetos políticos que asumen la colectividad superando el hiperindividualismo (Lipovetsky, 2016) y la injusticia del mundo.

Los Gl de la escuela(s) asumen en forma responsable, crítica y autónoma el autogobierno que caracteriza las escuelas democráticas, donde todos los interlocutores (docentes de la escuela, de la Universidad, agentes externos, docentes administrativos, etc.) se encuentran en las mismas condiciones para expresar sus puntos de vista e interactúan sin coerción, donde el diálogo es el instrumento que permite construir y reconstruir el mundo de la vida.

Estos espacios formados y consolidados entre la escuela y la Universidad, requieren agentes cuyos intereses de formación, construcción y liderazgo se identifiquen por tener en común la necesidad de transformar la dinámica escolar a partir de ideales formativos que tiendan a generar situaciones que propendan por el bienestar colectivo, posibilitando la construcción de acuerdos legitimados en procesos de discusión de ideas sobre un determinado tema de interés o acción local (Carvalho \& Chapani, 2012; Martínez \& Parga, 2014)

Bajo esta concepción de docente autónomo, investigador, intelectual, transformador, sujeto político y ante todo humano, el profesor puede mediar entre las decisiones nacionales y las opciones de proyecto o currículo de la escuela (Lopes, 2005, 2008), entre las características de los estudiantes y las que perfilan las políticas de mercado tendientes a la promoción de una cultura escolar basada en el respeto por la vida, la dignidad humana y la colectividad; procesos que serán largos, llenos de incertidumbres y de tensión, pero que organizados y 
planeados en colectivo harán posible la consolidación de híbridos curriculares ${ }^{3}$, a través de los cuales surjan nuevas políticas que garanticen el desarrollo humano (figura 16).

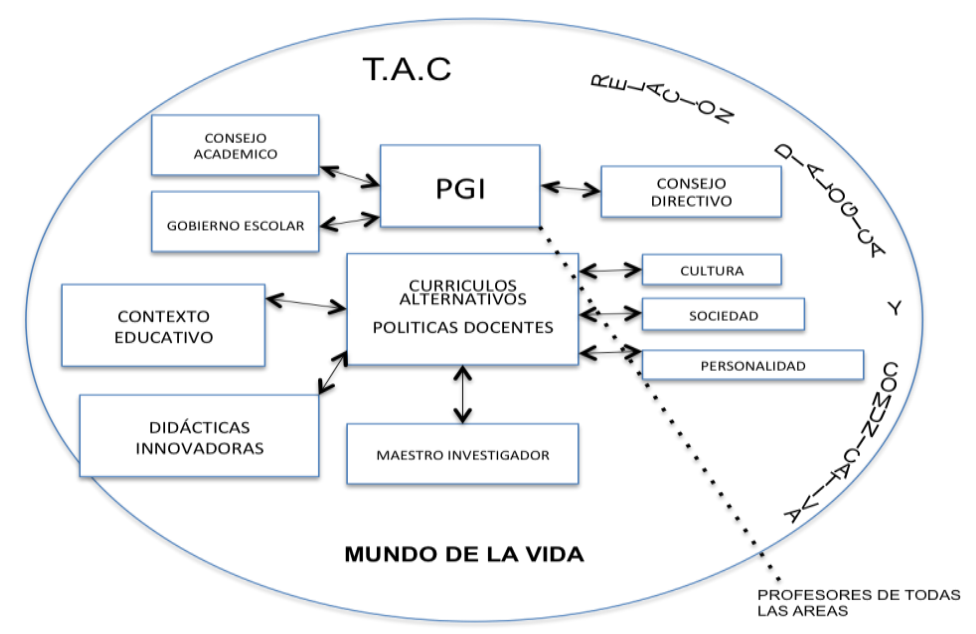

Figura 16. Gl como asociaciones libres.

Fuente. Autora con base en Carvalho \& Chapani (2012) y Lopes $(2005,2008)$

Los docentes al participar de los Gl como forma de asociación libre, debaten, cuestionan, proponen, gestionan desde la escuela la participación de agentes externos que posibiliten la reconstrucción de la esfera pública, tal como lo propone Huberman \& Levinson (1988) y Martínez et al. (2015) visualizado en la figura 17.

\footnotetext{
${ }^{3}$ Currículo Híbrido: Es un producto de la recontextualización de políticas internacionales, de prácticas culturales (escuela), de políticas de estados, regiones, municipios, gobiernos de otros países, agencias multilaterales, etc.; que han sido reinterpretados constituyéndose en productos híbridos, que no se podrán leer, sino se hacen nuevas reinterpretaciones Lopes $(2005 b, 2008 b)$
} 


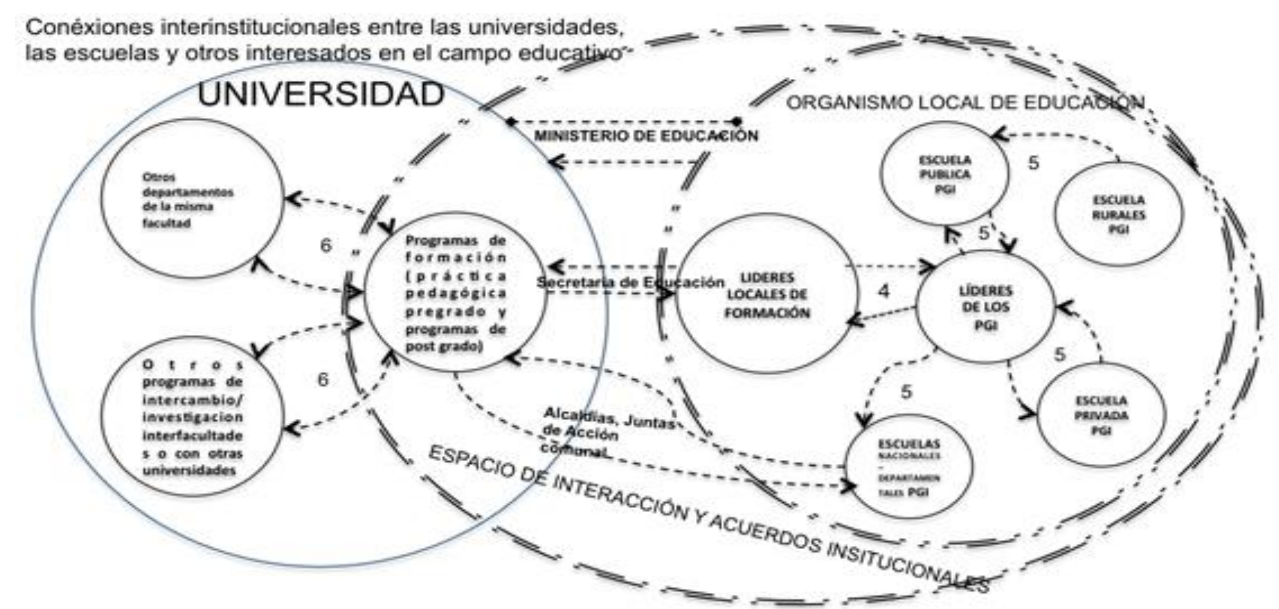

Figura 17. Hibrido de propuestas Huberman \& Levinson, (1988) / Martínez \& Salazar (2014) Fuente: Huberman y Levinson (1988)

Diehl (2015) en su tesis doctoral, afirma que movimientos como el ALBA, buscan la movilización del pueblo Latinoamericano, convocando a los ciudadanos del mundo a organizarse, además de reconocer que es a través de la educación que se gestan los cambios, se construye la colectividad de los pueblos y como lo ratifica Lipovesky, Harendt, Bauman, Sousa, entre otros, es la política la que cambia el mundo; menciona además que planteamientos estratégicos como los propuestos en la Carta de Belem (2009) pueden favorecer una acción política transformadora. En palabras de Diehl (2015):

Elevar el nivel cultural educacional, y la conciencia de la población, avanzar en la formación política de los militantes populares, promover procesos de formación política de masas, e impulsar el trabajo, promover un debate profundo sobre el modelo de desarrollo capitalista y sobre la necesidad de generar modelos alternativos en todos los planos, promover una batalla continental por la reforma agraria, contra el uso de semillas transgénicas, los agrocombustibles industriales y el agro-negocio en todas sus fases, visibilizar el aporte del trabajo no remunerado de las mujeres a la economía, e incorporar esa mirada en las luchas y propuestas políticas sobre la migración, la soberanía alimentaria y el modelo de desarrollo. (p.342)

Así pues, los Gl como organizaciones no institucionalizadas, que permitan el restablecimiento de la esfera pública, se constituyen en espacios de resistencia 0 
mejor contra hegemónicos, que podrían asumir y liderar discusiones de las temáticas planteadas, en especial de las que más afecten el contexto escolar, tal como lo plantea Levinson (2006a, 2008, 2010), Reis \& Galvão (2008), Pedretti \& Nazir (2011) y Ratcliffe \& Grace (2003b) entre otros, quienes manifiestan como CSC en el contexto CTSA favorecen la formación de sujetos políticos, seres militantes por el reconocimiento de la labor docente.

El GI a la luz de la teoría de campos de Bourdieu $4(1974,1996)$ se concibe como un campo social, en el que la formación es una adquisición cultural, un bien que se lucha para tener y construir la denominada educación científica y tecnológica que conlleve a la emancipación. Las interacciones sociales que se establecen entre los integrantes del Gl y los integrantes de la universidad, pueden ser entendidas como juegos propios del campo, en el que por más que se establezcan relaciones horizontales, se lucha por permanecer en el juego y mantener la dinámica dominante/dominado (D/d) con la de (d/D) y no la lucha tradicional caracterizada por espacios jerarquizados donde los integrantes de los grupos tengan intereses particulares y luchen por mantener la desigualdad, por obtener más capital sea cultural (más títulos y mejores oportunidades de escolaridad); material (representados en dinero por ascenso en el sistema educativo), simbólico (mejor status ante el grupo o la comunidad en general) y social (mejores relaciones interpersonales).

Para estudiar el campo de la formación de profesores, en este sentido, se debe analizar el sistema de relaciones que se establece al interior del Gl, ya que como profesores con diferente vinculo institucional y laboral tienen diferentes intereses, establecen luchas simbólicas por imponer una forma de pensar y de ver las cosas, una lucha por imponer una visión de mundo que se cree legitima y que en el caso

\footnotetext{
${ }^{4}$ Bourdieu se utiliza como referente de análisis para comprender las interacciones que se presentan en la escuela, especialmente por las diferencias de capital, mientras que el referente de Habermas alimenta la propuesta, indicando la utopía, lo que debe ser y a lo que se quiere llegar: superar las desigualdades y establecer relaciones horizontales.
} 
de la investigación constituye una lucha simbólica por una formación de profesores contrahegemónica, de relaciones horizontales, donde se comparte la ilusión de cooperación mutua por el capital cultural, por la lucha simbólica de legitimación de espacios de reflexión y aprendizaje basados en las discusiones que permitan direccionar una enseñanza de las ciencias crítica, donde se considera que al abordar las CSC con enfoque CTSA posiblemente se consolide un juego en el que se pretenda ganar capital cultural, distribuyendo y consumiendo equitativamente los bienes ganados: las transformaciones de sus prácticas escolares, los conocimientos (bienes) construidos colectivamente (Bourdieu \& Wacquant, 1995).

Finalmente, consolidar propuestas de formación de docentes a través de los Gl en un proceso de IUE, mitigando la exclusión y favoreciendo el trabajo colectivo, se constituye como una alternativa contra-hegemónica que en contravía a las políticas actuales, permita restablecer el mundo de la vida, repolitizando lo público y lo más importante "liderando propuestas que permitan un mundo más humano, justo e incluyente" que favorezcan ambientes de trabajo cooperativo y el posicionamiento crítico frente al modelo hegemónico que prioriza la competición (Correa \& Bazzo 2017); así como el reconocimiento del profesor como sujeto que construye conocimiento profesional y escolar (Martínez, 2017).

La propuesta de GI es una apuesta de trabajo colectivo alrededor de una CSC contextualizada con las necesidades de la escuela, es lo que Fleck ${ }^{5}(1986)$ denominaría circulo exotérico donde los participantes como CP pueden pertenecer a diferentes círculos exotéricos y esotéricos, así cada profesor construye un CPP fruto del trabajo del $\mathrm{CP}$ que se construye y reconstruye consolidando un EP particular como resultado de la circulación intracolectiva de ideas entre los profesores universitarios (círculos esotéricos), de la escuela y demás participantes.

\footnotetext{
${ }^{5}$ En el capítulo 3 se discute ampliamente la epistemología propuesta por este autor.
} 
Los profesores del Gl en el proceso de formación constituyen otros círculos esotéricos como pares académicos inmersos en este gran CP exotérico, acorde a los intereses que como CP han socializado en torno a la CSC, bien sea en forma disciplinar, didáctica, o consolidando nuevos EP que guiarán las prácticas de aula, cuyos resultados se verán reflejados en la planeación del trabajo docente, en las propuestas curriculares, en la forma de abordar las CSC, en los recursos que utilice, en los referentes epistemológicos y criterios de validez, en general, en las relaciones que establezca entre el razonamiento científico, tecnológico y social acorde a los propósitos educacionales de la enseñanza de las ciencias en el contexto educativo en el que está enmarcado su trabajo como profesional; de la misma manera motivará los estudiantes a empoderarse como ciudadanos, que pueden a la vez ser considerados como CP exotéricos consumidores de ciencia popular o de libro de texto, como muestra la figura 18 (Fleck,1986).

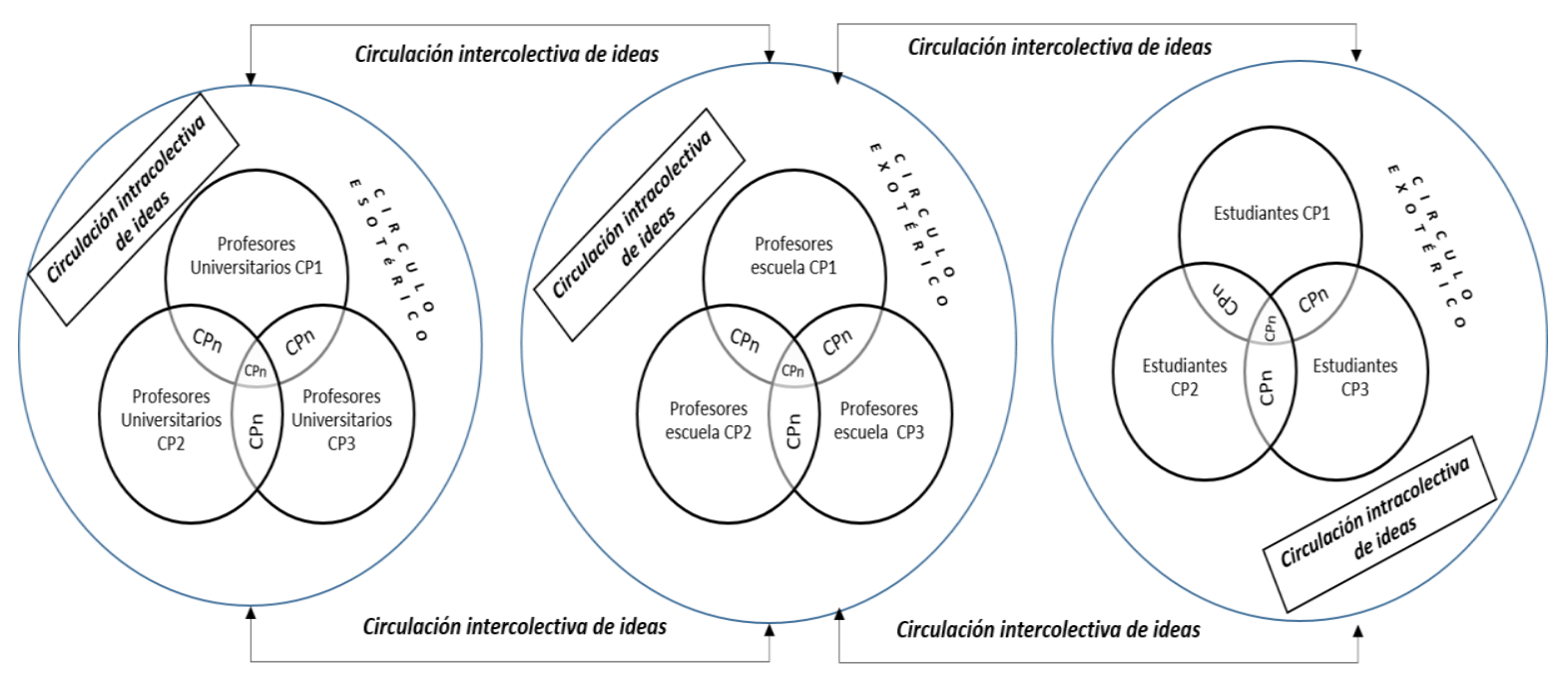

Figura 18. Circulación intercolectiva e intracolectiva de ideas entre los círculos esotéricos y exotéricos en la IUE.

Fuente. Autora con base en Fleck (1986), Delizoicov, Castilho, Cutolo, Ros, \& Lima (2002) 


\subsection{ENFOQUE CTSA Y CSC EN LA FORMACIÓN DE PROFESORES}

Después de casi seis décadas de aparición de los primeros movimientos activistas en 1960 en el Reino Unido y los EEUU como respuesta a la insatisfacción política/económica y a las problemáticas relacionadas con el desarrollo científico y tecnológico, así como a la degradación ambiental, hoy continúan vigentes y se consideran, como semilleros de lo que se considera movimiento CTSA.

Estos movimientos activistas defensores del interés público protestaron en contra de los procesos que conllevan al consumismo, la destrucción ambiental, la guerra de Vietnam, las empresas multinacionales y el uso de la energía nuclear y a favor de los derechos civiles. En ese sentido, es de mencionar el trabajo de Rachel Carson divulgado en su libro Primavera Silenciosa (1962), que contribuyó a la conformación de movimientos ecologistas contemporáneos.

Cutcliffe (2004), menciona que los estudios del movimiento CTS para la educación en sus inicios fueron disciplinares (1980), fue al pasar del tiempo que una sociología del conocimiento direccionó procesos de formación en instituciones universitarias anglosajonas y especialmente en EEUU con programas académicos centrados en la alfabetización tecnológica y la apropiación del conocimiento científico/tecnológico, que como menciona Díaz (1994) puede tener diferente significado cuando se orienta hacia la enseñanza de mayores conocimientos científicos (incidiendo en aspectos cognitivos) o hacia la formación en valores y actitudes (aspectos emotivos), pero que indistintamente son maneras de alfabetización que permiten a los ciudadanos capacitarse para tomar decisiones democráticas en una sociedad que está inmersa e impregnada por la ciencia y la tecnología (Aikenhead, 1985).

A finales de los 80 y mediados de los 90 varias agencias, sociedades profesionales y publicaciones en los EEUU y Europa mostraban indicaciones alarmantes de las implicaciones científicas y tecnológicas en la sociedad, revelando que las relaciones entre Ciencia y Tecnología son complejas y 
requieren una planeación interdisciplinar para comprender no solo los beneficios, sino los efectos colaterales que generalmente se ignoran (Cutcliffe, 2004); develando así, la existencia de una división entre dos sociedades que no se comunican: la de los científicos y la de los humanistas; algo así, como la presencia de una cultura dentro del enfoque CTS orientada hacia la interpretación del contexto social que se denominó "constructivismo social".

Por lo tanto, el enfoque CTS en la década de los 90 estuvo asociado a las llamadas "guerras de las ciencias duras (ciencias naturales, matemáticas e ingenierías) con las ciencias blandas (humanidades y sociales)", pero el enfoque interdisciplinar posibilitó el cambio de los principios metodológicos, enriqueciéndose con miradas y criterios de otras disciplinas que es lo que a partir del año 2000 se ha venido fortaleciendo, en donde las relaciones CTS se constituyen como un enfoque de enseñanza de las ciencias cercana a la cultura, donde los saberes científicos y tecnológicos asumidos como constructos prácticos y colectivos pueden transformar la forma de vida de una sociedad, en la que se deben formar ciudadanos críticos, que participen activamente de dichas prácticas apropiándolas.

Con la superación de las coyunturas mencionadas, la dimensión social de la ciencia y la tecnología comparten como núcleo común el rechazo de la imagen de ciencia como actividad pura y neutra, la crítica a la concepción de la tecnología como ciencia aplicada y neutra y, la promoción de la participación pública en la toma de decisiones (Auler \& Bazzo, 2001; Linsingen, 2007; Palacios et al., 2005).

En este contexto, se hace necesario mencionar, la manera como se ha dado la formación de los profesores en el contexto del enfoque CTS, para lo cual es necesario recordar que en la década de 1960 tenía protagonismo la educación en ciencias que implementaba nuevos proyectos curriculares basados en métodos experimentales, los expertos hacían el material didáctico y ofrecían a los profesores cursos de formación continuada para "capacitarlos" en la utilización de 
dichos materiales y brindar directrices curriculares, lo que muestra la repetición en el aula de un modelo proyecto, sin contextualizar el escenario escolar, ni los intereses de los participantes.

En la década de 1970 se da énfasis a la educación técnica, se crean en Colombia los CEDID (Centros de Enseñanza Diversificados Distritales), los INEM (Institutos Nacionales de Educación Media), el SENA (Servicio Nacional de Aprendizaje), entre otros, para dar respuesta a la formación para el trabajo, en la que los profesores eran llevados a programas de formación fuera del país, para prepararlos en el manejo de máquinas, herramientas y diversas tecnologías que permitieran cumplir con el objetivo de formar mano de obra calificada en los sectores populares de la sociedad. En ese contexto la formación de profesores se correspondía con las dinámicas de la década anterior, ya que los profesores seguían los manuales diseñados por los especialistas (Gómez, 2005).

Martínez (2010b), menciona que fue a partir de la década de 1980 - 1990 que se evidenciaron algunas cuestiones políticas, pedagógicas y sociales que orientaron la reestructuración de los currículos de ciencias hacia una enseñanza de las ciencias con enfoque CTSA, dando mayor relevancia a las estrategias de enseñanza centradas en problemáticas ambientales. A mediados de 1990 los programas de formación de profesores buscaban comprender la realidad de la escuela y promover cambios en las prácticas de aula, así como en los saberes pedagógicos y epistemológicos relacionados con los contenidos escolares a ser enseñados y aprendidos, rescatando así el papel del profesor, comprendiendo la complejidad de su CPP e identidad profesional. De este modo, se evidencia que la década de 1990 se caracteriza por una racionalidad práctica, contraria a la racionalidad técnica que prevaleció en 1960.

Cachapuz (2000), Cachapuz, Paixão, Lopes, \& Guerra (2008) y Fernández, Gil, Alís, Cachapuz, \& Praia (2002) evidencian el énfasis que han dado las investigaciones actuales a la inmersión del movimiento CTSA, develándola como 
una línea de investigación desde la década de los 90, y proponiendo a la vez que al articular CTSA con la enseñanza por investigación, el papel del profesor se descentraliza y los temas de discusión estarán ligados a preocupaciones sociales, políticas o económicas, a problemas socio ambientales reales que involucran a la ciencia y tecnología, creando las condiciones para que dichos aprendizajes sean útiles en el día a día y no sólo desde una perspectiva instrumental en la que los conocimientos son inertes.

En América Latina el movimiento CTSA emerge de la reflexión de la CTS como competencia enmarcada en las políticas públicas, conocido como Pensamiento Latino-Americano de Ciencia, Tecnología y Sociedad (PLACTS ${ }^{6}$ ). las reflexiones surgidas alrededor de lo que significaba el movimiento, eran escritas por científicos e ingenieros en busca de diferentes metodologías e instrumentos que permitieran el desarrollo local de los conocimientos científicos y tecnólogos para la ciencia y la tecnología como un objeto de estudio público y una estrategia de desarrollo social y económico (Linsingen, 2007).

Contrario a los movimientos norteamericanos y europeos, los PLACTS abordan la Ciencia y la Tecnología como un proceso social con características particulares que dependen de los contextos, mostrando la no neutralidad y universalidad de Ciencia y la Tecnología. Como lo plasma Auler $(2007,2011)$ a través de las figuras 13 y 14, donde la primera representa la supuesta neutralidad de la Ciencia y la Tecnología como una comprensión poco crítica de las interacciones CTS (comprensión ingenua), mostrando la manera como las construcciones históricas de superioridad/neutralidad del modelo de decisiones tecnocráticas, la perspectiva salvacionista/redentora atribuida a la Ciencia y Tecnología y el determinismo

\footnotetext{
${ }^{6}$ Surgen en un momento histórico, de transferencia tecnológica, en el que se emprende una crítica que cuestiona el modelo de industrialización, sus representantes Varsavsky $(1969,1976)$,Herrera $(1971,1973)$ y Sábato (1982) entre otros, quienes eran en su mayoría investigadores en el campo de las Ciencias Naturales de universidades Argentinas, quienes desde la década de los 60 y 70 afirmaban que el proceso de transferencia de tecnología, no se transferían herramientas neutras: se transfería un modelo de sociedad (Auler \& Delizoicov, 2015).
} 
tecnológico alimentan el modelo tradicional/lineal de progreso; y la segunda refleja la manera como los problemas que se investigan atienden a las particularidades de una sociedad, por tanto son importantes en ese contexto espacio temporal y al no ser seleccionadas como problemas de investigación no contribuyen en la atención de las problemáticas.

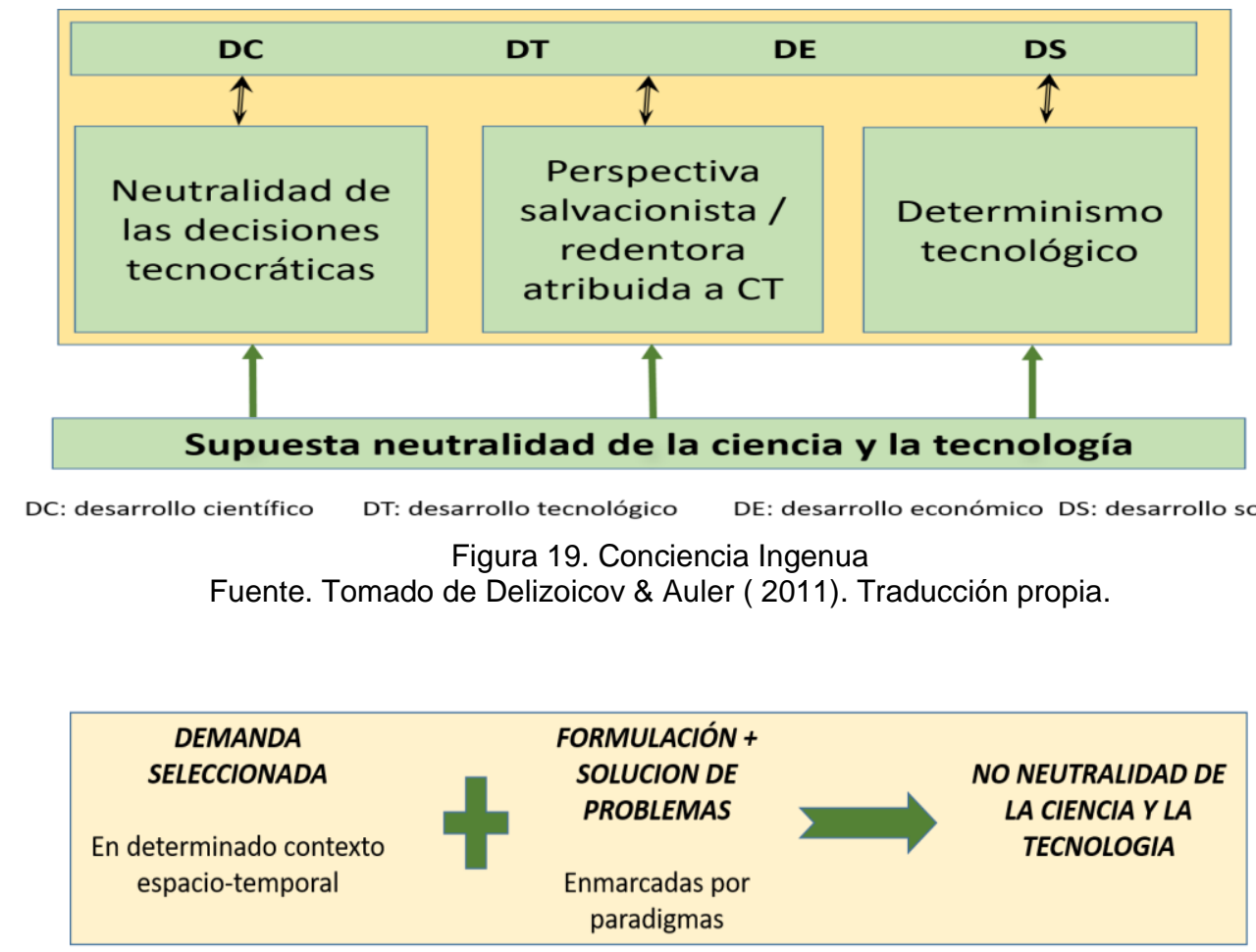

Figura 20. No neutralidad de la Ciencia y la Tecnología Fuente. Auler (2007, p.10). Traducción propia.

En general, en el contexto Latinoamericano la emergencia de la enseñanza de las ciencias con enfoque CTS es de naturaleza crítica (Martínez, 2012) y humanística (Santos, 2008), en la que evidencia la necesidad de que los ciudadanos lideren y participen de las discusiones públicas sobre las implicaciones sociales, políticas, éticas y ambientales de la Ciencia y la Tecnología.

Por tanto, pensar en la enseñanza de las ciencias desde la práctica del profesor, requiere la participación activa del mismo como sujeto investigador, para definir las estrategias de enseñanza, los problemas a abordar, los contenidos curriculares y 
extracurriculares, los objetivos de aprendizaje y de formación humana. Lo anterior implica todo un proceso de planeación de aula, articulado al currículo, al Proyecto Educativo Institucional (PEI) donde se contextualiza la práctica pedagógica y didáctica; Así como Castro, Santos, Rosa, \& Auler (2015) proponen: lograr una aproximación curricular Freire-CTS estructurando el currículo en torno a temáticas o problemas reales, planeadas en forma interdisciplinar y cuyos resultados sean la búsqueda de la democratización de procesos decisorios, un currículo que potencializa la cultura de la participación y disminuye la repitencia, la evasión y la exclusión.

Para Martínez (2012), la idea del profesor como sujeto activo de su propia práctica es una construcción que requiere establecer relaciones con sus pares como son los profesores de su misma área, profesores de otras áreas, administradores educativos e investigadores que interactúan en espacios sociales e históricos.

Para Santos \& Mortimer (2016), la principal característica del currículo de enfoque CTS es formar ciudadanos científicamente informados, capaces de tomar decisiones, actuar, debatir, posicionarse, comprender lo que está en juego en el discurso de los especialistas, ayudar en la toma de decisiones sobre problemáticas socio ambiéntales en las que está inmersos; además de promover el diálogo, favorecer el desarrollo del raciocinio crítico y la autonomía intelectual.

En la enseñanza con abordaje CTSA el centro de atención y de acompañamiento es el estudiante en contraposición a la enseñanza tradicional, que se centra en los contenidos, pero para darse este panorama, la escuela debe abrir sus puertas a la comunidad, al medio social del estudiante, lo que implica revisar los tiempos y propuestas curriculares que en la mayoría de los casos presentan contenidos acabados y centrados en las disciplinas, sin mayores espacios discursivos. De esta forma, la enseñanza de las ciencias en el contexto CTSA tiene un papel transformador, que podría contribuir a la formación de ciudadanos, a atender las 
orientaciones curriculares, de tal manera que favorezca la construcción de conocimientos escolares y el desarrollo de habilidades de pensamiento crítico como la síntesis, la reflexión crítica y la evaluación de sus propias ideas ante situaciones que involucren posiciones sociales y éticas.

Pedretti \& Nazir (2011), afirman que hay mucha confusión en torno al eslogan de CTSA independiente de ser utilizado por muchos educadores en el mundo, por tal razón, elaboran una matriz que permite realizar un análisis crítico de las perspectivas y prácticas en las que se ha abordado en enfoque CTSA en los últimos cuarenta años (tabla 4), en ella se visibiliza la importancia que se ha dado a la alfabetización científica de una forma generalizada como herramienta de toma de decisiones fundamentada, de desarrollo de capacidad de análisis de información y para el establecimiento de relaciones entre ciencia, ética y raciocinio moral; también deja ver como las CSC constituyen una fuente de comprensión significativa de las relaciones CTSA.

Las corrientes de enseñanza categorizadas por Pedretti \& Nazir (2011), ofrecen una escala de oportunidades para contextualizar la enseñanza de las ciencias en el escenario CTSA, pero también muestran el fortalecimiento que se da al desarrollo tecnológico como alternativa de solución para la mayoría de problemas sociales, al igual que mantiene una imagen de ciencia libre de valores universales y de la imagen estereotipada de los científicos (Matos, 2014).

Otro aporte interesante para el abordaje CTS en el contexto Latinoamericano lo ofrece la investigación de Strieder (2012), que establece una matriz donde relaciona CTS con los propósitos de la educación científica, a la que aporta una articulación de CTSA como referente epistemológico y didáctico/pedagógico, como se observa en la figura 21. Dicho aporte plantea tres categorías para el aspecto epistemológico: racionalidad científica, desarrollo tecnológico y participación social 
y para los propósitos de la educación en ciencias plantea: las percepciones, los cuestionamientos y el compromiso social.

\title{
RELACIONES CTS
}

\author{
PROPÓSITOS \\ EDUCACIONALES
}

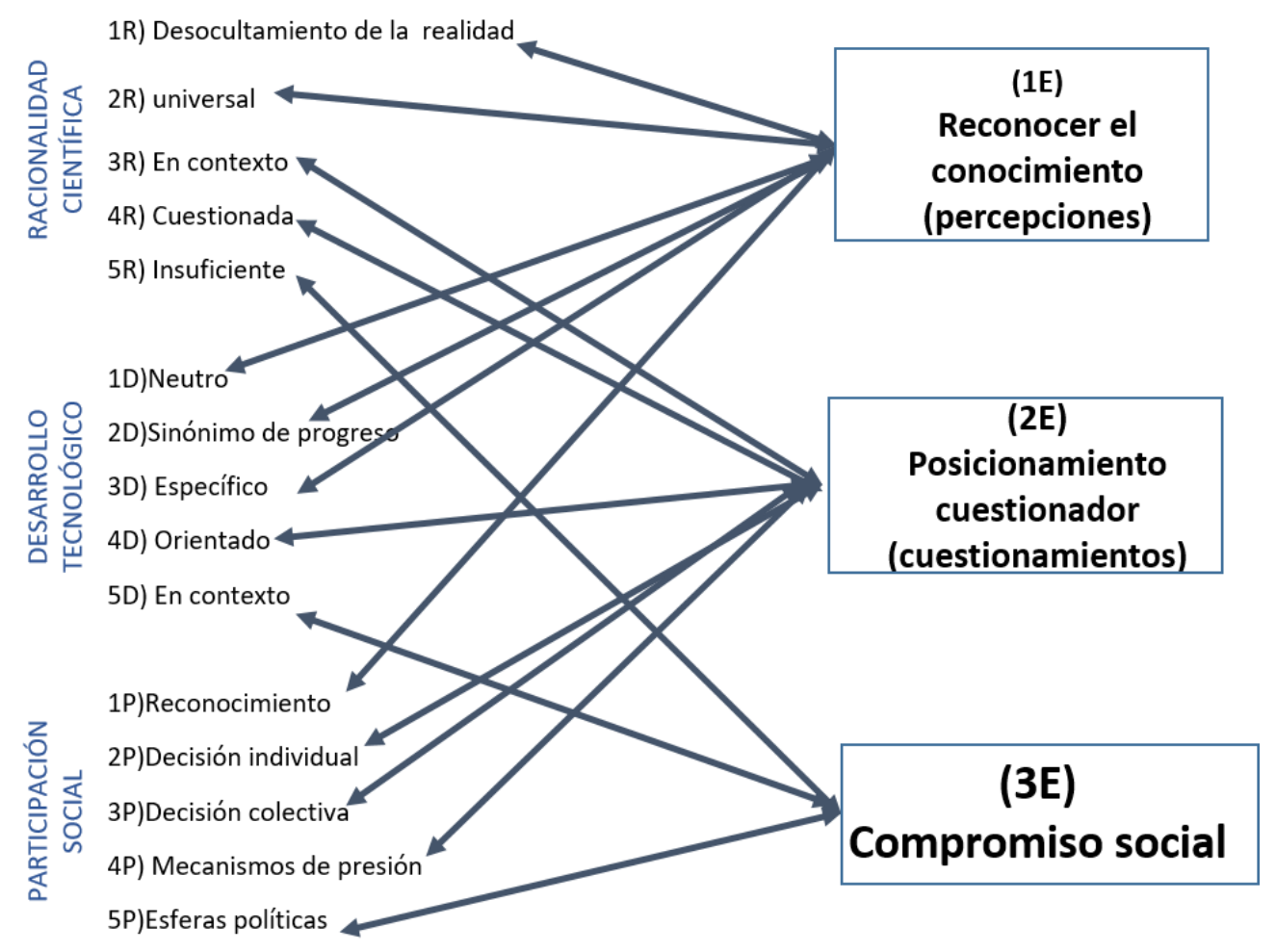

Figura 21. Articulación entre parámetros CTS y propósitos educacionales Fuente. Strieder (2012). Traducción propia 
Tabla 4. Perspectivas de enseñanza CTSA

\begin{tabular}{|c|c|c|c|c|}
\hline $\begin{array}{l}\text { PERSPECTIVA } \\
\text { DE ENSENAANZA }\end{array}$ & FOco & $\begin{array}{l}\text { OBJETIVOS DE LA EDUCACION } \\
\text { CIENTIFICA }\end{array}$ & $\begin{array}{l}\text { ESTRATEGIAS } \\
\text { METODOLÓGICAS }\end{array}$ & EJEMPLO DE ESTRATEGIAS \\
\hline 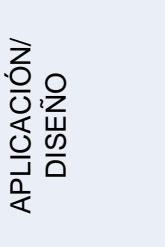 & $\begin{array}{l}\text { Solución de problemas } \\
\text { mediante el diseño de nueva } \\
\text { tecnología o la modificación de } \\
\text { la tecnología existente con } \\
\text { énfasis en la investigación y las } \\
\text { habilidades }\end{array}$ & $\begin{array}{l}\text { Utilitario - Práctico } \\
\text {-Resolución de problemas } \\
\text {-Transmisión de disciplina } \\
\text { conocimiento y habilidades } \\
\text { técnicas }\end{array}$ & $\begin{array}{l}\text { Cognitivo } \\
\text { Experimental } \\
\text { Pragmático } \\
\text { Creativo }\end{array}$ & $\begin{array}{l}\text { Aprendizaje basado en problemas } \\
\text { Diseñar y construir } \\
\text { Artefactos }\end{array}$ \\
\hline 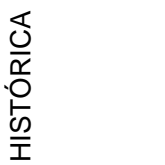 & $\begin{array}{l}\text { Comprender el arraigo histórico } \\
\text { y sociocultural de las ideas } \\
\text { científicas y el trabajo de los } \\
\text { científicos }\end{array}$ & $\begin{array}{l}\text { Logro cultural e intelectual } \\
\text { Valor intrínseco (interesante, } \\
\text { emocionante, necesario) }\end{array}$ & $\begin{array}{l}\text { Creativo } \\
\text { Reflexivo } \\
\text { Afectivo }\end{array}$ & $\begin{array}{l}\text { Casos históricos } \\
\text { Juego de roles } \\
\text { Drama } \\
\text { Simulaciones }\end{array}$ \\
\hline 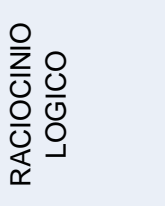 & $\begin{array}{l}\text { Comprender los problemas } \\
\text { Toma de decisiones sobre } \\
\text { cuestiones sociocientíficas a } \\
\text { través de la consideración de } \\
\text { evidencia empírica }\end{array}$ & $\begin{array}{l}\text { Ciudadanía } \\
\text { Responsabilidad cívica } \\
\text { Toma de decisiones } \\
\text { (personal y social) } \\
\text { Transacción de ideas }\end{array}$ & $\begin{array}{l}\text { Reflexivo } \\
\text { Cognitivo }\end{array}$ & $\begin{array}{l}\text { Uso de cuestiones socio-científicas - Análisis de } \\
\text { riesgo / beneficio - Análisis de los interesados } \\
\text {-Uso de modelos de argumentación - Modelos de } \\
\text { toma de decisiones - Debates }\end{array}$ \\
\hline 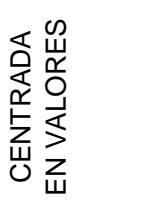 & $\begin{array}{l}\text { Comprender los problemas } \\
\text { Toma de decisiones sobre } \\
\text { cuestiones sociocientíficas a } \\
\text { través de la consideración de la } \\
\text { ética y el razonamiento moral }\end{array}$ & $\begin{array}{l}\text { Ciudadanía } \\
\text { Responsabilidad cívica } \\
\text { Toma de decisiones } \\
\text { (personal y social) } \\
\text { Transacción de ideas }\end{array}$ & $\begin{array}{l}\text { Afectivo } \\
\text { Moral } \\
\text { Lógico } \\
\text { Crítico }\end{array}$ & $\begin{array}{l}\text {-Estudios de caso -Análisis de cuestiones } \\
\text { sociocientíficas - Uso de marcos filosóficos } \\
\text { morales - Clarificación de valores } \\
\text { - Toma de decisiones morales }\end{array}$ \\
\hline 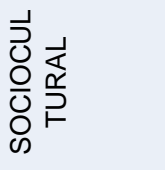 & $\begin{array}{l}\text { Comprender que la ciencia y la } \\
\text { tecnología existen en un } \\
\text { contexto sociocultural más } \\
\text { amplio }\end{array}$ & $\begin{array}{l}\text { Logro cultural e intelectual } \\
\text { Transacción de ideas }\end{array}$ & $\begin{array}{l}\text { Holístico } \\
\text { Reflexivo } \\
\text { Experimental } \\
\text { Afectivo }\end{array}$ & $\begin{array}{l}\text { Estudios de caso - Uso de cuestiones socio- } \\
\text { científicas - Inclusión de alternativa - sistemas de } \\
\text { conocimiento, por ejemplo, tradicional y espiritual } \\
\text { - Cuenta cuentos -Currículo integrado }\end{array}$ \\
\hline 은 & $\begin{array}{l}\text { Criticando / resolviendo } \\
\text { problemas sociales y } \\
\text { ecológicos a través de la } \\
\text { acción o acción humana }\end{array}$ & $\begin{array}{l}\text { Ciudadanía } \\
\text { Responsabilidad cívica } \\
\text { Resolución de problemas } \\
\text { Transformación / agencia / } \\
\text { emancipación }\end{array}$ & $\begin{array}{l}\text { Creativo } \\
\text { Afectivo } \\
\text { Reflexivo } \\
\text { Crítico } \\
\text { Experimental }\end{array}$ & $\begin{array}{l}\text { Uso de cuestiones socio-científicas - Estudios de } \\
\text { caso - Proyectos comunitarios- Debates } \\
\text {-Desarrollando planes de acción- Uso de } \\
\text { contextos locales y globales }\end{array}$ \\
\hline
\end{tabular}

Fuente. Pedretti \& Nazir (2011, p. 607-608). Traducción propia. 
Los parámetros epistemológicos según Strieder (2012), representan interfaces entre Ciencia Tecnología Sociedad y Ambiente pensadas en el contexto de enseñanza de las ciencias, enfatizando que la interacción CTSA no es simplemente una unión de contenidos científicos y tecnológicos articulados a cuestiones sociales. De igual manera Pedretti \& Nazir (2011) plantean la complejidad en el establecimiento de relaciones CTSA, sin embargo, muestran que la racionalidad científica aunque está relacionada con la ciencia, no se reduce a ella, la crítica no está centrada en la ciencia, pero sí en el "modelo" planteado socialmente; lo mismo sucede con el desarrollo tecnológico (relacionado con la tecnología) en el que el problema está en "el modelo de desarrollo" que viene asociado al "modelo de ciencia y sociedad", así mismo no se pueden determinar posibilidades de participación social en ese contexto, pero sí del papel que tiene la sociedad en ese mundo científico y tecnológico racional y desarrollista.

Para cada uno de los parámetros o categorías epistemológicas Strieder (2012) asoció un nivel de desarrollo, que permite comprender la complejidad de las relaciones CTSA, ofreciendo además al investigador (profesores de diferente contexto educativo) un mapa de relaciones e interacciones bien sea para comprender la complejidad de las mismas, o para dar sentido a su práctica de aula y trabajo del investigador al articularlas a los propósitos educacionales planteados en la misma matriz o contextualizados local, nacional o globalmente como se observa en la figura 22. 


\begin{tabular}{|c|c|c|c|c|}
\hline & Niveles & RELACIONES CTS & $\begin{array}{l}\text { PROPÓSITOS } \\
\text { EDUCACIONALES }\end{array}$ & \\
\hline \multirow{5}{*}{ 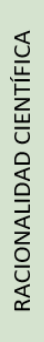 } & Ciencia para comprender el mundo & $\begin{array}{l}\text { 1R) Desocultamiento de } \\
\text { la realidad }\end{array}$ & \multirow{5}{*}{ 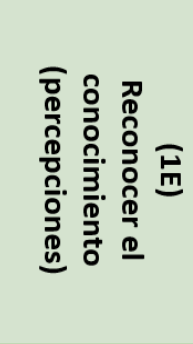 } & \multirow{5}{*}{$\begin{array}{l}\text { El desarrollo de percepciones } \\
\text { Implica buscar elementos que } \\
\text { contribuyan a la ilustración, } \\
\text { aplicación y ejemplificación del } \\
\text { conocimiento científico escolar }\end{array}$} \\
\hline & Ciencia buena o mala & 2R) universal & & \\
\hline & Ciencia vulnerable provisional & 3R) En contexto & & \\
\hline & $\begin{array}{l}\text { Ciencia limitada por las prácticas } \\
\text { sociales }\end{array}$ & 4R) Cuestionada & & \\
\hline & Ciencia insuficiente & 5R) Insuficiente & & \\
\hline \multirow{5}{*}{ 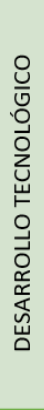 } & $\begin{array}{l}\text { Tecnología: Todo aparato presente } \\
\text { en la sociedad }\end{array}$ & 1D)Neutro & \multirow{5}{*}{ 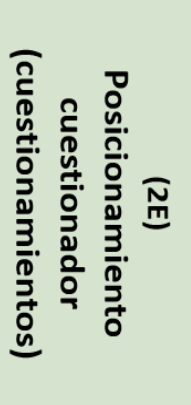 } & \multirow{5}{*}{$\begin{array}{l}\text { El desarrollo de cuestionamientos } \\
\text { implica la defensa por la } \\
\text { comprensión de cuestiones sociales } \\
\text { relacionadas con la ciudadanía, } \\
\text { aunque no controvertidas, pero } \\
\text { compartidas ampliamente y } \\
\text { consideradas como problemáticas } \\
\text { en la sociedad actual; más que } \\
\text { contextualizar el conocimiento } \\
\text { científico escolar, busca discutir, } \\
\text { por ejemplo, beneficios y maleficios } \\
\text { de los productos de la ciencia. }\end{array}$} \\
\hline & Ciencia aplicada & $\begin{array}{l}\text { 2D)Sinónimo de } \\
\text { progreso }\end{array}$ & & \\
\hline & Clase de conocimiento & 3D) Específico & & \\
\hline & Tecnología con propósitos políticos & \multirow{2}{*}{ 4D) Orientado } & & \\
\hline & $\begin{array}{l}\text { Tecnología que suple las } \\
\text { necesidades básicas }\end{array}$ & & & \\
\hline \multirow{5}{*}{ 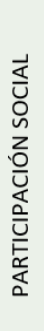 } & $\begin{array}{l}\text { Reconocimiento de la presencia de } \\
\text { la CT en la sociedad }\end{array}$ & 1P)Reconocimiento & \multirow{5}{*}{$\begin{array}{lll}n & 3 & \\
0 & 0 & \omega \\
0 & 0 & m\end{array}$} & \multirow{5}{*}{$\begin{array}{l}\text { El desarrollo de compromisos } \\
\text { sociales implica el desarrollo de } \\
\text { competencias para que la sociedad } \\
\text { pueda lidiar con problemas de } \\
\text { diferentes naturalezas, teniendo } \\
\text { condiciones de hacer una lectura } \\
\text { crítica de la realidad que } \\
\text { actualmente está marcada por } \\
\text { desequilibrios sociales, políticos, } \\
\text { éticos, culturales y ambientales. }\end{array}$} \\
\hline & Discusión de riesgos y beneficios & 2P)Decisión individual & & \\
\hline & $\begin{array}{l}\text { Discusión de problemas e impactos } \\
\text { y las transformaciones }\end{array}$ & 3P)Decisión colecti & & \\
\hline & Identificación de contradicciones & $\begin{array}{l}\text { 4P) Mecanismos de } \\
\text { presión }\end{array}$ & & \\
\hline & Compresión y discusión de políticas & 5P)Esferas políticas & & \\
\hline
\end{tabular}

Figura 22. Matriz de relación entre parámetros CTSA y educacionales por niveles de complejidad Fuente. Autora con base en Strieder (2012) y Strieder \& Kawamura (2014)

Strieder \& Kawamura (2014) comentan, que a partir de la revisión de cada una de las categorías planteadas (racionalidad, desarrollo y participación) se establecen diferentes abordajes CTSA, que al ser presentadas de manera desarticulada se relacionan, pero lo que guía y da sentido a dicha articulación, son los distintos propósitos educacionales que están asociados al desarrollo de las percepciones, de los cuestionamientos y compromisos sociales considerados como los referentes pedagógicos y didácticos. En palabras de Strieder (2012):

Una educación científica que contribuya al desarrollo de percepciones entre el conocimiento científico escolar y el contexto del alumno. Relacionándose con la 
construcción de una nueva imagen de conocimiento científico escolar, dando énfasis tanto a los cuestionamientos presentes en el día a día, como a las cuestiones científicas y tecnológicas. En ese caso, los aspectos más relacionados a la ciencia, a la tecnología y a la sociedad contribuyen para contextualizar el conocimiento científico a ser trabajado, buscando una aproximación a la vivencia cotidiana del alumno.

Una educación científica que contribuya al desarrollo de cuestionamientos sobre situaciones que implique aspectos científicos, tecnológicos y/o sociales. Más que contextualizar el conocimiento científico escolar, pretende discutir las implicaciones del desarrollo científico-tecnológico en la sociedad, busca una comprensión sobre la utilización responsable de los recursos naturales y aparatos tecnológicos.

Una educación científica que contribuya $\mathrm{m}$ ante problemas aun no establecidos y que involucra aspectos de ciencia, tecnología y sociedad. La mayor intención, está relacionada al desarrollo de competencias para que la sociedad pueda lidiar con problemáticas de diferente naturaleza, teniendo condiciones para hacer una lectura crítica de la realidad que, actualmente, está marcada por desequilibrios sociales, políticos, éticos culturales y ambientales (p.166-167)

Es de resaltar que las articulaciones entre CTS como referente epistemológico y los propósitos educacionales como referentes pedagógico/didáctico, explicitados en la matriz diseñada por Strieder (2012) y visualizadas en la figura 15 y 16 , ofrecen un fundamento teórico y un instrumento práctico a los profesores para que, como seres políticos, con autonomía y participación, contextualicen sus prácticas de aula a través de la sistematización y reflexión colectiva de dichas perspectivas.

Levinson (2006a, 2008, 2010), Pedretti \& Nazir (2011) y Strieder (2012) entre otros, también organizan las investigaciones realizadas en el campo CTSA, ofreciendo diversos panoramas de reflexión. Así pues, se evidencia una relación análoga de lo que sucede en el mundo real con el mundo escolar, posibilitando al 
profesor una forma e comprender cómo se construye el conocimiento científico y el conocimiento escolar.

Los aspectos descritos permiten ampliar la matriz de Strieder, pero resaltando la posibilidad que ofrece el abordaje de CSC (Figura 17) en la formación de profesores con sentido crítico, que al trabajar y reflexionar en forma colectiva comprenden la complejidad de las relaciones CTSA y las posibilidades que ofrece para formar ciudadanos críticos, participativos, capaces de organizarse y tomar decisiones frente a las diversas problemáticas que suceden o que pueden suceder y que tienen repercusiones desde lo local, nacional y global.

Como ya se había mencionado, en Levinson (2006a), las CSC al ser introducidas en los currículos como forma de discusión y comprensión de los dilemas sociales relacionados con la ciencia y la tecnología, eran de naturaleza más social, se debatían en torno a la situación controversial, no necesariamente a las implicaciones relacionadas con la ciencia y la tecnología, temáticas como el "antirracismo y el multiculturalismo" eran un ejemplo, posteriormente por los avances en el campo de la ingeniería genética, surge la necesidad de debatir en torno de la bioética.

Autores como Zeidler, Sadler, Simmons, \& Howes (2005) realizan la distinción entre el movimiento CTS y los currículos articulados con CSC, mencionando que el primero prioriza el impacto de la ciencia y la tecnología en la sociedad, dejando de lado las implicaciones morales y éticas que son la base de las CSC; sin embargo, Pedretti \& Nazir (2011) reconocen que aunque para estos autores el movimiento CTSA es limitante en los aspectos mencionados, comparten prácticas similares, además de reconocer la importancia de la alfabetización científica y tecnología para la toma de decisiones fundamentadas, por el contrario lo que se devela es la complementariedad y reciprocidad de las CSC con el campo CTSA. 
Sadler (2004) menciona que el abordaje de CSC, necesariamente implica raciocinio informal, ya que atienden a son problemas complejos, abiertos, polémicos, sin solución predeterminada, mientras que Zeidler et al. (2005) sugiere que el raciocinio informal basado en emociones durante la toma de decisiones, puede tener estructuras lógicas y coherentes tanto como las que se basan en raciocinios formales.

Los referentes epistemológicos de la matriz propuesta por Strieder (2012) permiten evidenciar la proximidad y complementariedad de las interacciones CTSA y las CSC como se evidencia en la figura 23 , en la que cada una de las características de las CSC propuestas por Ratcliffe \& Grace (2003) interactúan con los elementos de la racionalidad científica, técnica y social, a la vez que se articulan a los niveles y propósitos de la educación científica. Por tanto las CSC permiten una comprensión más amplia y profunda de CTSA, favorecen la formación de ciudadanos para la actuación en la sociedad democrática y evidencian como se articulan las decisiones a valores éticos y morales. 


\begin{tabular}{|c|c|c|c|c|c|}
\hline & Niveles & RELACIONES CTS & $\begin{array}{c}\text { PROPÓSITOS } \\
\text { EDUCACIONAL } \\
\text { ES }\end{array}$ & & CSC \\
\hline \multirow{5}{*}{ 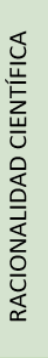 } & $\begin{array}{l}\text { Ciencia para comprender el } \\
\text { mundo }\end{array}$ & $\begin{array}{l}\text { 1R) Desocultamiento } \\
\text { de la realidad }\end{array}$ & \multirow{5}{*}{ 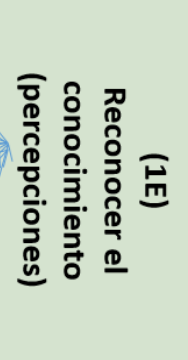 } & \multirow{5}{*}{$\begin{array}{l}\text { El desarrollo de } \\
\text { percepciones Implica buscar } \\
\text { elementos que contribuyan } \\
\text { a la ilustración, aplicación y } \\
\text { ejemplificación r del } \\
\text { conocimiento científico } \\
\text { escolar }\end{array}$} & Base científica /conocimientos de frontera \\
\hline & Ciencia buena o mala & 2R) universal & & & $\begin{array}{l}\text { Pueden requerir algún entendimiento de probabilidad } \\
\text { y riesgo }\end{array}$ \\
\hline & Ciencia vulnerable provisional & 3R) En contexto & & & Poco delimitadas, abordadas multidisciplinarmente y \\
\hline & $\begin{array}{l}\text { Ciencia limitada por las prácticas } \\
\text { sociales }\end{array}$ & 4R) Cuestionada & & & mecuememente comirovertiads \\
\hline & Ciencia insuficiente & 5R) Insuficiente & & & $\begin{array}{l}\text { Tienen información incompleta, hay lagunas en los } \\
\text { registros de datos, informes }\end{array}$ \\
\hline \multirow{5}{*}{ 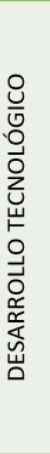 } & $\begin{array}{l}\text { Tecnología: Todo aparato } \\
\text { presente en la sociedad }\end{array}$ & 1D)Neutro & \multirow{5}{*}{ 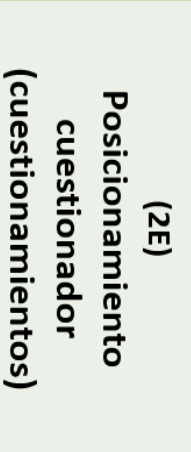 } & \multirow{5}{*}{$\begin{array}{l}\text { El desarrollo de cuestionamientos } \\
\text { implica la defensa por la } \\
\text { comprensión de cuestiones } \\
\text { sociales relacionadas con la } \\
\text { ciudadanía, aunque no } \\
\text { controvertidas, pero compartidas } \\
\text { ampliamente y consideradas } \\
\text { como problemáticas en la } \\
\text { sociedad actual; más que } \\
\text { contextualizar el conocimiento } \\
\text { científico escolar, busca discutir, } \\
\text { por ejemplo, beneficios y } \\
\text { maleficios de los productos de la } \\
\text { ciencia. }\end{array}$} & \\
\hline & Ciencia aplicada & $\begin{array}{l}\text { 2D)Sinónimo de } \\
\text { progreso }\end{array}$ & & & $\begin{array}{l}\text { Involucran productos tecnológicos que tiene impacto } \\
\text { en contextos sociales y ambientales }\end{array}$ \\
\hline & Clase de conocimiento & 3D) Específico & & & \\
\hline & $\begin{array}{l}\text { Tecnología con propósitos } \\
\text { políticos }\end{array}$ & 4D) Orientado & & & $\begin{array}{l}\text { Implican un análisis de costo beneficio en el cual los } \\
\text { riesgos interactúan con los valores }\end{array}$ \\
\hline & $\begin{array}{l}\text { Tecnología que suple las } \\
\text { necesidades básicas }\end{array}$ & 5D) En contexto & & & $\begin{array}{l}\text { Pueden involucrar consideraciones sobre la } \\
\text { sustentabilidad. }\end{array}$ \\
\hline \multirow{5}{*}{ 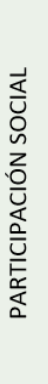 } & Reconocimiento de la presencia & 1P)Reconocimiento & \multirow{5}{*}{ 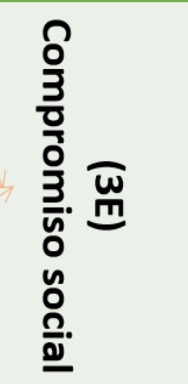 } & \multirow{5}{*}{$\begin{array}{l}\text { El desarrollo de compromisos } \\
\text { sociales implica el desarrollo de } \\
\text { competencias para que la } \\
\text { sociedad pueda lidiar con } \\
\text { problemas de diferentes } \\
\text { naturalezas, } \\
\text { condiciones de hacer una lectura } \\
\text { crítica de la realidad que } \\
\text { actualmente está marcada por } \\
\text { desequilibrios sociales, políticos, } \\
\text { éticos, culturales y ambientales. }\end{array}$} & Implica valores de raciocinio ético \\
\hline & Discusión de riesgos y beneficios & 2P)Decisión individual & & & $\begin{array}{l}\text { Implica la formación de opiniones y la realización de } \\
\text { lecciones personales y social }\end{array}$ \\
\hline & $\begin{array}{l}\text { Discusión de problemas e } \\
\text { impactos y las transformaciones }\end{array}$ & 3P)Decisión colectiva & & & $\begin{array}{l}\text { Frecuentemente divulgados por los medios masivos de } \\
\text { comunicación, destacando los intereses de los mismos. }\end{array}$ \\
\hline & Identificación de contradicciones & $\begin{array}{l}\text { 4P) Mecanismos de } \\
\text { presión }\end{array}$ & & & Lidian con problemas locales, nacionales y globales en \\
\hline & $\begin{array}{l}\text { Compresión y discusión de } \\
\text { políticas }\end{array}$ & 5P)Esferas políticas & & & \\
\hline
\end{tabular}

Figura 23. Referentes CTSA, principios educativos de enseñanza de las ciencias y CSC

Fuente. Autora con base en (R. Levinson, 2010; Martínez, 2014; Pedretti \& Nazir, 2011; Ratcliffe \& Grace, 2003a; Strieder, 2012) 
Esta interfaz CTSA/CSC viene siendo utilizada como metodología de enseñanza que promueve la formación de ciudadanos críticos, que toman decisiones acerca de cuestiones controversiales que involucran la ciencia y la tecnología, que además integran conocimientos de orden multidisciplinar, están cargadas de valores que exigen posicionamientos individuales y colectivos, que las hace potencialmente propulsoras de participación socio política en un contexto cultural, social, económico y político (Martínez, 2014).

Binatto, Chapani, \& Duarte (2015) analizan los presupuestos teóricos y las posibles contribuciones del enfoque CTSA a la formación reflexiva de profesores con perspectiva crítica, encontrando que hay una relación entre estas referencias (CTSA/formación reflexiva), consideran la enseñanza y el aprendizaje de los docentes como prácticas sociales sustentadas por principios ético-políticos que deben ser explícitos en los procesos formativos; consideran la ciencia y la tecnología como un aspecto importante que incide en la organización del pensamiento e interviene en la sociedad y por lo tanto, se asume en forma crítica; valorizan la democracia y toman la educación como una forma de emancipación.

La formación continuada de profesores podría enfocarse bajo la perspectiva CTSA con orientación reflexiva y crítica, convirtiéndose en un escenario interdisciplinar, cuyo trabajo colectivo desarrollaría estudios y propuestas de investigación en equipo de docentes, permitiendo implementar propuestas con enfoque CTSA en sus aulas de clase, y llegar a constituirse como una propuesta de formación institucional que favorece la inserción y permanencia de los profesores (Binatto et al., 2015).

Al respecto, Correa \& Bazzo (2017) mencionan que ante los actuales modelos de formación hegemónicos que priorizan la competición, minimizan las cuestiones humanas y llevan al sujeto al conformismo y la obediencia (sumisión y resignación) es necesario el planteamiento de procesos de formación de 
profesores en el contexto CTSA que contribuya con ambientes de aprendizaje colaborativos, que promuevan la cooperación, la humanización y el posicionamiento crítico con respecto a los procesos civilizatorios actuales, mencionando además que la formación de profesores en el contexto CTSA no puede limitarse a los profesores de ciencia, tecnología o áreas afines, debe ser abordado también los profesores de las ciencias humanas y sociales, entre otras, dada la centralidad de los cambios científicos y tecnológicos en el día a día.

La perspectiva CTSA en los procesos de formación docente, va más allá de las cuestiones relativas a la incorporación de estudiantes en el mercado de trabajo o de procesos de formación permanente, ella debe ampliar las condiciones para hacer un análisis que reconozca el aspecto humano, así como las implicaciones que acarrea el desarrollo científico y tecnológico en la sociedad. Desafortunadamente, como los cambios son graduales, los profesores como los demás trabajadores se acostumbran, se ajustan a las situaciones, mostrando poca o ninguna reacción ante dichas problemáticas, así que terminan aceptándolas e intensificándolas, limitando la calidad de vida humana (Vilches et al., 2008).

Pinheiro, Silveira, \& Bazzo (2007), afirman que los medios de comunicación, al igual que el sistema económico vigente, contribuyen en mantener el statuquo, principalmente por la existencia de políticas poco transparentes, empresariales e industriales que irrespetan y desvalorizan el trabajo humano, la alienación social fruto de las necesidades humanas, la desigualdad e injusticia social, la evaluación excluyente que clasifica a los profesionales arbitrariamente, y como afirma Correa \& Bazzo (2017), los profesores por falta de financiamiento en lugar de estar escribiendo libros, investigando, orientado críticamente a los alumnos, perpetúan las normas al seguir una realidad llena de criterios establecidos por un grupo de burócratas que creen que esta forma competitiva basada en números, es el camino efectivo de la educación. 
En relación con lo anterior, Conrado \& El-Hani (2010) mencionan que el profesor tiende a mantener una posición subordinada, porque las habilidades relacionadas al desarrollo del pensamiento crítico y la capacidad de discutir e investigar sobre informaciones relevantes para resolver problemáticas posiblemente nunca fueron abordadas en el proceso de formación básica y muchas veces ni siquiera a nivel superior, creando lagunas entre la técnica y el desarrollo humano de los sujetos.

La formación de docentes en contexto CTSA abordando CSC, posiblemente puede contribuir para develar las contradicciones de la realidad, buscando comprenderlas para posiblemente propiciar su superación, siempre que el referente sea mantener la calidad de vida de todos los seres que habitan el planeta. En este contexto Bazzo \& Bazzo (2011) afirma:

[...] CTS se configura en la triada -ciencia-tecnología-sociedad- más compleja que una simple serie sucesiva, lo que exige un análisis de sus relaciones reciprocas con mayor rigor de lo que requeriría la ingenia aplicación de la clásica relación entre ellas. En relación a la educación, [...] es la responsable de mantener y perpetuar la cultura los valores éticos y morales de un determinado grupo humano circunscrito por el tiempo/espacio, por las interconexiones y situaciones socio/históricas, así como por la promoción de cambios que hacen necesarios a el progreso de la calidad de vida de los humanos. (p.5)

En ese sentido para Correa \& Bazzo (2017), la formación de docentes en forma interdisciplinar y con enfoque CTSA favorece la formación de profesores críticos, capaces de transformar la realidad educativa, permitiendo que los estudiantes bajo su orientación puedan establecer conexiones entre lo aprendido y las situaciones cotidianas, proporcionando oportunidades para interactuar con el medio, debatir y platear soluciones a los problemas sociales en los que están inmersos. Recalcando además, que una educación emancipadora pasa por la concepción, formación y actitud de los profesores, quienes tienen el papel de crear espacios 
dialógicos, de reflexión, de cuestionamiento, de poder decisorio sobre las acciones y soluciones socialmente construidas.

En este sentido, la formación de profesores como profesionales críticos y reflexivos en el contexto del enfoque CTSA utilizando CSC puede constituirse en un derrotero que guie la educación y en especial la enseñanza de la ciencias, es a través de ella que se lograrán cambios significativos en la calidad de vida de la población, son los profesores quienes a través de sus instituciones de formación contribuyan en la construcción de un tejido social más humano, participativo, respetuoso y humilde a partir de los conocimientos que han construido; en este sentido se establece una relación entre las características de las CSC, las categorías relevantes para la comprensión del CPP, los ejes DOC, el CPD y el CPD, las relaciones CTSA como se ve en la figura 24.

Lo anterior significa que, acorde a Strieder (2012) cuando el propósito educacional está orientado a favorecer el desarrollo del compromiso social, los saberes del profesor se categorizan como deseables, tendrá un EP transformador acorde a la HdPR será un profesor integrador siempre que busque discutir las limitaciones del conocimiento científico para comprender y plantear soluciones a los problemas sociales locales y hacerlos extensivos a las implicaciones globales, enfatizando la importancia de plantear y luchar por la apertura de otros modelos de desarrollo que satisfagan las necesidades básicas de la población, independientes del lucro económico sin desequilibrar la naturaleza, buscando una cultura de la participación como seres políticos. 


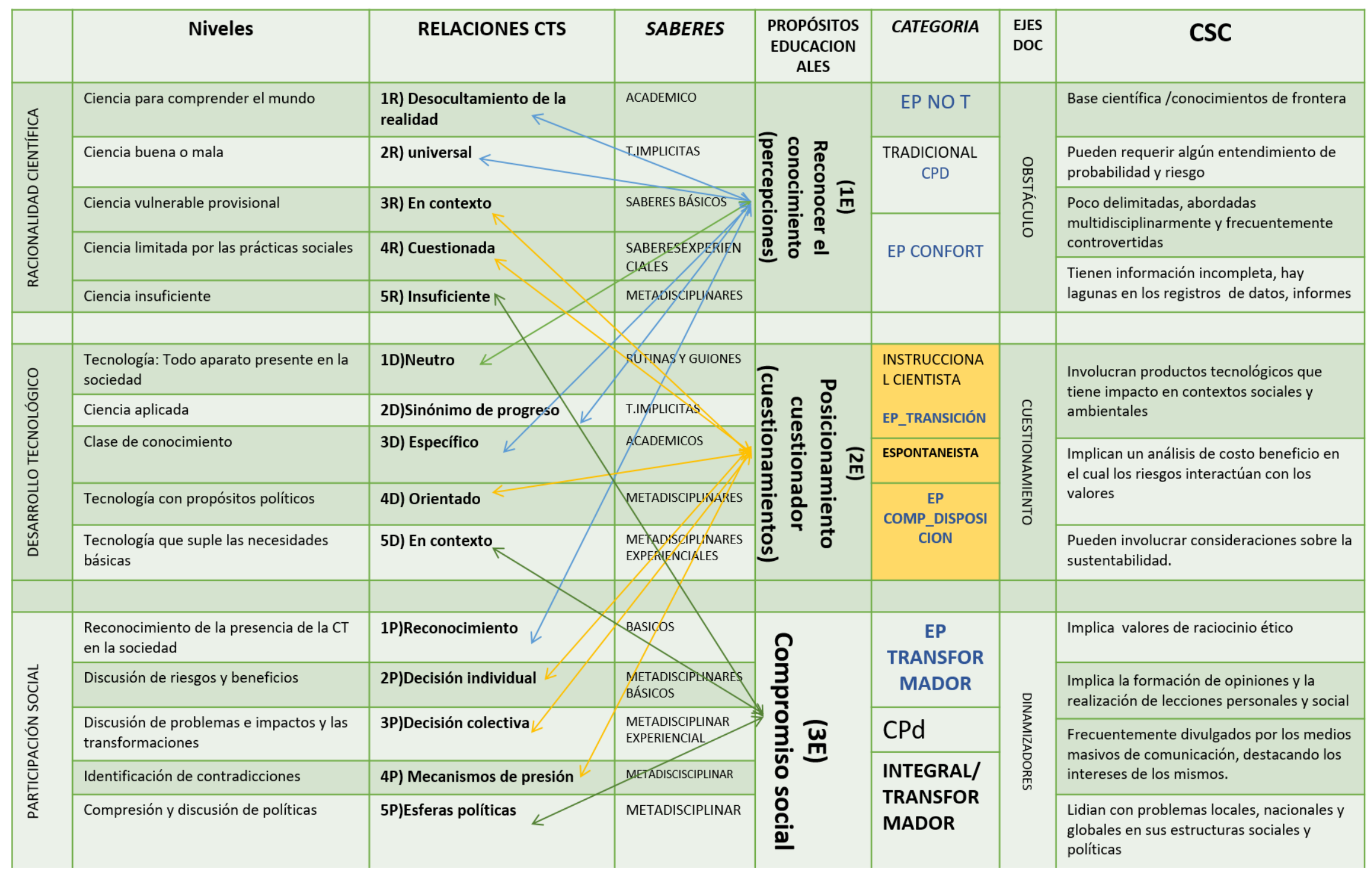

Figura 24. Relación entre CTSA, CSC y CPP

Fuente autora con mase en Martínez(2014), Martínez, (2016, 2017), Ratcliffe \& Grace (2003a), Strieder (2012), y Solís \& Rivero (2012) 
En este contexto, teóricamente CTSA favorece el CPP, ya que al abordar CSC asumiendo una postura crítica y humanizadora, el profesor está en la capacidad de evaluar los referentes epistemológicos en los que se basan sus saberes y los que retoma cuando construye el conocimiento escolar con los estudiantes, sus fuentes y criterios de selección ya no se limitarán al libro de texto ni al currículo, por el contrario, al no encontrar fuentes tradicionales, ni instruccionales, asumirá una postura crítica, considerará los obstáculos que se le presentan, siempre que esté en un proceso de diálogo permanente con sus pares y reflexivo consigo mismo.

La universidad en esta medida, es el escenario de reflexión, y debe constituirse como observatorio que ofrece a los profesores en formación inicial y continuada la posibilidad de orientar, transformar, investigar e innovar consecuentemente a la reflexión de su práctica investigativa colaborativa con pares académicos que lo forman o lo formaron, de tal manera que pueda configurar su conocimiento o un modelo transformador e integrador que favorezca el CPP.

Por lo anterior, se propuso un proceso de formación de docentes en ejercicio con enfoque CTSA abordando CSC que posibilitará el CPP deseable de los profesores del Gl a la luz de la epistemología Fleckiana, por tal razón, se presentan a continuación los aportes de dicha epistemología que se constituirá como uno de los referentes de análisis de la presente investigación.

Es pertinente mostrar el proceso de construcción de las relaciones CPP y CSC enunciadas en la figura 24 , algunas se incorporaron en la presente tesis y otras quedaron como semilleros de otras investigaciones que por su complejidad, no alcanzaron a quedar develadas pero que generan nuevas posibilidades de futuras investigaciones; así, uno de los presupuestos abordados fue la relación de las categorías epistemológicas (racionalidad científica, desarrollo tecnológico y participación social) con las características de las CSC, las categorías de análisis 
de la HpPR y las emergentes que se obtienen del análisis de datos en el contexto epistemológico de Fleck.

Por ejemplo, los profesores caracterizados con un EP en estado de confort evidencian que en sus intervenciones (talleres, entrevistas, debates, etc.) asumen que las CSC son conocimientos de frontera de la ciencia, que no tiene explicación en un solo campo disciplinar y que para contextualizarlos se analizan factores sociales, éticos, políticos, culturales, económicos, científico/tecnológicos y de riesgo (salud - ambiente) utilizando los referentes científicos para el desocultamiento de la realidad, es decir, como una forma de explicar lo que sucede en la realidad, en términos positivistas de ejemplificación, desde una visión positivista y no critica; por tanto, se hace evidente que el maestro tiene como propósito educacional reconocer el conocimiento, buscar dónde se evidencian los hechos que fundamentan determinado fenómeno o hecho en forma descontextualizada.

Lo anterior, para efectos del análisis de los datos, permite al investigador plantear que posiblemente las CSC en este caso se constituyen en un obstáculo para el CPP; sin embargo, el uso de la matriz, apenas evidencia la construcción de supuestos surgidos de las interacciones teóricas y de los resultados obtenidos, pero que posibilita a futuro un sinnúmero de investigaciones que se pueden desarrollar para intentar la comprensión del CPP y establecer HdPR que permitan diseñar estrategias que relacionen estos referentes epistemológicos con cada una de la CSC, los propósitos educacionales y el mismo CPP. 


\section{CAPÍTULO 3. EPISTEMOLOGÍA FLECKIANA}

Al considerar el CPP como un hecho particular y epistemológicamente diferenciado, se toma como referente a Ludwin Fleck, quien a partir de un estudio de caso de la reacción de Wasserman fundamenta la teoría social del conocimiento, que para el caso de la presente investigación posibilita la comprensión de la manera como el profesor construye el conocimiento entendido como un constructo cuyo origen es socio histórico, más aún cuando se pretende proponer un proceso de formación permanente de profesores en la IUE y asumiendo CSC en el contexto CTSA, para lo cual no hay que desconocer el respaldo de investigaciones que han abordado a Fleck como referente de formación de profesores, como se evidencia en la figura 25.

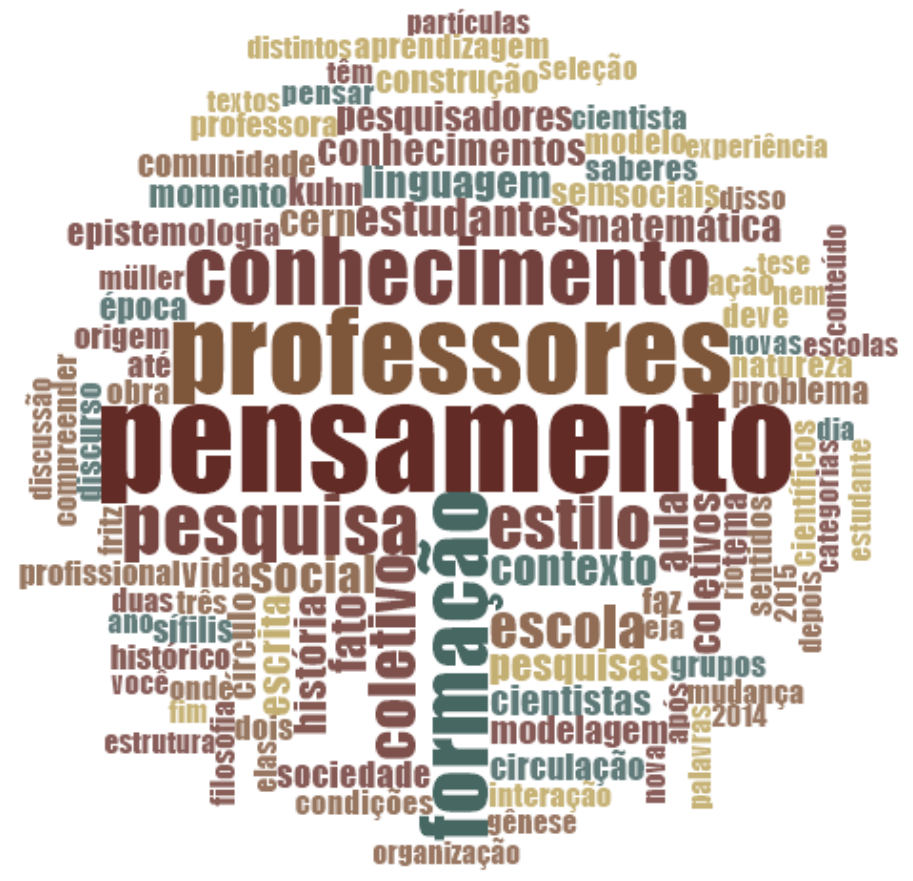

Figura 25. Investigaciones en torno a la formación de profesores en el contexto epistemológico de Fleck. Fuente. Estado del arte del estilo de pensamiento en profeso de formación de profesores

Fleck (1986) afirma: "El conocer representa la actividad más condicionada socialmente de la persona y el conocimiento es la creación social por excelencia" 
(p.89). Por tanto, el conocer, en cuanto a actividad social está ligado a las condiciones sociales de las personas, va más allá del pensamiento individual e incluso de las generalizaciones del sujeto, de su propio estilo de pensamiento; el conocer al estar ligado a los presupuestos culturales y sociales que van en dirección al cumplimiento las leyes de la organización de sus grupos, es decir, "ni al sujeto ni al objeto le pertenecen una realidad independiente, toda existencia se basa en la acción recíproca y es relativa" (Fleck ,1929, p. 426). Además el conocimiento es histórico porque presenta un desarrollo en el tiempo, permite identificar el proceso de evolución que supera las visiones lineales y absolutistas, evidenciando los hechos que explican los aciertos y desaciertos en las formas como se construye la ciencia.

Teniendo en cuenta la relevancia epistemológica de Fleck que permite comprender como se construye el conocimiento científico, es necesario resaltar algunos elementos (categorías) como el carácter social e histórico del saber, el estilo de pensamiento (EP), el colectivo de pensamiento (CP), la circulación de ideas (intracolectiva, intercolectiva), el hecho científico, los círculos (exotéricos/esotéricos), y la ciencia de revista, de manual y de libro de texto.

\subsection{CARÁCTER SOCIAL E HISTÓRICO DEL SABER}

Fleck entiende el proceso de construcción del conocimiento como una triada en la que el objeto esta conectado a un contexto (2) (estado del conocimiento/realidad objetiva) por conexión pasiva (1) y el sujeto a un estilo de pensamiento que comparte con un colectivo determinado por conexión activa (3) como se muesta en la fígura 26 (Souza, 2015, p.50), posibilitando hacer una analogia de este modelo de construcción del conocimiento científico con el modelo de construcción del CPP y en general la enseñanza de las ciencias. 


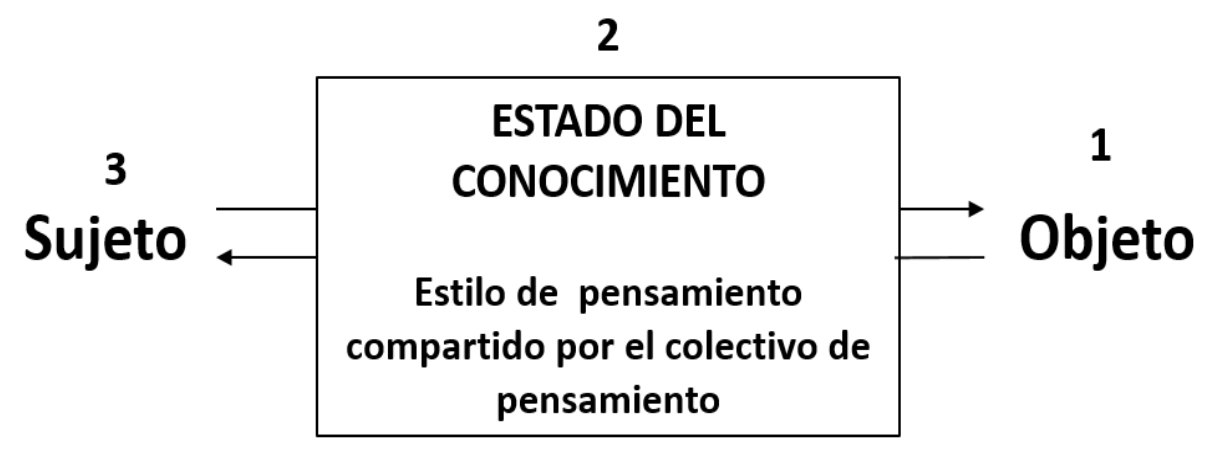

Figura 26. Relación sujeto y objeto en el estado del conocimiento: "Fenomenología Fleckiana" Fuente. Souza (2015)

Para Fleck no existen observaciones, ni experiementaciones neutras, estas son realizadas por sujetos pertenecientes a una comunidad socialmente construida, su pensamiento depende del entorno social en el que vive y de la átmosfera social que respira, no en él mismo. Al introducir el estado del conocimiento como un tercer elemento, se defiende el conocer como un producto social, histórico y cultural, en el que la realidad objetiva se puede descomponer en secuencias históricas e ideas pertenecientes al colectivo, aunque "el CP se compone de individuos, no es una suma lo que lo caracteriza, ya que el individuo no tiene nunca, o casi nunca consciencia del EP colectivo, que casi siempre ejerce sobre su pensamiento una coerción absoluta" (Fleck,1986, p.88); un CP bien organizado es el portador de un saber que supera la capacidad de cualquier individuo.

La historicidad en la construcción del conocimiento cientifico, es visibilizada por Fleck, cuando afirma que no existe una generación espontánea de conceptos, estos, por asi decirlo, tienen un origen ancestral, histórico, que denomina protoidea $^{7}$, concebida como un instrumento que le permite identificar los vinculos de las representaciones científicas con su génesis histórica, evidenciando como las ideas del presente, estan ligadas al pasado y estas se ligarán a las del futuro, a pesar de las variaciones de los EP. En palabras de Fleck (1986):

7 ideas vagas, imprecisas, ni verdaderas o falsas, pero que tienen una función heurística capaz de regular el proceso que involucra mutaciones de los EP 
[...] querámoslo o no, no podemos librarnos de un pasado que -con todos sus errores- sigue vivo en conceptos heredados, en las formas de concebir los problemas, en los programas de la enseñanza formal, en la vida diaria, en el lenguaje y en las instituciones. No existe ninguna generatio spontanea de los conceptos, sino que están - valga la expresion-determinados por sus antepasados. Lo pasado es mucho mas peligroso -o, mejor dicho, sólo es peligroso- cuando nuestros enlaces con el se mantiene inconscientes y desconocidos. (p.67)

Fleck (1986), establece el condicionamiento histórico del saber, manifestando que "las protoideas han de verse como esbozos histórico-evolutivos de las teorías actuales y su surgimiento tiene que comprenderse socio-cognoscitivamente"(p.72). Según él, muchos avances científicos fueron posibles por la presencia de protoideas, como en el estudio de caso de la sífilis y su relación con el desarrollo de la reacción de Wassermann; sin embargo, no todo hecho científico proviene de protoideas y no todas las protoideas se cristalizan en hechos científicos, pero la teoría del conocimiento no puede ser indiferente al hecho de que muchos conceptos se desarrollen de esta forma.

En lo que concierne a otras protoideas, tales como la protoidea del átomo o la de los elementos, tampoco podemos decidir, si eran sacadas de su contexto temporal, falsas o correctas, pues corresponden a otro colectivo de pensamiento, a otro estilo de pensamiento. Para el pensamiento científico de hoy son inadecuadas, pero para sus creadores eran correctas (Fleck, 1986, p. 72).

En síntesis, el conocimiento además de ser el resultado de procesos históricos y sociales es construido por un CP formado por individuos en interacción socio cultural que, al establecer conexiones activas y pasivas con el saber permite un movimiento continuo, dinámico, de reelaboración incesante, donde una conexión pasiva, puede ser considerada activa y viceversa, ambas están presentes una en la otra, se engendran y se constituyen (Fleck,1986).

. En términos de Fleck (1986): 
De la misma forma que no hay un "todo", tampoco hay un "último", esto es, un fundamento desde el que se pueda construir lógicamente el conocimiento. El camino que proporcionan las ideas y verdades se mantiene sólo mediante el movimiento continuo y la interacción. (p.98)

[...] Los elementos pasivos y activos no son separables completamente ni lógica ni históricamente. Ciertamente, ni siquiera se puede inventar un cuento de hadas que no contenga algunas conexiones obligadas. En este sentido, el mito y la ciencia se diferencian sólo en el estilo: la ciencia intenta recoger en su sistema un máximo de esos elementos pasivos, sin tener en consideración su viscosidad; el mito contiene pocos elementos de este tipo, pero compuestos artísticamente. (p.142)

\subsection{ESTILO Y COLECTIVO DE PENSAMIENTO}

Los elementos que inciden en la construcción de conocimiento (individuo, colectivo y realidad objetiva), se relacionan gracias a redes colectivas (figura 27), que tejen los individuos que hacen parte de un $\mathrm{CP}$, este a su vez representa las concepciones dominantes de una época, incluyendo restos de concepciones pasadas y predisposiciones de concepciones futuras, que Fleck (1986) denomina EP:

El estilo de pensamiento consiste, en una determinada actitud y en el tipo de ejecución que lo consuma. Esta actitud tiene dos partes estrechamente relacionadas entre sí: disposición para un sentir selectivo y para la acción consecuentemente dirigida. [...] Queda caracterizado por los rasgos comunes de los problemas que interesan al $\mathrm{CP}$, por los juicios que el pensamiento colectivo considera evidentes y por los métodos que emplea como medio del conocimiento. El estilo de pensamiento también puede ir acompañado por el estilo técnico y literario del sistema de saber. (p.145) 


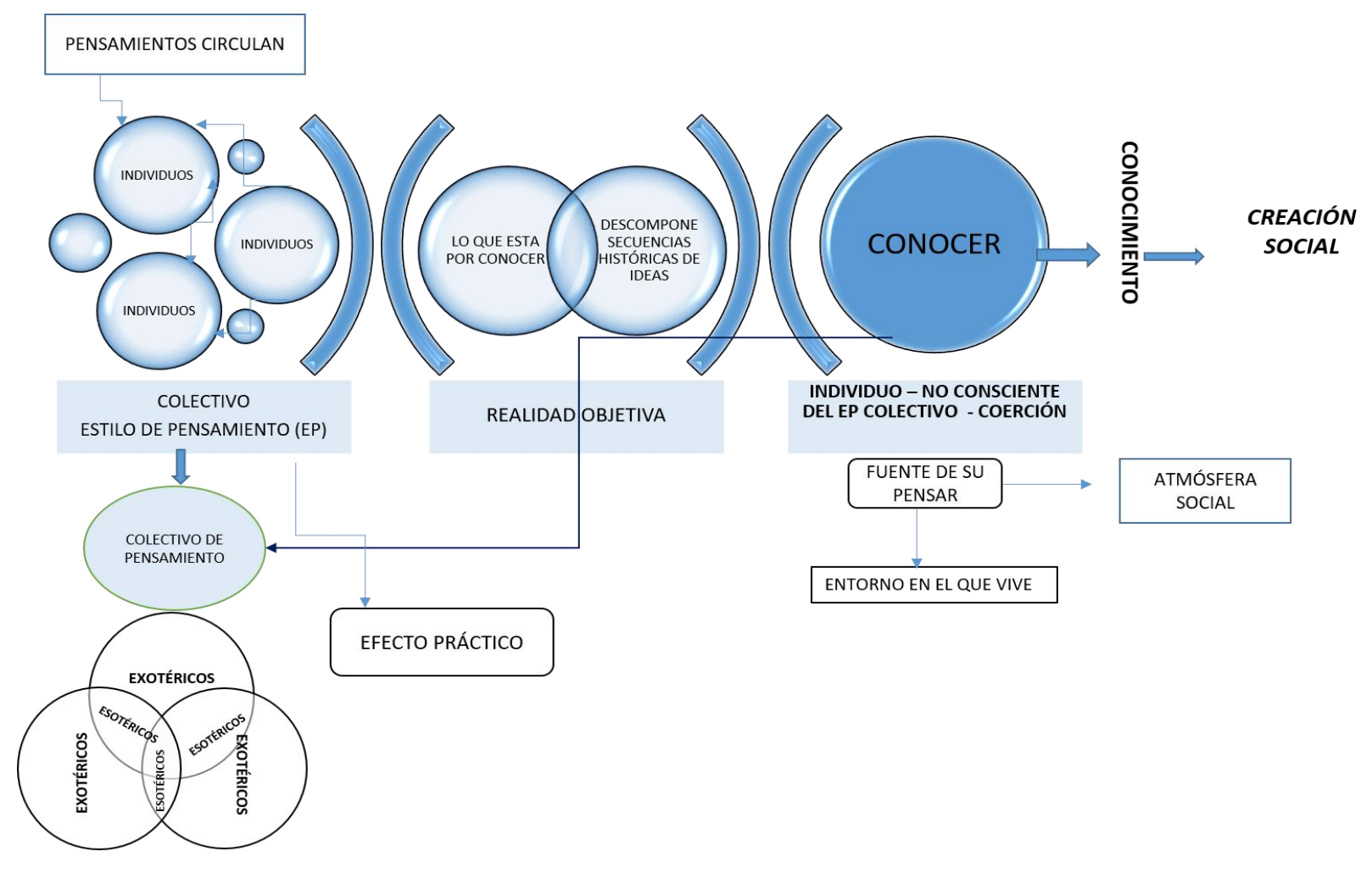

Figura 27. Sociogénesis del conocimiento de Fleck.

Fuente. Autora con base en Fleck (1986)

La disposición respecto a percibir y actuar conforme a un EP de forma dirigida y restringida, proporciona a los individuos del CP una visión estilizada, que se logra por medio de un proceso formativo de tradición y costumbre, en el que se ha aprendido a observar, se ha adquirido la habilidad/capacidad para la percepción científica, erradicando "las visiones confusas que se presentan producto de la primera observación inadecuada" que mezcla diferentes EP, sensaciones y sentimientos; en este terreno el individuo avanza/retrocede (similar a una HdPR) por tierra movediza sin encontrar suelo firme, en términos de Fleck (1986):

El ver formativo (Gestaltsehen) directo exige el estar experimentado en el campo de pensamiento de que se trate. Solo después de mucha experiencia, quizás tras un entrenamiento preliminar se adquiere la capacidad para percibir inmediatamente un sentido, una forma (Gestalt), una unidad cerrada al mismo tiempo desde luego se pierde la capacidad de ver cualquier cosa que contradiga dicha forma. Pero es justamente tal disposición para el percibir dirigido lo que 
constituye el componente principal del EP. Así, el ver formativo (Gestaltsehen) es una función del EP. [...]. Por contraste, el ver confusa inicial no está impregnado por el estilo. Se mezclan temas fragmentarios por el estilo. De estilos distintos amontonados caóticamente y actitudes contradictorias que llevan al ver no orientado de un lado a otro: es la lucha entre los distintos campos conceptuales de visión. No hay nada fijo o acabado. Todo puede verse bajo un prisma o bajo otro. Falta la firmeza, la coacción, la resistencia, "el suelo firme de los hechos". (P.138139)

Bajo esa misma perspectiva, Massoni \& Moreira (2015) mencionan que el EP persiste, como una especie de armonía de las ilusiones (estructuras persistentes y rígidas), siempre que permita nuevas comprensiones frente a la innovación, con diferentes grados de intensidad mencionados a continuación:

1. La contradicción parece impensable: cuando una concepción invade un sistema de pensamiento, penetra en la vida cotidiana y en el lenguaje, en las expresiones verbales, se constituye en un punto de vista de la comunidad en general, por tanto, no hay contradicción.

2. Lo que no cabe en el sistema de pensamiento es desapercibido: toda teoría abarcadora pasa por dos fases: en la primera, sólo son percibidos los hechos que encajan con precisión, ya que el sistema de pensamiento se presenta como una totalidad estructurada, plausible para su época que posee poder promovedor (ejemplo: la teoría clásica que explicaba que las enfermedades infecciosas eran causadas por un agente vivo y diminuto, sin ver que ese agente podía existir también en los sanos); en la segunda fase, aparecen las dificultades, las excepciones de las que el sistema de pensamiento no da cuenta (lo que Kuhn llamó más tarde anomalías) y que al final, pueden ultrapasar el número de casos regulares y terminar generando mutaciones .

3. Lo que no cabe en el sistema de pensamiento es silenciado: las excepciones son silenciadas (por ejemplo, en la física, los movimientos del planeta Mercurio contradecían las leyes de Newton, aunque los expertos 
tenían este conocimiento, se lo ocultaron al público en general, ya que se oponían a las ideas dominantes y solo fueron citados cuando se volvieron útiles para ejemplificar la Teoría de la Relatividad.

4. Para no contradecir el sistema se hace un gran esfuerzo de conciliación: el sistema de pensamiento se cierra por lo menos para una época, alineándose al EP de forma que los científicos tienden a reinterpretar toda la innovación de acuerdo con el EP vigente.

5. Se percibe, representa y describen estados de cosas que corresponden a puntos de vista en vigor (así existan puntos de vista contrarios) porque lo que está en juego es la realización de los sueños de los científicos. "El carácter cerrado de los sistemas, así como las interacciones entre lo conocido, lo que quede por conocer y el cognoscente garantizan la armonía dentro del sistema. Pero al mismo tiempo [...] aseguran la armonía de las ilusiones" (Fleck,1986, p.85), precisamente por esta razón no se pueden desenmascarar desde dentro del EP.

Pero ¿cómo romper con la armonía de las ilusiones? Para responder a la pregunta, Fleck, adiciona la fase de las complicaciones (aumento de las excepciones), e incorpora la categoría "circulación intercolectiva de ideas" como resultado de las posibles transformaciones del EP. La mencionada circulación de ideas podría pasar por tres etapas distintas: instauración, extensión y trasformación; en la que la extensión puede prolongarse indefinidamente hasta romper la armonía de las ilusiones del EP del momento, que podría también considerarse como uno de los efectos de las protoideas.

En cuanto al CP, este se forma cuando dos o más personas intercambian ideas de cuya duración depende la generación de estructuras de pensamiento que ninguno de los participantes por sí sólo podría conseguir. Por tanto el CP se refiere a cualquier comunidad de personas en la que haya intercambio de ideas o se mantenga cualquier tipo de interacción intelectual (comercial, militar, artística, moda, religión, política, deportiva, científica, etc.) (Fleck, 1986;1979) 
Sin embargo, el CP se da por la unión de individuos, es el portador de un EP que supera la capacidad individual, "es comparable a un partido de futbol, a una conversación o al actuar de una orquesta" (Fleck, 1986, p.145). En cada uno de los contextos humanos se expresan valores, hábitos, términos técnicos, un lenguaje estilizado y cerrado, que son compartidos por los miembros de las comunidades; también hay confianza entre ellos, porque de su actuar dependen las creaciones o el producto que se obtenga de su EP.

Al portador comunitario del EP lo llamamos CP. Este concepto, en tanto medio de investigación de la condicionalidad social del pensamiento no debe ser entendido como un grupo fijo o una clase social. Es, por decirlo así, un concepto más funcional, que substancial, comparable, por ejemplo, al concepto de campo de fuerza de la física. (Fleck, 1986, p. 149)

Por lo tanto, estos CP pueden ser causales o momentáneos, se organizan y reorganizan, compartiendo nuevos intereses y posiblemente al prolongar la duración de dichos CP el EP adquiere una estructura formal (CP estables), se producen nuevos saberes, se producen nuevos conocimientos, como lo que sucede en las comunidades científicas, en palabras del autor:

Los colectivos de pensamiento estables permiten investigar exactamente el estilo de pensamiento y las características sociales generales de los colectivos de pensamiento en sus relaciones reciprocas. Las comunidades de pensamiento estables (o comparativamente estables) cultivan, como otras comunidades organizadas, una cierta exclusividad formal y temática. Disposiciones legales y hábitos arraigados, a veces un lenguaje especial - 0 al menos términos especiales- aíslan formalmente, aunque no de forma absolutamente obligatoria, a la comunidad de pensamiento (Fleck, 1986, p. 150)

En los CP existen muchos círculos interseccionados (círculos/subcírculos/grupos/ subgrupos), con una estructura general que abarca a todas las comunidades de pensamiento, en ella se forma "un pequeño círculo esotérico y un gran circulo exotérico formado por los componentes del CP en torno a una determinada creación del pensamiento, sea esta un dogma de fe, una idea científica o un 
pensamiento artístico" (Fleck,1986, p 152). El primer círculo, está formado por un pequeño grupo de profesionales que trabajan en un área específica, ubicados en el centro del pequeño círculo (expertos especializados) y en la periferia del mismo, los que trabajan en áreas afines (expertos generales); en el segundo círculo (exotérico) se concentran la mayor parte de los componentes del CP (diletantes instruidos) como se visualiza en la figura 28.

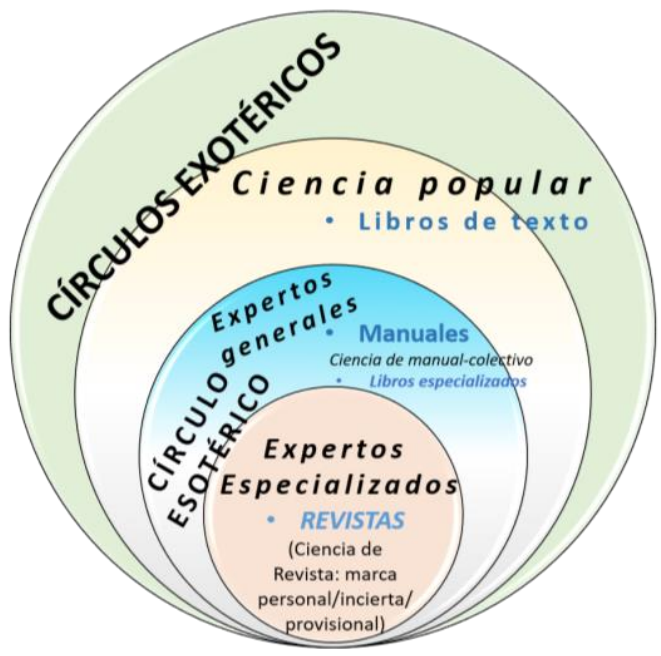

Figura 28. Círculos que conforman los CP.

Fuente. Autora basada en el libro La génesis y el desarrollo de un hecho científico (GDHC)

La relación del circulo exotérico no se da directamente con el hecho científico, se establece por la mediación indirecta del circulo esotérico, siempre se establecen relaciones entre los círculos esotéricos con sus círculos exotéricos correspondientes; por ejemplo, una Facultad de Ciencia y Tecnología conforma un $\mathrm{CP}$, formado por círculos esotéricos a saber: el de los tecnólogos, los físicos, químicos y los biólogos, cada uno de ellos seria exotérico con respecto a los otros; en el caso de los químicos serian exotéricos con respecto al colectivo esotérico de los de tecnología, los físicos y los biólogos, a su vez, estos tres serían exotéricos para los químicos (esotéricos). De esa misma manera, al interior de cada grupo se consolidan nuevos círculos exotéricos y esotéricos, en el caso de la Química (analítica, orgánica, inorgánica, ambiental, etc.) los de inorgánica serian exotéricos 
para cada una de las otras especialidades (esotéricas) y cada una de ellas sería exotérica para los de inorgánica. Al respecto Fleck (1986) afirma:

Hay una jerarquía entre los que están iniciados y muchos hilos que unen tanto los distintos niveles dentro del círculo como los distintos círculos. El circulo exotérico no tiene relación directa con aquella creación del pensamiento, sino solamente una indirecta a través de la mediación del circulo esotérico [...]. Pero estos iniciados, tampoco son independientes; son más o menos dependientes -ya sea consciente o inconscientemente- de la "opinión pública", es decir, de la opinión del circulo exotérico. Surge así, la unidad intrínseca del EP y su tendencia a la persistencia. (p.152)

Estableciéndose, por lo tanto, una relación de los círculos esotéricos con sus círculos exotéricos correspondientes, basados en relaciones de confianza entre los primeros "iniciados" y en las necesidades objetivas de los que ingresan, así cuando menor es la distancia entre los individuos del mismo circulo esotérico con los del exotérico más simplificada es la traducción del hecho; esta superposición entre círculos exotéricos y esotéricos, es lo que Fleck denomina relación de la elite con la masa. Si la masa tiene una posición más fuerte (circulo exotérico) con respecto a la elite (circulo esotérico) se teje una relación democrática, donde hay progreso y desarrollos de las ideas, si es lo contrario, la elite se aísla y el colectivo es dominado por un "secretismo y dogmatismo" que conduce al conservadurismo y la inmovilidad; caso análogo puede suceder entre el maestro y el alumno (discípulo).

Fleck (1986), menciona que la Iniciación de un individuo en un EP y la introducción en una ciencia, es epistemológicamente análoga; es un entrenamiento por un periodo largo de aprendizaje, en el que se evidencia el protagonismo de ideas netamente autoritarias, "es como si el espíritu santo descendiera sobre el novicio para hacer visible lo que hasta entonces había sido invisible" (p.151). el autor enfatiza, que la palabra impresa, el cine, la radio, en general los medios de comunicación posibilitan ese entrenamiento a pesar de la distancia y el escaso 
contacto que se dé entre los individuos de un determinado circulo esotérico con sus miembros exotéricos.

Los círculos esotéricos necesitan la opinión de los círculos exotéricos para legitimar sus saberes o conocimientos, de esta forma, se lleva a cabo un proceso de comunicación o circulación de las ideas y métodos; se establecen relaciones de dependencia intelectual entre los círculos, pero esta comunicación entre ellos ocurre de forma distinta, como se observa en la figura 29.

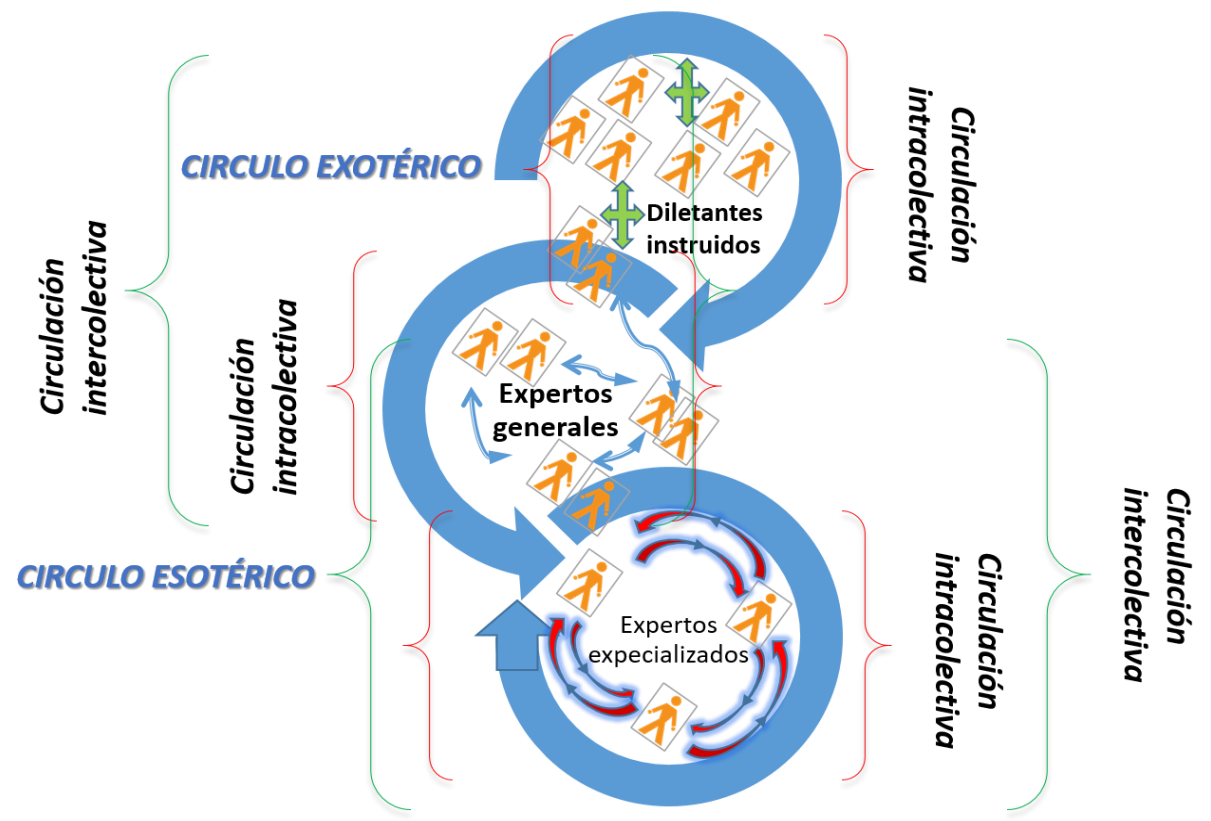

Figura 29. Circulación de ideas entre los $\mathrm{CP}$ Fuente: autora con base en el libro GDHC

\subsubsection{Circulación de ideas}

El proceso comunicativo para Fleck (1986) no ocurre sin transformación, esto quiere decir que cuando hay circulación de los pensamientos de individuo a individuo, siempre se producen cambios debido a las relaciones que cada uno de ellos establece con dichos pensamientos y después de esa serie de transformaciones no queda prácticamente nada del contenido original, por tanto el 
conocimiento que circula y se comunica, ya no es del individuo "concreto" que inició con el proceso de circulación del pensamiento, sino que es del colectivo, de un CP. "La comunicación no ocurre nunca sin transformación y sin que se produzca una remodelación acorde con el estilo, que intracolectivamente se traduce en un reforzamiento e intercolectivamente en un cambio fundamental del pensamiento comunicado" (p.158).

Delizoicov, Carneiro, \& Delizoicov (2004) mencionan que el cambio de ideas en los CP ocurre a través de una circulación intra e intercolectiva de ideas. La primera sucede al interior del CP y es característica del proceso de formación de pares; la segunda se realiza con fines de diseminación y popularización de los EP que puede ocurrir en el interior de un colectivo o entre diferentes CP. Por esto, cuando mayor es la diferencia entre los EP, menor es la circulación intercolectiva, posiblemente porque los principios que orientan los miembros de cada colectivo son diferentes, no son afines; y si la diferencia es menor, la circulación intercolectiva genera menos conflictos, que posiblemente transformen los valores individuales de los EP involucrados, generando nuevas ideas, nuevos rumbos de investigación en ciertas áreas correlacionadas.

En este sentido, la palabra es un objeto especial de circulación intercolectiva, caracterizada por un tono estilístico particular, que cambia en dicha circulación produciendo cierta variación en su significado y, por tanto, siendo la responsable de los cambios en los valores de pensamiento, que pueden ser parciales, totales 0 inequívocos; algo semejante ocurre cuando un individuo pertenece a varios $\mathrm{CP}$, en este caso al igual que la palabra, "actúa como un vehículo en el tráfico de pensamiento" (Fleck,1986, p.156), y en este caso no sólo puede ocurrir desvio de significado sino acorde al EP que profese, de la vida psíquica individual; ciertas relaciones las puede considerar como creencias o como materias de saber, en palabras del autor:

Si los estilos de pensamiento son muy distintos, entonces puede mantenerse su aislamiento en el mismo individuo, mientras que si, por el contrario, se trata de 
estilos de pensamiento más parecidos, no es tan fácilmente posible una separación tal, pues el conflicto que se establece entre estilos de pensamiento estrechamente relacionados hace imposible su coexistencia dentro del individuo y condena a la persona a la improductividad o la creación de un estilo de pensamiento especial situado entre ambos. (Fleck,1986, p. 157)

La comunicación intracolectiva, en la visión de Fleck, (1986) y Kuhn \& Fleck (1979) ocurre de forma determinada dentro del circulo esotérico, como ya se mencionó, entre sus pares, de la que es posible que emerja un hecho que desarrollará un EP determinado para los receptores, que se constituyen en los seguidores de este EP, sin salir de este CP específico; para explicar lo anterior, realiza una analogía con el mundo de la moda:

La disposición a notar inmediatamente lo que está de moda y a considerarlo absolutamente importante, el sentimiento de la unión con otros miembros del colectivo y la confianza ilimitada en los miembros del circulo esotérico forman la particular actitud del colectivo de pensamiento de la moda. Los seguidores más fieles de la moda se encuentran en la periferia del círculo esotérico y no tiene ningún contacto directo con los dictadores poderosos que forman el círculo esotérico. Sólo mediante los conductos reglamentarios de circulación intracolectiva les llega, despersonalizadas e impuestas mediante este camino, "las creaciones". Aun así, nada parece impuesto; se dice sencillamente [...] "lo que usted necesita para este invierno" o [...] "en Paris la mujer lleva" [...). Sin embargo, esto resulta una coerción de las más fuertes, puesto que no es sentida como dominio o poder, sino como necesidad evidente. (Fleck,1986, p.154-155).

Comprender el proceso de comunicación que ocurre en los $\mathrm{CP}$, permite conocer la formación de los individuos cuando ingresan en una comunidad científica y en forma análoga, la manera como se inicia la formación escolar, en la que como ciudadanos construyen en forma colectiva una concepción del mundo, para la cual se deben preparar e interactuar entre círculos exotéricos y esotéricos, estableciendo dinámicas de comunicación intra e intercolectiva que les permitan además de la posible solución de problemas del contexto, apropiarse de los 
significados, del lenguaje, de los métodos y prácticas de un $\mathrm{CP}$, transformarlos, prolongarlos o crear nuevos EP que les permitan constituirse como intelectuales, críticos y participativos que habitan en una aldea global.

\subsubsection{Colectivo de pensamiento científico (CPC)}

Al igual que cualquier $\mathrm{CP}$, el CPC está formado por círculos esotéricos y exotéricos, para que los individuos ingresen a ellos deben tener un tiempo de aprendizaje (años de formación), en el que la introducción didáctica a este EP se da como una "suave coerción", en el que los hábitos de pensamiento y las normas del CP adquieren neutralidad al ser percibidas como las únicas manifestaciones posibles (Fleck, 1986).

El circulo esotérico, como se dijo antes, está formado por expertos especializados que son los investigadores más instruidos que abordan un problema de investigación (circulo interno de la figura 28 o intercepto de la figura 30), pero a este círculo también pertenecen los "especialistas generales", investigadores que abordan problemas similares, y en el círculo exotérico estarán todos los "diletantes instruidos", para quienes la relación entre los círculos eso y exotéricos es indirecta y ocurre por las diversas formas que el grupo esotérico utiliza para diseminar el pensamiento.

Fleck divide entonces la comunicación de la ciencia en: Ciencia de Revista (Expertos especializados), Ciencia de manuales (especialistas generales) y ciencia de los libros de texto (diletantes instruidos); Las dos primeras constituyen la Ciencia especializada, lo que indica que cada vez que el conocimiento científico es reestructurado, al ser diseminado de una forma de comunicación más especializado a otra menos especializada, se va tornando más simple, popular, apodíctico y gráfico, más exotérico (Ciencia popular), como se visualiza en la figura 30 . 


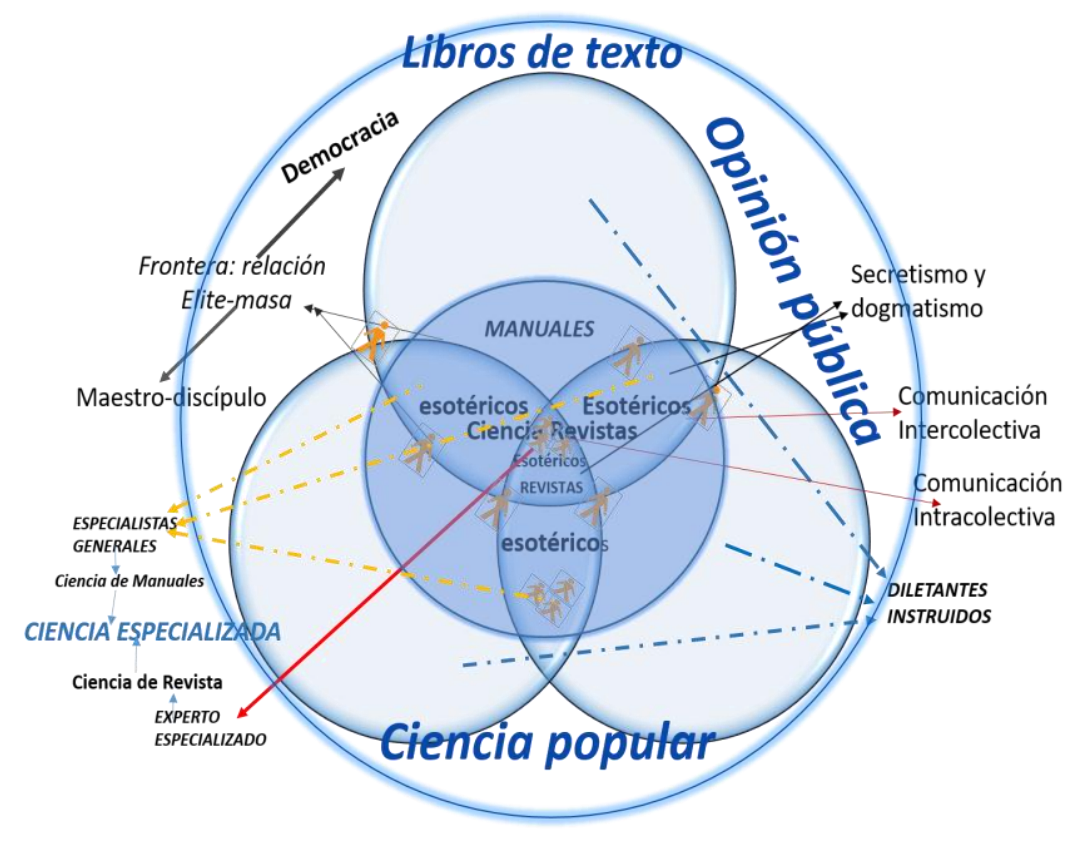

Figura 30. Ciencia Especializada Vs Ciencia Popular Fuente. Autora con base en el libro GDHC

La ciencia popular, es un elemento complejo, especial, especulativo, es fantasioso, para no especialistas (diletantes adultos con formación general), pero que supone la mayor parte del conocimiento científico de todas las personas y debe ser valorado epistemológicamente, tanto por los científicos más especializados, como por los diletantes con formación general. Este tipo de ciencia, no debe ser entendida como la ciencia introductoria de los libros de texto, su principal objetivo es construir una "concepción del mundo" a los no especialistas, además de establecer una interacción con el saber especializado (al tiempo que surge de él, ejerce un efecto retroactivo sobre él mismo).

Este tipo de ciencia, es una simplificación de la ciencia especializada. Gracias a esta simplificación, al grafismo usado y la apodícticidad, el saber se torna más cercano a lo real, a lo "humano"; por tanto, el grafismo de un saber, se constituye en una herramienta para los especialistas, quienes recurren a él cuándo quieren ser leídos (comprendidos) por otros; aquí, Fleck (1986) evoca el modelo de llave y cerradura utilizada en la serología, mencionado que "la imagen logra supremacía 
sobre las pruebas específicas y a menudo regresa, en este papel nuevo, al especialista" (p.164), este grafismo emotivo le confiere seguridad al saber, indicando su transito del centro esotérico a su periferia exotérica.

Tal saber exhaustivamente especializado carece de la más mínima claridad y es inadecuado para todo caso práctico. Debe tenerse presente que tal estructura piramidal no conduciría a elementos generales recurrentes, que, caso de que fueran descritos separadamente, simplificarían básicamente la construcción. Permanecemos siempre en el mismo nivel conceptual, siempre equidistantes de los "conceptos fundamentales", [...] certeza, sencillez y grafismo surgen solo en el saber popular. Ahí es donde el experto obtiene su fe en esta triada como ideal del conocimiento. En eso consiste el significado epistemológico general de la ciencia popular. (Fleck,1986, p. 162-163).

En oposición a la ciencia popular, la ciencia especializada se torna pública a través de la "Ciencia de Revista" caracterizada por ser provisional, incierta, con un lenguaje propio y con rasgos personales, esta ciencia de revista, a través de la circulación intracolectiva del pensamiento, se compila en manuales (Ciencia de manuales), que representan un trabajo colectivo en el que ha seleccionado, mezclado, ajustado y moldeado el sistema de saberes dominantes, que serán obligatorios para todos los especialistas (consolidándose así, la percepción orientada); estos manuales están caracterizados por utilizar un lenguaje más impersonal y se constituyen como una ciencia progresiva y no contradictora, surgida a partir de los debates de especialistas del circulo esotérico y consigo mismos.

Parte de la circulación esotérica de las ideas se consuma ya dentro del investigador mismo: dialoga consigo mismo, sopesa, compara y decide. Cuanto menos se acomode esta decisión a la ciencia del manual, cuanto más original y audaz sea el estilo de pensamiento personal, tanto más durará la consumación del proceso de colectivización de sus resultados. (Fleck,1986, p.168). 
Por lo tanto, la visión de ciencia para los individuos en la sociedad no es homogénea, varía de acuerdo al grado de especialización del $\mathrm{CP}$, de la circulación de ideas y del mecanismo que opera en su transformación.

\subsubsection{Hecho científico}

Fleck (1986), define el hecho científico como "una relación conceptual conforme al EP que es analizable desde el punto de vista de la historia y de la psicología -ya sea esta individual o colectiva-, pero que nunca es reconstruible en todo su contenido desde esos puntos de vista" (p.130). Así, resalta la importancia de la triada del proceso de construcción del conocimiento (figura 26) y la relación inseparable entre las partes activas y pasivas del saber en el interior de los CP que determinan el avance, retroceso o estancamiento de los hechos que generan la transformación de conceptos, dando solución a un problema (entendido como la verdad) y posiblemente haciendo mutaciones en el EP.

Cuando Fleck define la resistencia como lo que se opone a la libre arbitrariedad del pensamiento, se refiere a como esta resistencia determina el hecho científico, lo que puede ser para algunos puede no ser para otros, por lo tanto, el hecho está asociado al pensamiento colectivo y a las reglas que establecen la dinámica de los EP y CP. Fleck (1986) describe cómo surge un hecho científico:

Primeramente, hay una señal de resistencia en el pensar caótico inicial, después una determinada coerción de pensamiento y. finalmente una forma directamente perceptible. El hecho siempre ocurre en el contexto de la historia del pensamiento, y es el resultado de un estilo de pensamiento determinado. La meta de todas las ciencias empíricas es la elaboración de este "suelo firme de los hechos". (p.141) 
El hecho científico como resultado de un EP, implica "ver y actuar direccionadamente", resultado de la coerción del pensamiento, de los intereses intelectuales del CP; donde "la señal de resistencia" de lo que le fue contradictorio, tiene que tener eficacia dentro del CP y estar presente en cada componente, de tal manera que sea lo que mantenga la cohesión del pensamiento del grupo, así el hecho es definido como "señal o aviso de resistencia en el colectivo de pensamiento" (Fleck, 1986, p.149).

El teórico enfatiza, que los hechos nunca son independientes de otros, se presentan como una amalgama, "un híbrido" de avisos individuales o de un sistema de saberes que obedece a sus propias leyes, lo que hace que un hecho repercuta sobre muchos otros y cada cambio o descubrimiento que se dé influye sobre un espacio ilimitado hasta que se conviertan en creaciones nuevas del CP, caracterizado por el engranaje de los hechos en equilibrio e interacción continua, dando solidez "al mundo de los hechos" que se convierten en verdades. En palabras de Fleck (1986): "cuanto menos interconexo es el sistema de saber, más mágico es, menos estable y más capacidad prodigiosa tiene su realidad, siempre según el estilo de pensamiento colectivo" (p.149). 


\section{CAPITULO 4. METODOLOGÍA DE INVESTIGACIÓN}

Esta investigación se enmarca en el paradigma cualitativo con método de estudio de caso único y técnica de observación participante; la producción de conocimientos es el resultado del análisis de los aportes y dificultades del abordaje de la CSC en la construcción del CPP en ejercicio, en el marco de un programa de formación de profesores en la interfaz universidad escuela con enfoque CTSA a la luz de la epistemología de Fleck.

Lo anterior con el propósito de comprender e interpretar lo que sucede en un grupo de profesores de diferentes áreas, interesados en abordar CSC de carácter local, propias de la crisis social, de la legitimación y desmotivación (de la racionalidad científica, tecnológica y social) que caracteriza a la mayor parte de los estudiantes de la jornada nocturna de una Institución Educativa ubicada en la localidad de Ciudad Bolívar al sur de la Ciudad de Bogotá.

Es importante aclarar que por la naturaleza de la investigación los conocimientos construidos no serán neutros ni completos, emergen de un campo humano, lleno de tensiones y rupturas; sin embargo, manteniendo un equilibrio natural surge la armonía de ilusiones (Fleck, 1986) para mantenerse en este estado hasta que se generen nuevas tensiones, pues se trata del mundo de la vida.

Denzin \& Lincoln (1994) consideran que la investigación cualitativa es un campo de indagación por derecho propio, en la que se entrecruzan disciplinas, campos y problemáticas; así, cualquier descripción de lo que constituye la investigación cualitativa debe estar dentro de un campo histórico complejo; significa cosas diferentes en cada uno de esos momentos, es un multi-método focalizado que incluye interpretación y aproximaciones naturalistas al objeto de estudio. 
Los investigadores cualitativos estudian las cosas en su situación natural, tratando de entender o interpretar los fenómenos en términos de los significados que la gente les otorga, esto incluye la recolección y el uso de una variedad de materiales empíricos (estudios de caso, experiencia personal, introspección, historias de vida, entrevistas, textos de observación, históricos, de interacción y visuales) que describen la rutina, los momentos problemáticos y los significados en la vida de los individuos; así, el investigador cualitativo es un bricoleur, en palabras de Denzin \& Lincoln (1994):

Las múltiples metodologías de la investigación cualitativa pueden ser vistas como un bricolaje y el investigador como un bricoleur. [...] Un bricoleur es una especie de "Jack para todo tipo de trabajos o un profesional del tipo "hágalo Ud. Mismo" [...] el bricoleur produce un bricolaje, esto es, un conjunto de piezas unidas, un tejido de prácticas que dan soluciones a un problema en una situación concreta. "La solución (bricolaje), como el resultado del método del bricoleur, es una construcción (emergente)" [...] que cambia y toma nuevas formas a medida que se aplican nuevas herramientas, métodos y técnicas al rompecabezas. (p.2)

En la investigación cualitativa se producen datos descriptivos, se utilizan las propias palabras habladas o escritas de las personas, y la conducta observable, como mencionan Taylor \& Bogdan (1986); se caracteriza además por ser inductiva, holística (las personas no se reducen a variables, son un todo) y humana ya que la sensibilidad que caracteriza al investigador (naturalista no instructivo, comprensivo, sin predisposición) es fundamental para su realización.

Miles y Huberman (1984), consideran como características básicas de la investigación cualitativa, el prolongado e intenso contacto del investigador con el campo o situación de vida estudiado, pretendiendo alcanzar una visión holística e intentando capturar los datos sobre las percepciones de los actores desde dentro, a través de un proceso de profunda atención, de comprensión empática y de suspensión o ruptura de las preconcepciones sobre los tópicos objetos de discusión; se utilizan relativamente pocos instrumentos estandarizados, el 
investigador es el principal instrumento de medida y la mayor parte de los análisis se realiza con palabras.

Para Ludke \& André (1986), las características básicas que configuran una investigación cualitativa son: el ambiente natural como su fuente de datos y el investigador como su principal instrumento; la naturaleza descriptiva de los datos recolectados a través de transcripciones de entrevistas y de testimonios, fotografías, dibujos y extractos de diferentes tipos de documentos; el interés del investigador por verificar cómo se manifiesta el problema en estudio en las actividades, en los procedimientos y en las interacciones cotidianas; la tentativa de capturar la "perspectiva de los participantes" a través de diversos medios de chequeo, de procesos de discusión abiertos con los participantes o de la confrontación con otros investigadores para que el análisis de los datos siga un proceso inductivo.

Moreira \& Caleffe (2008), consideran que la investigación cualitativa permite la interpretación de la problemática que se aborde, permitiendo describir e investigar la realidad social; este tipo de investigación es vista como una actividad interactiva e interpretativa, realizada por el contacto de las personas, usando como procedimientos metodológicos técnicas etnográficas como la observación participante, entrevistas, historias de vida, entre otras. Las más utilizadas en la presente investigación fueron la observación participante y la entrevista.

En la observación participante, como mencionó Taylor \& Bogdan (1986) el diseño de la investigación permanece flexible; tanto antes como durante el proceso de investigación los rasgos específicos de su enfoque evolucionan en la medida que avanza la misma; es decir, hasta que no se está dentro del campo, no se sabe qué preguntar, qué hacer, ni cómo hacer. Muchos de los investigadores que usan este método, ingresan al campo investigativo sin hipótesis ni preconcepciones.

Para Moreira (2002) el observador participante tiene que involucrarse con el grupo a investigar, debe "aculturarse", siendo capaz de observar, interpretar, discernir, 
desarrollar la perspectiva holística, siendo a la vez observador y participante; sin embargo, la ventaja de ser observador participante parece ser al mismo tiempo la principal dificultad: al tiempo que intenta pertenecer a la cultura investigada, debe ser a la vez capaz de "mirarla desde afuera", interpretarla y describirla.

En este caso particular, la autora de esta tesis es coordinadora de la Institución Educativa Guillermo Cano Isaza jornada nocturna y la encargada de hacer la IUE, de orientar el trabajo académico y de convivencia de profesores del Gl y estudiantes de la institución. Lo anterior, por un lado, puede fortalecer el proceso de inmersión en el Gl, por contar con la posibilidad de ser a la vez observador y participante; por otro lado, puede generar una dificultad debido al rol institucional que ejerce la investigadora centrado en gestionar procesos académicos y de convivencia.

En correspondencia con lo anterior, el observador participante debe saber controlar, ubicarse como observador externo, evaluar y reflexionar, de tal manera que su rol no genere tenciones adicionales al campo de investigación, donde la humildad siempre está presente. Taylor \& Bogdan (1986), mencionan que la humildad debe ser una de las características del observador participante, que la gente donde se hace la investigación sepa que el investigador es el tipo de persona con la que puede expresarse sin temor a revelar algo.

Esta investigación se centra entonces, en un caso único de estudio que permite la comprensión de situaciones complejas y particulares del contexto; para poder hacerlo, el estudio debe estar direccionado al descubrimiento, enfatizar en la interpretación en contexto, retratar la realidad en forma completa y profunda, utilizar diversas fuentes de información, revelar experiencias ocultas y permitir generalizaciones naturales, tratar de representar a los diferentes y a veces conflictivos puntos de vista presentes en una situación social, en correspondencia a lo planteado por Lüdke \& André (1986). 
En el ámbito educativo, los casos pueden ser personas, programas o personas y programas, estos se caracterizan por ser únicos, específicos, complejos en su funcionamiento, e integrados; su abordaje puede ser intrínseco, instrumental y colectivo; en el primero se pretende una comprensión del caso concreto, no se trata de construir teoría; el segundo se utiliza para profundizar un tema o afinar una teoría, en este tipo el caso es secundario, juega un papel de apoyo, facilitando la comprensión de algo; y el colectivo se realiza cuando el interés se centra en la indagación de un fenómeno, población o condición general (Stake, 2007).

Por otro lado, para Yin (1994) los diseños de casos únicos son aquellos que centran su análisis en un único caso, y su utilización se justifica si:

- Podemos fundamentar su uso en la medida en la que tenga un carácter crítico, o que el caso permita confirmar, cambiar, modificar o ampliar el conocimiento sobre el objeto de estudio.

- Sobre la base de su carácter extremo o unicidad. El carácter único e irrepetible que interviene en el contexto educativo justifica, por sí mismo, el diseño.

- Tiene un carácter revelador inmerso, es decir que el caso es revelador de una situación concreta

- Se utiliza como un primer análisis exploratorio o como preludio de un estudio de caso múltiple (Rodríguez et al.,1996).

En ese orden de ideas, la presente investigación está diseñada como caso único, conformado por profesores de diferentes áreas de la jornada noche y de los documentos que allí se generan, fruto de entrevistas, del ejercicio del investigador como observador participante, de los planes y programas o secuencias didácticas que se generen, constituyéndose en este sentido como un caso único instrumental.

Según Stake (2007), este tipo de caso se justifica también por su naturaleza crítica que coincide con el propósito de esta investigación, de configurar un CP 
(GI) de profesores en un proceso de formación en la IUE, construyendo un CPP deseable al abordar CSC con enfoque CTSA. Este tipo de caso se constituye además por su unicidad, por el carácter revelador inmerso en cada uno de sus participantes, que además de ser profesionales de diferentes áreas, tienen un contexto de vida particular, unos saberes fundamentados en la experiencia o en teorías implícitas que les permite configurar su CPP como único y finalmente se configura como caso único por ser un primer análisis exploratorio.

En el estudio de caso propuesto, los datos pueden ser utilizados desde diferentes metodologías; análisis del discurso, de contenido y Análisis Textual Discursivo (ATD), este último será el dispositivo de la análisis de la presente investigación con apoyo el software NVivo11, lo que contribuye a que se consolide como un estudio de caso único en donde se genera nuevo conocimiento, posiblemente para la educación científica y/o la formación de profesores, pasando de la descripción a la construcción de conocimientos emergentes, contextualizados a la luz de los referentes teóricos mencionados.

Como Yin (1994) menciona, podría favorecer la construcción de proposiciones teóricas que al ser propuestas o desarrolladas en otros contextos posibiliten nuevas alternativas de formación de profesores o se constituyan como un fundamento teórico que favorezca el CPP en la IUE y la conformación de CP/GI que permite movilizar un EP.

En este estudio de caso, por la constante necesidad de interpretar y comprender los aportes y dificultades al CPP cuando se abordaban CSC con enfoque CTSA en el marco de un programa de formación de profesores en IUE, se presentaron modificaciones en las temáticas iniciales, en las que sólo se había considerado una CSC, pero luego se encontraron otras acordes al contexto laboral, a los intereses de los integrantes del Gl, sin embargo, esto no influyó en la consolidación del Gl, por el contrario mejoró al ambiente de trabajo.

En esta tentativa de caracterizar la investigación cualitativa en la que se enmarca 
la presente investigación, es necesario comprender los fundamentos epistemológicos y reconocerlos como un campo histórico, dinámico. En ese sentido, Fleck (1986) considera que los conocimientos construidos en la investigación científica, están atados a presupuestos culturales y sociales; aspecto relacionado con los procesos de interpretación y comprensión que se realicen en el Gl.

Las técnicas de recolección de datos utilizadas como observadora participante (observaciones, actas, apuntes personales, notas, memos), grabaciones de audio, fotografías, charlas informales, el mismo trabajo cotidiano de interacción permanente en espacios laborales y de descanso; adicionalmente los cuestionarios (2), el taller teórico-práctico (1), la entrevista focal y la semiestructurada, representan una de las formas más adecuadas para consolidar prácticas, creencias y valores de los investigados según Taylor \& Bogdan (1986); teniendo en cuenta además que se constituyeron como el corpus de la investigación y representan los recursos o elementos externos analizados en el software NVivo11.

En relación con lo anterior, Flick (2004), afirma que la entrevista semiestructurada es la más utilizada en la investigación cualitativa. La flexibilidad en este tipo de entrevista permite que los cuestionamientos y respuestas estén orientados por los referentes teóricos y los propósitos asociados a la investigación, en la cual pueden emerger hipótesis en la medida que el entrevistado expone sus ideas y desarrolla sus argumentos. Este tipo de entrevista facilitó la recolección de datos en la investigación en la medida que el diálogo entre el observador participante y el entrevistado se daba naturalmente, en un ambiente de confianza, donde las preguntas inicialmente planeadas se reestructuraban y el orden en el planteamiento lo direccionaba la misma conversación.

La entrevista es una de las estrategias más usadas en el proceso de investigación cualitativa, facilitando la conversación cara a cara, la realización del mapa 
(cartografía social) el intercambio de las ideas, creencias, prácticas, valores y sistemas clasificatorios de universos sociales específicos, más o menos bien delimitados; permite además, establecer conexiones, triangular datos y lo más importante: comprender y develar detalladamente las creencias, actitudes, valores y motivaciones de cada uno de los profesores investigados o del caso en particular, así como posibilitar conexiones entre los saberes dominantes y deseables presentes en el discurso del profesor (Duarte, 2004).

Según Manzini (2004) existen tres tipos de entrevistas: estructurada, semiestructurada y no estructurada. La primera es aquella que contempla preguntas cerradas, semejantes a los cuestionarios, en la que el entrevistador organiza una ruta de preguntas y sigue la misma, sin percibir la relación de reciprocidad que está siendo construida en la conversación con el entrevistado; la semiestructurada esta direccionada por una ruta o direccionamiento previamente elaborado, pero no hay imposición de un orden rígido de preguntas que son de naturaleza abierta, permitiendo la realización de otras preguntas que conlleven a comprender la información presentada e indaguen sobre cuestiones momentáneas, que tengan relevancia en el proceso de investigación; y no estructurada, es aquella que ofrece libertad en la formulación de preguntas e intervención del entrevistado.

Otros autores como Bauer y Gastell (2002) (citados por Silva, Costa, \& Jesus, 2016) mencionan que la entrevista como grupo focal es un debate abierto accesible a todos los asuntos de interés común, donde no hay diferencia entre el status de los participantes del grupo, lo interesante en ella es la discusión racional en el sentido de respeto y escucha por los pensamientos y opiniones del otro; mencionando además, que la diferencia entre una entrevista individual y una grupal, es que en la primera las respuestas son exploradas en detalle, el entrevistado es el centro de atención de la misma, mientras en la segunda el entrevistador tiene un papel de moderador entre los participantes, es quien los motiva a hablar y a tomar posición frente a lo dicho por los otros participantes (tabla 5). 


\section{Tabla 5. Comparación entre entrevista individual y focal}

\begin{tabular}{|c|c|c|}
\hline İtem & Entrevista individual & pal \\
\hline 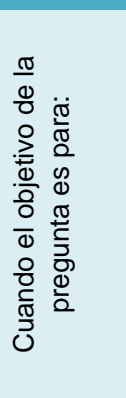 & $\begin{array}{l}\text {-Explorar en profundidad el mundo de la } \\
\text { vida del individuo. } \\
\text {-Hacer un estudio de caso con } \\
\text { entrevistas repetidas en el tiempo. } \\
\text { - Validar un instrumento o cuestionario } \\
\text { (investigación cognitiva). }\end{array}$ & $\begin{array}{l}\text {-Explorar el espectro de actitudes, } \\
\text { opiniones y comportamientos. } \\
\text {-Observar los procesos de consenso y } \\
\text { divergencia. } \\
\text { - Orientar al investigador a un campo de } \\
\text { investigación y al uso de un lenguaje } \\
\text { local. } \\
\text {-Adicionar detalles contextuales o } \\
\text { pensados como cuantitativos. }\end{array}$ \\
\hline 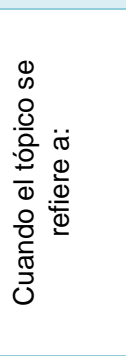 & $\begin{array}{l}\text {-Experiencias individuales, detalladas, } \\
\text { preferencias y biografías personales. } \\
\text {-Asuntos de sensibilidad particular que } \\
\text { pueden provocar ansiedad. }\end{array}$ & $\begin{array}{l}\text {-Asuntos de interés público o } \\
\text { preocupación común, por ejemplo, del } \\
\text { campo de la política, media, } \\
\text { comportamiento de los consumidores, } \\
\text { placer, nuevas tecnologías. } \\
\text {-Asuntos y preguntas familiares de } \\
\text { naturaleza relativamente no familiares o } \\
\text { hipotéticas. }\end{array}$ \\
\hline 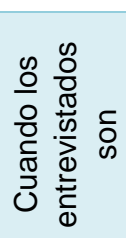 & $\begin{array}{l}\text {-Difíciles de agrupar; por ejemplo, } \\
\text { personas de edad, mamás con hijos } \\
\text { pequeños, personas enfermas. } \\
\text {-Entrevistados de la elite o alto status. } \\
\text { Niños menores de siete años. }\end{array}$ & $\begin{array}{l}\text { No tiene orígenes tan diversos que } \\
\text { puedan inhibir la participación en la } \\
\text { discusión del tópico. }\end{array}$ \\
\hline
\end{tabular}

Fuente. Bauer y Gastell (2002) En: Silva et al. (2016, p. 5)

La utilización de entrevistas focales, permite al investigador comprender a los sujetos involucrados en la investigación, a partir de las interacciones colectivas que surgen durante el intercambio de ideas, promoviendo resultados inesperados, que difícilmente se obtendrían de una entrevista común o con la aplicación de un cuestionario.

Respecto a la metodología de análisis, se usó el Análisis Textual Discursivo (ATD) concebido como un camino de pensamiento del investigador, en el que se asume un viaje sin mapa, fundamentado en la libertad del pensamiento, como movimiento dinámico a partir del cual el investigador construye sin punto determinado de partida o de llegada. Este tipo de análisis puede ser comprendido como un proceso auto organizado y emergente, de construcción de comprensiones en los que los nuevos entendimientos emergen de una secuencia recursiva de desmontaje de textos, establecimiento de relaciones y aceptación de un nuevo 
emergente (Moraes \& Galiazz, 2007).

Acorde al carácter de la investigación presentada, enfocada en conocer las ventajas y desventajas de abordar CSC con enfoque CTSA en la construcción del CPP del profesor al interior del GI de los profesores en un proceso de formación en la IUE, el ATD constituye una metodología importante para el análisis de datos, permitiendo establecer categorías emergentes con una mirada crítica y comprensiva de lo que ocurre al interior del $\mathrm{Gl}$, en el contexto social en el que los profesores desarrollan su práctica profesional y laboral; así como también, posibilita reconocer los aportes de procesos de formación en el contexto de la investigación del CPP, y el vínculo de los propósitos de enseñanza con el desarrollo de la racionalidad científica, tecnológica y social. En palabras de Correa \& Bazzo (2017):

Es urgente, por lo tanto, la necesidad de preparar una fuerza de trabajo equipada con talentos que incorporen a su modelo mental y a sus actividades una postura más proactiva, critica y reflexiva; profesionales que, teniendo en mente la complejidad del mundo en que viven, sepan que nadie por si sólo tiene el conocimiento necesario para que las cosas sucedan, cuya autoimagen no sea la de "otra pieza en el engranaje", un "recurso humano" como sucedía en la era industrial, pero si la de alguien que piensa y participa del mundo y su alrededor.(p.66)

El ATD se sitúa entre el abordaje de análisis de contenido (AC) y el análisis del discurso $(A D)$ focalizándose en la profundidad y complejidad de los fenómenos, tanto el $A C$ como el $A D$ y el análisis textual (AT) se encuentran en un único dominio correspondiente al ATD. Es posible utilizarlos por separado, analizar un hecho utilizando cada una de las estrategias mencionadas, indicando que el ATD asume presupuestos que lo localizan entre el $A C$ y el $A D$, pero que en conjunto constituyen una herramienta dinámica para plantear y construir texto como lo plantea Moraes \& Galiazzi (2007).

$A C$ y $A D$ pueden ser concebidos como formas de moverse en un río; la primera se 
asemeja a hacer el recorrido siguiendo la corriente del mismo y la segunda enfrentando la corriente y el ATD puede moverse a favor $y$ en contra corriente, tendiendo más a explorar en la profundidad del río. Lo planteado se visualiza en la figura 31 (Moraes \& Galiazz, 2007).
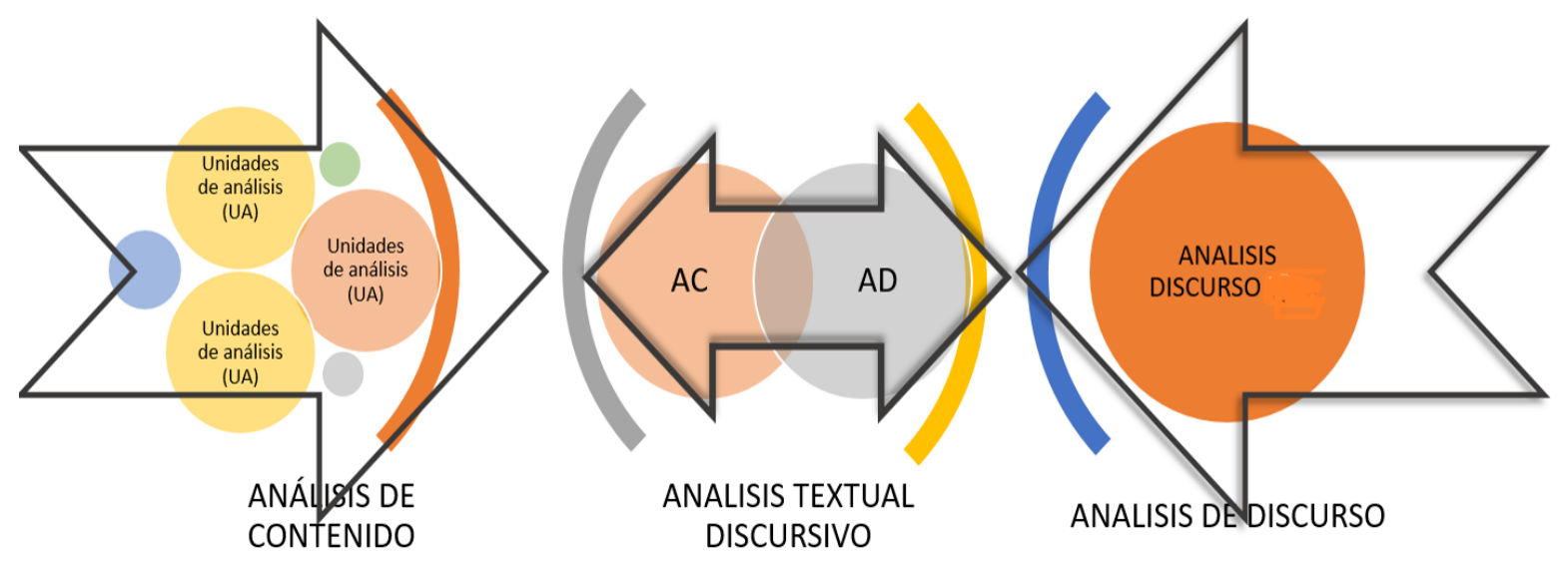

Figura 31. AC y $A D$ en un continuo de características polarizadas Fuente. Autora con base en Moraes \& Galiazzi (2007)

En el ATD deben organizarse los datos, en este caso dicha tarea se realizó con la ayuda de un software Nvivo 11, teniendo en cuenta las siguientes etapas propuestas por Moraes \& Galiazzi (2007):

- Desmontaje de los textos: implica examinar los textos detalladamente, fragmentarlos de acuerdo al fenómeno estudiado, en el caso de la investigación con la ayuda de las categorías utilizadas por (Martínez, 2016, 2017) presentadas en la figura 5, aterrizadas a la investigación. En esta etapa las partes fragmentadas del texto deben ser focalizadas según los detalles específicos, ya que en todo proceso de descomposición textual los detalles deben ser resaltados, y el investigador es el responsable de elegir la fragmentación de los mismos, así surgen las unidades de análisis (UA) que posteriormente se convertirán en las categorías de análisis.

- Establecimiento de relaciones: es el proceso de categorización, en el que se construyen relaciones entre las unidades base combinándolas, clasificándolas, reuniendo elementos unitarios hasta congregarlos en categorías. Para lo cual se requiere que el investigador lea, relea, recuerde, evoque los momentos en los que 
reunió la información, para que pueda seleccionar lo pertinente y eliminar los excesos, para que los pueda presentar en forma sintética y ordenada. "La categorización es un proceso de creación, ordenamiento y síntesis. Constituye al mismo tiempo procesos de construcción y de comprensión de los fenómenos investigados" (Moraes \& Galiazzi, 2007, p. 78). Las relaciones también pueden ser flexibles, si un elemento pertenece a un grupo específico de categoría, pero puede encajar en otro, no se hace obligatoria la exclusividad, una misma unidad puede ser leída desde diferentes perspectivas, puede incluso pertenecer a varias, por esta razón supera la fragmentación.

- Captando el nuevo emergente (comunicación): en la medida que se va categorizando (categorías a priori), surgen nuevas categorías (emergentes), que generalmente son más amplias que las iniciales; esta etapa se estructura a partir de las categorías apriori, interpretaciones y nuevos argumentos, representando así, en su conjunto, la teorización y la comprensión construida a partir de la investigación, lo que la hace más exigente, de mayor criterio para establecer relaciones entre las categorías, que deben ser descriptivas e interpretativas. En el caso de la presente investigación son consolidadas en la tabla 9.

- Un proceso auto organizado: considerado como ciclo de análisis, aunque está compuesto de elementos racionalizados y en cierta medida planeados, al ser visto como unidad puede ser comprendido como un proceso de auto organización del cual emergen nuevas compresiones o nuevos textos descriptivos y argumentativos. Descriptivos expresados por el sentido de los textos organizados, secuenciados y estructurados y argumentativos en lo referente a la teorización de la investigación, expresando las relaciones existentes entre las categorías que permitieron establecer las relaciones entre las a priori, las emergentes y gestar un proceso de comprensión de la situación abordada en la investigación, en busca de nuevas comprensiones, sentidos y significados.

Moraes \& Galiazzi (2007) grafican en forma general la manera como funciona el proceso de categorización: las categorías iniciales reúnen elementos con una aproximación muy estrecha formando categorías iniciales; posteriormente, en los 
otros niveles se reagrupan dichas categorías en ámbitos cada vez más amplios, siempre reuniendo lo que se encuentra próximo. En este modo de categorización se aprovecha todo el material disponible, hasta llegar a la creación de categorías finales que como se mencionó son los constructos teóricos descriptivos y argumentativos que dan la creación de la teoría posiblemente emergente o la comprensión del caso (figura 32).

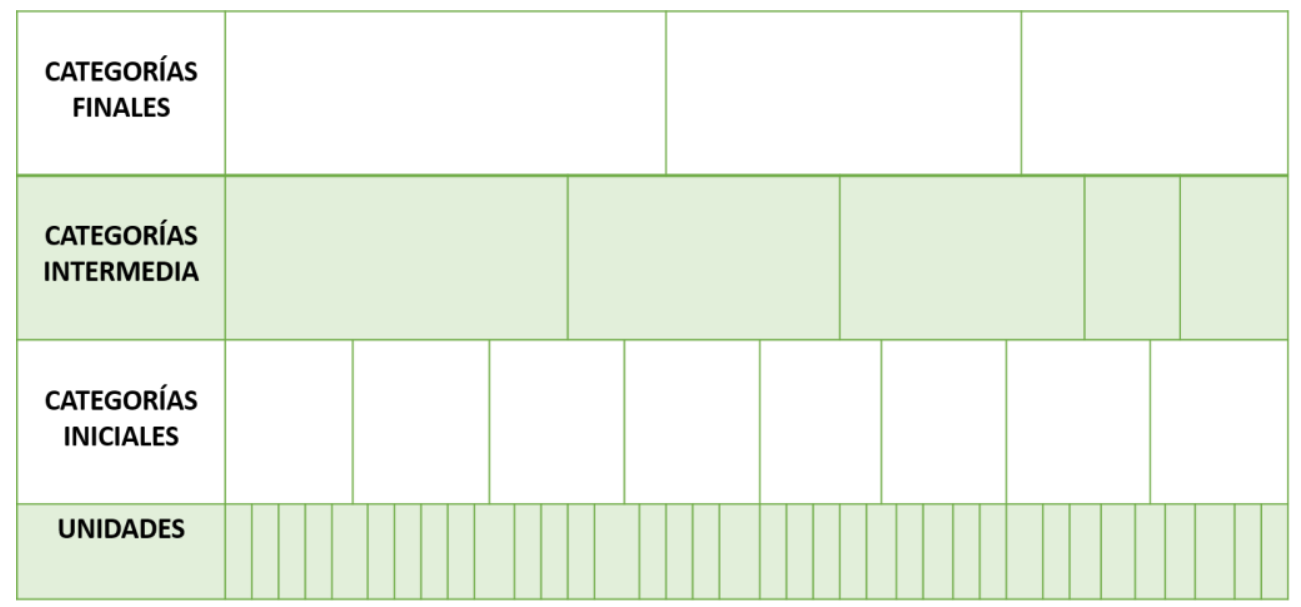

Figura 32. Categorización inductiva emergente.

Fuente. Moraes \& Galiazzi (2007)

Como herramienta de análisis en la tesis se hace uso del software NVivo11 que articulado con la metodología de análisis (ATD) se constituye en el eje articulador para comprender e interpretar los resultados que se presentan; este software trabaja con el concepto de proyecto, lo que implica que las fuentes de información, las categorías y los datos generados durante el proceso son almacenados en el mismo software.

\subsection{TRAYECTORIA METODOLÓGICA}

A continuación, se presentan las fases de la investigación y la descripción de los encuentros realizados durante el proceso de formación, indicando los objetivos, actividades realizadas, materiales utilizados y técnicas de registro en cada una de las etapas: 


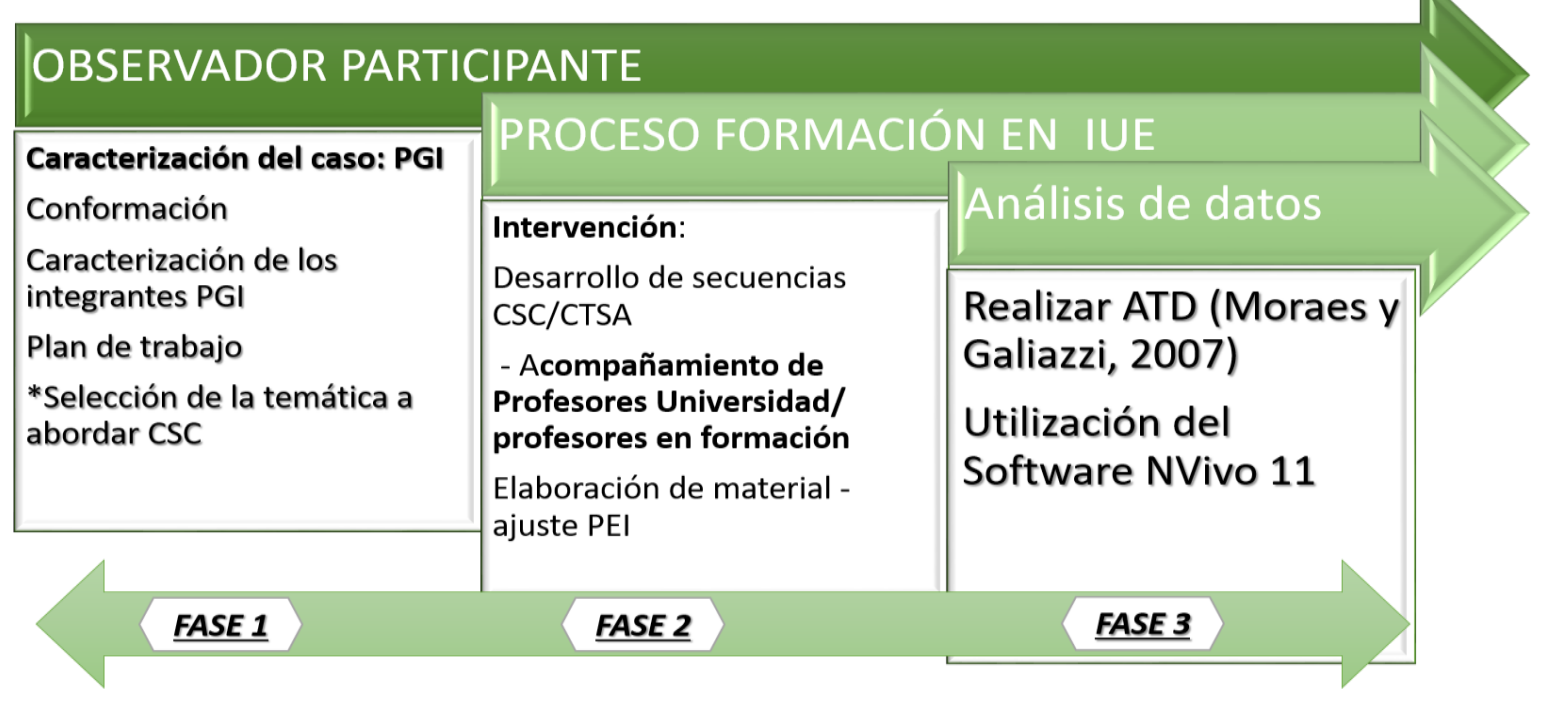

Figura 33. Fases metodológicas de la investigación

- Fase de caracterización: evidencia el proceso constitución del PGI en la IUE como un proceso de formación de profesores, la conformación y organización del mismo, así como el planteamiento de expectativas de trabajo y la selección de CSC.

- Fase de formación en IUE o la de intervención: reporta la metodología de trabajo pedagógico y didáctico realizado con los profesores, generalmente desarrollado en forma de secuencia didáctica y articulado con proyectos externos al colegio vinculados a la formación de docentes, dando también espacio a los estudiantes, devela la dinámica interna de trabajo asumida por el grupo, el acompañamiento de investigadores y profesores de la universidad tanto de la UPN como de la UNESP.

- Fase de análisis de datos: presenta los resultados obtenidos en el transcurso de la investigación a través del papel de la investigadora como observadora participante, la interacción ATD/NVivo como dispositivo de análisis, la HdPR que surge como resultado de las categorías iniciales y emergentes, los instrumentos utilizados y los productos generados al interior del grupo como producto del proceso de formación (secuencias 
didácticas, orientaciones curriculares y metodología colectivas visibilizadas en el PEI de la jornada, etc.),

Antes de profundizar en cada una de las fases, se presentan a continuación en la Tabla 6 las actividades planteadas en cada una de ellas. 
Tabla 6. Instrumentos utilizados durante el proceso de formación de profesores en la IUE al abordar CSC con enfoque CTSA en la IUE

\begin{tabular}{|c|c|c|c|c|c|c|}
\hline 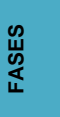 & & ACTIVIDADADES & INSTRUMENTO & $\begin{array}{l}\text { OBJETIVO ESPECIFFICO DEL } \\
\text { INSTRUMENTO }\end{array}$ & $\begin{array}{l}\text { ESPACIO } \\
\text { DE } \\
\text { TRABAJO }\end{array}$ & PERIODO \\
\hline \multirow{6}{*}{ 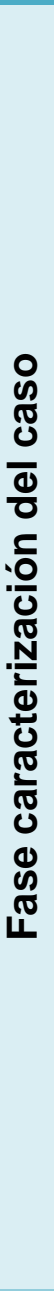 } & \multirow{6}{*}{ 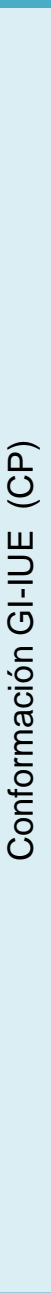 } & Convocatoria & $\begin{array}{l}\text { Acta } \\
\text { Observación } \\
\text { participante } \\
\text { (Anexo 1) }\end{array}$ & $\begin{array}{l}\text { Constituir un Gl en la IUE en el } \\
\text { marco de un programa Colombo } \\
\text { brasileño de formación de } \\
\text { profesores COL-UPN -531-12 }\end{array}$ & $\begin{array}{l}\text { Colegio } \\
\text { Guillerm } \\
\text { o Cano } \\
\text { Isaza } \\
\text { (GCl) }\end{array}$ & agosto 2013 \\
\hline & & Formación Gl & $\begin{array}{l}\text { Actas } \\
\text { (Anexo 2) }\end{array}$ & $\begin{array}{l}\text { Conformación del Gl como } \\
\text { proceso de formación de } \\
\text { docentes en IUE y de trabajo } \\
\text { interdisciplinar de los profesores } \\
\text { de la jornada noche del GCl. }\end{array}$ & $\begin{array}{l}\text { GCl } \\
5: 30 \quad- \\
6: 30 \mathrm{pm}\end{array}$ & Agosto 2013 \\
\hline & & Temática (s) a abordar & $\begin{array}{l}\text { Actas } \\
\text { grabaciones } \\
(\text { Anexo 2) }\end{array}$ & $\begin{array}{l}\text { Abordar temáticas en el contexto } \\
\text { de CSC acordes a las } \\
\text { necesidades locales y en especial } \\
\text { de población de jóvenes y } \\
\text { adultos. }\end{array}$ & $\begin{array}{l}\mathrm{GCl} \\
5: 30 \quad- \\
6: 30 \mathrm{pm}\end{array}$ & $\begin{array}{l}\text { Octubre } \\
2013\end{array}$ \\
\hline & & $\begin{array}{l}\text { Caracterización de los } \\
\text { profesores del Gl }\end{array}$ & $\begin{array}{l}\text { Cuestionario } \\
\text { inicial } \\
\text { (Anexo 3) }\end{array}$ & $\begin{array}{l}\text { Caracterizar los profesores de la } \\
\text { jornada nocturna en aspectos } \\
\text { relacionados con: datos } \\
\text { generales, formación profesional, } \\
\text { experiencia laboral y participación } \\
\text { en proyectos de investigación. }\end{array}$ & $\begin{array}{l}\text { Jornada } \\
\text { laboral y } \\
\text { correo }\end{array}$ & Agosto 2013 \\
\hline & & $\begin{array}{l}\text { Plan de trabajo - articulado a } \\
\text { Incitar (proyecto SED) }\end{array}$ & $\begin{array}{l}\text { Ficha Excel } \\
\text { (Anexo 4) }\end{array}$ & $\begin{array}{l}\text { Organizar y articular el proceso } \\
\text { de formación con el desarrollo de } \\
\text { un proyecto para estudiantes } \\
\text { Incitar. }\end{array}$ & $\begin{array}{l}\text { Jornada } \\
\text { pedagógi } \\
\text { ca (5 } \\
\text { horas) }\end{array}$ & Marzo 2014 \\
\hline & & $\begin{array}{l}\text { Inmersión en la formación a } \\
\text { través de la realización de }\end{array}$ & $\begin{array}{l}\text { Talleres IUE } 5 . \\
\text { IA. taller CSC }\end{array}$ & $\begin{array}{l}\text { Taller de IA sensibilización de la } \\
\text { importancia de investigar en el }\end{array}$ & GCI 5:30 & \\
\hline
\end{tabular}




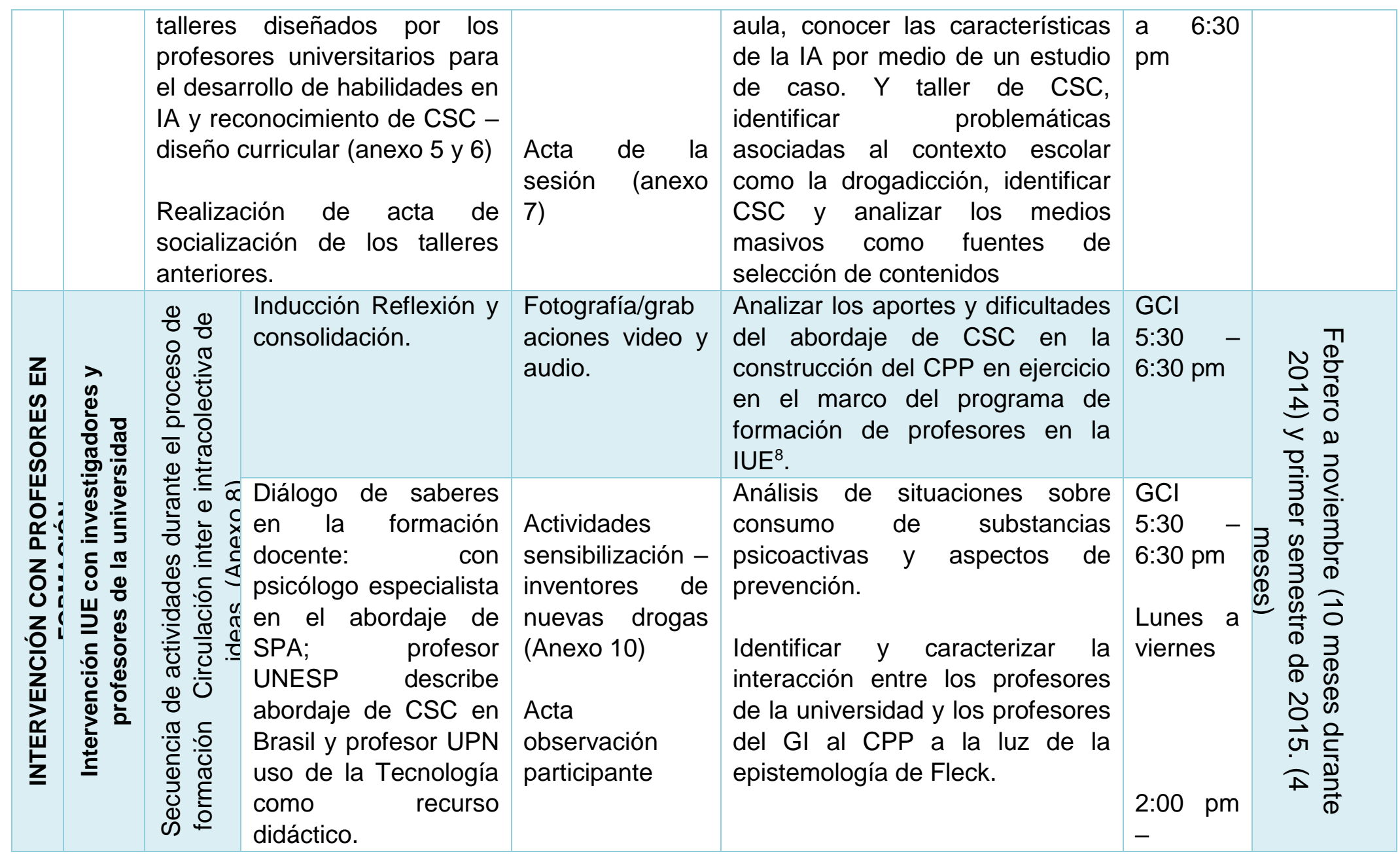

${ }^{8}$ En este tipo de investigaciones la información en sí misma no constituye los datos, estos son el resultado del proceso de investigación que se realiza a partir de los referentes teóricos y de las preguntas de investigación. 


\begin{tabular}{|c|c|c|c|c|c|c|}
\hline & & $\begin{array}{l}\text { Los profesores visitan } \\
\text { el Museo del Hombre: } \\
\text { http://bogotaturismo.g } \\
\text { ov.co/museo- } \\
\text { exposicion-el-hombre }\end{array}$ & $\begin{array}{l}\text { Taller } \\
\text { CSC/CTSA } \\
\text { GI } \\
\text { (Anexo 13) }\end{array}$ & $\begin{array}{l}\text { Interactuar con espacios de } \\
\text { formación no formal de manejo } \\
\text { de Spa desde el punto de vista } \\
\text { médico y de prevención al riesgo. } \\
\text { Diseñar un cuestionario taller de } \\
\text { cierre de actividades de } \\
\text { acompañamiento }\end{array}$ & $8: 00 \mathrm{pm}$ & \\
\hline & & $\begin{array}{l}\text { Primeras propuestas } \\
\text { para generar cambios } \\
\text { en las prácticas } \\
\text { profesionales (Anexo } \\
9,18 \text { ) }\end{array}$ & \begin{tabular}{l}
\multicolumn{2}{l}{ Cuestionario } \\
individual sobre \\
criterios de \\
selección y de \\
validez \\
(Anexo 14)
\end{tabular} & $\begin{array}{l}\text { Evaluar el aporte del abordaje de } \\
\text { las CSC en la dinámica del aula } \\
\text { de los profesores en ejercicio a } \\
\text { través de las actividades } \\
\text { realizadas con sus estudiantes. }\end{array}$ & $\begin{array}{l}\mathrm{GCl} \\
5: 30 \quad- \\
6: 30 \mathrm{pm}\end{array}$ & \\
\hline \multirow{2}{*}{ 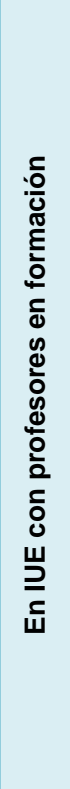 } & \multirow{2}{*}{ 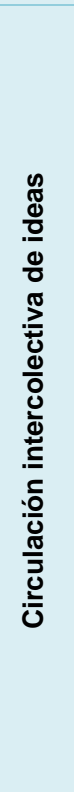 } & $\begin{array}{l}\text { Como estudiantes } \\
\text { universitarios (Anexo } \\
11 \text { ) } \\
\text { Como participantes } \\
\text { locales }\end{array}$ & \multirow[t]{2}{*}{$\begin{array}{l}\text { Fotografía y } \\
\text { videos - audio }\end{array}$} & $\begin{array}{l}\text { Socializar a la comunidad } \\
\text { educativa y de la localidad el } \\
\text { trabajo realizado en torno a la } \\
\text { CSC : drogadicción en jóvenes y } \\
\text { adultos y el proceso de formación } \\
\text { en IUE a través de un taller a } \\
\text { visitantes y Posters (Anexo } 11 \text { y } \\
\text { 12) }\end{array}$ & $\begin{array}{l}\text { 7:00 am } \\
5: 00 \mathrm{pm} \\
(10 \\
\text { horas) }\end{array}$ & $\begin{array}{l}\text { septiembre } \\
2015\end{array}$ \\
\hline & & $\begin{array}{l}\text { Con acompañamiento } \\
\text { de estudiantes en } \\
\text { formación (Anexo 17): } \\
\text { Residuos a la } \\
\text { CARTA: una cuestión } \\
\text { sociocientífica para } \\
\text { favorecer el desarrollo } \\
\text { profesional del profesor, } \\
\text { en un espacio de }\end{array}$ & & $\begin{array}{l}\text { Desarrollar una tesis de pregrado } \\
\text { entorno al CPP utilizando una } \\
\text { CSC (en el link anexo es la } \\
\text { pestaña 6). } \\
\text { http://catalogo.pedagogica.edu.co/cgi- } \\
\text { bin/koha/opac- } \\
\text { search.pl?q=au:Rodr\%C3\%ADguez\%20Hern } \\
\text { \%C3\%A1ndez,\%20Blanca\%20and\%20au:dire } \\
\text { ctora }\end{array}$ & $\begin{array}{l}\mathrm{GCl} \\
5: 30 \quad- \\
6: 30 \mathrm{pm}\end{array}$ & $\begin{array}{l}\text { Octubre } \\
\text { noviembre } \\
2015\end{array}$ \\
\hline
\end{tabular}




\begin{tabular}{|c|c|c|c|c|c|}
\hline & $\begin{array}{l}\text { articulación universidad- } \\
\text { escuela }\end{array}$ & & & & \\
\hline & Cierre acompañamiento IUE & $\begin{array}{l}\text { Entrevista focal } \\
\text { (grabada en } \\
\text { audio) } \\
\text { (Anexo 20) }\end{array}$ & $\begin{array}{l}\text { Evaluar la dinámica de las } \\
\text { interacciones y los efectos de la } \\
\text { participación en el programa de } \\
\text { formación de profesores en IUE } \\
\text { al CPP en el contexto } \\
\text { epistemológico de Fleck }\end{array}$ & $\begin{array}{l}\mathrm{GCl} \\
5: 30 \quad- \\
6: 30 \mathrm{pm}\end{array}$ & $\begin{array}{l}\text { Noviembre } \\
2015\end{array}$ \\
\hline \multirow{2}{*}{ 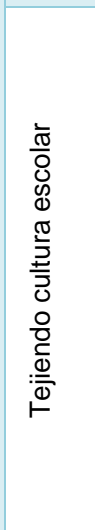 } & $\begin{array}{l}\text { Elaborando el PEl }- \\
\text { propuesta curricular (Anexo } \\
\text { 19) }\end{array}$ & \multirow[b]{2}{*}{$\begin{array}{l}\text { Entrevista semi } \\
\text { estructurada } \\
\text { individual } \\
\text { (Anexo 21) }\end{array}$} & $\begin{array}{l}\text { Diseñar un Proyecto Educativo } \\
\text { Institucional en el contexto de la } \\
\text { educación de Jóvenes y adultos } \\
\text { (PEI) }\end{array}$ & $\begin{array}{l}\mathrm{GCl} \\
5: 30 \quad- \\
6: 30 \mathrm{pm}\end{array}$ & $\begin{array}{l}\text { Enero } \\
\text { Junio } 2016\end{array}$ \\
\hline & $\begin{array}{l}\text { Diseñando secuencias CSC } \\
\text { (Anexo 16) } \\
\text { Acompañamiento de profesor } \\
\text { Universidad - uso de la } \\
\text { tecnología (Anexo 15) }\end{array}$ & & $\begin{array}{l}\text { Evaluar la dinámica de las } \\
\text { interacciones y los efectos de la } \\
\text { participación en el programa de } \\
\text { formación de profesores en IUE } \\
\text { al CPP en el contexto } \\
\text { epistemológico de Fleck }\end{array}$ & $\begin{array}{l}\mathrm{GCl} \\
5: 30 \quad- \\
10: 00 \mathrm{pm}\end{array}$ & $\begin{array}{l}\text { Julio } \\
\text { noviembre } \\
2016\end{array}$ \\
\hline 3 & \multicolumn{5}{|c|}{$\begin{array}{c}\text { ANÁLISIS DE DATOS (2017) } \\
\text { ATD /SOFTWARE NVIVO A LA LUZ DE UNA HdPR }\end{array}$} \\
\hline
\end{tabular}

Fuente. Actividades e instrumentos diseñados en el transcurso de la investigación CPP al abordar CSC/CTSA en IUE 


\subsubsection{Convocatoria y formación del GI-IUE (CP)}

La realización de la investigación se llevó a cabo de manera articulada con el programa Colombo-brasileño de formación de profesores de ciencias en la IUE entre la UPN y Colciencias, para lo cual se convocó a diferentes escuelas para conformar Gl con la particularidad de ser profesores de las escuelas, pero en la que al menos uno de sus integrantes estuviera en la escuela y la universidad. En este caso la autora de la tesis hace parte de las dos instituciones del colegio IED $\mathrm{GCl}$ donde labora como coordinadora (académica y de convivencia) y en la UPN donde es profesora catedrática del departamento de Química y estudiante del programa de doctorado en Educación.

El IED GCI es una Institución Educativa del distrito ubicado al sur de la Ciudad (Bogotá), en la localidad 19 denominada Ciudad Bolívar. Es una de las localidades más vulnerables de la capital, caracterizada porque sus habitantes son víctimas del desplazamiento, de la falta de recursos, han pasado por procesos de reinserción, allí muchos barrios se han forjado espontáneamente producto de la invasión (Anexo 19 y 23), y de altos niveles de corrupción.

El GCl tiene tres jornadas académicas: mañana, tarde y noche. La jornada diurna tiene horario de 6:10 am a 12:20 pm (mañana), de 12:30 pm a 6:25 pm (Tarde) y la nocturna de 6:30 pm a 10:00 pm. Por el alto consumo de sustancias Psicoactivas (SPA) (Anexo 22) se utiliza como estrategia, dar espacio para el descanso al ingreso de la jornada, de tal manera que se permite el ingreso de estudiantes de 6:30 a 6:45 y a las $6: 50 \mathrm{pm}$, se inicia el primer bloque de clase (6:50 - 8:30 pm) y el segundo de (8:30 a 10:00 pm); la convocatoria para participar en el programa de formación en IUE se realiza en la jornada noche, por el vínculo laboral de la autora de la tesis.

Los docentes ingresan a las 5:30 pm, realizan reuniones de área, planeación y demás actividades escolares dirigidas por la coordinadora de 5:30 a 6:30 pm de lunes a viernes, dicho espacio se aprovecha para realizar la convocatoria. Los docentes acostumbrados a realizar procesos de formación permanente en lugares 
diferentes al contexto laboral y generalmente asociados a estímulos económicos, reflejan atención frente a lo que se propone, pero sus miradas se cruzaban y murmuraban: "otro proyecto más, ahora qué toca hacer, más trabajo... si aquí hay bastante", proyectando además la desconfianza que genera lo que viene de fuera de la escuela y en especial de la universidad.

Lo anterior, es fruto del imaginario que tienen los docentes sobre ser usados como objeto de investigación académica, alimentado por experiencias en las que se han construido teorías para una práctica escolar, pero que pocas veces llegan a los mismos profesores investigados. Son pocas las investigaciones en las que el investigador y el investigado construyen conocimiento como pares académicos (Gamboa, 2007) y como menciona (Bortoletto, Freitas, Oliveira, \& Carvalho, 2016) la tensión y las dificultades del trabajo docente son producto de la pérdida de autonomía causada por procesos de burocratización que conllevan a la proletarización del trabajo docente.

Ante estas "miradas de desconfianza y murmullos" de los profesores, se les pregunta por las problemáticas del contexto escolar, especialmente las que se presentan en su diario vivir, su respuesta (similar a como cuando se pregunta a los estudiantes sobre algo que les gusta, por ser obvio, cotidiano, fácil de comprender) fue:

La falta de interés por el estudio, el bajo nivel académico, la deserción constante por causas laborales, por cambio de domicilio o (en tono desalentador) por amenazas, por problemas económicos, la exclusión e incluso el asesinato de algunos de nuestros estudiantes que tienen problemas con la justicia, por consumo de SPA, por ajuste de cuentas, etc. Otras causas no tan frecuentes pero que se han dado por suicidio (nuevamente vuelven los murmullos y remembranzas por estudiantes que han perdido la vida por esta última causa).

Una profesora usando una analogía con las calles problemáticas de la ciudad por el consumo dice: 
En este colegio tenemos la calle del "Bronx", "la ele", "Cinco huecos"; hay venta y consumo de SPA [...] ¿Qué vamos a hacer con los estudiantes que encontremos consumiendo? ¿Llamamos a la policía? ¿Los llevamos a coordinación o para la calle? ¿Vamos a seguir permitiendo que los consumidores sigan ingresando a sus filas más personas sanas? ¿A los pocos que no consumen? ¿Qué posición vamos a tomar? ¿Qué medidas vamos a tomar?...

Preguntas como las anteriores, ponen en evidencia la realidad escolar, en la que la universidad posiblemente por falta de recursos que garanticen su autonomía no ha participado, disminuyendo su labor social por responder a políticas de mercado (Caetano, Costa, \& Domingues, 2009).

Por su parte Tardif (2000), hace referencia al distanciamiento entre los saberes profesionales de los profesores de la escuela y los conocimientos de los profesores universitarios, recalcando que la práctica profesional no es un espacio de aplicación de los conocimientos universitarios:

Ella es, en la mejor de las hipótesis, un proceso de filtración, que los diluye y los transforma en función de las exigencias del trabajo; ella es, en la peor de las hipótesis, un muro contra el cual se ven jugar y morir conocimientos universitarios considerados inútiles, sin relación con la realidad del trabajo diario del docente ni con los contextos concretos del ejercicio docente.

[...] Diciendo de una manera más polémica, si los investigadores universitarios quieren estudiar los saberes profesionales del área de enseñanza, deben salir de sus laboratorios, salir de sus gabinetes de la universidad, soltar sus computadores, soltar sus libros y los libros escritos por sus colegas que definen la naturaleza de la enseñanza, los grandes valores educativos o las leyes del aprendizaje, e ir directamente a los lugares donde los profesionales de la enseñanza trabajan, para ver cómo ellos piensan y hablan, cómo trabajan en los salones de clase, cómo transforman los programas escolares para hacerlos efectivos, cómo interaccionan con los padres de los estudiantes, con sus compañeros de trabajo, etc. (p.12)

Finalmente, Chapani (2010) dice: 
La formación de profesores ha servido principalmente como socialización, eventualmente como expresión de alguna resistencia, pero poco ha colaborado en la construcción de propuestas contra-hegemónicas, radicadas en el mundo de la vida, arraigadas en el mundo de la vida. (p.202)

Así, a pesar de las prevenciones de los profesores, frente al programa de formación, se evidenció la preocupación generalizada por la problemática del uso/abuso de las SPA, se reflexionó alrededor de algunas de las afirmaciones mencionadas por los profesores, como por ejemplo si, ¿realmente todos los estudiantes son consumidores? ¿Qué tipo de sustancias consumen?, ¿Con qué frecuencia?, ¿Qué nivel de consumo se presenta? ¿Qué medidas tomar, para el manejo del mismo?, entre otras.

De esta manera se develó, la posibilidad de participar de la convocatoria, la necesidad de formación de los profesores de la escuela en interacción con los profesores de la universidad, para construir y reconstruir el CPP de ambas instituciones en un contexto particular: la escuela.

Una vez finalizada la presentación del programa de formación de profesores en IUE, se acordó, el diseño de un instrumento que permitiera conocer si los estudiantes consumían SPA; así mismo, se concretó la articulación de la iniciativa con la construcción de un proyecto direccionado por la Secretaria de Educación Distrital (SED) denominado Incitar, cuyo objetivo era favorecer la cultura ciudadana.

El Gl de profesores de la jornada noche del $\mathrm{GCl}$ consolidado en el marco del proyecto de formación IUA Colombo Brasileño, se ajusta a la jornada laboral docente, de tal manera que no sea "un proyecto más" sino el eje articulador que adicional a la formación de profesores se convierte en un semillero de tejido social 
y cultural que posibilite la formación de un CP caracterizado por la construcción de un EP dado por la construcción social del conocimiento escolar y del CPP.

La orientadora de la jornada e integrante del Gl hace una presentación de los resultados obtenidos a través de una encuesta de caracterización de los estudiantes de la jornada noche del $\mathrm{GCl}$, dichos resultados reflejan la preocupación de los profesores, por el alto consumo de las SPA en cada uno de los ciclos de Educación de Jóvenes y Adultos (EJA), hace entrega a cada profesor del informe obtenido de la muestra de estudiantes caracterizados por ciclo (Anexo 22), evidenciando que el $70 \%$ de los estudiantes son consumidores de SPA en diferentes niveles: abusivo, experimental, social e inicial; siendo el primero el de mayor frecuencia.

Acorde con al lema institucional, ¡No a la Droga!, ¡Sí a la vida!, ¡Aquí trabajamos por el conocimiento, la dignidad, la paz y la democracia con justicia social, los docentes abordaron la controversia denominada "Legalización de la droga /producción /consumo) en Colombia: un mal o una solución”.

Una de las grandes problemáticas a las que se ha enfrentado la sociedad es el fenómeno de la producción, tráfico y consumo de drogas, especialmente psicoactivas, puesto que el consumo de las mismas afecta la salud pública de los ciudadanos y la producción/tráfico genera inseguridad, violencia y enriquecimiento ilícito.

En este contexto el Gl retoma los planteamientos de Cohen (2004), quien considera que la educación es uno de los medios más adecuados para reducir los daños asociados al consumo de SPA, ya que prevenir contra el consumo como política no ha generado resultados positivos, cobra más valor, educar sobre las drogas que en contra de las mismas; se trata de no juzgar, disculpar o condenar el consumo de drogas, sino de entender los factores asociados a su existencia. Así, 
la apuesta por una educación del consumidor resulta interesante y se orienta a un dialogo abierto y honesto, respetando el derecho de este a tomar sus propias decisiones.

De este modo, la propuesta de formación de profesores en ejercicio en la IUE favorece la consolidación de un espacio de reflexión, de construcción de saberes alrededor de unas temáticas de interés para los docentes, que direcciona la estilización del pensamiento de este colectivo o Gl. Los participantes como pares académicos, al tener un interés común, luchan internamente contra sus propias incertidumbres y contradicciones de pensamiento, generan estados de equilibrio, intentan mantener o consolidar a través del diálogo la construcción y reconstrucción de ideas alrededor de dicha temática (Fleck, 1986).

El proceso de formación como Gl se realizó en la escuela, en una franja diaria de 5:30 pm a 6:30 pm y en jornadas pedagógicas o semanas de desarrollo institucional de 5:30 pm a 10:00 pm. Se articula el proceso de formación de profesores en la IUE al proyecto Incitar, el Gl participó de una convocatoria propuesta por la SED cuyo propósito, como se mencionó anteriormente, era la promoción de capacidades ciudadanas, enmarcado en el contexto de la CSC y de las mismas actividades programadas al interior del Gl. (Ver Anexo 4).

Una vez planteadas las actividades, se desarrollaron al interior del Gl talleres que permitieran reflexionar alrededor de la labor docente, de las prácticas de aula y el papel del profesor como investigador-reflexivo así:

- Taller de investigación- acción e inducción a la caracterización de las CSC (Anexo 5).

- Taller basado en CSC sobre el uso y abuso de las SPA y diseño curricular (Anexo 6). 
Se realizaron a su vez, diversas actividades de sensibilización, de comprensión y fortalecimiento del trabajo en equipo, de la necesidad de saber escuchar y evaluar, así como de la apropiación de las capacidades ciudadanas y toma de decisiones informadas, siempre con una visión crítica/reflexiva del manejo que dan los medios masivos de comunicación a las problemáticas y cómo se asume cada una de ellas dependiendo de la credibilidad que tiene quien las expone o socializa.

\subsubsection{Caracterización de los profesores del GI}

Para la caracterización de los profesores del PGI se aplicó un cuestionario (Anexo 3) a los 19 profesores, de los cuales 7 son de planta (o en propiedad), 11 de horas extras y la orientadora. En el cuestionario se consideraron los siguientes aspectos: datos generales de los profesores: edad, género, título de pregrado, nivel de estudios, cargo actual que desempeñan, tiempo de servicio e informaciones sobre las experiencias en el campo de trabajo como profesor y algunos aspectos de la perspectiva CTSA. El cuestionario utilizado constituye un elemento secundario en esta investigación, con el que se pretendió registrar de manera sistemática y ordenada la información antes mencionada, este sólo fue de tipo exploratorio (Muñoz, 2003).

Los profesores del GI presentan edades que oscilan entre los 30 y 64 años, de ellos $60 \%$ mujeres y $40 \%$ hombres quienes además de laborar en el $\mathrm{GCl}$ jornada nocturna, trabajan en jornada contraria $(50 \%$ en colegios privados de jornada única, 20\% empleos independientes ( 1 contador, un abogado y dos ingenieros), $20 \%$ en la jornada mañana o tarde del mismo colegio o de colegios próximos y el restante sólo en la jornada nocturna); como se observa en la gráfica 32 casi el $74 \%$ de los profesores están pensionados o próximos a pensionarse ${ }^{9}$; entre los

\footnotetext{
${ }^{9}$ Los docentes nombrados ante el decreto 2277 hasta 1980 se pensionan a los 50 años, los nombrados entre 1981 - 2003 a los 55 años y pueden laborar hasta los 65 años en Colombia.
} 
más jóvenes esta la orientadora y un docente de Biología, vale la pena mencionar que es de horas extras. La experiencia laboral está muy relacionada con la edad, tiempo en el que han ocupado cargos relacionados con su profesión de docente en la básica primaria y en mayor proporción en la educación básica y media.

En cuanto a la formación, todos los profesores del GI son licenciados: 4 en Ciencias Sociales, 4 en Matemáticas, 4 en Humanidades (español-ingles), 3 en Ciencias Naturales (Biologia-Química, Ciencias Naturales y Biología), 2 de Tecnología, una de primaria y la orientadora, en cuanto a la formación postgradual, solo uno de ellos tiene Maestria en Educación, los demás han ascendido en el escalafon a través de cursos cortos ofrecidos por la SED u otras modalidades.

Otros aspecto relevante frente a los conocimientos de los profesores, está relacionado con el manejo de un segundo idioma y el uso de la tecnologia, en el primer aspecto el $58 \%$ no tiene manejo de un segundo idioma, solo un $16 \%$ presenta un buen nivel del mismo (habla, lee y escribe);respecto a los conocimientos que se tienen de la tecnología y su uso, el $73 \%$ tiene conocimientos básicos, relacionados con paquetes de officce, un menor número conoce software especializado y hace uso de TIC; sin embargo, hay que aclarar que para los profesores de planta lo mínimo exigido es el uso del correo, generalmente asistido por terceros.

Para abordar la temática de la formación de profesores en IUE y la relación con el conocimiento del enfoque CTSA, se dio la necesidad de saber, si los profesores del GI conocían este enfoque o lo relacionaban con el PEI institucional por ser de naturaleza técnica, el $90 \%$ de los profesores desconocen el enfoque, incluyendo a los profesores de Ciencia y Tecnología (figura 32).

A la pregunta relacionada con la investigación como profesor, el $58 \%$ de los profesores del GI responden que investigan en el aula, el restante dice que no lo hace, sin embargo este resultado se contradice, ya que el $68 \%$ de los profesores 
dicen no haber participado de proyectos de investigación en los últimos cinco años.

Adicionalmente al cuestionario, la observación participante fue el instrumento transversal de la investigación, dado que la investigadora hace también parte de la escuela, conoce sus dinámicas y a los profesores, eso hace que se genere un equilibrio frente al direccionamiento de la investigación, ella se encarga de mencionar los procesos a realizar, no los impone, dinamiza, contribuye con el quehacer del grupo en general; esto le facilitó la recolección de datos, el registro y análisis de hábitos, comportamientos, actitudes y formas de abordar la práctica pedagógica, pero sin tener que estar dando cuenta al grupo de ello.

\subsection{SEGUNDA FASE O INTERVENCIÓN: FORMACIÓN DE PROFESORES EN IUE}

Para dar inicio al programa de formación en la IUE se diseñaron algunas actividades de reflexión con los profesores, con la pretensión de indagar y reflexionar acerca del perfil de los estudiantes de la jornada noche, hacer visible la importancia del trabajo en equipo regulado por el diálogo y el trabajo entre pares académicos (profesores de la misma área, de diferente área, universitarios y profesionales especializados).

La EJA es una dimensión olvidada en la formación de profesores ya que no se contempla en la formación inicial, el desconocimiento hace que la EJA se perciba como un ejercicio básico, de reposición de una escolaridad perdida, a la que solo acuden las personas que necesitan certificar su escolaridad, pertenecientes a grupos sociales de bajos recursos económicos, provenientes generalmente del campo (sector rural), o personas que han sido excluidas de la escuela, mujeres cabezas de familia, estudiantes con necesidades educativas especiales y/o con características físicas o mentales particulares; en fin, los excluidos de la escuela, 
de la sociedad, del mundo. Los marginados que tienen como factor común la pobreza (Budel, 2016).

Sin embargo, la población que accede a la EJA ya no es en su mayoría adulta, los jóvenes que han sido excluidos del sistema escolar acceden a estos programas, así como también los que han tenido que acceder al campo laboral y eso les ha impedido continuar con su formación, posiblemente por injusticias vividas, pérdida de derechos, ausencia de familia, etc., situaciones que el profesor de EJA debería conocer y contextualizar antes de emprender cualquier tipo de formación disciplinar.

Las situaciones mencionadas deben ser reflexionadas por los profesores del $\mathrm{Gl}$, a su vez deben suscitar la autoevaluación de sus prácticas como tejedores de sociedad, de cultura para empezar a movilizar su pensamiento, sus conocimientos, su CPP a un EP crítico, humano a través de la formación continua, en compañía de pares académicos pertenecientes a otros círculos de pensamiento, cuyos EP se direccionen hacia el nivel integral/transformador.

Hoy más que nunca, la educación y el aprendizaje de esta población, se consolida como una clave para liberar las fuerzas creativas de las personas, de los movimientos sociales y de las naciones; que permitan el reconocimiento de los jóvenes y adultos como personas portadoras de cultura, que al igual que los profesores, educan, cuidan de sí mismos y de sus familias y por tanto poseen múltiples saberes, saben del valor social de la escritura mucho más que los que están en el sistema escolar ya que han estado inmersos en "la escuela de la vida" (Ireland, 2013).

En este contexto, se consideró fundamental que antes de iniciar cualquier proceso de formación, los profesores del Gl iniciaran esa "suave coerción" (Fleck, 1986, p. 151) hacia la construcción del EP de un profesor de EJA consciente y conocedor 
de la población escolar con la que interactúa en su día a día, de tal forma que le permita construir CPP epistemológicamente diferenciado (Martínez, 2017).

Ahora bien, las actividades planteadas se organizaron en cuatro bloques: El primero, denominado "inducción-reflexión y consolidación", con dos actividades que muestran las debilidades que presenta el trabajo docente aislado, independiente y acrítico. A partir de este planteamiento se propusieron las siguientes actividades que pretendían representar el rol del estudiante para valorar el significado de las capacidades ciudadanas:

1. ¿Qué ciudadano queremos formar? ¿Cómo lo hacemos y bajo qué perspectiva curricular se orienta?

2. Vivenciando las Capacidades ciudadanas: el sentido de la vida, el cuerpo y la naturaleza; dignidad y derechos; sensibilidad y manejo de las emociones; participación y convivencia; deberes y respeto por los derechos de los demás e identidad.

El segundo bloque, denominado "diálogo de saberes en la formación de docentes", contempló nueve actividades que permitieron trabajar en equipo, diseñar actividades y recursos didácticos (como pares académicos); y lo más importante, participar y asumir posturas frente al tema de la "Legalización de la droga (producción/consumo) en Colombia: un mal o una solución", dichas actividades se relacionan a continuación

1. Determinación de la CSC.

2. Tomando posición ante la legalización de SPA.

3. Me vuelvo especialista.

4. Visita de un especialista (Norman -SED).

5. Charlas con grupos de consumidores "estudiantes".

6. Elaboración de material didáctico por áreas.

7. Visita de Michel (Unesp, Brasil). 
8. Formación espiritual bajo la orientación de un filósofo.

9. Experiencia de GI de Brasil presentada por el profesor Michel Carnio.

Dichas actividades (Anexo 8), contextualizaron a los docentes acerca de la función social que tienen como constructores de cultura, develaron las posiciones individuales y arraigadas frente al consumo de sustancias psicoactivas, relacionadas a las políticas asociadas y la forma de ver este tipo de problemática o CSC como algo que no se debe abordar en la escuela, sino que, por el contrario, se debe combatir, eliminar y excluir, al igual que los consumidores.

En el trascurso del desarrollo de las actividades, se evidencian las dificultades disciplinares que poseen los docentes al no poder argumentar con referentes científicos, socioculturales y éticos, los riesgos del consumo asociados a la salud y el ambiente.

Lo anterior hizo evidente la necesidad de establecer un acompañamiento y trabajo dialógico entre los propios docentes de diferentes áreas, personas externas y especializadas que permitieran un proceso de formación de docentes críticos, reflexivos, transformadores y contextualizados respecto a a las exigencias de la sociedad actual, pero ante todo a las exigencias de la escuela como posibilitadora de conocimiento, así como también permitió reconocer la necesidad de mantener espacios de formación en los cuales todos aprendan del discurso de los otros y se generen propuestas de carácter investigativo tanto para la universidad como para la escuela.

El tercer bloque de planeación y diseño titulado: Primeras propuestas para los grandes cambios en las prácticas profesionales y en la formación docente (ver Anexo 9 y 18), tiene 3 actividades denominadas:

1. Mapa conceptual

2. Propuestas curriculares por áreas 


\section{Estudio de caso}

El desarrollo de ese bloque constituyó un ejercicio inicial que se consideró como una innovación por el grupo de profesores, no sólo por la complejidad de la CSC abordada, sino por la incertidumbre que generaba el desarrollo de una secuencia didáctica con estudiantes que viven en el consumo y que tal como lo manifiestan los trabajos realizados en otros ambientes (Camarotti, Kornblit, \& Leo, 2013; Hopenhayn, 2002; Medina, Ferriani, \& Carvalho, 2010), en muchas ocasiones se tiende a la contra prevención, contrario a lo deseable que es la mitigación, además de la alfabetización científica que permite a la población de la institución tomar decisiones argumentadas, responsables y éticas acerca de la producción y el consumo de SPA.

Finalizando la etapa de intervención con los profesores expertos de la Universidad y los invitados externos especialistas en la temática, los profesores del $\mathrm{Gl}$ aceptaron el acompañamiento de profesores en formación inicial; uno de ellos realizó el trabajo de grado de pregrado abordando la CSC denominado: Residuos a la carta: una CSC para favorecer el desarrollo profesional del profesor en un espacio de articulación Universidad Escuela ${ }^{10}$.

Para el desarrollo del trabajo de grado mencionado, los profesores asisten a la universidad como estudiantes, hacen uso del laboratorio como parte de la SD planteada por la estudiante, previamente realizan una charla de reflexión con un profesor Investigador, líder del proyecto de formación IUE Colombo-Brasileño. Producto de esta intervención, los profesores del Gl, en compañía de la maestra en formación participan en el foro local, se socializa la experiencia de trabajo: estudiante en formación/profesores en ejercicio a través de la CSC y abordaje de las SPA en el contexto institucional (Anexo 10, 11 y 12).

http://catalogo.pedagogica.edu.co/cgi-bin/koha/opac-

search.pl?q=au:Rodr\%C3\%ADguez\%20Hern\%C3\%A1ndez,\%20Blanca\%20and\%20au:dir ectora 
Es válido aclarar, que todas las intervenciones a realizar con los estudiantes, eran socializadas al interior del Gl, dramatizadas entre los mismos docentes, debatidas, ajustadas y posteriormente desarrolladas con los estudiantes; finalizada la intervención con los jóvenes y adultos, los profesores socializaban en la franja de formación los resultados obtenidos, reflexionaban, compartían algunas experiencias de vida que los estudiantes socializaban y que en el discurso de los profesores, (punto de vista de la investigadora) se evidenciaban grados de sensibilidad y emocionalidad, posiblemente por el contenido de los relatos.

Los profesores del Gl dan apertura al desarrollo de otros trabajos de pregrado en torno al uso de CSC con estudiantes, en los que ellos validaban algunos instrumentos de aplicación, y al finalizar el semestre socializaban en forma de feria de la ciencia con la presencia de profesores en ejercicio/profesores en formación/estudiantes de cada ciclo. (Anexo 17).

Una vez finalizado el proceso de formación, se entregó un segundo cuestionario, para ser desarrollado de forma individual, con el fin de caracterizar las herramientas y ayudas didácticas que usa el profesor; es decir, saber las fuentes y criterios de selección de contenidos asociados a las CSC, los contenidos escolares, los criterios de validez, referentes epistemológicos y la didáctica del abordaje de las CSC, así como también para conocer el imaginario que tenían los profesores acerca del acompañamiento de la universidad en el proceso de formación en IUE, además de analizar los aportes y dificultades del proceso de formación (Anexo 14). Finalmente se realizó un taller teórico-práctico que le sirviera al profesor de referente para elaborar la SD de cada área (Anexo 13).

El último bloque fue considerado como ejercicio piloto, en la medida que los profesores están en esa "confusión inicial" en la que falta la firmeza, coacción, resistencia, y el "suelo firme de los hechos" (Fleck,1986, p.139), la investigadora entonces como observadora participante, da la confianza, la seguridad y el acompañamiento para indicar a los profesores que todo lo que planean, de forma crítica, contemplando aspectos del desarrollo científico, tecnológico y social, 
adquiere más trascendencia cuando se socializa o comparte con el Gl, ya que como grupo de pares académicos, reflexionan de forma crítica, en debate abierto a la luz de los propósitos educacionales (Strieder, 2012).

Así, los docentes libremente empiezan a circular fotografías de lo que sucede al interior de las aulas, muestran trabajos realizados por los estudiantes y sugieren formas de socialización de los mismos en forma institucional, la profesora que más circula fotografías y actividades realizadas en el aula es la profesora (PC1) del área de Ciencias y la PT1 de Tecnología, (Anexo 9); las profesoras de Ciencias humanas proponen un plan lector de método EFGHI (Explorar, Formular preguntas, Gestionar el aprendizaje, Hacer mapas, resúmenes, etc., Hablar e Investigar) usando lecturas con CSC/CTSA; los de Ciencias Sociales proponen abordar otras CSC como el de territorio para ciclo 1 a 3 (contexto local-colegio), la gobernanza del agua (ciclo 4) y soberanía alimentaria (ciclo 5 y 6); los de matemáticas direccionados por el profesor PM1 y la orientadora profundizan en temas disciplinares $\mathrm{y}$ hacen talleres de espiritualidad/emocionalidad por las características de la población; para terminar se trabaja en el planteamiento de un PEI para la jornada nocturna (Anexo 19).

Posteriormente, se convoca al cierre y evaluación del proceso de formación utilizando una entrevista focalizada, a través de un miembro externo a la escuela pero del grupo de investigación (Anexo 20);el objetivo era caracterizar las contribuciones y las dificultades vividas por los profesores del Gl al abordar CSC con enfoque CTSA, evaluar el proceso de formación de profesores en la IUE en el marco de referencia del proyecto mencionado, al igual que establecer los aportes a la construcción del CPP como CP emergente.

En la investigación, se realizaron, en esta fase de intervención, dos entrevistas: una focal (Anexo 20) y una semiestructurada (Anexo 21); en la focal los profesores debatieron su postura en torno a la CSC abordada, evidenciando su carácter polémico, humano, pero también develando posturas radicales que se respetaban y quedaban para la reflexión; la entrevista semiestructurada permitió comprender 
la postura de cada uno de los profesores en cada una de las situaciones planteadas, a su vez contribuyó al reconocimiento de los aportes y las limitaciones del proceso, conocer aspectos que los profesores al interior del GI no socializan, pero que en forma más personalizada develan de forma sincera y espontánea, lo que requirió planeación previa y evaluación interna de validación, de tal modo que las preguntas realizadas correspondieran a los objetivos de la investigación.

\subsection{TERCERA FASE O DE ANÁLISIS}

El análisis se realizó utilizando como dispositivo de análisis el ATD a través del software Nvivo11, que como ya se mencionó se estructura en forma de proyecto. El corpus de la investigación son los recursos (datos de investigación), a partir de los cuales se inicia el ATD, antes de establecer las analogías entre el ATD y el software NVivo11, es necesario conocer algunos comandos y estructura general del software.

Entre las principales estructuras del proyecto están los nodos que pueden ser libres o creados por el investigador como categorías iniciales, estos nodos almacenan la información, la codifican y pueden asumir significados diferentes acordes al trabajo de investigación. Existen estructuras llamadas casos que permiten al investigador realizar una trasposición entre el caso investigado y crear los casos en el software que son los que pueden recibir atributos (Johnston, 2006). Las principales herramientas que presenta son:

- Creación de documentos compuestos: el software genera informes y extractos en los que se indica la credibilidad de la investigación, otro documento que ofrece es textual, allí solo indica el nombre del investigador, los objetivos y detalles del estudio que se realiza. Una de las formas de confirmación de la validez de la investigación puede ser visibilizada al solicitar la consulta de codificación, en la que reúne toda la codificación 
realizada sobre un nodo o palabra en particular, es decir realiza triangulación doble en técnicas y agentes (Stake, 2007).

- Diario del proyecto: el investigador puede crear carpetas y mantener en el programa directamente para guardar los datos, gráficas, informes, consultas, etc., lo que realice con los datos ingresados es viable de ser guardado y servir de ayuda al investigador.

- Importación de atributos: una de las características de la investigación cualitativa, es disponer de información sobre las personas (edad, profesión, estudios, etc.), lugares, que en el programa constituyen los atributos, aunque el programa puede crear nuevos atributos y revisar los existentes.

- Datos: independiente de formato del archivo, es viable de ser considerado como recurso y por tanto puede recibir todos los formatos (RTF, PDF, Excel, jpg, wav, etc.).

Una mayor información del software se puede revisar en el siguiente link http://download.qsrinternational.com/Document/NVivo11forMac/11.4.0/es-

MX/NVivo-for-Mac-Getting-Started-Guide-Spanish.pdf

Además de los anteriores aspectos, dicha herramienta permite la articulación de las herramientas al ATD apoyando al investigador en el establecimiento de categorías emergentes, en el proceso de sistematización de las categorías y subcategorías que se van construyendo en el transcurso de la investigación, muchas veces orienta nuevas comprensiones al facilitarle el mapeo de los datos, minimiza los tiempos de transcripción y favorece el trabajo colectivo entre otras, como se muestra en la tabla 7 . 
Tabla 7. Funcionalidad del software NVivo11 en investigación cualitativa

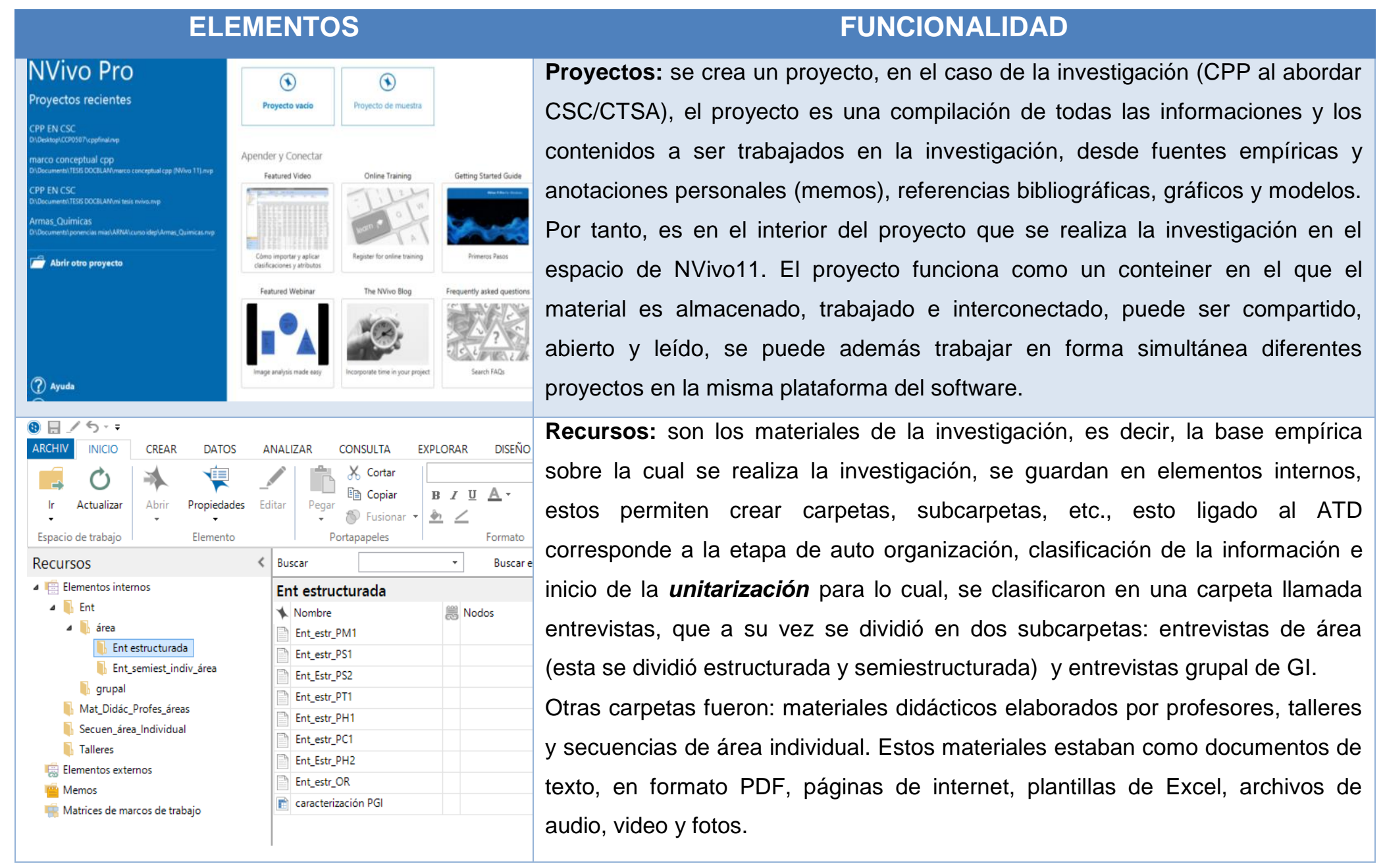




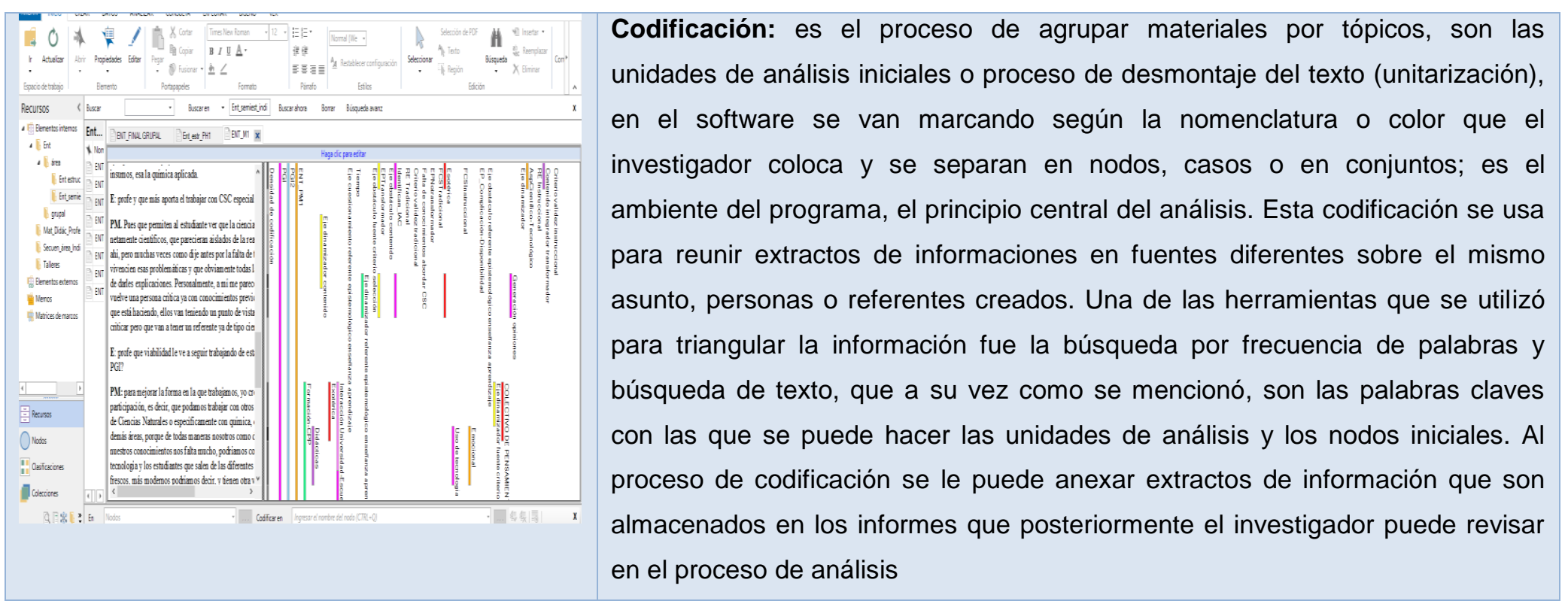




\begin{tabular}{|c|c|c|c|c|c|}
\hline \multirow{2}{*}{ 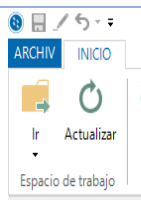 } & DATOS ANALI & ZAR CONSULTA & EXPLORAR DIEENO & & \multirow{11}{*}{$\begin{array}{l}\text { Nodos: son los lugares en los cuales se guarda la información codificada, } \\
\text { correspondiente a una sola temática o palabra clave/llave, en donde los } \\
\text { materiales semejantes estarán almacenados para el análisis de modo que se } \\
\text { puedan crear patrones e ideas emergentes (en ATD: establecimiento de } \\
\text { relaciones). Así, por ejemplo, inicialmente sólo existía los nodos de: Contenidos } \\
\text { Escolares Asociados a la CSC (CEA-CSC), Criterio de Validez que Legitiman la } \\
\text { CSC (CV), Referentes Epistemológicos de la CSC (RE), Fuentes y Criterios de } \\
\text { Selección de Contenidos Asociados a la CSC (FCS); haciendo un paralelo con } \\
\text { el ATD esta etapa correspondería a las categorías iniciales en las que se han } \\
\text { establecido relaciones entre las unidades de análisis y los subnodos } \\
\text { (Contenidos Escolares } \quad \text { Tradicionales (CET), Expontáneistas (CEE), } \\
\text { Instruccionales Cientístas (CEl) e Integradores transformadores (CEIT), todos } \\
\text { agrupados en la categoría Contenidos Escolares Asociados a la CSC (CEA } \\
\text { CSC). }\end{array}$} \\
\hline & 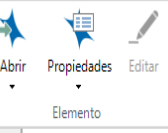 & $\begin{array}{l}\text { X Cortar } \\
\text { Peger Copiar } \\
\text { Pertapapeles }\end{array}$ & $I \mathbb{U} \underline{A}$. & & \\
\hline \multirow{8}{*}{ 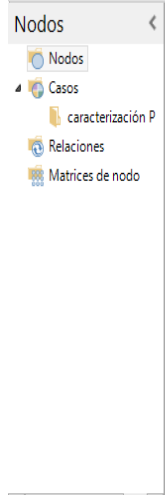 } & \multicolumn{4}{|l|}{ Buscar } & \\
\hline & \multicolumn{4}{|l|}{ Nodos } & \\
\hline & \multicolumn{2}{|c|}{$\begin{array}{l}\text { Nombre } \\
\text { CPP ALABORDARCSC }\end{array}$} & \multicolumn{2}{|c|}{ El Conocimiento Prófesional Deseable ne es un estado ideal, } & \\
\hline & \multirow{2}{*}{\multicolumn{2}{|c|}{ 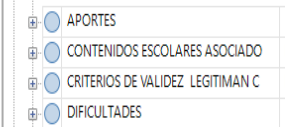 }} & \multicolumn{2}{|c|}{$\begin{array}{l}\text { Las SCC involucran controversias publicas, discutidas en los } \pi \\
\text { Principios y supuestos que permiten detemminar LA LEGTIIII }\end{array}$} & \\
\hline & & & \multicolumn{2}{|l|}{ Dinamizadores, obstáculos $y$ Gu } & \\
\hline & 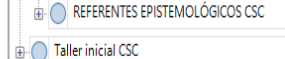 & 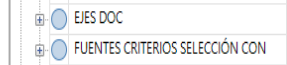 & & \\
\hline & \multicolumn{2}{|c|}{ 由 calacterización PG t tabla } & & & \\
\hline & $\begin{array}{l}0 \text { Quées investigs } \\
0 \text { Qué cómo inv } \\
\text { Oroblemas sercrc }\end{array}$ & & & & \\
\hline Recursos & & & & \\
\hline
\end{tabular}




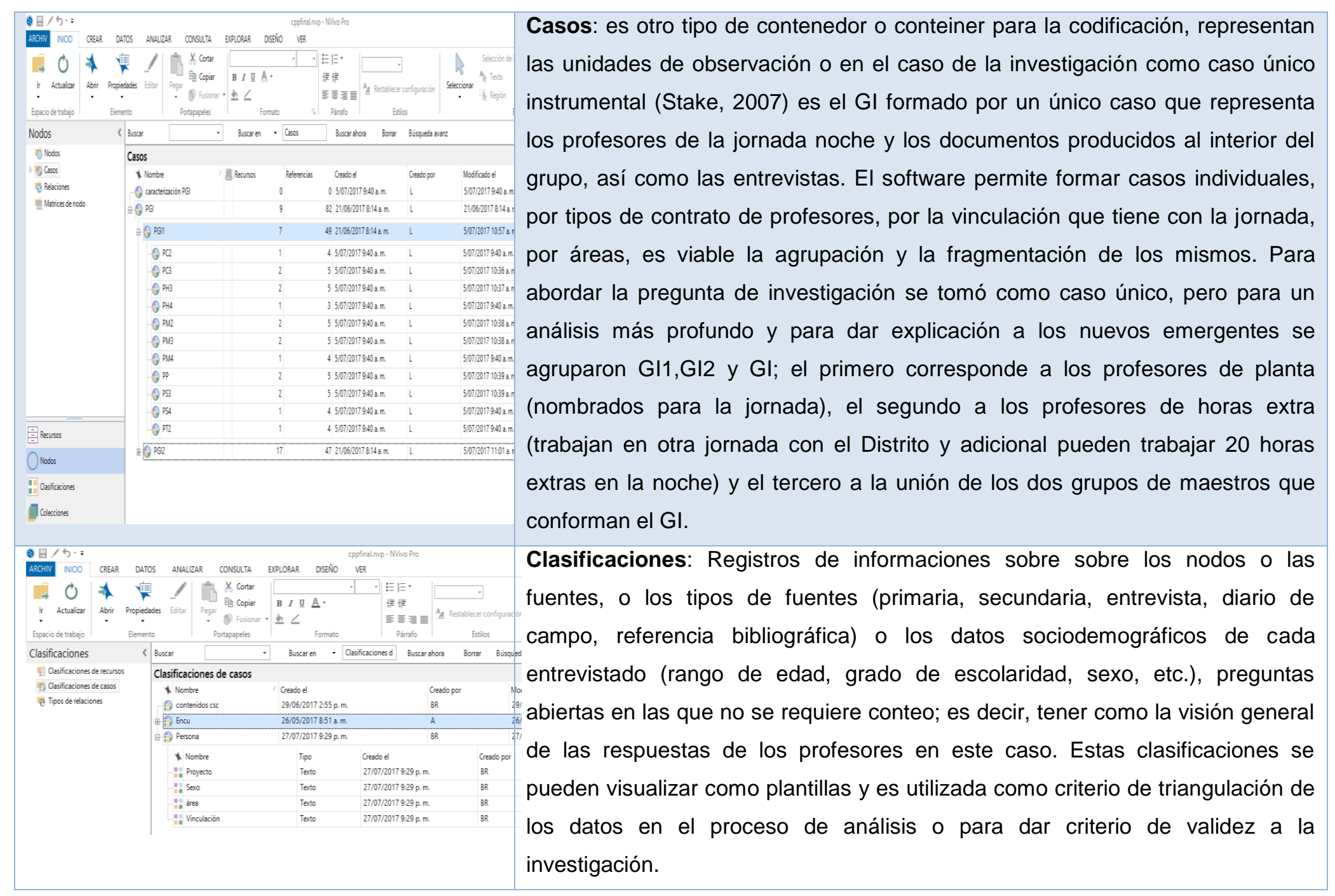




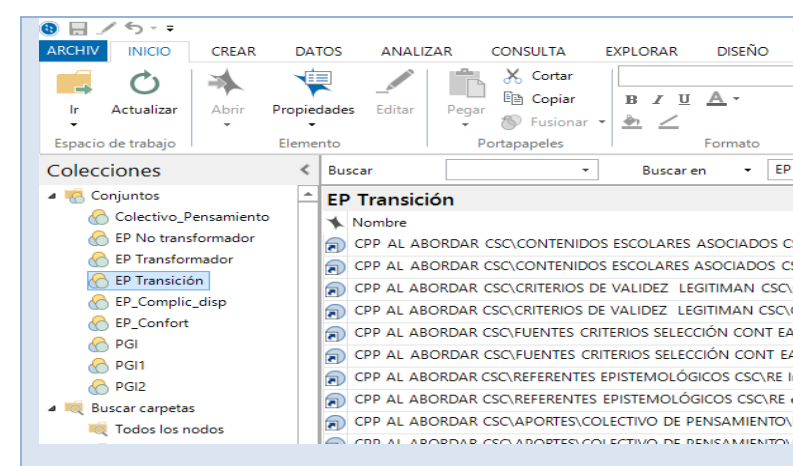

Colecciones: podría decirse que es la parte versátil del programa, donde el investigador puede agrupar o hacer categorías mayores, pero basadas en la relación categorías establecidas como nodos iniciales, nodos emergentes, casos particulares del caso único o el gran caso; es decir, permiten sintetizar, concluir o hacer textos o propuestas teóricas emergentes e indica lo que Moraes \& Galiazzi (2007) mencionan como "un continuo resurgir de Fenix" (p.193).

Fuente: Autora con base en el ATD, el Software Nvivo11 y el proyecto CPP al abordar CSC /CTSA en la IUE 
En la siguiente tabla se presenta las analogías existentes entre el ATD y el software NVivo11.

Tabla 8. Analogía entre ATD y las funciones del software NVivo11

\begin{tabular}{|c|c|}
\hline ATD & Software NVivo \\
\hline Corpus & Elementos internos /externo \\
\hline Unitarización & $\begin{array}{l}\text { Selección de materiales textuales del } \\
\text { corpus }\end{array}$ \\
\hline $\begin{array}{l}\text { Unidades de significado/ } \\
\text { Unidades de análisis }\end{array}$ & Codificación \\
\hline Palabras clave & Nodos libres \\
\hline Establecimiento de relaciones & $\begin{array}{l}\text { Memos iniciales } \\
\text { Nodos } \\
\text { Clasificaciones }\end{array}$ \\
\hline Categorías iniciales & Nodo ramificado \\
\hline Categorías intermedias & $\begin{array}{l}\text { Nodos que contiene subnodos y forman } \\
\text { casos, pueden estar vinculados a memos } \\
\text { y observaciones }\end{array}$ \\
\hline Categorías emergentes & Colecciones (conjuntos) \\
\hline $\begin{array}{l}\text { Procesos auto organizado - ciclo } \\
\text { de análisis }\end{array}$ & Consultas/informes y mapas \\
\hline Caracterización general del caso & Clasificaciones \\
\hline
\end{tabular}

Fuente. Autora con base en el ATD y software NVivo11

En ambos dispositivos de análisis se inicia con el acceso a los documentos de análisis, así como para el ATD el Corpus es la materia prima que requiere ser seleccionada, clasificada y organizada en necesario tener los elementos internos, "los documentos textuales de análisis constituyen significantes a partir de los cuales son construidos significados relativos a los fenómenos investigados" (Moraes \& Galiazz, 2007).

En el ATD el paso siguiente es la unitariación o fragmentación del texto, el investigador es el que decide de qué manera los fragmentará; en el software se puede hacer automaticamente, es decir, se puede hacer una búsqueda por frecuencia de palabras o búsqueda de texto, en la que se indican los textos en 
los que encontró mayor conteo y la ubicación en el proyecto (elementos internos), el investigador selecciona las palabras apropiadas o clave, como nodos libres y al ubicarlas en los documentos hace la codificación como una unidad de análisis. Por ejemplo, en la investigación la búsqueda por palabras frecuentes arrojó la siguiente marca de nube (en términos del software), posteriormente serán analizadas.

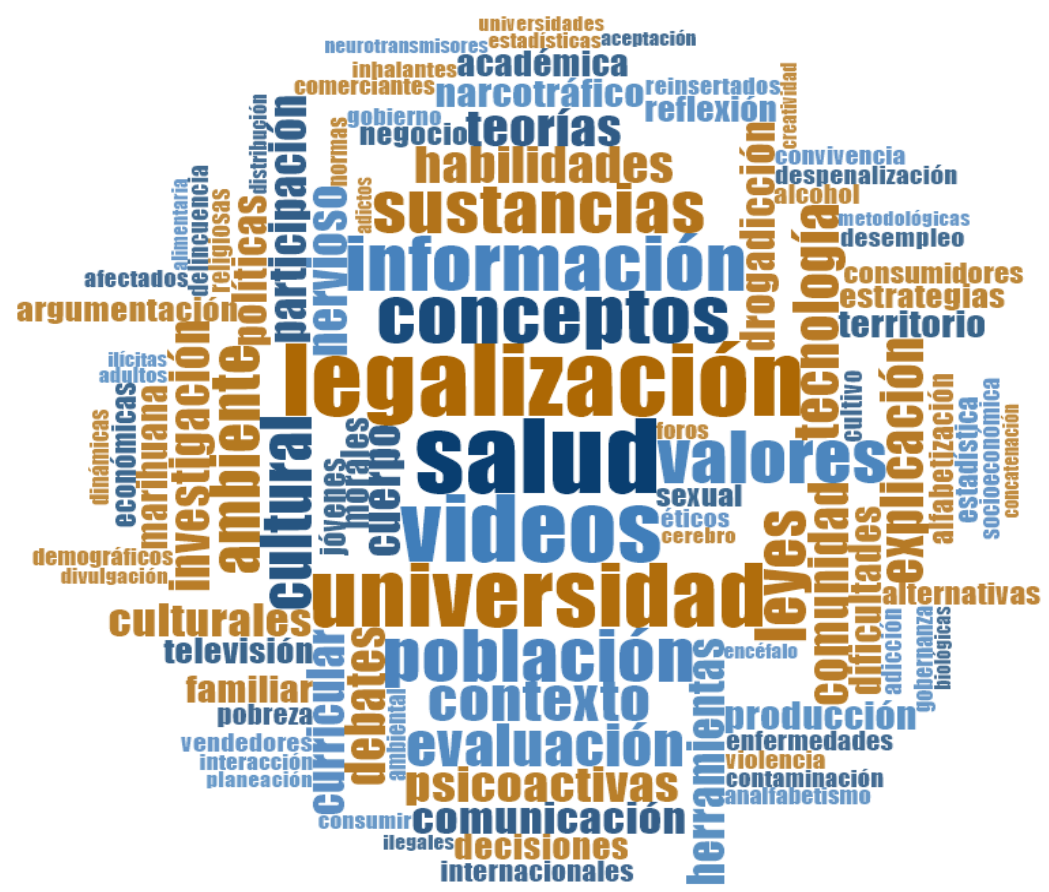

Figura 34. Frecuencia de palabras en el corpus de análisis textual del CPP al abordas CSC/CTSA en IUE. Fuente. NVivo11

Como se evidencia en la figura 34, las palabras de mayor frecuencia utilizadas en los textos y discurso de los profesores son reportadas en forma numérica y visual, orientan al investigador sobre los objetivos propuestos, sobre las palabras claves y en qué documentos encontrarlas (en este caso las de mayor frecuencia: salud, legalización, videos, Universidad, etc.).

Por medio de este mismo recurso, se genera una rejilla o mapa ramificado (figura 35) y un análisis de conglomerados (figura 36). Los cuales en términos de Moraes \& Galiazzi (2007) permiten al investigador realizar el proceso de unitarización en 
las tres etapas propuestas por los autores: fragmentación de los textos (unitarización o desmontaje), codificación de cada unidad (establecimiento de relaciones o categorización), reescritura de cada unidad de modo que asuma un significado (comunicación) lo más completo posible en sí mismo y atribución de un nombre o título para cada unidad producida.

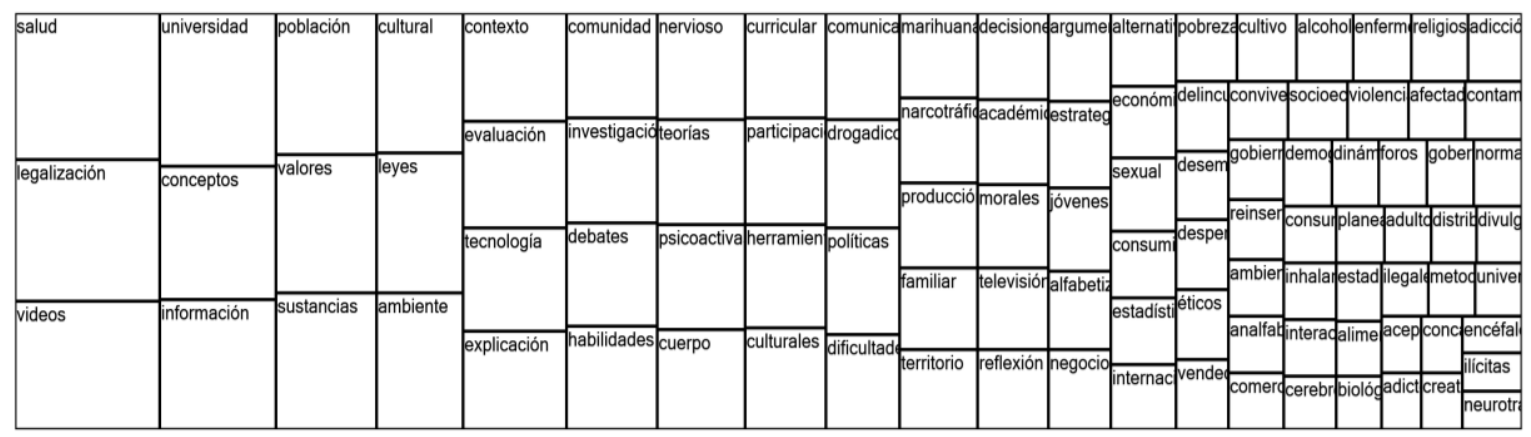

Figura 35. Mapa ramificado de frecuencia de palabras del proyecto: CCP al abordar CSC/CTSA en IUE Fuente. Nvivo 11

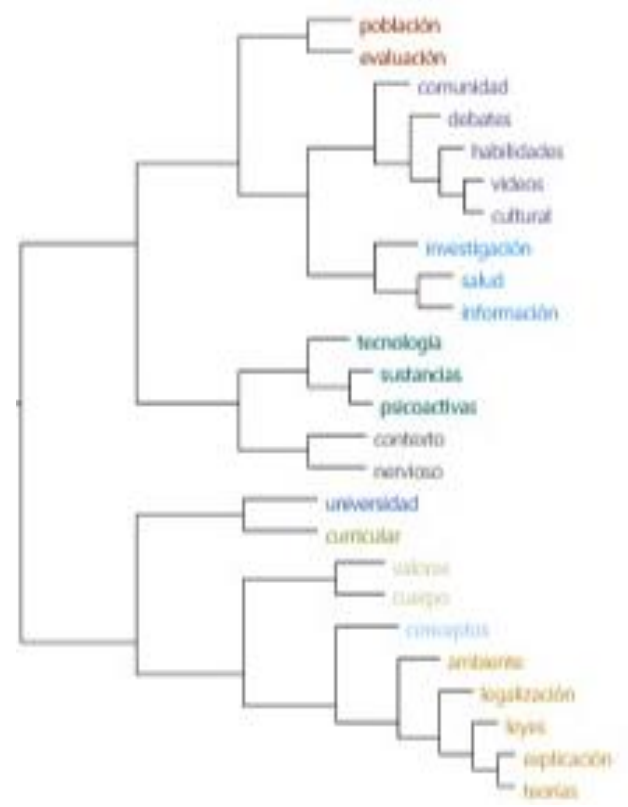

Figura 36. Análisis de conglomerados

Fuente. NVivo11 proyecto CPP al abordar CSC/CTSA en IUE 
Otro recurso complementario al ATD en la etapa de fragmentación y selección de unidades de análisis es la consulta por búsqueda de texto (figura 37), si el investigador ya tiene categorías iniciales o establecidas.

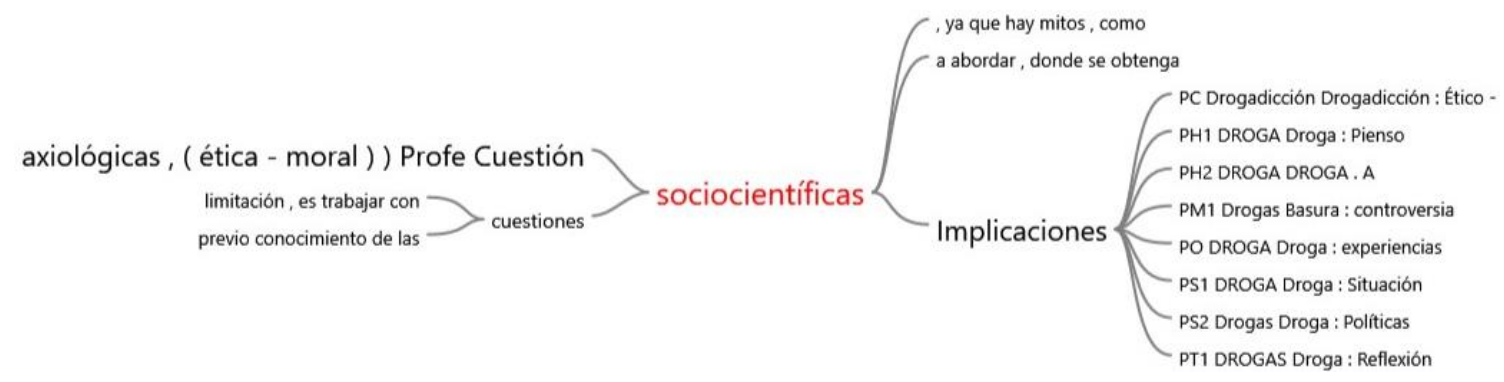

Figura 37. Árbol de palabras

Fuente. Proyecto CPP al abordar CSC/CTSA en IUE

El software usado es una herramienta útil y amigable en el proceso de fragmentación de los textos o unitarización, dando al investigador la posibilidad de clasificar, establecer relaciones y empezar a producir texto, que puede ir asociado a los memos iniciales; por ejemplo, se pueden escribir las relaciones que establecen los profesores con las CSC, este memo inicial se puede almacenar en consultas, luego solicitar un informe y relacionar los memos hechos con las entrevistas, las consultas o los casos, etc., y, en función de observador participante realizar procesos de triangulación entre los mismos textos, fotos y video, etc.

Sin embargo, hay que aclara como menciona Lage (2011) que el software por sí sólo no aumenta o disminuye la calidad de la investigación; la calidad está directamente relacionada con el dato y la adecuación de los procesamientos metodológicos del problema a investigar, además de la experiencia del investigador.

Las categorías iniciales, se agrupan en nodos, que serían las categorías emergentes o podrían ser las categorías de análisis iniciales con las que el investigador inicia el proceso de fragmentación, así al codificar los textos 
(recursos) se forman los nodos y al buscar por consultas pueden establecer todas las relaciones entre los documentos, entre las palabras clave, las consultas (triangula información), esto le permite al investigador reflexionar sobre los datos, elaborar ideas y empezar a construir categorías más amplias en nodos de caso, por ejemplo.

El ATD transforma al investigador la medida en que pone de manifiesto la importancia del análisis en todas sus etapas (unitarización, categorización, comunicación) hasta llegar a la etapa de auto organización posibilitando la comprensión de la investigación; una vez se han creado los nodos, se establecen relaciones, se reagrupan, elaboran memos, se crean casos, con los instrumentos utilizados a partir de entrevistas, talleres, es decir, el software permite crear casos únicos de individuos o situaciones, o de grupos de personas como en la presente investigación (Roque Moraes \& Galiazzi, 2007; Stake, 2007).

A los casos, como unidades de observación (Gl) se les asigna atributos (en las clasificaciones) y estos a su vez, se agrupan, se separan, según el interés del investigador y el proceso de comprensión que está realizando en la investigación; en el ATD se busca agrupar las subcategorías (nodos) en categorías cada vez mayores que permitirán la construcción/reconstrucción del texto final; en el software los mapas ofrecen una visión mayor al investigador, generando nuevos textos que vinculados a memos orientan a la construcción de nuevas relaciones direccionadas a ese nuevo emergente (ATD), en el proyecto se refleja en la creación de colecciones (conjuntos) que en la investigación corresponde al paso de GI al de CP con EP como fundamento epistemológico del CPP y los hechos abordados equivalentes a las CSC con enfoque CTSA; un ejemplo, se muestra en la figura 38 que muestra cinco conjuntos ( correspondientes a cinco CP con un EP particularizado, identificados en el GI/CP. 


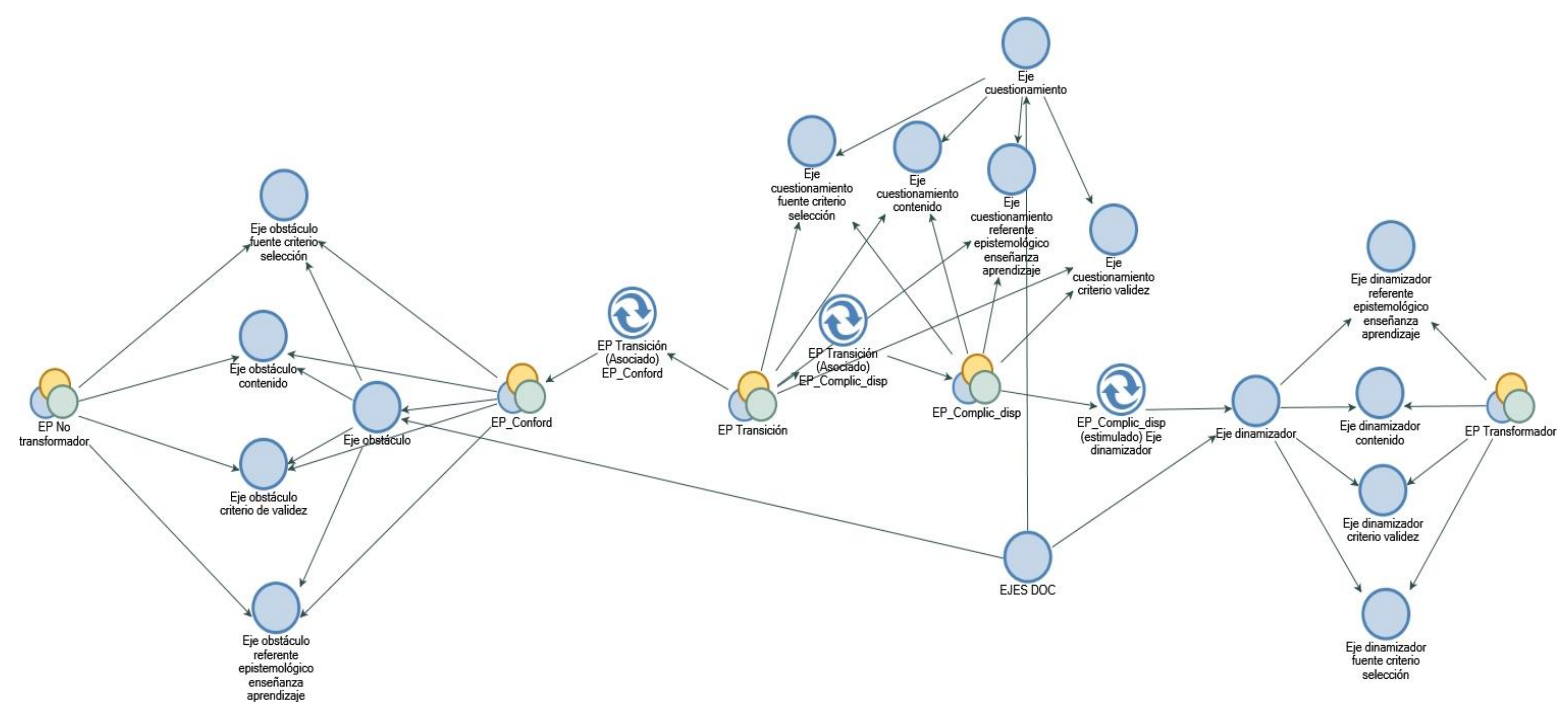

Figura 38. Mapa de nodos y colecciones

Fuente. Nvivo11 proyecto CSC CPP al abordar CSC/CTSA en IUE

Al igual que la tabla 24, esta emerge del análisis del contenido y queda en la presente investigación, como semillero de futuras investigaciones en torno a los ejes DOC, cuando se aborda una CSC; posibilitando, además, nuevas estrategias que permitan promover el CPP de estilos de pensamiento bien sea tradicional a otros integrales transformadores, 0 diseñando nuevas propuestas que permitan que los ejes obstáculo se establezcan como dinamizadores o cuestionamiento. 


\section{CAPITULO 5. CONOCIMIENTO PROFESIONAL DEL PROFESOR DE CIENCIAS SOBRE CUESTIONES SOCIOCIENTÍFICAS}

En este capítulo se analizan los datos obtenidos en el transcurso de la investigación a través del ATD, que surge como resultado emergente del ATD/Software NVivo11; todas las unidades de análisis, las categorías (nodos), los recursos o datos (corpus de la investigación) son codificados y descritos en un libro de códigos, con el número de referencias o registros realizados (unidades de análisis identificados); los nodos con referencia cero (0) indican que son categorías emergentes que surgen de otras categorías referenciadas en ese grupo de nodos que para esta investigación están contemplados en la tabla 9.

Para efectos de la escritura y comprensión de los resultados de la investigación, se hace pertinente empezar por comprender algunos resultados del proceso de caracterización del GI. Así pues, se inicia este análisis abordando la segunda pregunta de investigación: ¿Cómo se estructuró y se consolidó el Gl enfocado en el abordaje en CSC locales?

La investigación en el marco del proyecto de formación de profesores en IUE, ya tenía una intencionalidad: formar GI interesados en abordar CSC, en este contexto, la conformación del GI del GCl como una asociación libre, inmersa en la cultura escolar, donde las relaciones de poder son de tipo horizontal, constituye un reto para el investigador al actuar como observador participante, ya que como se mencionó anteriormente, la autora de la tesis, es la coordinadora académica de la institución.

El papel de observador participante, en el proceso de constitución del grupo y en el desarrollo de propuesta fue el de intentar describir la manera como los profesores del Gl comprenden y estructuran la cotidianidad de la realidad escolar de la EJA, develar y analizar las prácticas de aula y las actividades rutinarias que estructuran el CPP de estos profesores, así como los posibles aportes y dificultades al CPP de los mismos al abordar las CSC. 
Tabla 9. Libro de códigos (Nodos/Categorías Creadas y emergentes a partir del ATD)

\begin{tabular}{|c|c|c|c|}
\hline NOMBRE & SIGLA & DESCRIPCIÓN & $\begin{array}{c}\text { REFERENCIA } \\
\mathrm{S}\end{array}$ \\
\hline caracterización GI & $\mathrm{Gl}$ & Categoría deductiva que contiene los 19 profesores participantes del proceso de formación & 0 \\
\hline $\begin{array}{l}\text { Dificultades } \\
\text { enfrentadas }\end{array}$ & Dificultades & Categoría que agrupa características de las CSC que impiden el uso de las mismas en el aula & 19 \\
\hline $\begin{array}{l}\text { COMO ABORDAR LA } \\
\text { CSC EN UN CICLO }\end{array}$ & & $\begin{array}{l}\text { Los posibles beneficios del SSI van más allá de la formación de opiniones sobre temas científicos } \\
\text { específicos. La naturaleza inestable de las CSC junto con el interés generalizado ha convertido a estos } \\
\text { temas en una preocupación principal de aquellos que buscan mejorar la alfabetización científica entre } \\
\text { la comunidad en general (Kolsto, 2001). Los temas polémicos y socialmente relevantes pueden reflejar } \\
\text { la actitud del estudiante hacia su deber como ciudadano, participante en el proceso político } \\
\text { Se espera que mencione estrategias de aula: discusiones, debates, diálogos, planteamiento de casos }\end{array}$ & 13 \\
\hline $\begin{array}{l}\text { problemas ejercicio } \\
\text { profesional }\end{array}$ & & Referenciadas en el discurso cuando abordan las CSC & 19 \\
\hline Qué es investigación & & Unidades de análisis de contenido identificados a través de los talleres de IAP & 19 \\
\hline Qué y cómo investiga & & Acorde al taller de IAP y entrevista inicial. & 19 \\
\hline $\begin{array}{l}\text { CPP AL ABORDAR } \\
\text { CSC }\end{array}$ & 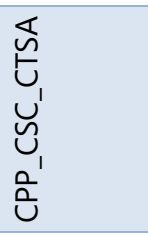 & $\begin{array}{l}\text { El Conocimiento Profesional Deseable no es un estado ideal, } \\
\text { sino que se puede formular como una hipótesis de progresión, que conlleva un } \\
\text { determinado itinerario de progresión y que implica una paulatina superación de } \\
\text { los obstáculos que se presentan en la evolución de este Conocimiento Práctico } \\
\text { Profesional en el Desarrollo Profesional del Profesorado. }\end{array}$ & 0 \\
\hline APORTES & A & Mencionados por el docente durante el proceso del formación & 0 \\
\hline $\begin{array}{l}\text { COLECTIVO } \\
\text { PENSAMIENTO }\end{array}$ & $\mathrm{CP}$ & $\begin{array}{l}\text { Grupo de docentes del } \mathrm{Gl} \text {, quienes construyen el conocimiento en colectivo, determinado por el } \\
\text { carácter social, histórico y cultural, donde cada participante comparte prácticas, concepciones, } \\
\text { tradiciones y normas o sea un estilo de pensamiento: Cp. político, científico, artístico, cultural, ético- } \\
\text { moral. }\end{array}$ & 24 \\
\hline $\begin{array}{l}\text { Características de la } \\
\text { CSC identificados }\end{array}$ & ICcsc & Identifican las características de la CSC: & 0 \\
\hline Contexto & CLG & $\begin{array}{l}\text { Abarcan problemas locales o globales entre los cuales esta: la minería a cielo abierta, la drogadicción, la } \\
\text { soberanía alimentaria, deforestación, gobernanza del agua, monocultivos, cultivos transgénicos, } \\
\text { manipulación genética, aborto, etc. }\end{array}$ & 34 \\
\hline Divulgación & DMM & $\begin{array}{l}\text { Son divulgados en los medios masivos de comunicación, donde se identifican los intereses de cierto } \\
\text { sector dominante o de los mismos medios }\end{array}$ & 19 \\
\hline
\end{tabular}




\begin{tabular}{|c|c|c|c|}
\hline Generación opiniones & GOEps & Posibilita la formación de opiniones a favor o en contra que van entre lo personal y lo social & 59 \\
\hline $\begin{array}{l}\text { Asumir posición } \\
\text { frente a la csc }\end{array}$ & PCSC & $\begin{array}{l}\text { Asume una posición sustentada en aspectos o referentes socioculturales, ético morales, sociopolíticos, } \\
\text { económicos, científico tecnológicos frente a la legalidad y prohibición }\end{array}$ & 12 \\
\hline $\begin{array}{l}\text { Asp Científico- } \\
\text { Tecnológico }\end{array}$ & $\mathrm{ACT}$ & Conceptos CT asociados al desarrollo tecnológico y la participación social & 6 \\
\hline $\begin{array}{l}\text { Asp científico- } \\
\text { tecnológico } \\
\text { legalización }\end{array}$ & ACTL & Aspectos científico tecnológicos que tiene en cuenta el profesor ante la legalización de la droga & 13 \\
\hline $\begin{array}{l}\text { Asp científico- } \\
\text { tecnológico } \\
\text { prohibición }\end{array}$ & ACTP & Aspectos científicos y tecnológicos abordados frente a la política de prohibición de la droga & 10 \\
\hline $\begin{array}{l}\text { Asp RiesgoSalud- } \\
\text { ambiente }\end{array}$ & ARSA & & 9 \\
\hline $\begin{array}{l}\text { Asp riesgo salud- } \\
\text { ambiente legalización }\end{array}$ & ARSAL & $\begin{array}{l}\text { Aspectos asociados al riesgo a la salud y al ambiente que el profesor tiene en cuenta si se legaliza la } \\
\text { droga }\end{array}$ & 26 \\
\hline $\begin{array}{l}\text { Asp riesgo salud- } \\
\text { ambiente prohibición }\end{array}$ & ARSAP & $\begin{array}{l}\text { Aspectos asociados al riesgo a la salud y al ambiente en el discurso del profesor al continuar con la } \\
\text { política de prohibición de la droga en Colombia }\end{array}$ & 25 \\
\hline Asp Sociocultural & ASC & Aspecto sociocultural en el que se justifica el uso de las CSC & 5 \\
\hline $\begin{array}{l}\text { Asp sociocultural de } \\
\text { la legalización }\end{array}$ & $\mathrm{ASCL}$ & Aspectos sociocultural contemplado al legalizarse la droga & 27 \\
\hline $\begin{array}{l}\text { Asp sociocultural de } \\
\text { la prohibición }\end{array}$ & ASCP & Posicionamiento frente a la política de prohibición de la droga en Colombia & 27 \\
\hline Asp Sociopolítico & ASP & Aspecto que involucra la política y la economía al abordar CSC & 5 \\
\hline $\begin{array}{l}\text { Asp sociopolítico } \\
\text { legalización }\end{array}$ & ASPL & Aspectos sociopolíticos asociados a la legalización de la droga & 13 \\
\hline $\begin{array}{l}\text { Asp sociopolítico } \\
\text { prohibición }\end{array}$ & ASPP & $\begin{array}{l}\text { Aspecto sociopolítico contemplado por el profesor ante la política de prohibición de la droga en } \\
\text { Colombia }\end{array}$ & 11 \\
\hline $\begin{array}{l}\text { Otros aspectos } \\
\text { legalización }\end{array}$ & OAL & Otros aspectos diferentes a los anteriores frente a la legalización de la droga & 4 \\
\hline $\begin{array}{l}\text { Otros aspectos } \\
\text { prohibición }\end{array}$ & OAP & Aspectos diferentes a los mencionados para asumir la política de prohibición de la droga & 5 \\
\hline
\end{tabular}




\begin{tabular}{|c|c|c|c|}
\hline $\begin{array}{l}\text { Información } \\
\text { incompleta }\end{array}$ & IICSC & $\begin{array}{l}\text { Las CSC no tiene un único campo de abordaje, son cuestiones o temáticas que al encontrarse en la } \\
\text { frontera de la ciencia o por su naturaleza controversial presentan información científica incompleta o } \\
\text { en confrontación. }\end{array}$ & 29 \\
\hline NaturalezaCientifica & NC & Basadas en áreas que están en la frontera del conocimiento científico & 11 \\
\hline $\begin{array}{l}\text { Relación } \\
\text { beneficio }\end{array}$ & $\mathrm{RCB}$ & $\begin{array}{l}\text { Caracterizadas por posibilitar un análisis de costo beneficio en la que los riesgos interactúan con los } \\
\text { valores, donde se establecen posibilidades y riesgos. }\end{array}$ & 21 \\
\hline Sustentabilidad & $\begin{array}{l}\text { SUSVsSO } \\
\text { S }\end{array}$ & $\begin{array}{l}\text { Abarca consideraciones sustentable (ligado al desarrollo social y humano en contexto política, cultural, } \\
\text { ético y estético), donde se reconoce que la CSC afecta el desarrollo humano, pero para ciertos sectores } \\
\text { de la sociedad o política mundial en la sociedad capitalista genera crecimiento económico }\end{array}$ & 15 \\
\hline $\begin{array}{l}\text { Valores- } \\
\text { razonamiento_ético_ } \\
\text { moral }\end{array}$ & VREM & $\begin{array}{l}\text { Contempla la postura de decisiones donde entra en juego los valores y razonamiento ético-moral ante } \\
\text { los dilemas abordados en la CSC }\end{array}$ & 0 \\
\hline Pmoral & $\mathrm{Pm}$ & Referente desde el cual asume un posicionamiento moral & 0 \\
\hline Moral Emotiva & ME & Basada en los sentimientos & 34 \\
\hline Moral Intuitiva & $\mathrm{MI}$ & No hay soporte, referente, se hace porque si o no, no hay justificación & 11 \\
\hline Razonamiento Moral & RM & Categoría que involucra decisiones de los profesores en este aspecto & 0 \\
\hline RM Consecuencialista & RMC & Razonamiento basada en relaciones causa efecto & 30 \\
\hline RM Deontológico & RMD & Razonamiento basado en principios & 19 \\
\hline $\begin{array}{l}\text { Estilos } \\
\text { pensamiento }\end{array}$ & EP & $\begin{array}{l}\text { Actitud del pensamiento de cada profesor, su disposición, el sentir del sujeto, la acción que realiza por } \\
\text { sus vivencias, por su recorrido histórico, las vivencias sociales y culturales; el que posee un sujeto que } \\
\text { participa de un proceso colectivo de prácticas, concepciones, tradiciones y normas propias del CP }\end{array}$ & 0 \\
\hline EP en transición & EPentrans & $\begin{array}{l}\text { EP de sujetos que se encuentran en conflicto con su actuar profesional, saben que los contenidos, } \\
\text { referentes, criterios de selección y criterios de validez utilizados en su disciplina y didáctica no responde } \\
\text { a las necesidades del contexto donde realiza su práctica profesional. }\end{array}$ & 0 \\
\hline $\begin{array}{l}\text { EP_Complicación- } \\
\text { Disponibilidad }\end{array}$ & EpFComp & $\begin{array}{l}\text { Fase de EP donde su pensamiento no encaja en la rutina diaria, encuentra excepciones, hay } \\
\text { desequilibrio }\end{array}$ & 70 \\
\hline EP_Confort & EpFC & $\begin{array}{l}\text { Fase donde el pensamiento encaja con el contexto de la escuela, de su estilo de pensamiento, en el } \\
\text { que todo está bien y reflexiona sobre su acción, lo importante es como él se siente }\end{array}$ & 20 \\
\hline EP No transformador & EPNot & $\begin{array}{l}\text { EP de los sujetos que están en confort con su práctica profesional, se caracterizan por usar contenidos, } \\
\text { referentes, criterios de validez epistemológica y de selección de tipo tradicional. }\end{array}$ & 10 \\
\hline
\end{tabular}




\begin{tabular}{|c|c|c|c|}
\hline EP Transformador & EPT & $\begin{array}{l}\text { EP de los sujetos que utilizan contenidos generalmente del contexto de los estudiantes, promueven la } \\
\text { formación ciudadana, promueven la enseñanza de las ciencias en forma crítica, asimiento como eje } \\
\text { articulador las CSC, sus referentes y criterios de validez surgen de los saberes populares en dialogo con } \\
\text { los de la Ciencia de Occidente. }\end{array}$ & 47 \\
\hline Formación-CPP & FCPP & $\begin{array}{l}\text { Forma de favorecer el desarrollo profesional del profesor y el CPP a través del PGI en la interacción } \\
\text { Universidad Escuela }\end{array}$ & 93 \\
\hline $\begin{array}{l}\text { Interacción } \\
\text { Universidad-Escuela }\end{array}$ & IU_E & $\begin{array}{l}\text { Programa de formación permanente de profesores, donde se favorece el trabajo colectivo y en el } \\
\text { mismo contexto escolar en interacción permanente con los docentes de la universidad, }\end{array}$ & 83 \\
\hline Esotérica & & Dinámica selectiva de especialistas que crean las formas de pensar & 14 \\
\hline Exotérica & & Consumidores de las ideas generadas, es grupo mayor, menos selectivo & 50 \\
\hline $\begin{array}{l}\text { Invocación } \\
\text { recuerdo }\end{array}$ & & Relaciona lo nuevo con experiencias anteriores que dejan huella, permiten reflexión del profesor & 34 \\
\hline Metodología & Mpgi & $\begin{array}{l}\text { Se adoptó una metodología cualitativa crítica colaborativa, este tipo de enfoque se conoce también } \\
\text { como investigación acción crítica y se caracteriza por el fuerte compromiso con la participación social, } \\
\text { el análisis filosófico del conocimiento basado en la tradición crítica de la escuela de Frankfurt e } \\
\text { involucra la participación de grupos interdisciplinarios de profesores, investigadores y estudiantes, } \\
\text { entre otros (Kemmis \& McTaggart, 2005). }\end{array}$ & 0 \\
\hline $\begin{array}{l}\text { Investigación- } \\
\text { Acción_Crítica }\end{array}$ & IAC & $\begin{array}{l}\text { Metodología del proceso de formación de docentes en la interacción Universidad-escuela, donde se } \\
\text { privilegia la investigación y formación continuada de profesores haciendo avanzar los conocimientos } \\
\text { producidos en la academia y en la escuela (Teles \& Ibiapina, 2009). }\end{array}$ & 22 \\
\hline $\begin{array}{l}\text { Desconocen_proceso } \\
\text { IAC }\end{array}$ & DIA & $\begin{array}{l}\text { Hay desconocimiento de la actividad investigativa que realizan acerca del tema abordado (droga- spa) } \\
\text { y socializan dando información en forma expositiva, los docentes escuchan, para ellos didácticamente } \\
\text { no hay alternativa de construcción del conocimiento, se asume que hay una asimilación recepción de la } \\
\text { misma }\end{array}$ & 21 \\
\hline Identifican_IAC & $\| A$ & $\begin{array}{l}\text { Conocen que su actuar en el aula a partir de las dificultades e intereses que surgen de la reflexión de la } \\
\text { práctica en acción son los insumos para que todo profesor sea investigador y está al alcance de todos. }\end{array}$ & 54 \\
\hline $\begin{array}{l}\text { CONTENIDOS } \\
\text { ESCOLARES } \\
\text { ASOCIADOS CSC }\end{array}$ & CEA-CSC & $\begin{array}{l}\text { Las CSC involucran controversias públicas, discutidas en los medios masivos de comunicación, } \\
\text { temáticas locales con implicaciones globales: clonación, soberanía alimentaria, gobernanza del agua, } \\
\text { drogadicción, maltrato animal, polución, calentamiento global, etc.; generalmente esta categoría da } \\
\text { cuenta de las enseñanzas del profesor, de la integración que hace de conceptos, procedimientos, } \\
\text { actitudes y valores. Qué se enseña y cómo se estructuran para enseñar esos contenidos }\end{array}$ & 0 \\
\hline
\end{tabular}




\begin{tabular}{|c|c|c|c|}
\hline $\begin{array}{l}\text { Contenido } \\
\text { espontáneista }\end{array}$ & CEE & $\begin{array}{l}\text { Contenidos conceptuales que estén en la realidad inmediata del estudiante, de su cotidianidad, que } \\
\text { satisfacen los intereses, actitudes y habilidades de los mismos. }\end{array}$ & 1 \\
\hline $\begin{array}{l}\text { Contenido } \\
\text { instruccional }\end{array}$ & CEI & $\begin{array}{l}\text { Saberes disciplinares actualizados, incorporación de algunos conocimientos no disciplinares (técnico). } \\
\text { Los contenidos deben ser preparados por especialistas, que sean prácticos, secuenciales. Son } \\
\text { adaptaciones de las disciplinas. }\end{array}$ & 25 \\
\hline $\begin{array}{l}\text { Contenido integrador } \\
\text { transformador }\end{array}$ & CEIT & $\begin{array}{l}\text { Conocimientos escolares que integran diversos referenciales (disciplinares, cotidianos, csc, csv, } \\
\text { conocimiento multidisciplinar, Se abordan temáticas no curricularizadas, generalmente están en los } \\
\text { medios masivos de comunicación, no tiene solución en un solo campo disciplinar. }\end{array}$ & 117 \\
\hline Contenido tradicional & CET & $\begin{array}{l}\text { Información fundamental de la cultura vigente, donde se busca la reproducción y simplificación } \\
\text { disciplinares. Se centra en conceptos, definiciones y temas tipo listado, donde no hay criterios claros y } \\
\text { reflexionados de la organización en la que se enseñan. }\end{array}$ & 18 \\
\hline $\begin{array}{l}\text { CRITERIOS DE } \\
\text { VALIDEZ LEGITIMAN } \\
\text { CSC }\end{array}$ & CVL-CSC & $\begin{array}{l}\text { Principios y supuestos que permiten determinar LA LEGITIMIDAD DE LA CSC, temas de frontera, } \\
\text { permite formación de opiniones, evidencias incompletas, involucra valores y razonamiento ético, se } \\
\text { pueden abordar desde lo local a lo global, hay relación costo beneficio, probabilidad y riesgo }\end{array}$ & 0 \\
\hline $\begin{array}{l}\text { Criterio validez } \\
\text { espontáneista }\end{array}$ & CVE & $\begin{array}{l}\text { Se realiza mediante la observación directa y el análisis del trabajo del estudiante (especialmente en } \\
\text { grupo) centrado en las destrezas y actitudes. La ciencia es vista como un proceso de indagación y la } \\
\text { enseñanza facilita el descubrimiento de los alumnos, por tanto es válido cuando se satisface el } \\
\text { estudiante, se valida desde la cotidianidad del estudiante }\end{array}$ & 0 \\
\hline $\begin{array}{ll}\text { Criterio } & \text { validez } \\
\text { instruccional } & \end{array}$ & CVI & $\begin{array}{l}\text { Pruebas que midan lo que el estudiante memorizó de la clase (igual al libro/currículo). Hay } \\
\text { correspondencia entre los conceptos y los procedimientos. Aplican los métodos de los expertos. }\end{array}$ & 40 \\
\hline $\begin{array}{l}\text { Criterio validez } \\
\text { integrador } \\
\text { transformador }\end{array}$ & CVIT & $\begin{array}{l}\text { Formas alternativas de evaluar, elaboraciones textuales o productos de los estudiantes, observaciones, } \\
\text { foros, mecanismos de participación, juegos de roles. Diseño de actividades prácticas alternativas- } \\
\text { indagación. Hay negociación entre los estudiantes y docentes acorde a criterios establecidos y } \\
\text { fundamentados. }\end{array}$ & 76 \\
\hline $\begin{array}{l}\text { Criterio } \quad \text { validez } \\
\text { tradicional }\end{array}$ & CVT & $\begin{array}{l}\text { Pruebas que midan lo que el estudiante memorizo de la clase (igual al libro/currículo), el que decide si } \\
\text { está bien o no es el profesor acorde a lo que establece el texto guía. }\end{array}$ & 31 \\
\hline DIFICULTADES & Dif & $\begin{array}{l}\text { Asociadas a las CSC con enfoque CTSA que limitan que sean las temáticas utilizadas por los docentes } \\
\text { como eje estructurante de la formación científica de los estudiantes }\end{array}$ & 0 \\
\hline Didácticas & DDA & $\begin{array}{l}\text { Desconocimiento de didácticas alternativas y contextualizadas en un enfoque acorde a la enseñanza de } \\
\text { las ciencias }\end{array}$ & 41 \\
\hline Emocional & DENeg & $\begin{array}{l}\text { Reacción a las informaciones que una persona recibe de las relaciones con el entorno y cuya intensidad } \\
\text { depende de las evaluaciones subjetivas que se realizan sobre ellas, afectando a nuestro propio } \\
\text { bienestar, esas evaluaciones subjetivas son influenciadas por los conocimientos previos y las creencias }\end{array}$ & 46 \\
\hline
\end{tabular}




\begin{tabular}{|c|c|c|c|}
\hline & & que poseemos; una emoción depende de lo que es importante para nosotros (Bisquerra, 2005). & \\
\hline $\begin{array}{l}\text { Falta de } \\
\text { conocimientos } \\
\text { abordar CSC }\end{array}$ & DFC & $\begin{array}{l}\text { Al ser las CSC temáticas de frontera de la ciencia, no se tiene los conocimientos suficientes para } \\
\text { comprender dichas temáticas, haciendo difícil entender las mismas y abordarlas con los estudiantes }\end{array}$ & 34 \\
\hline Habilidad Escritural & DHE & $\begin{array}{l}\text { Dificultad para elaborar escritos, para expresar y redactar lo que se piensa o argumentar en forma } \\
\text { textual nuestro discurso }\end{array}$ & 9 \\
\hline $\begin{array}{l}\text { Políticas } \\
\text { organizacional } \\
\text { interna }\end{array}$ & DPOI & $\begin{array}{l}\text { Las políticas generales o escolares que se establecen en cada institución para distribuir la asignación } \\
\text { académica, de proyectos o estilos de trabajo, donde se fracciona el trabajo especializado en áreas o } \\
\text { estamentos de tipo disciplinar, asignaturas, áreas, dependencias, etc. }\end{array}$ & 19 \\
\hline Tiempo & DT & Falta de tiempo para hacer la planeación que depara abordar CSC & 11 \\
\hline Uso de tecnología & DDT & $\begin{array}{l}\text { No se tiene los conocimientos básicos para en tecnología, hay un desconocimiento de los recursos } \\
\text { tecnológicos y uso de las TIC }\end{array}$ & 19 \\
\hline EJES DOC & DOC & $\begin{array}{l}\text { Dinamizadores, Obstáculos y Cuestionamientos que indican la complejidad del pensamiento del } \\
\text { profesor. }\end{array}$ & 0 \\
\hline Eje Cuestionamiento & $\mathrm{EC}$ & $\begin{array}{l}\text { Aspectos sobre los cuales no hay una coherencia o hay preguntas, pueden ser asociados al EP en } \\
\text { transición }\end{array}$ & 5 \\
\hline $\begin{array}{l}\text { Eje cuestionamiento } \\
\text { contenido }\end{array}$ & & $\begin{array}{l}\text { Posibilidad de usar CSC pero no sustenta el soporte de no ser eje del currículo, sabe que aportes pero } \\
\text { no es acogido porque para él docente posiblemente acarrea exigencias que él no cree poder } \\
\text { desarrollar }\end{array}$ & 32 \\
\hline $\begin{array}{l}\text { Eje Cuestionamiento } \\
\text { Criterio Validez }\end{array}$ & ECCV & $\begin{array}{l}\text { Reconoce la potencialidad de las CSC para evaluar que el conocimiento escolar es social e histórico } \\
\text { pero no las usa por la tradición escolar. }\end{array}$ & 11 \\
\hline $\begin{array}{l}\text { Eje cuestionamiento } \\
\text { fuenter criterio } \\
\text { selección }\end{array}$ & ECFCS & $\begin{array}{l}\text { Las CSC son interesantes pero son difíciles de abordar porque no encuentran en todos los textos y se } \\
\text { perdería tiempo que necesitan para abordar lo que es de la cultura escolar. }\end{array}$ & 30 \\
\hline $\begin{array}{l}\text { Eje cuestionamiento } \\
\text { referente } \\
\text { epistemológico } \\
\text { enseñanza } \\
\text { aprendizaje }\end{array}$ & ECREEA & $\begin{array}{l}\text { Las CSC al no ser parte de los conocimientos científicos netamente dichas, no hay conocimientos para } \\
\text { comparar si están aprendiendo o no }\end{array}$ & 32 \\
\hline
\end{tabular}




\begin{tabular}{|c|c|c|c|}
\hline Eje dinamizador & ED & $\begin{array}{l}\text { La existencia de creencias explícitas sobre cómo debería ser la enseñanza de las ciencias, nos muestra el } \\
\text { deseo de cambio de algunos docentes, en lo denominamos concepciones movilizadoras (F. de G. } \\
\text { Ballenilla \& Porlán, 2003; C Martínez, 2005; Ramírez, 2005; E. Solís, Porlán, \& Rivero, 2008), siendo un } \\
\text { buen punto de apoyo a la hora de sustentar procesos de toma de conciencia de los obstáculos } \\
\text { profesionales. En definitiva, el cambio profesional es un proceso complejo y gradual, de ahí nuestro } \\
\text { interés por investigar las transiciones de los profesor }\end{array}$ & 6 \\
\hline $\begin{array}{l}\text { Eje dinamizador } \\
\text { contenido }\end{array}$ & EDC & Desencadenan el desarrollo profesional y el mejoramiento de las propuestas de enseñanza & 61 \\
\hline $\begin{array}{l}\text { Eje dinamizador } \\
\text { criterio validez }\end{array}$ & EDCV & $\begin{array}{l}\text { Aspectos mencionados por el profesor que viabilizan el uso de CSC como criterio de formación de los } \\
\text { estudiantes más importante que el centrarse en contenidos curricularizados de tipo tradicional }\end{array}$ & 24 \\
\hline $\begin{array}{lr}\text { Eje } & \text { dinamizador } \\
\text { fuente } & \text { criterio } \\
\text { selección } & \end{array}$ & EDFCS & $\begin{array}{l}\text { Viabilidad que da el profesor para usar otras fuentes diferentes al los libros de texto escolar, intento de } \\
\text { usar CSC abordadas en noticias, revistas especializadas, videos, analizar documentales, etc. }\end{array}$ & 53 \\
\hline $\begin{array}{l}\text { Eje dinamizador } \\
\text { referente } \\
\text { epistemológico } \\
\text { enseñanza } \\
\text { aprendizaje }\end{array}$ & EDREEA & $\begin{array}{l}\text { Viabilidad de abordar CSC como forma de abordar conocimientos populares, concepciones de los } \\
\text { estudiantes como tipo de conocimiento de los mismos. }\end{array}$ & 31 \\
\hline Eje Obstáculo & EO & $\begin{array}{l}\text { El profesorado de manera inconsciente repite los esquemas aprendidos y se constituyen como una } \\
\text { forma normalizada de ejercer su profesión. Al cuestionarse esta rutina de acción anclada en una } \\
\text { cosmovisión tradicional de la escuela, se hace desde un discurso teórico con pocas conexiones con la } \\
\text { práctica. Por lo tanto, se erigen como un conjunto de obstáculos endógenos para el cambio de los } \\
\text { profesores. Los estereotipos sobre la escuela ejercen un papel disuasorio, constituyéndose en } \\
\text { obstáculos exógenos para él. }\end{array}$ & 0 \\
\hline $\begin{array}{l}\text { Eje Obstáculo } \\
\text { Contenido }\end{array}$ & EOC & $\begin{array}{l}\text { Como esquema aprendido en la escuela asume que debe enseñar lo mismo, con los mismos recursos, } \\
\text { posiblemente por el contexto de la misma escuela, se da lo de siempre porque es parte de la cultura } \\
\text { escolar construida. }\end{array}$ & 43 \\
\hline $\begin{array}{l}\text { Eje Obstáculo Criterio } \\
\text { de Validez }\end{array}$ & EOCV & $\begin{array}{l}\text { Usa los criterios de la cultura escolar, no producción de conocimientos, por tanto lo que se hace en la } \\
\text { escuela no es conocimiento, no es legítimo. }\end{array}$ & 14 \\
\hline $\begin{array}{l}\text { Eje Obstáculo fuente } \\
\text { criterio selección }\end{array}$ & EOFCS & $\begin{array}{l}\text { Considera que las CSC al no estar curricularizadas no permiten cumplir con los propósitos de la escuela, } \\
\text { lo importante es un texto fácil de uso tradicional porque lo que se debe enseñar es la ciencia } \\
\text { construida. }\end{array}$ & 34 \\
\hline
\end{tabular}




\begin{tabular}{|c|c|c|c|}
\hline $\begin{array}{l}\text { Eje obstáculo } \\
\text { referente } \\
\text { epistemológico } \\
\text { enseñanza } \\
\text { aprendizaje }\end{array}$ & EOREEA & $\begin{array}{l}\text { Considerar que las CSC no son temáticas que puedan ser abordadas desde la ciencia escolar porque } \\
\text { ellas son complejas, los estudiantes no aprenderían lo científico }\end{array}$ & 25 \\
\hline $\begin{array}{l}\text { FUENTES CRITERIOS } \\
\text { SELECCIÓN CONT EA } \\
\text { CSC }\end{array}$ & FCS & $\begin{array}{l}\text { Los que el profesor usa para abordar el contenido como textos, revistas, noticieros, artículos } \\
\text { especializados, etc. }\end{array}$ & 0 \\
\hline FCS Expontáneistas & FCSE & $\begin{array}{l}\text { Siempre está alineado con los gustos de los estudiantes, la temática a trabajar surge acorde, al interés } \\
\text { de estudiantes hasta agotar sus expectativas, no se parte de una planeación del docente, cambia según } \\
\text { expectativa del estudiante y se deben desarrollar sus propuestas. }\end{array}$ & 2 \\
\hline FCS Instruccional & FCSI & $\begin{array}{l}\text { Las actividades didácticas se alternan entre exposiciones y prácticas, generalmente en forma de } \\
\text { secuencia de descubrimiento dirigido (método científico). Planificadas con rigor, presentando los } \\
\text { conocimientos ordenados acorde a su nivel de dificultad y estableciendo conceptos llave que cierran o } \\
\text { abren el acceso a otros. Se presentan los contenidos bien elaborados y validados para cualquier } \\
\text { contexto y orientados para superar los errores conceptuales }\end{array}$ & 46 \\
\hline $\begin{array}{l}\text { FCS Integrador } \\
\text { transformador }\end{array}$ & FCSIT & $\begin{array}{l}\text { Las actividades didácticas deben ser abordada en torno a problemas (controversias) CSC, CSV, } \\
\text { buscando diferentes alternativas de solución y análisis (sociocultural, sociopolítico, legislativo, } \\
\text { científico- tecnológico, riesgo (salud-ambiente), ético-moral). Hay diversidad de fuentes desde textos } \\
\text { especializados a los manejados en los medios masivos de comunicación, respaldo en investigaciones. }\end{array}$ & 63 \\
\hline FCS Tradicional & FCST & $\begin{array}{l}\text { Actividad centrada en la exposición hecha por el profesor, con apoyo de libros de textos y ejercicios de } \\
\text { revisión, por lo tanto el criterio es de autoridad externa. }\end{array}$ & 23 \\
\hline $\begin{array}{l}\text { REFERENTES } \\
\text { EPISTEMOLÓGICOS } \\
\text { CSC }\end{array}$ & RE_CSC & $\begin{array}{l}\text { Diferentes tipos de conocimiento que intervienen en la clase, pueden ser de la ciencia, currículo, } \\
\text { conceptos de los estudiantes, creencias populares }\end{array}$ & 0 \\
\hline RE espontáneista & REE & $\begin{array}{l}\text { Para educar al alumno, que vive en una realidad inmediata, se satisface el estudiante, los referentes son } \\
\text { los deseos de los estudiantes }\end{array}$ & 2 \\
\hline RE Instruccional & REI & $\begin{array}{l}\text { Referente fundamental el conocimiento científico o el curricular elaborado por expertos y que el } \\
\text { docente lo asume para desarrollarlo. }\end{array}$ & 26 \\
\hline $\begin{array}{l}\text { RE Integrador } \\
\text { Transformador }\end{array}$ & REIT & $\begin{array}{l}\text { Enseñanza debe proporcionar transformación progresiva del conocimiento hasta modelos más } \\
\text { complejos que le permitan entender el mundo y actuar en él; referente esencial el conocimiento } \\
\text { didáctico, científico, metadisciplinar, se basa en los conceptos que están en la cotidianidad y son } \\
\text { controversiales, }\end{array}$ & 62 \\
\hline
\end{tabular}




\begin{tabular}{|c|c|c|c|}
\hline RE Tradicional & RET & $\begin{array}{l}\text { el currículo tradicional, los lineamientos curriculares, los establecidos fundamentalmente siguiendo } \\
\text { directrices externas de homogenización }\end{array}$ & 29 \\
\hline Taller inicial CSC & Tal_In & Taller presentado como exploratorio & 0 \\
\hline $\begin{array}{l}\text { CARACTERISTICAS DE } \\
\text { LA CSC DROGA }\end{array}$ & & $\begin{array}{l}\text { Las creencias de los maestros sí importan. Son estas creencias las que impactan la instrucción en el aula } \\
\text { y el material presentado a los estudiantes diariamente. Las opiniones personales de los educadores son } \\
\text { especialmente importantes en el examen de csc se han descrito como "dilemas sociales con } \\
\text { asociaciones conceptuales o técnicas con la ciencia" (Wu \& Tsai, 2007, p.1666), }\end{array}$ & 13 \\
\hline CSC L_N_G & & $\begin{array}{l}\text { Los lados contrastantes de un tema controvertido abordan el tema desde } \\
\text { premisas fundamentalmente diferentes. Estas diferencias incluyen "creencias clave, entendimientos, } \\
\text { valores. }\end{array}$ & 11 \\
\hline EVALUACIÓN & & $\begin{array}{l}\text { Los profesores, no un grupo externo, son frecuentemente los que hacen el } \\
\text { decisión de evitar abordar los aspectos sociales de los problemas científicos a los que se enfrentan } \\
\text { (Hodson, 2009). La evasión de estos temas es probablemente el resultado de los conflictos de múltiples } \\
\text { fuentes que pueden surgir cuando se incluye el CSC en el aula. }\end{array}$ & 9 \\
\hline $\begin{array}{l}\text { EXPLIQUE POR QUE } \\
\text { SE TRATA DE UNA } \\
\text { CSC }\end{array}$ & & $\begin{array}{l}\text { La comprensión limitada del tema entre los docentes (Davis, Petish, \& Smithey, 2006). Los puntos de } \\
\text { vista de los docentes sobre las prácticas adecuadas en el aula imponen una barrera significativa cuando } \\
\text { se intenta implementar algún tema innovador en el currículo escolar (Michael Huberman \& } \\
\text { Middlebrooks, 2000). CSC puede suscitar opiniones fuertes y diferentes (Bauer, 1998); por lo tanto, los } \\
\text { temores sobre el comportamiento de los estudiantes y los posibles argumentos que pueden surgir son } \\
\text { otra preocupación común. }\end{array}$ & 12 \\
\hline Fun_Cient_CSC & & $\begin{array}{l}\text { Los debates sobre estos temas a menudo están tan cargados de emociones que algunos los han } \\
\text { descrito como guerras entre dos religiones (Ruse, 2005), con un lado del debate enfocado en el avance } \\
\text { del hombre a través de la ciencia y el lado opuesto centrado en la creencia en lo divino. La más pública } \\
\text { de estas batallas ha involucrado la evolución de los seres humanos. }\end{array}$ & 9 \\
\hline $\begin{array}{l}\text { MEDIOS DE } \\
\text { COMUNICACIÓN }\end{array}$ & $\mathrm{MC}$ & $\begin{array}{l}\text { Los medios de comunicación a veces se constituyen como la única fuente de información sobre ciertos } \\
\text { temas de actualidad científica y tecnológica para el público en general, sin embargo la forma } \\
\text { intencional en la que se transmiten las noticias científicas dificulta el análisis crítico y la toma de postura } \\
\text { informada (Nelkin, 2001). }\end{array}$ & 13 \\
\hline $\begin{array}{l}\text { METODOLOGÍA PARA } \\
\text { ABORDAR CSC }\end{array}$ & & $\begin{array}{l}\text { Los puntos de vista de los docentes sobre las prácticas adecuadas en el aula imponen una barrera } \\
\text { significativa cuando se intenta implementar algún tema innovador en el currículo escolar (Michael } \\
\text { Huberman \& Middlebrooks, 2000). CSC puede suscitar opiniones fuertes y diferentes (Bauer, 1998); por } \\
\text { lo tanto, los temores sobre el comportamiento de los estudiantes y los posibles argumentos que } \\
\text { pueden surgir son otra preocupación común. Otros temores incluyen quién es el más adecuado para }\end{array}$ & 11 \\
\hline
\end{tabular}




\begin{tabular}{|c|c|c|c|}
\hline & & los temas que deben incluirse y $\mathrm{c}$ & \\
\hline P. ENUNCIADO & & $\begin{array}{l}\text { Para explorar los temas completamente, creo que es importante comprender los aspectos más } \\
\text { controvertidos de las CSC, evaluar las creencias del docente sobre los aspectos controvertidos de la } \\
\text { CSC seleccionada, y para evaluar la calidad del razonamiento y las lentes de toma de decisiones } \\
\text { utilizadas por estos educadores. }\end{array}$ & 12 \\
\hline POSICION CSC & PosCSC & $\begin{array}{l}\text { El debate de la CSC involucra a los estudiantes en la negociación de ideas diversas y la formulación de } \\
\text { posiciones que usan experiencias de vida, valores éticos y evidencia científica para alcanzar un } \\
\text { consenso y tomar decisiones. (Hygino, Janeiro, \& Janeiro, 2013). }\end{array}$ & 12 \\
\hline RECURSOS & & Recursos tecnológicos utilizados en la elaboración de secuencias didácticas & 12 \\
\hline RELACION CSC ÁREA & & $\begin{array}{l}\text { Sadler \& Zeidler (2004) y debe verse como importante entre todos los educadores de ciencias. Este } \\
\text { estudio examina tres de los aspectos más críticos que impactan las creencias de los maestros sobre la } \\
\text { cobertura de CSC: 1) la voluntad de los docentes de aceptar CSC en el currículo de ciencias, 2) los } \\
\text { factores que afectan las conclusiones antes mencionadas, y 3) las variaciones en el razonamiento entre } \\
\text { y entre los partidarios de CSC y aquellos que se oponen a la inclusión de los temas seleccionados. }\end{array}$ & 13 \\
\hline $\begin{array}{l}\text { RELACIÓN } \\
\text { CURRÍCULO DROGA }\end{array}$ & & $\begin{array}{l}\text { La cobertura adecuada de CSC en el aula puede mejorar la comprensión conceptual de conceptos } \\
\text { científicos más amplios (Linn, Shear, Bell, \& Slotta, 1999) habilidades generales de razonamiento } \\
\text { científico (Anagün \& Özden, 2010), y dan como resultado una mejor comprensión de la naturaleza de la } \\
\text { ciencia como lo demuestran los estudiantes, CSC se han utilizado para mejorar las habilidades de } \\
\text { pensamiento crítico y la capacidad de los estudiantes para relacionar ideas divergentes. }\end{array}$ & 14 \\
\hline $\begin{array}{l}\text { TEMÁTICAS QUE SE } \\
\text { PUEDEN ABORDAR } \\
\text { COMO CSC }\end{array}$ & & $\begin{array}{l}\text { La relación de numerosas CSC con la moralidad, la ética y / o la religión puede ser un factor importante } \\
\text { para explicar la escasez de cobertura de SSI en numerosas clases de ciencias (Gibson, 2004). La } \\
\text { naturaleza relevante de ciertos temas los hace más susceptibles a los impactos culturales e históricos en } \\
\text { comparación con sus contrapartes menos interesantes universalmente. Se cree que las creencias del } \\
\text { público tienen más probabilidades de afectar el comportamiento de los maestros }\end{array}$ & 14 \\
\hline
\end{tabular}

\section{Fuente: Nvivo11 proyecto CSC CPP al abordar CSC/CTSA en IUE}


El Gl del GCl formado por profesores de planta y de horas extras se agrupa en el Software como Gl en el que Gl1 representa los profesores de horas extras y el GI2 los profesores de planta, estos últimos, por su condición laboral entregaron todos los documentos solicitados y los del Gl2 participaron del proceso de formación pero no todos entregaron documentos sugeridos como talleres y SD, posiblemente porque en el contrato laboral no se contemplan espacios para el trabajo institucional, por lo que siempre participaron de jornadas pedagógicas, y espacios de formación en el horario de trabajo, así como de actividades realizadas con los estudiantes; sin embargo siempre estaban dispuestos a participar, especialmente cuando llegaban a la escuela profesores de la universidad, profesionales de la SED o futuros profesores en formación inicial.

Los profesores en el software se identifican con la letra $\mathrm{P}$ que indica profesor, la siguiente letra el área ( $\mathrm{M}$ : matemáticas, $\mathrm{S}$ : sociales, $\mathrm{T}$ : Tecnología, $\mathrm{H}$ : humanidades, P: primaria, O: orientación) y un número, que indica el número de maestros por área; así, PC1 profesor de ciencias 1, PC2 profesor de ciencias 2 y PC3 profesor de ciencias 3, así sucesivamente, con las otras áreas. (Figura 39).

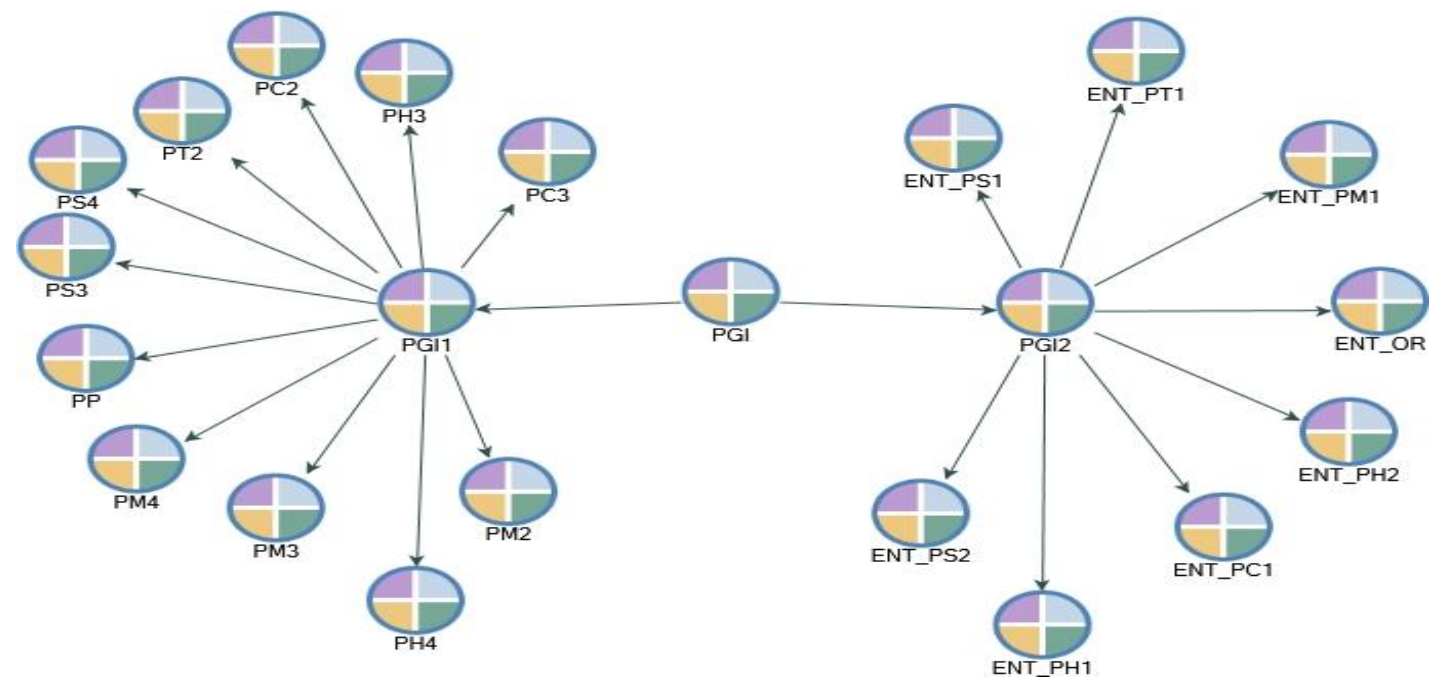

Figura 39. $\mathrm{GI} \mathrm{GCl} \mathrm{(G1} \mathrm{profesores} \mathrm{horas} \mathrm{extras/G2} \mathrm{profesores} \mathrm{de} \mathrm{planta)}$ Fuente NVivo11. Proyecto CPP al asumir CSC/CTSA en la IUE 
Así, una vez formado el $\mathrm{Gl}$ en el que se debate/dialoga y se construye conocimiento profesional como campo de formación, reconocido como una asociación libre (figura 15 y 16), se inician debates sobre el tema de interés común y que realmente fue lo que permitió consolidar el grupo, ya que como lo mencionó uno de los profesores, no querían hacer un proyecto más; estaban interesados en la posible solución de una problemática del contexto escolar: mitigar el problema de consumo del SPA e ir consolidando el Gl como un campo de formación de docentes capaces de reflexionar sobre sus propias prácticas, junto a sus pares y los profesores universitarios, que contribuyeron con el desarrollo de posturas críticas, creativas, autónomas y transformadoras.

Cuando el profesor menciona, no querer hacer un proyecto más, se develan la angustia de la colonización del mundo de la vida por la racionalidad instrumental en la que el Estado a través de sus instituciones públicas legisla para hacer cumplir las reglas del mercado, pero también, muestra la actitud de los profesores, acostumbrados a la pasividad y rutina escolar, en la que solo se espera lo que viene de fuera para empezar a abordar tareas, generalmente con fines de rendición de cuentas o de la implementación de políticas, en el caso de la jornada nocturna de reinserción, en la que los maestros eran preparados mental y psicológicamente para asumir en sus aulas el trabajo con personas que dejaban sus armas y que recibirían beneficios económicos por reincorporarse a la sociedad, pero no fueron acompañados para promover una formación específica y contextualizada a las necesidades de los mismos.

Lopes \& Carvalho (2017) aluden a "la soledad profesional" a la que se acostumbran los profesores una vez terminan su primera graduación, ya que salen a ejercer su carrera profesional, pero son recibidos en el mundo de la vida como proletarios generalmente, y en ese proceso de proletarización como menciona Contreras (1997) pierden la autonomía, su capacidad creadora e innovadora y permiten la alienación a través del cumplimiento de normas, de políticas externas 
al contexto escolar, se acostumbraron a la soledad profesional de sus instituciones formadoras y se dejaron alienar por la rutina escolar, posiblemente fruto del proceso de su propia formación como estudiantes de educación básica y profesores en formación inicial, donde predominaron los saberes académicos, y se estructuró en sus mentes y en sus cuerpos CPD (Solís \& Rivero, 2013), en palabras de Conrado \& El-Hani (2010):

Uno de los problemas centrales del sistema educacional reside en el hecho de que las habilidades de pensamiento crítico: análisis, discusión e investigación sobre información relevante para la resolución de problemas, entre otros aspectos, deberían ser aprendidas en la enseñanza fundamental y media, muchas veces no son desarrolladas ni siquiera en la educación superior. (p.4) traducción propia.

Los profesores de Gl en la caracterización, mencionan lo que han tenido que soportar durante sus años de trabajo como profesores:

"la agresión verbal de los estudiantes, - el desinterés por el estudio, - la presencia de estudiantes drogados permanentemente en sus aulas, - las malas palabras, - la falta de normas que acompañen procesos de convivencia, - el consumo en el aula de pegante, marihuana, etc.,- la falta de lectura y de buenos hábitos, - gente que sólo viene a que los pasen y "no hacen nada", - la mediocridad, - los jóvenes nunca traen los padres cuando se les llama y toca seguirlos manteniendo en el aula, -el hambre, el cansancio de algunos de ellos que vienen a dormir, llegan tarde y se quieren ir temprano, etc."

Son algunos de los comentarios, que develan las angustias que Lopes \& Carvalho (2017) mencionan, las angustias que tiene el profesor y que posiblemente la universidad que los formó se olvidó de establecer una formación continuada que sirviera de apoyo, de continuidad a un proyecto de formación para toda la vida $y$, por falta de procesos de acompañamiento pertinente para este contexto escolar, muchos profesores ejercen violencia simbólica hacia los jóvenes y adultos, 
quienes independiente de la edad son "estudiantes", provenientes de procesos de exclusión, de violencia de toda clase, con muchas carencias económicas, con necesidades educativas especiales como menciona Silva (2016):

Pensar en la formación de profesores de jóvenes y adultos es pensar en las especificidades de los sujetos, los cuales presentan características históricas e historias de vida distintas, tales como: trabajadores proletarios, desempleados, amas de casa, jóvenes, tercera edad, sujetos con diferencias culturales, étnicas, religiosas y de creencias. Sujetos trabajadores que llegan a veces tarde a la escuela, exhaustos y con sueño y quieren salir más temprano, eso cuando pueden llegar a la escuela. (p.16)

Lo que justifica las afirmaciones de los profesores antes mencionadas, y que por tanto es una posible consecuencia de la falta de formación de profesores para atender a esta población, evidencian los procesos de formación inicial que no han preparado al estudiante (profesor en formación) para conocer primero a la población con la que van a desarrollar su CPP.

Es necesario aclarar que como método de investigación de caso único, no pretende abordar los casos individuales, sin embargo, por las bondades del programa (NVivo11) el caso único se puede fragmentar, acorde a los intereses del investigador; adicional a lo anterior, como es un grupo interdisciplinar de docentes y profesiones (licenciado y otra profesión como ingeniería, derecho, contador, orientador), se quiso identificar un discurso por área, es decir, el discurso del profesor de ciencias (PC1), matemáticas (PM1) y tecnología (PT1), el de sociales (PS1) y el de humanidades (PH2) que como se visualiza son del Gl2 aun así participaron de todo el proceso de formación; de la misma forma los profesores del Gl1 son profesores con otro tipo de vinculación (hora que se trabaja se paga), pero que independientemente de esta particularidad, cuando están en el Gl están en las mismas condiciones profesionales de los demás profesores y, que como $\mathrm{CP}$, en terminología de Fleck serían los expertos generales del circulo esotérico 
(figura 28); a título de hipótesis se tiene la ilusión de que los que van a mantener el circulo esotérico de especialistas como CP con un EP integral transformador serán los del GI2, quienes lucharán por mantener una armonía de las ilusiones, harán una suave "coerción didáctica" a todos los que lleguen a formar parte del GI1 para construir un EP que como colectivo permita mantener la dinámica movilizadora del currículo; términos que explicaremos en el capítulo seis, originado a partir de categorías emergentes.

Por lo tanto, vamos a iniciar esta primera parte haciendo uso del cuestionario inicial de caracterización en aspectos relacionados con la investigación y el conocimiento del enfoque CTSA, para luego analizar la posible movilidad del pensamiento del profesor, a la luz de una HdPR surgida de la hibridación de la HdPR de Levinson (2008) tabla 3, Pedretti \& Nazir (2011) tabla 4, (Martínez, 2000, 2016, 2017), Martínez \& Valbuena (2013), Martínez (2000, 2016, 2017) figura 11, Strieder (2012), Fleck (1986), que al ser integradas, se resumen en la tabla 9 tomadas como unidades de referencia, nodos (categorías preestablecidas y emergentes) en el software NVivo11 y representadas esquemáticamente en la figura 40.

Hay que aclarar, que estas relaciones no son construidas por la investigadora en forma teórica, sino que surgen del proceso de análisis del contenido y del discurso de toda la información obtenida en el proceso de investigación, y por tanto, emerge como categoría construida y develada que indica cómo se construyó el marco teórico y se ajusta a la interpretación de los resultados obtenidos, es decir se construye conocimiento alrededor del uso de las CSC tomando como referencia la información y datos que respaldaron dicho proceso de investigación. 


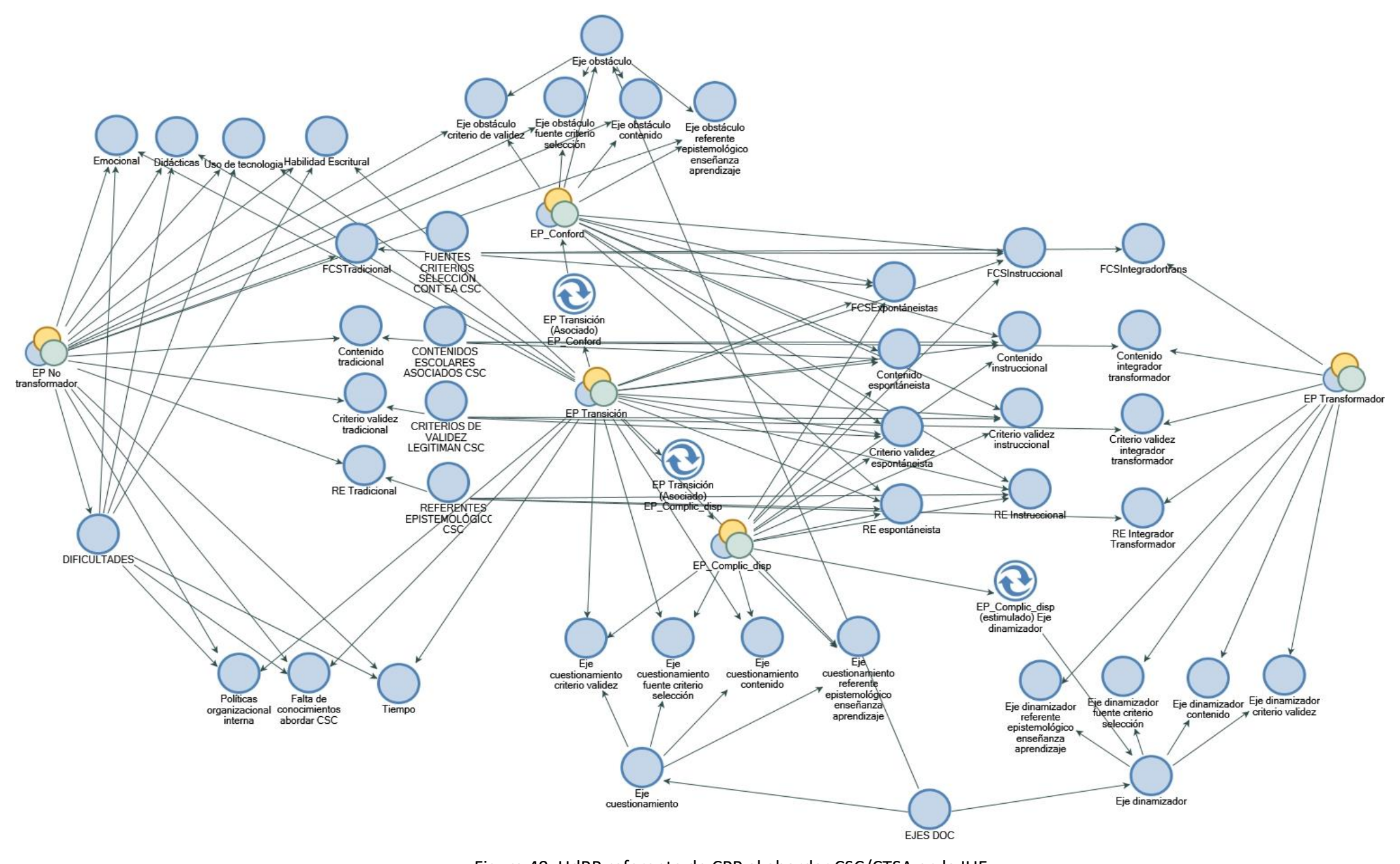

Figura 40. HdRP referente de CPP al abordar CSC/CTSA en la IUE

Fuente. Autora con base los resultados del ATD según los referentes teóricos de Fleck (1986); Levinson (2008); Martínez (2000, 2016, 2017); Martínez \& Valbuena (2013); Martínez (2014); Pedretti \& Nazir (2011); Ratcliffe \& Grace (2003ㄹ) y Strieder (2012) articulados a través del ATD y Software NVivo11 
Los aspectos a considerar en el cuestionario de caracterización, son los relacionados con el concepto investigación y conocimiento del enfoque CTSA, en el primer caso los profesores, como se mencionó anteriormente, no investigan en la escuela, ni consideran la investigación como parte fundamental de la actividad del profesor, los que mencionan que investigan lo hacen en colegios privados o en empresas (segunda profesión), ni siquiera mencionan que lo han hecho como producto de los cursos que han tomado durante la formación permanente.

Los profesores con menos experiencia profesional, evidencian por sus respuestas y por la misma rutina escolar, que tienen que trabajar en diferentes partes y horarios para empezar a disfrutar de ciertas comodidades que no se tenían en su formación inicial, o para cumplir con responsabilidades que hacen parte de sus nuevas vidas, con nuevos hogares (adquisitivas en bienes/raíces, artefactos, carros, o por formación de nuevas familias).

Adicional a lo anterior, el $90 \%$ de los profesores tienen dos o más empleos, el $10 \%$ que sólo trabaja en la noche, corresponde a profesores pensionados, que han consolidado un capital económico significativo; sin embargo, no consideran la investigación como parte de su formación y son las personas más reacias a hacer otras actividades, posiblemente ya "están cansadas" de las actividades escolares, de todas las cosas que tienen que hacer para rendir cuentas, de la semanas de receso, de proyectos obligatorios, de las problemáticas que tienen que afrontar en su día a día. Imaginario que se ha vuelto cultural, porque mencionan que acorde a las características de la población requieren conocer lo básico:

[...]"sólo necesitan conocer lo básico" porque que más van a hacer en la vida, "si no lo hicieron cuando jóvenes, ahora menos"; "ese señor (aproximadamente 65 70 años) solo viene a borrar el tablero, porque no sabe ni leer/escribir, pero está en ciclo 3 (sexto y séptimo), estará esperando pasar al siguiente ciclo sin hacer nada", esos gamines, toca empezar a depurar la jornada, hay mucho chino (jóvenes de 13 a 18) y no dejan concentrar a la gente adulta". 
Comentarios como los anteriores, se hacen extensivos, empiezan generalmente por los profesores que mencionan tener mayor experiencia laboral y se prolifera "se vuelve viral" en el imaginario de los profesores que llegan a vincularse y se hacen intensivas a las otras jornadas, sin embargo, en reuniones generales convocadas para colegios de EJA, la mayor parte de los profesores tienen imaginarios de este tipo de educación; nuevamente se refleja a través de los discursos de los profesores la falta de acompañamiento de las instituciones formadoras de profesores (Lopes \& Carvalho, 2017) y de formación de profesores para EJA (Silva, 2016).

Estas posiciones, comentarios develados, son producto histórico, la escuela no es el único lugar donde se escuchan, como fruto de una población marginalizada, de menos recursos económicos $y$, que ha vivido y vivirá violentada en todas sus formas, es la resultante de un sistema capitalista, de una visión instrumental de la educación y de una enseñanza descontextualizada, posiblemente como menciona Conrado \& El-Hani (2010) producto de una formación de docentes también instrumental.

La EJA, históricamente contextualizada en el periodo de la esclavitud, en la alfabetización para evangelizar "aculturar" nativos, siempre ha estado relegada a las personas más necesitadas, a los habitantes de sectores populares, a los excluidos, y en la mente de los profesores se ha perpetuado, posiblemente por falta de formación en este campo que atiende a las exigencias de políticas neoliberales del Banco Interamericano de Desarrollo BID, del Fondo Monetario Internacional (FMI) y otras políticas locales de quieren perpetuar el poder a través de la mano de obra barata, por mantener un sistema de "esclavitud moderna" hacia, los excluidos, víctimas del conflicto o de la descomposición social (Gentil, 2005). 
Rios, Vieira, \& Silva (2017), mencionan que la EJA no debe ser entendida como una forma de reponer la escolaridad, este sistema debe tener una identidad propia, aprovechando la diversidad de perfiles de los educandos en relación con la edad, el nivel de escolaridad, sus experiencias de vida; esta población constituida en la modernidad actual en gran medida por jóvenes que no se alejaron de la escuela por cuenta propia, fueron alejados porque el sistema escolar tradicional no creo las condiciones para mantenerlos, fueron estudiantes difíciles de manejar, los que rompen las normas y la convivencia, los que no tiene un acudiente responsable que acompañe el proceso educativo (Araújo \& Souza, 2017; Arroyo, 2015; Romao \& Gadotti, 2011).

Naiff, Naiff, Pereira, \& Ávila (2015) investigan sobre el imaginario que tienen los profesores de la EJA que es su mayoría se refieren a: el trabajador que se esfuerza e intenta superarse para ser apto para el mercado laboral, personas que no trabajan no estudian, etc., Sin embargo no se menciona que los problemas de deserción posiblemente son causados por el propio sistema de enseñanza, caracterizado por tener currículos inadecuados, una deficiente formación inicial y continuada de los profesores, evaluaciones estandarizadas que insisten en responsabilizar a los estudiantes por su propio fracaso escolar; la sobrecarga laboral de los profesores; el número de estudiantes que deben orientar y el imaginario creado de abordar las clases para una población de EJA como si fueran estudiantes de la educación formal.

Todo este panorama, es exteriorizado en el diálogo con los docentes del Gl, quienes independientemente del tipo de contratación, consideran que su profesión está limitada por las características de los estudiantes, teniendo que lidiar problemáticas, como las mencionadas en la tabla 10.

Tabla 10. Intervenciones vivencias de los profesores en las aulas

Int1 Falta de apoyo de las familias a los estudiantes, la pobreza, la influencia de los medios de comunicación sobre los estudiantes, 


\begin{tabular}{|c|c|}
\hline & coholismo, drogas, baja autoestima etc. \\
\hline Int2 & $\begin{array}{l}\text { ser muy exigente y no compartir con los estudiantes mediocres ya que } \\
\text { no se les puede exigir en su formación. }\end{array}$ \\
\hline Int3 & $\begin{array}{l}\text { El trabajo con estudiantes en proceso de reinserción, desplazados, } \\
\text { habitantes de calle. }\end{array}$ \\
\hline $\operatorname{lnt} 4$ & $\begin{array}{l}\text { Pandillismo, drogadicción, habitantes de calle, grupos desmovilizados, } \\
\text { reinsertados. }\end{array}$ \\
\hline Int5 & Problemas de aprendizaje, de adicciones y de convivencia \\
\hline Int6 & $\begin{array}{l}\text { Indisciplina constante de algunos estudiantes, falta de respeto al } \\
\text { docente, agresividad entre compañeros y con el docente, alumnos } \\
\text { consumidores de sustancias psicoactivas, alumnos con trastornos de } \\
\text { aprendizaje, falta de compromiso con la asignatura, alumnos con } \\
\text { carencias afectivas y maltratados, alumnos sin recursos económicos. } \\
\text { alumnos desplazados, etc. }\end{array}$ \\
\hline Int7 & $\begin{array}{l}\text { La envidia de otros docentes, la pocas ganas de estudiar y de trabajar } \\
\text { de los diferentes grupos. }\end{array}$ \\
\hline Int8 & $\begin{array}{l}\text { Problemas del sector público, de índole económico, nunca hay } \\
\text { presupuesto, falta de maquinaria y equipo. }\end{array}$ \\
\hline Int9 & Falta de herramientas para el desempeño de la labor docente. \\
\hline Int10 & $\begin{array}{l}\text { Consumo de SPA, población LGBTI, violencia intrafamiliar, abuso } \\
\text { sexual, agresiones físicas o matoneo amenazas, etc. }\end{array}$ \\
\hline Int11 & Falta de disciplina en las aulas y de recursos especializados. \\
\hline Int12 & $\begin{array}{l}\text { te de los estudiantes y la } \\
\text { o } 230\end{array}$ \\
\hline
\end{tabular}

Fuente. NVivo11 nodo caracterización

En este ítem se quisieron socializar casi todas las participaciones, evidenciando el gran porcentaje de docentes del GI, con unos imaginarios de la EJA muy similares a los que históricamente se han dado y que las políticas neoliberales han intentado mantener y perpetuar, pero, lo más preocupante, es que la labor de los docentes en este tipo de población esté alienado posiblemente por la rutina de la escuela, por la formación de profesores lejos del contexto escolar, por falta de políticas públicas que además de dar respuesta a las necesidades de la formación, responden a políticas del mercado y hacen que el docente a través de sus prácticas de aula, contribuya con la perpetuación del poder y sin posibilidad de desarrollar su autonomía y liderazgo (Araújo \& Souza, 2017; Bourdieu \& Passeron, 2001a; Gentil, 2005). 
Intervenciones como Int2, Int5, Int6, Int 11 e Int12 develan docentes que añoran un sistema educativo tradicional, posiblemente en el que fueron formados (Conrado \& El-Hani, 2010), quieren aulas silenciadas, ordenadas, en las que los estudiantes no se pueden mover sin la aceptación del profesor; el profesor muestra que está desarmado ante los problemas sociales; les preocupa no tener herramientas de control, no hay normas ni sanciones excluyentes del sistema educativo, se sienten "abandonados - soledad profesional" (Lopes \& Carvalho, 2017)

El discurso del profesor manifiesta, ese estado de inconformidad con la población que maneja a la que tiene que enseñar; devela la falta de procesos de formación que le permitan conocer sensibilizar y comprender que la EJA es un campo fecundo y prometedor para realizar prácticas educativas, con posibilidad de reorganización del currículo articulado por CSC con enfoque CTSA que permita a los estudiantes independientemente de sus características ser reconocidos como personas, que tienen saberes, que tienen una historia, un lugar donde se construyan conocimientos escolares y profesionales. Por tanto, es a través de la consolidación de las asociaciones libres que se podrán soñar, planear, estructurar imaginarios para una población que desea estar en el sistema educativo adecuado (Bernardino, 2008; Freire, 2006).

Por último, la Int7, pone en evidencia, las relaciones interpersonales que se tejen en el ambiente escolar por parte de los profesores, semejantes a las que viven los estudiantes, algunos sienten la envidia, también se escuchan comentarios fuera de tono en el ambiente laboral, parece que no se estuviera hablando del campo educativo; la escuela es el escenario de reproducción de la sociedad, es el mundo de la vida como afirma Habermas (1987); en el sistema escolar hay luchas de poder, por mantener prestigio reconocimiento, por evidenciar quien tiene más 
capital económico, cultural y social (Bourdieu \& Passeron, 2001b), (Gutiérrez, 2014).

Panoramas como el mencionado, hacen parte de la cultura escolar, estos evidencian la precaria formación de profesores con un perfil no estructurado ni específico para la EJA; adicionalmente se evidencia que el imaginario de los profesores no está la investigación, posiblemente asumen que con población con las características mencionadas no se puede investigar, sumado esto a la falta de tiempo para la formación permanente; otros profesores carecen de disposición posiblemente porque ya han dedicado su vida al trabajo escolar hasta lograr la pensión, o los otros profesores con menos años de experiencia laboral, porque hasta ahora están acumulando capital económico para satisfacer las necesidades materiales, para mantenerse en el juego; como se evidencia en la figura 41, en la que el $60 \%$ de los integrantes del $\mathrm{Gl}$, tienen compromisos laborales en la jornada contraria, tanto en espacios formales como no formales (los que no colocan actividades no formales laboran en la industria, en bienes y servicios, en comunidades religiosas, son independientes (abogados, contadores, ingenieros), los otros trabajan en colegios privados formales de tiempo completo; es decir, tienen una carga laboral, poco humanizada, lo que hace que sus capacidades profesionales no puedan ser evidenciadas por la premura de cumplir con las otras exigencias también del campo laboral.

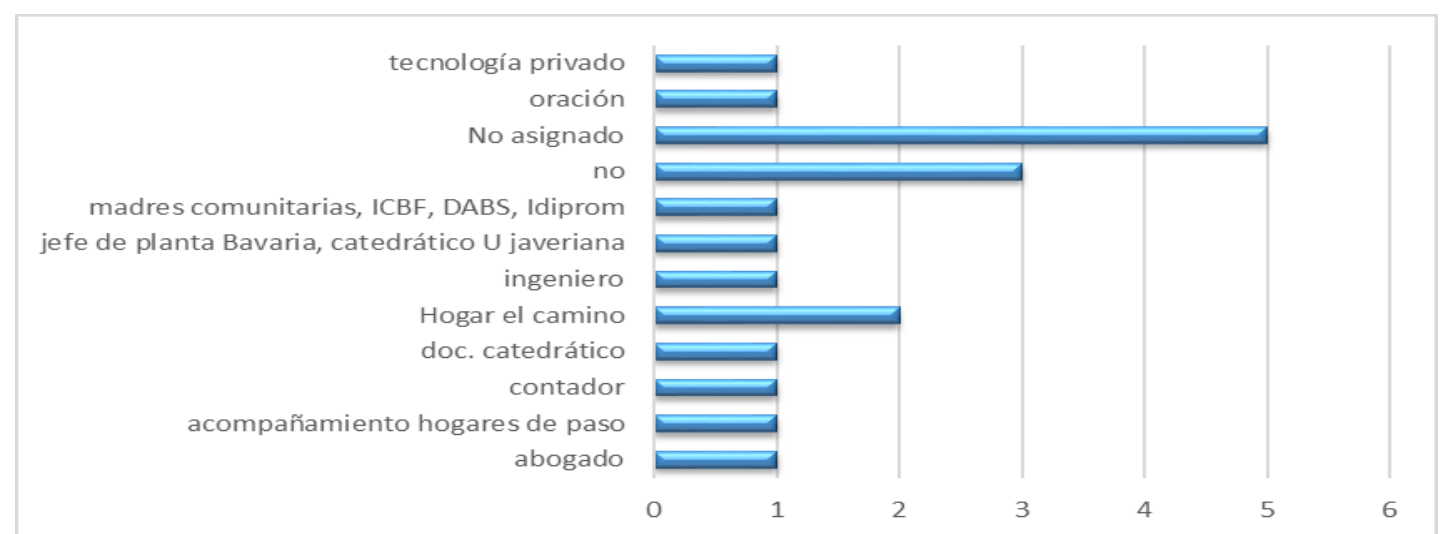

Figura 41. Otras actividades independientes de la jornada escolar en espacios no formales 
Otro aspecto que permite comprender, por qué no se investiga en la escuela está asociado a la misma rutina escolar, a la estructura organizativa de la EJA, que no ha independizado la estructura curricular, ni el proceso de evaluación del sistema escolar de la enseñanza para básica y media tradicional, por lo que debe expedir certificaciones con las mismas áreas y asignaturas estándar contempladas por el MEN. Los profesores tienen una hora en cada aula en la que pueden trabajar con de 30 o 40 estudiantes, lo que conlleva a que el docente siga masificando su discurso y no promueva el diálogo ni la participación.

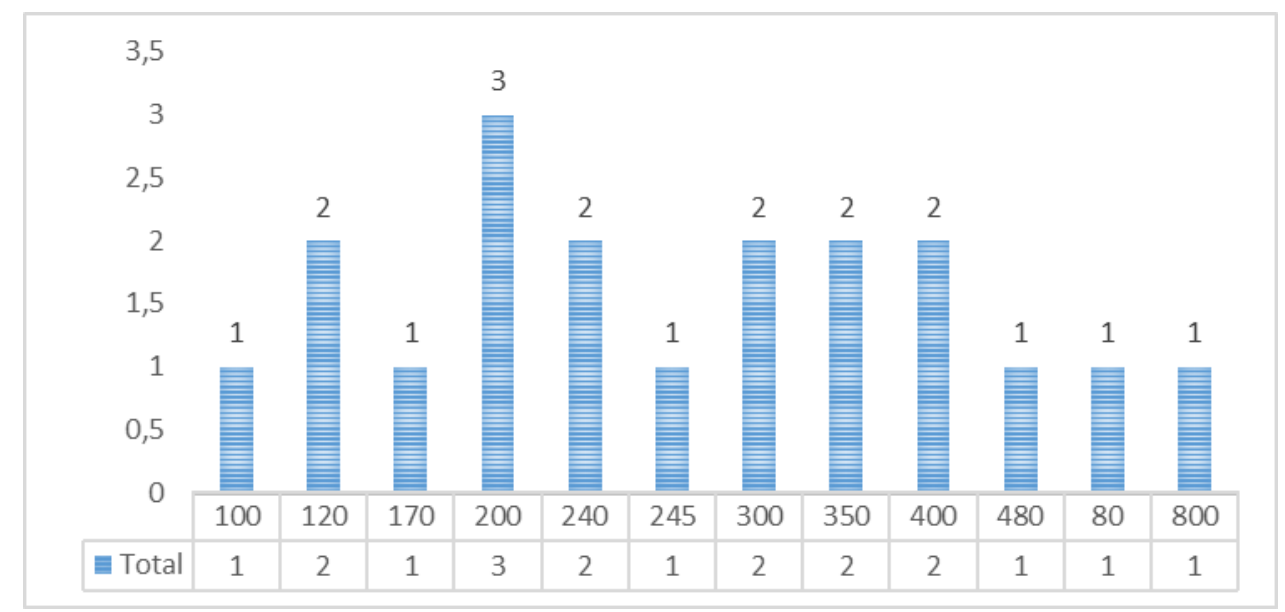

Figura 42. Número de estudiantes a cargo en la jornada laboral.

Hay que aclarar, que en la EJA se proyectan número de matrículas por aula que superan los 40 estudiantes; es decir, por aula se matriculan hasta 50 estudiantes, pero por los diferentes problemas de esta población, generalmente se reducen los grupos a la mitad, sumado lo anterior a los procesos de exclusión que realizan los profesores o el mismo sistema escolar; por lo tanto, un profesor puede tener todos los estudiantes de la jornada y en el caso de la orientadora, si existen 800 estudiantes puede tenerlos a cargo, aunque como se mencionó anteriormente, se inicia con una población muy numerosa, pero realmente finaliza la mitad o menos.

En este sentido, la concepción de investigación, interiorizada y promulgada (habitus institucionalizado en los profesores) por los docentes del Gl, y que se devela en el proceso de caracterización, justifica la ausencia de procesos 
investigativos en la escuela, y en particular en la EJA, que posiblemente por su origen de violencia y precariedad histórica, cultural y social se han perpetuado; tampoco se han creado políticas que orienten los modelos de formación permanente para los profesores que atienden esta población. Hay ausencia de profesores que en el ejercicio de su autonomía dinamicen prácticas innovadoras que favorezcan la cultura por la investigación, ellos han permitido que la racionalidad técnica invada totalmente el mundo de la vida y han perdido su autonomía profesional como lo menciona Contreras (1997).

Así, los profesores, especialmente los del Gl2 consideran la investigación alejada de su profesión, comentan que la escuela no da tiempo, hay muchas actividades que deben realizar, no hay presupuesto, incentivos; adicionalmente la investigación no ha permeado la cultura escolar.

A pesar de que los profesores del Gl tienen una formación profesional, un capital cultural institucionalizado (Gutiérrez, 2004) con una trayectoria docente de más de 15 años de experiencia laboral, garantizada por el título universitario, develan la falta de diálogo entre pares, predomina la tiranía entre ellos, "el matoneo simbólico" la ausencia de trabajo en equipo.

Son estas las características del campo escolar, del contexto de la EJA del GI del $\mathrm{GCl}$, en donde los profesores han constituido un habitus particular, impidiendo que se reconozcan como constructores de cultura, tejedores de sociedad; por el contrario en sus diálogos añoran, la necesidad de perpetuar prácticas tradicionales centradas en el respeto a las normas establecidas en forma vertical; extrañan una escuela que garantice relaciones de poder, que percibe al profesor como símbolo de autoridad y respeto. De esta manera con sus acciones, responden a políticas de mercado, a políticas alienadoras, que no transforman, que no forman ciudadanos críticos, participativos e informados, capaces de negociar acuerdos que conlleven a una convivencia pacífica, armónica y democrática. 
Una vez caracterizado el campo de formación en el que se realiz, la propuesta, vamos a describir y socializar los resultados que se obtuvieron durante el proceso formativo al interior del $\mathrm{Gl}$ del $\mathrm{GCl}$ de la jornada nocturna y que surgen como producto del análisis del corpus de la investigación, utilizando como dispositivo de análisis el ATD y del software NVivo11 como se mencionó en la metodología.

Para abordar la pregunta de investigación: ¿Qué caracteriza el CPP de los profesores del GI que tiene como eje central la construcción de conocimientos alrededor de las CSC?, es necesario mencionar que el ATD permite al investigador partir de unas categorías iniciales que en el corpus de la investigación se seleccionaron como unidades de análisis (UA)/unidades de registro(UR) a través del programa NVivo; de esta manera, las UA/UR se hacían a la luz de HdPR de la figura 40; es decir, se identificaba las UA/UR en las categorías: Contenidos (CEA-CSC), Criterio de Validez (CVL-CSC), Fuentes y Criterios de Selección (FCS-CEA-CSC), Referente Epistemológico (RE-CSC) y ejes DOC (Dinamizadores, Obstáculo y Cuestionamiento) como se visualiza en la figura 43 y cuya descripción se evidencia en la tabla $9^{11}$.

\footnotetext{
${ }^{11}$ Todas las figuras de nodos se ven la frase cortada, porque es una foto de la pantalla para visualizar los nodos, por niveles, el texto completo, que es un documento exportable de NVivo es el contenido que se presenta en la tabla 9.
} 


\begin{tabular}{|c|c|c|}
\hline קו & 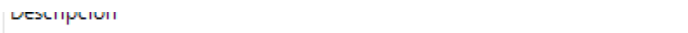 & mpurus \\
\hline CONTENIDOS ESCOLARES ASOCIADOS CSC & Las CSC involucran controversias públicas, discutidas en los medios masi & CEA-CSC \\
\hline Contenido integrador transformador & Conocimientos escolares que integran diversos referenciales(disciplinare & CEIT \\
\hline Contenido instruccional & Saberes disciplinares actualizados, incorporación de algunos conocimie & CEI \\
\hline Contenido tradicional & Información fundamental de la cultura vigente, donde se busca la repro & CET \\
\hline Contenido espontáneista & Contenidos conceptuales que esten en la realidad inmediata del estudia & CEE \\
\hline CRITERIOS DE VALIDEZ LEGITIMAN CSC & Principios y supuestos que permiten determinar LA LEGITIMIDAD DE LA & CVL-CSC \\
\hline Criterio validez tradicional & Pruebas que midan lo que el estudiante memorizo de la clase (igual al li & $\mathrm{CVT}$ \\
\hline Criterio validez instruccional & Pruebas que midan lo que el estudiante memorizó de la clase (igual al li & $\mathrm{CVl}$ \\
\hline Criterio validez integrador transformador & Formas alternativas de evaluar, elaboraciones textuales o productos de I & CVIT \\
\hline Criterio validez espontáneista & Se realiza mediante la observación directa y el análisis del trabajo del es & CVE \\
\hline DIFICULTADES & Asociadas a las CSCcon enfoque CTSA que limitan que sean las temática & Dif \\
\hline EJES DOC & Dinamizadores, Obstáculos y Cuestionamientos que indican la compleji & $\mathrm{DOC}$ \\
\hline FUENTES CRITERIOS SELECCIÓN CONT EA CSC & Los que el profesor usa para abordar el contenido como textos, revistas, & FCS_CEA_CSC \\
\hline FCSInstruccional & Las actividades didacticas se alternan entre exposiciones y prácticas, gen & FCSI \\
\hline FCSIntegradortransformador & Las actividades didácticas deben ser abordada en torno a problemas (co & FCSIT \\
\hline FCSTradicional & Actividad centrada en la exposición hecha por el profesor, con apoyo de & FCST \\
\hline FCSExpontáneistas & Siempre esta alineado con los gustos de los estudiantes, la temática a tr & FCSE \\
\hline REFERENTES EPISTEMOLÓGICOS CSC & Diferentes tipos de conocimiento que intervienen en la clase, pueden s & RE_CSC \\
\hline RE Tradicional & el curriculo tradicional, los lineamientos curriculares, los establecidos fu & RET \\
\hline RE Integrador Transformador & Enseñanza debe proporcionar transformación pregresiva del conocimie & REIT \\
\hline RE Instruccional & referente fundamental el conocimiento cientifico o el curricular elaborad & REI \\
\hline RE espontáneista & Para educar al alumno, que vive en una realidad inmediata, se satisface & REE \\
\hline
\end{tabular}

Figura 43. Nodos/categorías y subcategorías iniciales

Fuente. NVivo11. Proyecto CPP al asumir CSC/CTSA en la IUE

Estas categorías iniciales, fueron agrupadas en categorías más grandes, que permitían articular el $A C$ y $A D$ a través de la identificación de los aspectos asociados a las características de las CSC con enfoque CTSA (Figura 44). 


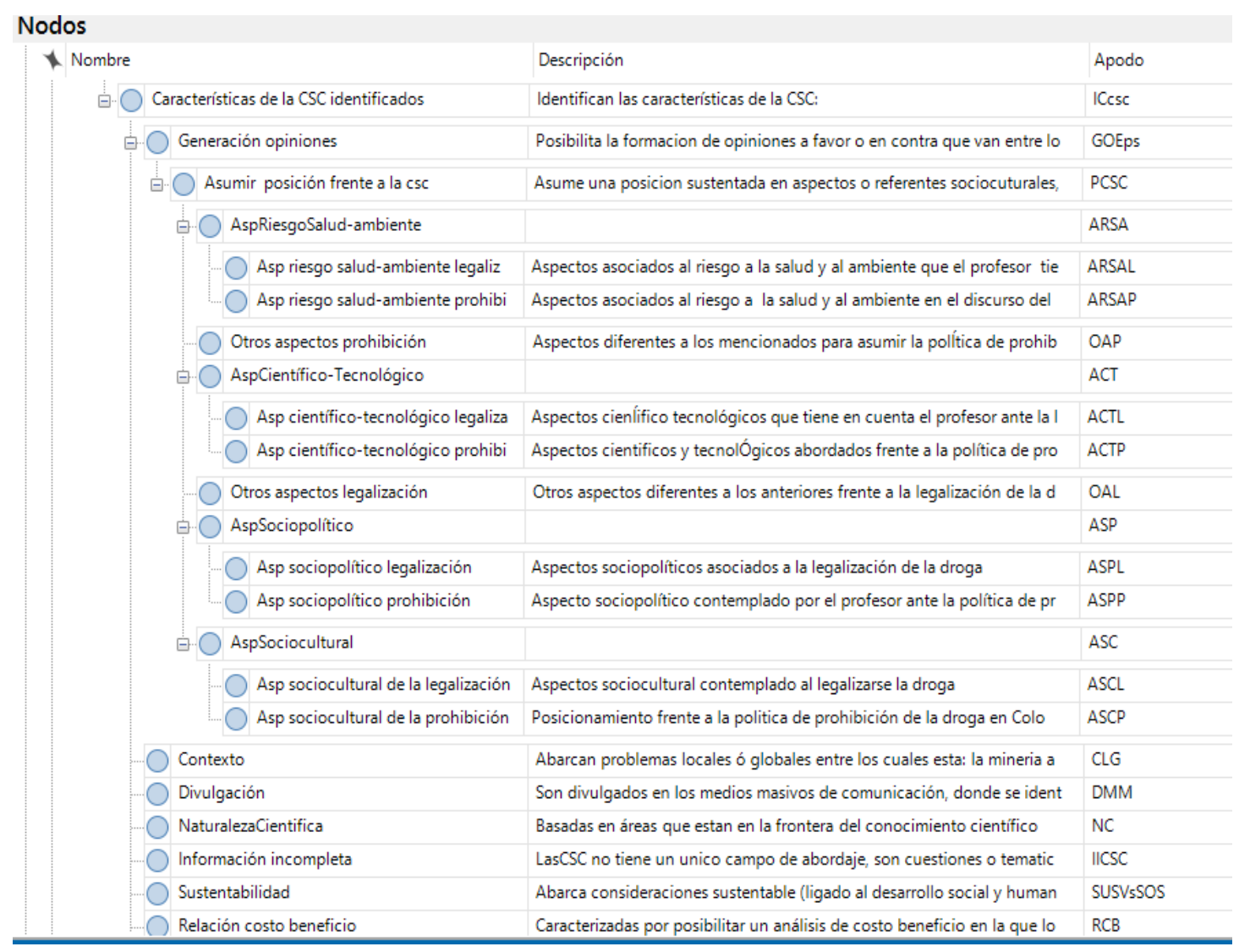

Figura 44. Categorías y subcategorías/Nodos asociados a las CSC Fuente. NVivo. Proyecto CPP al asumir CSC/CTSA en la IUE

Asi fue posible en conjunto del ATD/Software NVivo11 tener como categoría emergente el Colectivo de pensamiento (CP), Estilo de Pensamiento (EP) y formación IUE (Figura 45), las cuales serán abordados en el capítulo seis y analizados a la luz de la teoría Epistemología de Fleck. 


\begin{tabular}{|c|c|c|}
\hline \multicolumn{3}{|l|}{ Nodos } \\
\hline Nombre & Descripción & Apodo \\
\hline CPP AL ABORDAR CSC & El Conocimiento Profesional Deseable no es un estado ideal, & CPP_CSC_CTSA \\
\hline$\because$ APORTES & & A \\
\hline$\boxminus \bigcirc$ PGI_COLECTIVO_PENSAMIENTO & Grupo de docentes del PGI quienes construyen el conocimiento en cole & CP_PGI \\
\hline Formación-CPP & Forma de favorecer el desarrollo profesional del profesor y el CPP a trav & FCPP \\
\hline Interacción Universidad-Escuela & Programa de formación permanente de profesores, donde se favorece el & IU_E \\
\hline Exotérica & Consumidores de las ideas generadas, es grupo mayor, menos selectivo & \\
\hline Esotérica & Dinámica selectiva de especialistas que crean las formas de pensar & \\
\hline Invocación al recuerdo & Relaciona lo nuevo con experiencias anteriores que dejan huella, permit & \\
\hline$\because \bigcirc$ Metodología & Se adoptó una metodología cualitativa crítica colaborativa, este tipo de & Mpgi \\
\hline$\boxminus \bigcirc$ Investigación-Acción_Crítica & Metodologia del proceso de formación de docentes en la interacción Un & IAC \\
\hline Identifican_IAC & Conocen que su actuar en el aula a partir de las dificultades e intereses & IIA \\
\hline Desconocen_proceso_IAC & Hay desconocimiento de la actividad investigativa que realizan acerca d & DIA \\
\hline Estilos de pensamiento & Actitud del pensamiento de cada profesor, su disposición, el sentir del s & EP \\
\hline EPNotransformador & EP de los sujetos que estan en conford con su práctica profesional, se c & EPNot \\
\hline EPTransformador & EP de los sujetos que utilizan contenidos generalmente del contexto de & EPT \\
\hline$\square \bigcirc$ EPentransición & EP de sujetos que se encuentran en conflicto con su actuar profesional, s & EPentrans \\
\hline EP_Complicación-Disponibilidad & Fase de EP donde su pensamiento no encaja en la rutina diaria, encuentr & EpFComp \\
\hline EP_Confort & Fase donde el pensamiento encaja con el contexto de la escuela, de su & EpFC \\
\hline
\end{tabular}

Figura 45.Categorías emergentes: Aportes/Dificultades CP_EP/Formación IUE Fuente. NVivo. Proyecto CPP al asumir CSC/CTSA en la IUE

Las UA/UR, las categorías/nodos iniciales y emergentes de todo el proceso de análisis se visualizan en la figura 46 , que es análoga a la propuesta del ATD propuesta por Moraes \& Galiazzi (2007).

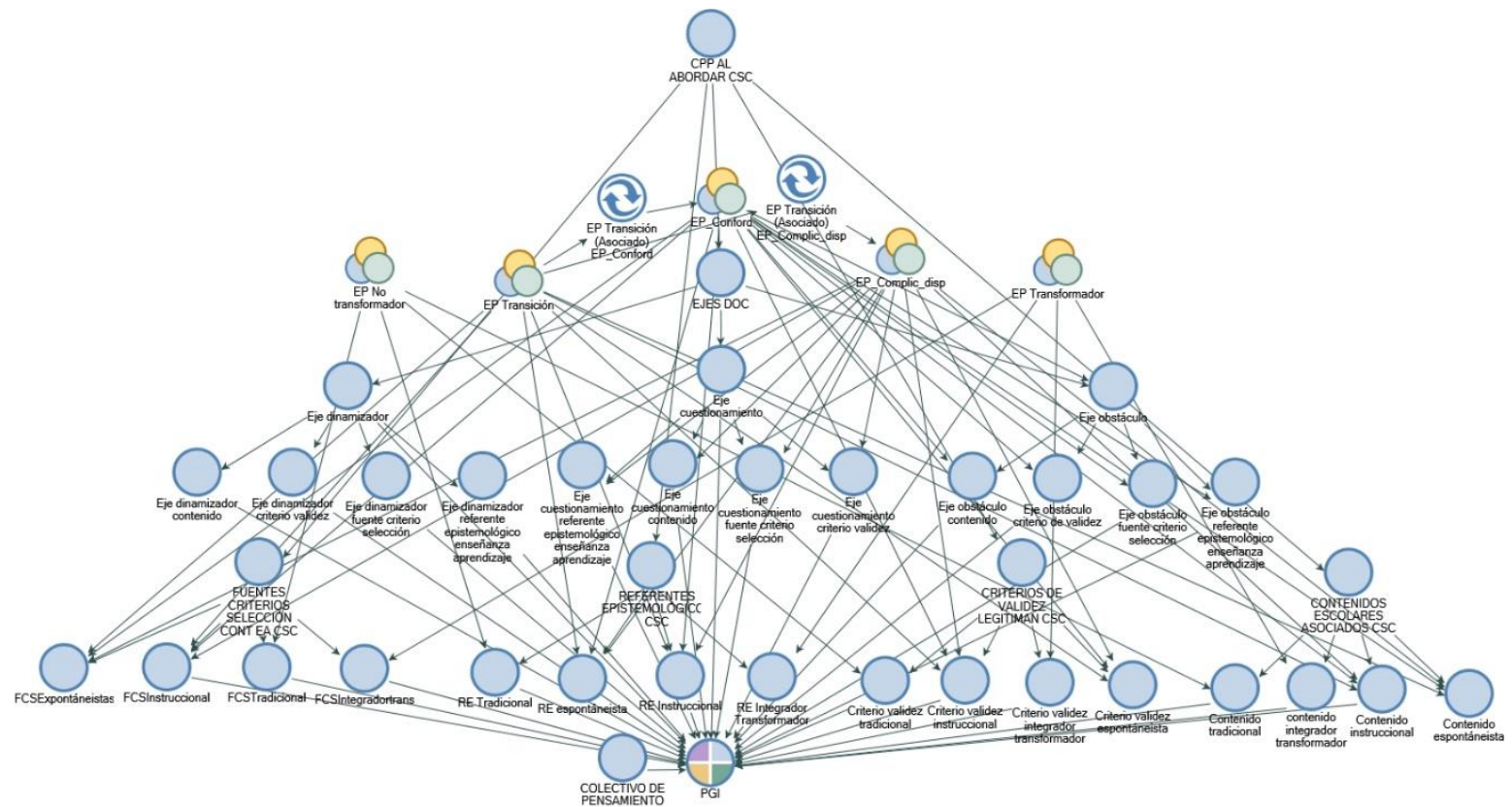

Figura 46. Categorías iniciales y emergentes/AC-AD/ATD analogía figura 30 (Moraes \& Galiazzi, 2007) Fuente. NVivo11 Proyecto CPP al asumir CSC/CTSA en la IUE 
La figura 46, también muestra la complejidad del pensamiento del profesor, en este caso muestra el escenario de movilidad del pensamiento que los profesores del Gl presentaron durante el proceso de formación; en el cual los profesores según los contenidos, referentes, criterios de validez, fuentes y criterios de selección asociados a las CSC abordaron en los procesos de planeación y ejecución de sus prácticas pedagógicas y didácticas, en las que la mayor parte de ellos transitaron por el EP tradicional pasando a uno transformador, otros permanecieron en el tradicional evidenciando las características y problemáticas que ocasiona salir del estado de confort, teniendo fases de transición (confort/disposición cambio) y otros haciendo progresiones y regresiones entre lo tradicional y la disposición al cambio; sin embargo, a través de los ejes DOC se visualizó y comprendió dichas fases, así como presentan una gama de posibilidades, los formadores de profesores e investigadores para el diseño de estrategias que permitan movilizar los obstáculos en dinamizadores, en términos de (Martínez, 2016, 2017), los ejes DOC permitieron comprender la complejidad del CPP, así como también la movilidad del EP en el transcurso del proceso de formación en el Gl en IUE como $\mathrm{CP}$, en términos de progresión regresión (figura 40).

Algunos de los fragmentos seleccionados como ejes de cuestionamiento se identificaron en los siguientes planteamientos:

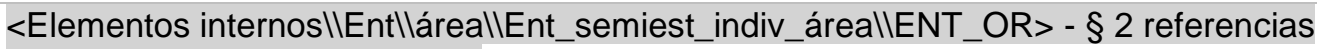
codificadas [Cobertura 6,08\%]

Referencia 1 - Cobertura 2,71\%

en la forma de trabajo en el PGI es el tiempo, el tiempo nos limita mucho, entonces muy poquito tiempo hace que no sean proyecto fuerte, otra problemática adicional es el manejo de algunas herramientas de tecnología, ya que ellos no saben, desconocen las mismas,

Referencia 2 - Cobertura 3,37\%

como los profesores no saben usar la tecnología, eso me ha permitido acercarme a los profesores porque cuando ellos se les toca a presentarle las unidades didácticas yo generalmente estoy como con ellos en cada una de las áreas y me toca mostrarles recursos, videos, que ellos pueden seleccionar acorde a sus propios contenidos 
Que dan luces a la escuela, a la investigadora y al mismo ente promotor de políticas educativas en el campo de la formación de profesores, acerca de la necesidad de contemplar espacios de calidad en la misma escuela, así los profesores podrían garantizar la construcción de conocimiento escolar acorde a las problemáticas del contexto educativo y construir a la vez CPP, pero que por el contrario se ve afectado por la falta de tiempo y la falta de manejo de la tecnología, aspectos que la universidad podría contemplar en el diseño de programas de formación en IUE.

Un fragmento identificado como eje dinamizador fue:

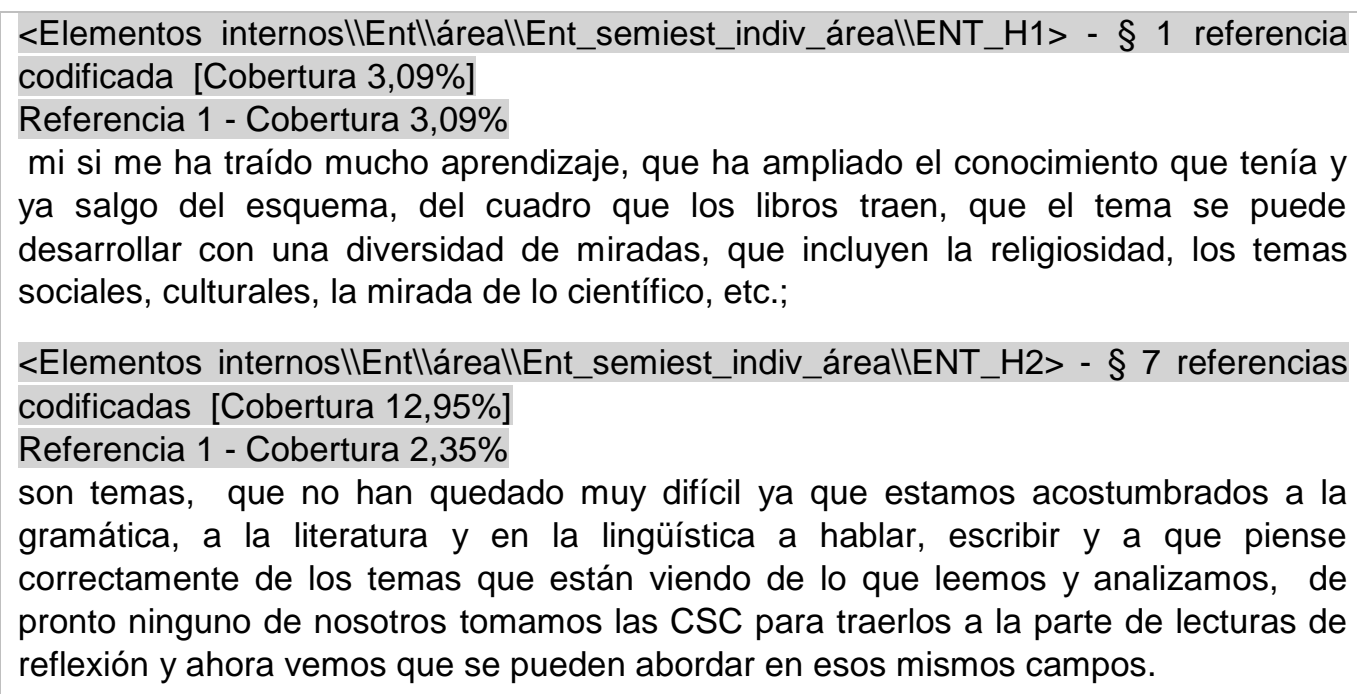

En los que se referencian las bondades de abordar CSC, se evidencia el cambio de fuentes y criterios de selección que le proporcionan CPP y el sentir frente a los procesos de enseñanza.

Y, como eje obstáculo:

<Elementos internos \|Ent|láreal\Ent_semiest_indiv_áreal\ENT_H2> - § 1 referencia codificada [Cobertura 3,51\%]

Referencia 1 - Cobertura 3,51\%

cuando aborta la CSC, en este caso de la droga

PH2: para el tema, primero en la falta de conocimiento, especialmente sobre las clases de droga, porque los estudiantes hacen un comentario y saben más que nosotros, y cuando nos reunimos entre nosotros los profesores, hay compañeros que comentan las clases, los precios, la problemática por competición de los mismos, y los profesores de ciencias generalmente conoce los componentes, o sea uno tiene que estudiar todo, desde el componente, donde las 
consiguen, hasta la competición por los precios ¿por qué ocurren estas cosas?

<Elementos internos \|Ent|láreal|Ent_semiest_indiv_áreallENT_M1> - 33 referencias codificadas [Cobertura 8,14\%]

Referencia 1 - Cobertura 2,85\%

claro que tiene otras implicaciones en cuanto a la forma de hacerlo por ejemplo, la parte de tiempo porque definitivamente no se puede gastar el mismo tiempo ya gastamos mucho más tiempo;

En esta se devela que el desconocimiento del contenido de la CSC es uno de los impedimentos del abordaje de las CSC, el profesor evidencia la posición que tiene frente a la temática, la angustia que se genera y la reflexión frente a la misma, indicando posibles actuaciones y la viabilidad de su abordaje curricular, pero que sumado al desconocimiento del contenido esta la carencia del tiempo. Estos obstáculos deben ser considerados puntos críticos para ser abordados en los procesos de formación de profesores y en el contexto escolar, se hace imperativo buscar estrategas de acompañamiento a los profesores para que se constituyan realmente en tejedores de conocimiento social, que constituyan redes sociales, capaces de dar posibles alternativas "reales" a las problemáticas de la escuela y su comunidad en general.

Para la construcción de la categoría de aportes, nos permitimos hacer un recorrido inductivo, a la luz de la HdPR, así pues, empezaremos a mostrar los resultados que se obtienen de las UA/RA de los nodos (categorías) de contenidos obtenidos de los talleres, SD, debates realizados, y de la observación participante. 


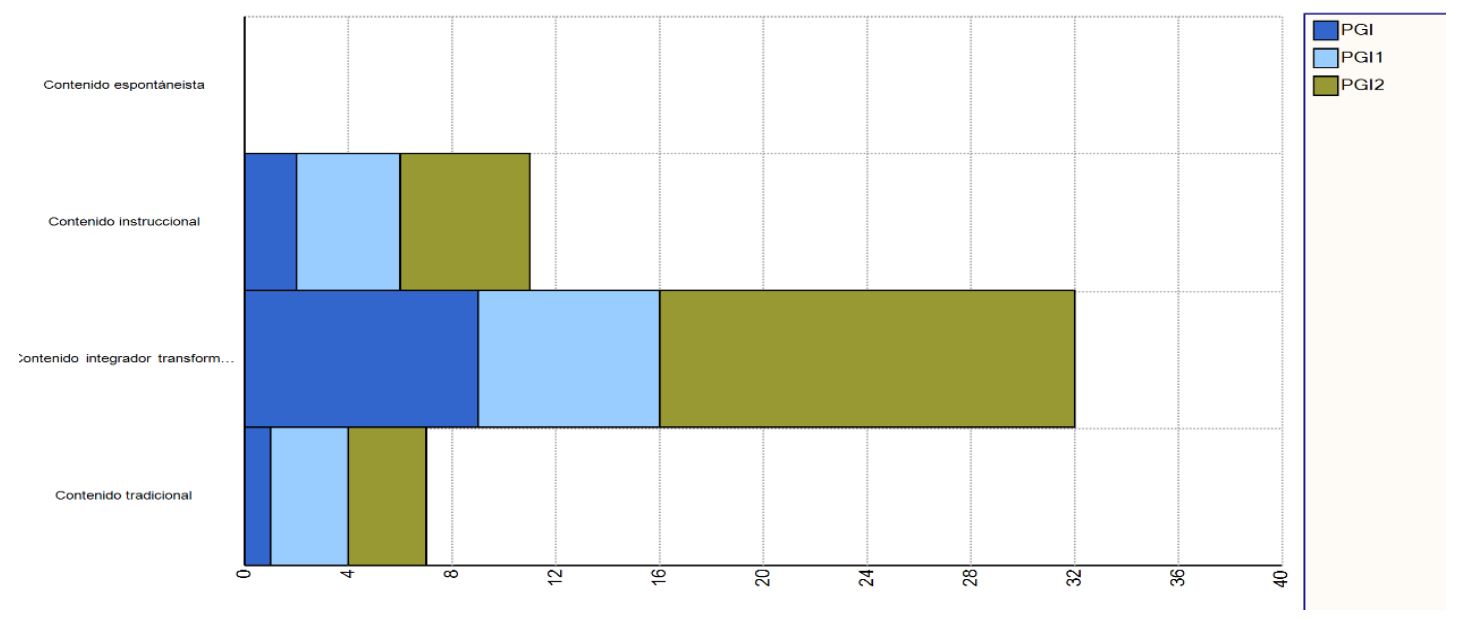

Figura 47. Contenidos utilizados por los profesores GI Fuente NVivo11. Categoría CEA-CSC

Producto de las entrevistas, las SD, talleres y actividades desarrolladas a lo largo del proceso de formación los profesores del GI utilizan CEA-CSC de la categoría CEIT seguido de CEI y en menor número de CET, aunque el programa permite diferenciar los aportes de los profesores clasificados por el tipo de contratación (figura 47), es válido mencionar que tanto unos como otros empiezan a cuestionarse y evaluar positivamente el uso de las CSC en el currículo, como temática para ser abordada en este contexto, algunas de las intervenciones que se clasifican en las categorías mencionadas se muestran en la tabla 11.

Tabla 11. Contenidos abordados por el GI

\begin{tabular}{|l|l|l|}
\hline Int1 & $\begin{array}{l}\text { Hacer debates hechos por los entonces ha servido mucho para el } \\
\text { colegio }\end{array}$ \\
\hline Int2 & $\begin{array}{l}\text { [...] el tema de la seguridad alimentaria, que involucra desde el manejo } \\
\text { del clima para la cosecha, lo religioso, cultural, mitos, los daños } \\
\text { globales, por el uso de agrotóxicos y manipulación de semillas, toda la } \\
\text { ciencia y tecnología que ha incidido en el desplazamiento de la mano } \\
\text { de obra, que hay más cosas de máquinas, computadoras, más fácil } \\
\text { facilidad de conocer, mejor dicho a mi si se me ha abierto mucho la } \\
\text { mente }\end{array}$ \\
CEIT & Int3 & $\begin{array}{l}\text { [...] ello se dan cuenta que las problemáticas como la droga, la misma } \\
\text { educación sexual son temas que se viven y se sienten no solamente en } \\
\text { la institución, sino también pueden ser temas de familia, de sus amigos, }\end{array}$ \\
\hline
\end{tabular}




\begin{tabular}{|c|c|c|}
\hline & & $\begin{array}{l}\text { de su propio estilo de vida, e incluso conozco profesores en los que sus } \\
\text { hijos tiene este tipo de problemática, solo que como es de un profesional } \\
\text { como nosotros, es algo privado, que no se dice o se aborda como los } \\
\text { estudiantes nuestros, en fin, este tipo de trabajo hace que los mismos } \\
\text { profesores se apropien el tema y lo consideren interesante. }\end{array}$ \\
\hline & $\operatorname{lnt} 4$ & $\begin{array}{l}\text { [...]tema de los medicamentos me gustó muchísimo, se habla de normas } \\
\text { a nivel internacional, en fin las CSC cuando uno lee las identifica, ahh } \\
\text { estas son CSC, son temas que se han abordado, pero no como ahora, } \\
\text { el tema de los medicamentos, el yacón, el de las medicinas naturales, } \\
\text { los que tuvieron temas relacionados con el ambiente, también los de la } \\
\text { chía porqué tienen que ver con uno y así son más fáciles de abordar, de } \\
\text { asimilar uno se interesa más con los temas que están relacionados } \\
\text { con el contexto del profesor y se considera que así como en ese } \\
\text { contexto de educación de adultos es más motivante. }\end{array}$ \\
\hline \multirow{5}{*}{ CEI } & Int1 & $\begin{array}{l}\text { Abordaje de diferentes temáticas, diseño de filtros para hidrolisis } \\
\text { obtención de Hidrogeno, levitación magnética }\end{array}$ \\
\hline & Int2 & $\begin{array}{l}\text { Las actividades de lectura dentro del área de lenguaje, se fomenta la } \\
\text { lectura con la idea de mejorar la comprensión de textos y por } \\
\text { consiguiente la redacción, la ortografía; las actividades dramáticas } \\
\text { fomentan un mayor manejo corporal y oral dentro del área }\end{array}$ \\
\hline & Int3 & Exposiciones y experimentos \\
\hline & Int4 & $\begin{array}{l}\text { También los estudiantes se motivan muchísimo cuando les toca hacer } \\
\text { cosas como de manipulación de alimentos, talleres y participación }\end{array}$ \\
\hline & Int5 & $\begin{array}{l}\text { Establecer la ecuación de crecimiento exponencial de un cultivo de } \\
\text { bacterias, determinar la cantidad de sustancia psicoactiva presente en } \\
\text { el torrente sanguíneo de un paciente después de un determinado } \\
\text { tiempo, estadísticas sobre la incidencia de las sustancias psicoactivas } \\
\text { en la destrucción de las familia de los consumidores, }[\ldots . . . .\end{array}$ \\
\hline \multirow{3}{*}{ CET } & INT1 & $\begin{array}{l}\text { Conceptos matemáticos y su didáctica, abordando temas y dedicando } \\
\text { tiempo. }\end{array}$ \\
\hline & Int2 & $\begin{array}{l}\text { En el área de sociales se trabaja nuestro planeta: continentes, océanos, } \\
\text { sistemas montañosos, sistema solar. Lógicamente nuestro planeta tiene } \\
\text { medio ambiente. }\end{array}$ \\
\hline & Int3 & $\begin{array}{l}\text { Funciones exponenciales, lineales, logarítmicas, estadísticas, análisis de } \\
\text { gráficas y situaciones, razones y proporciones, porcentajes }\end{array}$ \\
\hline
\end{tabular}

Fuente. Matriz de codificación categoría CEA-CSC

Cuando al profesor se le pregunta sobre las temáticas que abordó en el proceso de formación, bien sean producto de los talleres en los que participó en forma de 
debate con especialistas (anexo 8, 15), como par académico de estudiantes en formación o como acompañante evaluador y participante de trabajos de grado realizados por los estudiantes en el proceso de IUE (anexo 11 y 12) y socializados por estudiantes de la noche en feria de la ciencia (17 y 18), mencionan la importancia de abordarlos desde las diferentes disciplinas, desde los aportes que deja no sólo a los estudiantes de EJA, sino a los mismos profesores, por ser temáticas muy próximas a las necesidades sentidas y vividas por los mismos profesores como lo menciona el profesor en la Int 4: "están relacionados con el contexto del profesor y se considera que así como en ese contexto de educación de adultos es más motivante"

Como lo evidencian las intervenciones (Int1, int2 e int4) clasificadas como CEIT, la oportunidad de usarlas en el currículo es fruto del proceso de formación en la IUE, en la que los docentes al igual que los adultos cambian su mirada de corte tradicional, dando respuesta a la satisfacción por abordar temas más cercanos a sus intereses, de esta manera, se sienten importantes, escuchados por sus profesores y visitantes externos, sus voces silenciadas por tradición, ahora cobran vida, quieren contar sus saberes y compartir sus conocimientos culturales.

En paralelo a las emociones manifiestas por los estudiantes, los profesores quieren compartir con otros los aportes del abordaje de CSC, hacen a la par con los estudiantes eco de sus aprendizajes, de lo que tenían que hacer para orientar los trabajos de los estudiantes, comentan al interior del GI lecturas abordadas, socializan los comentarios hechos por estudiantes que les demuestran que son expertos en algunas temáticas porque trabajan en ese campo, porque conviven con las problemáticas abordadas, y que son los profesores los que ahora pueden aprender de dichas experiencias y a través del diálogo dar valor a los contenidos curriculares; pero lo más importante fue reflexionar sobre aspectos que no habían sido tenidos antes en cuenta (lo ético, moral, lo tecnológico, lo científico, cultural, sociopolítico, de riesgo, etc.) posiblemente por su formación disciplinar y/o la fragmentación del conocimiento a que han estado acostumbrados. 
En los espacios de formación del Gl se presentan avances de lo planeado en las SD y la forma como participarán en la feria escolar, los profesores comentan trabajos, lecturas asociadas al plan lector que les permiten orientar sus trabajos de aula y organizar el trabajo, reconocen la labor del par universitario, los aportes al conocimiento disciplinar y a la didáctica de sus clases; a la par que aprenden nuevas cosas, también aportan saberes fundamentados en la experiencia, rutinas y guiones de acción, saberes experienciales que han forjado en su vida profesional y laboral.

Gamboa (2007), menciona que muchas investigaciones que se realizan en las universidades tienen exclusivamente un papel de cumplimiento de requisitos para la obtención de un título; se hacen en forma independiente de los intereses del contexto local, de los estudiantes, de sus propias características, y de los profesores titulares(los de la escuela) porque como se mencionó, lo importante es el título. Es diferente la formación mediada y articulada por los integrantes del $\mathrm{Gl}$ a través de procesos de formación en la IUE, en la que tanto los profesores de la escuela como los de la universidad, así sean de formación inicial están en el mismo nivel de importancia, de respeto y rol; los de la universidad traen sus propuestas de investigación a desarrollar y los profesores de la escuela son los que evalúan y a través de procesos de diálogo, discusión, evaluación y consenso, determinan qué es lo que finalmente llegará a los estudiantes, es un trabajo hombro a hombro como pares académicos, en el que no sólo se beneficia un campo de formación, hay beneficio de todos los actores y agentes del campo (Levinson, 2008).

Temáticas como las SPA y la educación sexual abordada por los profesores del Gl y mencionadas en la Int 3, son CSC como menciona Simonneaux \& Legardez (2010) que generan debate en la sociedad, en la ciencia y en la enseñanza; por lo tanto para abordarlas en el aula, requieren de una reflexión socio-epistemológica, ya que son el reflejo de las representaciones y sistemas de valores de la sociedad, del ser humano que como integrante de la misma, tiene vivencias en este aspecto, 
bien sean producto del campo laboral, del barrio, de sus amigos o familiares cercanos, e incluso, como se afirma en esta intervención, puede ser una problemática del propio profesor o de su entorno familiar.

La participación en un taller de formación con los profesores (Anexo 10), en la que ellos eran creadores de drogas, generó reflexiones acerca de las necesidades de una población que no tiene formación, que no elige autónomamente, permitiendo que los medios masivos de comunicación, los intereses de los productores, o de ciertos sectores, permeen en los intereses de los mismos y hagan que ellos sean consumidores, o vendedores de los productos creados.

$\mathrm{Ni}$ siquiera los profesores como profesionales ponen en juego los conocimientos construidos durante sus vidas para elegir críticamente lo más adecuado para su salud o "necesidades creadas", entonces que esperar de una población marginada, violentada, a quienes no se les han enseñado los aportes y dificultades de la racionalidad científica, del desarrollo tecnológico y la importancia de participar crítica y autónomamente de las decisiones que a largo o corto plazo van a interferir en su calidad de vida. Sin embargo, los profesores comprenden que es necesario formar a los estudiantes en estas temáticas para que como ciudadanos puedan tomar decisiones pertinentes y responsables, así como también, ellos como profesionales, reflexionen críticamente acerca de sus decisiones.

En la Int 4, los profesores comprenden que las temáticas abordadas en el contexto escolar, debe ser interesantes para los estudiantes, deben ser aquellas que tienen incidencia en la vida de los mismos y en la de los profesores, las que se abordan con pasión, las que se desarrollan con plenitud académica, porque saben que al hacerlo, se ponen en juego saberes populares, tradiciones, creencias, saberes científicos y tecnológicos que al ser analizados, estudiados y evaluados críticamente, contribuyen con la construcción del CPP.

Algunas de las intervenciones que abordan los contenidos como CEI (Int2 e Int5) permiten comprender que el profesor aunque puede participar del trabajo en 
equipo asumido por el $\mathrm{Gl}$, lo ve como algo que sirve de ejemplificación de las temáticas disciplinares, como el caso del profesor de matemáticas, o de pasos específicos de comprensión lectora, evadiendo el debate, la toma de posición de los individuos; posiblemente lo que interesa a estos profesores es enseñar la disciplina, la que conocen y las CSC le dan la posibilidad de dinamizar dichas temáticas, sólo en términos de garantizar una buena comprensión, no de reflexionar e ir más allá del contenido. Lo anterior también se evidencia cuando PM1 diseña la secuencia (Anexo 16) en torno a la droga, menciona aspectos a trabajar, pero en términos de ejemplificar el uso de la temática y termina haciendo ejercicios descontextualizados, tradicionales, que no alcanzan ni siquiera la categoría de problema, solo buscan mecanizar técnicas rutinarias, o mantener ocupados a los estudiantes, sin llevar a cabo procesos de reflexión y contextualización.

La Int 1,3 y 4 de CEI, le ven la utilidad al abordaje de CSC para el desarrollo de actividades experimentales, para llevar secuencia de hechos, para fortalecer procesos de seguimiento de instrucciones, pero no identifican la potencialidad de desarrollo de habilidades argumentativas propias del pensamiento crítico, la importancia de formar a los estudiantes para que participen precisamente del desarrollo tecnológico y de la racionalidad científica; en estos profesores sigue gobernando la racionalidad instrumental y la concepción de tecnología como salvacionista o determinista (Auler \& Delizoicov, 2015).

Las intervenciones categorizadas como CET, ponen de manifiesto el desconocimiento de la CSC y sus características, los profesores la ven como problemas ambientales, que solo se deben nombrar y que sirven como forma de ejemplificar, es como si ese mundo de la vida para estos profesores fuese ficticio, porque conciben el escenario escolar como la guardería por horas, en este caso del adulto, que debe cumplir ciertas horas en un espacio determinado para que se llene de los contenidos tradicionales o curricularizados que posteriormente el maestro da por vistos; la int 3 manifiesta unos contenidos matemáticos en los que 
lo principal es lo disciplinar, para ellos, lo primero que se debe entender son los conceptos, luego viene la ejemplificación, por lo tanto, para estos profesores, mientras no se garantice un tiempo adecuado para el desarrollo de los contenidos disciplinares, no es posible la comprensión de otras temáticas.

Como menciona Tardif (2000), los saberes de los profesores son existencialistas, sociales y pragmáticos, son temporales, saberes remodelados en función de los cambios de la práctica profesional de las situaciones de trabajo, en la que su evolución y transformación se da a través de la historia de vida, de sus vivencias en la carrera profesional; sólo el trabajo colectivo permite nuevas construcciones, nuevas prácticas, que permitan al profesor romper la armonía de las ilusiones (Fleck, 1986).

Para Martínez (2017), las categorías contenidos, referentes epistemológicos, criterios de validez, fuentes y criterios de selección permiten comprender el CPP, y están ligadas a los fines de la enseñanza de las ciencias, de sus prácticas de aula; en este sentido las Int 1, 3 y 4 de la categoría CEI son consideradas como dinamizadoras de contenido, que posiblemente con el acompañamiento en el proceso de formación, los mismos profesores a través de la HdPR transiten a un nivel integral transformador, de la misma manera las intervenciones que están en la categoría de CET podrían ser considerados como ejes cuestionamiento, ya que el profesor identifica la CSC pero por factores asociados a su CPD, o por los procesos de alienación a los que ha estado acostumbrado en el contexto escolar, ve en las CSC aspectos ejemplificadores, de los cuales ni el mismo es consciente (estado de confort) y podrían hacer que el profesor continúe en el nivel tradicional.

Extrayendo del Gl los profesores de planta GI2 (figura 48) a través de un sólo instrumento (entrevista semiestructurada) se visualiza la movilidad del CPP del profesor; como indica Tardif (2000), los saberes que han construido los profesores a lo largo de la vida no son inmutables, ni descontextualizados e individuales; estos pueden cambiar a partir de las reflexiones constantes sobre sus prácticas, en interacción con sus pares académicos, discutiendo la pertenencia de las 
mismas en el contexto laboral y social; es en estos espacios del Gl de formación, donde el profesor potencia sus saberes en la medida en que son objetivados y socializados.

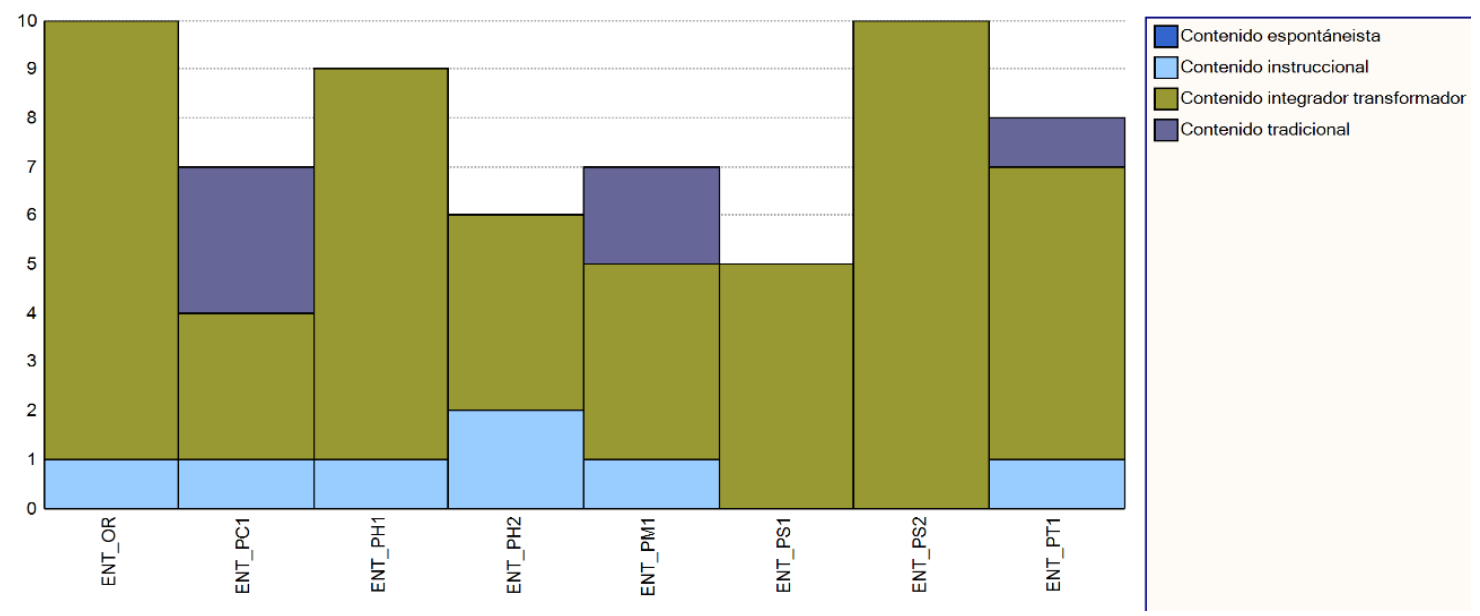

Figura 48 Contenidos abordados por los profesores del PGI2.

Vale la pena mencionar, que los contenidos espontaneistas para el Gl no son significativos, hay una ausencia de UA/UR que indique que los profesores del Gl tengan en cuenta las concepciones de la realidad inmediata de los jóvenes y adultos; posiblemente por las características propias de la EJA no se trata de abordar contenidos que satisfacen "caprichos" de los mismos, pero si evidencia el distanciamiento existente entre los profesores y estudiantes, ni siquiera se parte de supuestos, de posibilidades para lograr el aprendizaje, o al menos hacerlo significativo, lo que podría constituir en un eje de cuestionamiento, ya que aunque no se satisfacen dichas necesidades a nivel de "capricho" pueden ser consideradas como formas de reconocimiento de las necesidades o posibles temáticas que se podrían abordar desde las necesidades o intereses de los estudiantes.

Otra mirada, que presenta la figura 48, es la familiaridad de las temáticas para algunas disciplinas y profesiones; CSC que abordan las SPA, la sexualidad, son más familiares para los profesores que desarrollan proyectos trasversales (P_OR/PC) como si fueran de una disciplina y no como su nombre lo indica; lo que 
puede significar una alternativa, para que los proyectos transversales sean abordados a partir de CSC y curricularizados en forma transversal, de tal manera que se articulen las acciones, se planee en conjunto y no hayan áreas 0 profesores específicos asumiendo dichos proyectos, sino por el contrario su mapeo y planeación se haga desde el $\mathrm{Gl}$, se integren áreas y actividades, que posiblemente además de mitigar las problemáticas que se contemplan en dichos proyectos, sea un escenario de aprendizaje para los profesores del GI.

Finalmente, al hacer un recuento de palabras vinculadas la categoría contenidos, se pueden apreciar como lo indica la figura 49, los temas que abordan los profesores en el Gl según sus inquietudes y las necesidades propias del contexto escolar, estos deberían ser los ejes articuladores del currículo, algunos fueron abordados en el diseño de la SD, plan lector o como actividades que surgían de los proyectos transversales.

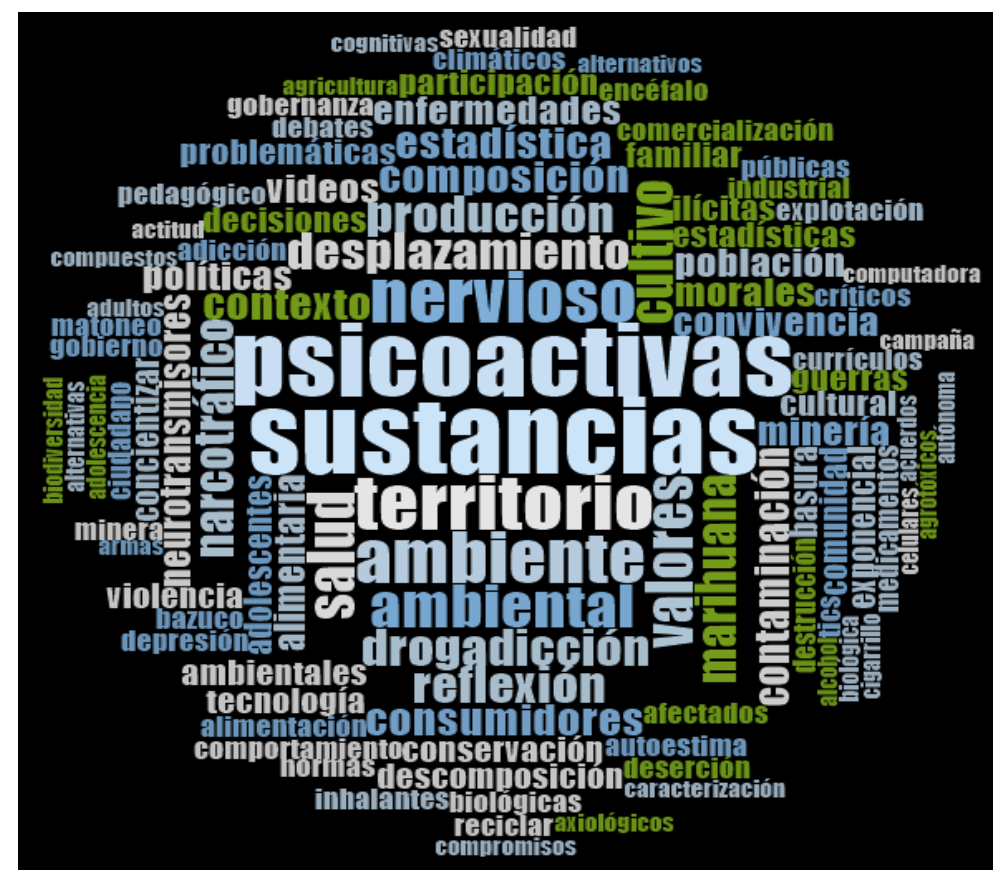

Figura 49. Contenidos que abordan en talleres, SD, debates, como fuente del currículo. Fuente. Frecuencia de palabras en marca de nube. Software NVivo11

Los profesores del Gl evidencian que al ser conscientes de la presencia del uso/abuso-producción/consumo del mercado de las drogas, pero en especial de 
las SPA, conciben temáticas relevantes para abordar desde el currículo y articularlas con proyectos obligatorios como del Tiempo Libre y Prevención de la drogadicción, que siempre estaba destinado a realizar actividades aisladas por el servicio de orientación, ahora como temática central (anexo 4, 6 al 13) era un escenario de formación, en el que los profesores a través del discurso mencionan la metodología abordada al interior del grupo, identifican las etapas de un proceso de investigación y la forma en la que van presentando los avances o resultados del proceso, como lo mencionan en la siguiente intervención:

\section{Referencia 7 - Cobertura 0,02\%}

[...] pues de hecho es una investigación de campo es Investigación, Acción Participativa; entonces nosotros, inicialmente trabajamos lecturas, hicimos exposiciones, así como lo nombraba PT3, primero trabajamos nosotros como profes como áreas. En tecnología, esta ciencias naturales y tecnología.

Lo primero que hicimos fue mirar un poquito el entorno que teníamos, que teníamos muchos chicos que estaban consumiendo y de hecho los tenemos dentro de la institución nos llegan muchos muchachos que están consumiendo. Entonces al ver la problemática, lo segundo que hicimos fue como empaparnos de lo que se estaba dando a nivel de nuestro entorno; abordamos varios de los textos y temas, que la marihuana, que el bazuco, tipos de sustancias psicoactivas. Entonces cada uno como que se apropió de cada una de ellas. Las leímos, las organizamos por temáticas diferentes, desde su origen, toda la composición y todas las implicaciones que tenía. Luego trabajamos en varias sesiones en grupos y esas sesiones las hicimos, hicimos una jornada pedagógica y cada uno, nos organizamos por áreas y cada área tenía que consultar una sustancia diferente, específica y sus acciones a nivel general. Entonces a nivel social, biológico, físico, tecnológico, todo alrededor de ella, que es la intención de las CSC.

Como se evidencia en la intervención, los profesores, identifican los aspectos que implican abordar CSC desde el diálogo en grupo y cómo estas temáticas al ser abordadas desde la perspectiva de la salud para que los jóvenes y adultos puedan asumir una posición moral consigo mismos y con los demás en términos de cuidado de sí mismos y del otro, pero para lograrlo, se debe favorecer, precisamente el desarrollo de la autoestima en los estudiantes, desarrollar habilidades tanto cognitivas como socioafectivas que le permitan tomar decisiones asertivas al enfrentarse a situaciones que lo pongan en riesgo, como lo que se evidencia a través del trabajo socializado por los profesores a través del anexo 9 
y13, en donde se evidencia que los profesores son conscientes de su función como líderes en la prevención del uso/abuso de SPA, tanto para aquellos que estando inmersos en el consumo para evitar que sigan consumiendo de forma abusiva y los que están en alto riesgo no caigan en la problemática o no lleguen a abusar en el uso de sustancias.

La metodología en la que abordaron las SPA se puede visualizar en el árbol de palabras, el cual se obtiene de las conexiones y triangulaciones de todos los datos asociados al nodo contenidos, en los que los profesores del Gl los relacionan (figura 50).

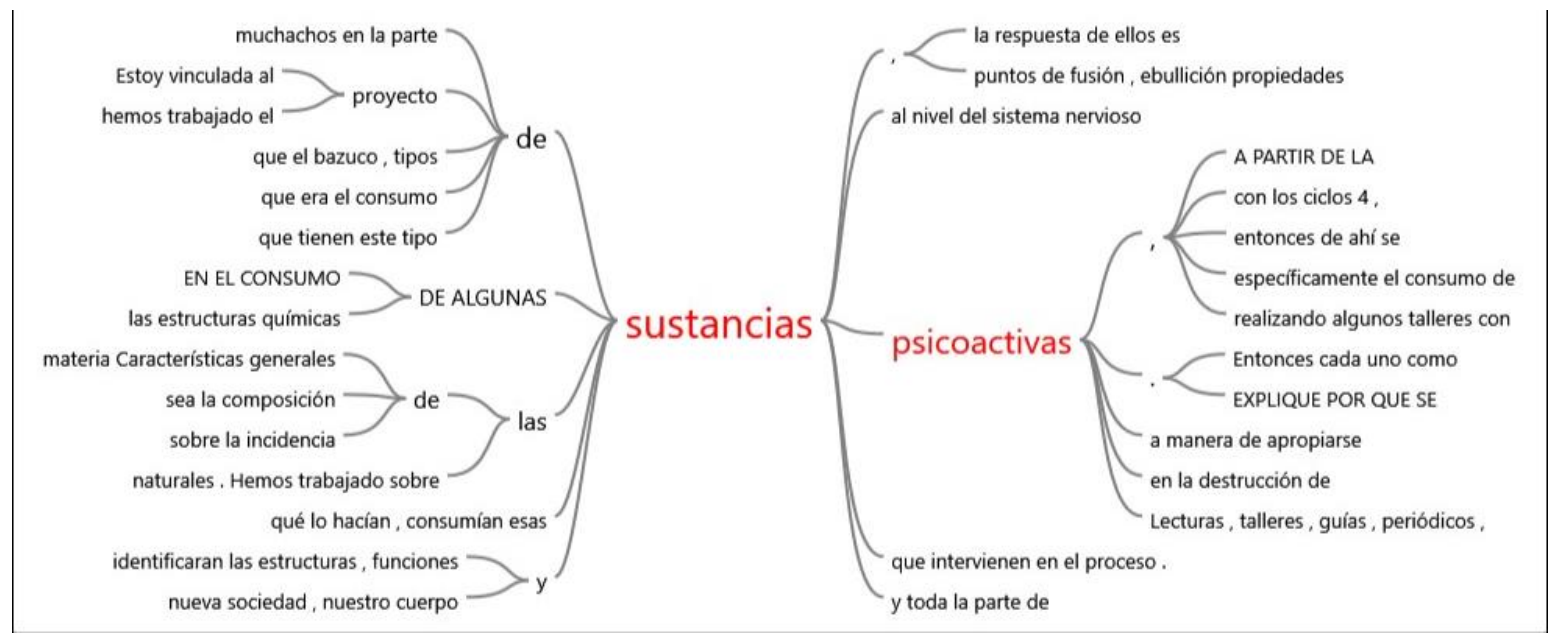

Figura 50. Árbol de palabras, alrededor de SPA como CSC

Fuente. Categoría (Nodo) CEA_CSC abordados por los profesores del PGI en IUE

En esta figura, se menciona la vinculación a la CSC por intermedio de un proyecto de la jornada, las temáticas abordadas (clases de sustancias) los aspectos implicados (especialmente mencionan lo científico y lo social, en este caso) la adecuación a los ciclos, la metodología de abordaje con los estudiantes y los recursos empleados.

Siguiendo una de las rutas que se trazan al activar una conexión (Figura 51), esta permite comprender el discurso del profesor, cuando aborda el consumo en el aula 
de clase de química, donde además de enseñar los contenidos propios de la disciplina, aborda las SPA como eje articulador de la disciplina.

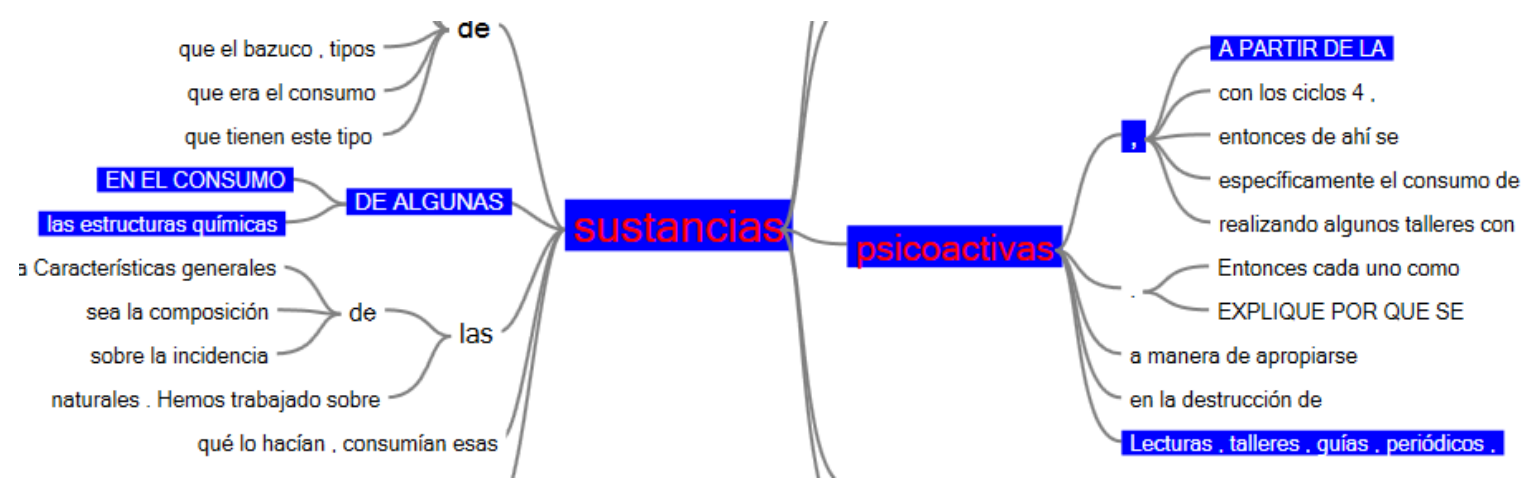

Figura 51. Formación de texto -intencionalidad del participante del GI Fuente. NVivo11. Árbol de palabras.

Lo mismo se podrá hacer con cada una de las palabras utilizadas con mayor o menor frecuencia por los profesores del Gl y así determinar el contexto en el que se abordan, otro ejemplo, es cuando se aborda el tema de los valores, en el que se contextualiza el costo/beneficio del mercadeo de drogas ilícitas para beneficio de determinados grupos económicos y cómo la sociedad es violentada, dando además alternativas para abordar el tema en cada uno de los ciclos.

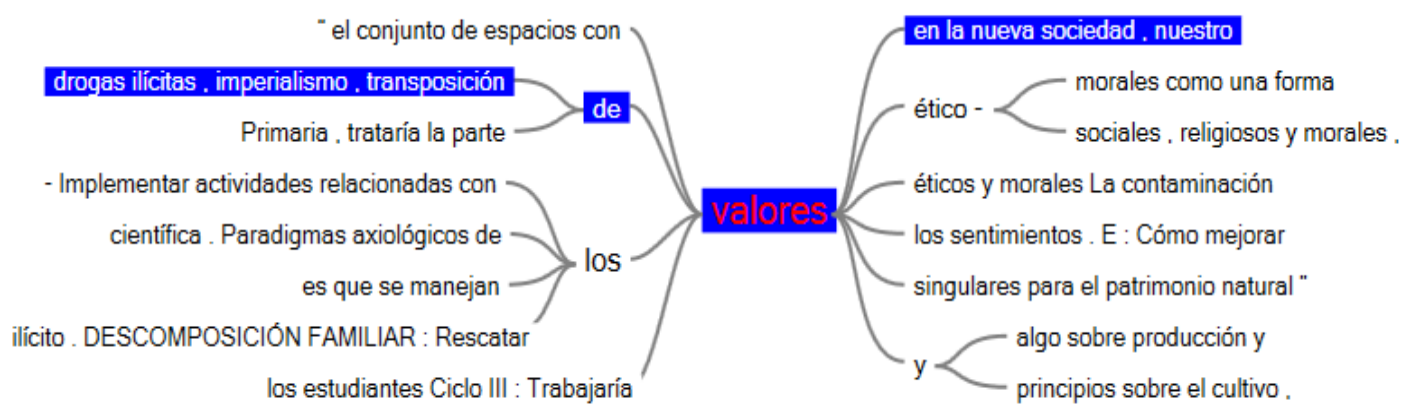

Figura 52. valores como aspecto a considerar al abordar CSC_CTSA como contenido Fuente. NVivo11. Árbol palabras

Es de gran importancia reconocer, que los profesores empiezan a configurar un diálogo propio en lo relacionado a compartir conocimientos propios de la temática en la que han profundizado y como asumen que esta práctica del consumo de sustancias es tan antigua como el hombre mismo, se contextualizan con la 
diferencia entre drogas licitas e ilícitas, lo asocian además al comercio internacional de las mismas, los valores éticos y morales implicados, así como emerge la relación con el riesgo no solo a la salud (cuerpo) sino a la salud ambiental (patrimonio natural).

Otras temáticas que se evidenciaron como CSC y que fueron abordadas por ciclos como se evidencia en el PEI (Anexo 19) y en las intervenciones de los profesores correspondientes al CEIT (tabla 11).

En la categoría (nodo) RE-CSC están asociados a los RE IT los profesores del GI utilizan además de los referentes disciplinares, los referentes de la cotidianidad, de la cultura y en especial los que provienen de problemáticas asociadas al contexto de los estudiantes, a conocimientos metadisciplinares que movilizan el CPP al CPD, como se evidencia en la figura 53.

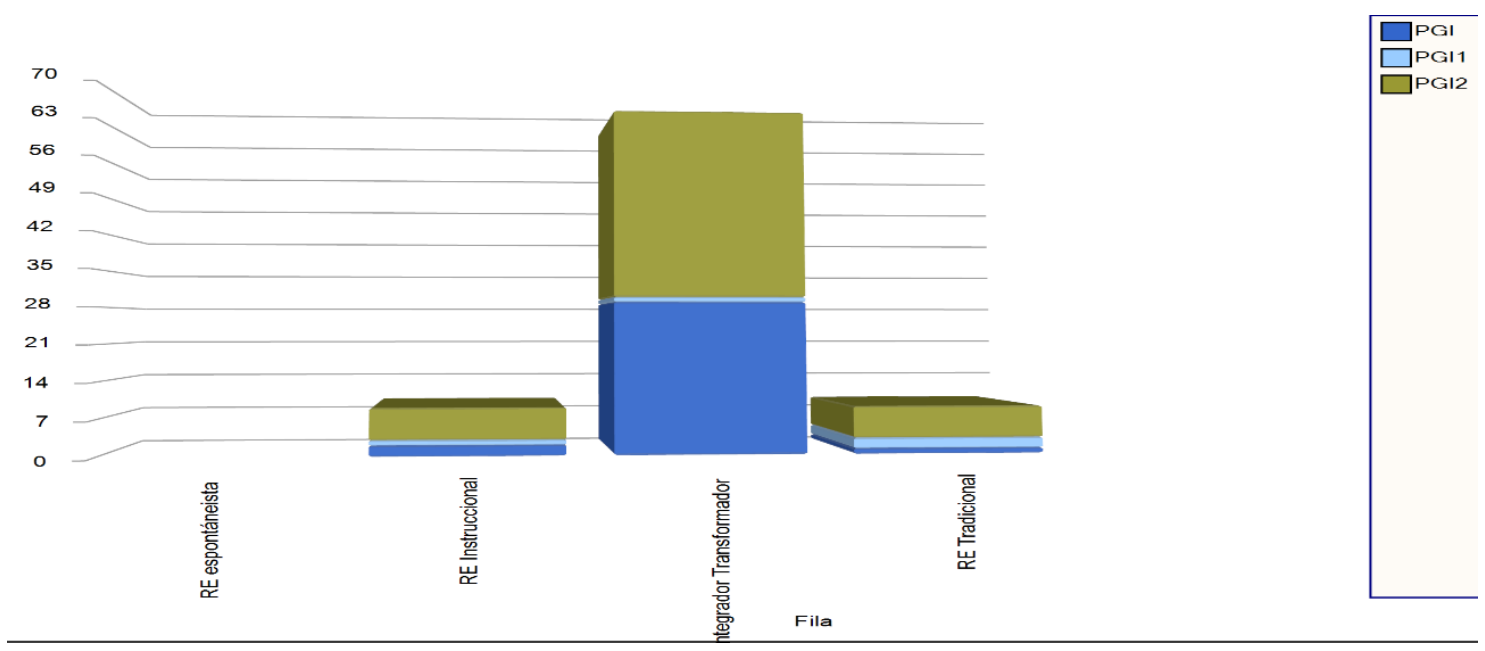

Figura 53. RE_CSC

Fuente. Categoría (nodo) RE_CSC

Los profesores asumen las CSC como temáticas que posibilitan innovar, es decir son una fuente de conocimiento o saber práctico, que, al ser abordados curricularmente, le permiten conocer más de su propia disciplina, reconocer los conocimientos del otro, del adulto como fuente de conocimientos socialmente construidos, con una cultura e historias de vida que pueden ser escritos, 
repensadas y socializadas, como lo indican las Int1, in2 e int3 categorizadas como REIT (Tabla 12).

La Int 1, muestra como el profesor tiene en cuenta esa transformación progresiva del conocimiento, ya no está totalmente ligado al desarrollo curricular, ahora evidencia que es a través del discurso elaborado por los estudiantes, de la construcción de sus argumentos, del debate, que puede conocer la posición y construcciones alrededor de las CSC abordadas.

En la Int2 comenta la metodología de la clase; sin embargo, se evidencia, que está abordando la clase disciplinar, pero que sus referentes epistemológicos, están en los medios masivos de comunicación, en las lecturas y videos; en la Int 3 se evidencian las angustias (Lopes \& Carvalho, 2017) que vive el profesor, en este caso al abordar CSC que antes no estaban contempladas en su repertorio de acción, pero también cómo a partir de sus propias reflexiones y procesos de socialización en el GI se asumen nuevas posiciones como profesor investigador y orienta su actuar en el aula, que guiará sus prácticas utilizando RE-IT.

Tabla 12. UA/RA asociados a la categoría RE_CSC

\begin{tabular}{|c|c|c|}
\hline \multirow[b]{3}{*}{ REIT } & Int1 & $\begin{array}{l}\text { Participación de los estudiantes, debates y reflexiones, feria de la ciencia, } \\
\text { donde se pueda determinar los procesos de argumentación }\end{array}$ \\
\hline & Int2 & $\begin{array}{l}\text { Voy a escribir esta frase por qué la relacioné con lo que dijo el profesor, } \\
\text { con lo que lo que leímos en el periódico, con lo que vi en el video, etc., }\end{array}$ \\
\hline & Int3 & $\begin{array}{l}\text { Se identifican algunas dificultades significativas en los discursos de los } \\
\text { estudiantes, se analiza y se conoce cuál es la posición de las personas, } \\
\text { de esta manera uno crece bastante porque al menos uno mismo llega } \\
\text { la reflexión o se pone uno a pensar, yo pensaba y creía que debían } \\
\text { pensar algo similar a lo mío, pero no todos tenemos que pensar } \\
\text { igual, tenemos que comprender que hay muchas problemáticas, que } \\
\text { invitan a la gente a hacer una lectura diferente de la realidad. }\end{array}$ \\
\hline \multirow[t]{2}{*}{ REI } & INT1 & $\begin{array}{l}\text { Definición del concepto, formulación de la ecuación y / o función, } \\
\text { desarrollo de ejercicios aplicando el algoritmo y /o el concepto. Aplicación } \\
\text { del concepto en situaciones de la vida cotidiana y / o en situaciones } \\
\text { relacionadas con las diferentes ciencias }\end{array}$ \\
\hline & INT2 & xplicación de las consecuencias anatómicas y fisiológicas de las drogas. \\
\hline
\end{tabular}


\begin{tabular}{|c|c|l|}
\hline \multirow{2}{*}{ RET } & Int1 & $\begin{array}{l}\text { Funcionamiento de las neuronas y el impulso, sistema nervioso y } \\
\text { neurotransmisores. }\end{array}$ \\
\cline { 2 - 3 } & Int2 & Los datos estadísticos y tablas de análisis \\
\hline
\end{tabular}

Fuente. Software NVivo11 categoría RE-CSC

Las intervenciones del REI (int1 e Int2) al igual que los contenidos, son direccionados a conocimientos prácticos, que conlleven al desarrollo de habilidades para trabajar desde la disciplina, asumiendo una racionalidad científica para comprender el mundo, desde lo vivencial y desde lo tecnológico, como una ciencia aplicada a lo social, pero que no tiene condición humana, está alejada de ser evaluada o puesta en contradicción, indicando un propósito educacional basado en las percepciones, sin cuestionamientos tecnológicos ni compromisos sociales (Levinson, 2008; Pedretti \& Nazir, 2011; Ratcliffe \& Grace, 2003a; Strieder, 2012).

Los REI de las Int1 y int2 develan referentes netamente científicos, a partir de los cuales se debe responder a un currículo centrado en contenidos para formar desde percepciones científicas, ilustrativas privilegiando la ciencia hecha, que solo requiere ser interiorizada y aplicada en contextos científicos, esto para Levinson (2008) sería un modelo deficitario.

Semejante a la situación mencionada en el párrafo anterior, pero de una forma más declarativa de los RET están las Int1 y 2 en las que prevalecen los referentes epistemológicos de la ciencia declarativa, en la que la CSC posiblemente solo cumple una función dinamizadora para el profesor, para la apertura o cierre de una temática en particular, pero no es utilizada como potencial controversial, ya que posiblemente, el profesor no está preparado como menciona Levinson (2006) para abordar de otra manera las temáticas, o posiblemente los estudiantes acostumbrados a modelos de enseñanza tradicional, reclaman la presencialidad de la temática abordada en forma tradicional. 
Los RE-CSC utilizados por los profesores del GI, al abordar CSC con enfoque CTSA en general, son REIT como se visualiza en la figura 54 y 55 , es decir, sus $\mathrm{RE}$ están basados en las problemáticas sociales, que deben ser abordadas a partir de la reflexión, de debates que permitan la participación de los estudiantes, que cambien esa visión desesperanzadora inicial de la EJA que está inmersa en sus pensamientos, para Pedretti \& Nazir (2011) corresponde a una Enseñanza de las Ciencias con una perspectiva desde la socio-ecojusticia, cuyo foco central se desarrolla en torno a la crítica y la posible solución a problemas sociales y ecológicos a través de la acción humana; para Levinson se constituye como un enfoque dialógico, de negociación, en donde los referentes epistemológicos, no sólo están en el corpus de la ciencia, son de naturaleza descontextualizada de la academia, pero contextualizado en lo local e interdisciplinar. (tabla 3 y 4 ).

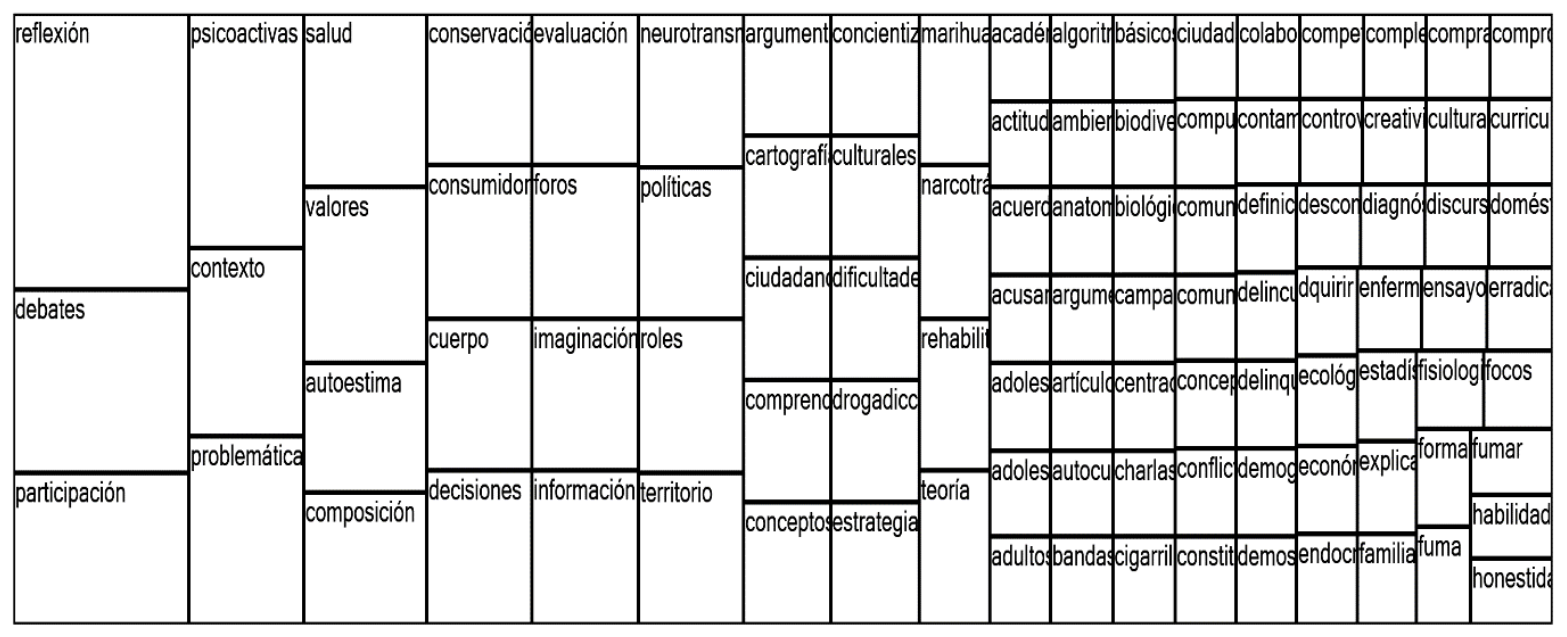

Figura 54. Mapa ramificado de RE-CSC en el PGI

Fuente. NVivo11 UA/RA codificados para RE-CSC con enfoque CTSA

La figura 54, muestra que es a través de la reflexión, el debate y la participación que se abordan las CSC y que uno de los productos, es la identificación de los referentes epistemológicos de esos conocimientos escolares que se construyen a partir de las problemáticas que hacen parte del contexto de la población escolar, en este caso de jóvenes y adultos. 


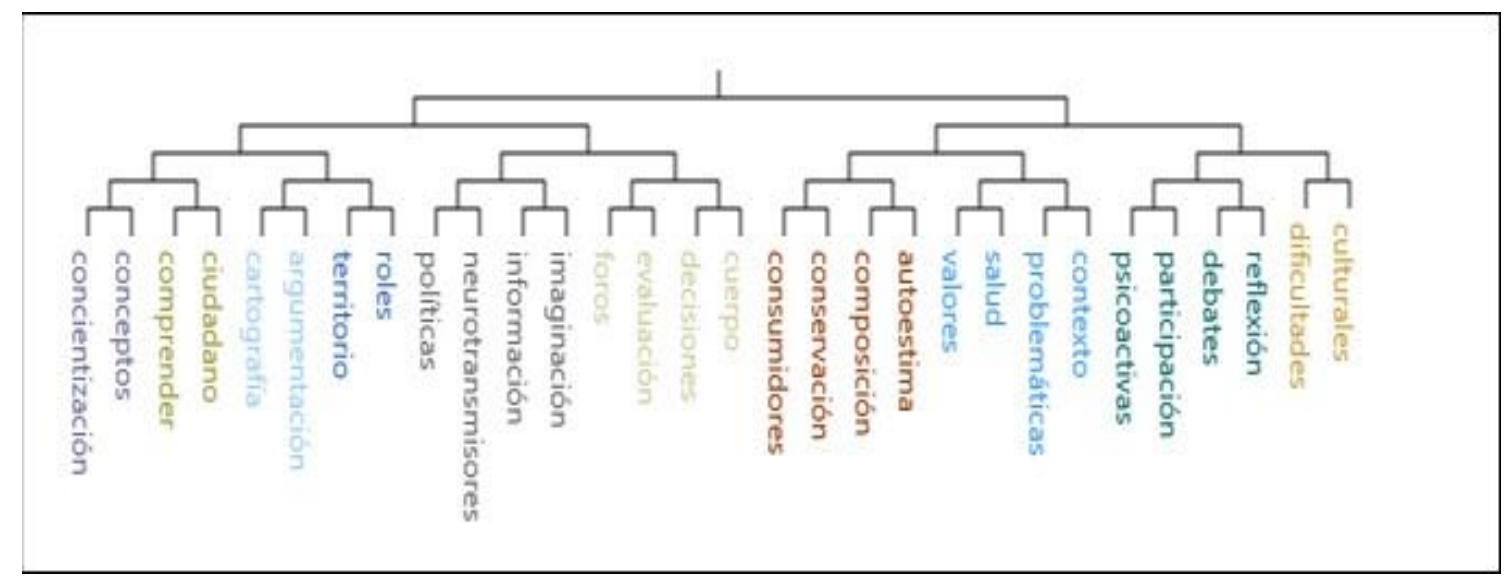

Figura 55. Análisis de conglomerados de los RE-CSC Fuente. Nodo RE-CSC en IUE

La figura 55 muestra como los profesores del Gl abordan como fuentes de conocimientos, nuevos referentes epistemológicos, categorizados en dos grandes grupos: el primero de tipo cultural basado en la reflexión y la participación de las temáticas que se abordan (como SPA) y, el segundo grupo direccionado a lo metodológico, a la manera de abordarlo sabiendo que se asumen posiciones, lo cual tiene implicaciones que conllevan al sujeto (estudiante) a tomar decisiones, a ejercer la ciudadanía, a comprender y argumentar las CSC, en las cuales debe participar por medio del debate, de foros, hacer dinámicas que antes no estaban en su repertorio de actuación, de esta manera el grupo como Gl lucha por tener legitimidad, construir nuevos referentes acordes a los problemas locales, a las necesidades de su contexto laboral y social.

Cuando los profesores mencionan la reflexión (figura 56) como estrategia metodológica, la relacionan con un ejercicio ciudadano, producto de un ejercicio que no solo es de aula, es de aprendizaje y construcción de conocimiento para el propio diseñador de las actividades del aula, de las actividades de aprendizaje, diseñadas y planeadas para que tanto el estudiante como el profesor construyan conocimientos particulares y diferenciados (Martínez, 2017). 


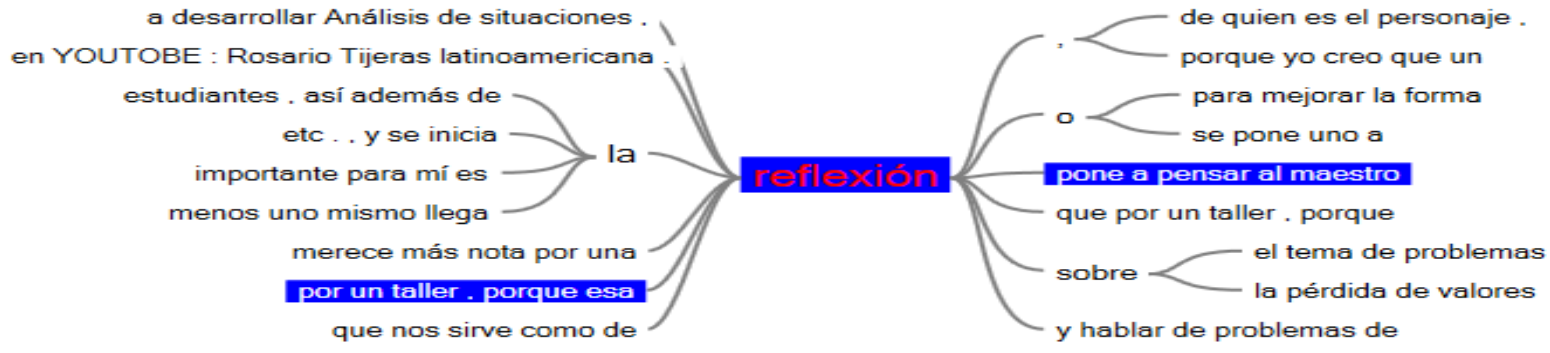

Figura 56. Estrategia metodológica como referente del conocimiento IT de los profesores del PGI Fuente. NVivo nodo RE_CSC en IUE

Las reflexiones del profesor en la acción y sobre la acción, como se evidencia en algunas intervenciones y en las relaciones que se establecen en el Gl evidencian como los profesores asumen su papel de constructores de currículo, y como menciona (Apple \& García, 2003) se diferencian de ser simples ejecutores de currículos elaborados $u$ orientados por directrices externas al contexto escolar.

En la categoría de FCS-CSC (Figura 57) los profesores del GI, utilizan diversas fuentes para seleccionar los contenidos, asumen las CSC como temáticas que no sólo aportan a la formación de los estudiantes, sino a la de ellos mismos, les permite volver a vivir en la universidad ("imaginario de universidad donde se investiga"), disfrutan aprendizaje, explorar y no buscar en una sola fuente "el libro de texto", además logran identificar temáticas de interés para los estudiantes, posiblemente, porque ellos están inmersos en dichas problemáticas, así el conocimiento es compartido y distribuido entre los participantes de esa construcción del conocimiento (Levinson, 2010). 

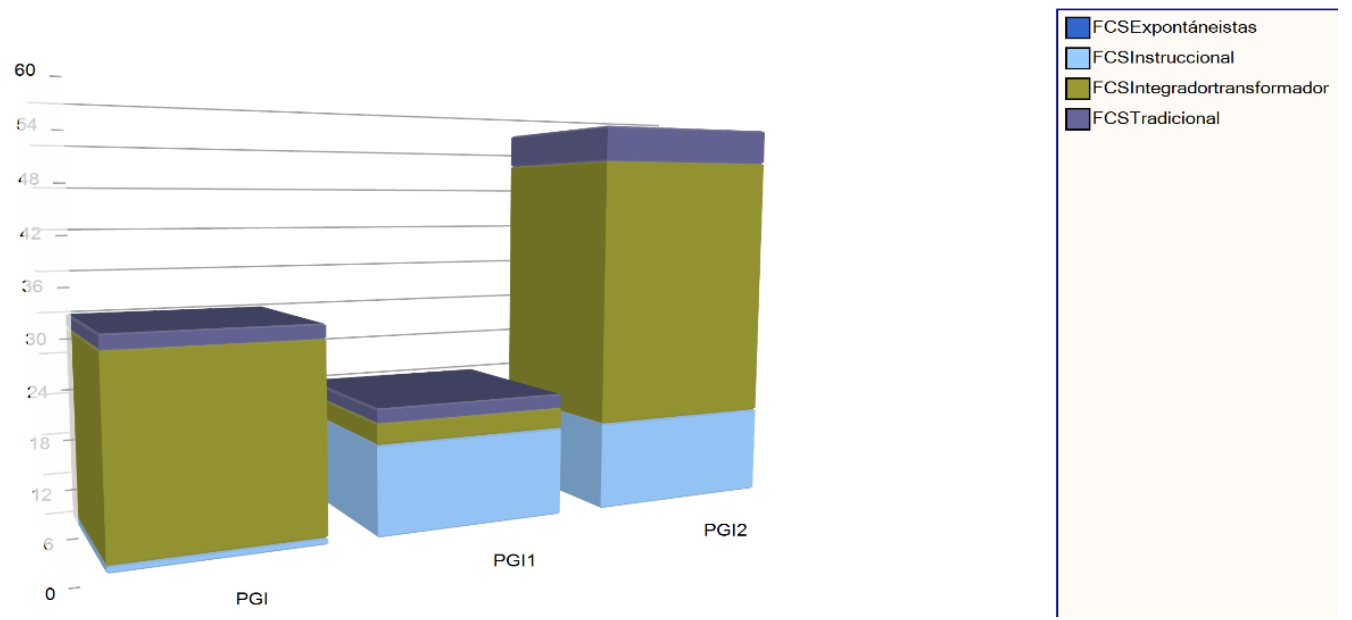

Figura 57. FCS CSC abordadas por el GI en IUE Fuente. NVivo11 nodo FCS-CSC en IUE

Levinson $(2008,2010)$ menciona que cuando el profesor utiliza como FCS las CSC que emergen de las necesidades de los participantes, el conocimiento está subordinado a las necesidades de los colectivos y la formación desde lo pedagógico y didáctico favorece la alfabetización científica y tecnológica; Strieder, (2012) sintetiza diciendo que las relaciones CTSA deben evidenciar una ciencia insuficiente y cuestionada, un desarrollo tecnológico orientado y en contexto, pero lo más importante es lograr la participación social de los estudiantes, que al igual que los profesores, puedan hacer una lectura crítica de la realidad, marcada por desequilibrios sociales, ambientales, éticos, políticos y culturales; que es lo se empezó a gestar en el GI una vez viabilizó el abordaje de las CSC.

Las UA/RA en esta categoría evidencian que los profesores utilizan como FCS además de las CSC, diversas fuentes, que le exigen rigurosidad al trabajo del profesor como profesional, como lo indican las diversas intervenciones categorizadas como FCSIT (int1 a Int5). 


\section{Tabla 13. FCS-CSC utilizados por los profesores del GI en la IUE}

\begin{tabular}{|c|c|c|}
\hline \multirow{5}{*}{ FCSIT } & $\ln 1$ & $\begin{array}{l}\text { Claro que eso también, vino a cambiar inclusive con las noticias, el uso de las } \\
\text { mismas en la clase, con el periodismo, la televisión, por radio y redes que no } \\
\text { tienen que el chico tiene que ver porque cuando se hace la construcción de } \\
\text { oraciones, se mencionan noticias de actualidad, }\end{array}$ \\
\hline & Int2 & $\begin{array}{l}\text { Uno tiene que estudiar todo, desde el componente, donde las consiguen, hasta } \\
\text { la competición por los precios ¿por qué ocurren estas cosas? por qué } \\
\text { evolucionan y el desarrollo en tecnología que usan, etc., son algunas de las } \\
\text { limitaciones más importantes, porque uno por lo general no tiene ese } \\
\text { conocimiento y ellos hacen preguntas que nunca había escuchado, hasta la } \\
\text { forma de consumo tienen diferentes formas }\end{array}$ \\
\hline & Int3 & $\begin{array}{l}\text { Establecer los vínculos, las relaciones curriculares, es difícil, porque uno } \\
\text { siempre se ha dedicado a la parte de la literatura y la gramática, con ejemplos } \\
\text { muy del contexto de la literatura bien sea griega, o la que se aborde pero muy } \\
\text { disciplinar, no contextualizada y menos de índole controversial }\end{array}$ \\
\hline & Int 4 & $\begin{array}{l}\text { [...] se buscan más referentes en cuanto al contexto, las implicaciones de las } \\
\text { CSC en la vida, en la toma de decisiones de los estudiantes, empiezan a } \\
\text { respetar más al estudiante, en pensar en ellos como personas, como seres } \\
\text { humanos independiente del problema que tengan, empiezan a tener } \\
\text { respeto por él, por el adulto }\end{array}$ \\
\hline & $\ln 5$ & $\begin{array}{l}\text { Casi todas las CSC en el área de sociales, porque muestran problemáticas de } \\
\text { tipo social, porque en ella involucramos todas las estructuras de la sociedad, } \\
\text { que se ven afectadas por el consumidor y qué es algo circular, porque el } \\
\text { consumidor afecta la familia y la familia afecta al consumidor, el consumidor } \\
\text { afecta a la sociedad y viceversa, [...] }\end{array}$ \\
\hline \multirow[b]{2}{*}{ FCSI } & Int1 & $\begin{array}{l}\text { La recolección de datos, tabulación de los mismos con miras a organizarlos } \\
\text { para poder inferir sobre estos, es tal vez lo que más podría relacionarse con el } \\
\text { área de Matemáticas. La ESTADISTICA es [...], una segunda herramienta es } \\
\text { la ENCUESTA...la cual conlleva a preparar un cuestionario bien elaborado, } \\
\text { tanto así que permita al encuestador tratar el tema de las drogas }[\ldots] .\end{array}$ \\
\hline & Int2 & $\begin{array}{l}\text {..tema ambiental se trata cuando hablamos de factores y elementos del clima } \\
\text { a nivel general, pero profundizamos un poco más sobre las causas y } \\
\text { consecuencias de la alteración del clima y sus agentes contaminantes en las } \\
\text { características climáticas de Colombia y sus efectos en la producción y la } \\
\text { afectación en la economía nacional. }\end{array}$ \\
\hline FCST & $\operatorname{lnt} 1$ & $\begin{array}{l}\text { Porque así sean de la noche los chicos se van a presentar un examen y no van } \\
\text { a tener la opción de conocer las temáticas, entonces el tiempo destinado a las } \\
\text { CSC sacrifica el tiempo de lo que se debería dar y no se dio. }\end{array}$ \\
\hline
\end{tabular}

Fuente. Nodo FCS-CSC software NVivo11

Los profesores (Int1 e Int3) que tienen como FCSIT mencionan que sus fuentes son los medios masivos de comunicación, pero estos deben ser seleccionados asumiendo una posición crítica; el conocimiento científico no está sólo en textos, 
está en todo: en las problemáticas que tiene los estudiantes, en el contexto de la escuela. Al proponer temáticas que favorezcan la construcción del conocimiento escolar y del profesor como profesional, se establecen relaciones horizontales de poder, el maestro es autónomo y crítico (Martínez, 2010b); se empieza a gestar una visión por el conocimiento con limitaciones académicas, una ciencia insuficiente, con un uso responsable de la tecnología, la cual debe suplir necesidades básicas en el contexto propio de la vida de las personas y ser ante todo contextualizada en una esfera política de participación (Strieder, 2012).

Vale la pena resaltar la Int4, que evidencia uno de los posibles resultados de la falta de acompañamiento al profesor de la que habla Lopes \& Carvalho (2017), y de la especificidad en la formación de profesores para EJA (Silva, 2016), que hace que el profesor manifieste verbalmente estas apreciaciones de lo que ha escuchado a sus colegas (profesores) cuando menciona, que los profesores han cambiado la forma de pensar con respecto al adulto, en sus palabras: "[...] como seres humanos independiente del problema que tengan, empiezan a tener respeto por él, por el adulto" (Int4 FCSIT); esta afirmación, muestra la imagen de un profesor centrado en un modelo de enseñanza deficitario (Levinson, 2008) en el que el orden jerárquico o estatus del estudiantes es inferior al profesor y podría pensarse que el profesor "no conoce a sus estudiantes"; es una educación que promueve la alienación, y en la que tanto el estudiante como al profesor son objetos, no sujetos de derecho; en este sistema las FCS siempre serán las impuestas, las que orientan la validez del conocimiento para rendir cuentas (Freire, 2005).

La Int5 revela a un profesor con unos referentes muy disciplinares, lo que evidencia la importancia del aspecto social de las CSC, pero que da a entender que hay especialidades que las pueden abordar fácilmente, como las Ciencias Sociales, lo que es favorable pero muestra el desconocimiento científicotecnológico así como el potencial que permite relacionar los propósitos 
educacionales con las CSC y las relaciones CTSA, sin embargo, en el proceso de formación, representa un dinamizador de posibilidades, en las que el profesor una vez comprenda el compromiso social de la ciencia y la tecnológica, pueda planear estrategias basadas en el debate y la participación, donde el profesor como ser social, fomente la participación en las esferas públicas.

Las intervenciones, que develan las FCS-CSC como FCSI plantean la valoración que tienen los profesores por los contenidos y las metodologías instruccionales, aquí el profesor utiliza como criterios temáticos los de la disciplina articulados con las CSC que pueden servir de ejemplo de abordaje de la temática disciplinar no de la CSC como lo mencionan en la int1, sin embargo, se podría decir que aunque hay resistencia al abordaje de las CSC con todas las implicaciones que se generan (Levinson, 2008; Reis \& Galvão, 2008) el sólo hecho de abordarlas, ya es un avance, una posibilidad o disposición al cambio.

La siguiente intervención, muestra que aunque el profesor asume el ambiente como CSC, lo hace para comprender la temática, igual que el anterior, para dinamizar su comprensión pero sin reflexión y comprensión de la misma que convoque a la participación ciudadana y que promueva la transformación de la visión utilitarista de la naturaleza.

Las FCST la UA/RA ubicadas en esta categoría, evidencian un profesor que reconoce que las CSC al ser controversiales, de diálogo, reflexión, de toma de decisiones, requieren de mayor preparación para ser abordadas en el aula, pero no las usa porque primero debe responder a las exigencias de las pruebas externas; lo importante para este profesor no son los intereses de los estudiantes, el mismo lo menciona: "así sean estudiantes de la noche", con esa fase devela también la concepción de precariedad por la EJA, en la que se debe dar lo mínimo olvidando la capacidad y los saberes de esta población. 
La figura 58 muestra las principales fuentes y criterios de selección utilizados por los profesores del GI cuando abordan CSC, en la que la CSC SPA representó el eje articulador del discurso de la mayoría de profesores del Gl, quienes utilizaron videos, documentales, visita de expertos, abordaron las temáticas asumiendo posiciones éticas morales, contemplaron riesgos ambientales y humanos, consideraron los aspectos socio culturales, económicos, políticos de la producción/ consumo; los cuales se evidencian en el diseño de las SD (Anexo 16) y la realización de un taller de cierre de actividades de formación (Anexo 13).

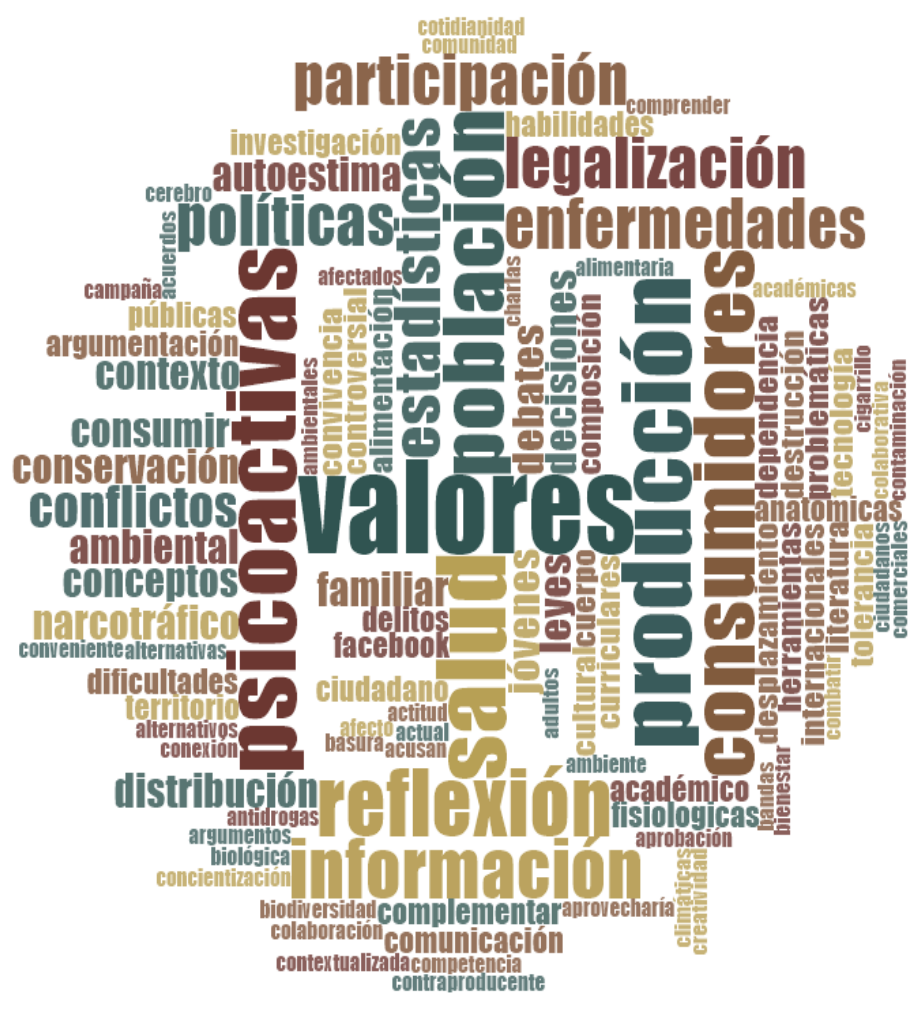

Figura 58. FCS_CSC de los profesores del GI

Fuente NVivo11.

Las FCS develadas en el corpus de la investigación, son las problemáticas del contexto escolar abordadas controversialmente como las SPA, la relación productores/consumidores, al igual que resaltar la importancia de los valores como eje estructurante, permite situar a los individuos como seres capaces de reflexionar y asumir posiciones según sus referentes ético/morales en un contexto 
social, histórico, en el que los medios masivos influyen, pero que al promover una participación crítica, autónoma y reflexiva desarrollan la habilidad de evaluar sus posiciones y de esta manera favorecer el CPP y el escolar en el caso de la EJA.

Las FCS utilizadas en la elaboración de SD y de actividades propias del anexo 8 que corresponden a la formación de especialistas, utilizan material basado en fuentes conseguidas en centros especializados como hospitales (Vistahermosa), por medio de conocidos y/o amigos de centros de rehabilitación, videos y talleres de sitios web que abordaban estas temáticas, es decir, empieza la movilidad que implica salir del texto escolar tradicional para encontrar otras fuentes que pueden evaluar y mostrar la naturaleza incompleta de la ciencia, la incertidumbre de las CSC (anexo 8, 9,10, 16 y 18) y la construcción del CPD.

En cuanto a los CV-CSC que legitiman las CSC, se puede visualizar en la figura 59 que son consecuentes con los CEA-CSC, las FCS y los RE que utiliza cuando aborda CSC.

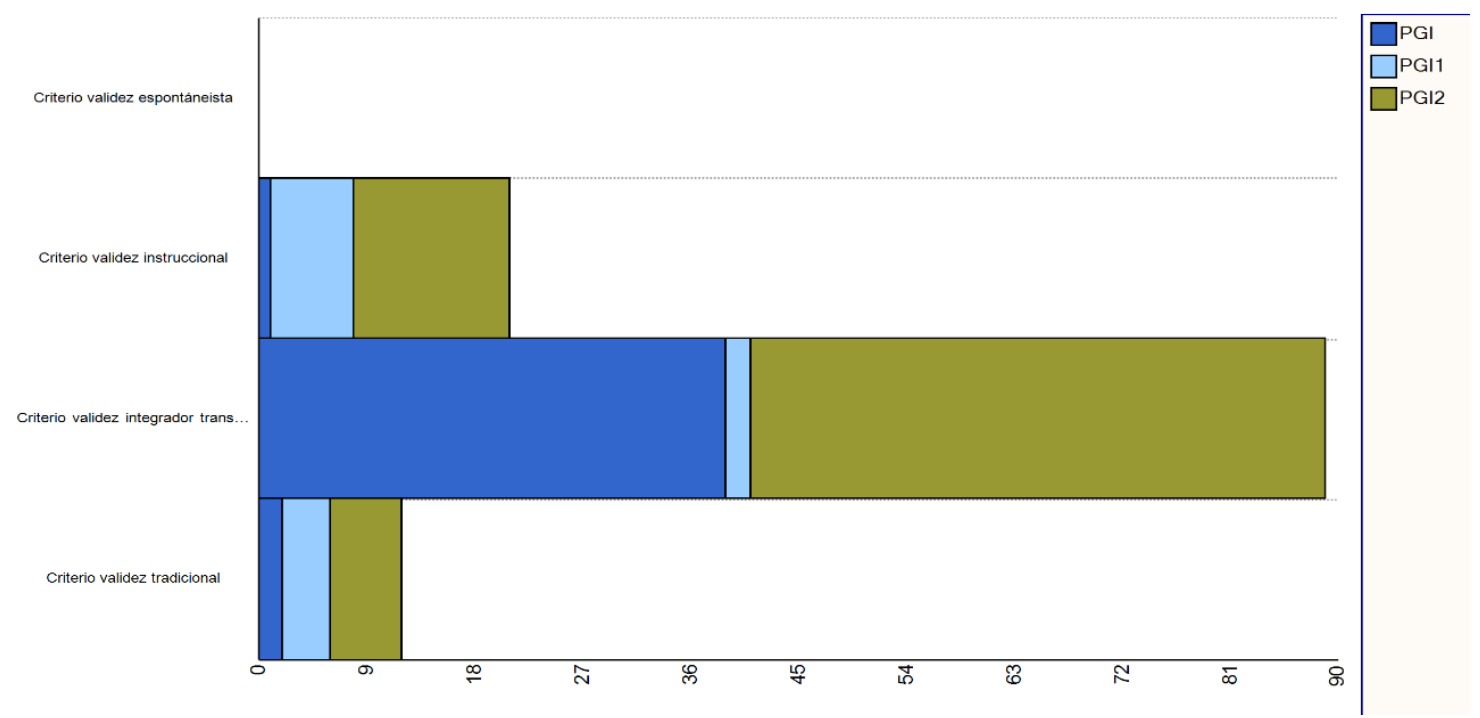

Figura 59. CV_CSC del GI Fuente NVivo11. Categoría CV_CSC 
La mayoría de los profesores del GI utilizan CVIT, sin embargo, producto de la cultura escolar, de la rendición de cuentas, de los estándares curriculares, de la normatividad vigente (movilidad del estudiante para expedir boletines y/o certificaciones) los profesores entran en conflicto permanente, porque sienten estar trabajando para dos sistemas totalmente diferentes, una centrado en lo cuantitativo y el otro que es incierto, como las mismas CSC.

Sousa (2016), plantea la búsqueda de conocimientos y criterios de validez para el conocimiento que den visibilidad y credibilidad a las prácticas cognitivas de los pueblos, de las clases, de los grupos sociales que han estado históricamente victimizados, excluidos y oprimidos por el colonialismo y el capitalismo global, posiblemente los profesores son los que deben llevar esta bandera de búsqueda, de reconocimientos de los saberes, de esas prácticas cognitivas que menciona Souza y más aún cuando el contexto laboral y social de la mayoría de docentes es el de los desfavorecidos y marginados.

En la tabla 14 se muestran fragmentos de afirmaciones o comentarios de docentes, en los que mencionan algunos criterios de validez. Para los profesores del GI con CVIT se circunscriben a la participación del estudiante, tomar posición y según la Int1 a la capacidad de reflexionar y evaluar sus propias respuestas.

Tabla 14. CV-csC

\begin{tabular}{|l|l|l|l|}
\hline Int1 & $\begin{array}{l}\text { Hay ejercicios como los juegos de roles, donde se invita a los estudiantes a } \\
\text { asumir papeles de instituciones o personas o sólo se pregunta qué haría si fuera } \\
\text { uno de los personajes de la lectura, entonces los muchachos dicen si, la } \\
\text { respuesta es esta, pero yo por lo menos no daría esa respuesta por esta razón, } \\
\text { o creo que es esta por los siguientes motivos o circunstancias y esta es una de } \\
\text { las formas de entrar en la discusión o debate. }\end{array}$ \\
\cline { 2 - 2 } & Int2 & $\begin{array}{l}\text { Que si por ejemplo, se habla de política en un contexto histórico, } \\
\text { geográfico, que sepa qué tipo de territorio es por el que se pregunta, que pueda } \\
\text { establecer relaciones de los hechos que suceden en diferentes contextos o } \\
\text { territorios y reflexione que lo que sucede en un lado, puede tener consecuencias } \\
\text { o puede suceder en otro } \\
\text { [...] mostraba la vida y la muerte de esa ave por la presencia de las basuras, de } \\
\text { los escombros que votan en los páramos y humedales, por lo tanto, él invento }\end{array}$ \\
\hline
\end{tabular}




\begin{tabular}{|c|c|c|}
\hline & & $\begin{array}{l}\text { un cuento, donde decía porque el pájaro murió y comenzaron a establecer } \\
\text { relaciones con las noticias muy del momento, mencionaban que era similar a } \\
\text { lo que ocurría en la Guajira, pero le decían en ese lugar no hay páramos, pero el } \\
\text { aludía al antagonismo que se evidenciaba ocasionado por la sequía, más por la } \\
\text { crisis social y de derechos humanos que se evidenciaba por el cambio climático, } \\
\text { por la contaminación y la corrupción política, en fin interesante. }\end{array}$ \\
\hline & Int4 & $\begin{array}{l}\text { Ellos pueden ser evaluables por los talleres, las reflexiones, lo más importante } \\
\text { para mí es la reflexión, porque yo creo que un chico merece más nota por una } \\
\text { reflexión que por un taller, porque esa reflexión pone a pensar al maestro y a } \\
\text { todos los estudiantes, como lo que se vio reflejado en el juego que hicimos con } \\
\text { hilos, donde los mismos estudiantes se sinceran, comparten sus experiencias y } \\
\text { con sus reflexiones posiblemente van a mitigar el consumo de otros. }\end{array}$ \\
\hline \multirow[b]{2}{*}{ CVI } & Int1 & $\begin{array}{l}\text { Por medio de la participación individual y grupal, mediante un debate y una } \\
\text { mesa redonda }\end{array}$ \\
\hline & Int2 & $\begin{array}{l}\text { Lengua Castellana: escritos y lecturas relacionadas con la droga, resaltando la } \\
\text { palabra droga. } \\
\text { Matemática: porcentaje de droga según los últimos años y mirar si ha } \\
\text { aumentado o disminuido. } \\
\text { Sociales: regiones de Colombia productoras de droga y consecuencias para la } \\
\text { producción agrícola de nuestro país, exportaciones ilícitas. } \\
\text { Ciencias Naturales: las drogas y cuidado de nuestro cuerpo. } \\
\text { Tecnología: máquinas utilizadas en el procesamiento de las drogas. }\end{array}$ \\
\hline \multirow{3}{*}{ CVT } & Int1 & Analizando gráficas y estadísticas \\
\hline & Int2 & $\begin{array}{l}\text { Estas CSC no se pueden evaluar, no hay conocimiento específico de nada, si } \\
\text { viene drogado el estudiante, pues obviamente que no sabe ni con quién están, } \\
\text { es difícil evaluar, hay otros estudiantes que trabajan estando drogados, rinden } \\
\text { posiblemente por la clase de droga que consumen y no se preocupan, ni dicen } \\
\text { que si está bien o mal, porque a veces no se sabe su comportamiento, de pronto } \\
\text { sea por la dosis, por lo que consumen, lo único que registro es la asistencia. }\end{array}$ \\
\hline & Int3 & Haciendo ejercicios \\
\hline
\end{tabular}

Fuente. NVivo11. Nodo CV_csc

La Int2 de la categoria CVIT evidencia que el profesor valora las analogias que hace el estudiante al abordar CSC; pero lo más importante que se comprende en esta intervencion, es la intensionalidad del profesor, al querer que los estudiantes reflexionen, que sus acciones no sólo afectan lo local, que lo que él puede hacer en su contexto tiene efectos positivos y/o negativos globalmente y lo que se hace alli, trasciende a lo global.

En la int 3, el profesor se siente a gusto, está satisfecho con el trabajo realizado con los estudiantes (expresiones de emocionalidad positiva), resalta la capacidad del estudiantes para comprender, hacer analogias, usar estrategias de actuación y 
personificación (abordadas en lo disciplinar), para asumir posiciones y tomar decisiones haciendo uso del derecho ciudadano.

En la Int4 se hace explicito el papel de la reflexión, que indica la capacidad del ser humano de evaluar, de trascender del concepto y ahora ponerlo en acción en su vida cotidiana, esta reflexión, es la que el profesor estaba esperando, es un CV particularizado; sin embargo, se evidencia, la ausencia de participacion de los estudiantes en los procesos de evaluación, el profesor evalua las reflexiones, los procesos y habilidades que desarrollan los estudiantes, pero no mencionan la forma, ni los criterios que socializaron con los estudiantes para evaluar el proceso.

Los CVI el maestro los evidencia en forma metodológica y procedimental, lo importante es el método, hizo las actividades propuestas pero no recalca en que debe ser una participación reflexiva y crítica, sigue predominando lo instrumental como lo muestra la int1 en la int2, el maestro asume que es la división del trabajo la que garantiza el trabajo en equipo, cada quien hace algo y al final se suma y se obtiene lo deseado, como en una empresa, pero olvida establecer los nexos, las conexiones que garanticen la armonia del conjunto, es lo que se da muhas veces en las univiersidades y la vision disciplinar del curriculo: cada quien hace su parte y el usuario lo integra, cada profesor aporta los conocimientos de la disciplina y el estudiante los integra en la vida práctica, los pone en acción; es decir, predomina la visión instrumental y la ejecucion de curriculos elaborados por expertos que se deben seguir para dar cumplimiento a los estandares establecidos (Apple \& García, 2003).

Finalmente, los CVT ven en las CSC temáticas que al ser complejas, no tienen la caracterísitica de un conocimiento terminado, con referentes o CV establecido, constituyen un problema para el profesor, ya que develan que sus conocimientos son insuficientes para abordar las CSC, le exige cuestionamiento, toma de 
posición, trabajo con el otro, consenso, que es lo que no le han enseñado durante el procesos de formación (Conrado \& El-Hani, 2010).

Lo anterior se corresponde con la reflexion que hace Levinson (2006b) quien afirma que cuando el profesor aborda controversias, debe ser consciente que en el aula existen posiciones éticas, económicas, políticas, normas científicas y antropológicas, entonces se pueden generar emociones por las discusiones o debates que se establecen; basarse en controversias, es por tanto, ir más allá de la brújula de cualquier profesor, independiente de la versalidad que pueda tener en la temática.

La frecuencia de palabras para la categoria CVL-CSC, permite identificar los CV que en conjunto utilizaron los profesores a través de los debates, talleres y en general durante el proceso de formación y que se clasificaron para esta categoria, como lo muestra la nube de palabras de la figura 60 , en la que se muestra que uno de los criterios de validez fundamental en el abordaje de CSC es la participacion, seguida de procesos de reflexión, de posiciones en las se que ponen en juego los valores, el pensamiento o acciones centradas en lo colectivo y no lo individual (la comunidad), los debates, la toma de decisiones, el abordaje de las drogas ilicitas (SPA). 


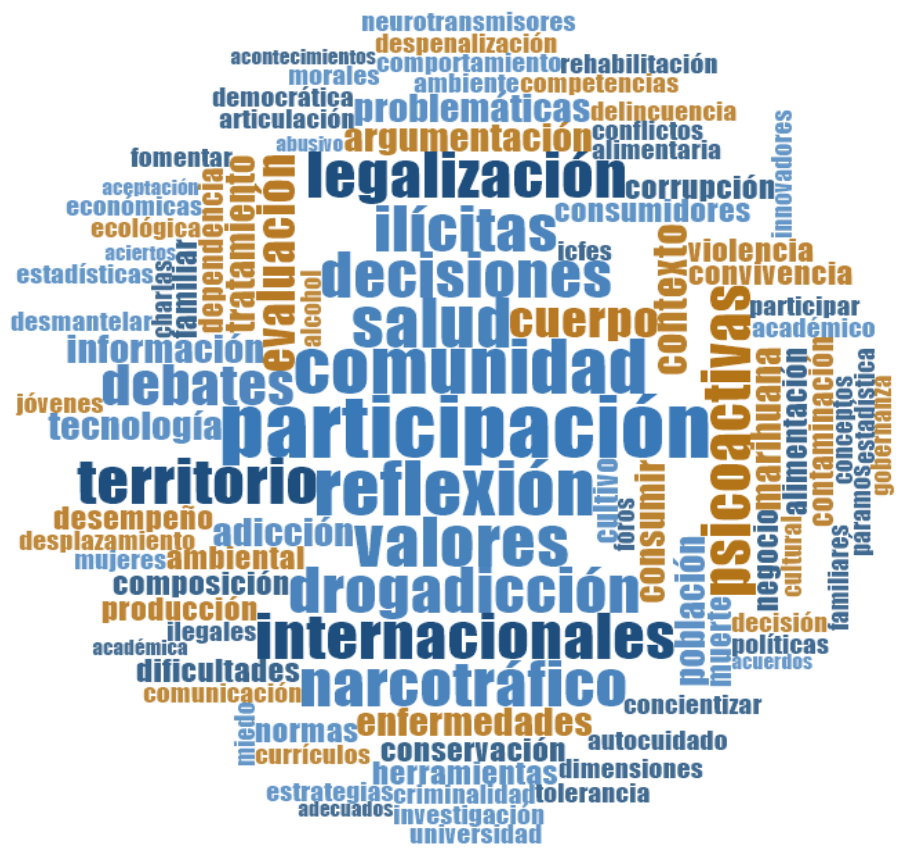

Figura 60. CV utilizados por los profesores al abordar CSC Fuente. Nvivo11, nodo CV_CSC

La figura 61 y 62 muestran el contexto en el que el profesor abordó dicho CV, al seguir la ruta de la palabra la podemos encontrar en el documento, taller y/o entrevista focal o semiestructurada, como se aprecia en la tabla 15.

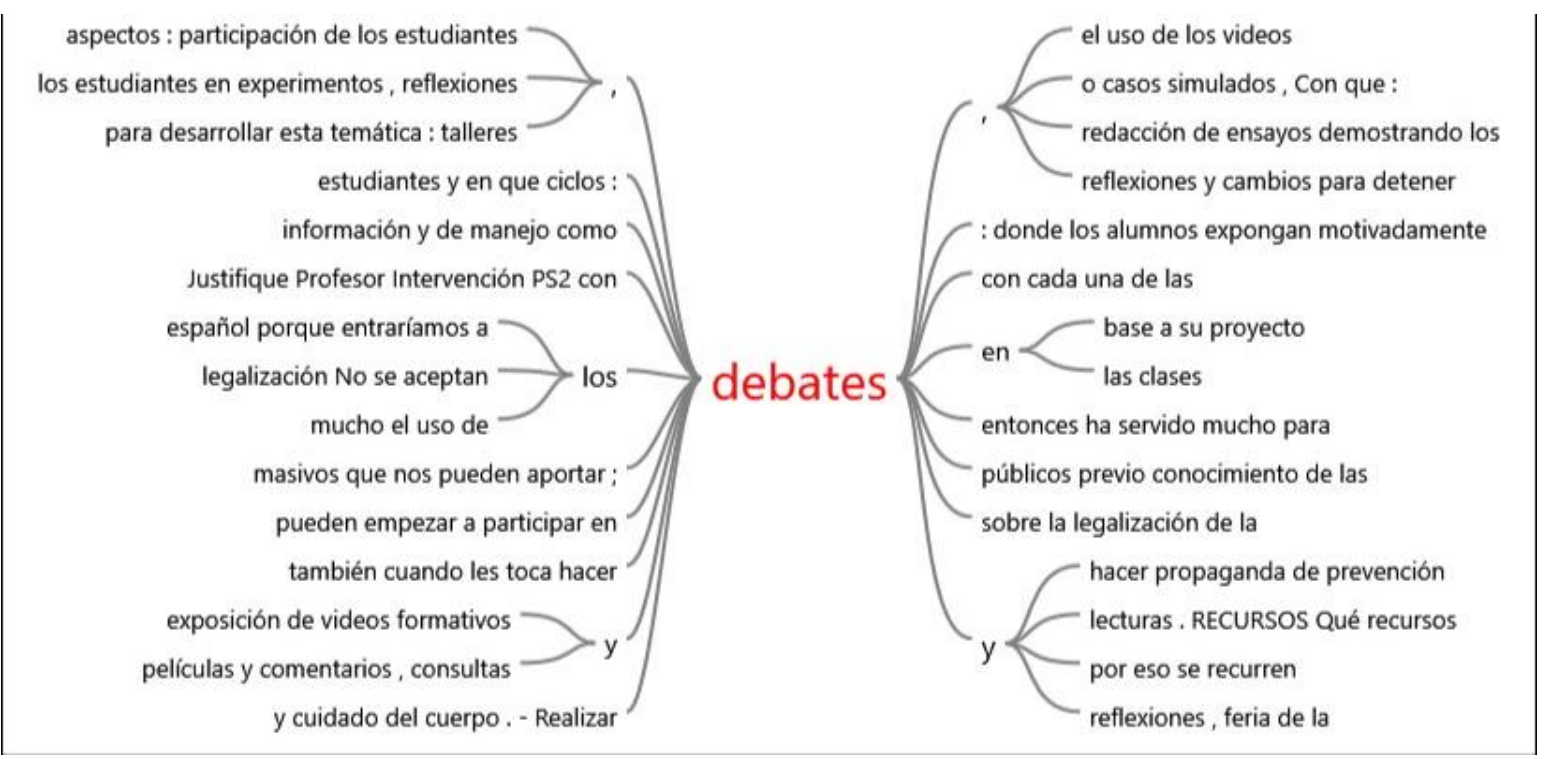

Figura 61. Debate como CV utilizado por los profesores del GI Fuente. Nvivo11, búsqueda de texto 
En este contexto, los debates son utilizados por el profesor, para abordar las CSC, sin embargo, develan que en su preparación se usaron estrategias que permitieron al estudiante o al mismo profesor participar, para lo cual utilizó como FCS películas, exposiciones, video foros, actividades de prevención, procesos de reflexión, desarrollo de casos similares y escritos, que permitieron la consolidacion del debate como CVIT y de estrategia metodológica para el abordaje de las CSC,

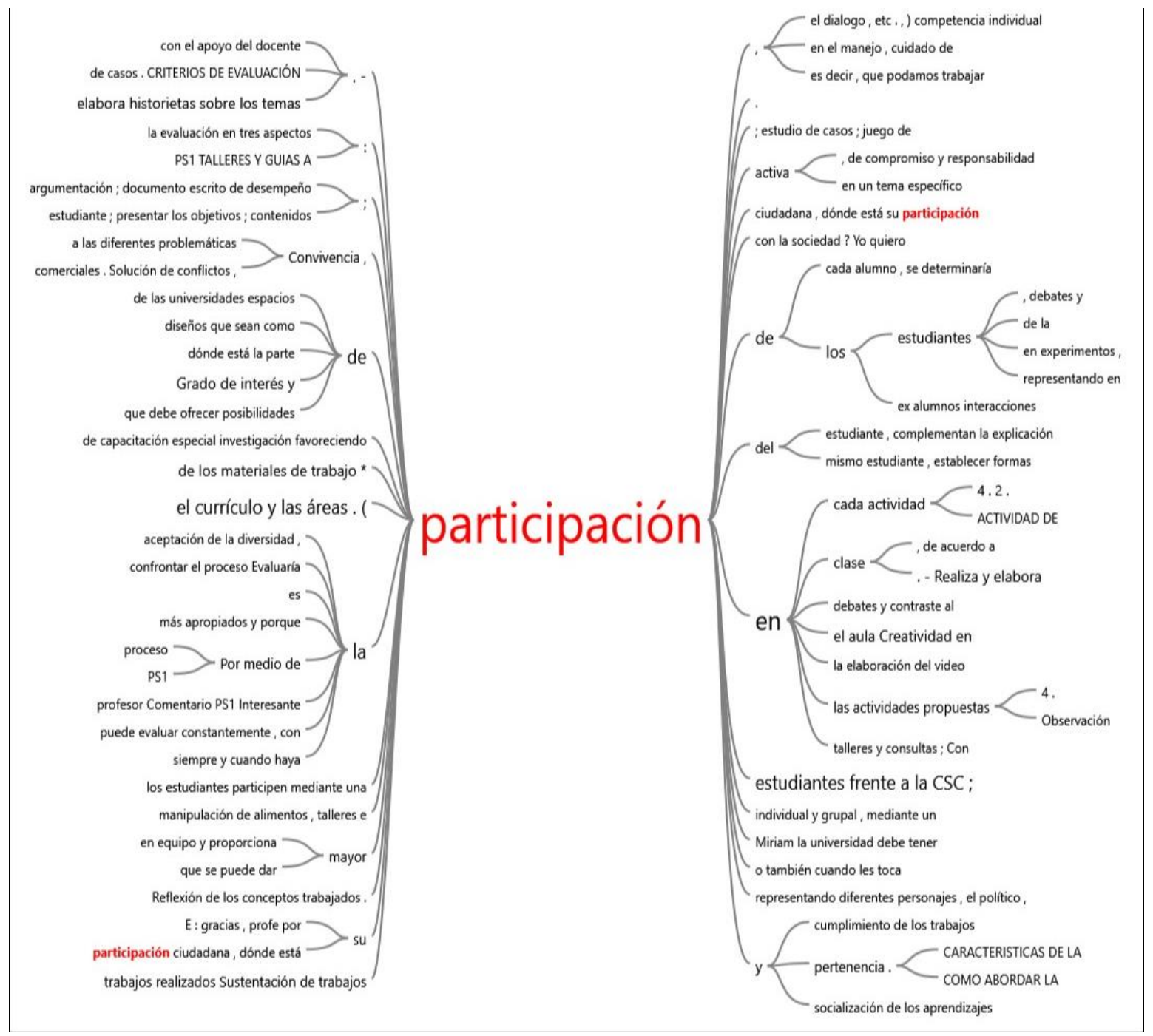

Figura 62. Árbol de palabras, indica el contexto de la participación como CV asumido por el profesor del GI Fuente. NVivo11 contexto de la partición en el corpus de la investigación. 
En esta figura, se evidencia la importancia que dan los profesores del $\mathrm{Gl}$ a los procesos de participación como CVIT, en la cual se viabilizan estrategias asociadas a la escritura, al planteamiento de historias, de elaboración de líneas de vida, en la realización de consultas y talleres hasta la participación oral a partir de la elaboración de videos cortos, de sustentaciones argumentativas, procesos de diálogo, juegos de roles, sustentación de trabajos, entre otros; pero también, se devela la exigencia que hace el profesor a la universidad como par acompañante en el proceso de formación; la universidad debe ofrecer espacios de participación en investigaciones que le garanticen un acompañamiento y evaluación permanente.

\section{Tabla 15. CV utilizados por los profesores del GI}

\begin{tabular}{|c|c|}
\hline CV & Contexto \\
\hline \multirow[b]{3}{*}{ 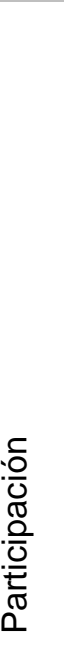 } & $\begin{array}{l}\text { Los estudiantes comienzan a desarrollar su parte moral, algunas de sus habilidades } \\
\text { experiencias las usan como una forma de investigar, sobre temas de interés se fomenta } \\
\text { el trabajo en equipo y proporciona mayor participación y socialización de los } \\
\text { aprendizajes de tal manera que son más significativos. } \\
\text { Participación estudiante frente a la CSC, se debe abordar la evaluación en tres } \\
\text { aspectos: participación de los estudiantes, debates y reflexiones, feria de la ciencia, } \\
\text { donde se pueda determinar los procesos de argumentación }\end{array}$ \\
\hline & $\begin{array}{l}\text { Que se puede evaluar constantemente, con la participación en clase, de acuerdo a las } \\
\text { consultas y sugerencias, igualmente con el cine foro, y ojalá con las salidas } \\
\text { pedagógicas, aportando sus impresiones, experiencias, con sus labores diarias, siendo } \\
\text { críticos, observadores y constructores de sus proyectos. }\end{array}$ \\
\hline & $\begin{array}{l}\text { Como: a través del análisis de las causas, las consecuencias y las relaciones entre los } \\
\text { elementos que intervienen en cada CSC, pero siempre y cuando haya la participación } \\
\text { de los estudiantes en experimentos, reflexiones, debates, o casos simulados; Con que: } \\
\text { con la elaboración de informes, gráficas, artefactos elaborados por ellos mismos. }\end{array}$ \\
\hline & $\begin{array}{l}\text { Asumir posiciones críticas y utilizar los medios de comunicación como un medio de } \\
\text { comunicación y recurso para la información y de manejo como debates en las clases. } \\
\text { Con debates públicos previo conocimiento de las CSC a abordar, donde se obtenga } \\
\text { como resultado las causas y los efectos del tema a tratado y posibles soluciones. }\end{array}$ \\
\hline & los debates o sugerencias de familiares y amigos sobre \\
\hline
\end{tabular}

Fuente. NVivo11 Frecuencia de palabras.

Asi, la participación y el debate como uno de los CV con mayor frecuencia mencionados por los profesores del Gl, permiten la manifestacion de otros criterios asociados como el cuestionamiento ético-moral, las habilidades que favorecen la 
investigacion, el trabajo en equipo y procesos comunicativos, como la socialización del manejo de CSC como mecanismo de participación.

Adicionalmente, se plantea la necesidad de participar en situaciones experiementales, salidas pedagógicas, las cuales eran desconocidos para estos estudiantes, el diseño de proyectos conjuntos con otras áreas, que le permitan abordar las CSC desde diferentes perspectivas.

Finalmente, es viable afirmar que los profesores al abordar CSC hacen que los referentes o estructuras permitan comprender el CPP dinámicamente, pues favorece la movilidad del pensamiento del profesor, así como su construcción/reconstrucción a la luz de la HdPR (figura 40), al variar los CEA-CSC, los REL-CSC, FCS-CSC y CVL-CSC da cuenta de la movilidad de sus conocimientos de un estilo de pensamiento tradicional a uno integrador transformador, permaneciendo en estados intermedios o permaneciendo en el mismo, tomando posición informada y reflexionada sobre el mismo (espontaneista /instruccional).

Al analizar todo el corpus de la investigación usando como dispositivo el ATD y con los resultados obtenidos, podemos igualmente afirmar, que los profesores del GI no utilizan contenidos que surgen del gusto de los estudiantes, las figuras 48 , $49,54,58$ y 61 lo hacen evidente es decir, lo fundamental para el Gl no es satisfacer sus deseos; sin embargo en el discurso analizado en los referentes del CPP mencionados, se develan las emociones que emergen del maestro cuando ve el trabajo de los estudiantes, cuando escuchan los discursos de los mismos al socializar los trabajos direccionados en el aula, de la misma manera, casi todos los términos que usa el maestro es en función de los estudiantes, de sus aprendizajes, consideramos que posiblemente, sea la resultante de la visión de la EJA, de las rutinas y guiones de acción, de esos saberes dominantes que caracterizan el CPP, pero también, posiblemente sea por el imaginario de la edad de los estudiantes, que como se mencionó, también es un paradigma alejado de la 
realidad: los estudiantes de la EJA, son ahora niños y niñas excluidos del sistema educativo convencional.

Martínez (2016, 2017), menciona que los ejes DOC permiten conocer la complejidad del CPP y en este sentido, las figuras 38 y 40 evidencian el contexto de estos ejes en la HdPR. En la investigación se observa que los ejes dinamizadores favorecen el CPP hacia un EP integral transformador, los ejes obstáculo son identificados como los causantes de estructuras de pensamiento que impiden la movilidad de los profesores y los mantiene en un estado de confort para mantenerse en un EP tradicional y los ejes cuestionamiento, son aquellos que empiezan a gestar insatisfacción en el EP del profesor, pero pueden ser positivos o negativos, dependiendo de los factores asociados a este, pueden movilizar el EP de los profesores al integral transformador o mantenerlo en EP tradicional, y/o espontaneista/instruccional.

Los ejes DOC fueron categorizados como se observa en la figura 63 acorde a los criterios establecidos en la tabla 9. Al graficar estos ejes DOC en términos de contenidos, criterios de validez, fuentes y criterios de selección, y referentes epistemológicos, encontramos que los profesores del Gl asumen las CSC como fuentes dinamizadoras del CPP, seguido de los ejes obstáculo y cuestionamiento. (figuras 63 a 67). 


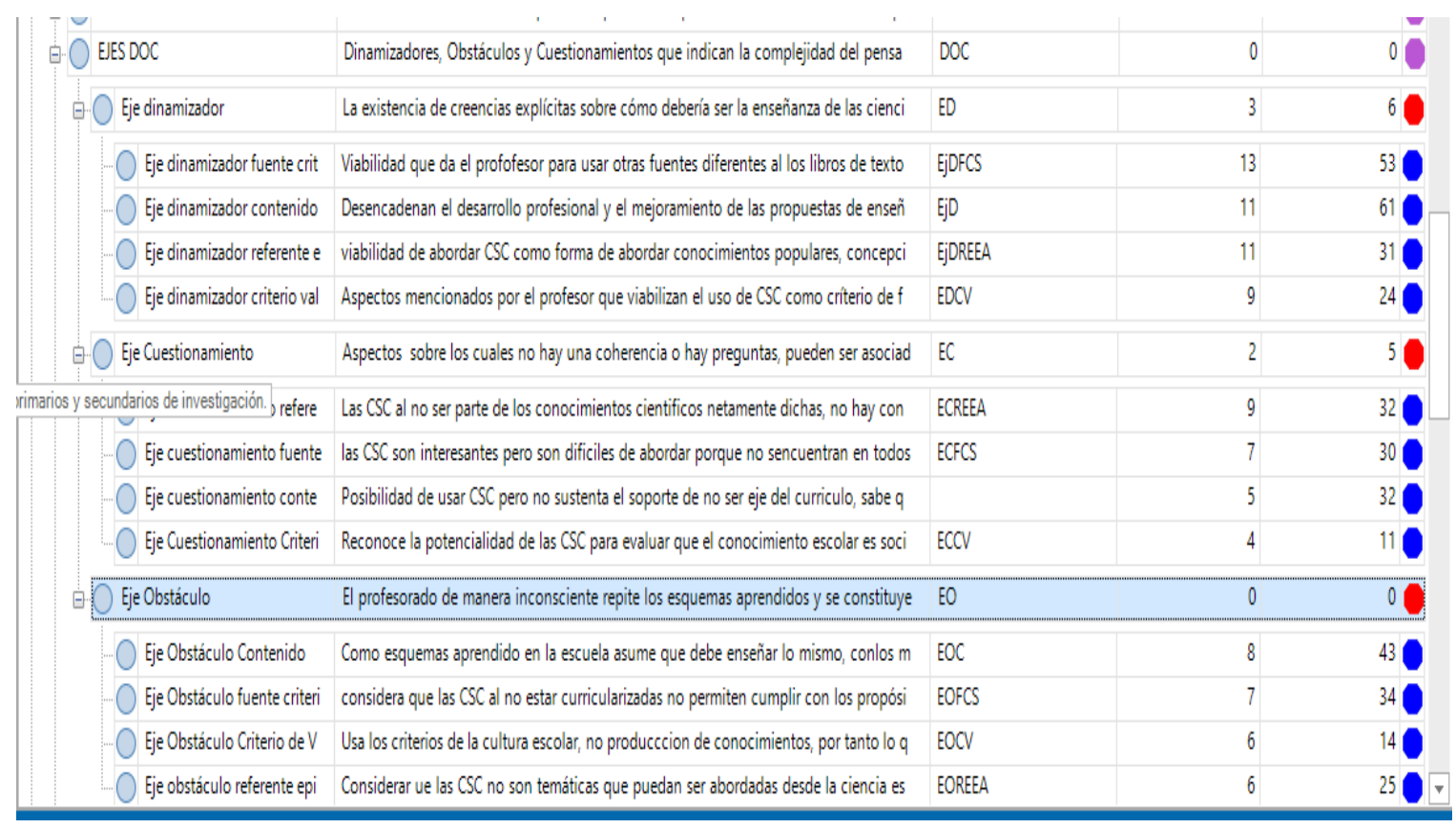

Figura 63. Categorías (nodos) asociados al CPP como ejes DOC Fuente NVivo11 proyecto CPP al asumir CSC-CTSA en la IUE

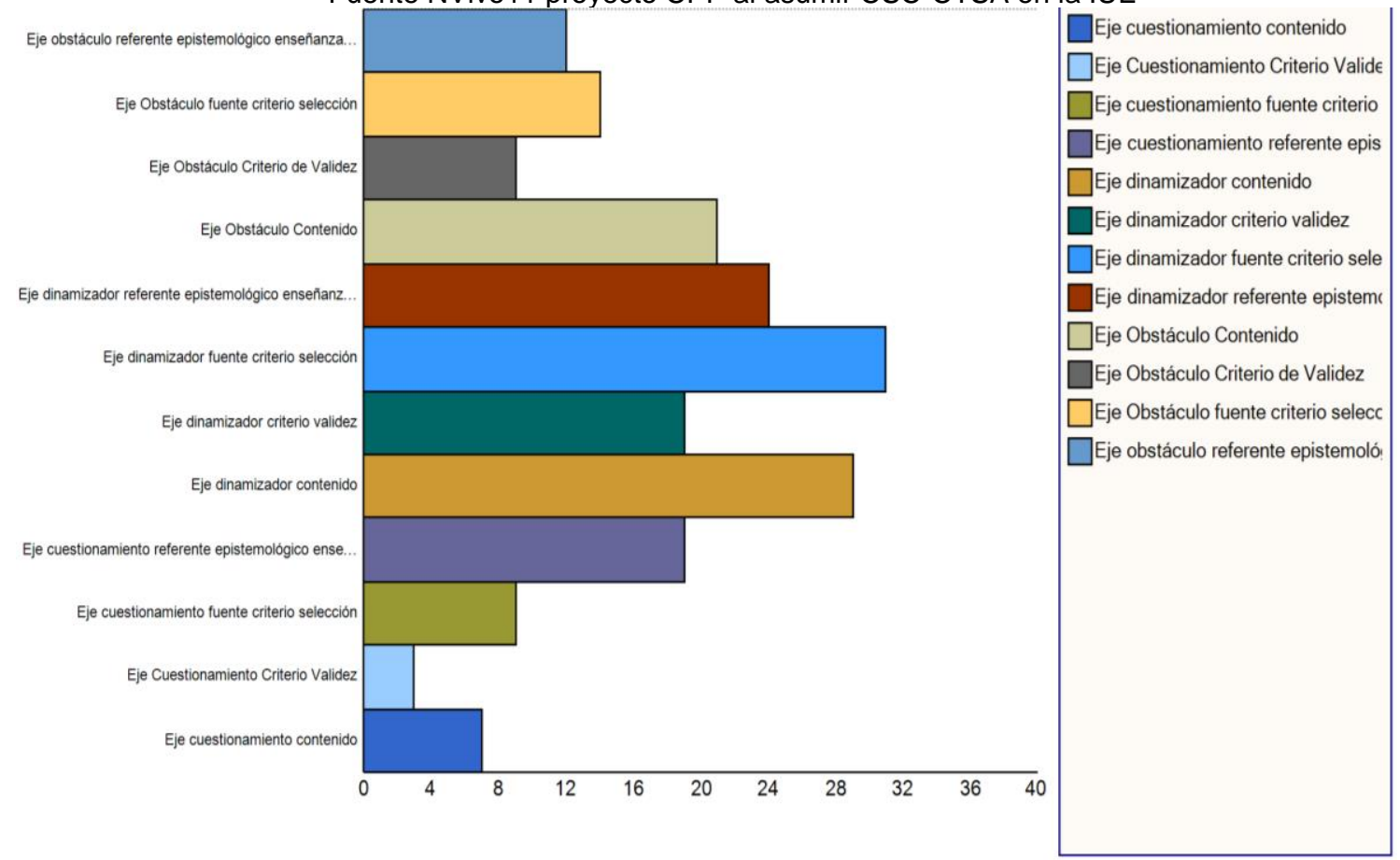

Número de referencias de codificación

Figura 64. Ejes DOC

Fuente. NVivo11 nodo ejes DOC 
Los ejes DOC según Ballenilla (2003), Martínez (2016), Martínez \& Valbuena (2013) y Martínez \& Martínez (2012) permiten al investigador dar razón de la complejidad del CPP, en este sentido, al abordar las CSC, estas inciden en el CPP en forma dinamizadora en mayor proporción, sin embargo son dinamizadores de criterios de selección y de referentes epistemológicos posiblemente por las características inherentes a las CSC (Martínez, 2014), las cuales se articulan a la racionalidad científica, al desarrollo tecnológico y a la participación social acorde a los propósitos educacionales de la Enseñanza de las Ciencias.

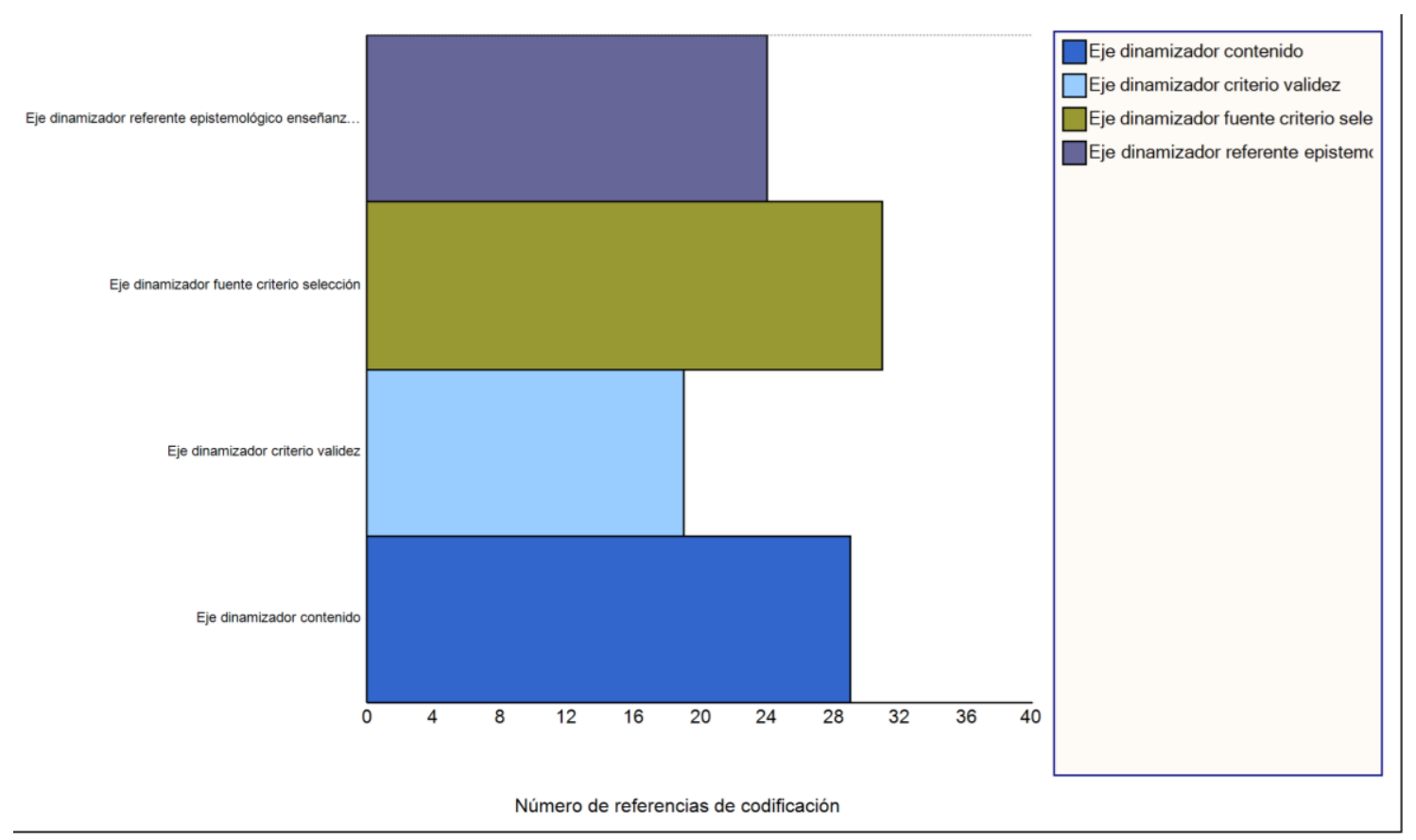

Figura 65. Eje dinamizador del CPP Fuente NVivo11. Ejes DOC

Como lo evidencia una de las intervenciones de un profesor del Gl, al ser seleccionado como contenido:

me pareció muy interesante además de los contenidos la forma en que se emocionan los estudiantes, tanto por esos temas trabajados como por socializar lo que realizaron para indicar la importancia del páramo, del río, del humedal, de cómo son afectados cada uno de esos territorios por problemas económicos, sobre el uso de la minería, por todas las dificultades que se presentan en nuestro diario vivir; de esta manera empezaron a hablar de sitios, que querían conocer, o al menos los planteados en su discurso, se mencionó la necesidad decir a conocer el páramo por ejemplo. 
Como fuente de criterio de selección, como lo indica la intervención de otro profesor del Gl:

La primera actividad que el hago es una autobiografía, bueno, yo traigo un esquema para conocer los lugares de donde vienen, caracterizar los hechos más importantes haciendo preguntas claves y luego les digo que redacten su autobiografía y luego que lea y así que se caracterizó a cada uno de los estudiantes, conozco sus problemas, de tal manera que me permita acercarme a él y poder establecer diálogo con él.

Los ejes obstáculo, que fueron los que se identificaron en orden de complejidad, indican un predominio de las concepciones procedimientos o actitudes que no posibilitan el CPP (figura 66), es decir que su CPD tiene mayor incidencia al igual en el desarrollo profesional y la toma de decisiones para planear el trabajo del aula, en este sentido encontramos que el mayor obstáculo que encuentran al asumir las CSC, es precisamente asumirlas como contenido, para Levison corresponde al profesor que tiene como fuente de conocimiento el corpus de la ciencia, indica el desconocimiento del profesor al no encontrar fuentes fijas de contenido, las CSC las viven están inmersas en ellos, pero ni ellos mismos las pueden afrontar, les causa inseguridad y asumen perdida de rol (Levinson, 2006).
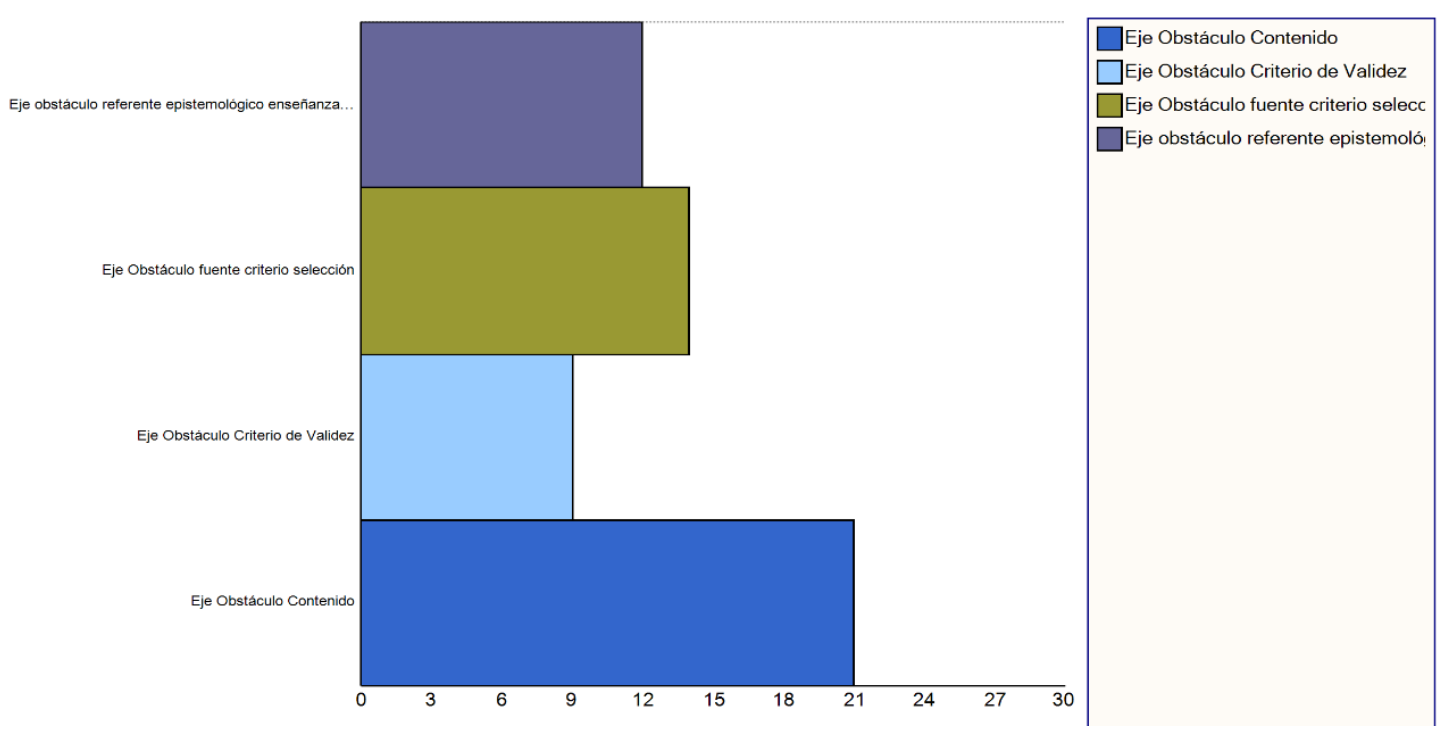

Figura 66. Eje Obstáculo en el CPP al abordar CSC/CTSA en IUE Fuente NVivo11 categoría ejes DOC 
Igualmente, los profesores que no dan viabilidad al abordaje de las CSC como ejes articuladores, le ven a las mismas una función utilitarista, de ejemplificación de la temática, para ellos el conocimiento disciplinar es lo esencial, como lo afirma un profesor del Gl:

La mayoría de estas CSC son viables en la aplicación, y de hecho hay muchas aplicaciones de la matemática en todas las áreas especialmente en ciencias, pero primero toca hacer el ejercicio

Ahora, los ejes de cuestionamiento, que indican fisuras que impiden cambios 0 movilidad del CPP al abordar CSC se aprecian en la figura 68, en la que se evidencia que al abordar estas temáticas, los profesores no tienen los referentes epistemológicos del conocimiento, es decir, para ellos su única fuente de conocimiento es el que tiene la ciencia positivista, la que se debe incorporar en la mente de los estudiantes, y ser asumida como un dogma de fe, en la que el profesor representa la autoridad científica para decir si está bien o mal (Levinson,2008). Sin embargo, estos ejes de cuestionamiento, al ser develados, socializados al interior del Gl podrían ser discutidos y confrontados, de tal manera que los pares académicos puedan plantear el abordaje de las mismas y posibilitar la movilidad de pensamiento del profesor.

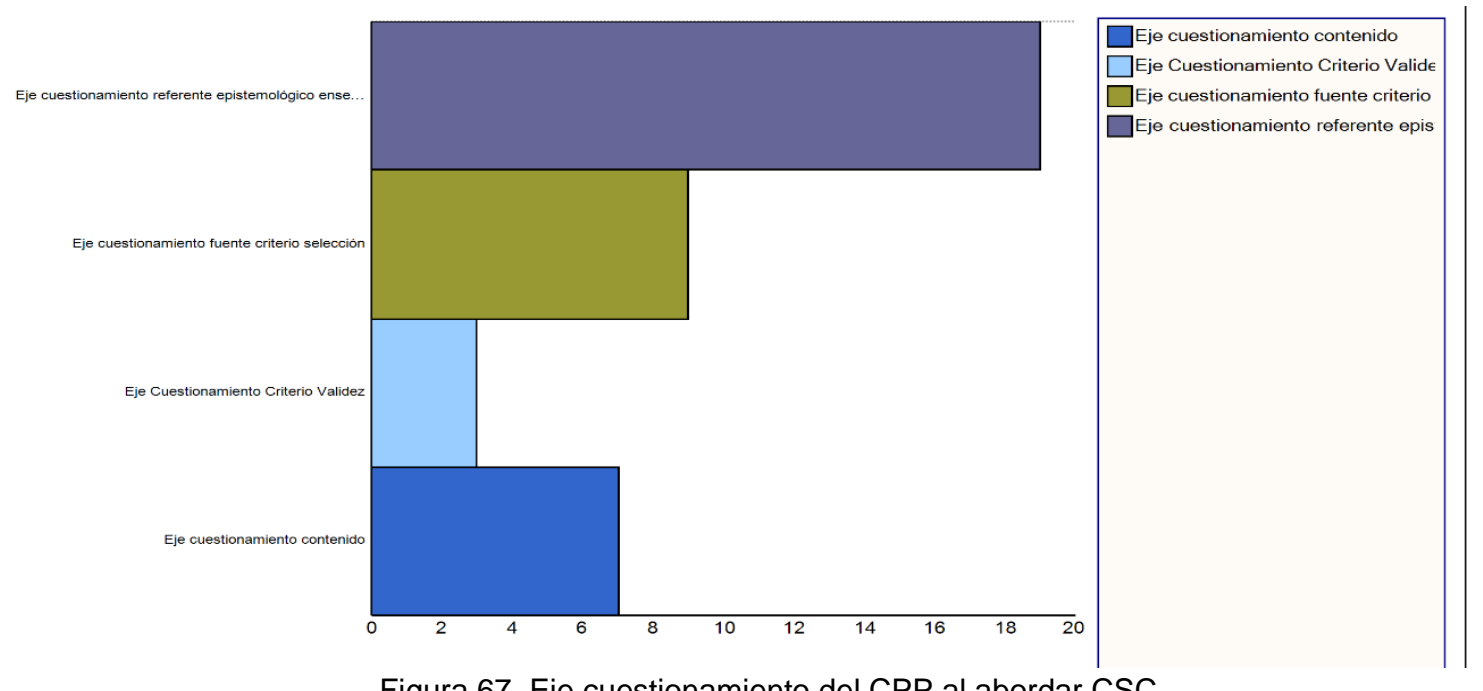

Figura 67. Eje cuestionamiento del CPP al abordar CSC

Fuente: Ejes DOC Software NVivo11 
Una de las intervenciones de un profesor del GI, muestra los cuestionamientos que hace al abordar CSC, y que constituye un cuestionamiento de referente epistemológico.

lo que más ha dificultado, no sé cómo decirlo, lo que hemos estado haciendo por grupos, porque es difícil encontrar relaciones entre nuestro propio currículo y ahora, el releer el propio plan curricular con el de ciencias es más dispendioso, sin embargo, vemos que hay mucha relación entre ciencia y tecnología

En este sentido los ejes DOC se constituyen en una herramienta para los investigadores en el campo del CPP, son los puntos críticos de control de calidad de un proceso científico y tecnólogos (PCC) con los cuales se pueden establecer rutas de formación que permiten al profesor investigador orientar sus prácticas investigativas, especialmente en la formación de profesores para que como el médico pueda controlar, diagnosticar e innovar en este campo.

Los profesores del GI al abordar las CSC consideran que son dinamizadores del CPP porque permiten la reflexión, desde sus prácticas de aula y se constituye en un CV porque permiten desarrollar el pensamiento crítico, que se aborda desde las dificultades de los estudiantes, lo que las establece como motivantes e interdisciplinares. Las CSC permiten desarrollar diferentes mecanismos de participación, tener fuentes de información mediáticas, están en la vida de las personas, algunos las llevan puestas otros están inmersos en ellas, otros las visualizan como enfermedades sociales, pero en conclusión brindan al docente un mar de posibilidades, cada uno puede elegir acorde a sus saberes, criterios e interés de formación y de contextualización (Figura 68).

Entre los dinamizadores que podrían movilizar el pensamiento del profesor están los procesos de reflexión que se generan al abordar CSC, las fuentes estadísticas e informativas basadas principalmente en los medios de comunicación y que por el hecho de estar al alcance de todos son una FCS-IT siempre y cuando el profesor evalúe críticamente la pertinencia de los mismos; las problemáticas asociadas a 
las CSC, el acompañamiento y papel de la universidad, el contexto, la controversia entre lo legal e ilegal.

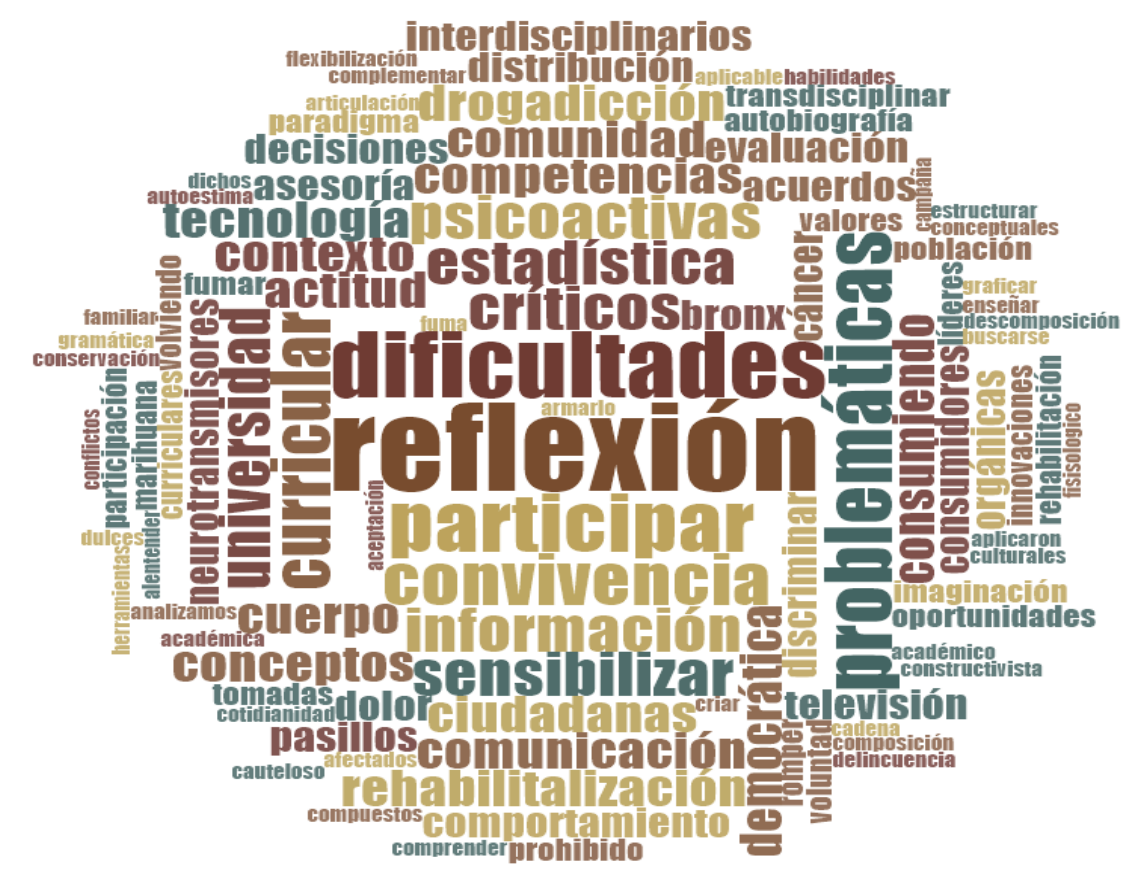

Figura 68. Frecuencia de palabras codificadas como ejes dinamizadores del CPP Fuente NVivo11

Uno de los mayores obstáculos mencionados por los profesores al abordar las CSC, es la tecnología, ya que como docentes del siglo XXI, este tema debería hacer parte de sus saberes disciplinares básicos; sin embargo, la mayor parte de los profesores del GI no usan las TIC, alguno solamente tiene correo personal, pero generalmente lo abren con ayuda de terceros, sus habitus institucionalizados no les permiten reconocer la potencialidad de la tecnología como herramienta esencial que permite el desarrollo del conocimiento Pedagógico y tecnológico del contenido (TPACK) como parte de ese CPP. En palabras de una profesora del Gl:

[...] otra problemática adicional es el manejo de algunas herramientas de tecnología, ya que ellos no saben, desconocen las mismas, entonces, como los profesores no saben usar la tecnología, eso me ha permitido acercarme a los profesores porque cuando ellos se les toca a presentarle las unidades didácticas, yo generalmente estoy como con ellos en cada una de las áreas y me toca mostrarles recursos, videos, que ellos pueden seleccionar acorde a sus propios contenidos. 
En síntesis, como se observa en la figura 69 los principales obstáculos asociados al abordaje de las CSC por los profesores están en el desconocimiento de la tecnología, los contenidos de la propia CSC, el cumplimento al currículo, el contexto en el que se labora, el hecho de tener que motivar a los estudiantes a tomar decisiones cuando era tema de sociales, la respuestas a las evaluaciones externas (ICFES), los estándares de evaluación, el manejo de temáticas como la droga que pueden ser contraproducentes tanto para el estudiante, como para la seguridad del profesor, el manejo de los medios de comunicación como fuentes y criterios de selección.

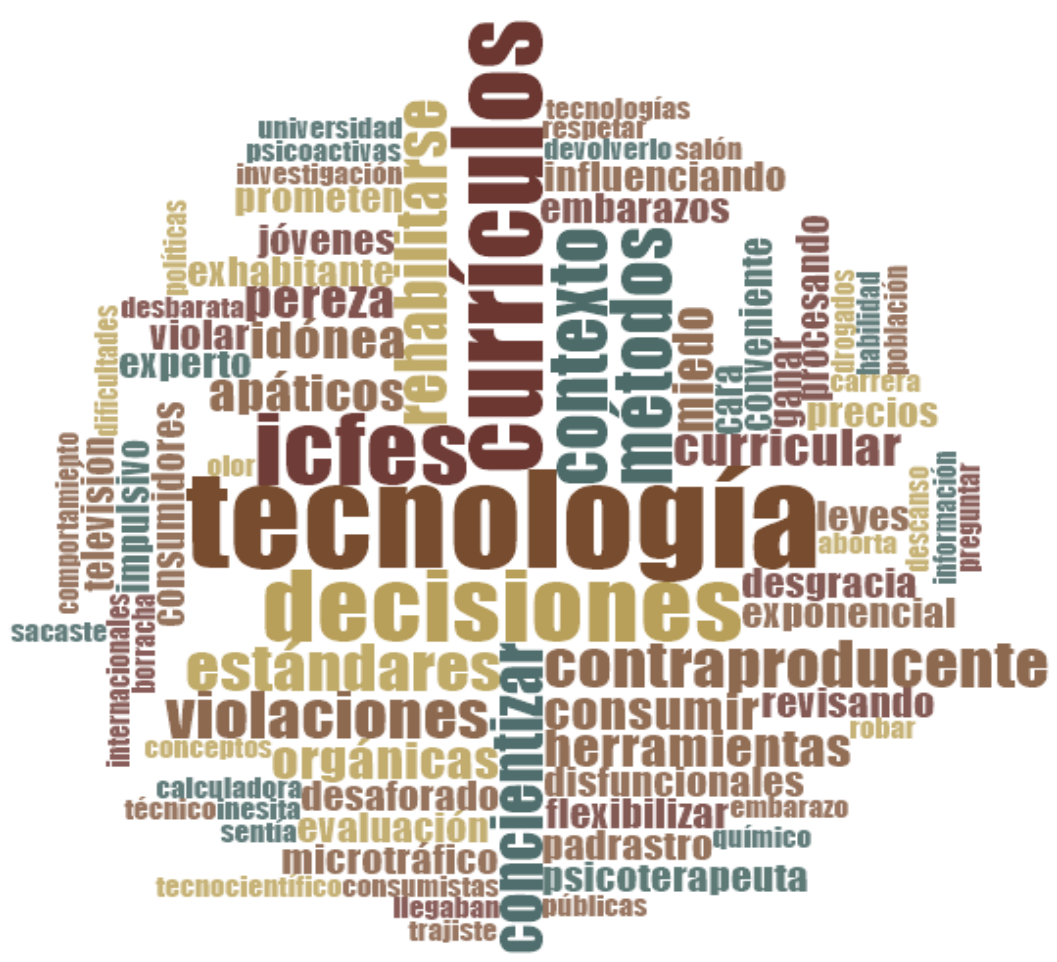

Figura 69. Eje Obstáculo del CPP al asumir CSC Fuente NVivo11

En cuanto a los ejes cuestionamiento, se puede apreciar en la figura 70 que los que más causan fisuras en la CPP son la tecnología y la universidad, la tecnología se identifica como eje obstáculo y como cuestionamiento, porque como lo menciona el profesor en su intervención, si los profesores la usaran y conocieran las bondades de la misma sería una fuente de criterio de selección e incluso un referente epistemológico. En palabras del profesor: 
El desarrollo tecnológico es una relación directa con el avance científico, especialmente en el manejo de drogas, sin embargo la vivencia la ven más los estudiantes con la tecnología del uso del celular, ya que la usa en forma incorrecta, a través de él consulta nuevas formas de consumo, nuevas drogas, está actualizado en ese mercadeo de la droga, posiblemente porque en nuestras mismas clases no motivamos a usar este aparato tecnológico en forma adecuada, de consulta, de investigación, se podría hacer uso de esta tecnología en el aula y profundizar en la consulta de temáticas propias de la CSC a trabajar, que no están en los textos o como dije antes acceder a los noticieros.

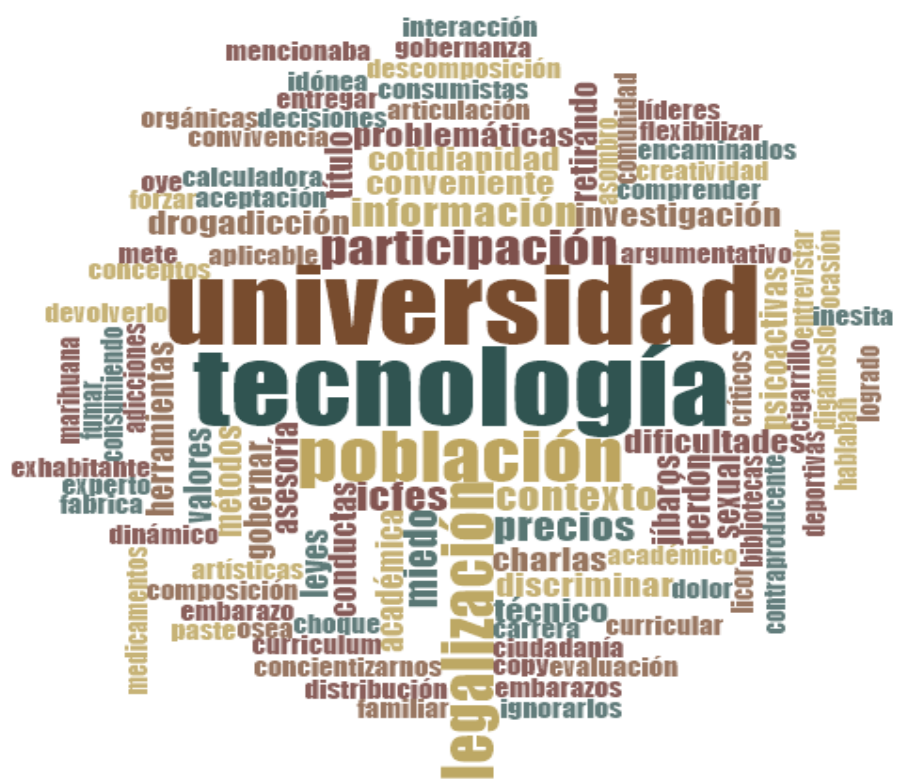

Figura 70. Eje Cuestionamiento del CPP al abordar CSC Fuente NVivo11

\section{La Universidad, es un referente de cuestionamiento porque algunos ven la intervención de la misma como ayuda siempre que le ofrezca posibilidades de interacción, en la que juntos se benefician como menciona la profesora:}

Cuándo nosotros como docentes, volvemos a veces la enseñanza de una forma muy rutinaria y olvidamos esa creatividad que debería ser el proceso escolar, entonces cuando viene los de la universidad, uno recuerda, retoma y vuelve nuevamente a querer innovar, hacer cosas diferentes, o se vuelve uno como más dinámico y se ve en las clases, porque no es que uno muchas veces no sepa, sino que a veces se deja llevar de la rutina, de hacer lo mismo de siempre, aparte nos enseña a aproximarnos a los estudiantes, a sus conocimientos, acercándonos a esa misma cotidianidad que están ahí, pero que a veces está muy lejos, se vuelve está muy familiar en el lenguaje que utilizan, aparte nosotros ya llevamos muchos años en el aula y si es bueno que gente joven venga refrescado y aproximándose con nosotros no solamente en conocimiento sino también en experiencias. 
Sin embargo, para otros la función de la universidad debería ser:

acompañamiento al docente del colegio en el diseño de sus propias herramientas, que ellos diseñen y los profesores lo usen en clase.

Para este profesor, la universidad es la que investiga, devela el viejo paradigma que está acostumbrado y el docente de aula ejecuta; otros docentes opinan lo contrario:

Sería mejor que se realizara en conjunto, en acompañamiento de la universidad y así diseñar nuestras propias herramientas.

Combinación de información entre la universidad de la escuela compartiendo herramientas para que la formación sea en conjunto.

Que muestra un proceso de formación de profesores en IUE, donde cada uno de los participantes asume responsabilidades como pares académicos, estableciendo diálogos horizontales, en los que las relaciones de poder están reguladas y legitimadas por el respeto, el reconocimiento de los saberes de cada campo de formación.

Finalmente, en la figura 71 , se visualiza que los ejes obstáculo identificados cuando el profesor aborda CSC, hacen que el estilo de pensamiento del profesor asuma las características de un EP no transformador (Fleck, 1979; Fleck,1971,1986), que para Martínez (2017) correspondería a un nivel tradicional; mientras los ejes cuestionamiento se presentan cuando el profesor da viabilidad, pero encuentra que las fuentes y criterios de selección están asociados a procesos de formación, los cuales debe trabajar como par académico, tener tiempo para abordarla de forma crítica, evaluar las FCS, determinar los CVL-CSC y los RE asociados; ejercer su función como profesional, no asumir la del proletario; estructurar el currículo, asumir posición crítica y evaluar su permanencia en un determinado EP, especialmente los que le impiden ejercer su trabajo como profesional (EP no transformadores o EP confort); además, de ser consciente de sus progresiones y regresiones a la luz de una HdPR en un espacio de formación como son las asociaciones libres y los ejes dinamizadores, que permiten al docente consolidar un EP transformador, cuando ha permanecido en 
ese estado de complicación, de incertidumbre, en el que la armonía de las ilusiones se fractura y se debe asumir nuevos EP.

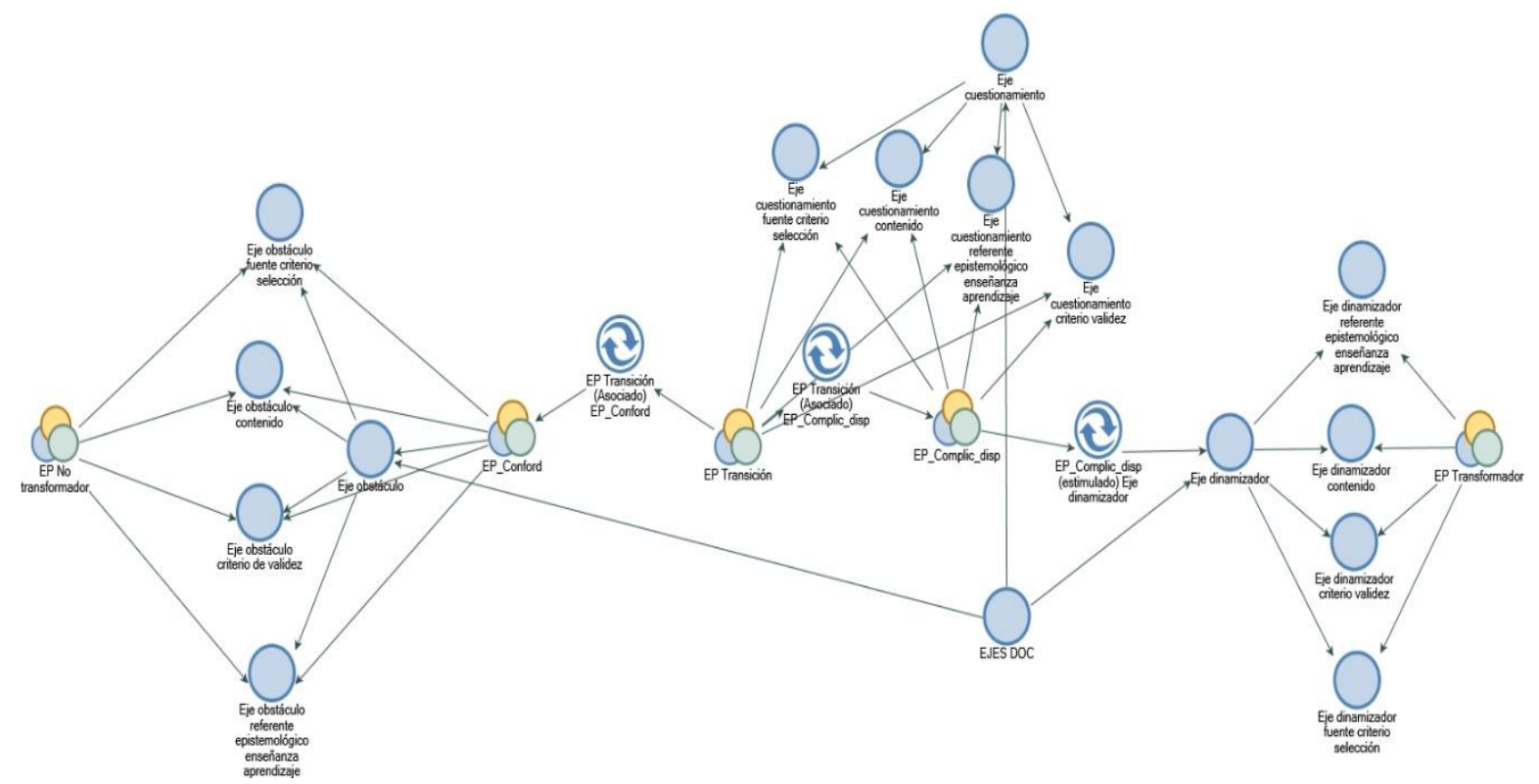

Figura 71. Ejes DOC complejidad del CPP al asumir CSC

Fuente NVivo 11

Una vez analizadas las categorías iniciales, se empieza a visibilizar que las características de las CSC asociadas a las categorías, anteriores y siguiendo a la fase tres del ATD (captando el nuevo emergente) permiten comprender y caracterizar otros aspectos del CPP, que están asociados a la formación ciudadana, a los criterios y propósitos de enseñanza de las ciencias y como Strieder (2012) plantea, al establecimiento de relaciones CTSA (figura 24).

En este sentido se encontró que cada una de las características de las CSC es utilizada en las SD, en los talleres que presentan los docentes y en el discurso de los mismos, y que por tanto, aportan al CPP como se aprecia en la figura 72. 


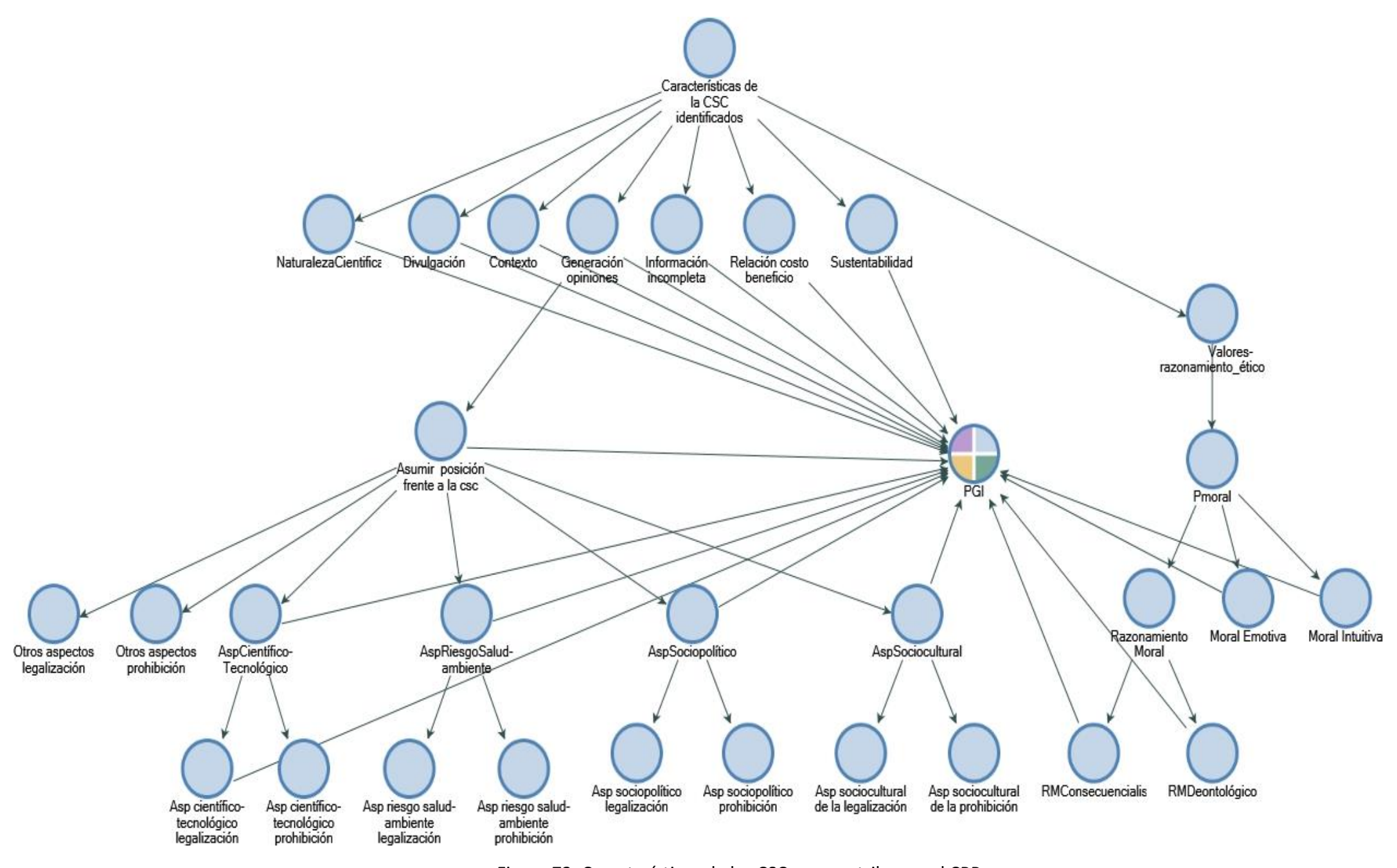

Figura 72. Características de las CSC que contribuyen al CPP Fuente Nvivo11 


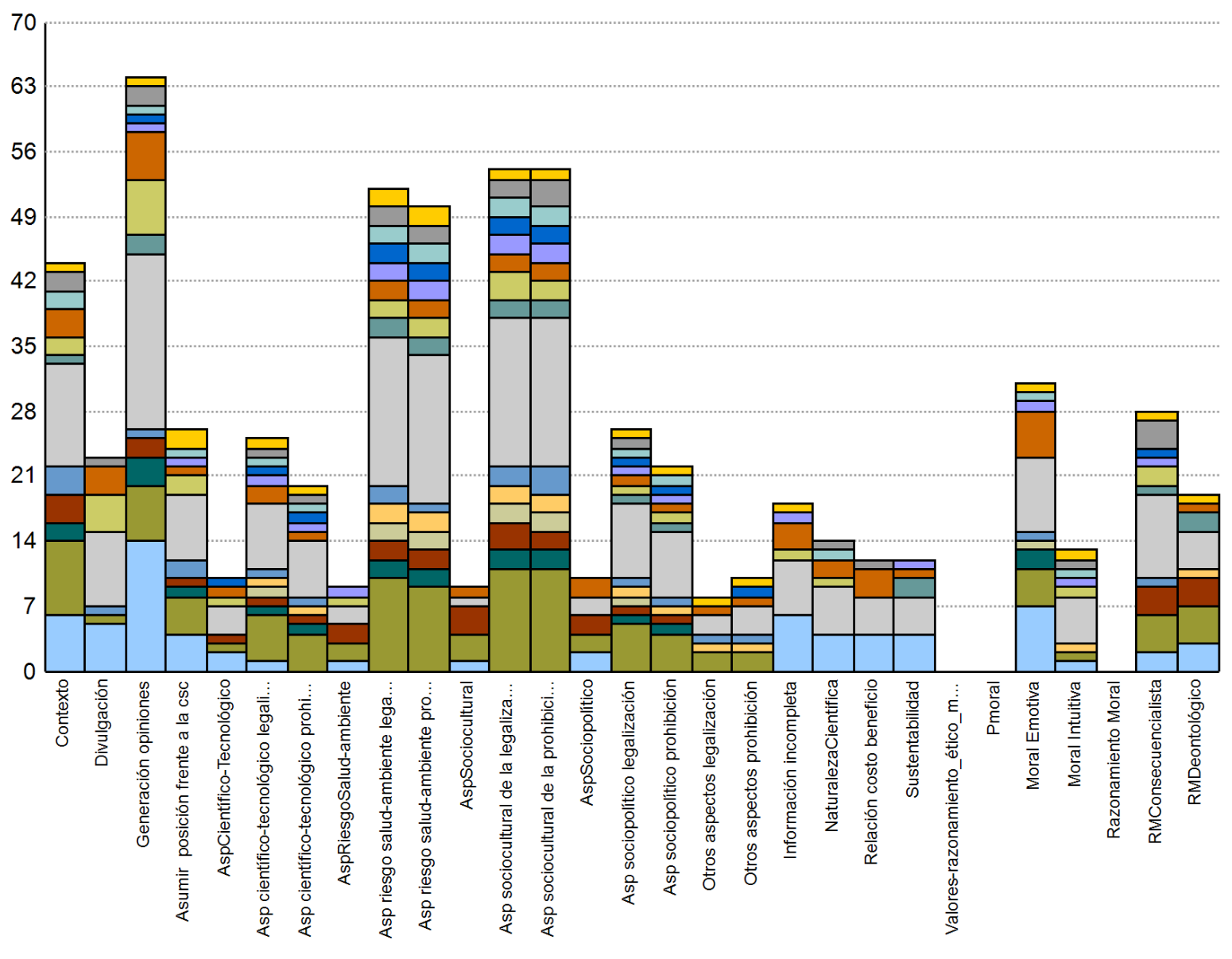

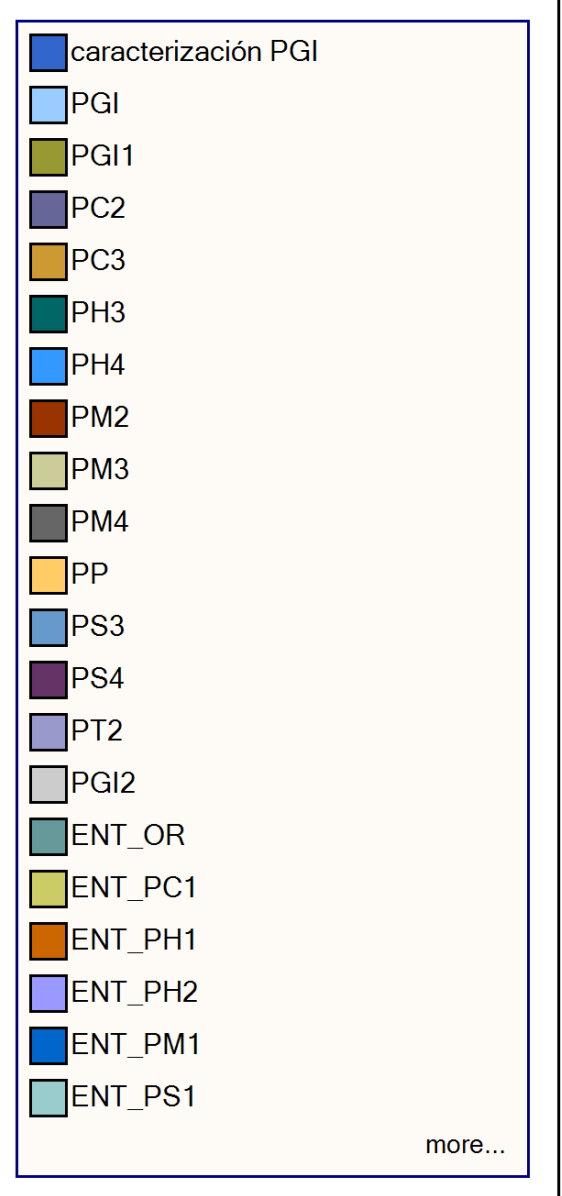

Figura 73. Características usadas con mayor frecuencia por los profesores del GI Fuente. Nodo Aportes - características de las CSC 
En la figura 73 se aprecia, que la característica más abordada por los profesores es la de generación de opiniones, aludiendo a la racionalidad científica que muestra la naturaleza incompleta de la misma, a la consideración de las CSC como conocimiento de frontera, su naturaleza controvertida y a las posibilidades de probabilidad y riesgo que abarcan; otra característica más utilizada es la que tiene que ver con las características socioculturales y de riesgo la salud y al ambiente.

La figura 74 y 75 permite identificar UA/RA en todo el corpus de la investigación y evidenciar que el Gl cuando aborda una discusión, debate, plantea una SD, elabora un taller o socializa una actividad para realizar con los estudiantes, toma como referentes dichas características para desarrollar o abordar la CSC, así como se muestra en la tabla 16.

Tabla 16. Intervenciones de los profesores del GI en las que se identifican las características de las CSC

\begin{tabular}{|c|c|}
\hline $\begin{array}{c}\text { Características } \\
\text { de las CSC }\end{array}$ & Intervenciones de profesores del GI \\
\hline $\begin{array}{l}\text { Naturaleza de la } \\
\text { ciencia }\end{array}$ & $\begin{array}{l}\text { Como el tema de la seguridad alimentaria, que involucra desde el manejo del } \\
\text { clima para la cosecha, lo religioso, cultural, mitos, los daños globales, por el } \\
\text { uso de agrotóxicos y manipulación de semillas, toda la ciencia y tecnología } \\
\text { que ha incidido en el desplazamiento de la mano de obra. }\end{array}$ \\
\hline Divulgación & $\begin{array}{l}\text { Inclusive con las noticias, el uso de las mismas en la clase, con el } \\
\text { periodismo, la televisión, por radio y redes que el chico tiene que ver porque } \\
\text { cuando se hace la construcción de oraciones, se mencionan noticias de } \\
\text { actualidad, se les dice. El presidente de los EE UU fue elegido por el pueblo... } \\
\text { Ellos empiezan la construcción de oraciones que se han dejado incompletas } \\
\text { y luego se les dice, donde está el sujeto, el predicado, el complemento, } \\
\text { etc., y se inicia la reflexión, de quien es el personaje, que aspectos conocen, } \\
\text { que opinan de los mismos, etc. }\end{array}$ \\
\hline Contexto & $\begin{array}{l}\text { Realmente tenemos que aceptar la realidad y esa es la realidad de nuestra } \\
\text { escuela, de nuestra sociedad y tenemos que aceptar la clase de muchachos } \\
\text { que tenemos, todos queremos tener estudiantes perfectos, que vengan a } \\
\text { estudiar }\end{array}$ \\
\hline $\begin{array}{l}\text { Generación de } \\
\text { opiniones }\end{array}$ & $\begin{array}{l}\text { Trabajar con cuestiones sociocientíficas, ya que hay mitos, como en el caso } \\
\text { de la droga y cuando se dice que hablar de ellas genera más consumo, } \\
\text { mayor incidencia riesgo de los estudiantes, de los chicos en ese consumo, en } \\
\text { el uso de drogas }\end{array}$ \\
\hline
\end{tabular}




\begin{tabular}{|l|l|}
\hline $\begin{array}{l}\text { Información } \\
\text { incompleta }\end{array}$ & $\begin{array}{l}\text { Ahí voy, vino un psicólogo, nos hizo taller, retroalimentando, pero no } \\
\text { sabíamos si era bueno o no. }\end{array}$ \\
\hline $\begin{array}{l}\text { Relación costo } \\
\text { beneficio }\end{array}$ & $\begin{array}{l}\text { Estamos en un país en este instante caótico, en este momento es un país } \\
\text { caótico. Donde hay muchas cosas confluyendo, un proceso de paz, hay un } \\
\text { problema de narcotráfico, hay un problema de petróleo, hay un problema de } \\
\text { economía que eso finalmente está afectando a nuestras familias. }\end{array}$ \\
\hline $\begin{array}{l}\text { Valores: } \\
\text { razonamiento } \\
\text { ético moral }\end{array}$ & $\begin{array}{l}\text { Se trajo un ex-habitante de calle, les comentó a ellos a "calzón quitao" que } \\
\text { eso no era lo mejor, que había sido bueno, había sido malo, no sabemos; } \\
\text { creo yo que finalmente quedan muchas preguntas, }\end{array}$ \\
\hline $\begin{array}{l}\text { Asumir } \\
\text { posiciones }\end{array}$ & $\begin{array}{l}\text { consideró que la forma cuando discutíamos determinada temática o cuando } \\
\text { trabajamos si la droga debería ser legal o no, aportó muchísimo, porque } \\
\text { muchas veces uno habla de la droga cierto, pero solamente con nuestras } \\
\text { experiencias, lo que dicen los medios de comunicación o como si estuviera } \\
\text { de moda la droga y ya, pero realmente uno está ajeno de todos los } \\
\text { componentes que traen, }\end{array}$ \\
\hline Sustentabilidad & $\begin{array}{l}\text { Ante la emergencia ecológica, cada uno de nosotros debemos minimizar el } \\
\text { consumo de agua y hacer siembra de árboles para trascender. }\end{array}$ \\
\hline
\end{tabular}

Fuente. Nodo características de las CSC Nvivo11

En la figura 67 se observa la que los profesores del Gl dan valor fundamental a los valores éticos y morales que se pueden abordar a través de las CSC, los cuales asocia con los aspectos ligados al riesgo a la salud y el ambiente, la sustentabilidad, la divulgación y la información incompleta de la misma. 


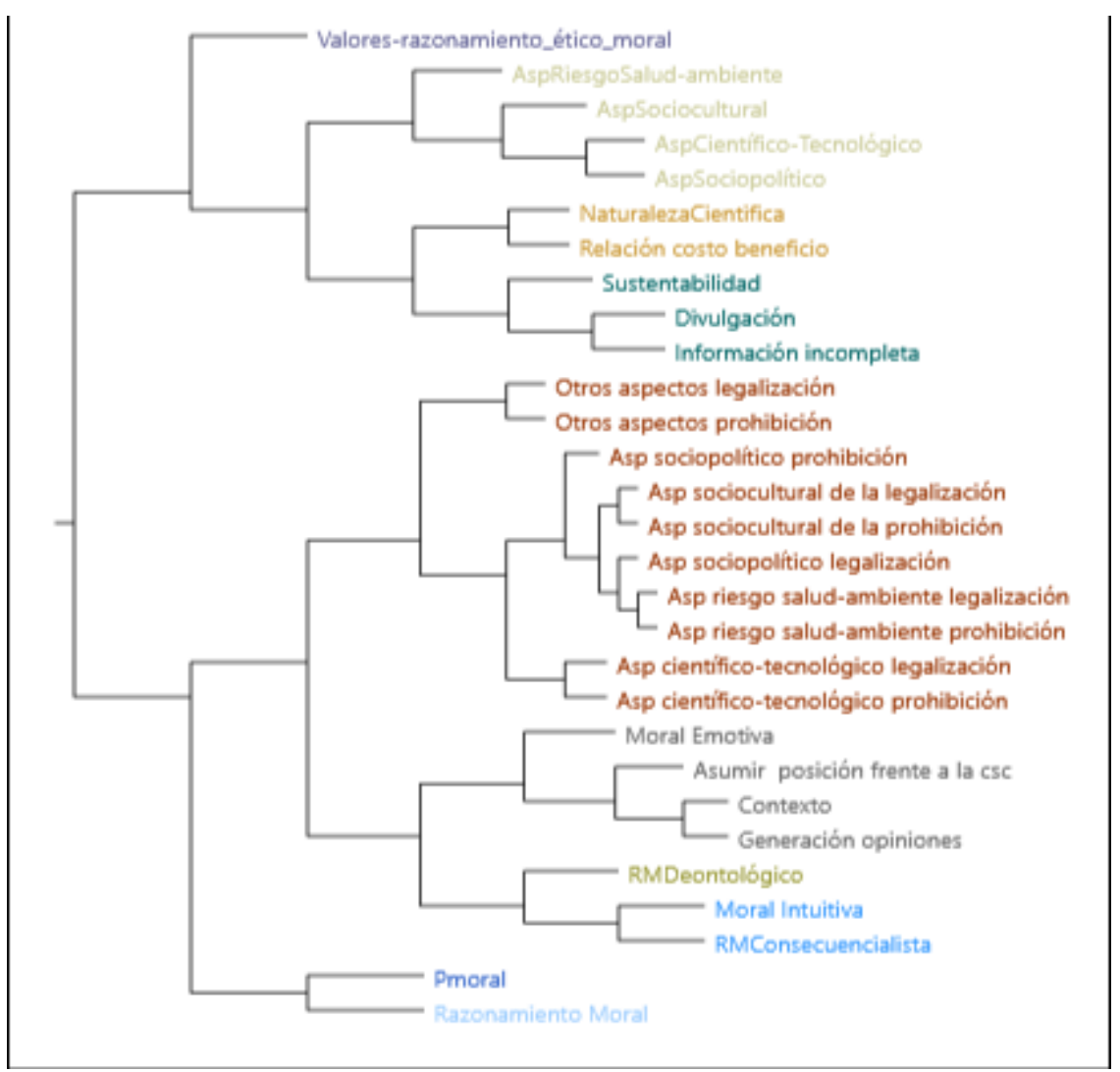

Figura 74. Conglomerados por similitud de codificación de las características de las CSC Fuente: Nodo Aportes/características de las CSC al CPP

Características asociadas a los aspectos sociopolíticos, socioculturales y científico tecnológicos, a asumir posiciones y generar opiniones, son abordadas desde consideraciones asociadas al razonamiento moral.

Cuando el profesor asume posiciones ético-morales, se puede evidenciar qué tipo de decisión aborda a la luz de la moral como razonamiento (consecuencialista o deontológico), como moral emotiva o intuitiva; desde la moral como razonamiento los profesores del Gl son más consecuencialista, seguidos por razonamientos emotivos y deontológicos (Figura 68).

Estas posiciones que asumen los docentes están asociadas a las teorías implícitas como fuente del CPD, posiblemente por sus principios y creencias de tipo religioso, sumado al desconocimiento en profundidad de la CSC abordada, 
pero que, en relación con la racionalidad tecnológica, permite evidenciar las relaciones que establecen los docentes en cuanto a la toma de decisiones y mirada del desarrollo científico-tecnológico desde una posición ético-moral.

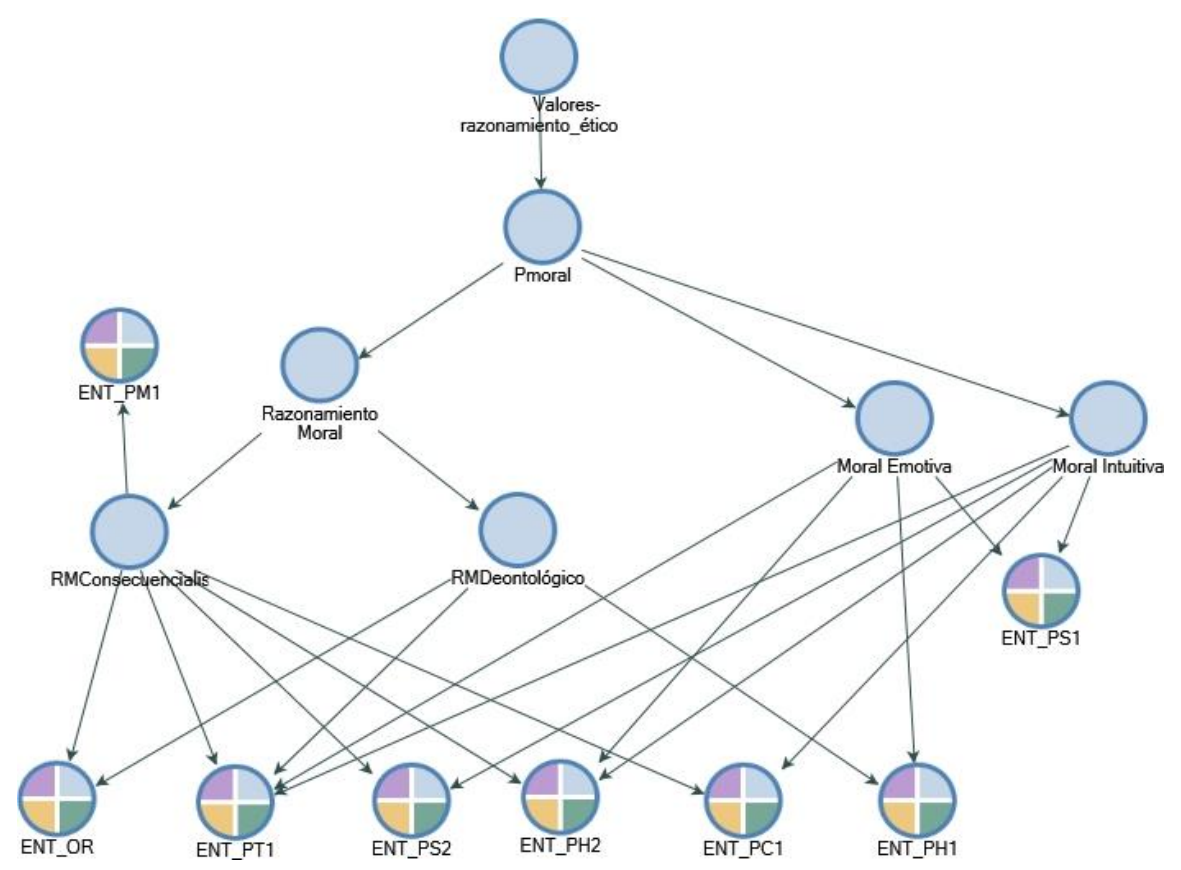

Figura 75. Razonamientos éticos y morales al abordar CSC Fuente. Nodo Características de las CSC

Los profesores dependiendo de la CSC abordada, direccionan la toma de decisiones teniendo encuentra sus emociones, como en el caso del abordaje de la legalidad e ilegalidad de las SPA, la producción/consumo.

Otro aspecto que se pueden encontrar en esta tercera fase de comunicación del ATD, es cuando en el trascurso del proceso de formación, se quiere conocer si ahora, en la marcha identifica que en la escuela se investiga, recordando inicialmente, que en la caracterización le da el papel de la investigación a la universidad y la escuela como simple reproductora (instrumental). 
A través del ATD y con el Software NVivo11 se aprecian los nodos que surgieron de las unidades de análisis alrededor de la concepción de investigación y del ejercicio de investigar en la escuela como se evidencia en la figura 76 , el nodo (categoría) de metodología de Investigación/acción/critica, (tiene 22 registros), este a su vez, presenta dos subcategorías (subnodos): identificación/desconocimiento de la IA, al ser trianguladas a partir de la entrevista focal, de las entrevistas semiestructuradas y del cuestionario de caracterización, adicional a los talleres realizados al interior del Gl, evidencia que identifican los aspectos y características de la IA en su gran mayoría (54 registros/tabla 9), pero que consideran que la escuela no es el lugar para investigar, mencionando las limitaciones que esta tiene; otros en menor número desconocen la IA y la consideran ajena a la escuela (21 registros/tabla 9), la identifican como una actividad del campo universitario.

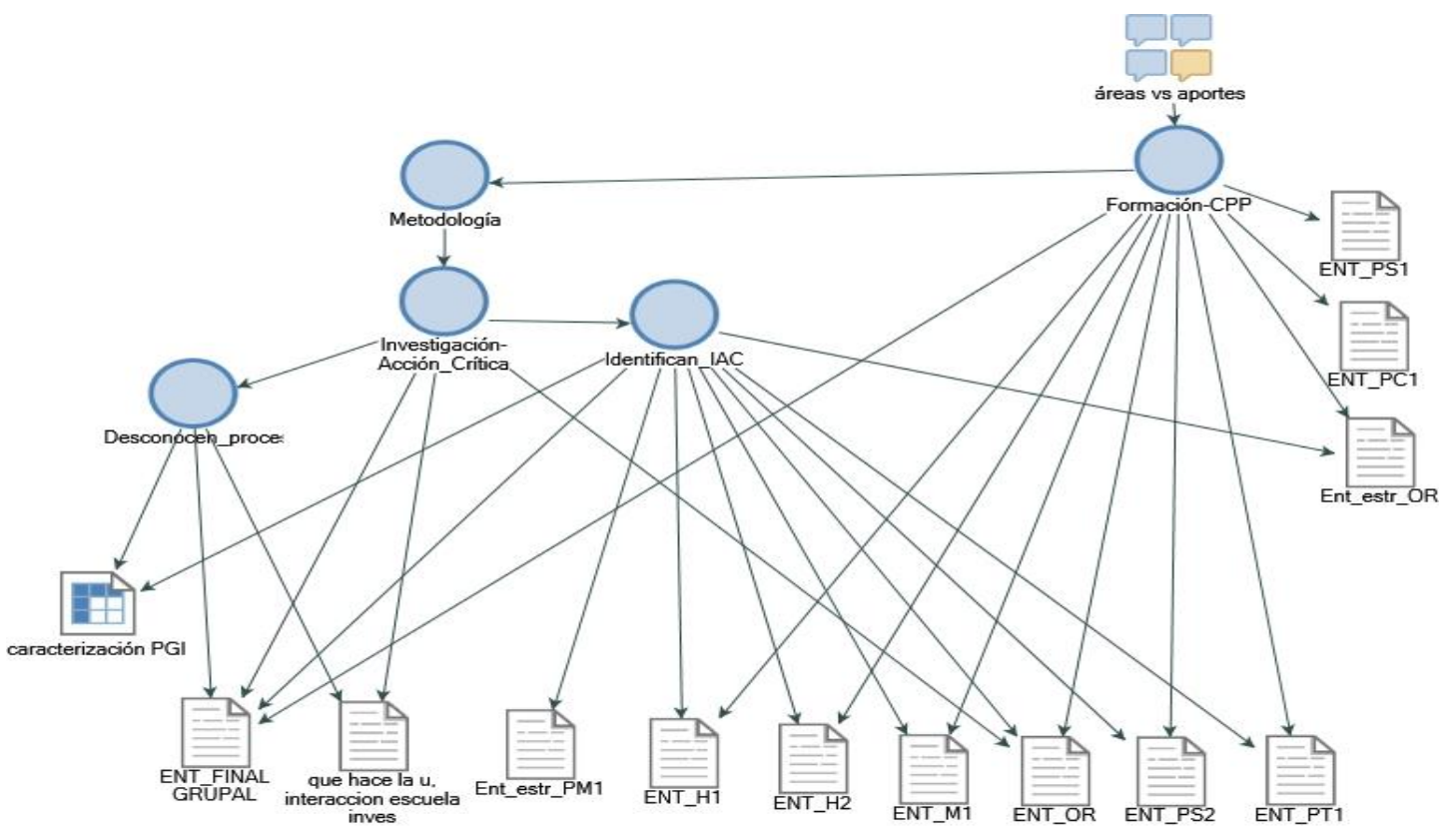

Figura 76. Visión que tiene los docentes del PGI de la investigación Fuente NVivo11 Proyecto CPP al asumir CSC/CTSA en la IUE

La figura 76 visualiza la metodología del proceso de formación de docentes en IUE, en la que al realizar los dos talleres: el primero relacionado con la investigación acción (IA), la contextualización teórica del proceso de formación y el 
segundo de diseño curricular abordando la CSC en torno de la drogadicción (Anexo 5 y 6), muestran que tanto el proceso de caracterización, como en las entrevistas semiestructuradas individuales y la focal consideran en alto porcentaje que realizan actividades de investigación en el proceso de formación y en el abordaje de las CSC, contrario a lo planteado en el proceso de caracterización inicial.

En la caracterización, en un alto porcentaje los profesores mencionan no investigar, ni tener participación en investigaciones en los últimos cinco años $\mathrm{y}, \mathrm{a}$ los que decían investigar no mencionaban que procedimiento empleaban para hacerlo, sin embargo, en la entrevista focal, los profesores empiezan a describir acciones que les permiten dar inicio al trabajo investigativo, comentan como se interesan por una problemática (Int 2), mencionan como a través de ella se planean acciones, se construyen procedimientos y discursos que posibilitan explicaciones y posibles soluciones a la problemática planteada, como se evidencia en sus intervenciones:

Tabla 17. Intervenciones Categoría Investigación

\begin{tabular}{|c|c|c|}
\hline \multirow{6}{*}{ 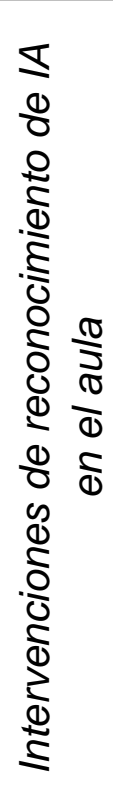 } & Int1 & $\begin{array}{l}\text { Hicimos unos talleres de sensibilización con ellos, que apuntaban hacia } \\
\text { la parte de sustancias psicoactivas, hicimos unos talleres a nivel de } \\
\text { dibujo; cómo nos veíamos antes, cómo nos creíamos ver después de } \\
\text { ese tipo de consumo. }\end{array}$ \\
\hline & Int2 & $\begin{array}{l}\text { Lo primero que hicimos fue mirar un poquito el entorno que teníamos, } \\
\text { que teníamos muchos chicos que estaban consumiendo y de hecho los } \\
\text { tenemos dentro de la institución nos llegan muchos muchachos que } \\
\text { están consumiendo. }\end{array}$ \\
\hline & Int3 & $\begin{array}{l}\text { Segundo que hicimos fue como empaparnos de lo que se estaba dando } \\
\text { a nivel de nuestro entorno. }\end{array}$ \\
\hline & Int4 & $\begin{array}{l}\text { Abordamos varios de los textos y temas, que la marihuana, que el } \\
\text { bazuco, tipos de sustancias psicoactivas. }\end{array}$ \\
\hline & Int5 & $\begin{array}{l}\text { Cada uno como que se apropió de cada una de ellas. Las leímos, las } \\
\text { organizamos por temáticas diferentes, desde su origen, toda la } \\
\text { composición y todas las implicaciones que tenía. }\end{array}$ \\
\hline & Int6 & Luego trabajamos en varias sesiones en grupos. \\
\hline & Ints & Entonce \\
\hline
\end{tabular}




\begin{tabular}{|l|l|}
\hline Int8 & $\begin{array}{l}\text { alrededor de ella, que es la intención de las CSC. } \\
\text { Uno sólo trabajo digamos decían profe y si hago un jabón, pero } \\
\text { utilizando la marihuana, y yo pues "hágale". Y que mire la composición } \\
\text { y mire, sino que después se les envolató la cosa y no dio y traemos la } \\
\text { planta y listo, ¿qué tiene y cómo es y pues sí lo podemos hacer? Y yo, } \\
\text { pues hagámoslo a ver. Una cosa es cuando usted fuma la marihuana y } \\
\text { otra cosa es cuando usted la procesa y la aplica es muy diferente. } \\
\text { Hicimos algunos compuestos. }\end{array}$ \\
\hline
\end{tabular}

Fuente. Unidades de registro NVivo categoría identifican IA

En las unidades de registro, el profesor comenta algunas actividades realizadas en el proceso de formación, que retoma en el trabajo con los estudiantes; no sólo abordando la metodología de trabajo, sino evidenciando cómo surge la necesidad de investigar con problemática vivida (Int2) y cómo se planea el proceso de formación alrededor de la temática; así como el significado de la CSC, sus aportes al ser abordadas (Int 7) y las posibilidades de investigar con los estudiantes en las prácticas de aula (int8).

Si recordamos en el proceso de caracterización el $90 \%$ de los docentes desconocían en enfoque CTSA, en la Int7 el docente menciona los aspectos que tiene en cuenta cuando aborda una CSC, los cuales permiten establecer las relaciones CTSA; de la misma manera menciona la didáctica que emplea para abordarlas, el trabajo en equipo, la formación de especialistas entre los mismos estudiantes, las implicaciones a nivel de salud y posiblemente ambiental en la Int3.

Así mismo reconocen que hacen IA cuando afirman:

Tabla 18. Reconocimiento de actividades investigativas

\begin{tabular}{|c|c|c|}
\hline \multirow{3}{*}{ 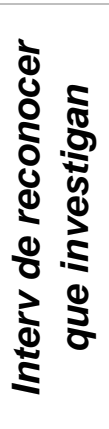 } & Int1 & $\begin{array}{l}\text { Pues de hecho es una investigación de campo es Investigación, Acción } \\
\text { Participativa; }\end{array}$ \\
\hline & Int2 & $\begin{array}{l}\text { investigación-acción básicamente que uno realiza en el aula. } \\
\text { orque se insistió muchísimo que dentro de cada área cómo se } \\
\text { ar esa temática }\end{array}$ \\
\hline & Int3 & $\begin{array}{l}\text { El proceso lector, básicamente se hacia ese trabajo, entonces los chicos } \\
\text { escribían, los chicos buscaban palabras desconocidas, los chicos me } \\
\text { preguntaban, debatíamos lo que ellos escribían. Porque de todas } \\
\text { maneras era investigación-acción de aula y de cada una de las áreas. }\end{array}$ \\
\hline
\end{tabular}


Int4 Estamos haciendo investigación y pues todo el tiempo nosotros hacemos investigación, de una u otra manera, todos somos docentes investigadores porque tu comienzas a mirar esta clase hoy me funcionó, la de ayer me funcionó con este otro grupo. ¿Qué le toca hacer? Mirar que cambias y modificas.

Fuente. Nvivo11 - nodo aportes CSC al proceso de formación.

En la Int4 el profesor se identifica como un investigador permanente, que quiere mejorar, fruto de la insistencia del proyecto de formación del que participó y que, por tanto, para él es vital investigar (Int2), lo menciona y afirma de forma natural, como algo obvio, ya los trabajos no son para que los estudiantes los hagan y aprendan siguiendo el método científico, es para que el maestro también investigue; así mismo, ya no sólo se investiga cuando se está en el laboratorio, ahora cualquier temática es apropiada para ser investigada, así, los estudiantes harán investigación direccionada a los intereses de las temáticas o CSC abordadas y el maestro hará investigación en este caso pedagógica y didáctica.

Otra interpretación de la Int4, es la identificación con el profesor como intelectual e investigador de su práctica, en el modelo de formación en IUE, planteando nuevas investigaciones, nuevas comprensiones y conocimientos desde su práctica pedagógica y didáctica, al mismo tiempo que les permite resolver problemas que le impiden interactuar con sus estudiantes, o al menos compartir formas de solucionarlos con sus pares académicos, pero ya no en términos de premio y castigo sino en términos de reflexión, diálogo y confrontación, de mínimos acuerdos, de respeto y participación; gestándose esta asociación libre, como un espacio para la reflexión, el diálogo entre pares y la construcción cooperativa de conocimientos (Elliot, 1990).

Los anteriores resultados preliminares, permiten afirmar, que en la escuela se empieza a consolidar un campo de formación interdisciplinar como Gl o asociación libre, empiezan a escucharse las voces de los que aun sueñan con una educación crítica y liberadora; ahora en los debates se vive la participación democrática, predomina el diálogo pedagógico, el deseo de trabajar en equipo y evidenciar los 
alcances que han logrado con sus estudiantes y posiblemente, los propios de ser profesor transformador.

Carvalho (2015) menciona que un modelo de formación docente no puede estar centrado únicamente en la escuela o en la universidad, estos deben estar enmarcados en la realización de proyectos comunes que busquen posibles soluciones o requieran ser debatidas y se conviertan en un medio de interlocución.

Para un número menor de profesores la investigación la deben realizar otras entidades como la universidad (Int2); además de considerar el ambiente escolar como no favorable para investigar, posiblemente por las limitaciones que ponen a los mismos (Int1); posiciones posiblemente provenientes de un estado de confort en el que se encuentra el docente y es consciente de los cambios que deben ocurrir para movilizar sus prácticas pedagógicas y didácticas.

Algunos registros que evidencian lo anterior son:

\section{Tabla 19. Intervenciones concepción de investigación}

\begin{tabular}{|c|c|c|}
\hline \multirow{6}{*}{ 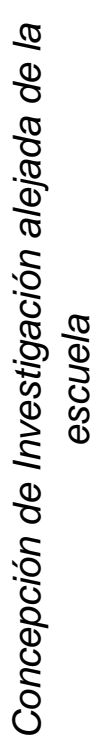 } & Int1 & Investigar si es importante, el lío es que a uno lo limiten. \\
\hline & Int2 & $\begin{array}{l}\text { Mientras que en EU todas las grandes investigaciones las dan las } \\
\text { universidades para la escuela, para las empresas para todo, quien lidera } \\
\text { esa parte investigativa son las universidades; en nuestro país, está } \\
\text { todavía eso muy rezagado. }\end{array}$ \\
\hline & Int3 & $\begin{array}{l}\text { La investigación es investigación como tal y no tiene la verdad absoluta, } \\
\text { siempre tiene la corrección para ir mejorando; pero tenemos que partir de } \\
\text { un punto. }\end{array}$ \\
\hline & Int4 & $\begin{array}{l}\text { Es aplicar un método científico y todo tipo información, con formulación de } \\
\text { hipótesis acerca de cierto fenómeno social o científico que se quiera } \\
\text { ampliar más en la escuela, empleando diferentes formas de investigación }\end{array}$ \\
\hline & Int5 & $\begin{array}{l}\text { Es cuando el estudiante construye conocimiento a partir de las } \\
\text { experiencias del aula. }\end{array}$ \\
\hline & Int6 & $\begin{array}{l}\text { Toda acción conducente a incentivar el cuestionamiento de la comunidad } \\
\text { educativa en relación con un tema específico teniendo resultados ciertos } \\
\text { y medibles. }\end{array}$ \\
\hline
\end{tabular}

Fuente. Nvivo11 Nodo investigación 
Algunos docentes como los que hacen la int4 e int6 están inmersos en el paradigma positivista, en el que todo debe ser medible, tangible y producir conocimientos como axiomas de verdad; es decir, para este docente no existe la investigación cualitativa.

En este sentido, ahora después de hacer un recorrido con la ayuda del ATD y el software NVivo11, podemos establecer la categoría que permite tener una comprensión de la movilidad del CPP, de lo que sucedió al interior del Gl de profesores en el proceso de formación en IUE al asumir CSC con enfoque CTSA en términos de aportes y dificultades, estas primeras comprensiones se realizaron a la luz de una HdPR (figura 40) siguiendo un orden inductivo, ahora haremos un proceso deductivo, siguiendo el mapa obtenido a partir de estas dos categorías como lo muestra la figura 77. 


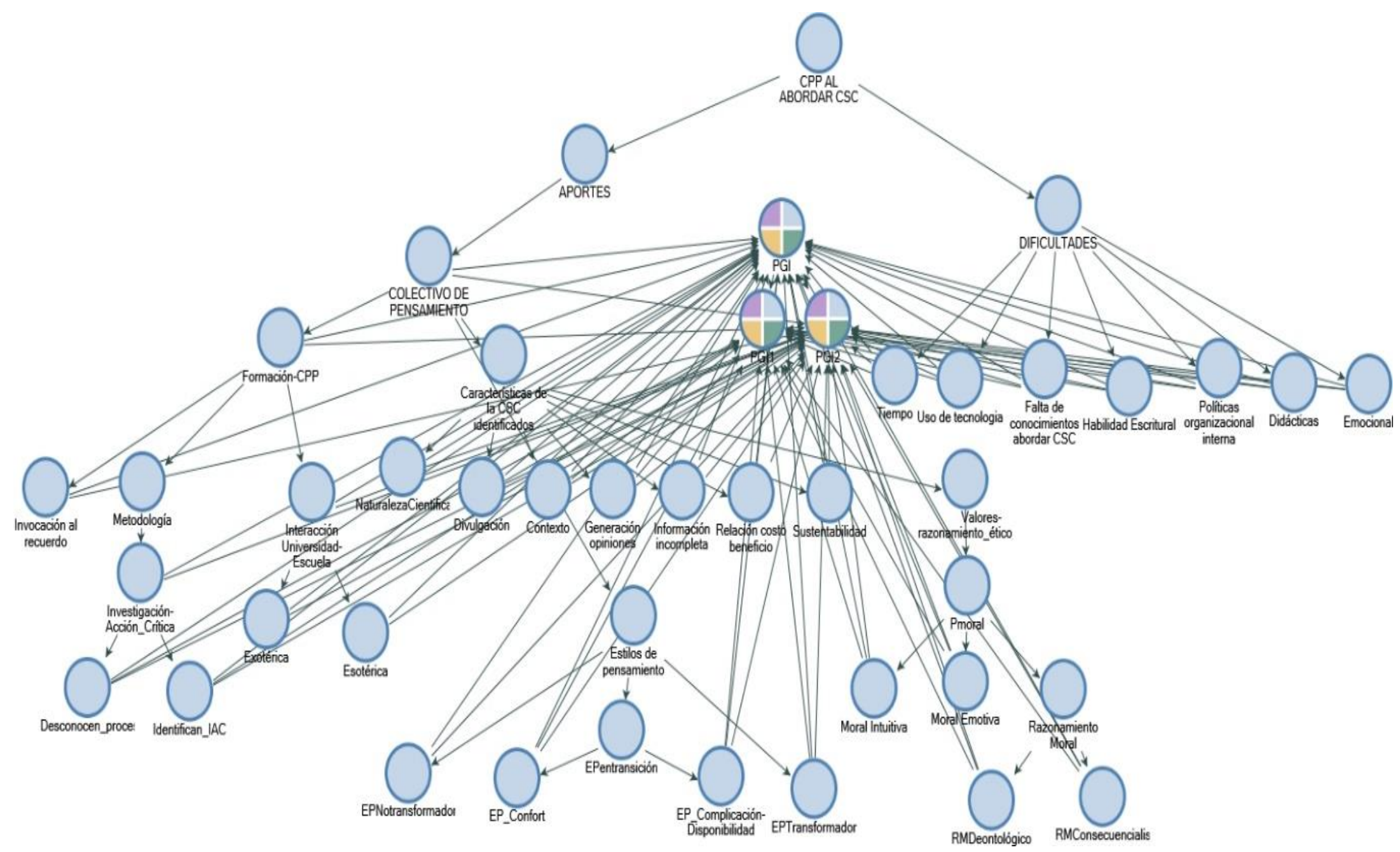

Figura 77. Aportes y dificultades del abordaje de CSC_CTSA en la formación de profesores en ejercicio en IUE Fuente. Nvivo11 Categoría aportes y dificultades 
En este sentido primero hablaré de los aportes (figura 78) mencionados por los profesores a través de la entrevista focal, la semiestructurada y haciendo triangulación con un segundo cuestionario (anexo 14) en el proceso de formación de profesores en la IUE al abordar CSC con enfoque CTSA. 


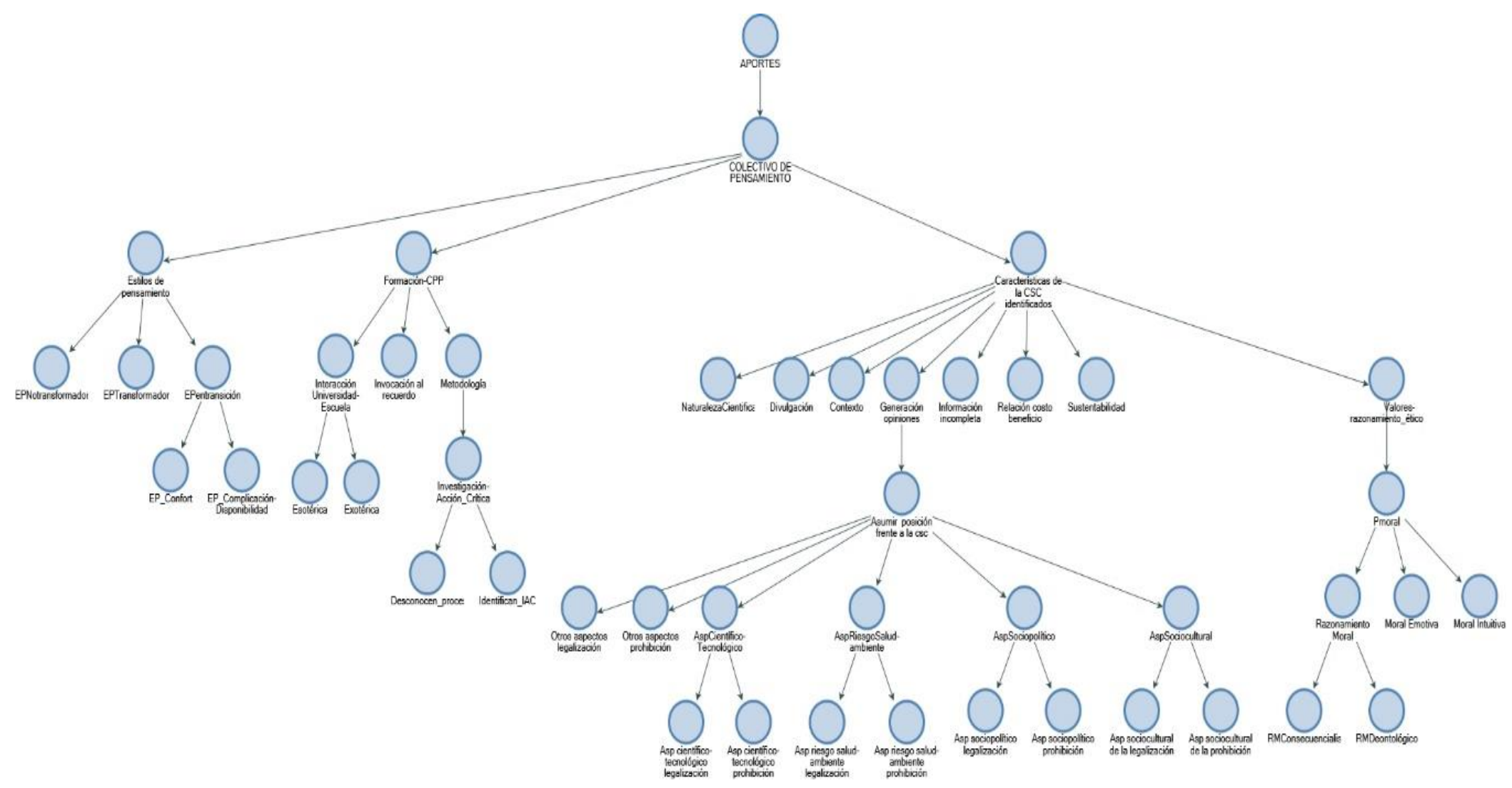

Figura 78. Aportes mencionados por los profesores al participar del programa de formación en IUE Fuente, Software Nvivo11 
Como se indicó que se empezaría a realizar el análisis en forma deductiva, es importante resaltar que uno de los grandes aportes, fue la constitución del Gl, el cual bajo la orientación de la teoría comunicativa de Habermas en el que el principio esencial hace alusión al tipo de relaciones que se establecen entre los integrantes del grupo, allí, como profesores e interlocutores, todos se encuentran en las mismas condiciones para expresar sus puntos de vista e interactuar sin coerción alguna. El lenguaje constituye el medio a través del cual los participantes dialogan de sus comprensiones construidas en el mundo de la vida y representadas en el mundo social, objetivo y subjetivo, en el que se busca que interlocutores establezcan un entendimiento.

Bajo el principio de interlocución en igualdad de condiciones y con la premisa del entendimiento bajo la argumentación como criterio ejemplar para alcanzar el consenso, el Gl, fue construyendo una relación de horizontalidad con la universidad, ya que esta valoraba este espacio educativo conforme sus saberes y experiencias, de las cuales se generaban aprendizajes mutuos. Esta construcción puede interpretarse como una asociación libre en términos de los planteamientos hechos por Habermas (1987), que como organización social en la IUE que propone una convicción práctica, en este caso referida al abordaje de cuestiones controvertidas de interés para los estudiantes y para el propio profesor como investigador. Así; se fue consolidando un espacio legítimo de diálogo entre escuela y universidad, pues, aunque las cuestiones tratadas son propias de la Escuela, su abordaje y análisis es de importancia social para mejorar la formación de los estudiantes en cuanto a ciudadanos reflexivos. La universidad ofrece su tradición académica para interpretar de mejor forma las controversias.

La construcción del GI, bajo la racionalidad comunicativa propia de una asociación libre se constituye como una pequeña esfera pública democrática en términos de los planteamientos de Habermas (1987), porque tiene la intención de orientar las acciones por los principios de igualdad y participación que constituyen una experiencia inicial para intervenir políticamente en la Escuela, tanto en el 
desarrollo de un currículo centrado en los problemas sociales relevantes como en la construcción de prácticas de enseñanza que fomenten un aprendizaje activo de los estudiantes conforme la orientación de los profesores cuyo compromiso con la planeación, la reflexión y la acción de su práctica constituye el ejercicio de su autonomía.

El principio de la construcción de asociaciones libres y de las esferas públicas en la construcción del Gl, también se interrelaciona con los presupuestos curriculares del Programa Colombo-Brasileño en términos de las dimensiones disciplinar, metadisciplinar, pedagógica, didáctica y contextual, tal como es considerado por Parga \& Pinzón (2014). Lo disciplinar es concebido más allá de la selección de contenidos específicos de las disciplinas, pues los problemas sociales y ambientales de la actualidad exigen que el profesor movilice los conceptos de tales disciplinas junto con sus saberes docentes, de tal forma que su enseñanza sea interesante para sus estudiantes en cuento trata de controversias cercanas a sus vidas como es el caso de las controversias abordadas en el transcurso de la formación en la IUE.

Así pues, la teoría de Habermas (1987), asociada a la teoría de Fleck (1986) permite comprender el proceso de construcción y reconstrucción del conocimiento del profesor a la luz de la HdPR (Figura 40), ya que articula el Gl con la idea de CP y así como la de CPP con la de EP. Por tanto, para Fleck (1986) el EP que caracteriza el CPP está influenciado por diversos elementos de carácter personal y profesional que construyó a lo largo de su historia, para Solís \& Rivero (2013) constituye el CPD, durante su formación escolar, del contacto que tuvieron con los profesores que los formaron y con las costumbres propias del sistema escolar en el que estuvieron inmersos.

Otro de los aportes mencionados por los profesores, fue el de la formación en IUE, como se evidencia en la siguiente tabla: 
Tabla 19. Intervenciones de los profesores del GI con respecto a la formación en la IUE

\begin{tabular}{|c|c|c|}
\hline Nodo & Int & Intervenciones \\
\hline \multirow{9}{*}{ 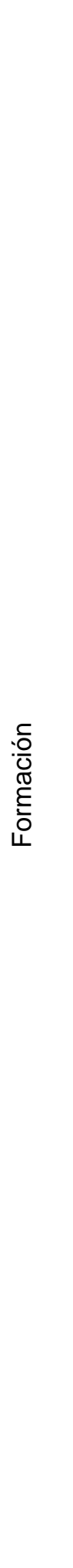 } & Int1 & $\begin{array}{l}\text { El no haber involucrado hace mucho tiempo estas temáticas en las que no sólo es } \\
\text { el convivir de los estudiantes, sino de la realidad del país, de la sociedad y solo di } \\
\text { importancia a la gramática, aplicada a lecturas de libros de texto, de pronto yo } \\
\text { hubiese sacado estudiantes más críticos, más analíticos. }\end{array}$ \\
\hline & Int2 & $\begin{array}{l}\text { La lectura se vuelve más crítica, muy reflexiva con mucho aprendizaje y amplió el } \\
\text { conocimiento porque se extiende más allá de los intereses de la literatura, ya que } \\
\text { involucra aspectos científicos, se identifican los aportes de la ciencia, de la propia } \\
\text { literatura, la biología, los aspectos políticos y económicos, mejor dicho se desarrolla } \\
\text { el pensamiento divergente. }\end{array}$ \\
\hline & Int3 & $\begin{array}{l}\text { Todas las CSC trabajadas, permiten a los profesores ser más dinámicos, además } \\
\text { aprendí hasta la temática propia que estaban abordando ellos, también cuando } \\
\text { estaba en clase en el ciclo cuatro, por ejemplo los estudiantes estaban preparando } \\
\text { las socializaciones de la gobernanza del agua y se sentían preocupados, pero } \\
\text { contentos a la vez porque otros ciclos los iban a escuchar, ellos se sentían como } \\
\text { profesores, como conferencistas, cuando pasaban frente a sus compañeros y los } \\
\text { maestros, se mostraban ansiosos, pero contentos de ser escuchados, de presentar } \\
\text { sus trabajos, de ser observados e importantes, porque de ellos dependía el éxito de } \\
\text { la actividad }\end{array}$ \\
\hline & Int4 & $\begin{array}{l}\text { Es una experiencia de trabajo, salimos de la rutina, hay un aprendizaje más, me } \\
\text { parece una ayuda, ya que nos hace consultar más y estar más actualizados, de } \\
\text { estar en la jugada como dicen los estudiantes que, por lo que obviamente motiva } \\
\text { muchísimo, tanto a nosotros nos actualizamos un poco, como los procesos que nos } \\
\text { desarrollamos con los estudiantes, son temas más llamativos, para ellos es más } \\
\text { interesante, }\end{array}$ \\
\hline & Int5 & $\begin{array}{l}\text { Tenemos que planear cualquier cosa, pensar bien antes de actuar, en el caso del } \\
\text { trabajo con estudiantes, los tenemos que conocer, antes de iniciar cualquier trabajo } \\
\text { con ellos, una forma que utilizo para conocerlos, }\end{array}$ \\
\hline & Int6 & $\begin{array}{l}\text { Para mejorar la forma en la que trabajamos, yo creería que se puede dar mayor } \\
\text { participación, es decir, que podamos trabajar con otros departamentos no } \\
\text { solamente con el de Ciencias Naturales o específicamente con química, deberían } \\
\text { existir estudiantes de las demás áreas. }\end{array}$ \\
\hline & Int7 & $\begin{array}{l}\text { Nosotros como docentes ya en ejercicio a pesar de nuestros conocimientos nos } \\
\text { falta mucho, podríamos conocer algunas herramientas de tecnología y los } \\
\text { estudiantes que salen de las diferentes carreras, tienen conceptos más frescos, } \\
\text { más modernos podríamos decir, y tienen otra visión, especialmente de tipo } \\
\text { didáctico, ya ven otras cosas que no manejamos y que a nosotros nos va ayudar a } \\
\text { innovar, a motivar a los mismos estudiantes y especialmente nuestros } \\
\text { requerimientos van asociados al uso de la tecnología y de la didáctica. }\end{array}$ \\
\hline & Int8 & $\begin{array}{l}\text { Cambia la mentalidad que tenemos acerca de la enseñanza, alguien decía una vez, } \\
\text { que no es lo mismo una experiencia de } 40 \text { años, qué } 40 \text { años haciendo lo mismo, } \\
\text { son cosas muy distintas; haciendo una secuencia, uno puede aprender muchas } \\
\text { cosas, es otra forma de enfocar los temas, de motivar a los estudiantes, no siempre } \\
\text { como lo hacemos. }\end{array}$ \\
\hline & & ha hecho que los profesores hablan del \\
\hline
\end{tabular}




\begin{tabular}{|l|l|l|l|l}
\hline & $\begin{array}{l}\text { espacio, no sólo para quejarse del tener más trabajo, sino que realmente es a } \\
\text { través del mismo pueden conocer a su población, saber algunas causas que los } \\
\text { llevan al consumo, a conocer qué tipo de droga se consumen, cómo se maneja un } \\
\text { muchacho que consume, cómo abordar un taller sin entrar en profundidad en la } \\
\text { temática cuando se sale de lo curricular. }\end{array}$ \\
\hline Int10 & $\begin{array}{l}\text { En mi trabajo, yo por ejemplo, ya no solamente preparo la guía para hacer los } \\
\text { talleres de educación sexual, temas de prevención y cuidado y manejo del tiempo } \\
\text { libre, también hago mis secuencia didáctica, adicional, también asumo unidades } \\
\text { didácticas de las otras áreas, me parece que son novedosas para la jornada } \\
\text { nocturna y que los profesores aprenden también en su proceso de preparación de } \\
\text { dichas secuencias, yo recomiendo mucho el uso de los debates, el uso de los } \\
\text { videos y los cines foros; en la selección de las lecturas para el PILEO (Proyecto } \\
\text { Institucional de Lectura, Escritura y Oralidad) los profesores también, se interesan } \\
\text { por que las mismas sean dinámicas y se vean las controversias, por ejemplo en } \\
\text { Matemáticas empezamos a mirar desde la misma estadística cómo abordarlas en el } \\
\text { aula y se aprende bastante. }\end{array}$ \\
\hline Int11 & $\begin{array}{l}\text { Miramos como abordar estas csc y la forma en que contribuye al aprendizaje de } \\
\text { los mismos docentes y que uno aprenda a que se articule las temáticas, a que se } \\
\text { vea una forma de trabajo más dinámica en la que la vida institución se vean } \\
\text { favorecida porque las mallas curriculares no son solamente los conocimientos que } \\
\text { se hacen, sino que son integrales en las que le apostamos a esa formación } \\
\text { ciudadana, la formación humana y a la academia misma. }\end{array}$ \\
\hline
\end{tabular}

Fuente. Nodo formación IUE

En este sentido, los profesores de las diferentes áreas, reconocen que el abordar CSC les permite conocer de las otras áreas, empiezan a cambiar fuentes y criterios de selección como se afirma en la int1 a int3, cuestionan las necesidades de formación, les genera inquietud, pero también satisfacción por el trabajo que hacen y de lo que logran hacer con los estudiantes.

Además de lo disciplinar, es necesario el conocimiento de la naturaleza social y valorativa del conocimiento de la ciencia, así, la enseñanza rescata el trabajo sobre las actitudes y la afectividad presente en el tratamiento de los contenidos disciplinares. Aquí cobra un papel notable el conocimiento metadisciplinar asociado a todos aquellos aspectos que van más allá de la propia lógica de las disciplinas y se pregunta por lo social, lo afectivo, lo valorativo y lo ético.

Lo pedagógico, lo didáctico y lo contextual abarca un compromiso del ejercicio profesional docente con la reflexión y construcción de conocimiento sobre la 
propia práctica, así, el profesor es autor de sus diseños curriculares (visibilizada en la int9 a int11) representados en unidades didácticas, secuencias de enseñanza, talleres y toda actividad docente construida e implementada conforme sus conocimientos disciplinares, metadisciplinares y contextuales.

Lo pedagógico en el currículo del programa de formación implica el desarrollo de un trabajo colaborativo y proactivo entre la universidad y la escuela, a partir del cual se construyen aprendizajes mutuos sobre la investigación docente. Así se busca superar el individualismo que ha gobernado el ejercicio docente. Además, esta formación abarca la incorporación de enfoques didácticos transversales, en los cuales se comprende la compleja selección de contenidos disciplinares y metadisciplinares en pro de la formación integral de los estudiantes.

Por lo anterior, los profesores como profesionales que trabajan en la escuela, tienen un papel transformador a través de su práctica de aula, contextualizándola (el mundo de la vida) en escenarios donde se legitime y reivindique la naturaleza humana, donde los estudiantes que asisten independiente de sus diferencias culturales y naturales son personas únicas, con evidentes necesidades de conocimiento, de comprensión, de reflexión y socialización, capaces de construir su propio discurso/ acción de forma responsable y autónoma (Gaviria \& Ospina, 2009).

Ser docente, exige un modelo de formación profesional capaz de gestionar su propio conocimiento, de reflexionar sobre su actuar en el aula, haciendo que sus estudiantes sean capaces proponer posibles soluciones ante problemas de su entorno, capaces de utilizar los conocimientos científicos y tecnológicos en la resolución de problemas y tomar decisiones argumentadas (Holbrook \& Rannikmae, 2009).

En cuanto a las dificultades, los profesores mencionan que las principales dificultades de abordar CSC en las aulas son: emocionales, la falta de tiempo, el desconocimiento de la tecnología, reconocen la falta de habilidad escritural, la falta 
de conocimientos para abordarlas, otras son de índole didáctico y de la política organizativa interna de la escuela. (Figura 79)

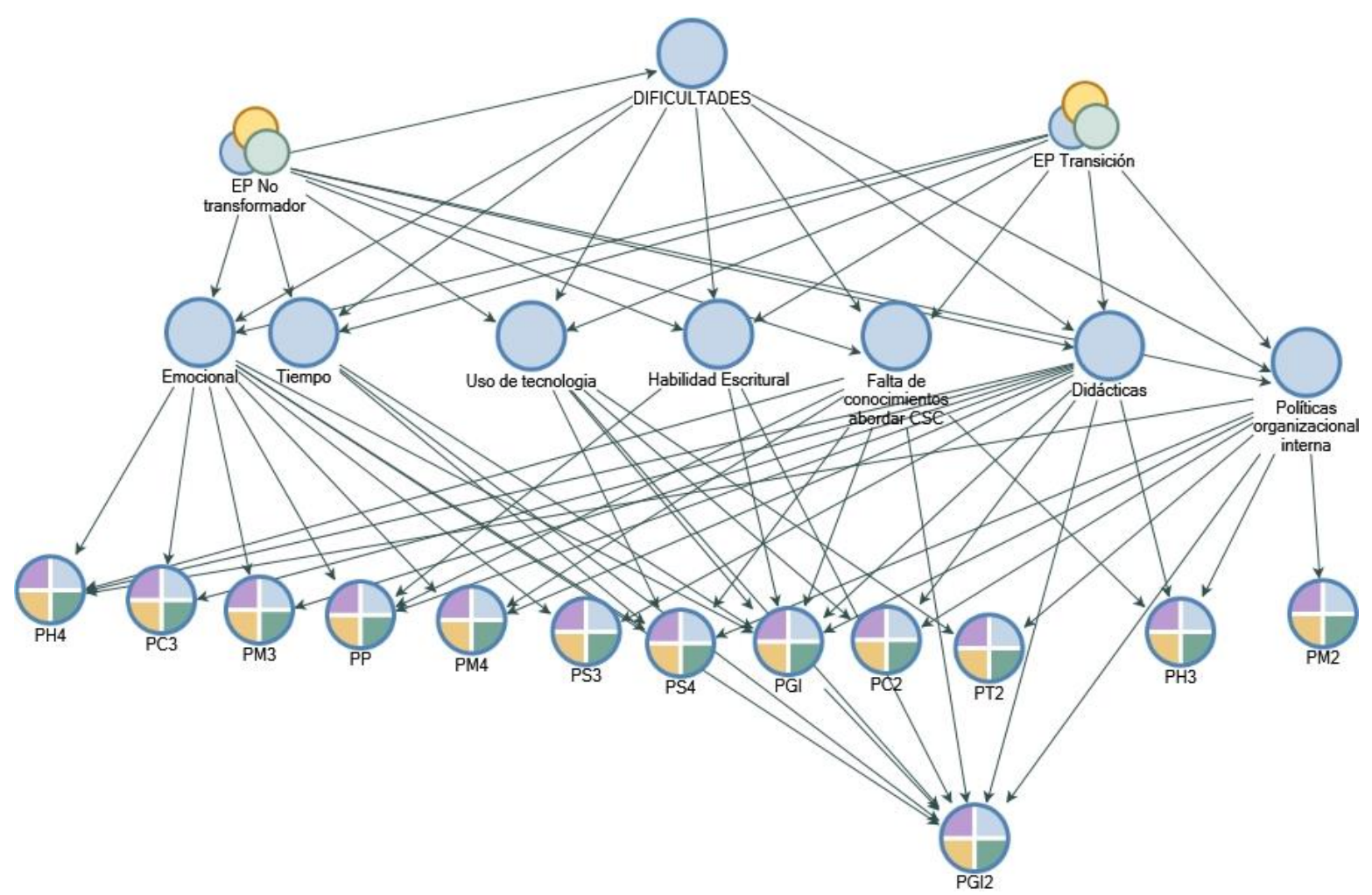

Figura 79. Dificultades en el abordaje de CSC

Fuente NVivo11

En la tabla 20 se muestran algunas intervenciones de los profesores que permiten conocer las dificultades que identificaron en el proceso de formación de profesores en la IUE.

Tabla 20. Intervenciones de los profesores de GI al hablar de las dificultades de abordar CSC

\begin{tabular}{|c|c|}
\hline & $\begin{array}{l}\text { Cuando trabajamos todos, cada uno aporta y cuando cada uno aporta, va uno cogiendo de } \\
\text { cada compañero la idea que tiene cada uno de lo que se habla, y eso hace que de una u } \\
\text { otra manera el trabajo se torne interdisciplinar o más bien transdisciplinar, innovador, } \\
\text { mirando lo que está haciendo cada compañero, tanto de la disciplina, como de otras, la } \\
\text { forma en la que él presenta el trabajo y le da una idea de cómo el maestro de otra área } \\
\text { aborda la temática que uno está trabajando. }\end{array}$ \\
\hline
\end{tabular}




\begin{tabular}{|c|c|}
\hline & Estudiantes con carencias en todos los aspectos, violentados física y verbalmente. \\
\hline \multirow{5}{*}{ 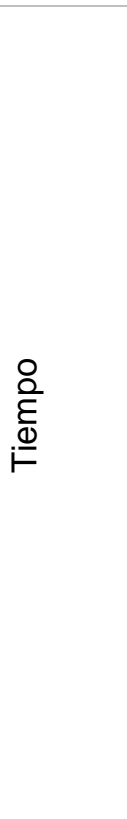 } & $\begin{array}{l}\text { Implicaciones en cuanto a la forma de hacerlo por ejemplo, la parte de tiempo porque } \\
\text { definitivamente no se puede gastar el mismo tiempo ya gastamos mucho más tiempo }\end{array}$ \\
\hline & $\begin{array}{l}\text { Pues una de las dificultades para abordar CSC tiene que ver con el mismo tiempo, porque } \\
\text { uno tiene que dejar de lado temas que en el caso mío de Matemáticas, uno sabe que son } \\
\text { muy importantes y que de pronto se van a evaluar en el examen del ICFES o de las } \\
\text { pruebas saber, porque así sean de la noche los chicos se van a presentar un examen y no } \\
\text { van a tener la opción de conocer las temáticas, entonces el tiempo destinado a las CSC } \\
\text { sacrifica el tiempo de lo que se debería dar y no se da. }\end{array}$ \\
\hline & $\begin{array}{l}\text { No tenemos la habilidad para hacerlo, ni el tiempo para meterse uno y estar como se dice, } \\
\text { estar cacharreando, eso le requiere más trabajo. }\end{array}$ \\
\hline & $\begin{array}{l}\text { Si yo quiero hacer análisis de imágenes, yo soy la que tengo que ir y mirar cuales son las } \\
\text { que quiero mostrar, sobre las cuales quiero hacer la reflexión o quiero que miren otras } \\
\text { cosas, que les generen impacto, para generar discusión o bueno, aprendizaje significativo y } \\
\text { la misma búsqueda del material de esas temáticas, significa que tengo que tener más } \\
\text { tiempo de preparación; }\end{array}$ \\
\hline & $\begin{array}{l}\text { Y también tenemos la dificultad a nivel de nosotros los maestros, porque después de cierto } \\
\text { tiempo la gente se amaña y no sigue uno preparándose, o sea no sigue esa inquietud y esa } \\
\text { capacidad de asombro, también se va perdiendo }\end{array}$ \\
\hline \multirow{3}{*}{ 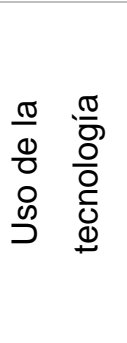 } & Falta de acceso a los laboratorios y uso de las TIC. \\
\hline & $\begin{array}{l}\text { Nosotros como docentes ya en ejercicio a pesar de nuestros conocimientos nos falta } \\
\text { mucho, podríamos conocer algunas herramientas de tecnología y los estudiantes que salen } \\
\text { de las diferentes carreras, tienen conceptos más frescos, más modernos podríamos decir. }\end{array}$ \\
\hline & $\begin{array}{l}\text { También redactamos en el cuaderno, por cuanto queremos escribir y redactar y hacer uso } \\
\text { de las Tic, digamos, no tenemos la habilidad para hacerlo, ni el tiempo para meterse uno y } \\
\text { estar como se dice, estar cacharreando, eso le requiere más trabajo. }\end{array}$ \\
\hline \multirow[b]{2}{*}{ 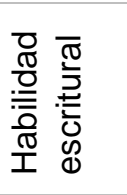 } & Falta de lector e interpretación de textos \\
\hline & $\begin{array}{l}\text { El trabajo, hay que escribir, los maestros somos muy buenos para hablar y poco de escribir } \\
\text { y esto, es porque no nos sentamos a plasmar las ideas, no tenemos el tiempo, y de pronto } \\
\text { si tenemos tiempo, nos sentamos y nos damos cuenta que tenemos esa dificultad; }\end{array}$ \\
\hline \multirow{3}{*}{ 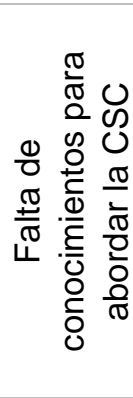 } & $\begin{array}{l}\text { La carencia de recursos(material didáctico, aulas especializadas, textos, etc.) y la falta de } \\
\text { apoyo por parte de padres y de la misma institución }\end{array}$ \\
\hline & Medio ambiente: Que debo conocer más para protegerlo \\
\hline & $\begin{array}{l}\text { Primero en la falta de conocimiento, especialmente sobre las clases de droga, porque los } \\
\text { estudiantes hacen un comentario y saben más que nosotros, y cuando nos reunimos entre } \\
\text { nosotros los profesores, hay compañeros que comentan las clases, los precios, la } \\
\text { problemática por competición de los mismos, y los profesores de ciencias generalmente } \\
\text { conoce los componentes, o sea uno tiene que estudiar todo, desde el componente, donde } \\
\text { las consiguen, hasta la competición por los precios ¿por qué ocurren estas cosas? }\end{array}$ \\
\hline \multirow{2}{*}{ 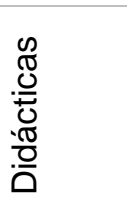 } & $\begin{array}{l}\text { Manejar temas de interés científico social en las posibles clases a desarrollar, emplear las } \\
\text { herramientas de las matemáticas para analizar diferentes CSC. }\end{array}$ \\
\hline & $\begin{array}{l}\text { Forma por el miedo que uno tiene al cambio, el miedo de buscar cosas nuevas, veníamos } \\
\text { de didácticas diferentes, eso sí se nota bastante, de una u otra manera venimos con } \\
\text { muchas dificultades y con didácticas diferentes, }\end{array}$ \\
\hline
\end{tabular}


A veces cuando se buscan relacionar estas CSC con los temas del currículo para un tema que esté trabajando $\mathrm{x} 0 \mathrm{y}$, unos dicen con qué lo puedo interrelacionar esa parte y que didáctica es mejor, entonces uno busca juegos, cosas o, que de pronto por el tiempo y la misma limitación del material es factible en que se requiera más tiempo de programación o de diseño del mismo maestro.

Fuente. Nodo dificultades Software NVivo11

Como de evidencia en el discurso de los profesores, y acorde a la caracterización inicial, los profesores del Gl están alejados del uso de la tecnología, sin embargo, esta puede ser un obstáculo que hace que el profesor permanezca en un EP no transformador, sin embargo, observamos que el profesor da viabilidad a esta formación, solicita acompañamiento y ojalá desde otras áreas; reconoce que este modelo de formación, le permite transitar por diferentes CP, aprender de ellos, apropiarse de discursos que antes eran desconocidos para él mismo y que ahora disfruta conocerlos.

En cuanto al factor tiempo, los profesores son conscientes de sus falencias disciplinares, reconocen que el abordaje de CSC les exige tiempo adicional al que está acostumbrados a invertir en las clases tradicionales; y el hecho de estar trabajando en otros escenarios diferentes, les exige de la planeación, de nuevas estrategias didácticas, de nuevas inversiones en tiempo y en su formación.

Una de las intervenciones evidencia claramente, la dificultad escritural, los maestros al no estar inmersos en procesos investigativos, no leen, no escriben, más de lo esencial, ya no se planea y menos en el contexto de la educación de EJA.

Las otras dificultades mencionadas, como las didácticas, las políticas de organización interna; hacen referencia a lo alejados que están del campo universitario, algunos han estandarizado la práctica pedagógica y didáctica. 
Ante este panorama de dificultades, el escenario de la formación en IUE debe empezar a ampliar el panorama, satisfacer la necesidad educativa de los profesores, que ya empezaron el cambio, ya se dio inicio esa suave inmersión didáctica que habla Fleck (1986).

En síntesis, en el proceso de formación de profesores en la IUE, adicional a la consolidación del GI como CP, los profesores al abordar CSC con enfoque CTSA identificaron que las características mismas de la CSC, aportan al CPP, al EP transformador; de las características de las CSC, la más desarrollada por los profesores fue la generación de opiniones. El siguiente aporte en orden de importancia se da a la IUE, en la que al formarse como CP, aprende a investigar y por tanto identifican en la metodología de Investigación Acción, una forma de inmersión del profesor en la investigación (figura 80).

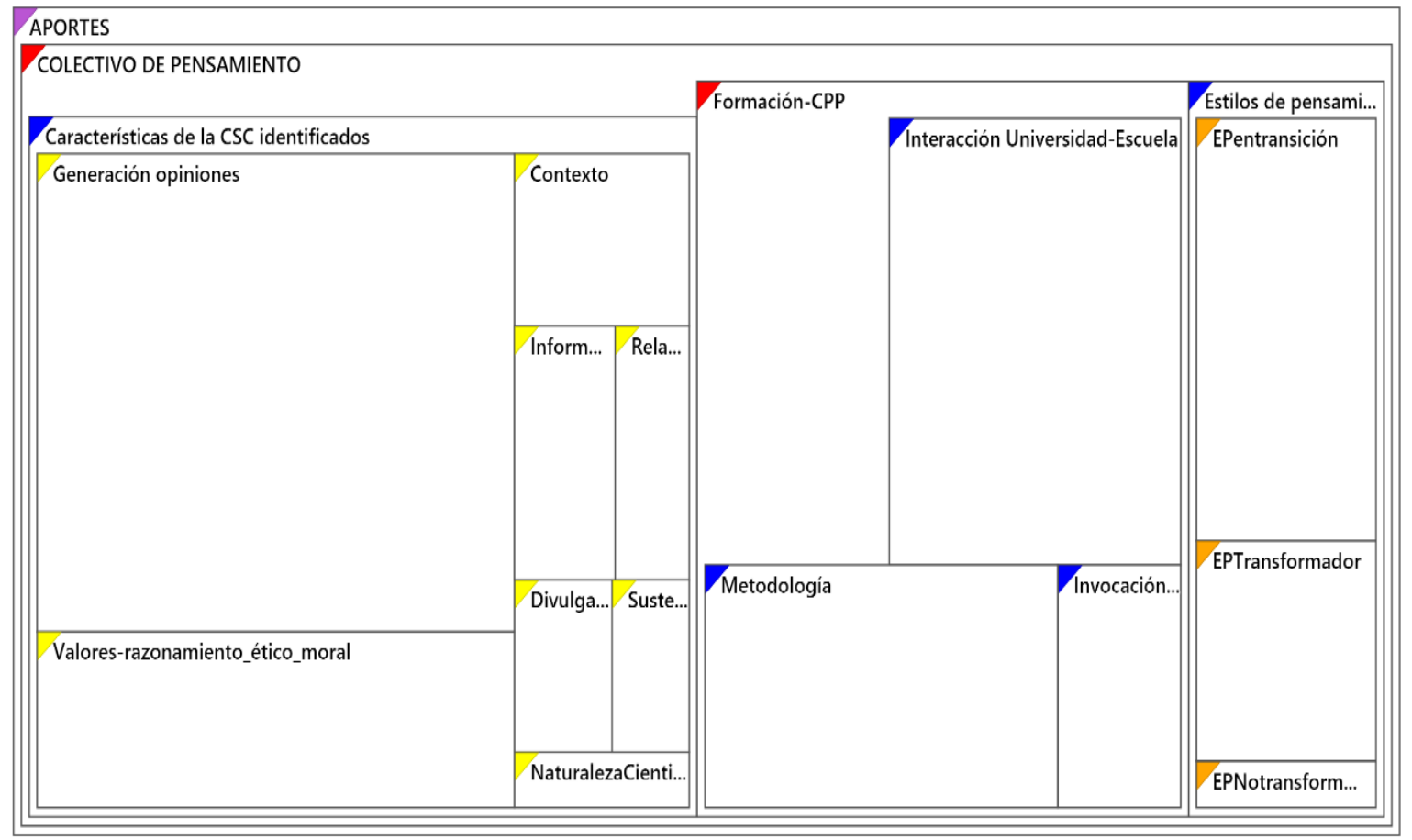

Figura 80. Aportes al proceso de formación en la IUE Fuente NVivo11. 
Las dificultades representadas en la figura 81 muestran que la emocionalidad y las didácticas son las que limitan abordar CSC, ya que el contexto de la educación de adultos está enmarcado en un ambiente de exclusión y de violencia, pero también otra dificultad no menos importante es la falta de conocimientos para abordar las CSC y el uso de la tecnología, y, otros aspectos inherentes al abordaje de las mismas son las políticas de organización de la escuela, que generalmente, están en el contexto de la rendición de cuentas.

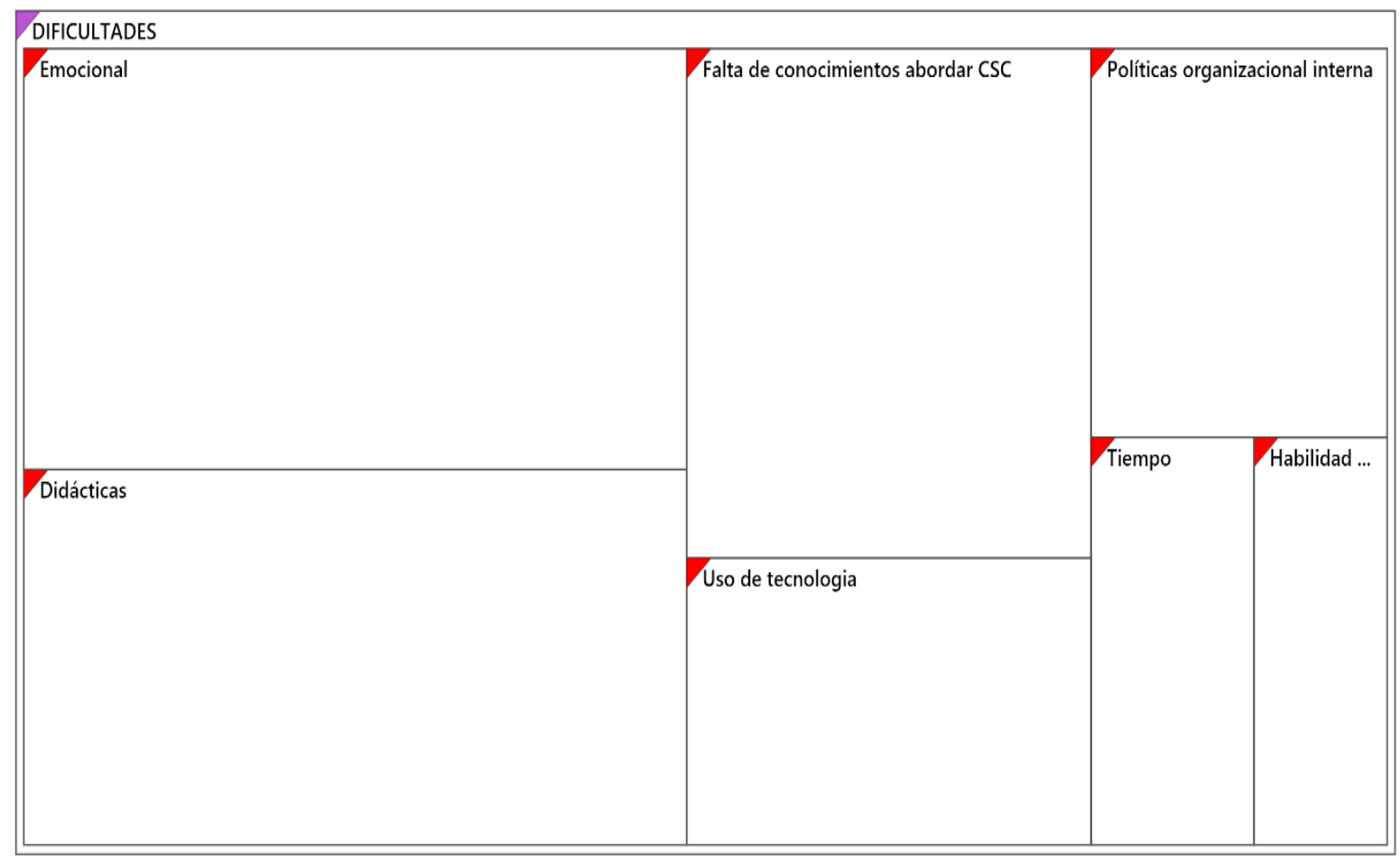

Figura 81. Dificultades de los profesores del GI al asumir las CSC Fuente Nvivo11 


\section{CAPITULO 6. COMPRENSIÓN DE CONSTRUCCIÓN DEL CPP A LA LUZ DE LA TEORIA EPISTEMOLOGICA DE FLECK}

En el presente capítulo se realiza una posible comprensión explicativa acerca de cómo se constituye (construcción/reconstrucción) el CPP al abordar CSC con enfoque CTSA en un proceso de formación en IUE a la luz de la epistemología de Fleck (1986), teniendo en cuenta que el CPP es un conocimiento epistemológicamente diferenciado, particular, evolutivo/constructivo, práctico y fundamentado (Martínez, 2017).

Al abordar la drogadicción como CSC y posteriormente limitarla por las características del contexto escolar a SPA, se inicia un proceso de desocultamiento de términos, que aparentemente, por vivencia, cotidianidad, por el manejo de los medios de comunicación, ya se conocían, al igual que opiniones en torno a dichas problemáticas, por lo que al iniciar el diálogo y debates en torno a la drogadicción, leyes, contexto, reflexiones, los profesores del Gl abordan temáticas relacionadas con las mencionadas en mayor frecuencia en la figura 82.

En este contexto al abordar las CSC como objeto de conocimiento, está inmerso en un estado de conocimiento contextualizado histórico, social y temporal, es decir, el conocimiento que existe en torno a la CSC no surge espontáneamente; el profesor tiene unas prenociones provenientes de mitos, del contexto cultural y social en el que está inmerso, de los saberes históricos y culturales que se tiene y se manifiesta a través de vivencia, por tanto la CSC en el caso de la drogadicción necesita ser abordado por los profesores quienes establecen conexiones activas con la CSC.

De esta forma la CSC relacionada con la drogadicción, por ejemplo, al ser abordada como CSC proviene de unas protoideas, del uso cultural, simbólico e idiosincrático de pueblos, pero que en el contexto escolar generan un "estado de 
conocimiento" al igual que el CPP particular, pero que debe ser abordado en colectivo y asumir un EP en el contexto del CP. Este contacto con la CSC como objeto de conocimiento con el EP de los profesores se dirección a un EP particular del colectivo, quienes a través de los procesos de formación tendieron abordar la CSC acorde a temáticas relacionadas con la legalización, que surge de la controversia entre la legalidad e ilegalidad, producción/consumo, uso/abuso.

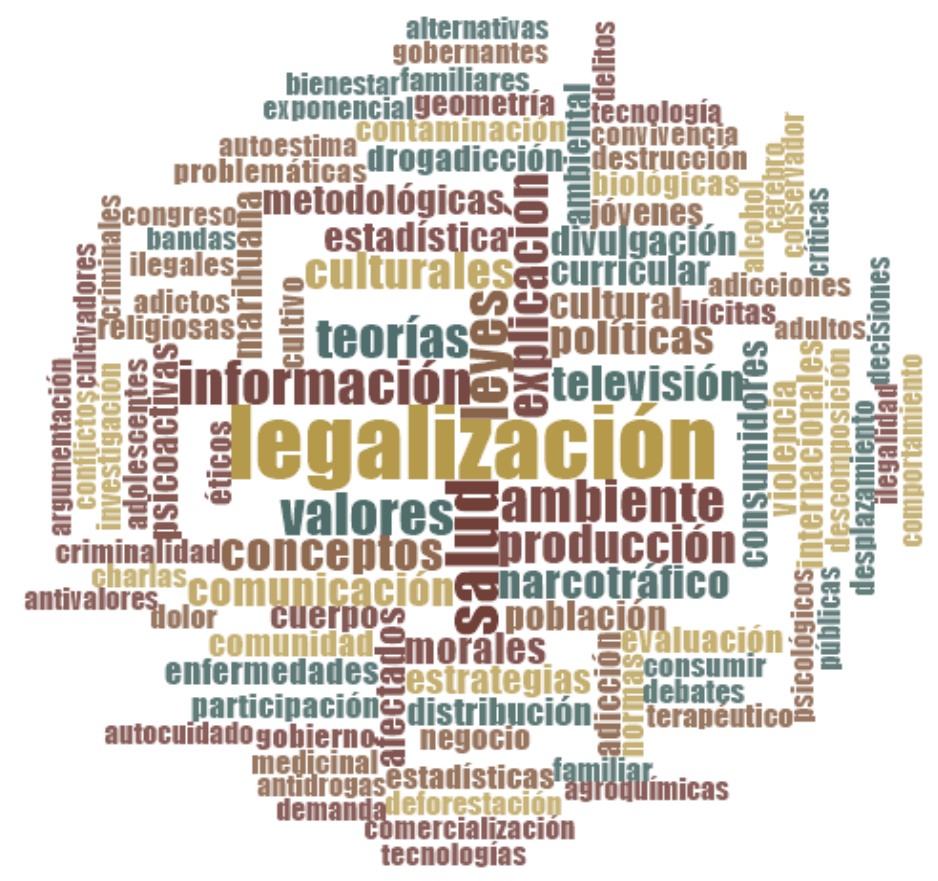

Figura 82. EP relacionado con la CSC en torno a la drogadicción Fuente. Nvivo11. Taller de caracterización de CSC

La naturaleza del CPP parte del supuesto que al ser un conocimiento práctico pero fundamentado, surge al igual que el conocimiento científico de procesos de construcción y reconstrucción, de procesos que se mutan, hibridan, que se construyen en colectivo, carentes de neutralidad y que se desarrollan a través del tiempo, en un proceso de evolución, pero contextualizados social, histórica y culturalmente, tal como es considerado por Fleck (1986) cuando afirma:

La fertilidad de la teoría del pensamiento colectivo se muestra precisamente en la posibilidad que nos proporciona para comparar e investigar de forma uniforme el pensar primitivo, arcaico, infantil y psicótico, aunque también puede aplicarse al 
pensamiento de un pueblo, de una clase o de un grupo de la índole que sea. Considero el postulado de "experiencia máxima" como la ley suprema del pensar científico, pues una vez que surgido la posibilidad de una epistemología comparada, este postulado se convierte en una obligación. (p.98)

Ofreciendo así, la posibilidad de comprender la construcción/deconstrucción del CPP al asumir el Gl como un colectivo, caracterizado por ser una asociación libre, en la que cada profesor se caracteriza por ser un sujeto de ese colectivo que comparte experiencias del aula, las angustias propias de la labor de profesor en el contexto escolar (EJA) estiliza su pensamiento (EP) acorde a las intencionalidades, propósitos, acuerdos/negociaciones y características propias del Gl como CP y que al abordar las CSC se constituyen en el "estado del conocimiento" que marcan el EP de cada uno de los profesores del CP.

Para Fleck (1986) "el estado del conocimiento" es decir, el contexto en el que se aborda es fundamental para explicar cómo surge el sistema de ideas alrededor de la CSC en este caso; la cual tiene implicaciones históricas, viene de un proceso evolutivo, de comercio internacional, de procesos de prohibición y en un contexto territorial, en que unos países son productores, otros consumidores, se establecen relaciones de oferta/demanda, regiones de tránsito y se generan alternativas a políticas de prohibición internacional, pero que en el contexto del mundo de la vida, se tejen nuevos conocimientos, nuevas posibilidades de abordar dichas CSC desde una mirada más humana.

La controversia, asumida desde la legalización, pone en juego diversos EP de los profesores del CP, entre ellas están: 


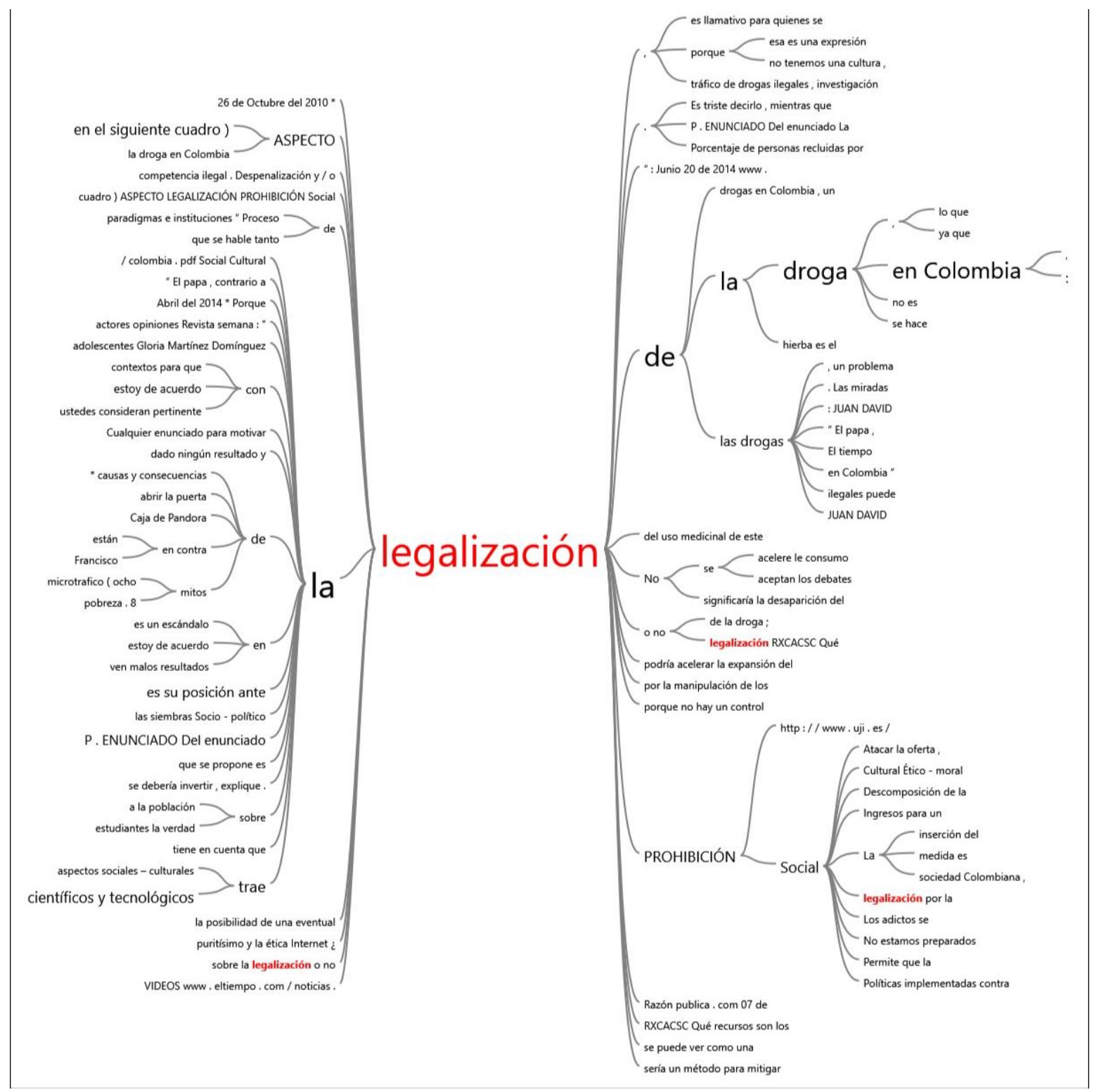

Figura 83. Aspectos abordados por el CP alrededor de la legalización como CSC Fuente NVivo11.taller

En la figura 83 se puede visualizar que los profesores asumen diversas posiciones frente a la controversia y haciendo uso de referentes sociales, culturales, éticos, políticos, se referencia a la ley, sin embargo, en muchas ocasiones tienden a predominar discursos monodisciplinares, por ejemplo, el del profesor PS1, que además a tener formación disciplinar en Sociales, es abogado. 
El investigador, experto o el profesor encargado de dinamizar el debate o diálogo debe mediar y establecer reglas de tal manera que la relación $D / d \circ d / D$ permanezca equilibrada, adicionalmente como son controversias en muchos planteamientos parece no llegarse a consensos, lo que hace que predominen las voces con más referentes disciplinares y no se discuta realmente posiciones basadas en el compromiso social y colectivo.

Sin embargo, no es viable desconocer la riqueza conceptual y emocional que se genera, ya que los profesores, comendan anécdotas culturales, hacen recuentos sociales, históricos, basadas en su propia formación o en el contexto particular de sus vivencias, lo que hace que en la mayor parte de las ocasiones se terminen los debates agradeciéndose unos a los otros por los aportes socializados o debatidos, al igual que surgen preguntas de tipo didáctico, del abordaje con los estudiantes, para lo cual se establecen conversatorios más especializados y vivenciales con los mismos profesores, de tal manera que predomine el diálogo, el intercambio de ideas, conocimientos y se favorezca el consenso y la negociación que se marcan por el EP que se va consolidando en el CP.

Para Fleck el sujeto, en este caso el profesor al participar en los procesos de construcción del conocimiento al interior del colectivo, está compartiendo prácticas, concepciones, tradiciones y normas características de su CP que están direccionadas por un EP particular; así, cuando llega un profesor nuevo a formar parte del CP tiene un EP "desordenado" es un observar "como un confuso inicial" (Fleck, 1986, p.138-139) que en el transcurso de los debates, en un contexto de principios negociados se perfila y estiliza a un "ver formativo directo y desarrollado".

En el proceso de formación de profesores en la IUE se establecen dos CP el de la Universidad y el de la escuela, y a través del programa de formación se buscó la interacción entre los profesores de la Universidad quienes acorde a Fleck 
representan los expertos especializados del circulo esotérico, los cuales generalmente pertenecen a diversos colectivos a la vez, es decir que un profesor independiente del colectivo del que forme parte puede pertenecer a varios colectivos; en este caso la autora de esta tesis forma parte del CP del grupo Alternaciencias y del colectivo escolar, pero a su vez en juntos colectivos hay varios colectivos; en este contexto, los profesores acompañantes de la universidad son los expertos especializados quienes a partir de sus investigaciones están caracterizados por el uso y creación de ciencia de revista, la autora de la tesis y los estudiantes en formación inicial son acorde al modelo, los expertos generales dentro del circulo esotérico, quienes a través del abordaje en sus clases y procesos de formación han asumido las ciencia de revista y la planean (trasposición) diseñan y adecuan a los escritos de dicha ciencia de revista a ciencia de manual (libros especializados), que posteriormente se desarrollaran con el circulo exotérico, considerando así a los profesores de la escuela, quienes generalmente utilizan la ciencia de los libros de texto, por su grafismo, sencillez y accesibilidad (ciencia popular).

Sin embargo, los profesores de las escuelas también pueden invertir dichos círculos; es decir, que en el contexto de la escuela, los profesores de la noche serán un CP perteneciente al círculo esotérico, son ellos los que tienen CPP del campo profesional y laboral propio, y a la vez cada una de las áreas es un CP, y los profesores del GI serán un CP formado por profesores de diversos colectivos, pero con un EP estilizado, cuyo principio fundamental se enmarca en la formación de jóvenes y adultos, de ciudadanos críticos que a partir del abordaje de CSC en el contexto CTSA pretenden promover la participación, la toma de decisiones de sus estudiantes y los profesores a la vez consolidarse como una asociación libre con pretensiones de formar parte de esferas públicas que permitan el cambio de la escuela, la construcción de conocimiento escolar y profesional de los profesores.

Así, la escuela como constructora de conocimientos escolares sería un circulo esotérico de profesores especialistas en la didáctica del aula; sin embargo, los 
profesores que están en juntos CP pueden hacer dinamizar el experto general los cuales facilitan la circulación intercolectiva de ideas; de tal manera que la interacción entre profesor de la universidad y profesor de la escuela establezca un nuevo CP especialista en el abordaje de CSC en el contexto de la EJA.

El EP de los profesores de la universidad corresponde al EP de los expertos especializados productores de ciencia de revista y los de los profesores del GI a los practicantes de ciencia de los libros de texto, evidenciándose la necesidad de articular la universidad y la escuela, cerrar la brecha entre los profesores que investigan y los consumidores de conocimiento, establecer nexos entre ambos campos como lo menciona Huberman \& Levinson (1988) y desde la comprensión epistemológica de Fleck se dinamiza..

En los procesos de interacción entre los profesores de Alternaciencias, los estudiantes en formación, se establece un proceso de circulación de ideas; si la circulación es al interior del grupo Alternaciencias se establece una circulación intracolectiva de ideas, lo mismo ocurre entre los profesores de Alternaciencias, los profesores en formación, en la que la circulación de ideas es de tipo intercolectivo, como se parecía en la figura 16, el mismo proceso ocurre en la IUE, los profesores de la Universidad con los de la escuela establecen una circulación interconectaba de ideas y entre los profesores del CP de la escuela ocurre una circulación intracolectiva de ideas.

En este proceso de circulación de ideas, la comunicación siempre cambia, se acomoda a los EP del CP, por lo anterior, tal como menciona Delizoicov \& Carneiro (2004) se acomoda a los EP del CP, si hay diversidad de EP en un colectivo, menor es la circulación intercolectiva, es decir, la universidad representada como circulo de especialistas debe garantizar un EP estilizado, en la que la circulación intracolectiva sea particular y tenga un EP particular, propio de dicho campo, que al establecer interacción intercolectiva con el circulo exotérico, tienda a mantener el EP particularizado y a través de procesos de coerción o 
suave inmersión pedagógica y didáctica logre la EP de los profesores de los círculos exotéricos.

Los profesores del GI pertenecen a otros $\mathrm{CP}$, ya que unos son de planta otros de horas extras, lo que hace que adquirieran un EP particular, cuando están abordando problemas propios del contexto escolar o están construyendo unos conocimientos particulares que los hace tomar decisiones, evaluar el contexto del abordaje propio de la CSC que desean abordar o están abordando en otro contexto escolar, sin embargo en el contexto de la EJA, cuando se abordan CSC como ejes estructurantes y articuladores de la Enseñanza de la Ciencia, se asume un EP particular, propio de cada profesor, pero en el contexto de un CP a la vez particular.

Entonces, los profesores del GI ahora como CP al abordar CSC y a la luz de la HdPR movilizaron sus pensamientos pasando algunos de un EP No Transformador a uno transformador; sin embargo, algunos permanecieron en un EP en transición, en el que posiblemente "la armonía de las ilusiones" lo caractericen como un EP en confort, mientras que, si se rompe esa armonía, podrá tener un EP de disposición al cambio, como lo indican las intervenciones socializadas en la tabla 21.

Tabla 21. EP presentes en el GI como CP

\begin{tabular}{|l|l|}
\hline \multicolumn{1}{|c|}{ EP } & \multicolumn{1}{c|}{ Intervención } \\
\hline Transfransformador & $\begin{array}{l}\text { Si usted no cumple esos currículos, que vienen estipulados desde } \\
\text { SED, que vienen escritos, que vienen unos estándares, entonces "ah } \\
\text { no, pues no se cumple y así mismo nos evalúa el ICFES. }\end{array}$ \\
\hline $\begin{array}{l}\text { Tomar decisiones sobre las problemáticas que nos rodean, lograr una } \\
\text { alfabetización científica, conocer lo básico para desarrollar procesos de } \\
\text { pensamiento, leer, indagar argumentar y reconocer los problemas del } \\
\text { entorno; a nivel personal, concientizarse en lo que lo perjudica y hacer } \\
\text { una autorreflexión, participar y relacionarse con los otros, conocer y ser } \\
\text { consciente de las consecuencias que puede ocasionar el no tomar } \\
\text { decisiones apropiadas. }\end{array}$ \\
\hline E EP_confort & En la siguiente sopa de letras encuentre 15 términos relacionados con \\
\hline
\end{tabular}


el uso de drogas. Escríbalos y construya una frase con cada una.

EP_complicación- uno por lo general no tiene ese conocimiento y ellos hacen disponibilidad preguntas que nunca había escuchado, hasta la forma de consumo tienen diferentes formas

Fuente. Nvivo. UA/RA codificados en la categoría (nodo) EP

Generalmente en el EP que predomina en las escuelas de educación básica y media se haces más visibles las características propias de la fase de formación académica de cada profesor Delizoicov et al. (2002) en este sentido, los profesores generalmente imitan el modelo de formación; por lo tanto, al concebirse el GI como un CP de forma direccionada al abordaje de CSC con enfoque CTSA, se introduce a los profesores en un campo del conocimiento que como indica Fleck (1986) es una introducción didáctica, el cual tendrá periodos de enseñanza puramente dogmática, pero que estimulen el pensamiento científico crítico, una vez se establece la lucha interna entre el EP de cada profesor y la del CP a través de circulación intra e intercolectiva de ideas, se va estilizando el pensamiento de cada profesor, va adquiriendo características particulares de dicho CP

Sin embargo, en el proceso de estilización, posiblemente se establecen complicaciones en el que los profesores pasaran por EP en transición en el que el trabajo de pares en la IUE a través de la circulación intercolectiva de ideas, como lo ocurrido en el Gl permitió a los profesores construir un CPP con un EP particular, que pertenece a un CP de EJA.

Tabla 22. Circulación inter e intracolectiva de ideas

\begin{tabular}{|l|l|l|}
\hline $\begin{array}{c}\text { Circulación } \\
\text { de ideas }\end{array}$ & & \multicolumn{1}{c|}{ Intervenciones } \\
\hline Intercolectiva & Int1 & $\begin{array}{l}\text { Me parece una actividad bonita, porque a veces uno preparar las cosas } \\
\text { sólo para dar definiciones, más no como salir del aula y el poder trabajar } \\
\text { con otras áreas, con otros profesionales y en especial de la universidad, } \\
\text { así como cuando vino el profesor de Brasil Michel. }\end{array}$ \\
\hline intracolectiva & Int2 & $\begin{array}{l}\text { Consideró que el vínculo de la universidad aporta a mi formación ya que } \\
\text { complementan la información que uno trae. }\end{array}$ \\
\hline $\begin{array}{l}\text { Territorio: interés de los docentes en el abordaje de este tema desde que } \\
\text { haya acompañamiento externo como el de la universidad y el visto desde } \\
\text { el quehacer de los mismos, falta de la investigación. }\end{array}$ \\
\hline
\end{tabular}


Int2 Cuando trabajamos todos, cada uno aporta y cuando cada uno aporta, va uno cogiendo de cada compañero la idea que tiene cada uno de lo que se habla, y eso hace que de una u otra manera el trabajo se torne interdisciplinar o más bien transdisciplinar, innovador, mirando lo que está haciendo cada compañero, tanto de la disciplina, como de otras, la forma en la que él presenta el trabajo y le da una idea de cómo el maestro de otra área aborda la temática que uno está trabajando

Fuente: software NVivo11 nodo formación

Los profesores del Gl como colectivo de pensamiento y circulo exotérico aprenden unos de los otros, de sus propios discursos, se moviliza en conocimiento en forma intracolectiva y reconocen el aporte de la universidad y los aprendizajes que realizan con los expertos de la universidad o de otras como la del profesor de la UNESP.

La figura 84 evidencia que en los profesores se movilizó a un EP transformador, es decir que el CP ejerce coerción a un nuevos integrantes hacia un EP transformador, sin embargo un número significativo de profesores está a la vez en un EP en complicación disposición, ya que el profesor puede formar parte de los dos o más colectivos, bien sea por los contenidos, referentes criterios de evaluación y fuentes que utilice para abordar la CSC. 


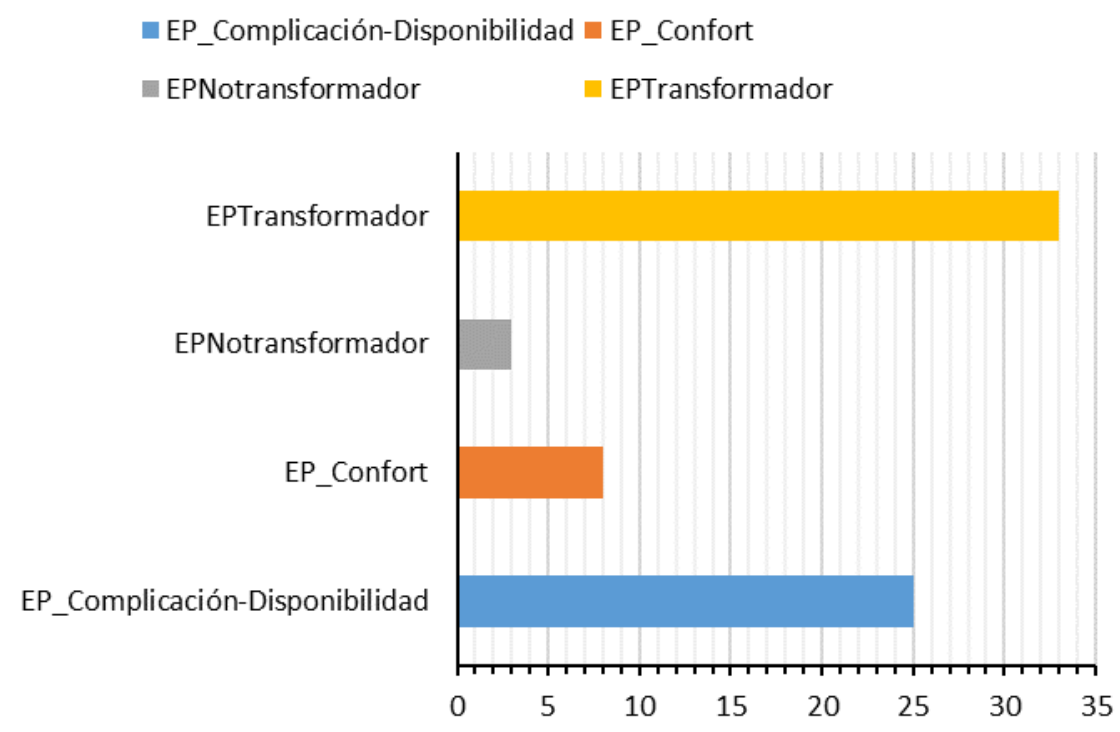

Figura 84. EP en el que se movilizaron los profesores del Gl Fuente NVivo 11 EP nodo aportes

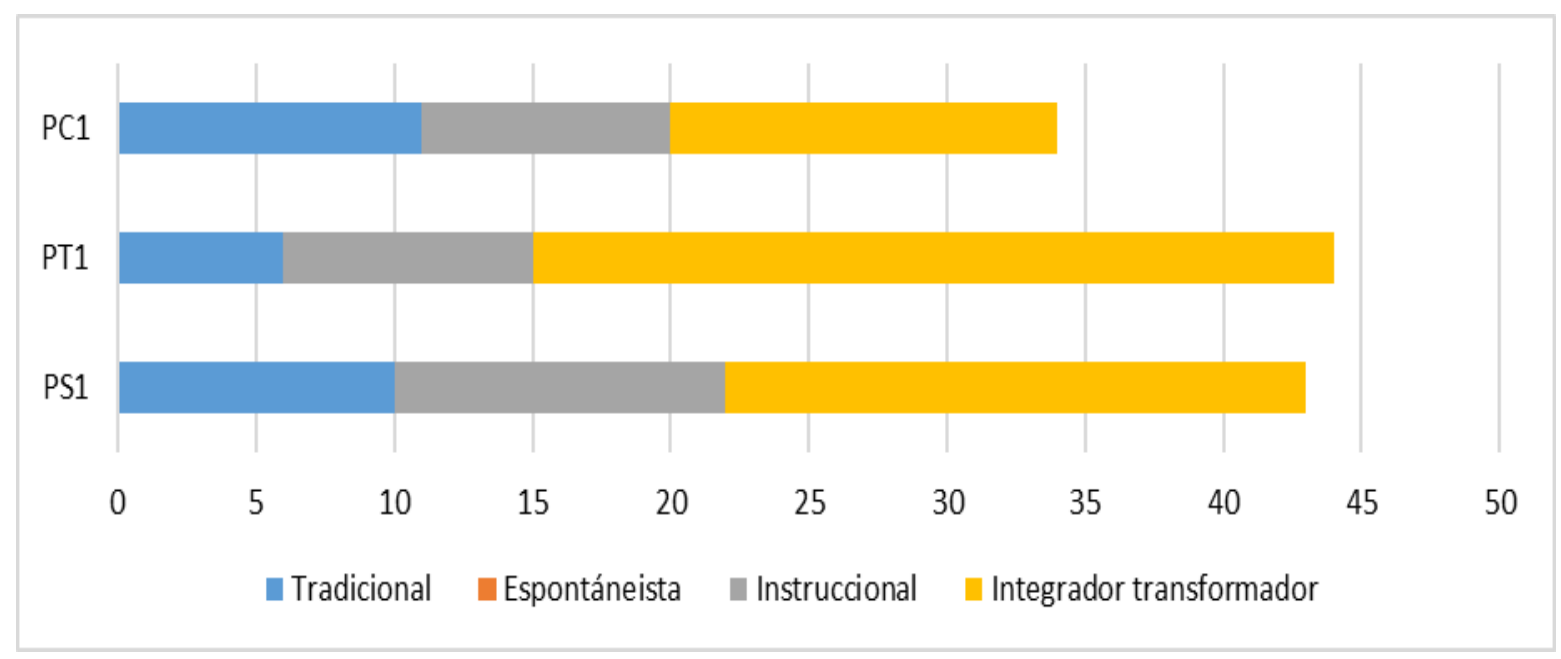

Figura 85. EP de tres profesores en particular Fuente NVivo11

La figura 85, muestra el caso particular de tres profesores del CP que pertenecen a tres $\mathrm{CP}$, pero la tendencia general es al CP transformador.

Al graficar los EP predominantes en el grupo de profesores de planta como semilleros del proceso de formación permanente, con un EP perfilado al ser transformador, se evidencia que los profesores a través de las entrevistas semiestructurada y focal, valoran los aportes del proceso de IUE al proceso de 
formación y sus aportes en cuanto a la interacción de los círculos esotéricos y exotéricos, así como a la circulación de ideas en forma intra e intercolectiva, realizada a través de los talleres, conversatorios, visitas de expertos y diálogos/debates establecidos.

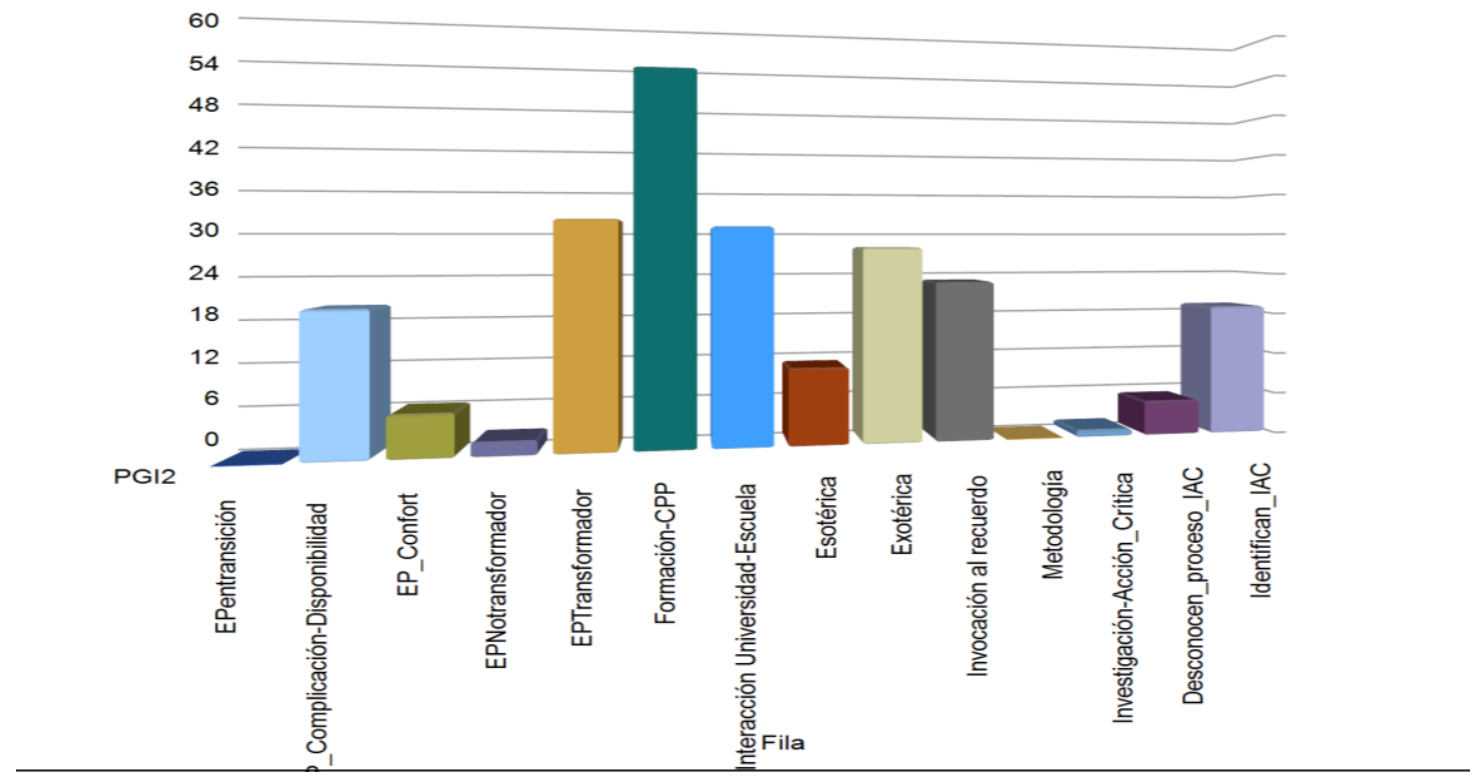

Figura 86. Aportes del proceso de IUE al proceso de formación y al CPP Fuente Nvivo11

De la misma manera, se muestra el EP que caracteriza al colectivo en mayor proporción (EP transformador y EP complicación/disponibilidad), resaltando igualmente que en el proceso de formación en IUE se reconoce como un proceso de investigación, en la que una de las metodologías que más apreciaron fue la invocación al recuerdo y los diálogos exotéricos establecidos.

Finalmente, se pueden visibilizar en conjunto los progresos y retrocesos de los profesores del Gl, como se aprecia en las figura 86 y 87 . 


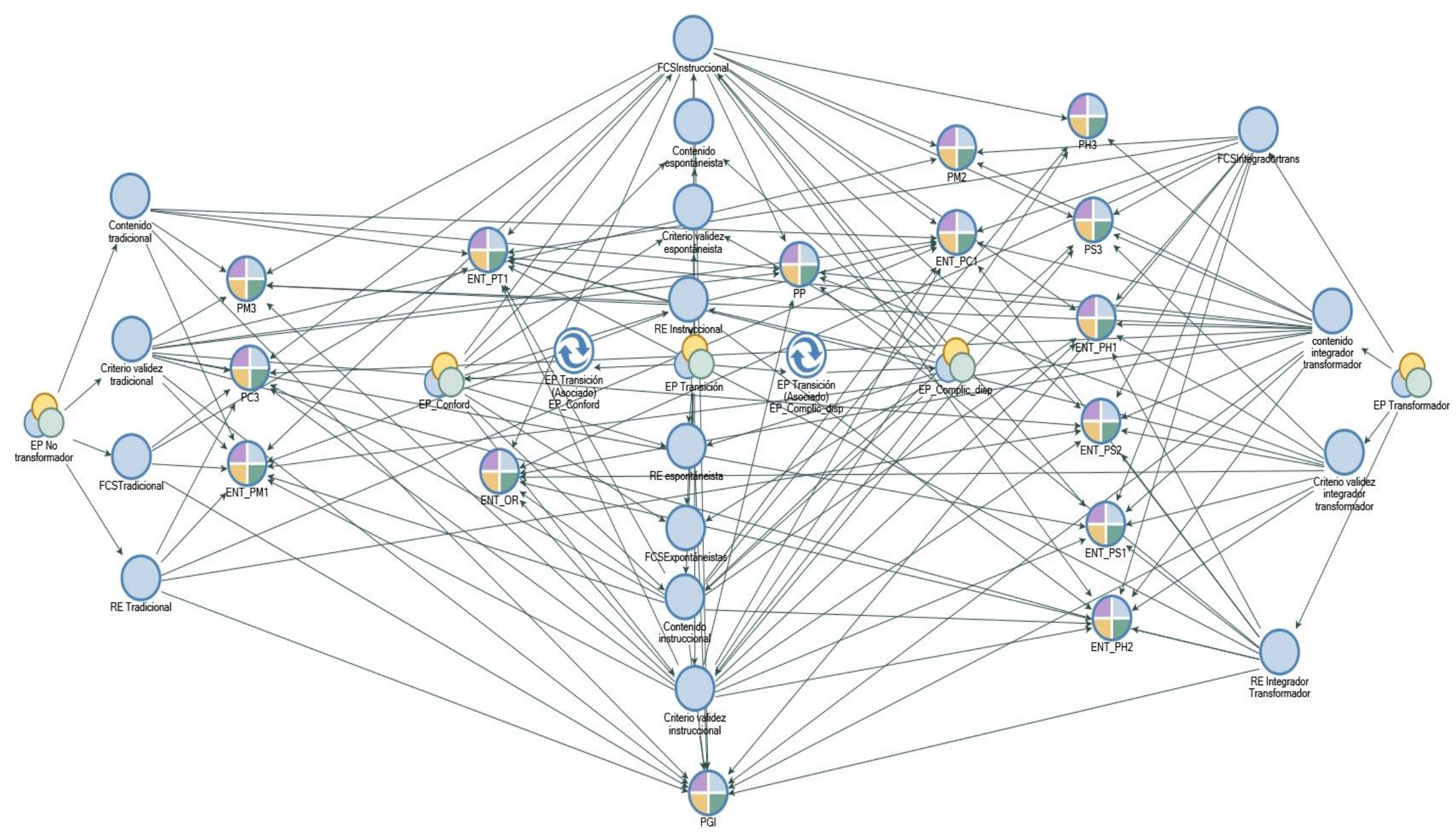

Figura 87. EP a la luz de la HdPR de los profesores del GI

Fuente $\mathrm{N}$ vivo11 
Se puede concluir que los profesores del Gl como CP se caracterizan en mayor proporción por haber estructurado un CPP con tendencia de EP transformador, caracterizado por abordar como contenidos CSC, pero en las que se evidencia que los referentes epistemológicos y las fuentes de selección que legitiman las CSC están en un EP de transición entre la complicación/disponibilidad, por los motivos antes mencionados. 


\section{CONCLUSIONES}

A partir del análisis realizado en los dos capítulos anteriores, se puede comprender que el abordaje de CSC favorece el CPP en un contexto de formación de profesores en la IUE, en la que los profesores constituyen un GI, que al configurarse como $\mathrm{CP}$, direcciona y perfila su EP. Para lo anterior se requirió:

8. conformar un Gl a la luz de la teoría de la acción comunicativa de Habermas (1987), en el que todos los profesores del grupo podían actuar libremente, sin coerción, pero que conscientes que ninguna investigación es neutra, la autora de la tesis como observadora participante, tuvo que alejar sus preconcepciones y acompañar el trabajo de formación estableciendo relaciones horizontales, que favorecieran un clima de trabajo al interior del Gl.

9. El EP estructurado por el CP tiende a ser transformador, especialmente porque aborda las CSC como ejes transversales y articuladores del currículo, pero las fuentes y criterios de selección, al igual que los referentes epistemológicos se configuran en estilos de pensamiento de transición, posiblemente porque al ser conocimientos de frontera, cuyos referentes están más en direccionamiento de los medios de comunicación que hacen parte en mayor proporción de la racionalidad instrumental, y no del mundo de la vida, los profesores por los procesos de formación en los que han sido formados, posiblemente ausentes del establecimiento de relaciones CTSA y de una formación crítica, asumen como una debilidad el abordaje de dichas cuestiones.

10. Los aportes al CPP se pudieron caracterizar a la luz de una HdPR en la que el ATD y el software NVivo11 facilitaron encontrar las unidades de análisis que permitieran comprender los contenidos, criterios de validez, referentes epistemológicos, fuentes y criterios de selección que utilizan los profesores al abordar las CSC, así como los ejes DOC, que finalmente evidencian la complejidad del CPP. En este sentido los contenidos 
escolares asociados a la CSC permiten comprender al profesor la naturaleza de la ciencia, posibilitan que tenga la opción de opinar a título de hipótesis y respaldarla teniendo en cuenta fuentes y criterios de selección que a su vez sean controversiales, simultáneamente posibilita al profesor evaluar de una forma crítica dichos medios y seleccionar acorde a los propósitos de enseñanza de la ciencia en el contexto de la racionalidad científica, de desarrollo tecnológico y de compromiso social, movilizando su pensamiento por diferentes estilos de pensamiento; las CSC por su carácter controversial se constituyen en ejes dinamizadores que acorde a la complejidad del conocimiento del profesor lo llevan a estados de transición, es en estos estados que la IUE es fundamental para acompañar al profesor a movilizar su Ep a estados que le permitan un desarrollo profesional y un CPd.

11. Los ejes DOC evidenciaron que las CSC son realmente dinamizadores del CPP, posiblemente por sus características como menciona Martínez (2014) y Ratcliffe \& Grace (2003a); pero también pueden ser obstáculo, cuando priman los saberes dominantes o CPD, constituyéndose en obstáculo de contenido, que acorde a las intervenciones realizadas por los profesores, abordar CSC les exige mayor tiempo de preparación de las clases, le exige la interacción interdisciplinar y transdiciplinar que no forma parte de la cultura del profesor, y los ejes cuestionamiento, que al indicar las fisuras del CPP se presentan en los referentes epistemológicos de las CSC asumidas como contenidos.

12. Del ATD surge la categoría emergente CP y EP que son equivalentes con GI y CPP a la luz de la teoría epistemológica de Fleck; en este contexto el $\mathrm{CP}$ se identifica por tener un EP que direcciona a dicho colectivo, pero para estilizar este pensamiento se asume una suave inmersión didáctica, en la que el profesor cuyo pensamiento está en la armonía de las ilusiones empieza a luchar internamente para comprender y asumir la inestabilidad que generan las CSC, es cuando a partir del par académico como colectivo 
de otro EP, empiezan a constituir uno nuevo, un hibrido que ingresa a un EP en transición hasta pasar al transformador, sin embargo no es un proceso fácil, es pasar de una ciencia de revista de expertos a una de libro de texto que corresponde a la ciencia escolar; es llegar a tener un ver estilizado, definido a partir de un ver confuso inicial.

13. Los profesores del Gl reconocen que la formación en IUE, permite al profesor tomar posición, pero desde una mirada crítica, social y humano, en la que contextualiza su praxis pedagógica y didáctica.

14. Al abordar las CSC también devela la posición ética-moral que de acuerdo con Sadler \& Zeidler (2004a) le permite reflexionar desde que miradas toma decisiones, y reconoce la historicidad del conocimiento, su carácter social y cultural.

En este sentido, la escuela debe consolidarse como un campo de formación permanente para los docentes, en donde se establezcan relaciones horizontales con pares académicos de la universidad en pro de la construcción de una asociación libre que propenda por el desarrollo profesional de los maestros en términos de la construcción de experiencias investigativas sobre su propia práctica.

El trabajo en equipo de docentes direcciona los intereses particulares y articula esfuerzos que hacen que el conocimiento no se perpetúe de manera fragmentada, como tradicionalmente lo mantiene la escuela; al contrario, este trabajo lleva a establecer nexos entre las disciplinas que constituyen el currículo escolar y permite a los profesores asumir posiciones reflexivas.

El abordaje de las CSC suscita en el Gl el planteamiento de estrategias de tipo investigativo que, además de generar cambios en la práctica de aula, pueden direccionar cambios curriculares que hagan de esta una propuesta de formación ciudadana y de articulación de conocimientos teóricos y saberes de la práctica 
profesional de docentes innovadores y responsables en estas asociaciones libres. Así, las CSC se constituyen en una herramienta que favorece el desarrollo de pensamiento crítico de docentes y estudiantes, que, al utilizar diversas actividades, favorece el tratamiento de problemáticas propias del contexto de los estudiantes.

Cada una de las CSC abordadas, manejó interrogantes usados como medio de reflexión, lo que mostró una negación, evidenciando que es un ejercicio que no se puede permitir en las escuelas. La temática más controversial fue el "uso/abuso de SPA, que al ser objeto de reflexión, podría motivar al consumo y ser interpretada como apertura a la permisividad, con lo que se olvida que es una realidad sentida del contexto escolar, que puede irrumpir en cualquier hogar sin elección de clase, raza, sexo o religión. Al ser abordada como CSC, mostró cambios significativos en el discurso de los docentes, especialmente, al permitir un diálogo interdisciplinar, donde las respuestas desde las disciplinas justifican la temática como apropiada para el debate y aprender de ella, al manejar marcos culturales, políticos y económicos que provocan controversia y posibilitan la mitigación de la misma.

El trabajo de pares académicos permitió, en el transcurso del proyecto, generar espacios de confianza en los dos escenarios (universidad-escuela). La universidad planteó interrogantes e inquietudes, generó procesos de reflexión que los miembros escolares asumieron con respeto, gusto y con liderazgo, punto que toman los representantes universitarios para invitar a plantear nuevos proyectos sobre temas controversiales de tipo local que involucren a los estudiantes, de tal manera que la escuela tome un papel dinamizador en la posible solución de problemas que afectan a la comunidad en general.

El diseño de unidades didácticas para ser abordadas por docentes permiten caracterizar la práctica de aula de cada uno de los docentes, caracterizar sus 
pensamientos y gestar investigaciones de tipo universitario sobre el conocimiento profesional del profesor.

El abordaje de CSC como herramienta que posibilita la puesta en escena de un diálogo reflexivo entre la universidad y la escuela hace que el maestro pueda poner en escena las capacidades ciudadanas que debe fomentar en sus estudiantes y establece entre los maestros un ambiente reflexivo que les permite escucharse, aprender del discurso del otro y asumir posiciones críticas como formadores de cultura.

El planteamiento de actividades para los estudiantes semejantes a las desarrolladas por los docentes muestra la intencionalidad de escuchar a estos últimos, de conocer su posición y, acorde al nombre de la institución (Guillermo Cano) y en calidad de estudiantes de EJA, fomentar la actividad crítica como estrategia metodológica que posibilita un aprendizaje individual y colectivo.

Al plantear actividades a los estudiantes como cursos de fotografía, visitas a museos y charlas con expertos, se posibilitó en ellos el desarrollo de habilidades prácticas y argumentativas que posiblemente los convocan a reflexionar sobre el uso de las SPA en su vida y la forma como han transformado e involucrado a sus familiares y amigos, aspectos que, al ser socializados en la última etapa, se convirtieron en temas de reflexión y de diseño de nuevas secuencias para los maestros, nuevos retos de investigación para los docentes universitarios y un acercamiento a profesionales interesados en la investigación social en el campo de la drogadicción.

En este contexto, y de acuerdo con los planteamientos de Maldaner (2014), la universidad a través de los programas de formación posgradual o de formación continua de profesores, debe gestar espacios colectivos de investigación entre los docentes en ejercicio y los universitarios, de tal manera que la formación se 
asuma en el contexto escolar que a su vez determina el tipo de experiencia que necesita desarrollar según las condiciones y pautas de trabajo con las que atiende a los estudiantes. Así, se establece un modelo de formación donde confluyen los intereses, conocimientos y situaciones universitarias con las necesidades escolares, de tal manera que escuela y universidad aprenden, investigan y trabajan como pares académicos. 


\section{BIBLIOGRAFÍA}

Abell, S. K. (2008). Twenty Years Later: Does pedagogical content knowledge remain a useful idea? International Journal of Science Education, 30(10), 1405-1416. https://doi.org/10.1080/09500690802187041

Acosta, R. R. (2011). El control de la profesión docente: algunos apuntes y análisis. Nodos y Nudos, 3(31).

Aikenhead, G. S. (1985). Collective decision making in the social context of science. Science Education, 69(4), 453-475.

Aikenhead, G. S., \& Ogawa, M. (2007). Indigenous knowledge and science revisited. Cultural Studies of Science Education, 2(3), 539-620.

Aires, J. A., \& Tobaldino, B. G. (2013). Os saberes docentes na formação de professores de Química participantes do PIBID. Química Nova Na Escola, São Paulo, 35(1), 1 13.

Albuquerque, M. V., Santos, S. A. dos, Cerqueira, N. T. do V, \& Silva, J. A. da. (2012). Educação alimentar: uma proposta de redução do consumo de aditivos alimentares. Revista Química Nova Na Escola, 34(2).

Álvarez, C., \& Osoro, J. M. (2011). Colaboración Universidad-Escuela para el desarrollo profesional docente. In Actas del III Congreso Internacional "Nuevas tendencias en la formación permanente del profesorado.

Anagün, Ş. S., \& Özden, M. (2010). Teacher candidates' perceptions regarding socioscientific issues and their competencies in using socio-scientific issues in science and technology instruction. Procedia - Social and Behavioral Sciences, 9, 981-985. https://doi.org/10.1016/j.sbspro.2010.12.271

Apple, M. (1993). El libro de texto y la política cultural. Revista de Educación, 301, 109126. 
Apple, M., \& García, F. P. (2003). Argumentando contra el neoliberalismo y el neoconservadurismo. Luchas por una democracia crítica en educación. Conferencia y coloquio. Con-Ciencia Social: Anuario de Didáctica de La Geografía, La Historia y Las Ciencias Sociales, 7, 83-127.

Araújo, L. R. de, \& Souza, S. R. de. (2017). LA EDUCACIÓN DE JÓVENES Y ADULTOS: CONCEPTO, FENÓMENO Y PARADIGMA. Revista Profissão Docente, 16(34).

Arroyo, M. G. (2015). O direito à educação e a nova segregação social e racial-tempos insatisfatórios. Educação Em Revista, 31(3), 15-47.

Arruda, Sergio, Lima, J. P. C., \& Passos, M. M. (2012). Um novo instrumento para a análise da ação do professor em sala de aula. Revista Brasileira de Pesquisa Em Educação Em Ciências, 11(2), 139-160.

Auler, D. (2007). Enfoque Ciência-Tecnologia-Sociedade: pressupostos para o contexto brasileiro. Ciência \& Ensino (ISSN 1980-8631), 1.

Auler, D. (2011). Novos caminhos para a educação CTS: ampliando a participação. CTS e Educação Científica: Desafios, Tendências e Resultados de Pesquisas. Brasília: Editora Universidade de Brasília, 73-97.

Auler, D., \& Bazzo, W. A. (2001). Reflexões para a implementação do movimento cts no contexto educacional brasileiro. Ciência \& Educação (Bauru), 7(1), 1-13. https://doi.org/10.1590/S1516-73132001000100001

Auler, D., \& Delizoicov, D. (2001). Alfabetização científico-tecnológica para quê? Ensaio Pesquisa Em Educação Em Ciências (Belo Horizonte), 3(2), 122-134.

Auler, D., \& Delizoicov, D. (2015). Investigação de temas CTS no contexto do pensamento latino-americano. Linhas Críticas, 21(45), 275-296.

Azevedo, M., Ghedin, E., Clara, M., Forsberg, S., Gonzaga, A., \& Oliveira. (2013). O enfoque CTS na formação de professores de ciências e a abordagem de questões sóciocientíficas. Atas Do IX Encontro Nacional de Pesquisa Em Educação Em Ciências, 1-8.

Azevedo, M. N., \& Abib, M. L. V. S. (2013). PESQUISA-AÇÃO E A ELABORAÇÃO DE SABERES DOCENTES EM CIÊNCIAS (Action-research and the elaboration of 
teaching knowledge in sciences). Investigações Em Ensino de Ciências, 18(1), 55.

Baca, L., Onofre, M., \& Paixão, F. (2014). O CONHECIMENTO DIDÁTICO DO CONTEÚDO DO PROFESSOR E SUA RELAÇÃO COM A UTILIZAÇÃO DE ATIVIDADES PRÁTICAS NAS AULAS DE QUÍMICA: UM ESTUDO COM PROFESSORES PERITOS DO SISTEMA EDUCATIVO ANGOLANO (Teacher Didactic Content Knowledge and its relation with the util. Investigações Em Ensino de Ciências, 19(1), 29.

Ballenilla, F. (2003). El practicum en la formación inicial del profesorado deficiencias de secundaria. Estudio de caso. Tesis Doctoral I: Planteamiento teórico, diseño y conclusiones de la investigación. Universidad de Sevilla.

Ballenilla, F. de G., \& Porlán, R. A. (2003). El" practicum" en la formación inicial del profesorado de ciencias de enseñanza secundaria: estudio de caso. Liberlibro.

Bañas, C., Pavón, R., Ruiz, C., \& Mellado, V. (2011). An action-research program with secondary education teachers' on teaching-learning energy: a case study. Revista Brasileira de Ensino de Física, 33(3), 1-9.

Barbosa, L. G. C., Caixeta, de C. L. M. E., \& Machado, A. H. (2012). Controvérsias sobre o aquecimento global: circulação de vozes e de sentidos produzidos em sala de aula. Ensaio Pesquisa Em Educação Em Ciências, 14(1).

Bardin, L. (1991). Análisis de contenido (Vol. 89). Ediciones Akal.

Batista, G., El-Hani, C., \& Carvalho, G. S. de. (2012). Condições de trabalho escolar, sua influência na saúde e no desenvolvimento profissional de professores de ciências: um estudo de caso com professores da Bahia. In VIII Encontro Nacional de Pesquisa em Educação em Ciências (ENPEC); Congresso Iberoamericano de Investigación en Enseñanza de las Ciéncias (CIEC) (pp. 1-12). ABRAPEC.

Bauer, M. (1998). The medicalization of science news-from the "rocket-scalpel" to the "gene-meteorite" complex. Social Science Information, 37(4), 731-751.

Bauman, Z. (2016). En busca de la política. Fondo de Cultura Económica.

Bazzo, J. L. S., \& Bazzo, W. A. (2011). INTERSEÇÕES CTS, DO DIREITO À ENGENHARIA: O HUMANO COMO FUNDAMENTO BÁSICO. 
Beane, J., \& Apple, M. (2000). Escuelas democráticas. Madrid: Morata.

Behrsin, M. C. D. (2011). TEACHING VOICES: ANALYSIS OF THE REFLECTIONS OF SCIENCE TEACHERS ABOUT THEIR PROFESSIONAL EXPERIENCE. Ensaio Pesquisa Em Educação Em Ciências (Belo Horizonte), 13(1), 73-86.

Beltrán, M. J. C., \& Martínez, L. F. P. (2014). ANÁLISIS DE LAS ESTRUCTURAS ARGUMENTATIVAS, CONSTRUIDAS POR ESTUDIANTES DE EDUCACIÓN MEDIA, SOBRE LA CUESTIÓN LOCAL DEL USO DEL AGUA DE LOS VALLADOS DE CAJICÁ. Gondola: Ensenanza Aprendizaje de Las Ciencias, 9(1), 103.

Bencze, J. L., Carter, L., \& Krstovic, M. (2014). Science \& Technology Education for personal, social \& environmental wellbeing: challenging capitalists' consumerist strategies. Revista Brasileira de Pesquisa Em Educação Em Ciências, 14(2), 39-56.

Beraza, M. A. Z. (2011). El practicum en la formación universitaria: Estado de la cuestiónn. Revista de Educacion, 354, 21-43. https://doi.org/issn: 0034-8082

Bernardino, A. J. (2008). Exigências na formação dos professores de EJA. VII Seminário de Pesquisa Em Educação Da Região Sul.

Bertram, A. (2014). CoRes y PaP-eRs como una estrategia para ayudar a los maestros de primaria principiantes a desarrollar su conocimiento didáctico del contenido. Educación Química, 25(3), 292-303.

Binatto, P. F., Chapani, D. T., \& Duarte, A. C. S. (2015). Formação reflexiva de professores de ciências e enfoque ciência, tecnologia e sociedade: possíveis aproximações. Alexandria: Revista de Educação Em Ciência e Tecnologia, 8(1), $131-152$.

Bisquerra, R. A. (2005). DE LA INVESTIGACIÓN EDUCATIVA. Revista Mexicana de Investigación Educativa, 10(25), 593-596.

Boris, Rodríguez, Fernando, C., \& Viafara, R. (2014). Pa-PeR al programa educativo por orientación reflexiva: una propuesta de formación para el profesorado de química. TED: Tecné, Episteme y Didaxis, (35).

Bortoletto, A., Freitas, Z. L., Oliveira, E. R. de, \& Carvalho, L. M. O. de. (2016). Sobre a constituição de um programa de formação de professores: a história de um grupo de 
pesquisa. In Formação de professores, questões sociocientíficas y avalição em larga escala Aproximando a pós-graduação da escola (p. 334). Bauru.

Bourdieu, P. (1974). O mercado de bens simbólicos. A Economia Das Trocas Simbólicas, 2.

Bourdieu, P. (1990). Una ciencia que incomoda. Sociología y Cultura, 79-94.

Bourdieu, P. (1996). Razões práticas: sobre a teoria da ação. Papirus Editora.

Bourdieu, P. (2008). El campo científico. Revista Redes, 24(7), 130-160. https://doi.org/10.1017/UPO9781844654031

Bourdieu, P., \& Passeron, J.-C. (2001a). Fundamentos de una teoría de la violencia simbólica. La Reproducción. Elementos Para Una Teoría Del Sistema de Enseñanza, $15-85$.

Bourdieu, P., \& Passeron, J. (2001b). Elementos para una teoría del sistema de enseñanza. Editorial Popular. https://doi.org/10.1017/CBO9781107415324.004

Bourdieu, P., \& Wacquant, L. L. (1995). Respuestas por una antropología reflexiva.

Braibante, M. E. F., \& Zappe, J. A. (2012). A química dos agrotóxicos. Química Nova Na Escola, 34(1), 10-15.

Britton, S. A., Tippins, D. J., \& Freeman, M. (2014). Citizen science as a framework for secondary science teacher preparation: A hermeneutic ethnography.

Bromme, R. (1988). Conocimientos profesionales de los profesores. Enseñanza de Las Ciencias: Revista de Investigación y Experiencias Didácticas, 6(1), 19-29.

Brum, W. P., \& Schuhmacher, E. (2014). ÉTICA NO ENSINO DE CIÊNCIAS: O POSICIONAMENTO DE PROFESSORES DE CIÊNCIAS SOBRE ETICIDADE DURANTE A ABORDAGEM DO TEMA TRANSGÊNICOS E SUAS IMPLICAÇÕES SOCIOAMBIENTAIS.

Budel, G. J. (2016). Ensino de química para a educação de jovens e adultos buscando uma abordagem ciência, tecnologia e sociedade. Universidade Tecnológica Federal do Paraná. 
Burmeister, M., Rauch, F., \& Eilks, I. (2012). Education for Sustainable Development (ESD) and chemistry education. Chemistry Education Research and Practice, 13(2), 59-68. https://doi.org/10.1039/C1RP90060A

Cachapuz, A. F. (2000). A procura da excelência na aprendizagem. Série-EstudosPeriódico Do Programa de Pós-Graduação Em Educação Da UCDB, (10).

Cachapuz, A., Paixão, F., Lopes, B., \& Guerra, C. (2008). Do estado da arte da pesquisa em educação em ciências: linhas de pesquisa e o caso "Ciência-TecnologiaSociedade." ALEXANDRIA Revista de Educação Em Ciência e Tecnologia, 27-49.

Caetano, A., Costa, A. R., \& Domingues, S. C. (2009). A produção do conhecimento das Universidades e a realidade escolar: uma análise crítica sobre o modelo atual de sociedade. Motrivivência, (30), 185-196.

Camarotti, A. C., Kornblit, A. L., \& Leo, P. F. Di. (2013). Prevención del consumo problemático de drogas en la escuela: estrategia de formación docente en Argentina utilizando TIC. Interface-Comunicação, Saúde, Educação, 17(46).

Carnio, M. P. (2011). TRATAMIENTO DE PROBLEMAS SOCIO-CIENTÍFICOS EN LA FORMACIÓN DE PROFESORES DE BIOLOGÍA: ALGUNOS ASPECTOS. Gondola: Ensenanza Aprendizaje de Las Ciencias, 6(1), 21.

Carr \& Kemmis. (1988). Teoría Crítica De La Enseñanza .Pdf.

Carta de Belem. (2009). SOCIAL, DPDELIII DE SALUD, MUNDIAL.

Carvajal, I. X., \& Martínez, L. F. (2014). ENCULTURACIÓN CIENTÍFICA A PARTIR DE LA ARGUMENTACIÓN: UNA CUESTIÓN SOCIOCIENTÍFICA (CSC) SOBRE IMPLANTES ESTÉTICOS. Góndola, Enseñanza y Aprendizaje de Las Ciencias.(Bogotá, Colombia), 9(1), 96-102.

Carvalho, L. M. O. de. (2015). Interação entre a escola básica e a pós-graduação: uma rede de Pequenos Grupos de Pesquisa (PGP). Eventos Pedagógicos, 78-97.

Carvalho, L. M. O. de, \& Chapani, D. T. (2012). A formação docente no âmbito das esferas $p$ úblicas democráticas. In W. L. ORQUIZA-DE CARVALHO, L. M.; CARVALHO (Ed.), Formação de Professores e Questões Sociocientíficas no Ensino de Ciências. (pp. 21-42). São Paulo: Educação para a Ciência. 
Carvalho, P. W. De, Carvalho, L. M. O. de, \& Junior, J. (2016). Formação de professores, questões sociocientíficas e avaliação em larga escala.

Carvalho, L. (2015). Formação de professores e questões sociocientíficas no ensino de ciências. Escrituras Editora e Distribuirdora de Livros Ltda.

Cassiano, K. F. D., \& Ribeiro, P. G. (2013). Caracterização do perfil formativo-profissional de formandos em química licenciatura Characterization of the training-professional profile of students the graduation in chemistry.

Castro, C., Santos, R., Rosa, S. E. da, \& Auler, D. (2015). Currículo temático fundamentado em Freire-CTS: engajamento de professores de física em formação inicial. Ensaio Pesquisa Em Educação Em Ciências, 17(2).

Castro, G. J., \& Hernández, U. (2013). El saber del maestro en contextos de diversidad socio-cultural: recuperación de las experiencias pedagógicas desde la interacción en red. Nodos y Nudos, 4(32).

Chapani, D. T. (2010). Políticas públicas e história de formação de professores de Ciências: uma análise a partir da teoria social de Habermas. Universidade Estadual Paulista (UNESP).

Chinn, P. W. U. (2012). Developing teachers' place-based and culture-based pedagogical content knowledge and agency. In Second international handbook of science education (pp. 323-334). Springer.

Cohen, J. (2004). Lograr una reduccion de los daños asociados a las drogas mediante la educación. (N. Heather, A. Wodak, E. Nadelmann, \& P. O'Hare, Eds.). La cultura de las drogas en la sociedad del riesgo.

Connelly, F. M., \& Clandinin, D. J. (1982). Personal Practical Knowledge at Bay Street School.

Conrado, D. M., \& El-Hani, C. N. (2010). Formação de cidadãos na perspectiva CTS: reflexões para o ensino de ciências. II Simpósio Nacional de Ensino de Ciência e Tecnologia (II SINECT), Ponta Grossa, UTFPR.

Contreras, J. D. (1997). La autonomía del profesorado. Ediciones Morata. 
Correa, L. F., \& Bazzo, W. A. (2017). Contribuições da Abordagem Ciência, Tecnologia e Sociedade para a Humanização do Trabalho Docente. Revista Contexto \& Educação, 32(102), 57-80.

Cruz, E. P., \& Barzano, M. A. L. (2016). SABERES DOCENTES: UM OLHAR PARA UMA DIMENSÃO NÃO EXIGIDA NAS TRAJETÓRIAS DE PROFESSORESPESQUISADORES DO CURSO DE LICENCIATURA EM CIÊNCIAS BIOLÓGICAS. Investigações Em Ensino de Ciências, 19(1), 117-139.

Cruz, L. (2011). El conocimiento práctico docente del profesor universitario en su interrelación con el marco epistemológico personal Departamento de Didáctica y Organización Educativa Universidad de Barcelona. Universidad de Barcelona.

Cutcliffe, S. H. (2004). Ideas, máquinas y valores: Los estudios de Ciencia, Tecnología y Sociedad (Vol. 15). Anthropos Editorial.

Davis, E. A., Petish, D., \& Smithey, J. (2006). Challenges new science teachers face. Review of Educational Research, 76(4), 607-651.

Delizoicov, D., \& Auler, D. (2011). Ciência, Tecnologia e Formação Social do Espaço: questões sobre a não-neutralidade. Alexandria: Revista de Educação Em Ciência e Tecnologia, 4(2), 247-273.

Delizoicov, D., Castilho, N., Cutolo, L. R. A., Ros, M. A. Da, \& Lima, A. M. C. (2002). Sociogênese do conhecimento e pesquisa em ensino: contribuições a partir do referencial fleckiano. Caderno Brasileiro de Ensino de Física, 19, 52-69.

Delizoicov, N. C., Carneiro, M. H. S., \& Delizoicov, D. (2004). O MOVIMENTO DO SANGUE NO CORPO HUMANO: DO CONTEXTO DA PRODUÇÃO DO CONHECIMENTO PARA O DO SEU ENSINO The motion of blood in human body: from the knowledge production context to its teaching. Ciência \& Educação, 10(3), $443-460$.

Denzin, N. K., \& Lincoln, Y. S. (1994). Ingresando al campo de la investigación cialitativa. Research in Education: A Conceptual Introduction. Glenview: Scott, Foresman and Company, 15.

Denzin, N. K., \& Lincoln, Y. S. (1994). Manual de investigación cualitativa (Vol. 1). Gedisa. 
Denzin, N. K., \& Lincoln, Y. S. (2011). The Sage handbook of qualitative research. Sage.

Denzin, N. K., \& Lincon, Y. S. (2006). Introdução da Pesquisa Qualitativa. O Planejamento Da Pesquisa Qualitativa.

Díaz, J. A. A. (1994). Los futuros profesores de enseñanza secundaria ante la sociología y la epistemología de las ciencias. Un enfoque CTS. Revista Interuniversitaria de Formación Del Profesorado, 19, 111-125.

Díaz, M. N., \& Jiménez, L. M. R. (2012). Las controversias sociocientíficas: temáticas e importancia para la educación científica. Revista Eureka Sobre Enseñanza y Divulgación de Las Ciencias, 9(1).

Diehl, D. A. (2015). A re-invenção dos direitos humanos pelos povos da América Latina: para uma nova história decolonial desde a práxis de libertação dos movimentos sociais.

Dourado, L., \& Matos, L. (2014a). A problemática dos organismos geneticamente modificados e a formação científica do cidadão comum: um estudo com alunos de escolas portuguesas. Ciência \& Educação (Bauru), 20(2).

Dourado, L., \& Matos, L. (2014b). A problemática dos organismos geneticamente modificados e a formação científica do cidadão comum: um estudo com manuais escolares de Ciências Naturais do $9^{\circ}$ ano adotados em Portugal. Ciência \& Educação (Bauru), 20(4).

Duarte, R. (2004). Entrevistas em pesquisas qualitativas. Educar Em Revista, (24).

Elliot, J. (1990). La investigación-acción en la escuela. Madrid: Morata.

Farré, A. S., \& Lorenzo, M. G. (2014). Para no seguir reinventando la rueda: El conocimiento didáctico en uso sobre los compuestos aromáticos. Educación Química, 25(3), 304-311.

Fernández, I., Gil, D., Alís, J. C., Cachapuz, A. F., \& Praia, J. (2002). Visiones deformadas de la ciencia transmitidas por la enseñanza. Enseñanza de Las Ciencias: Revista de Investigación y Experiencias Didácticas, 20(3), 477-488.

Fleck, L. (1929). Zur Krise der „Wirklichkeit “. Naturwissenschaften, 17(23), 425-430. 
Fleck, L. (1971). La Génesis y El Desarrollo De Un Hecho Científico, 7(1), 45-98. Retrieved from http://www.tecdigital.itcr.ac.cr/file/2785165/Fleck,_La_génesis_y_el_desarrollo_de_un_hecho_cientí fico.pdf

Fleck, L. (1979). Genesis and development of a scientific fact. Genesis and development of a scientific fact. University of Chicago Press Chicago.

Fleck, L. (1986). La génesis y el desarrollo de un hecho científico.

Flick, U. (2004). Introducción a la investigación cualitativa. Ediciones Morata SL Madrid.

Freire, P. (1994). Cartas a quien pretende enseñar. Siglo XXI.

Freire, P. (2005). Pedagogía del oprimido. Siglo xxi.

Freire, P. (2006). Pedagogía de la autonomía: saberes necesarios para la práctica educativa. Siglo XXI.

Freitas, Z. L., Carvalho, L. M. O. de, \& Oliveira, E. R. de. (2012). Educação de professores da universidade no contexto de interação universidade-escola. Ciência \& Educação (Bauru), 18(2), 323-334. https://doi.org/10.1590/S1516-73132012000200006

Fürkotter, M., Garboggini, D. G. A., Miotto, M. M., Mendonça, L. N., Moreira, M. L. V., \& Ferrari, L. Y. (2014). O que a Formação Contínua deve Contemplar?: o que dizem os professores. Educação \& Realidade, 39(3).

Gallego, A. M., Ariza, M., Armenteros, A., \& García, F. J. (2014). Creencias y actitudes del profesorado en relación a los cursos de desarrollo profesional y aprendizaje por investigación. Enseñanza de Las Ciencias, (Extra), 2878-2883.

Galvão, C., \& Reis, P. (2008). A promoção do interesse e da relevância do ensino da ciência através da discussão de controvérsias sociocientíficas La promoción del interés y de la relevancia de la enseñanza de la ciencia a traves de la discusión de controversias sociocientíficas, 131-135.

Gamboa, S. S. (2007). Pesquisa em educação: métodos e epistemologias. Argos.

García, C. (1999). Estudio sobre estrategias de inserción profesional en Europa. Revista Iberoamericana de Educación (№19, p. 101-143). 
García, C. (2007). La formación docente en la sociedad del conocimiento y la información: avances y temas pendientes. Olhar de Professor, 10(1).

Garritz. (1994). Ciencia-Tecnología-Sociedad a diez años de iniciada la corriente. Educación Química, 5(4), 217-223.

Garritz, A. (2012). Conocimiento didáctico del contenido. Mis últimas investigaciones: CDC en lo afectivo, sobre la estequiometría y la indagación. TED: Tecné, Episteme y Didaxis, 0(30)., 68-81.

Garritz, A. (2014). Celebración del vigésimo quinto aniversario de Educación Química. Elsevier.

Garritz, A., \& Ortega, N. (2013). El aspecto afectivo en la enseñanza universitaria. Cómo cinco profesores enseñan el enlace químico en la materia condensada. Las Emociones En La Enseñanza y El Aprendizaje de Las Ciencias y Las Matemáticas, 279.

Gaviria, M. B., \& Ospina, H. F. (2009). ¿ Es la institución educativa productora y reproductora de exclusión social? Infancias Imágenes, 8(1), 12.

Gentil, V. K. (2005). EJA: contexto histórico e desafios da formação docente. Centro de Referência Em Educação de Jovens e Adultos-CEREJA.

Gentile, N., Bosch, B., Mañas, F., Gorla, N., \& Aiassa, D. (2013). LA SITUACION AMBIENTAL DE UNA ZONA DE CULTIVO AFECTADA POR PLAGUICIDAS Y LAS REPERCUSIONES EN LA SALUD HUMANA.

Gianina, D., Leal, F., Comelin, A., Parra, M., \& Varelas, P. (2013). Conocimiento práctico de los profesores: sus características y contradicciones en el contexto universitario actual. Revista de La Educación Superior, 42(166), 35-53.

Giroux, H. (1990). Los profesores como intelectuales. Barcelona: Paidós.

Girox, H. (1990). Los profesores como intelectuales. Hacia Una Pedagogía Crítica.

Goes, L. F. De, Leal, S. H., Corio, P., \& Fernandez, C. (2013). Aspectos do conhecimento pedagógico do conteúdo de química verde em professores universitários de química. Educacion Quimica, 24(SPL.ISSUE1), 113-123. https://doi.org/10.1016/S0187- 
$893 \times(13) 72504-7$

Gómez, V. M. (2005). Modalidades de educación secundaria y formación de actitudes y disposiciones frente al conocimiento en Colombia. Revista Colombiana de Sociología, (25), 25.

Grossman, P. L., Wilson, S. M., \& Shulman, L. S. (1989). Teachers of substance: Subject matter knowledge for teaching. Profesorado, Revista de Currículum y Formación Del Profesorado, 9(2), 1-25.

Gutiérrez, A. B. (2004). Poder, hábitus y representaciones: recorrido por el concepto de violencia simbólica en Pierre Bourdieu. Revista Complutense de Educación, 15, 289300.

Habermas, J. (1987). Teoría de la acción comunicativa, I. Racionalidad de la acción y racionalidad social. Versión Castellana de Manuel Jiménez Rendón. Editorial Taurus. Madrid España.

Hodson, D. (2009). Teaching and Learning about Science: Language, Theories, Methods, History, Traditions and Values. Sense Publishers.

Holbrook, J., \& Rannikmae, M. (2009). The meaning of scientific literacy. International Journal of Environmental and Science Education, 4(3), 275-288.

Hopenhayn, M. (2002). Vida insular en la aldea global: paradojas en curso. Polis. Revista Latinoamericana, (2).

Huberman, M., \& Levinson, N. (1988). "Un modelo para el intercambio de conocimientos docentes entre universidad y escuelas." Revista de Educación, 286, 61-78.

Huberman, M., \& Middlebrooks, S. (2000). The dilution of inquiry: A qualitative study. International Journal of Qualitative Studies in Education, 13(3), 281-304.

Hygino, C. B., Janeiro, R. De, \& Janeiro, R. De. (2013). Modelos didáticos presentes na formação de futuros professores de química e física da região norte do estado do Rio de Janeiro , Brasil : encontros e desencontros entre concepções e formação, 49-58.

Imbernón, F. (1994). La formación del profesorado.

Imbernón, F. (2009). Formação permanente do professorado: novas tendências. São 
Paulo: Cortez.

Imbernón, F. (2011). Un nuevo desarrollo professional de professorado pada una nueva educación. Revista de Ciências Humanas, 12(19), 75-86.

Imbernón, F. (2012). Un nuevo desarrollo profesional del profesorado para una nueva educación. Revista de Ciencias Humanas, 12(19), 75-86.

Imbernon, F., \& Canto, P. J. (2013). La formación y el desarrollo profesional del profesorado en España y Latinoamérica. Sinéctica. scielomx.

Ireland, T. D. (2013). Revisitando a CONFINTEA: sessenta anos de defesa e promoção da educação de adultos. Revista Brasileira de Educação de Jovens e Adultos, 1(1), 14-28.

Jarauta, B.-B., \& Medina, J. L.-M. (2012). Saberes docentes y enseñanza universitaria.

Johnston, L. (2006). Software and method: Reflections on teaching and using QSR NVivo in doctoral research. International Journal of Social Research Methodology, 9(5), 379-391.

Kemmis, S., \& McTaggart, R. (2005). Communicative action and the public sphere. The Sage Handbook of Qualitative Research, 3, 559-603.

Kolsto, S. D. (2001). "To trust or not to trust,...'-pupils" ways of judging information encountered in a socio-scientific issue. International Journal of Science Education, 23(9), 877-901.

Lage, M. C. (2011). Utilização do software NVivo em pesquisa qualitativa: uma experiência em EaD Using NVivo software in qualitative research: a distance learning experience. ETD - Educação Temática Digital, 12(mar.), 198-226.

Lederman, N. G., \& Abell, S. K. (2014). Handbook of research on science education (Vol. 2). Routledge.

Leonard, A. (2010). La historia de las COSAS, De cómo nuestra obsesión por las cosas está destruyendo el planeta, nuestra comunidades y nuestra salud. Y Una Visión Del Cambio.

Levin, L. (2011). La construcción de la adicción como problema de conocimiento 
neurobiológico y las perspectivas de tratamientos. Una crítica al modelo médico hegemónico. Redes, 17(32).

Levinson, J. D. (2007). Forgotten racial equality: Implicit bias, decisionmaking, and misremembering. Duke Law Journal, 345-424.

Levinson, R. (2006a). SOCIO-SCIENTIFIC ISSUES: A STUDY OF TEACHERS ' REFLECTIONS, 41(4), 24-41.

Levinson, R. (2006b). Teachers' perceptions of the role of evidence in teaching controversial socio-scientific issues. The Curriculum Journal, 17(3), 247-262.

Levinson, R. (2006c). Towards a Theoretical Framework for Teaching Controversial Socioscientific Issues, 28(10), 1201-1224. https://doi.org/10.1080/09500690600560753

Levinson, R. (2007). Teaching controversial socio-scientific issues to gifted and talented students.

Levinson, R. (2008). Promoting the role of the personal narrative in teaching controversial socio-scientific issues. Science \& Education, 17(8-9), 855-871.

Levinson, R. (2010). Science education and democratic participation: An uneasy congruence? Studies in Science Education, 46(1), 69-119.

Lima, A. A., \& Nuñez, I. B. (2013). A análise do conhecimento pedagógico do conteúdo no planejamento de atividades com a utilização de modelos no ensino de química. Química Nova Na Escola, 36, 123-131.

Lima, V. A., \& Marcondes, M. E. R. (2011). Saindo Também se Aprende-O Protagonismo como um Processo de Ensino-Aprendizagem de Química.

Linn, M. C., Shear, L., Bell, P., \& Slotta, J. D. (1999). Organizing principles for science education partnerships: Case studies of students' learning about 'rats in space' and 'deformed frogs.' Educational Technology Research and Development, 47(2), 61-84. https://doi.org/10.1007/BF02299466

Linsingen, I. Von. (2007). Perspectiva educacional CTS: aspectos de um campo em consolidação na América Latina. Ciência \& Ensino (ISSN 1980-8631), 1.

Lipovetsky, G. (2016). De la ligereza (Vol. 501). Anagrama. 
Lombana, C., Delgado, F., \& Rickenmann, R. (2011). Un programa de formación continua con profesores de ciencias en el contexto de la relación museo-escuela.

Lopes, A. C. (2005a). Por que somos tão disciplinares? Educação Temática Digital, 9 , 201.econtextualização e Hibridismo. Currículo Sem Fronteiras, 5(2), 50-64.

Lopes, A. C. (2005b). Recontextualização e Hibridismo. Currículo Sem Fronteiras, 5(2), 50-64.

Lopes, A. C. (2008). Por que somos tão disciplinares? Educação Temática Digital, 9, 201.

Lopes, N. C. (2013). A constituição de associações livres e o trabalho com as questões sociocientíficas na formação de professores. Universidade Estadual Paulista (UNESP).

Lopes, N. C., \& Carvalho, W. L. P. de. (2013). Possibilidades e limitações da prática do professor na experiência com a temática energia e desenvolvimento humano no ensino de ciências. Revista Brasileira de Pesquisa Em Educação Em Ciências, 207226.

Lopes, N. C., \& Carvalho, W. L. P. de. (2017). Initial and continued teacher training: from licensees to the constitution of small research groups as free associations. Educação Em Revista, 33.

Ludke, M., \& André, M. (1986). Pesquisa em Educação: Abordagens Qualitativas. (Editora Pedagógica e Universitária - EPU, Ed.). São Paulo.

Lüdke, M., \& André, M. E. D. A. (1986). Metodologia científica para o professor pesquisador. Rio de janeiro: Lamparina.quisa em educação: abordagens qualitativas. Editora Pedagógica e Universitária.

Machado, M. A., \& Queiróz, G. R. P. (2012). A cultura de projetos, construída via parceria escola-universidade, contribuindo para a qualidade da formação inicial e continuada de professores. Revista Brasileira de Pesquisa Em Educação Em Ciências, 12(1), 93-116.

Maldaner, O. A. (2014). Formação de professores para um contexto de referência conhecido. Formação de Professores: Compreensões Em Novos Programas e Ações. ljuí, RS: Ed. UNIJUI, 15-41. 
Manzini, E. J. (2004). Entrevista semi-estruturada: análise de objetivos e de roteirosSeminário internacional sobre pesquisa e estudos qualitativos. Anais... Bauru: Universidade de São Carlos, 2004Disponível Em:< Http://Scholar. Google. Com/Scholar.

Marbà, A., Gairín, J., \& Talavera, M. (2013). Evaluación del conocimiento didáctico y científico del profesorado: el caso del sistema educativo de Panamá. Enseñanza de Las Ciencias: Revista de Investigación y Experiencias Didácticas, 31(3), 229-247.

Martínez, C. (2000). Las propuestas curriculares sobre el conocimiento escolar en el área de conocimiento del medio: dos estudios de caso en profesores de primaria. Tesis Doctoral. Programa Didáctica de las Ciencias Experimentales y Sociales, un enfoque interdisciplinar. Universidad de Sevilla, 648 p., Sevilla, España.

Martínez, C. (2005). De los contenidos al conocimiento escolar en las clases deficiencias. Revista Educación y Pedagogía, 17(43), 149-162.

Martínez, C. (2016). mor.

Martínez, C. A. (2016). El conocimiento profesional de los profesores de ciencias sobre el conocimiento escolar: dos estudios de caso, en aulas vivas y aulas hospitalarias del Distrito Capital de BogotáMartínez,. Universidad Distrital Francisco José de Caldas.

Martínez, C. A. (2017). Ser maestro de ciencias: productor de conocimiento profesional y de conocimiento escolar. Universidad Distrital Francisco José de Caldas.

Martínez, C. A. R., \& Martínez, V. (2012). El conocimiento escolar y las Hipótesis de Progresión : algunos fundamentos y desarrollos. Nodos y Nudos, 4(32), 50-64.

Martínez, C. A. R., \& Valbuena, E. U. (2013). El conocimiento profesional de los profesores deficiencias sobre el conocimiento escolar: resultados de investigación. Libros de los énfasis del Doctorado Interinstitucional en Educación. Bogotá, Colombia. Universidad Distrital Francisco José de Caldas.

Martínez, C. A. R., \& Valvuena, E. O. (2013). El conocimiento profesional de los profesores de ciencias de primaria sobre el conocimiento escolar: Un caso sobre los tipos de contenidos y referentes epistemológicos.

Martínez, C. A., \& Valbuena, E. O. (2013). El conocimiento profesional de los profesores 
de ciencias sobre el conocimiento escolar: resultados de investigación. Universidad Distrital Francisco José de Caldas.

Martínez, L. (2014). Cuestiones sociocientíficas en la formación de profesores de ciencias: aportes y desafíos. TED: Tecné, Episteme y Didaxis, (36).

Martínez, L. F. (2010). A abordagem de questões sociocientíficas na formação continuada de professores de ciências: contribuições e dificuldades. Universidade Estadual Paulista (UNESP).

Martínez, L. F. (2010). A abordagem de questões sociocientíficas na formação continuada de professores de ciências: contribuições e dificuldades.

Martínez, L. F. P. (2012). Questões sociocientíficas na prática docente: ideologia, autonomia e formação de professores. SciELO-Editora UNESP.

Martínez, L. F. P. (2014). Cuestiones sociocientíficas en la formación de profesores de ciencias: aportes y desafíos. Tecné, Episteme y Didacxis, (36), 77-94. Retrieved from http://revistas.pedagogica.edu.co/index.php/TED/article/viewFile/2913/2634

Martínez, L. F., Parga, D., Zapata, P. N., Rodríguez, B., \& Garzón, I. (2015). Formación de profesores y cuestiones sociocientíficas. Experinecias yb desafios en la interfaz universidad - escuela. (L. F. Martínez, D. Parga, \& I. Garzón, Eds.). Bogotá.

Martínez, L., \& Parga, D. (2013). Discurso ético y ambiental sobre cuestiones sociocientíficas: aportes para la formación del profesorado. Bogotá, DC: Universidad Pedagógica Nacional.

Martínez, L., \& Parga, D. (2014). Formación permanente de profesores en la interfaz universidad-escuela: currículo, fundamentos y roles. Una experiencia en construcción. Bogotá: Fondo Editorial, Universidad Pedagógica Nacional.[Links].

Martínez Pérez, L. F., \& Carvalho, W. L. P. de. (2012). Contribuições e dificuldades da abordagem de questões sociocientíficas na prática de professores de ciências. Educação e Pesquisa, 38(3), 727-741. https://doi.org/10.1590/S151797022012005000014

Massoni, N. T., \& Moreira, M. A. (2015). A Epistemologia de Fleck: Uma Contribuição ao Debate sobre a Natureza da Ciência. Alexandria, 8(1), 237-264. 
Matos, S. A. de. (2014). Abordagem Ciência, Tecnologia e Sociedade em uma disciplina do curso de especialização em ensino de ciências por investigação.

Medina, N. A., Ferriani, M. das G., \& Carvalho. (2010). Factores protectores de las familias para prevenir el consumo de drogas en un municipio de Colombia. Revista Latino-Americana de Enfermagem, 18.

Mellado, V. (2014). A formação eo desenvolvimento profissional de professores de ciências experimentais. Tecné, Episteme y Didaxis: TED, (35), 7-10.

Mellado, V., Borrachero, A. B., Brígido, M., Melo, L. V, Dávila, M. A., Conde, M. C., .. Guadalupe, M. (2014). Las emociones en la enseñanza de las ciencias. Enseñanza de Las Ciencias, 32(3), 11-36.

Melo, M. R., \& Villani, A. (2011). A evolução de uma professora na formação de licenciandos de Química numa perspectiva sócio-ambiental. Investigações Em Ensino de Ciências, 16(2), 291-315.

Miranda, C. T., Santos, J., Pinheiros, N., \& Silveira, R. (2011). Matemática e CTS: 0 ensino de medidas de áreas sob o enfoque da ciência tecnologia e sociedade em umPedretti, E. (2003). Teaching science, technology, society and environment (STSE) education. The role of moral reasoning on socioscientific issues and disc. Atas Do VIIIEncontro Nacional de Pesquisa Em Educação Em Ciências (ENPEC). Campinas (SP).

Moraes, R., \& Galiazz, do C. (2007). Análise textual: discursiva. (Editora Unijuí., Ed.).

Moraes, R., \& Galiazzi, M. (2007). Análise textual: discursiva. Editora Unijuí.

Moreira, H., \& Caleffe, L. G. (2008). Metodologia científica para o professor pesquisador. Rio de Janeiro: Lamparina.

Moreira, M. A. (2002). Pesquisa em educação em ciências: métodos qualitativos. Programa Internacional de Doctorado En Enseñanza de Las Ciencias. Universidad de Burgos, Espanha, 25-55.

Moreira, M. A. (2002). Pesquisa em Educação em Ciências: Métodos Qualitativos. Actas Del PIDEC, 4, 25-55. 
Moreno, D. F. S. (2015). Compreensões sobre a natureza da ciência de licenciandos a partir da experiência com questões sociocientíficas: possibilidades para a formação inicial. Universidade Estadual Paulista (UNESP).

Mundim, J. V., \& Santos, W. L. dos. (2012). Ensino de ciências no ensino fundamental por meio de temas sociocientíficos: análise de uma prática pedagógica com vista à superação do ensino disciplinar. Ciência \& Educação (Bauru), 18(4).

Muñoz, T. G. (2003). El cuestionario como instrumento de investigación/evaluación. Centro Universitario Santa Ana. Recuperado de Http://Cvonline. Uaeh. Edu. Mx/Cursos/Maestria/MTE/Gen02/Seminario_de_tesis/Unidad_4_anterior/Lect_El_Cu estionario. Pdf.

Naiff, L. A. M., Naiff, D. G. M., Pereira, J. M. M., \& Ávila, R. F. de. (2015). O que pensam os professores sobre seus alunos: aspectos psicossociais da Educação de Jovens e Adultos. Gerais: Revista Interinstitucional de Psicologia, 8(1), 19-32.

Nelkin, D. (2001). Molecular metaphors: the gene in popular discourse. Nature Reviews Genetics, 2, 555. Retrieved from http://dx.doi.org/10.1038/35080583

Niño, L. S. Z. (2005). Conceptos y prácticas del currículo y la evaluación:¿ Predominio de un enfoque? De La Perspectiva Instrumental a La Perspectiva Crítica., 119.

Niño, L. S. Z. (2013). Currículo y evaluación críticos: pedagogía para la autonomía y la democracia. Universidad Pedagógica Nacional, CIUP.

Nóvoa, A. (2009). Para una formación de profesores construida dentro de la profesión Towards a teacher training developed inside the profession. Revista de Educación, 350, 203-221.

Nussbaum, M. C. (2010). Sin fines de lucro. Por qué la democracia necesita de las huLipovetsky, G. (2016). De la ligereza (Vol. 501). Anagrama.manidades. Katz Editores.

Oliveira, B. E. T., \& Pino, J. C. (2013). Currículo escolar en el contexto de la situación de estudio: drogas - efectos y consecuencias en el ser humano. Educación Química, 24(3), 351-357. https://doi.org/10.1016/S0187-893X(13)72486-8

Oliveira, C. L., \& Santos, R. S. (2011). Impacts on the Emissions Monitoring System 
(OBD) Due to the Use of Biodiesel and Higher NOx Emissions. SAE Technical Paper.

Oliveira, E. (2012). "Reflexões sobre o ensino de inglês com língua estrangeira"professores de inglês em curso. Trabalhos Em Linguística Aplicada, 39(1).

Ormart, E., \& Brunetti, J. (2013). La formación de los docentes en competencias éticas. Nodos y Nudos, 4(35), 10-21.

Palacios, E. M. G., Galbarte, J. C. G., Cerezo, J. A. L., Luján, J. L., Gordillo, M. M., Osorio, C., \& Valdés, C. (2005). Ciencia, tecnología y sociedad: una aproximación conceptual. Organización de Estados Iberoamericanos (OEI).

Parga, D., Mora, W., \& Cárdenas, Y. (2014). Dimensión ambiental: una inclusión necesaria para la formación de profesores de química. Gondola: Ensenanza Aprendizaje de Las Ciencias, 9(1), 38.

Parga, D., \& Mora, W. M. (2014). El PCK, un espacio de diversidad teórica: Conceptos y experiencias unificadoras en relación con la didáctica de los contenidos en química. Educación Química, 25(3), 332-342. https://doi.org/https://doi.org/10.1016/S0187893X(14)70549-X

Parga, D., \& Pinzón, Y. (2014). El currículo del programa de formación de profesores en la interfaz universidad escuela. Martínez, D. et Al., Formación Permanente de Profesores En La Interfaz Universidad-Escuela: Currículo, Fundamentos y Roles. Una Experiencia En Construcción. Universidad Pedagógica Nacional. Bogotá.

Park, S., \& Oliver, J. S. (2008). Revisiting the conceptualisation of pedagogical content knowledge (PCK): PCK as a conceptual tool to understand teachers as professionals. Research in Science Education, 38(3), 261-284.

Pedretti, E. (2003). Teaching science, technology, society and environment (STSE) education. The Role of Moral Reasoning on Socioscientific Issues and Discourse in Science Education, 219-239.

Pedretti, E., \& Nazir, J. (2011). Currents in STSE education: Mapping a complex field, 40 years on. Science Education, 95(4), 601-626.

Perafán, A. (2015). El conocimiento profesional específico del profesor de ciencias asociado a una categoría, 10, 34-48. 
Perafán, G. A. E. (2013). La transposición didáctica como estatuto epistemológico fundante de los saberes académicos del profesor. Revista Folios, (37).

Pinheiro, N. M. A., Silveira, R. C. F., \& Bazzo, W. A. (2007). Ciência, tecnologia e sociedade: a relevância do enfoque CTS para o contexto do ensino médio. Ciência \& Educação (Bauru), 13(1).

Pinheiro, N. M., Silveira, R. M., \& Bazzo, W. A. (2007). Ciência, tecnologia e sociedade: a relevância do enfoque CTS para o contexto do ensino médio. Ciência \& Educação (Bauru), 13(1).

Porlán, R. A., Rivero, A. G., \& Pozo, M. del. (1997). Conocimiento profesional y epistemología de los profesores I: Teoría, métodos e instrumentos. Enseñanza de Las Ciencias, 15(2), 155-171. Retrieved from http://ddd.uab.cat/pub/edlc/02124521v15n2p155.pdf

Porlán, R. A., Rivero, A. G., \& Pozo, R. M. del. (1998). Conocimiento Profesional y Epistemología de los Profesores, II: Estudios Empíricos y Conclusiones. Enseñanza de Las Ciencias. Revista de Investigación y Experiencias Didácticas. 16 (2), 271-288.

Porlán, R., Pozo, R. M. del, Rivero, A. G., Harres, J., Azcárate, P., \& Pizzato, M. (2010). El cambio del profesorado de ciencias I: marco teórico y formativo. Enseñanza de Las Ciencias, 28(1), 31-46.

Porlán, R., \& Rivero, A. (1998). El conocimiento de los profesores: una propuesta formativa en el área de ciencias.

Porlán, R., Rivero, A., \& Pozo, M. del. (1998). Conocimiento profesional y epistemología de los profesores, II: Estudios empíricos y conclusiones. Enseñanza de Las Ciencias, 16(2), 271-288. https://doi.org/10.1016/j.sbspro.2015.11.222

Puello, J. F. S. (2013). “¿Quién sabe qué, cuándo, cómo?...jPara qué? Política, Políticas y Ciencia (nexos Criticos y critica de sus inconexiones)." In El Análisis y la Evaluación de las Políticas Públicas en la era de la Participación. Refleciones teóricas y estudios de casos. (pp. 141-171).

Ramírez, E. S. (2005). Concepciones Curriculares del Profesorado de Física y Química en Formación Inicial. Universidad de Sevilla. 
Ratcliffe, M., \& Grace, M. (2003a). Science education for citizenship: Teaching socioscientific issues. McGraw-Hill Education (UK).

Ratcliffe, M., \& Grace, M. (2003b). The nature of socio-scientific issues. Science Education for Citizenship, 178.

Recine, E., Gomes, Romeiro, R. C. F., Pinheiro, A. A. F., Oliveira, A. R. de, Teixeira, B. de A., Sousa, J. S. de, ... Monteiro, R. A. (2012). A formação em saúde pública nos cursos de graduação de nutrição no Brasil.

Reis, Pedro \& Galvão, C. (2008). Os professores de Ciências Naturais e a discussão de controvérsias sociocientíficas: dois casos distintos. Revista Electrónica de Enseñanza de Las Ciencias, 7, 746-772.

Reis. (2004). Controvérsias sócio-científicas: discutir ou não discutir?:Percursos de aprendizagem na disciplina de ciências da terra e da vida. Retrieved from http://hdl.handle.net/10400.15/89

Reis, P. G. R. dos. (2004). Controvérsias sócio-cientificas: discutir ou não discutir: percursos de aprendizagem na disciplina de ciências da terra e da vida. Universidade de Lisboa.

Reis, P. (2014a). Acción Socio-Política sobre Cuestiones Socio-Científicas: Reconstruyendo la Formación Docente y el Currículo1. Uni-Pluri/Versidad, 14(2), 16.

Reis, P. (2014b). Activist Science and Technology Education, 9. https://doi.org/10.1007/978-94-007-4360-1

Reis, P. (2016a). A Educação em Direitos Humanos através da discussão e ação sociopolítica sobre controvérsias sociocientíficas e socioambientais. Tecendo Diálogos Sobre Direitos Humanos Na Educação Em Ciências, 305-318.

Reis, P. (2016b). Formación de profesores: perspectivas de Brasil, Colombia, España y Portugal. Revista Electrónica Interuniversitaria de Formación Del Profesorado, 19(2).

Reis, P., \& Climent, N. (2012). Narrativas de profesores : refl exiones en torno al desarrollo personal y $p$ rofesional.

Rios, P. P. S., Vieira, A. R. L., \& Silva, T. O. (2017). EDUCAÇÃO DE JOVENS E 
ADULTOS NO CONTEXTO SEMIÁRIDO: SUJEITOS, CONTEXTOS E FORMAÇÃO DOCENTE. Encontro Internacional de Formação de Professores e Fórum Permanente de Inovação Educacional, 10(1).

Rivero, A., Pozo, R. M., Solís, E., Azcárate, P., \& Porlán, R. (2017). Cambio del conocimiento sobre la enseñanza de las ciencias de futuros maestros. Enseñanza de Las Ciencias: Revista de Investigación y Experiencias Didácticas, 35(1), 29-52.

Rodriguez, B., \& Martinez, L. (2014). Análisis del discurso didáctico crítico de profesores de ciencias al abordar cuestiones sociocientíficas. In Análisis del discurso didáctico crítico de profesores de ciencias al abordar cuestiones sociocientíficas (pp. 80-86).

Rodriguez, B., \& Martinez, L. (2015). ¿Las sustancias psicoactivas se debaten 0 combaten en la escuela? "Controversia por la legalidad/ilegalidad": una experiencia de formacion de docentes en la interfaz Universidad - escuela. In formación de profesores y Cuestiones Sociocientíficas experiencias y desafios en la interfaz universidad - escuela.

Rodríguez, B., \& Martínez, L. (2016). Reflexiones teóricas sobre el conocimiento didáctico del contenido y sus aportes a la formación del profesorado de ciencias. In D. L. Parga (Ed.), El Conocimiento Didáctico del Contenido en Quimica (pp. 177-200). Bogotá.

Rodríguez, G., Gil, J., \& García, E. (1996). Tradición y enfoques en la investigación cualitativa. Barcelona, Ediciones Aljibe.

Rodríguez, P. G. Z. (2013). ¿ PRÓTESIS PARA LA INMORTALIDAD? REFLEXIONES EN TORNO AL CÓDIGO TÉCNICO DE LA BIOMEDICALIZACIÓN DEL ENVEJECIMIENTO. Redes, 19(37).

Romao, J. E., \& Gadotti, M. (2011). Educação de adultos: cenários, perspectivas e formação de educadores. Educação de Adultos: Cenários, Perspectivas e Formação de Educadores.

Ruse, M. S. (2005). Technology and the evolution of the human: From Bergson to the philosophy of technology. Essays in Philosophy, 6(1), 27.

Sá, L. P., Kasseboehmer, A. C., \& Queiroz, S. L. (2013). Casos investigativos de caráter sociocientífico: aplicação no ensino superior de Química. Educación Química, 24, 
$522-528$.

Sadler, T. D. (2004). Moral and ethical dimensions of socioscientific decision-making as integral components of scientific literacy. Science Educator, 13(1), 39.

Sadler, T. D., \& Murakami, C. D. (2014). Socio - scientific Issues based Teaching and Learning: Hydrofracturing as an Illustrative context of a Framework for Implementation and Research, 14, 331-342.

Sadler, T. D., \& Zeidler, D. L. (2004a). The morality of socioscientific issues: Construal and resolution of genetic engineering dilemmas. Science Education, 88(1), 4-27.

Sadler, T. D., \& Zeidler, D. L. (2004b). The Morality of Socioscientific Issues: Construal and Resolution of Genetic Engineering Dilemmas. Science Education, 88(1), 4-27. https://doi.org/10.1002/sce.10101

Santos, M. dos, Amaral, C. L., \& Maciel, M. D. (2010). TEMAS SOCIOCIENTÍFICOS (CERVEJA) EM AULAS PRÁTICAS DE QUÍMICA NA EDUCAÇÃO PROFISSIONAL: UMA ABORDAGEM CTS. HOLOS, 4.

Santos, W. L. D. P. (2008). Educação científica humanística em uma perspectiva freireana: resgatando a função do ensino de CTS. Alexandria: Revista de Educação Em Ciência e Tecnologia, 1(1), 109-131.

Santos, W. L. P., \& Mortimer, E. F. (2016). Abordagem de aspectos sociocientíficos em aulas de ciências: possibilidades e limitações. Investigações Em Ensino de Ciências, 14(2), 191-218.

Schön, D. A. (1995). Knowing-in-action: The new scholarship requires a new epistemology. Change: The Magazine of Higher Learning, 27(6), 27-34.

Shulman, L. S. (2005). Conocimiento y enseñanza: fundamentos de la nueva reforma. Profesorado: Revista de Curriculum y Formación Del Profesorado, 9(2), 1-30.

Silva, P. F. da, \& Krasilchik, M. (2013). Bioética e ensino de ciências: o tratamento de temas controversos-dificuldades apresentadas por futuros professores de ciências e de biologia. Ciência \& Educação (Bauru), 19(2).

Silva, P. da, \& Krasilchik, M. (2013). Bioética e ensino de ciências: o tratamento de temas 
controversos-dificuldades apresentadas por futuros professores de ciências e de biologia. Ciência \& Educação (Bauru), 19(2).

Silva, J. (2016). Dialogos Formativos com os/as Professores/as da EJA e os pressupostos teóricos metodológicos Freirianos. Universidades do Estado de Bahia.

Silva, O. B., Oliveira, J. R. S. da, \& Queiroz, S. L. (2011). SOS Mogi-Guaçu: contribuições de um Estudo de Caso para a educação química no nível médio.

Silva, R. C. S., Costa, A. T., \& Jesus, M. P. de. (2016). O GRUPO FOCAL COMO TÉCNICA DE COLETA DE DADOS NA PESQUISA EM EDUCAÇÃO: ASPECTOS ÉTICOS E EPISTEMOLÓGICOS. Encontro Internacional de Formação de Professores e Fórum Permanente de Inovação Educacional, 9(1).

Simonneaux, J., \& Legardez, A. (2010). The epistemological and didactical challenges involved in teaching socially acute questions. The example of globalization. JSSEJournal of Social Science Education, 9(4).

Siqueira, J. B., Pinto, P., \& Cattani, G. C. (2013). UM ESTUDO EXPLORATÓRIO INTERNACIONAL SOBRE O DISTANCIAMENTO ENTRE A ESCOLA E A UNIVERSIDADE NO ENSINO DE CIÊNCIAS/(An international exploratory study about the gap between school and university on science education). Investigações Em Ensino de Ciências, 18(2), 365.

Solbes, J. (2013a). Contribución de las cuestiones sociocientíficas al desarrollo del pensamiento crítico (I): Introducción. Revista Eureka Sobre Enseñanza y Divulgación de Las Ciencias, 10(1).

Solbes, J. (2013b). Contribución de las cuestiones sociocientíficas al desarrollo del pensamiento crítico (II): Ejemplos. Revista Eureka Sobre Enseñanza y Divulgación de Las Ciencias, 10(2).

Solís, E. (2005a). Concepciones Curriculares del Profesorado de Física y Química en Formación Inicial. Universidad de Sevilla.

Solís, E. (2005b). Concepciones Curriculares del Profesorado de Física y Química en Formación Inicial. Universidad de Sevilla.

Solís, E., Porlán, R., \& Rivero, A. (2008). ¿ Qué Concepciones Curriculares del 
Profesorado de Ciencias en Formación Inicial pueden suponer un obstáculo. XXIII Encuentros de Didáctica de Las Ciencias Experimentales, Almería.

Solís, E. R., Porlán, R. A., \& Rivero, A. G. (2012). ¿ Cómo representar el conocimiento curricular de los profesores de ciencias y su evolución? Enseñanza de Las Ciencias. Revista de Investigación y Experiencias Didácticas, 30 (3) 9-30.

Solís, E. R., \& Rivero, A. G. (2012). La investigación en la formación inicial del profesorado: una aproximación a las concepciones curriculares del profesorado de Ciencias de Educación Secundaria., 1-35.

Solís, E. R., \& Rivero, A. G. (2013). La investigación en la formación inicial del profesorado: una aproximación a las concepciones curriculares del profesorado de Ciencias de Educación Secundaria. Conocimiento Profesional Del Profesor de Primaria y Conocimiento Escolar (Pp. 143-178).

Sousa, B. S. (2016). Para uma revolução democrática da justiça. Leya.

Sousa, B. S. (2017). Democracia y transformación social (Vol. 1). Siglo del Hombre Editores.

Sousa, R. S. de, Rocha, P. D. P., \& Garcia, I. T. S. (2012). Estudo de Caso em Aulas de Química: Percepção dos Estudantes de Nível Médio sobre o Desenvolvimento de suas Habilidades. Química Nova Na Escola, 34(4), 220-228.

Souza, R. D. de. (2015). Circulações de conhecimentos e práticas na formação inicial de professores de ciências: complicações, subsídios e possibilidades. Universidade Tecnológica Federal do Paraná.

Stake, R. E. (2007). Investigación con estudio de casos. Ediciones Morata.

Strieder, R. B. (2012). Abordagens CTS na educação científica no Brasil: sentidos e perspectivas. Universidade de São Paulo.

Strieder, R. B., \& Kawamura, R. D. (2014). Perspectivas de participação social no âmbito da educação CTS1. Uni-Pluri/Versidad, 14(2), 101.

Talanquer, V. (2014a). Razonamiento Pedagógico Específico sobre el Contenido (RPEC). Educación Química, 25(3), 391-397. https://doi.org/https://doi.org/10.1016/S0187- 
$893 \times(14) 70554-3$

Talanquer, V. (2014b). Razonamiento Pedagógico Específico sobre el Contenido (RPEC). Educacion Quimica, 25(3), 391-397. https://doi.org/10.1016/S0187-893X(14)70554-3

Tardif, M. (2000). Saberes profissionais dos professores e conhecimentos universitários. Revista Brasileira de Educação, 13(5), 5-24.

Taylor, S. J., \& Bogdan, R. (1986). Introducción a los métodos cualitativos de inveRodríguez, G., Gil, J., \& García, E. (1996). Tradición y enfoques en la investigación cualitativa. Barcelona, ediciones Aljibe.stigación. La búsqueda de significado. Buenos Aires: Paidós.

Teixeira, S. M., Souza, B. de F. E., Raposo, R. E., \& Silva, M. da F. N. (2014). CENAS E CENÁRIOS DAS QUESTÕES SOCIOAMBIENTAIS: MEDIAÇÕES PELA FOTOGRAFIA. Ensaio Pesquisa Em Educação Em Ciências, 16(1).

Teles, F. P., \& Ibiapina, I. M. L. de M. (2009). A pesquisa colaborativa como proposta inovadora de investigação educacional. Diversa. Ano, 2.

Topcu, M. S., Sadler, T. D., \& Yilmaz-Tuzun, O. (2010). Preservice science teachers' informal reasoning about socioscientific issues: The influence of issue context. International Journal of Science Education, 32(18), 2475-2495.

Torres, N. Y., \& Martínez, L. F. (2011). Desarrollo de pensamiento crítico en estudiantes de Fisioterapia, a partir del estudio de las implicaciones sociocientíficas de los xenobióticos. TED: Tecné, Episteme y Didaxis, (29).

Torres, Y. M. N., \& Solbes, J. M. (2014). Aspectos convergentes del pensamiento crítico y las cuestiones sociocientíficas. Góndola, Enseñanza y Aprendizaje de Las Ciencias, 2014, Vol. 9, Num. 1, p. 1-13.

Valvuena, E. (2007). El conocimiento didáctico del contenido biológico: estudio de las concepciones disciplinares y didácticas de futuros docentes de la universidad pedagógica nacional (Colombia). Universidad Complutense de Madrid. https://doi.org/ISBN: 978-84-693-1123-3

Vázquez, Á. A., Aponte, A., Manassero, M.-A.-M., \& Montesano, M. (2014). Una secuencia de enseñanza-aprendizaje sobre un tema socio-científico: análisis y 
evaluación de su aplicación en el aula. Educación Química, 25, 190-202.

Vázquez, Á., \& Cruz, A. M. (2014). Formación del profesorado en naturaleza de la ciencia mediante investigación-acción. Praxis \& Saber, 5(9).

Vilches, A., Gil, D. P., Toscano, J. C., \& Macías, Ó. (2008). Obstáculos que pueden estar impidiendo la implicación de la ciudadanía y, en particular, de los educadores, en la construcción de un futuro sostenible: Formas de superarlos. Revista Iberoamericana de Ciencia Tecnología y Sociedad, 4(11), 139-162.

Walters, J. M., \& Gardner, H. (1984). The Development and Education of Intelligences.

Wendel, F. M., \& Silva, C. A. da T. e. (2011). As fotonovelas no ensino de química. Química Nova Na Escola, 33(1), 25-31.

Wu, Y., \& Tsai, C. (2007). High School Students' Informal Reasoning on a Socio-scientific Issue: Qualitative and quantitative analyses. International Journal of Science Education, 29(9), 1163-1187. https://doi.org/10.1080/09500690601083375

Yin, R. (1994). Investigación sobre estudio de casos. Diseño y métodos. Applied Social Research Methods Series, 5(2).

Zeidler, D. L., Sadler, T. D., Simmons, M. L., \& Howes, E. V. (2005). Beyond STS: A research-based framework for socioscientific issues education. Science Education, 89(3), 357-377. https://doi.org/10.1002/sce.20048

Zeidler, D. L., Walker, K. A., Ackett, W. A., \& Simmons, M. L. (2002). Tangled up in views: Beliefs in the nature of science and responses to socioscientific dilemmas. Science Education, 86(3), 343-367. https://doi.org/10.1002/sce.10025 


\section{ANEXOS}

